\title{
CÁlCULO DE DESLOCAMENTOS EM PAVIMENTOS DE EDIFÍCIOS DE CONCRETO ARMADO
}

Mônica Cristina Cardoso da Guarda

Tese apresentada à Escola de Engenharia de São Carlos, da Universidade de São Paulo, como parte dos requisitos para a obtenção do Título de D outora em Engenharia de Estruturas.

Orientador: Márcio Antônio Ramalho

São Carlos 2005 
Ficha catalográfica preparada pela Seção de Tratamento da Informação do Serviço de Biblioteca - EESC/USP

Guarda, Mônica Cristina Cardoso da
G914c Cálculo de deslocamentos em pavimentos de edifícios de concreto armado / Mônica Cristina Cardoso da

Guarda. -- São Carlos, 2005.

Tese (Doutorado) -- Escola de Engenharia de São Carlos-Universidade de São Paulo, 2005.

Área: Engenharia de Estruturas.

Orientador: Prof. Dr. Márcio Antônio Ramalho.

1. Concreto armado - deslocamentos - elementos finitos. 2. Concreto armado - análise não-linear. I. Título. 
A meus pais,

Adelino Bastos da Guarda e

Maria Rosa Cardoso da Guarda 


\section{AGRADECIMENTOS}

Ao Prof. Márcio Antônio Ramalho, pela orientação, incentivo, paciência e amizade demonstrados durante toda a elaboração desse trabalho.

À minha família, que sempre me apoiou nos momentos que precisei.

À amiga Juliana Soares Lima, pelas idéias, pelo apoio incondicional, pelo incentivo e pela amizade.

Aos professores Libânio Miranda Pinheiro, José Samuel Giongo e Márcio Roberto Silva Corrêa pela amizade e pelo incentivo.

Às amigas Sônia Medeiros de Oliveira, Maria Anita Pessoa Martinelli e Tatiana Bittencourt Dumêt, pelo apoio e pela amizade de sempre.

A Maria Nadir Minatel, por toda sua atenção e ajuda na confecção das referências bibliográficas, e também pela amizade.

Aos amigos, professores e funcionários do SET, pela receptividade, pelo carinho e pela atenção.

A todos os amigos do Departamento de Construção e Estruturas da Universidade Federal da Bahia.

À CAPES, pela bolsa de estudos.

A todos que, direta ou indiretamente, contribuíram para a elaboração deste trabalho. 


\section{SUMÁRIO}

RESUMO

i

ABSTRACT

ii

\section{CAPÍTULO 1}

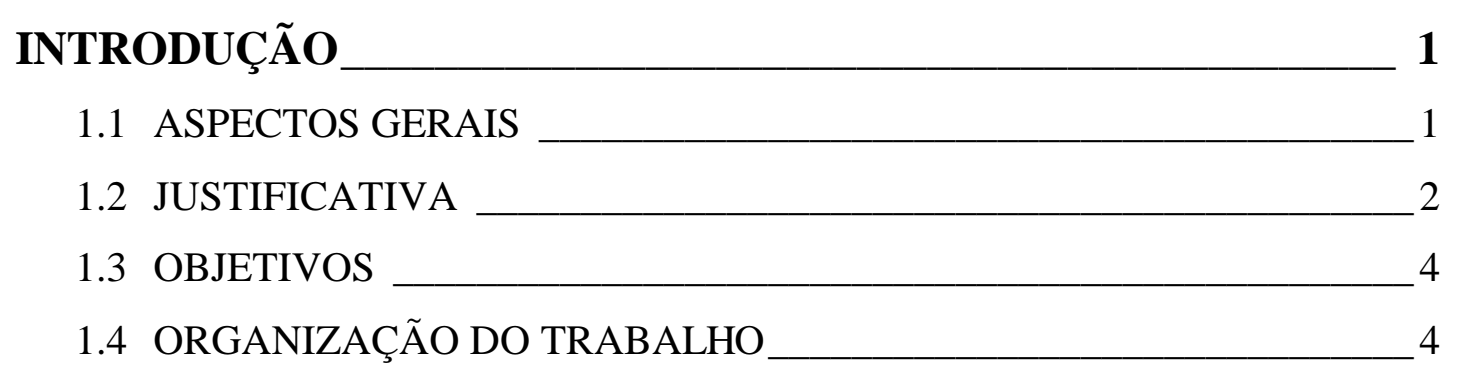

\section{CAPÍTULO 2}

DESLOCAMENTOS EM ELEMENTOS FLETIDOS

2.1 INTRODUÇÃO 7

2.2 FATORES QUE AFETAM OS DESLOCAMENTOS 7

2.2.1 PROPRIEDADES DO CONCRETO 8

a) Resistência à Compressão 8

b) Módulo de Elasticidade 9

c) Resistência à Tração 11

2.2.2 FISSURAÇÃO 14

2.2.3 RETRAÇÃO 16

2.2.4 FLUÊNCIA 18

2.3 CÁLCULO DOS DESLOCAMENTOS 19 
a) Seção Transversal Homogeneizada __________________________ 20

b) Momento de Fissuração ____________________________________ 22

c) Momento de Inércia Efetivo __________________________________ 23

2.3.2 CÁLCULO DE DESLOCAMENTOS IMEDIATOS ______________-_ 25

a) Vigas e Lajes Armadas em uma Direção _______________________ 26

b) Lajes Armadas em duas Direções_____________________________ 33

2.3.3 CÁlCULO DOS DESLOCAMENTOS DIFERIDOS NO TEMPO______ 36

a) Cálculo da deformação por Fluência ________________________ 37

b) Cálculo da deformação por Retração __________________________ 38

c) Processos Simplificados ______________________________-__ 40

2.4 CONTROLE DOS DESLOCAMENTOS __ 43

2.4.1 CÁLCULO DOS DESLOCAMENTOS___________________________ 43

a) Aceitabilidade Sensorial_____________________________________ 44

b) Interferências no Uso das Estruturas ___________________________ 44

c) Danos em Elementos não Estruturais __________________________ 45

d) Efeitos em Elementos Estruturais____________________________ 45

2.4.2 CRITÉRIOS DE ALTURAS MÍNIMAS _________________________ 45

2.5 CONSIDERAÇÃO DAS AÇÕES __ 46

2.5.1 TIPOS DE AÇÕES_________________________________________ 46

2.5.2 COMBINAÇÃO DE AÇÕES _________________________________ 47

2.6 RECOMENDAÇÕES NORMATIVAS _ 48

2.6.1 RECOMENDAÇÕES DA NBR 6118 (2003) ______________________ 48

a) Combinação de Ações______________________________________ 48

b) Cálculo do Momento de Fissuração__________________________ 49

c) Cálculo do Momento de Inércia Efetivo _________________________ 50

d) Cálculo do Módulo de Elasticidade do Concreto_________________ 51

e) Determinação do Deslocamento Imediato_________________________ 52

f) Determinação do Deslocamento Diferido__________________________ 52

g) Comparação com Valores Limites de Deslocamentos ______________ 53

2.6.2 RECOMENDAÇÕES DO ACI 318 (2002) _______________________________ 56

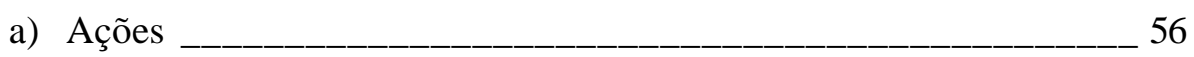

b) Alturas mínimas ___________________________________________ 56

c) Cálculo do Momento de Fissuração__________________________ 59

d) Cálculo do Momento de Inércia Efetivo ______________________ 59 
e) Cálculo do Módulo de Elasticidade do Concreto_________________ 60

f) Determinação do Deslocamento Imediato_______________________ 60

g) Determinação do Deslocamento Diferido________________________ 60

h) Comparação com Valores Limites de Deslocamento_______________ 61

2.6.3 RECOMENDAÇÕES DO CEB-FIP (1991) _______________________ 62

a) Combinação de Ações________________________________________ 62

b) Cálculo do Momento de Fissuração___________________________ 63

c) Cálculo do Módulo de Elasticidade do Concreto___________________ 63

d) Determinação dos Deslocamentos a Partir da Curvatura Média __-__- 64

e) Processo Simplificado_________________________________________ 67

f) Comparação com Valores Limites __________________________-_ 68

g) Alturas Mínimas________________________________________-__ 68

2.6.4 RECOMENDAÇÕES DO EUROCODE 2 (1992) __________________ 70

a) Combinação de Ações____________________________________ 70

b) Cálculo do Momento de Fissuração__________________________ 70

c) Cálculo do Módulo de Elasticidade do Concreto_________________ 70

d) Determinação dos Deslocamentos Imediatos a Partir da Curvatura Média ________________________________________________ 71

e) Determinação dos Deslocamentos Diferidos a Partir da Curvatura Média __________________________________________________-_ 72

f) Comparação com Valores Limites de Deslocamentos __________-__ 73

g) Alturas Mínimas_____________________________________________ 74

2.6.5 EXEMPLO DE CÁLCULO ____________________________________ 74

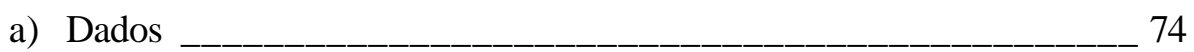

b) Parâmetros Utilizados ____________________________________ 75

c) Valores dos Deslocamentos______________________________________ 77

d) Comparação com os Valores Limites____________________________ 79

e) Análise dos Resultados ___________________________________ 81

2.7 CONSIDERAÇÕES FINAIS___ 82

\section{CAPÍTULO 3}

DESLOCAMENTOS EM LAJES ISOLADAS __ 85

3.1 INTRODUÇÃO _ 85

3.2 CARACTERÍSTICAS DAS LAJES _ 86 
3.2.1 TIPOS DE LAJES 86

3.2.2 VÃOS DAS LAJES ___________________________________________ 86

3.2.3 CASOS DE CARREGAMENTO__________________________________ 87

a) Carregamento $\mathrm{C} 1$ _________________________________________ 87

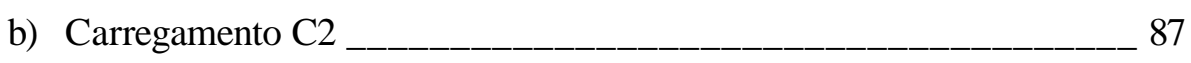

c) Carregamento C3 _________________________________________ 87

3.3 PARÂMETROS ADOTADOS __ 88

3.3.1 COMBINAÇÕES DAS AÇÕES _________________________________ 88

3.3.2 MATERIAIS ___________________________________________________ 89

3.3.3 CONDIÇÕES DO AMBIENTE__________________________________ 89

3.3.4 IDADE DE APLICAÇÃO DAS AÇÕES_________________________ 90

3.4 CÁlCULO DOS DESLOCAMENTOS _ 90

3.4.1 DISCRETIZAÇÃO DAS LAJES________________________________ 90

3.4.2 DETERMINAÇÃO DAS ARMADURAS________________________ 91

3.4.3 VALORES DOS DESLOCAMENTOS__________________________ 91

3.5 ANÁLISE DOS RESULTADOS __ 93

3.5.1 INFLUÊNCIA DOS PARÂMETROS DE CÁLCULO______________ 93

a) Tipos de lajes _________________________________________________ 93

b) Resistência à Compressão do Concreto ________________________ 94

c) Casos de Carregamento______________________________________ 95

3.5.2 RELAÇÃO ENTRE DESLOCAMENTOS DIFERIDOS E IMEDIATOS 95

3.5.3 CRITÉRIOS DE ALTURA MÍNIMA ____________________________ 99

a) Critério com Base na Relação Menor Vão-Altura Mínima__________ 99

b) Expressão para o Cálculo da Altura Mínima___________________ 104

c) Exemplos de Cálculo ___________________________________ 111

\section{CAPÍTULO 4}

DESLOCAMENTOS EM VIGAS ISOLADAS___ 119

4.1 INTRODUÇÃO _ 119

4.2 CARACTERÍSTICAS DAS VIGAS _ 119

4.2.1 TIPOS E PROPRIEDADES DAS VIGAS_______________________- 119

4.2.2 CARREGAMENTO DAS VIGAS______________________________ 121

4.3 PARÂMETROS ADOTADOS _ 123

4.3.1 COMBINAÇÕES DE AÇÕES _________________________________ 123 
4.3.2 MATERIAIS 123

4.3.3 CONDIÇÕES AMBIENTAIS________________________________ 123

4.3.4 IDADE DE APLICAÇÃO DAS AÇÕES________________________-_ 123

4.4 CÁlCULO E VERIFICAÇÃO DOS DESLOCAMENTOS $\_123$

4.4.1 DISCRETIZAÇÃO __________________________________________ 124

4.4.2 DETERMINAÇÃO DAS ARMADURAS _______________________ 124

4.4.3 VALORES DOS DESLOCAMENTOS ______________________ 124

4.5 ANÁLISE DOS RESULTADOS _ 125

4.5.1 INFLUÊNCIA DOS PARÂMETROS DE CÁLCULO_____________ 125

a) Dimensão dos Pilares ______________________________________ 125

b) Aumento da Largura da Viga________________________________ 129

c) Armadura de Compressão_________________________________ 130

d) Resistência Característica do Concreto à Compressão_____________ 133

e) Casos de Carregamento______________________________________ 133

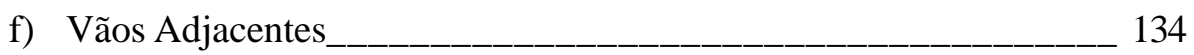

\subsubsection{COEFICIENTE MULTIPLICADOR DOS DESLOCAMENTOS}

IMEDIATOS_____________________________________________-_ 135

4.5.3 ALTURAS MÍNIMAS_____________________________________- 139

a) Relação Vão-Altura Mínima _______________________________ 140

b) Expressão para o Cálculo da Altura Mínima____________________ 147

c) Exemplo de Cálculo ______________________________________ 153

\section{CAPÍTULO 5}

DESLOCAMENTOS EM PAVIMENTOS

5.1 INTRODUÇÃO 157

5.2 CONSIDERAÇÕES GERAIS 157

5.3 PAVIMENTO 1 159

5.3.1 VALORES DOS DESLOCAMENTOS____________________________ 160

5.3.2 ANÁLISE DOS RESULTADOS_______________________________ 164

a) Deslocamentos Imediatos ___________________________________ 164

b) Deslocamentos Diferidos __________________________________ 167

5.3.3 ALTURAS MÍNIMAS_______________________________________ 170

a) Alturas Mínimas das Lajes _____________________________-_ 171

b) Alturas Mínimas das Vigas _______________________________ 173 
5.4 PAVIMENTO 2 175

5.4.1 VALORES DOS DESLOCAMENTOS 176

5.4.2 ANÁLISE DOS RESULTADOS_______________________________ 180

a) Deslocamentos Imediatos _____________________________-_ 180

b) Deslocamentos Diferidos _____________________________-_ 183

5.4.3 ALTURAS MÍNIMAS____________________________________ 186

a) Alturas Mínimas das Lajes _____________________________-_ 186

b) Alturas Mínimas das Vigas_______________________________ 188

5.5 PAVIMENTO 3

5.5.1 VALORES DOS DESLOCAMENTOS

5.5.2 ANÁLISE DOS RESULTADOS___________________________-_ 196

a) Deslocamentos Imediatos ________________________________ 196

b) Deslocamentos Diferidos ______________________________ 199

5.5.3 ALTURAS MÍNIMAS_____________________________________ 202

a) Alturas Mínimas das Lajes ________________________________ 202

b) Alturas Mínimas das Vigas _____________________________-__ 204

5.6 PAVIMENTO 4 _ 205

5.6.1 VALORES DOS DESLOCAMENTOS__________________________-_ 205

5.6.2 ANÁLISE DOS RESULTADOS______________________________ 211

a) Deslocamentos Imediatos ____________________________-__-_ 211

b) Deslocamentos Diferidos ___________________________________ 213

5.6.3 ALTURAS MÍNIMAS _ 215

a) Alturas Mínimas das Lajes ___________________________________ 215

b) Alturas Mínimas das Vigas________________________________ 216

5.7 CONSIDERAÇÕES FINAIS___ 218

5.7.1 VALORES DOS DESLOCAMENTOS_______________________ 218

5.7.2 VALORES DAS ALTURAS MÍNIMAS _____________________-_ 220

\section{CAPÍTULO 6}

\section{CONCLUSÕES}

6.1 INTRODUÇÃO__ 221

6.2 CÁlCULO DOS DESLOCAMENTOS _ 221

6.3 DESLOCAMENTOS EM LAJES ISOLADAS _ 222

6.4 DESLOCAMENTOS EM VIGAS ISOLADAS _ 225 
6.5 DESLOCAMENTOS EM PAVIMENTOS

ANEXO A

A.1 ASPECTOS GERAIS 231

A. 2 VALORES DOS DESLOCAMENTOS DAS LAJES 231

A.3 VALORES DOS DESLOCAMENTOS DAS VIGAS 240

REFERÊNCIAS BIBLIOGRÁFICAS 243

BIBLIOGRAFIA COMPLEMENTAR 249 


\section{RESUMO}

GUARDA, M.C.C. (2005). Cálculo de deslocamentos em pavimentos de edifícios de concreto armado. São Carlos. 253p. Tese (Doutorado) - Escola de Engenharia de São Carlos, Universidade de São Paulo.

Neste trabalho, são estudados os deslocamentos de vigas, lajes e pavimentos completos em concreto armado, submetidos a carregamentos perpendiculares aos seus eixos e planos. Utiliza-se para tanto o programa ANPAV, desenvolvido no SET-EESC-USP, que permite o cálculo dos deslocamentos considerando-se o comportamento não-linear do concreto armado por meio de todos os fenômenos modernamente considerados com esse objetivo. Assim, a partir de elementos finitos estratificados em filamentos, no caso de elementos de barra tridimensional, ou camadas, no caso dos elementos de placa, podem ser considerados os efeitos da fissuração, da retração, da fluência, e da colaboração do concreto tracionado entre as fissuras para a rigidez à flexão dos elementos. Inicialmente, então, são calculados os deslocamentos de um elevado número de lajes e vigas isoladas e, a partir da análise dos resultados, é avaliada a influência dos parâmetros envolvidos neste cálculo. Sugerem-se, tanto para lajes quanto para vigas, expressões para o cálculo de coeficientes multiplicadores dos deslocamentos imediatos para a avaliação dos deslocamentos diferidos no tempo, e também são feitas propostas para a determinação de uma altura mínima para esses elementos. Com a utilização dessas alturas mínimas, pode-se garantir que o estado limite de deformação excessiva não será atingido, dispensando-se a necessidade do cálculo dos deslocamentos propriamente ditos e simplificando-se enormemente o trabalho de projetistas dessas estruturas. Por fim, são estudados pavimentos de edifícios residenciais e seus deslocamentos são calculados a partir de análises linear e não-linear, sendo os resultados obtidos comparados de forma a se validar alguns modelos e expressões desenvolvidas na análise dos elementos isolados.

Palavras -chave: Concreto armado; deslocamentos; elementos finitos; análise-não linear 


\section{ABSTRACT}

GUARDA, M.C.C. (2005). Deflection calculations of reinforced concrete building floors. São Carlos. 253p. Tese (Doutorado) - Escola de Engenharia de São Carlos, Universidade de São Paulo.

This work presents an analysis of deflections for reinforced concrete beams, slabs and floors under perpendicular loading. The ANPAV program - a finite-element program developed at SET-EESC-USP that allows estimating the deflections considering reinforced concrete nonlinear behavior - is used. With finite layered-elements for beams and plates it is possible to evaluate deflections taking into account cracking, shrinkage, creep and tension stiffening. Firstly, deflections for a wide range of isolated beams and slabs cases are calculated in order to evaluate the influence of several important parameters. Then, multiplier coefficients for assessing long term deflections from immediate deflections and minimum thickness expressions to ascertain serviceability limit states are suggested, both for beams and slabs. Finally, deflections for residential building floors are calculated for linear and non-linear analysis and the results are compared in order to validate the models and parameters obtained from isolated beams and slabs.

Key words : Reinforced concrete; deflections; finite elements; non-linear analysis 


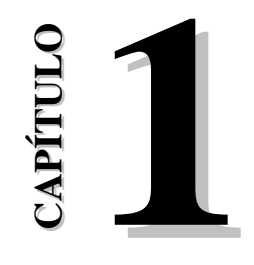

\section{INTRODUÇÃO}

\subsection{ASPECTOS GERAIS}

Até o fim da década de cinqüenta, os projetos estruturais apontavam o uso de elementos robustos, com uma capacidade de carga, em geral, muito maior que a necessária. Apesar de a grande preocupação ser a garantia da segurança, as vigas e lajes acabavam não apresentando problemas de deslocamentos excessivos justamente devido à sua grande rigidez.

Com o aprimoramento das técnicas de análise estrutural e das ferramentas computacionais, pode-se conhecer melhor a distribuição das cargas e os esforços em cada peça. Paralelamente, o desenvolvimento da tecnologia dos materiais utilizados na construção das estruturas de concreto permitiu a produção e o uso tanto de concretos com resistências mais elevadas quanto o de armaduras com tensões de escoamento mais altas. Com isso, houve uma redução das seções transversais das vigas e das espessuras das lajes, levando a elementos mais esbeltos.

Essas modificações nas características dos projetos, por outro lado, contribuíram significativamente para um maior nível de fissuração das peças, diminuindo sua rigidez e aumentando seus deslocamentos. Em alguns casos, esses deslocamentos tornaram-se tão expressivos que, para evitá-los, seria necessária a adoção de alturas maiores que as requeridas pelo dimensionamento à flexão. Por isso, a questão da estimativa e do controle dos deslocamentos vem sendo cada vez mais importante para os projetos de hoje em dia.

Os deslocamentos excessivos em um elemento estrutural podem causar diversos danos, não só à sua própria funcionalidade e estética, como à de outros elementos, estruturais 
ou não, que a ele estejam ligados. São exemplos desses danos o mau funcionamento de portas e janelas, o acúmulo de água em lajes de cobertura e a vibração excessiva em lajes de piso. Problemas como esses usualmente nada têm a ver com a segurança, mas provocam desconforto e, até mesmo, certa desconfiança dos usuários em sua resistência, principalmente se os deslocamentos forem visíveis a olho nu.

Sendo assim, na elaboração de um projeto estrutural em concreto armado, observa-se a necessidade de se considerar não apenas os requisitos de segurança, afastando a possibilidade de ruína, mas também os critérios de utilização, em especial os de deslocamentos excessivos, contribuindo para um desempenho satisfatório da estrutura em serviço.

\subsection{JUSTIFICATIVA}

Como já foi mencionado, os avanços da tecnologia dos materiais e das técnicas de análise estrutural proporcionaram uma redução das seções transversais das vigas e das espessuras das lajes. Com isso, embora se tenha obtido uma maior eficiência desses elementos, os pavimentos vêm se tornando cada vez mais flexíveis, e os problemas de deslocamentos excessivos, mais comuns. A necessidade de se efetuar uma avaliação consistente dos deslocamentos passou, então, a ser fundamental para o bom desempenho das estruturas em serviço.

Nesse contexto, as normas para o projeto de concreto estrutural vêm exigindo a verificação dos deslocamentos nos elementos fletidos. Os objetivos dessas prescrições vão desde a redução das necessidades de manutenção e reparos nas estruturas, até a garantia de que um elemento, apesar dos deslocamentos em relação à posição inicial, possa atender a critérios mínimos de aceitação tanto do ponto de vista estrutural quanto estético. Para isso, podem ser utilizados dois procedimentos: ou a adoção de uma altura mínima para a qual os deslocamentos já estariam verificados, ou o cálculo dos deslocamentos em cada elemento e sua posterior comparação com valores limite.

No primeiro procedimento, se a altura de um elemento for superior a um determinado limite, que deve ser respeitado independentemente da altura requerida pelo dimensionamento à flexão, pode-se admitir que seus deslocamentos não causarão danos à edificação. Alguns desses critérios de altura mínima são bastante simples, essencialmente empíricos, e baseados na observação e na experiência adquirida ao longo dos anos, para cada tipo de elemento estrutural. Outros, propostos por estudos mais recentes, já têm abordagens mais racionais, mas ainda fornecem expressões muito complexas. Diante disso, percebe-se a 
conveniência de se desenvolverem novos critérios de altura mínima, de aplicação prática, que consigam dosar as simplif icações e a necessidade de se considerarem diversos fatores importantes para o estudo dos deslocamentos.

No segundo procedimento, os deslocamentos podem ser determinados por diversos métodos, que consideram, com maior ou menor aproximação, a não-linearidade do concreto. Já os valores limites são pré-definidos pelas normas, variando de uma para outra, para os diferentes tipos de situações. Muitas vezes, entretanto, esse tipo de verificação torna-se um pouco complicada, e são duas as dificuldades principais: a previsão do comportamento em serviço, que envolve uma estimativa coerente das ações, da fissuração, da retração e da fluência, e o estabelecimento de valores limites razoáveis para cada caso, uma vez que eles variam em função de uma série de características do elemento em si e da estrutura. Além disso, trabalhos como o de GHALI (1993), o de SHERIF \& DILGER (1998), o de GILBERT (1999) e o de SCANLON et al. (2001), dentre outros, apontam alguns problemas usuais no cálculo dos deslocamentos por processos simplificados, relacionados, especialmente, aos valores adotados para o momento de inércia efetivo e para o multiplicador dos deslocamentos imediatos, em determinadas situações.

É bem verdade que a evolução de técnicas numéricas para a análise estrutural permitiu o desenvolvimento de programas computacionais para o cálculo dos deslocamentos a partir de relações constitutivas do material. Com isso, tornou-se possível uma melhor consideração tanto da influência da armadura e da colaboração do concreto tracionado existente entre as fissuras, para a rigidez à flexão da peça (tension stiffening), quanto dos fatores que provocam a não linearidade do material, como a fissuração, a retração e a fluência. Mas, na prática, a utilização desses programas não é usual, principalmente devido às dificuldades de acesso a essas ferramentas e ao maior tempo gasto para a execução do cálculo dos deslocamentos. Assim, os processos simplificados, apesar de suas limitações, ainda são bastante empregados nos projetos estruturais. O que é necessário fazer para melhorar os valores obtidos é calibrá-los e ajustá-los aos resultados de processos mais rigorosos.

Dentro dessa ótica e considerando-se o lançamento da norma brasileira de concreto estrutural, a NBR 6118 (2003), é necessário se avaliar os processos simplificados propostos, conhecer suas limitações e comparar seus resultados a valores experimentais e de outras normas. Além disso, tendo-se comentado as facilidades encontradas com a utilização dos critérios de altura mínima, percebem-se as vantagens de se introduzir um critério desse tipo na NBR 6118 (2003). Assim sendo, apesar de já ser conhecido há muito tempo, o problema dos deslocamentos excessivos ainda tem muito o que ser estudado. 


\subsection{OBJETIVOS}

O objetivo deste trabalho é estudar o comportamento de vigas, lajes e pavimentos com relação a seus deslocamentos, a partir da utilização de modelos numéricos mais rigorosos. Assim, poder-se-á avaliar qualitativamente e quantitativamente a influência dos diversos parâmetros envolvidos no cálculo desses deslocamentos, desenvolvendo-se critérios para a determinação da altura mínima para vigas e lajes de concreto armado que satisfaçam as verificações dos estados limites de deformações excessivas da NBR 6118 (2003). Esses critérios são estudados principalmente considerando-se os edifícios residenciais usuais, sugerindo valores e expressões que possam vir a subsidiar execução de cálculos que se utilizem desse procedimento normativo e que seja de simples e fácil aplicação. Além disso, são avaliadas as prescrições da NBR 6118 (2003) para o cálculo dos deslocamentos em elementos fletidos, com ênfase para os deslocamentos diferidos no tempo. Finalmente, avaliam-se exemplos completos de pavimentos de edifícios residenciais, de forma a apresentar os resultados com e sem a consideração da não-linearidade física dos materiais, e a aplicação das expressões para a determinação da altura mínima dos elementos isolados. Sugere-se, ainda, a obtenção dos deslocamentos não-lineares através de resultados prévios lineares convenientemente multiplicados por coeficientes que possam prever os efeitos de fissuração e fluência que usualmente estão presentes nesses pavimentos.

\subsection{ORGANIZAÇÃO DO TRABALHO}

No capítulo 2, apresenta-se um resumo atual e bem estruturado sobre os principais conceitos envolvidos no cálculo dos deslocamentos imediatos e diferidos no tempo. Além disso, são feitas considerações gerais sobre a fissuração, a fluência e a retração do concreto, além dos procedimentos para o cálculo e verificação dos deslocamentos fornecidos pelas seguintes normas de projeto de concreto estrutural: NBR 6118 (2003), ACI 318 (2002), CEB-FIP (1991) e sua atualização BULLETIN FIB (1999), e EUROCODE 2 (1992) e seu projeto de revisão EUROCODE FINAL DRAFT (1999).

Nos capítulos 3 e 4, tem-se o estudo dos deslocamentos de lajes e vigas em concreto armado, respectivamente. Estes elementos foram considerados isoladamente e seus deslocamentos foram calculados empregando-se o programa ANPAV, desenvolvido no SET-EESC-USP por OLIVEIRA (2001). A partir dos resultados obtidos, foi avaliada, quantitativamente e qualitativamente, a influência dos parâmetros adotados nos cálculos, colaborando para o entendimento do comportamento desses elementos com relação aos 
deslocamentos. Apresenta-se também uma proposta para o cálculo da altura mínima que satisfazem às verificações do estado limite de deformações excessivas impostas pela NBR 6118 (2003).

No capítulo 5 encontra-se o estudo de um pavimento completo de um edifício residencial para o qual são comentados os parâmetros necessários à sua análise e é apresentada uma comparação dos resultados obtidos com aqueles provenientes de uma análise linear convencional.

Por fim, no capítulo 6, são apresentadas as conclusões, algumas considerações finais sobre as análises realizadas e sugestões para novas pesquisas.

No anexo A são fornecidos alguns dos deslocamentos obtidos para as lajes e vigas isoladas. 


\section{2}

\section{DESLOCAMENTOS EM ELEMENTOS FLETIDOS}

\subsection{INTRODUÇÃO}

Quando um elemento estrutural é submetido a esforços de flexão, os pontos de seu eixo apresentam deslocamentos em relação à posição original. Uma parcela desses deslocamentos surge logo após a aplicação do carregamento: são os deslocamentos iniciais ou imediatos. A outra corresponde aos acréscimos que ocorrem com o passar do tempo: são os deslocamentos diferidos no tempo ou de longa duração. Assim, pode-se dizer que a posição final do elemento é função tanto do carregamento imposto quanto dos efeitos dependentes do tempo.

Neste capítulo, apresentam-se algumas considerações importantes ao entendimento tanto dos deslocamentos imediatos quanto dos diferidos, em elementos estruturais submetidos à flexão simples. São comentados os fatores que influenciam nos valores desses deslocamentos e alguns processos de cálculo utilizados. Além disso, são ressaltadas algumas formas usuais de verificação dos elementos em serviço. Por fim, destacam-se as principais recomendações normativas sobre a avaliação dos deslocamentos, constantes da NBR 6118 (2003), do ACI 318 (2002), do CEB-FIP (1991) e da sua atualização FIB (1999), e do EUROCODE 2 (1992) e do seu projeto de revisão EUROCODE FINAL DRAFT (2001).

\subsection{FATORES QUE AFETAM OS DESLOCAMENTOS}

Vários são os fatores que exercem influência, em maior ou menor escala, sobre a ordem de grandeza dos deslocamentos. Como menciona o ACI 435.2R (1966), podem ser 
citados, dentre outros: o tipo, a grandeza e o histórico do carregamento; o vão e as condições de apoio do elemento estrutural; as propriedades geométricas de sua seção transversal; as propriedades dos materiais utilizados; a fissuração, a retração e a fluência do concreto; as taxas de armadura de tração e de compressão; e o processo de execução da estrutura. Alguns deles afetam diretamente os valores dos deslocamentos, como o vão e o carregamento. Outros, indiretamente, como a taxa de armadura de compressão, que, na realidade, interfere na retração. Algumas dessas relações são comentadas a seguir.

\subsubsection{PROPRIEDADES DO CONCRETO}

As propriedades do concreto que exercem influência direta no cálculo dos deslocamentos são a resistência à tração e o módulo de elasticidade. Entretanto, a resistência à compressão, representada por seu valor característico $\mathbf{f}_{\mathbf{c k}}$, influencia indiretamente, já que, na ausência de dados experimentais, outras propriedades do concreto, como a resistência à tração e o módulo de elasticidade, podem ser determinadas a partir de correlações com o $\mathbf{f}_{\text {ck. }}$.

\section{a) Resistência à Compressão}

Vários fatores influenciam na resistência do concreto à compressão, mas pode-se dizer que ela é controlada basicamente pelas propriedades da pasta de cimento hidratada. Essas propriedades estão associadas à relação água-cimento, ao grau de hidratação, ao processo de cura, ao tipo e classe de resistência do cimento, ao tipo e quantidade de adições, aos aditivos, e à resistência e rigidez dos agregados. MEHTA \& MONTEIRO (1994) apresentam a forma com que cada um desses parâmetros afeta a resistência do concreto à compressão.

De um modo geral, o aumento do $\mathbf{f}_{\text {ck }}$ acarreta uma redução dos deslocamentos finais. A parcela inicial é diminuída tanto com o aumento do módulo de elasticidade e, conseqüentemente, da rigidez do elemento, quanto com a melhoria da resistência à tração na flexão, retardando o início da fissuração. Já a parcela diferida é atenuada devido à diminuição da fluência e da retração por secagem. Cabe comentar, entretanto, que a redução dos deslocamentos não tem a mesma proporção do aumento da resistência do concreto à compressão, e também que, se esse aumento for obtido a partir de um consumo muito elevado de cimento, os benefícios decorrentes da resistência mais alta podem até ser anulados pelo crescimento da retração química. 


\section{b) Módulo de Elasticidade}

Para materiais elásticos-lineares, de acordo com a Lei de Hooke, a tensão $\sigma$ é diretamente proporcional à deformação $\varepsilon$, ou seja:

$$
\sigma=\mathrm{E} \varepsilon
$$

A constante $\mathbf{E}$ que define a relação linear entre a tensão e a deformação é o chamado módulo de elasticidade.

Apesar do material concreto não apresentar um comportamento elástico-linear, tendo um diagrama tensão-deformação curvo, admite-se para cada valor de tensão atuante, associar um valor para o módulo de elasticidade secante.

De acordo com CUNHA \& FRANÇA (2000), o módulo de elasticidade secante considerado em uma determinada faixa de tensões na qual se deseja avaliar as deformações, permite a utilização de análises simplificadas levando-se em conta a característica não-linear do concreto. Desta forma, pela Figura 2.1, o módulo de elasticidade secante AB representa a aproximação do trecho $\mathrm{AB}$ pelo trecho A'B', da mesma forma que o módulo de elasticidade secante CD representa a aproximação do trecho CD pelo C'D'.

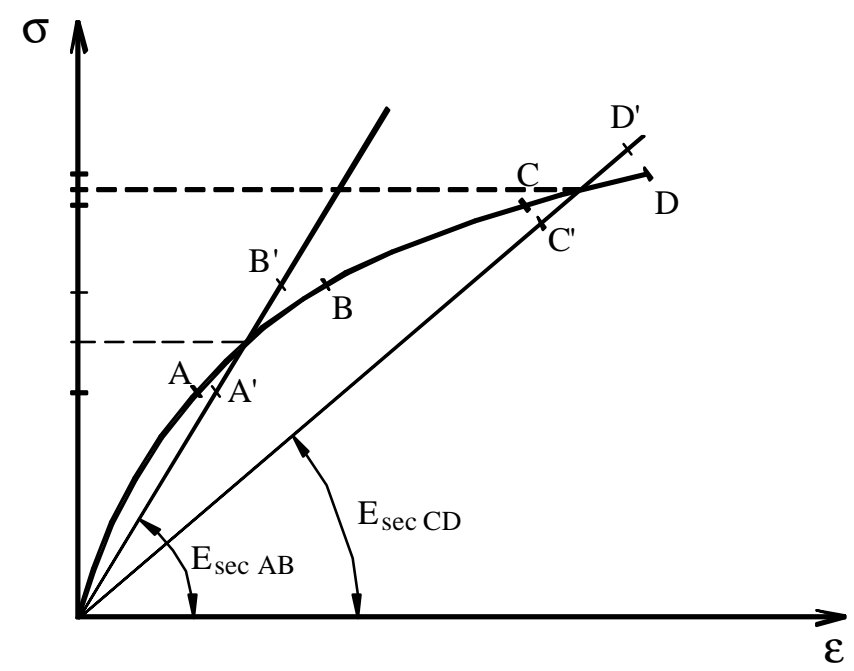

Figura 2.1 - Representação do módulo de elasticidade secante por faixa de tensão

(CUNHA \& FRANÇA, 2000)

A determinação experimental do módulo de elasticidade é feita a partir do diagrama tensão-deformação do concreto submetido à compressão. A partir desse diagrama, podem ser definidos alguns tipos de módulo de elasticidade, mas para fins de avaliação dos deslocamentos costuma-se utilizar apenas dois: o módulo de elasticidade tangente inicial, usado em análises mais rigorosas, baseadas em análise não-linear, e o módulo de elasticidade secante, usado em análises simplificadas, baseadas em análise linear. 
O módulo de elasticidade tangente inicial, $\mathbf{E}_{\mathbf{c i}}$, segundo a NBR 6118 (2003), é considerado como o módulo de elasticidade cordal equivalente a 0,5 MPA e $0,3 \mathrm{f}_{\mathrm{c}}$, e o módulo de elasticidade secante, $\mathbf{E}_{\mathrm{cs}}$, é definido como o módulo de elasticidade cordal equivalente a $0,5 \mathrm{MPa}$ e $0,45 f_{c}$, onde $\mathbf{f}_{\mathrm{c}}$ é a resistência à compressão do concreto. E a relação entre o módulo de elasticidade tangente inicial $\mathbf{E}_{\mathbf{c i}}$ o o módulo de elasticidade secante $\mathbf{E}_{\mathbf{c s}}$ é de 0,85 , ou seja:

$$
\mathrm{E}_{\mathrm{cs}}=0,85 \cdot \mathrm{E}_{\mathrm{ci}}
$$

O módulo de elasticidade do concreto é influenciado pelo módulo de elasticidade de seus componentes, principalmente os da pasta de cimento hidratada e dos agregados. De acordo com o FIB (1999), seu valor pode ser calculado a partir dos módulos de seus componentes, já existindo vários modelos que os levam em consideração. Entretanto, este procedimento torna-se pouco prático, pois apresenta o inconveniente de se ter que ensaiar a pasta e os agregados para a determinação de seus módulos de elasticidade. Por isso, com o intuito de simplificar tal estimativa, vários pesquisadores e normas de cálculo sugerem relações empíricas para a determinação de $\mathbf{E}_{\mathbf{c}}$. $\mathrm{O}$ principal parâmetro utilizado nessas relações é a resistência característica à compressão, o que, segundo o FIB (1999), se justifica com a hipótese de que o módulo de elasticidade da pasta de cimento hidratada é influenciado pela porosidade da mesma forma que a resistência à compressão do concreto.

As expressões fornecidas por algumas normas de cálculo são dadas a seguir na Tabela 2.1, e os resultados por elas fornecidos para diversos valores de resistência característica à compressão são representados na Figura 2.2.

Tabela 2.1 - Expressões para a determinação do módulo de elasticidade tangente inicial

\begin{tabular}{|l|c|}
\hline \multicolumn{1}{|c|}{ NORMA } & EXPRESSÃO \\
\hline NBR 6118 (2003) & $\mathrm{E}_{\mathrm{ci}}=5600 \cdot \sqrt{\mathrm{f}_{\mathrm{ck}}}$ \\
\hline ACI 318 (2002) & $\mathrm{E}_{\mathrm{c}}=4733 \cdot \sqrt{\mathrm{f}_{\mathrm{ck}}}$ \\
\hline CEB -FIP (1991) & $\mathrm{E}_{\mathrm{ci}}=2,15 \cdot 10^{4} \cdot\left[\frac{\left(\mathrm{f}_{\mathrm{ck}}+8\right)}{10}\right]^{1 / 3}$ \\
\hline EUROCODE 2 (1992) & $\mathrm{E}_{\mathrm{ci}}=9500 \cdot\left(\mathrm{f}_{\mathrm{ck}}+8\right)^{1 / 3}$ \\
\hline
\end{tabular}

Vale ressaltar que o ACI 318 (2002) apresenta apenas a expressão para o cálculo do módulo de elasticidade secante. Assim, na Figura 2.2, para efeito de comparação, os valores 
resultantes dessa expressão foram divididos por 0,85 , para a obtenção do módulo de elasticidade tangente inicial.

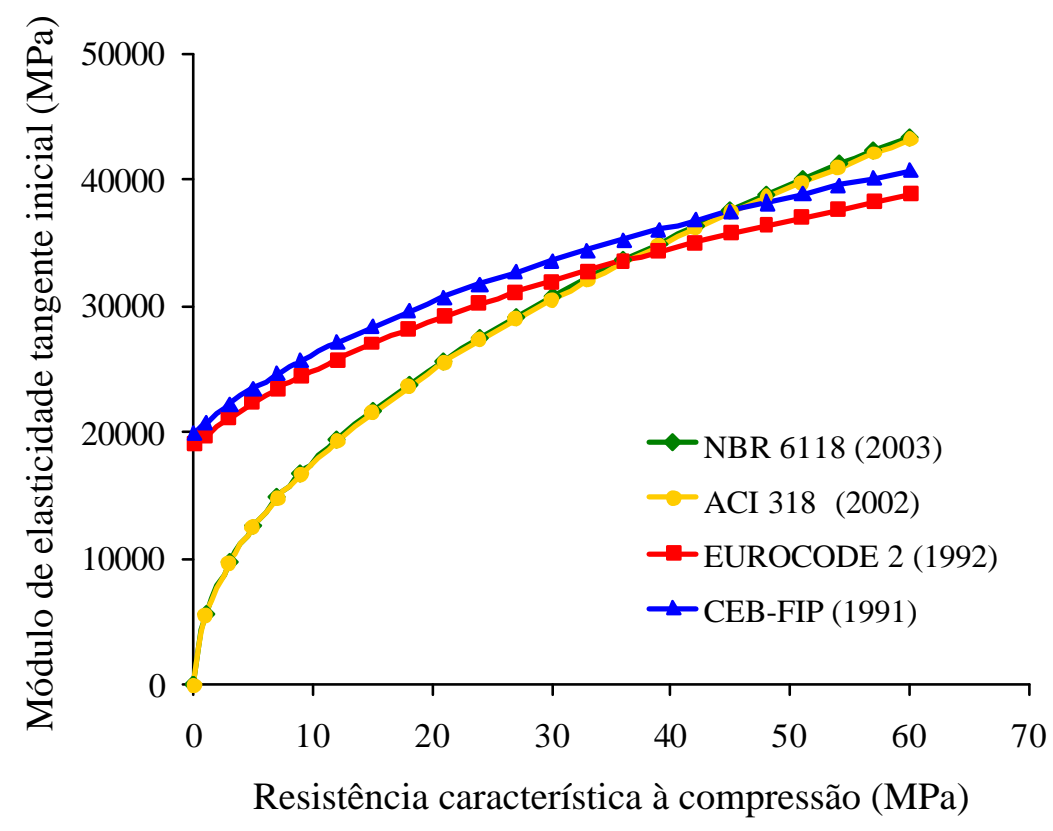

Figura 2.2 - Valores do módulo de elasticidade de acordo com algumas normas de cálculo

Quanto aos deslocamentos, sabe-se que para elementos submetidos à flexão simples e de acordo com os conceitos da Teoria da Elasticidade, estes são inversamente proporcionais aos valores de rigidez, sendo esta definida como o produto entre o módulo de elasticidade do material e o momento de inércia da seção transversal. Portanto, quanto maior for o módulo de elasticidade, menores serão os deslocamentos.

\section{c) Resistência à Tração}

Apesar de não influir significativamente no comportamento do concreto no estado limite último, a resistência à tração apresenta uma importância particular no estudo dos deslocamentos. É que ela define o início da fissuração, embora já existam microfissuras provocadas por tensões internas geradas durante o processo de endurecimento antes mesmo do carregamento ser aplicado. A fissuração causa uma diminuição na rigidez dos elementos fletidos e, conseqüentemente, um aumento de seus deslocamentos, conforme será visto adiante.

Como comentam LEONHARDT \& MÖNNIG (1977), podem ser definidos três tipos de ensaios para a determinação da resistência à tração. São eles: resistência à tração direta; resistência à tração na flexão e resistência à tração indireta ou por compressão diametral. 
A resistência à tração direta seria o melhor parâmetro para se avaliar o comportamento do concreto sob esforços de tração. Entretanto, como explicam HILSDORF \& MÜLLER (1999), o ensaio para a sua determinação, chamado de ensaio de tração axial, apresenta muitas dificuldades de execução, sendo utilizado quase que exclusivamente em pesquisas.

Já para a obtenção da resistência à tração na flexão, utilizam-se vigas biapoiadas de concreto simples submetidas à flexão, sendo esta provocada, em geral, por duas cargas concentradas nos terços do vão. Por ser mais simples, esse ensaio é mais usual que o de tração direta.

Quanto à resistência à tração indireta, sua determinação é feita através do ensaio de corpos-de-prova cilíndricos submetidos à compressão diametral, chamado de split cylinder test. Vale ressaltar que este ensaio foi desenvolvido pelo ilustre pesquisador brasileiro, Prof. Lobo Carneiro, por isso, é chamado em alguns países de ensaio brasileiro. Seus resultados são maiores que os da resistência à tração direta e menores que os da resistência à tração na flexão.

$\mathrm{Na}$ falta de valores experimentais, as normas de cálculo apresentam expressões para a determinação das resistências do concreto à tração em função da resistência característica do concreto à compressão $\mathbf{f}_{\mathbf{c k}}$. Assim, na Tabela 2.2, são fornecidas algumas expressões para a determinação da resistência média à tração, $\mathbf{f}_{\mathbf{c t m}}$, segundo algumas normas, sendo o MPa a unidade para as resistências, e, na Figura 2.3 tem-se uma comparação dos resultados. Observa-se que os resultados são bastante próximos. Apenas a expressão do ACI 318 (2002) leva a valores superiores que os das demais normas, sendo que à medida que a resistência à compressão aumenta, essa diferença diminui.

Tabela 2.2 - Expressões para o cálculo da resistência à tração

\begin{tabular}{|c|c|}
\hline NORMA & EXPRESSÃO \\
\hline NBR 6118(2003) & $\mathrm{f}_{\mathrm{ctm}}=0,30 \cdot \mathrm{f}_{\mathrm{ck}}^{2 / 3}$ \\
\hline ACI 318 (2002) & $\mathrm{f}_{\mathrm{ctm}}=0,623 \cdot \sqrt{\mathrm{f}_{\mathrm{ck}}}$ \\
\hline CEB -FIP (1991) & $\mathrm{f}_{\mathrm{ctm}}=\alpha_{\mathrm{fctm}}\left(\frac{\mathrm{f}_{\mathrm{ck}}}{\mathrm{f}_{\mathrm{cko}}}\right)^{2 / 3}$ \\
\hline EUROCODE 2(1992) & $\mathrm{f}_{\mathrm{ctm}}=0,30 \cdot \mathrm{f}_{\mathrm{ck}}{ }^{2 / 3}$ \\
\hline$\alpha_{\mathrm{fctm}}=1,4$ & $\mathrm{f}_{\mathrm{cko}}=10 \mathrm{MPa}$ \\
\hline
\end{tabular}




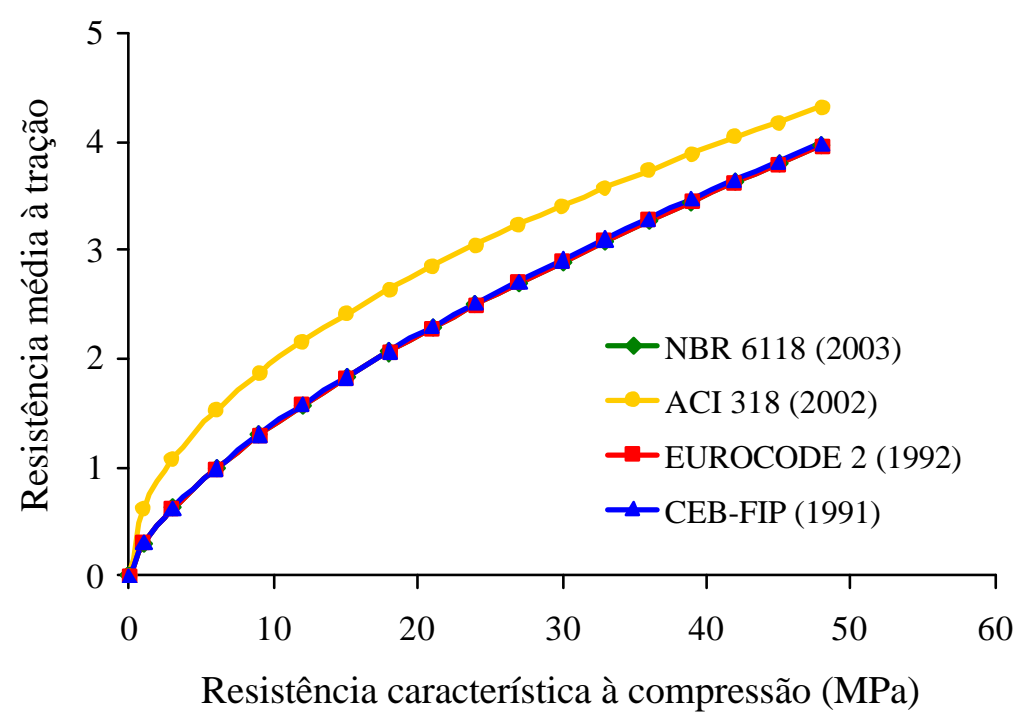

Figura 2.3 - Resistência à tração de acordo com algumas normas de cálculo

Conforme comentado anteriormente, mesmo antes da aplicação do carregamento, já existem microfissuras na região da interface entre a pasta de cimento e o agregado, chamada de zona de transição, que são geradas durante o processo de endurecimento da pasta, e causadas pela exudação, retração por secagem, entre outro fatores. O comportamento dessa região influencia significativamente o módulo de elasticidade e a resistência à tração, já que normalmente é aí onde o concreto rompe com um nível de solicitação inferior a resistência da pasta e do agregado. A Figura 2.4 ilustra a evolução da fissuração nessa interface.

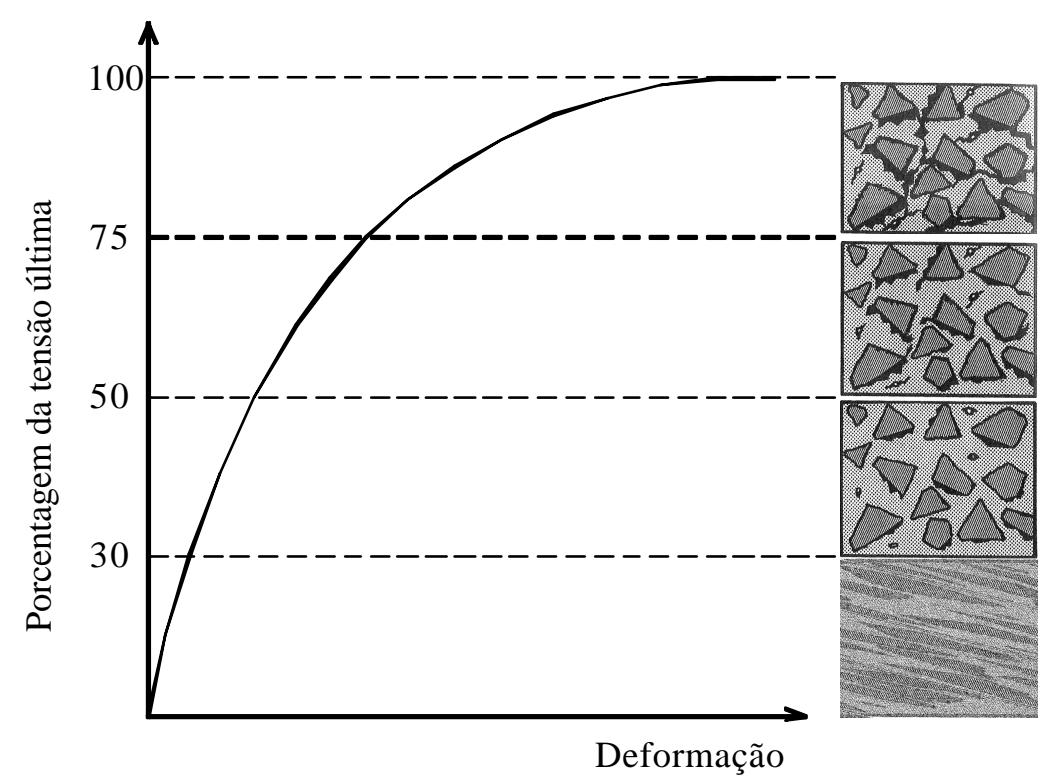

Figura 2.4 - Evolução da fissuração na interface entre a pasta e o agregado para concreto sob compressão uniaxial, (METHA \& MONTEIRO, 1994) 


\subsubsection{FISSURAÇÃO}

Como já foi comentado, os deslocamentos em elementos fletidos são inversamente proporcionais aos valores da rigidez à flexão. Para elementos em concreto armado, a rigidez depende do estágio de fissuração de cada peça, considerado através da variação do momento de inércia. Assim sendo, para compreender o desenvolvimento dos deslocamentos em vigas e lajes, é necessário se conhecer um pouco o comportamento das peças na presença de fissuras.

É usual a ocorrência de fissuras em estruturas de concreto armado. Embora já existam as microfissuras na zona de transição entre a pasta e o agregado, conforme mencionado anteriormente, admite-se que a fissuração comece quando a resistência à tração do concreto seja atingida.

Na Figura 2.5, tem-se um diagrama momento-curvatura típico de um elemento em concreto armado submetido à flexão, e nele é apontada a evolução da fissuração com o nível de solicitação.

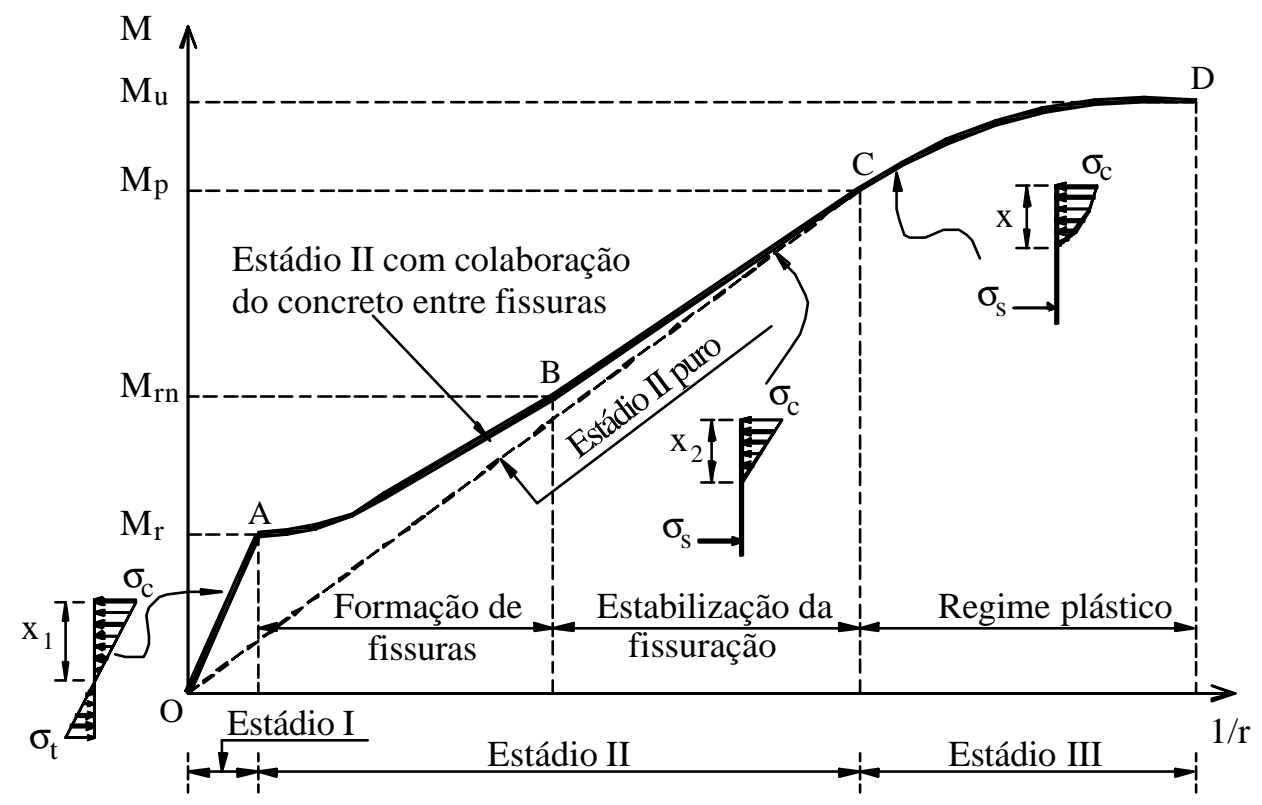

Figura 2.5 - Diagrama momento-curvatura de um elemento fletido.

Para pequenos valores de momentos, trecho $\mathrm{AO}$, a seção não apresenta fissuras, ou seja, a tensão máxima de tração é menor que a resistência do concreto à tração, e pode-se admitir um comportamento elástico e linear (Estádio I). Neste caso, tanto o concreto da região comprimida como o da tracionada, além da armadura, colaboram para a rigidez à flexão do elemento. Para as condições de serviço, apenas alguns trechos dos elementos fletidos apresentam essas características. 
Quando a tensão máxima de tração atinge a resistência do concreto à tração (ponto A), surge a primeira fissura na região onde o momento fletor é máximo, e, à medida que o momento solicitante aumenta de valor surgem novas fissuras. Assim, a contribuição do concreto na zona tracionada diminui, reduzindo também a rigidez à flexão. Essa formação de fissuras ocorre até certo nível de solicitação (ponto B). A partir daí, o aumento da solicitação não acarreta a formação de novas fissuras, mas as existentes apresentam maiores aberturas e comprimentos. Isso ocorre até que as seções transversais já possam ser consideradas totalmente fissuradas (ponto C). Esta fase de abertura e estabilização das fissuras caracteriza o Estádio II.

Em serviço, a maior parte das seções transversais dos elementos fletidos de concreto armado rabalham nesses dois últimos estágios, para as quais a rigidez é determinada desprezando-se a parcela do concreto da região tracionada.

No Estádio III, mesmo sem acréscimo significativo de momento, o elemento continua a se deformar. A linha neutra de aproxima da face comprimida, ocorrendo uma ruína secundária por esmagamento do concreto (ponto D).

Percebe-se, então, que para um elemento fletido que apresenta momentos fletores variando ao longo do vão, surgirão seções não fissuradas, nas regiões onde o momento fletor é mais baixo, e seções parcialmente ou totalmente fissuradas, nas regiões de momento fletor mais elevado. Este comportamento pode ser observado, por exemplo, na viga representada na Figura 2.6, submetida a um carregamento considerado uniformemente distribuído: as seções transversais nas regiões próximas aos apoios, onde os momentos fletores tendem a zero, não apresentam muitas fissuras, já na região do meio do vão, onde os valores dos momentos são mais altos, as seções estão bastante fissuradas.

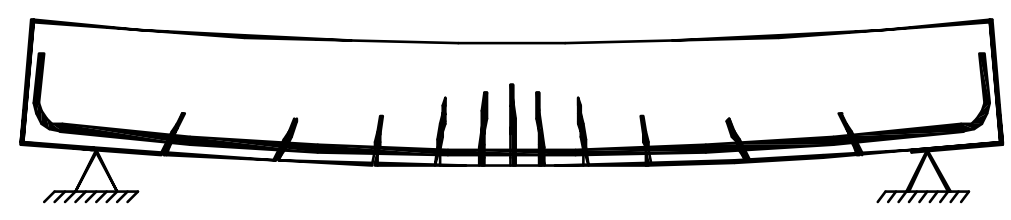

Figura 2.6 - Exemplo de distribuição das fissuras em uma viga

Desta forma, a seção que apresenta menor rigidez é aquela localizada na posição de uma fissura, e, obviamente, a seção de maior rigidez é aquela localizada em um trecho sem fissuras. Assim, pela Figura 2.6, pode-se notar que entre as seções fissuradas, existem trechos de concreto íntegro e que, portanto, ainda apresentam alguma resistência à tração, colaborando, desta forma, para a rigidez à flexão da viga. Este comportamento é chamado de 
enrijecimento devido ao concreto tracionado (tension stiffening), e é de fundamental importância para a avaliação dos deslocamentos. Sua desconsideração pode levar a uma subestimativa considerável da rigidez à flexão, já que as seções seriam consideradas totalmente fissuradas, e o diagrama momento curvatura seria representado pela linha tracejada OC, mostrada na Figura 2.5.

Portanto, para se determinar a rigidez à flexão a ser utilizada no cálculo dos deslocamentos de um elemento estrutural, em suas condições de serviço, é essencial uma análise criteriosa do seu estágio de fissuração.

\subsubsection{RETRAÇÃO}

A retração é caracterizada pela diminuição do volume de um elemento de concreto, independentemente das ações nele atuantes, e progressivamente com o tempo. Sua ordem de grandeza é influenciada por diversos fatores, podendo-se citar os materiais constituintes e a dosagem do concreto, o tempo, as condições ambiente de umidade e a temperatura, a geometria do elemento estrutural, a idade do concreto quando começa o processo de secagem, e a quantidade de armadura de compressão e de tração. Comentários sobre a relação entre esses aspectos e a retração podem ser encontrados em MEHTA \& MONTEIRO (1994), LEONHARDT \& MÖNNIG (1977), WANG \& SALMON (1985) e no ACI 435.2R (1966).

A depender de sua causa, podem ser definidos alguns tipos de retração. São eles: a retração plástica, a retração por carbonatação, a retração química (ou endógena) e a retração por secagem.

A retração plástica ocorre por perda de água do concreto ainda na sua fase de endurecimento. A retração por carbonatação é causada pela reação da pasta de cimento hidratada com o dióxido de carbono do ar, na presença de umidade. A retração química, provocada pelas reações químicas que ocorrem na pasta de cimento, está associada ao avanço da hidratação do cimento, e não tem relação com as condições do ambiente. Já a retração por secagem acontece a partir da evaporação da água não fixada quimicamente no concreto, quando este é exposto a um ambiente com umidade relativa menor que $100 \%$.

Assim, a retração começa logo que o concreto é lançado, com a retração plástica, e aumenta com o tempo devido ao processo de secagem. Após alguns anos, entretanto, esse aumento é praticamente desprezível. Segundo o ACI 435.2R (1989), com um ano do início da retração, esta já apresenta aproximadamente $80 \%$ do valor que teria com vinte anos. 
Vale ressaltar que, se um elemento de concreto, após a secagem, for submetido a um processo de molhagem, a retração apresenta certo grau de reversibilidade, como indicado na Figura 2.7.

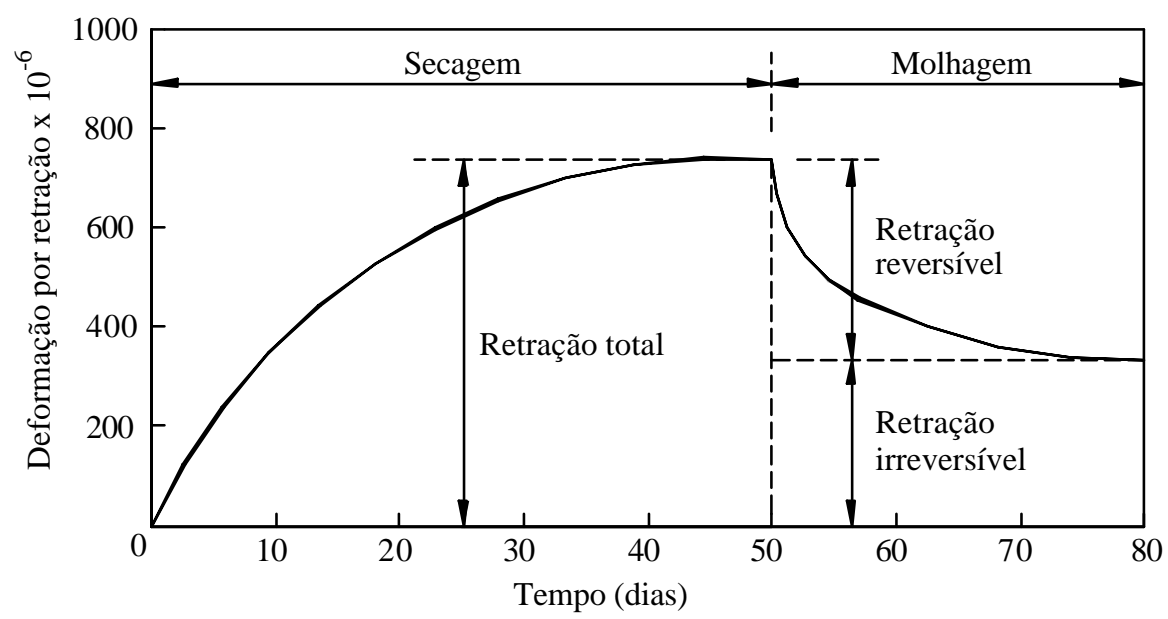

Figura 2.7 - Reversibilidade da retração (MEHTA \& MONTEIRO, 1994)

Utilizando-se procedimentos de moldagem e cura adequados, além de uma dosagem conveniente para o concreto, a retração plástica pode ser minimizada e até evitada. Já para as retrações por secagem e química, que têm valores razoáveis nos diversos tipos de concreto, o controle é bem mais difícil. No caso dos concretos de alta resistência, como há menos quantidade de água livre após a hidratação, a retração por secagem é menor que em concretos de resistência normal, mas ainda significativa. Por outro lado, a retração química é consideravelmente maior.

Desta forma, para o projeto estrutural, pode-se supor que a retração do concreto é dada pelo somatório das retrações por secagem e química. Apesar do CEB-FIP (1991) e do EUROCODE (1992), por exemplo, apresentarem expressões para o cálculo da deformação por retração apenas com a parcela devida à retração por secagem, suas recentes revisões, FIB (1999) e EUROCODE FINAL DRAFT (2001), já as apresentam como o somatório das duas parcelas. Vários pesquisadores também apresentam modelos para a determinação da deformação por retração através do estudo de suas parcelas, como GILBERT (2001) e BAZANT (2001).

Se as estruturas pudessem trabalhar livremente, a retração não traria grandes conseqüências. Entretanto, tal fato não ocorre na prática devido à presença de apoios, de elementos adjacentes, e da armadura. Essa restrição à livre deformação por retração é que gera problemas como a fissuração de regiões previamente íntegras, e o aumento tanto da abertura das fissuras já existentes como dos deslocamentos. 
No caso particular dos elementos fletidos, a maior ou menor influência da retração também depende da assimetria, tanto no posicionamento quanto nas áreas de aço das armaduras de tração e de compressão. É que, como a armadura de tração normalmente é maior que a armadura de compressão, o encurtamento devido à retração na região tracionada é menor que na região comprimida, fazendo com que surja uma curvatura adicional na mesma direção da curvatura devida à flexão. Conseqüentemente, há um aumento nos deslocamentos.

\subsubsection{FLUÊNCIA}

Em uma peça de concreto submetida a ações de longa duração, a água não fixada quimicamente, existente nos microporos do gel de cimento, é comprimida e evapora. Isso provoca uma diminuição do volume do elemento, que é a chamada fluência.

Apesar de serem fenômenos distintos, a fluência e a retração costumam ser tratadas conjuntamente. Isto ocorre, dentre outros motivos, porque ambas são caracterizadas pela perda de água adsorvida da pasta de concreto, são influenciadas basicamente pelos mesmos fatores e têm como consequiência o aumento das deformações e dos deslocamentos com o tempo.

Assim como retração, a fluência aumenta com uma taxa mais acentuada no início do processo, diminuindo com o tempo, e também é parcialmente reversível. Se a carga for removida após um certo período, parte da fluência é recuperada elasticamente, restando ainda uma porção residual, como pode ser visto na Figura 2.8.

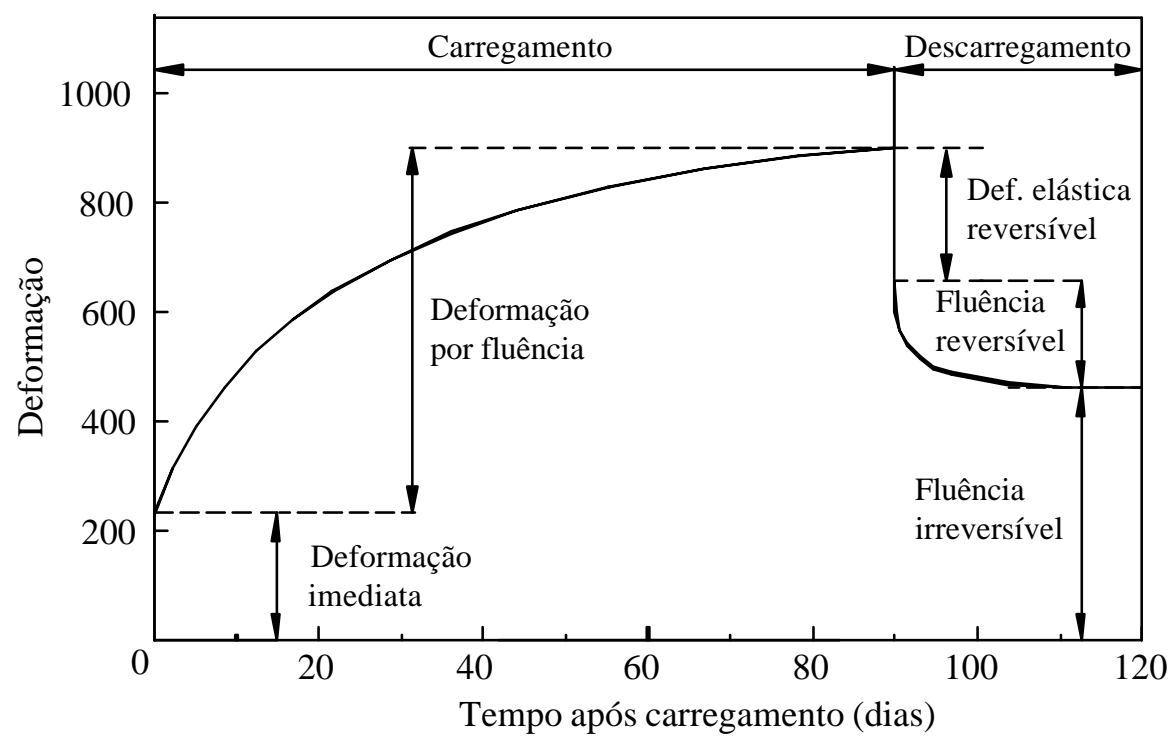

Figura 2.8 - Reversibilidade da fluência (MEHTA \& MONTEIRO, 1994) 
É importante ressaltar, entretanto, que a fluência e a retração são fenômenos com bases conceituais distintas. Enquanto na retração por secagem a origem da perda de água é a diferença de umidade entre o elemento de concreto e o meio ambiente, na fluência, essa perda está associada à aplicação continuada de uma ação. Além disso, a duração e a intensidade das ações, bem como a idade do concreto ao primeiro carregamento, são aspectos relevantes ao estudo da fluência, mas que não influenciam na retração.

De uma maneira geral, o que se observa é que a fluência provoca um acréscimo significativo das deformações do concreto na zona comprimida, conforme representado na Figura 2.9, para uma seção no Estádio II. Como na zona tracionada esse acréscimo é consideravelmente menor, já que é muito pequena a contribuição do concreto e a fluência do aço é praticamente desprezível, a deformação na armadura praticamente não se altera. A posição da linha neutra se aproxima da armadura de tração e observa-se uma curvatura adicional à de flexão, que provoca o aumento da curvatura final, e conseqüentemente, dos deslocamentos. Pode-se notar que o aumento da deformação de compressão é muito maior do que o aumento da curvatura.

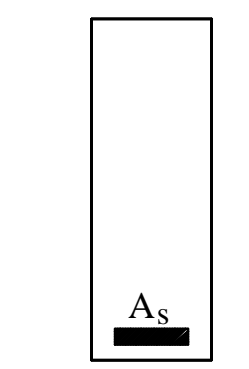

Seção transversal

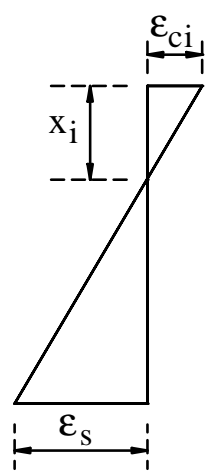

Deformações imediatas devidas ao carregamento

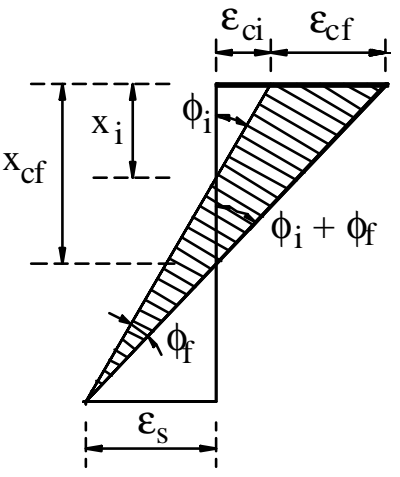

Deformações após a ocorrência da fluência

Figura 2.9 - Efeito da fluência na curvatura de uma seção (WANG \& SALMON, 1985)

Para o cálculo dessas deformações devidas à fluência, existem vários modelos que fornecem bons resultados, dentre os quais pode-se citar o de GHALI \& FAVRE (1986), o do CEB-FIP (1991), o de BAZANT (2001), e o do EUROCODE 2 (1992).

\subsection{CÁLCULO DOS DESLOCAMENTOS}

Para a determinação dos deslocamentos, tanto imediatos quanto diferidos, vários métodos podem ser empregados, como é apresentado nos itens seguintes. 


\subsubsection{CONSIDERAÇÕES INICIAIS}

Os diferentes métodos para o cálculo dos deslocamentos utilizam alguns parâmetros em comum, discutidos neste item.

\section{a) Seção Transversal Homogeneizada}

Para uma melhor estimativa do valor do momento de inércia de uma seção de concreto armado, é necessário se considerar a influência das armaduras de tração e de compressão. Para isso, uma possibilidade é a utilização da seção homogeneizada, na qual se substitui a área de aço por uma área equivalente de concreto, dada por $\left(\mathrm{E}_{\mathrm{s}} / \mathrm{E}_{\mathrm{c}}\right) \cdot \mathrm{A}_{\mathrm{s}}$. Como a relação entre os módulos de elasticidade do aço e do concreto, também chamada de razão modular, é representada por $\alpha_{\mathrm{e}}$, a área equivalente de concreto é dada por $\alpha_{\mathrm{e}} \cdot \mathrm{A}_{\mathrm{s}}$.

A rigor, nos casos em que essa área equivalente desloca uma área de aço $\mathbf{A}_{\mathbf{s}}$ da armadura de tração, para peças no Estádio I, ou $\mathbf{A}_{\mathbf{s}}$, da armadura de compressão, as áreas equivalentes de concreto são dadas por $\left(\alpha_{\mathrm{e}}-1\right) \cdot \mathrm{A}_{\mathrm{s}}$ ou $\left(\alpha_{\mathrm{e}}-1\right) \cdot \mathrm{A}_{\mathrm{s}}^{\prime}$, respectivamente.

Considerando-se a seção transversal não fissurada, ilustrada na Figura 2.10, de um elemento submetido à flexão simples, para o cálculo do momento de inércia da seção homogeneizada, que, nesse caso, leva em conta a contribuição do concreto da região tracionada, deve-se inicialmente determinar a posição da linha neutra. Esta pode ser obtida igualando-se a zero o momento estático em relação à linha neutra. Desta forma, tem-se:

$$
x_{I}=\frac{\frac{b \cdot h^{2}}{2}+\left(\alpha_{e}-1\right) \cdot A_{s} \cdot d+\left(\alpha_{e}-1\right) \cdot A_{s}^{\prime} \cdot d^{\prime}}{b \cdot h+\left(\alpha_{e}-1\right) \cdot A_{s}+\left(\alpha_{e}-1\right) \cdot A_{s}^{\prime}}
$$

logo, o momento de inércia vale:

$$
I_{I}=\frac{b \cdot h^{3}}{12}+b \cdot h \cdot\left(x_{I}-\frac{h}{2}\right)^{2}+\left(\alpha_{e}-1\right) \cdot A_{s} \cdot\left(d-x_{I}\right)^{2}+\left(\alpha_{e}-1\right) \cdot A_{s}^{\prime} \cdot\left(x_{I}-d^{\prime}\right)^{2}
$$

sendo:

b a largura da seção transversal;

h a altura da seção transversal;

$\alpha_{\mathrm{e}} \quad$ a razão entre os módulos de elasticidade do aço e do concreto;

d a distância do centro de gravidade da armadura de tração até a fibra mais comprimida; 
d' a distância do centro de gravidade da armadura de compressão até a fibra mais comprimida;

$\mathbf{A}_{\mathrm{s}} \quad$ a área de aço da armadura de tração;

$\mathbf{A}_{\text {s }} \quad$ a área de aço da armadura de compressão;

$\mathbf{x}_{\mathbf{I}}$ a altura da linha neutra, em relação à face comprimida;

I $\mathbf{I}$ o momento de inércia da seção não fissurada homogeneizada.

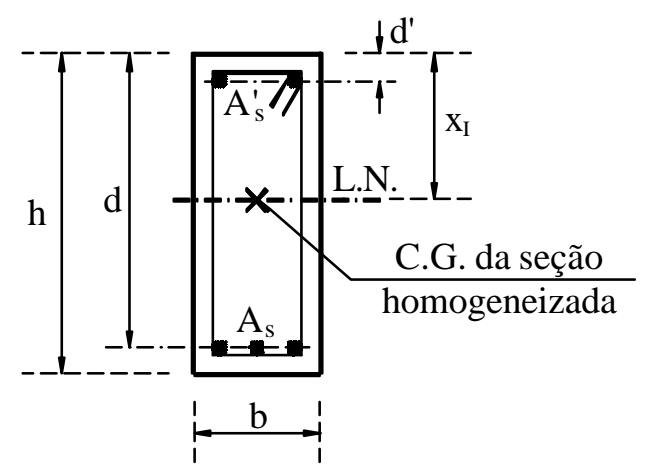

Figura 2.10 - Seção transversal não fissurada

É importante ressaltar que a diferença entre o valor do momento de inércia da seção homogeneizada $\mathbf{I}_{\mathbf{I}}$, e o momento de inércia da seção bruta de concreto $\mathbf{I}_{\mathbf{c}}$, é pequena para vigas com taxas de armadura usuais, como demonstrado por NAWY (1996). Por isso, podese utilizar o valor de $\mathbf{I}_{\mathbf{c}}$ em vez de $\mathbf{I}_{\mathbf{I}}$ no cálculo dos deslocamentos. Entretanto, para vigas densamente armadas, os efeitos da armadura já são mais significativos e devem ser considerados.

Analisando agora, uma seção transversal fissurada, de um elemento submetido à flexão simples, o cálculo do momento de inércia é semelhante ao de uma seção não fissurada. A única diferença é que o concreto sob tração, região tracejada na Figura 2.11, é desprezado. Assim, a posição da linha neutra é determinada a partir da equação:

$$
\frac{\mathrm{b} \cdot \mathrm{x}_{\mathrm{II}}^{2}}{2}+\left[\alpha_{\mathrm{e}} \cdot\left(\mathrm{A}_{\mathrm{s}}^{\prime}+\mathrm{A}_{\mathrm{s}}\right)-\mathrm{A}_{\mathrm{s}}^{\prime}\right] \cdot \mathrm{x}_{\mathrm{II}}+\left[\mathrm{A}_{\mathrm{s}}^{\prime} \cdot \mathrm{d}^{\prime}-\alpha_{\mathrm{e}} \cdot\left(\mathrm{A}_{\mathrm{s}}^{\prime} \cdot \mathrm{d}^{\prime}+\mathrm{A}_{\mathrm{s}} \cdot \mathrm{d}\right)\right]=0
$$

Na qual se iguala a zero o momento estático em relação à linha neutra da seção. Assim, o momento de inércia é dado por:

$$
I_{I I}=\frac{b \cdot x_{I I}^{3}}{3}+\left(\alpha_{e}-1\right) \cdot A_{s}^{\prime} \cdot\left(x_{I I}-d^{\prime}\right)^{2}+\alpha_{e} A_{s}\left(d-x_{I I}\right)^{2}
$$

na qual: 
$\mathbf{x}_{\text {II }}$ é a altura da linha neutra da seção fissurada, em relação à face comprimida;

III é o momento de inércia da seção fissurada no Estádio II.

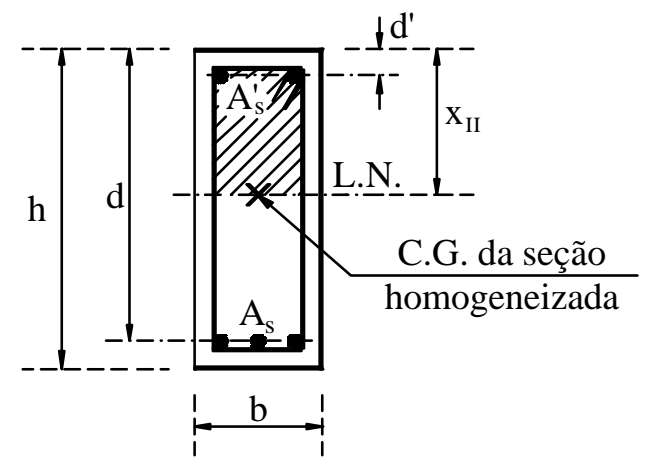

Figura 2.11 - Seção transversal fissurada

\section{b) Momento de Fissuração}

O momento de fissuração pode ser definido como aquele que provoca a primeira fissura em uma peça de concreto submetida à flexão. Nesse ponto, a tensão de tração atuante atinge a resistência do concreto à tração.

De acordo com a Resistência dos Materiais, o momento fletor atuante em uma seção é dado por:

$$
\mathrm{M}=\frac{\mathrm{I} \cdot \sigma}{\mathrm{y}}
$$

sendo:

$\sigma \quad$ a tensão de flexão atuante na seção;

I o momento de inércia de seção;

y a distância da fibra mais comprimida à linha neutra.

A partir da eq.(2.5), pode-se escrever o momento de fissuração como:

$$
\mathrm{M}_{\mathrm{r}}=\frac{\mathrm{I}_{\mathrm{c}} \cdot \mathrm{f}_{\mathrm{ctm}}}{\mathrm{y}_{\mathrm{t}}}
$$

na qual:

I $\quad$ é o momento de inércia da seção bruta de concreto;

$\mathbf{f}_{\text {ctm }} \quad$ é o módulo de ruptura do concreto, ou a resistência do concreto à tração na flexão;

$\mathbf{y}_{\mathbf{t}} \quad$ é a distância do centro de gravidade da seção à fibra mais tracionada. 
Pode-se observar que, como já comentado, é permitido o uso do momento de inércia da seção bruta de concreto no lugar do momento de inércia da seção homogeneizada, $\mathbf{I}_{\mathbf{I}}$. Entretanto, segundo o ACI 435.2R (1966), o uso de $\mathbf{I}_{\mathbf{c}}$ fornece bons resultados apenas para vigas pouco fissuradas e com baixas taxas de armadura, podendo provocar uma subestimativa dos deslocamentos se aplicado em outros casos.

\section{c) Momento de Inércia Efetivo}

Como visto anteriormente, ao longo de um vão de um elemento fletido em concreto armado, encontram-se seções fissuradas e não fissuradas, com o concreto íntegro entre as fissuras colaborando para a rigidez da peça. Pode-se concluir, então, que existem seções nas quais o momento de inércia será menor do que o momento de inércia da seção não fissurada homogeneizada, e maior do que o momento de inércia da seção fissurada homogeneizada.

Visando à avaliação da influência da fissuração e da colaboração do concreto tracionado entre as fissuras no momento de inércia da seção transversal, BRANSON (1965) realizou um estudo experimental em vigas retangulares e $\mathrm{T}$, simplesmente apoiadas e contínuas, submetidas a carregamentos uniformemente distribuídos e de curta duração. Baseado nos resultados de seus ensaios e nos de outros pesquisadores, ele sugeriu a utilização de um valor médio de momento de inércia, compreendido entre o momento de inércia da seção não fissurada $\mathbf{I}_{\mathbf{c}}$ e o da seção fissurada homogeneizada $\mathbf{I}_{\text {II }}$, chamado de momento de inércia efetivo, dado por:

$$
\mathrm{I}_{\mathrm{e}}=\left(\frac{\mathrm{M}_{\mathrm{r}}}{\mathrm{M}}\right)^{\mathrm{m}} \cdot \mathrm{I}_{\mathrm{c}}+\left[1-\left(\frac{\mathrm{M}_{\mathrm{r}}}{\mathrm{M}}\right)^{\mathrm{m}}\right] \cdot \mathrm{I}_{\mathrm{II}} \leq \mathrm{I}_{\mathrm{c}}
$$

sendo:

$\mathbf{M}_{\mathbf{r}} \quad$ o momento de fissuração;

M o momento fletor atuante na seção transversal;

I $\quad$ o momento de inércia da seção bruta de concreto;

III o momento de inércia da seção de concreto fissurada, no Estádio II;

m a potência que define se o momento de inércia está sendo calculado para seções individuais ou para todo um vão.

Para a determinação do momento de inércia efetivo em seções individuais de um vão qualquer, a potência $\mathbf{m}$ da eq.(2.7) deve ser igual a 4. Já para um valor médio correspondente a todas as seções ao longo do comprimento do vão, a potência $\mathbf{m}$ deve ser igual a 3, e a eq.(2.7) passa a ser escrita como: 


$$
I_{e}=\left(\frac{M_{r}}{M_{\text {máx }}}\right)^{3} \cdot I_{c}+\left[1-\left(\frac{M_{r}}{M_{\text {máx }}}\right)^{3}\right] \cdot I_{I I} \leq I_{c}
$$

na qual $\mathbf{M}_{\text {máx }}$ é o momento fletor máximo atuante no vão.

O ACI 435.2R (1966) e NAWY (1996) recomendam, principalmente para vigas com altas taxas de armadura, o uso do momento de inércia da seção não fissurada homogeneizada $\mathbf{I}_{\mathbf{I}}$, dado pela eq.(2.2), em vez de $\mathbf{I}_{\mathbf{c}}$ na eq.(2.8).

No caso de vigas contínuas, os momentos de inércia efetivos para as regiões de momento positivo e negativo normalmente não têm o mesmo valor. Ainda assim, o ACI 435.5R (1973), permite considerar apenas o momento de inércia da seção do meio do vão, desprezando os momentos negativos nos apoios, já que, muitas vezes, a seção que governa os deslocamentos é a central. Entretanto, também fornece outras opções, podendo-se obter o valor do momento de inércia efetivo por tramo a partir de:

- uma média ponderada entre o momento de inércia efetivo da região de momento positivo e o da região de momentos negativos nos apoios, dada por:

$$
\mathrm{I}_{\mathrm{e}}=0,70 \cdot \mathrm{I}_{\mathrm{m}}+0,15 \cdot\left(\mathrm{I}_{\mathrm{e} 1}+\mathrm{I}_{\mathrm{e} 2}\right)
$$

na qual, $\mathbf{I}_{\mathbf{m}}$ é o momento de inércia efetivo para a seção do meio do vão e $\mathbf{I}_{\mathbf{e} 1}$ e $\mathbf{I}_{\mathbf{e} 2}$ são, respectivamente, o momento de inércia efetivo da seção do apoio esquerdo e o momento de inércia efetivo da seção do apoio direito.

- uma média simples entre o momento de inércia efetivo da região de momento positivo e o da região de momentos negativos nos apoios, dada por:

$$
I_{e}=\frac{I_{m}+\frac{1}{2} \cdot\left(I_{e 1}+I_{e 2}\right)}{2}
$$

É importante ressaltar que, apesar de ser bastante empregada, a eq.(2.8) apresenta algumas limitações. Além de não considerar a influência de alguns parâmetros importantes, há situações em que a sua utilização não conduz a bons resultados.

Os ensaios de AL-ZAID et al. (1991), por exemplo, mostram que o tipo de carregamento aplicado em vigas pode influir nos valores de $\mathbf{I}_{\mathrm{e}}$. Ao contrário do que indica a eq.(2.8), os momentos de inércia efetivos variaram para vigas iguais, submetidas ao mesmo 
momento fletor, apenas com a diferença de que, em algumas, atuavam cargas concentradas, e em outras, cargas distribuídas. Os valores calculados de $\mathbf{I}_{\mathbf{e}}$ ficaram mais próximos dos experimentais obtidos com a carga distribuída, sendo até $25 \%$ menores que os obtidos para cargas concentradas. Tentando minimizar esse problema, AL-ZAID et al. (1991) sugerem que a potência $\mathbf{m}$ da eq.(2.7) tenha valores diferentes para cada tipo de carregamento.

Já os ensaios de AL-SHAIKH \& AL-ZAID (1993) para vigas mostram a grande influência da taxa de armadura no momento de inércia efetivo. Percebeu-se que, quanto maior a taxa de armadura, maiores os valores de $\mathbf{I}_{\mathbf{e}}$. Nesses ensaios foram obtidos valores de $\mathbf{I}_{\mathrm{e}}$ até 55\% maiores que os valores calculados utilizando-se a eq.(2.8), para peças densamente armadas. AL-SHAIKH \& AL-ZAID (1993) ainda comentam que, mesmo se utilizando o momento de inércia da seção não fissurada homogeneizada $\mathbf{I}_{\mathbf{I}}$ na eq.(2.8), o efeito total da armadura não é suficientemente considerado. A solução apresentada por eles é que a potência $\mathbf{m}$ da eq.(2.7) passe de uma constante para uma expressão em função da taxa de armadura.

GHALI (1993) e SHERIF \& DILGER (1998) mostram que a eq.(2.8) não fornece bons resultados para os casos de momentos atuantes muito próximos do momento de fissuração e para os casos de elementos com taxas de armadura muito baixas, nos quais os deslocamentos são subestimados. Não há boa aproximação de resultados também para os casos de vigas com momentos constantes ao longo da maior parte do vão, como conclui GHALI (1993).

Apesar dessas considerações, a eq.(2.8) pode fornecer uma boa estimativa dos valores do momento de inércia efetivo, principalmente para elementos com taxas de armadura de tração superiores a 0,6\%, e submetidos a um momento máximo significativamente maior que o momento de fissuração, como comenta GILBERT (1999).

\subsubsection{CÁLCULO DE DESLOCAMENTOS IMEDIATOS}

O deslocamento imediato é função, principalmente, do tipo e da grandeza do carregamento aplicado, do nível de fissuração, do comprimento do vão, das condições de apoio, das propriedades geométricas da seção transversal e das propriedades dos materiais, aço e concreto. Além disso, é calculado de formas diferentes para elementos lineares, como vigas e lajes armadas em uma direção, e elementos bidimensionais, como lajes armadas em duas direções. 


\section{a) Vigas e Lajes Armadas em uma Direção}

Para vigas e lajes armadas em uma direção, o cálculo dos deslocamentos imediatos pode ser efetuado desde que se conheçam ou se possam estimar as relações momentocurvatura das seções desses elementos.

A curvatura de uma seção pode ser definida como a mudança do ângulo entre as extremidades de uma unidade de comprimento do elemento. É dada pelo inverso do raio de curvatura da seção, $\mathbf{1 / r}$, e é função do momento fletor atuante, como pode ser visto na Figura 2.5.

A rotação total entre dois pontos quaisquer ao longo do comprimento de um elemento será dada, então, pelo somatório das rotações relativas de todas as seções existentes entre eles. Este somatório pode ser representado pela integral da curvatura entre os dois pontos, ou seja:

$$
\theta=\int\left(\frac{1}{r}\right) d x
$$

onde $\theta$ é a mudança de ângulo entre os pontos.

$\mathrm{Na}$ Figura 2.12, tem-se representado um trecho da seção longitudinal de um elemento, dividido em segmentos delimitados pelos pontos 1, 2, 3 e 4 . Nota-se que o deslocamento final na extremidade (ponto 4), em rela ção à posição inicial, é dado por:

$$
\mathrm{a}=\theta_{1} \delta_{\mathrm{x}}+\theta_{2} \delta_{\mathrm{x}}+\theta_{3} \delta_{\mathrm{x}}=\Sigma \theta_{\mathrm{i}} \delta_{\mathrm{x}}
$$

ou

$$
a=\int \theta d x
$$

Assim, substituindo-se a eq.(2.11) na eq.(2.12), tem-se o deslocamento total a, dado por:

$$
\mathrm{a}=\iint\left(\frac{1}{\mathrm{r}}\right) \mathrm{dx}
$$

sendo $1 / \mathbf{r}$ a curvatura de cada seção considerada. 


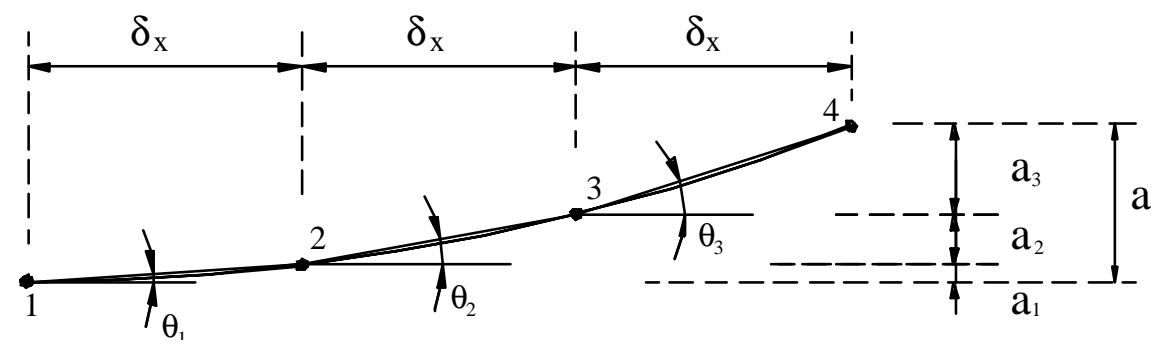

Figura 2.12 - Deslocamentos decorrentes da rotação dos segmentos de um vão

(BEEBY, 1999)

Com base nos conceitos da Resistência dos Materiais, admitindo-se um material homogêneo com comportamento elástico e linear, e também a hipótese de que as seções planas antes da deformação permanecem planas após a deformação, a curvatura pode ser escrita como:

$$
\frac{1}{\mathrm{r}}=\frac{\mathrm{M}}{\mathrm{EI}}
$$

sendo:

M o momento fletor atuante na seção;

E o módulo de elasticidade do material;

I o momento de inércia da seção transversal.

Para o material concreto armado, o estado de fissuração do elemento exerce importante influência na curvatura, devido à variação do momento de inércia das seções transversais, já comentada anteriormente. Por isso, assim como foi adotado para o momento de inércia, deve-se utilizar uma curvatura média, definida entre as curvaturas correspondentes às seções não fissuradas, no Estádio I, e às seções fissuradas, no Estádio II. Esse valor médio deve levar em consideração a colaboração do concreto íntegro existente entre as fissuras (tension stiffening), representando melhor o comportamento da peça fissurada.

Para a avaliação do comportamento intermediário entre o Estádio I e II, considere-se, inicialmente, um elemento em concreto armado submetido a um esforço axial de tração $\mathbf{N}$, como ilustrado na Figura 2.13. Ele não apresentará fissura enquanto a tensão de tração provocada por $\mathbf{N}$ for menor que a resistência à tração do concreto. Portanto, a primeira fissura ocorrerá quando:

$$
\mathrm{N}=\mathrm{N}_{\mathrm{r}}=\mathrm{f}_{\mathrm{ct}}\left[\mathrm{A}_{\mathrm{c}}+\left(\alpha_{\mathrm{e}}-1\right) \mathrm{A}_{\mathrm{s}}\right]=\mathrm{f}_{\mathrm{ct}} \mathrm{A}_{\mathrm{I}}
$$


na qual:

$\mathbf{N}_{\mathbf{r}}$ é o valor do esforço axial que produz a primeira fissura,

$\mathbf{f}_{\text {ct }}$ é a resistência à tração direta do concreto,

$\mathbf{A}_{\mathbf{c}} \quad$ é a área de concreto,

A sé a área de aço,

$\alpha_{\mathrm{e}} \quad$ é a entre o módulo de elasticidade do aço e o módulo de elasticidade secante do concreto,

A é a área da seção homogeneizada, no Estádio I.

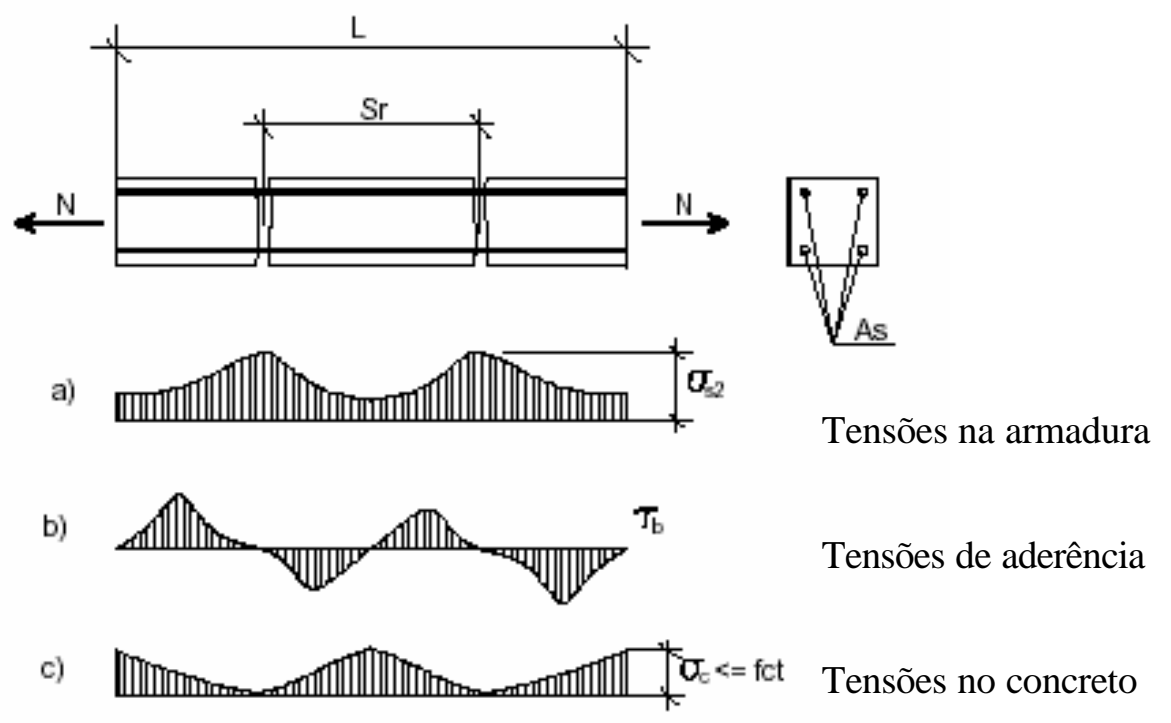

Figura 2.13 - Tensões em um elemento de concreto armado fissurado e submetido à tração direta

Imediatamente antes de ocorrer a primeira fissura, a seção está no Estádio I, assim, a tensão no concreto é igual à sua resistência à tração $\mathbf{f}_{\mathrm{ct}}$, e a tensão no aço é igual a $\alpha_{\mathbf{e}} \mathbf{f}_{\mathrm{ct}}$. Logo após o início da fissuração, a seção da primeira fissura tem comportamento típico do Estádio II, ou seja, a tensão de tração no concreto se anula, e toda a tração passa a ser resistida pela armadura, que sofre uma deformação maior que a do concreto adjacente, o que resulta na abertura da fissura. Neste instante, a tensão na armadura $\sigma_{\mathrm{sr}}$ vale:

$$
\sigma_{\mathrm{sr}}=\frac{\mathrm{N}_{\mathrm{r}}}{\mathrm{A}_{\mathrm{s}}}
$$

Fora da fissura, a contribuição do concreto íntegro tende a diminuir a deformação do aço, e a uma distância $\mathbf{s}_{\mathbf{r}}$ ocorre uma nova fissura. 
Para $\mathbf{N}>\mathbf{N}_{\mathbf{r}}$, a seção está no Estádio II, a tensão no concreto é nula, e a tensão e a deformação na armadura são dadas por:

$$
\begin{gathered}
\sigma_{\mathrm{s} 2}=\frac{N}{A_{s}} \\
\varepsilon_{\mathrm{s} 2}=\frac{N}{E_{\mathrm{s}} A_{\mathrm{s}}}
\end{gathered}
$$

na qual:

$\sigma_{\mathrm{s} 2}$ é a tensão na armadura em uma seção fissurada, com $\mathrm{N}>\mathbf{N}_{\mathbf{r}}$,

$\varepsilon_{\mathbf{s} 2}$ é a deformação da armadura em uma seção fissurada, com $N>\mathbf{N}_{\mathbf{r}}$,

Es é o módulo de elasticidade do aço.

Observa-se que entre fissuras consecutivas, a tensão de tração no concreto é menor que a sua resistência à tração, e a tensão no aço é menor que $\sigma_{\mathrm{s} 2}$. Deste modo, a deformação na armadura varia ao longo do elemento, de um valor máximo em uma seção fissurada, a um valor mínimo na seção onde é maior a colaboração do concreto. Pode-se considera-la com um valor médio de:

$$
\varepsilon_{\mathrm{sm}}=\frac{\Delta \ell}{\ell}
$$

sendo:

$\varepsilon_{\mathrm{sm}} \quad$ a deformação média da armadura,

$\ell \quad$ é o comprimento o elemento,

$\Delta \ell \quad$ é o alongamento do elemento.

Fica evidente que essa deformação média da armadura $\varepsilon_{\text {sm }}$ é menor que a deformação da armadura em uma seção fissurada $\varepsilon_{\mathrm{s} 2}$, tem-se:

$$
\varepsilon_{\mathrm{sm}}=\varepsilon_{\mathrm{s} 2}-\Delta \varepsilon_{\mathrm{s}}
$$

na qual, $\Delta \varepsilon_{\mathrm{s}}$ é a redução na deformação da armadura devido à colaboração do concreto entre fissuras para a resistência à tração.

Na Figura 2.14, tem-se a representação gráfica da variação da deformação média da armadura com a força $\mathbf{N}$. Percebe-se que ela está situada entre duas retas que representam as deformações da armadura no o Estádio I e para o Estádio II. Vale ressaltar que para a reta 
correspondente ao Estádio I é considerada uma situação hipotética para a armadura, na qual o Estádio I continua mesmo para $\mathbf{N}>\mathbf{N}_{\mathrm{r}}$. E a deformação da armadura neste estádio pode ser expressa por:

$$
\varepsilon_{\mathrm{s} 1}=\varepsilon_{\mathrm{c} 1}=\frac{\mathrm{N}}{\mathrm{E}_{\mathrm{c}}\left[\mathrm{A}_{\mathrm{c}}+\left(\alpha_{\mathrm{e}}-1\right) \mathrm{A}_{\mathrm{s}}\right]}=\frac{\mathrm{N}}{\mathrm{E}_{\mathrm{c}} \mathrm{A}_{\mathrm{I}}}
$$

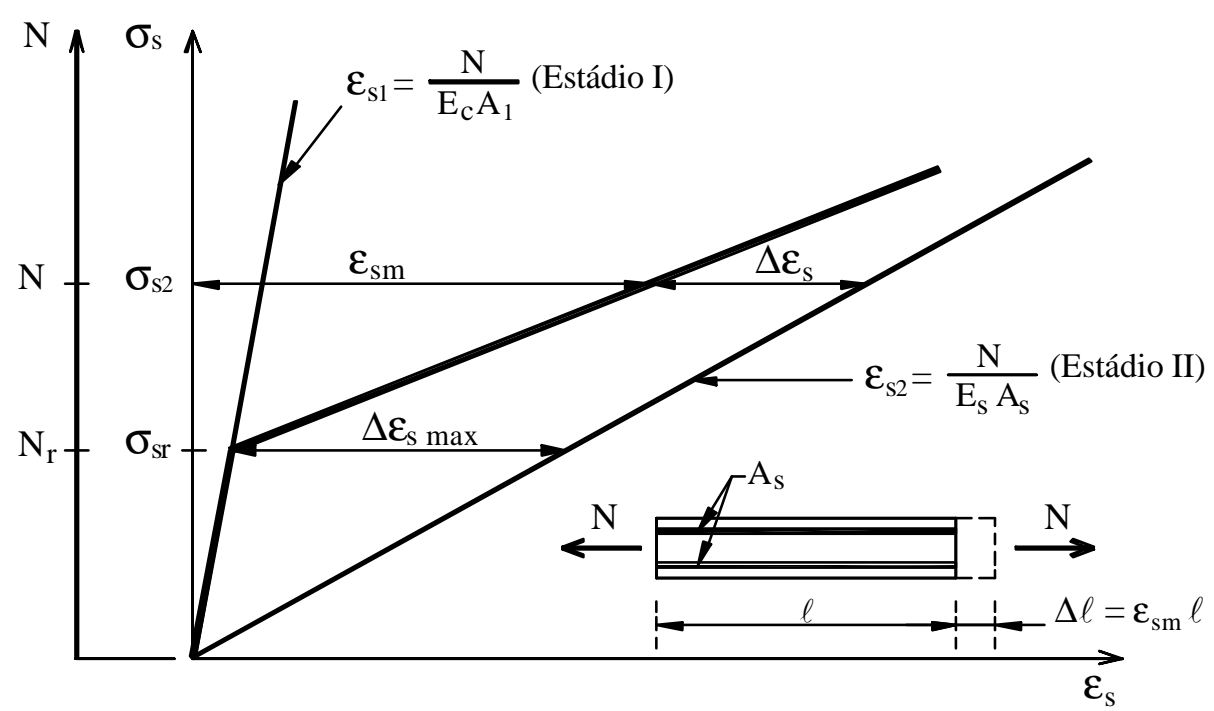

Figura 2.14 - Variação da deformação da armadura com a carga N

A valor máximo da redução da deformação da armadura provocada pela colaboração do concreto ocorre no início da fissuração, e segundo o CEB Bulletin d'Information n.158-E (1985), tem-se:

$$
\Delta \varepsilon_{\mathrm{s}}=\Delta \varepsilon_{\mathrm{smax}} \cdot \frac{\sigma_{\mathrm{sr}}}{\sigma_{\mathrm{s} 2}}
$$

E, de acordo com a Figura 2.14, pode-se escrever:

$$
\Delta \varepsilon_{\mathrm{s} \max }=\left(\varepsilon_{\mathrm{s} 2}-\varepsilon_{\mathrm{s} 1}\right) \frac{\sigma_{\mathrm{sr}}}{\sigma_{\mathrm{s} 2}}
$$

Substituindo-se as eqs. (2.16) e (2.17) na eq. (2.15), obtém-se

$$
\varepsilon_{\mathrm{sm}}=\varepsilon_{\mathrm{s} 2}\left[1-\left(\frac{\sigma_{\mathrm{sr}}}{\mathrm{s} 2}\right)^{2}\right]+\varepsilon_{\mathrm{s} 1}\left(\frac{\sigma_{\mathrm{sr}}}{\sigma_{\mathrm{s} 2}}\right)^{2}
$$


e, chamando-se:

$$
\varsigma=\left[1-\left(\frac{\sigma_{\mathrm{sr}}}{\sigma_{\mathrm{s} 2}}\right)^{2}\right]
$$

chega-se a seguinte expressão para a deformação média da armadura:

$$
\varepsilon_{\mathrm{sm}}=(1-\varsigma) \varepsilon_{\mathrm{s} 1}+\varsigma \varepsilon_{\mathrm{s} 2}
$$

sendo $\varsigma$ um coeficiente adimensional que representa o nível de fissuração do elemento, e tem valor nulo para seções não fissuradas. Pode ser calculado também a partir da expressão:

$$
\varsigma=1-\left(\frac{\sigma_{\mathrm{sr}}}{\sigma_{\mathrm{s} 2}}\right)^{2}=1-\left[\left(\frac{\mathrm{N}_{\mathrm{r}}}{\mathrm{A}_{\mathrm{s}}}\right) \cdot\left(\frac{\mathrm{A}_{\mathrm{s}}}{\mathrm{N}}\right)\right]^{2}=1-\left(\frac{\mathrm{N}_{\mathrm{r}}}{\mathrm{N}}\right)^{2}
$$

Portanto, o coeficiente $\varsigma$ é dado por:

$$
\varsigma=1-\left(\frac{\sigma_{\mathrm{sr}}}{\sigma_{\mathrm{s} 2}}\right)^{2} \quad \quad \operatorname{com} \sigma_{\mathrm{s} 2}>\sigma_{\mathrm{sr}}
$$

ou,

$$
\varsigma=1-\left(\frac{\mathrm{N}_{\mathrm{r}}}{\mathrm{N}}\right)^{2} \quad \operatorname{com} \mathrm{N}>\mathrm{N}_{\mathrm{r}}
$$

Para levar em consideração as propriedades de aderência das barras da armadura, e, também, a influência da duração e da repetição do carregamento, o CEB-FIP (1978) introduziu os coeficientes $\beta_{1}$ e $\beta_{2}$ na expressão do coeficiente $\varsigma$, ou seja:

$$
\varsigma=1-\beta_{1} \beta_{2}\left(\frac{\sigma_{\mathrm{sr}}}{\sigma_{\mathrm{s} 2}}\right)^{2}=1-\beta_{1} \beta_{2}\left(\frac{\mathrm{N}_{\mathrm{r}}}{\mathrm{N}}\right)^{2}
$$

na qual:

$\beta_{1} \quad$ é o coeficiente que leva em consideração a aderência da armadura,

$\beta_{2} \quad$ é o coeficiente que leva em consideração o carregamento.

Admitindo que a fissuração tenha um efeito na curvatura das seções semelhante ao seu efeito na deformação por tração axial, a partir da eq. (2.18), a curvatura média das seções de um elemento submetido à flexão simples é igual a: 


$$
\left(\frac{1}{r}\right)=(1-\zeta)\left(\frac{1}{r}\right)_{1}+\zeta\left(\frac{1}{r}\right)_{2}
$$

na qual:

$\left(\frac{\mathbf{1}}{\mathbf{r}}\right)_{1}$ é a curvatura correspondente a seções no estádio I, dada por:

$$
\left(\frac{1}{\mathrm{r}}\right)_{1}=\frac{\mathrm{M}_{\mathrm{r}}}{\mathrm{E}_{\mathrm{c}} \mathrm{I}_{1}}
$$

$\left(\frac{\mathbf{1}}{\mathbf{r}}\right)_{2}$ é a curvatura correspondente a seções no estádio II, dada por:

$$
\left(\frac{1}{\mathrm{r}}\right)_{2}=\frac{\mathrm{M}}{\mathrm{E}_{\mathrm{c}} \mathrm{I}_{\mathrm{II}}}
$$

$\mathbf{M}_{\mathrm{r}} \quad$ é o momento de fissuração;

M é o momento fletor atuante seção;

$\mathbf{I}_{1}$ e $\mathbf{I}_{\text {II }}$ são os momentos de inércia das seções homogeneizadas não fissurada e fissurada, respectivamente;

$\mathbf{E}_{\mathbf{c}} \quad$ é o módulo de elasticidade do concreto;

$\zeta \quad$ é um coeficiente adimensional que representa o nível de fissuração, e é dado por:

$$
\begin{cases}\zeta=0 & \operatorname{para}_{\mathrm{r}} \leq \mathrm{M} \\ \zeta=1-\beta_{1} \beta_{2}\left(\frac{\mathrm{M}_{\mathrm{r}}}{\mathrm{M}}\right)^{2} & \text { para } \mathrm{M}_{\mathrm{r}} \geq \mathrm{M}\end{cases}
$$

$\beta_{1} \quad$ é o coeficiente que leva em consideração a aderência da armadura, e vale:

$\left\{\begin{array}{l}\beta_{1}=1,0 \text { para barrasde alta aderência; } \\ \beta_{1}=0,5 \text { para barraslisas; }\end{array}\right.$

$\beta_{2} \quad$ é o coeficiente que leva em consideração o carregamento, e vale:

$\left\{\begin{array}{l}\beta_{2}=1,0 \text { para primeiro carregamento; } \\ \beta_{2}=0,5 \text { para cargas de longa duração ou com um grande número de ciclos } .\end{array}\right.$

Alguns pesquisadores como GHALI \& FAVRE (1986) e GHALI (1993), e algumas normas como o CEB-FIP (1991) e o EUROCODE (1992), apresentam expressões para o cálculo da curvatura média. 
Para a determinação dos deslocamentos segundo a curvatura média, seria necessária uma dupla integração ao longo de todo o vão do elemento, como indica a eq.(2.13). Este processo, entretanto, nem sempre é de fácil execução manual, e muitas vezes necessita da utilização de técnicas numéricas. BEEBY (1999), inclusive, apresenta os passos para a elaboração de uma planilha para o cálculo dos deslocamentos em vigas a partir da curvatura, utilizando a Regra do Trapézio.

Com o intuito de evitar o uso de técnicas numéricas complexas e de simplificar o cálculo dos deslocamentos, costuma-se assumir o concreto armado como um material de comportamento elástico e linear. Sendo assim, a curvatura pode escrita de acordo com a eq.(2.14). Substituindo-se essa equação na eq.(2.13), e fazendo as integrações, para todo o comprimento, pode-se escrever o deslocamento máximo de uma viga como:

$$
\mathrm{a}_{\max }=\beta \frac{\mathrm{M} \ell^{2}}{\mathrm{EI}}
$$

sendo $\ell$ o comprimento do vão da viga, e $\beta$ um coeficiente que depende das condições de apoio e de carregamento. Por exemplo, $\beta=5 / 48$ para viga simplesmente apoiada e uniformemente carregada, e $\beta=1 / 4$ para vigas em balanço e uniformemente carregadas.

Esse tipo de procedimento simplificado torna-se bastante interessante em termos práticos, já que permite que as expressões para o cálculo dos deslocamentos sejam tabeladas em função do tipo de carregamento e das condições de apoio. E apesar de o concreto armado, quando fissurado, não apresentar mais um comportamento elástico, a utilização da eq.(2.18) fornece bons resultados, desde que a fissuração do concreto seja, de alguma forma, levada em consideração. Isso pode ser feito a partir da utilização do momento de inércia efetivo, dado pela eq.(2.8).

Existem outros métodos simplificados para o cálculo de deslocamentos imediatos em vigas ou lajes armadas em uma direção, como, por exemplo, o Método Bilinear e o Método dos Coeficientes Globais, fornecidos pelo CEB 158-E (1985). Um resumo de alguns desses métodos podem ser encontrados em GHALI \& FAVRE (1986) e em BEEBY (1999).

\section{b) Lajes Armadas em duas Direções}

Assim como para as vigas e lajes armadas em uma direção, a determinação dos deslocamentos imediatos em lajes armadas em duas direções também deve considerar as condições de apoio e a fissuração da peça, além dos demais fatores anteriormente mencionados. Entretanto, as dificuldades encontradas para esses elementos são bem maiores 
que para os elementos lineares, especialmente devido ao seu comportamento bidimensional, como explica o ACI 435.6R (1974).

Segundo PARK \& GAMBLE (2000), as dificuldades principais são a estimativa de um valor de rigidez à flexão a ser utilizado e a determinação de uma expressão simples para o deslocamento imediato.

Quanto ao valor da rigidez à flexão a ser utilizado, o ACI 318 (2002) permite a consideração do momento de inércia efetivo dado pela própria eq.(2.8), apesar dela ter sido desenvolvida com base em ensaios de vigas de seções retangulares ou T. Entretanto, GILBERT (1985) lembra que os momentos atuantes nessas vigas ensaiadas eram aproximadamente o dobro de seus momentos de fissuração, situação não usual para lajes armadas em duas direções. Nelas, os momentos atuantes são apenas pouco superiores aos de fissuração. Assim, os valores de $\mathbf{I}_{\mathbf{e}}$ calculados com a eq.(2.8) seriam muito próximos dos valores da inércia da seção bruta de concreto, podendo levar à subestimativa dos deslocamentos.

Além disso, SCANLON \& MURRAY (1982) ressaltam que a restrição à livre retração, causada pela armadura e pelos apoios, é bem mais significativa nessas lajes que nas vigas, e pode provocar a fissuração antes mesmo da aplicação de cargas. Para contornar esse problema, o ACI 435.9R (1985) sugere uma redução de aproximadamente 50\% no valor da resistência à tração na flexão utilizada no cálculo do momento de fissuração, o que leva a uma diminuição do valor de $\mathbf{I}_{\mathbf{e}}$, e, conseqüentemente, a um aumento dos deslocamentos calculados. Esses deslocamentos, segundo TAM \& SCANLON (1986), têm apresentado uma boa correlação com deslocamentos medidos em campo, demonstrando assim a validade do procedimento sugerido.

Já para o cálculo dos deslocamentos imediatos, embora vários métodos possam ser utilizados, poucos conduzem a expressões simples. Um deles é o método clássico baseado na Teoria da Elasticidade, cuja equação geral, que governa o comportamento forçadeslocamento das placas, pode ser escrita como:

$$
\frac{\partial^{4} \delta}{\partial x^{4}}+2 \frac{\partial^{4} \delta}{\partial x^{2} \partial y^{2}}+\frac{\partial^{4} \delta}{\partial y^{4}}=\frac{p}{D}
$$

sendo:

$\mathbf{x}, \mathbf{y}$ os eixos coordenados;

$\delta \quad$ o deslocamento da placa;

p a ação transversal por unidade de área;

D a rigidez à flexão por unidade de largura, dada por: 


$$
\mathrm{D}=\frac{\mathrm{Eh}^{3}}{12\left(1-v^{2}\right)}
$$

E o módulo de elasticidade do concreto;

h a espessura da placa;

v o coeficiente de Poisson.

Para lajes retangulares com carregamento uniformemente distribuído, por exemplo, sua solução é dada por:

$$
\mathrm{a}=\mathrm{C} \frac{\mathrm{p} \ell^{4}}{\mathrm{D}}=\mathrm{C} \frac{12\left(1-v^{2}\right) \mathrm{p} \ell^{4}}{\mathrm{E} \mathrm{h}^{3}}
$$

na qual $\mathbf{C}$ é um coeficiente que depende das condições de contorno e da relação entre os vãos da laje.

Como os valores típicos do coeficiente de Poisson para o concreto variam de 0,15 a 0,25, o termo $\left(1-v^{2}\right)$ vale de 0,94 a 0,98 . Portanto, a influência deste parâmetro é muito pequena e a sua desconsideração acarreta um erro final de 2 a $6 \%$. Desprezando-o, a eq.(2.24) pode ser reescrita como:

$$
\mathrm{a}=\alpha \frac{\mathrm{p} \ell^{4}}{\mathrm{Eh}^{3}}
$$

sendo $\alpha$ um coeficiente semelhante a $\mathbf{C}$, que depende das condições de contorno e da relação entre os vãos da laje, cujos valores podem ser encontrados em vários trabalhos como PINHEIRO (1993). Colocando-se essa expressão em função da rigidez à flexão, tem-se:

$$
\mathrm{a}=\alpha \frac{\mathrm{bp} \ell^{4}}{12 \mathrm{EI}}
$$

sendo:

b a largura da base da seção transversal;

I o momento de inércia da seção transversal.

Embora o método clássico possa conduzir a expressões simples como a eq.(2.22), ele só fornece soluções para alguns casos de condições de contorno e forma de painéis. Para soluções mais gerais, pode-se adotar o método dos elementos finitos, cuja utilização vem crescendo com a popularização dos computadores. Os programas baseados neste método 
permitem o cálculo dos deslocamentos em lajes com formas, condições de contorno e carregamentos quaisquer. OLIVEIRA (2001), DOTREPPE et al (1973), JOFRIET \& MCNEICE (1971) e ZIENKIEWICZ (1977), dentre outros, apresentam procedimentos para a determinação dos deslocamentos utilizando este método.

Outros métodos para a determinação dos deslocamentos em lajes podem ser encontrados no ACI 435.6R (1974), no ACI 435.9R (1991), em GHALI \& FAVRE (1986) e em SILVANY (1996), dos quais destacam-se o das vigas cruzadas, o dos pórticos equivalente, e o da analogia de grelha.

\subsubsection{CÁLCULO DOS DESLOCAMENTOS DIFERIDOS NO TEMPO}

A consideração dos deslocamentos diferidos no tempo é de fundamental importância para a avaliação dos deslocamentos finais, pois seus valores são usualmente maiores que os da parcela imediata. Eles são causados, principalmente, pela retração e pela fluência do concreto.

Uma forma de se calcular os deslocamentos é a partir da deformação. Para um elemento de concreto submetido, em um instante inicial $\mathbf{t}_{\mathbf{0}}$, à uma tensão constante $\sigma\left(\mathbf{t}_{\mathbf{0}}\right)$, a deformação total em um instante $\mathbf{t}$, é composta pelas seguintes parcelas:

$$
\varepsilon_{\mathrm{c}}(\mathrm{t})=\varepsilon_{\mathrm{ci}}\left(\mathrm{t}_{0}\right)+\varepsilon_{\mathrm{cc}}\left(\mathrm{t}, \mathrm{t}_{0}\right)+\varepsilon_{\mathrm{cs}}\left(\mathrm{t}, \mathrm{t}_{0}\right)
$$

sendo:

$\varepsilon_{\text {cc }}\left(\mathbf{t}, \mathbf{t}_{\mathbf{0}}\right)$ a deformação devida à fluência do concreto, no período de $\mathrm{t}_{0} \mathrm{a} \mathrm{t}$,

$\varepsilon_{\mathrm{s}}\left(\mathbf{t}, \mathbf{t}_{\mathbf{0}}\right)$ a deformação devida à retração do concreto, no período de $\mathrm{t}_{0} \mathrm{a} \mathrm{t}$,

$\varepsilon_{\mathrm{ci}}\left(\mathbf{t}_{\mathbf{0}}\right)$ a deformação inicial no instante $\mathrm{t}_{0}$, dada por:

$$
\varepsilon_{\mathrm{ci}}\left(\mathrm{t}_{0}\right)=\frac{\sigma\left(\mathrm{t}_{0}\right)}{\mathrm{E}_{\mathrm{ci}}\left(\mathrm{t}_{0}\right)}
$$

$\sigma\left(\mathbf{t}_{\mathbf{0}}\right) \quad$ a tensão no instante $\mathrm{t}_{0}$,

$\mathbf{E}_{\mathbf{c i}}\left(\mathbf{t}_{\mathbf{0}}\right)$ o módulo de elasticidade tangente do concreto no instante $\mathrm{t}_{0}$.

Os cálculos das deformações causadas pela fluência e pela retração, de acordo com o CEB-FIP (1991), são apresentados nos itens a seguir. Existem vários trabalhos que apresentam tais cálculos, como os GHALI \& FAVRE (1986), BAZANT (2001) e GILBERT (2001), dentre outros, além, é claro, dos fornecidos por normas de cálculo como o FIB (1999) e o EUROCODE 2 (1992). Entretanto, optou-se por apresentar o modelo do CEB-FIP 
(1991), pois é o utilizado no programa de análise estrutural ANPAV, que será empregado para as análises dos deslocamentos neste trabalho.

\section{a) Cálculo da deformação por Fluência}

A deformação devida à fluência é determinada, segundo o CEB-FIP (1991), por:

$$
\varepsilon_{\mathrm{cc}}\left(\mathrm{t}, \mathrm{t}_{0}\right)=\frac{\sigma_{\mathrm{c}}\left(\mathrm{t}_{0}\right)}{\mathrm{E}_{\mathrm{ci}, 28}} \cdot \phi\left(\mathrm{t}, \mathrm{t}_{0}\right)
$$

na qual:

$\mathbf{E}_{\mathrm{ci}, 28}$ é o módulo de elasticidade do concreto a 28 dias com a temperatura de $20{ }^{\circ} \mathrm{C}$ e a umidade relativa maior que $95 \%$,

$\phi\left(t, \mathbf{t}_{0}\right)$ é o coeficiente de fluência.

O coeficiente de fluência é dado por:

$$
\phi\left(t, t_{0}\right)=\phi_{0} \beta_{c}\left(t-t_{0}\right)
$$

sendo $\phi_{\mathbf{0}}$ o valor de referência do coeficiente de fluência para a idade $\mathbf{t}_{\mathbf{0}}$ e $\beta_{\mathbf{c}}\left(\mathbf{t}-\mathbf{t}_{\mathbf{0}}\right)$ é um coeficiente que define o desenvolvimento da fluência ao longo do tempo. Seus valores são calculados a partir das seguintes expressões:

$$
\phi_{0}=\phi_{\mathrm{HR}} \cdot \beta\left(\mathrm{f}_{\mathrm{cm}}\right) \cdot \beta\left(\mathrm{t}_{0}\right)
$$

sendo:

$$
\begin{aligned}
& \phi_{\mathrm{HR}}=1+\frac{1-\frac{\mathrm{HR}}{100}}{0,215 \cdot \mathrm{h}^{1 / 3}} \\
& \beta\left(\mathrm{f}_{\mathrm{cm}}\right)=\frac{5,3}{\left(\frac{\mathrm{f}_{\mathrm{cm}}}{100}\right)^{0,5}} \\
& \beta\left(\mathrm{t}_{0}\right)=\frac{1}{0,1+\left(\mathrm{t}_{0 \mathrm{f}}\right)^{0,2}}
\end{aligned}
$$

E,

$$
\beta_{\mathrm{c}}\left(\mathrm{t}-\mathrm{t}_{0}\right)=\left[\frac{\mathrm{t}-\mathrm{t}_{0}}{\beta_{\mathrm{H}}+\mathrm{t}-\mathrm{t}_{0}}\right]^{0,3}
$$


sendo:

$$
\beta_{\mathrm{H}}=150\left\{1+\left[1,2 \frac{\mathrm{HR}}{100}\right]^{18}\right\} \frac{\mathrm{h}}{100}+250 \leq 1500
$$

na qual:

HR é a umidade relativa do ambiente onde se situa a estrutura, em \%,

$\mathbf{f}_{\mathrm{cm}} \quad$ é a resistência do concreto aos 28 dias,

h é a altura equivalente, dada por:

$$
\mathrm{h}=\frac{2 \mathrm{~A}_{\mathrm{c}}}{\mathrm{u}}
$$

$\mathbf{A}_{\mathbf{c}} \quad$ é a área da seção transversal do elemento,

u é o perímetro da seção transversal em contato com o ambiente,

$\mathbf{t}_{\mathbf{0 f}}$ é idade de aplicação do carregamento corrigida em função da temperatura, de acordo com:

$$
\begin{aligned}
& \mathrm{t}_{\mathrm{T}}=\sum_{\mathrm{i}=1}^{\mathrm{i}=\mathrm{n}} \Delta \mathrm{t}_{\mathrm{i}} \mathrm{e}^{-\left[\frac{4000}{273+\mathrm{T}\left(\Delta \mathrm{t}_{\mathrm{i}}\right)}-13,65\right]} \\
& \mathrm{t}_{0 \mathrm{f}}=\mathrm{t}_{0, \mathrm{~T}}\left[\frac{9}{2+\left(\mathrm{t}_{0, \mathrm{~T}}\right)^{0,5}}+1\right]^{\alpha} \geq 0,5 \text { dias }
\end{aligned}
$$

$\mathbf{t}_{\mathbf{T}} \quad$ é a idade corrigida com a temperatura,

$\mathbf{T}\left(\Delta \mathbf{t}_{\mathbf{i}}\right)$ é a temperatura durante o período $\Delta \mathbf{t}_{\mathbf{i}}$,

$\Delta \mathbf{t}_{\mathbf{i}} \quad$ é o período em que ocorre a temperatura $\mathbf{T}\left(\Delta \mathbf{t}_{\mathbf{i}}\right)$,

$\mathbf{t}_{\mathbf{0}, \mathbf{T}} \quad$ é a idade de aplicação do carregamento, corrigida de conforme a eq.(2.33).

$\alpha \quad$ é um coeficiente que depende do tipo de cimento:

$\alpha=-1$ para cimento de endurecimento lento,

$\alpha=0$ para cimento de endurecimento normal,

$\alpha=1$ para cimento de alta resistência inicial e endurecimento rápido.

\section{b) Cálculo da deformação por Retração}

A deformação causada pela retração que se desenvolve desde um instante de referência, $\mathbf{t}_{\mathrm{s}}$, até o instante $\mathbf{t}$, pode ser estimada, segundo o CEB-FIP (1991), a partir de:

$$
\varepsilon_{\mathrm{cs}}\left(\mathrm{t}, \mathrm{t}_{\mathrm{s}}\right)=\varepsilon_{\mathrm{cs} 0} \cdot \beta_{\mathrm{s}}\left(\mathrm{t}-\mathrm{t}_{\mathrm{s}}\right)
$$


na qual:

t é idade do concreto no momento em que se calculam as deformações,

$\mathbf{t}_{\text {s }}$ é a idade do concreto em começa a retração,

$\varepsilon_{\text {cso } 0}$ é o valor de referência da retração,

$\beta_{s}\left(t, t_{s}\right)$ é a função de evolução da retração com o tempo.

O valor de referência para a retração é calculado pela expressão:

$$
\varepsilon_{\mathrm{cs} 0}=\varepsilon_{\mathrm{c}}\left(\mathrm{f}_{\mathrm{cm}}\right) \cdot \beta_{\mathrm{HR}}
$$

com:

$$
\varepsilon_{\mathrm{c}}\left(\mathrm{f}_{\mathrm{cm}}\right)=\left[160+10 \beta_{\mathrm{sc}}\left(9-\frac{\mathrm{f}_{\mathrm{cm}}}{\mathrm{f}_{\mathrm{cm} 0}}\right)\right] \cdot 10^{-6}
$$

$\mathrm{e}$,

$$
\begin{array}{ll}
\beta_{\mathrm{HR}}=-1,55\left[1-\left(\frac{\mathrm{HR}}{100}\right)^{3}\right] & \text { para } 40 \%=\mathrm{HR}<99 \% \\
\beta_{\mathrm{HR}}=0,25 & \text { para } \mathrm{HR}=99 \%
\end{array}
$$

sendo:

$\mathbf{f}_{\mathbf{c m}}$ a resistência média à compressão do concreto aos 28 dias,

$\mathbf{f}_{\mathrm{cm} 0}=10 \mathrm{MPa}$,

$\beta_{\text {sc }} \quad$ o coeficiente que leva em consideração o tipo do cimento, e vale:

$\beta_{\mathrm{sc}}=4$ para cimentos de endurecimento lento,

$\beta_{\mathrm{sc}}=5$ para cimento de endurecimento normal,

$\beta_{\mathrm{sc}}=8$ para alta resistência inicial e endurecimento rápido.

HR a umidade relativa do ambiente onde se situa a estrutura, em \%.

E a função que leva em consideração a evolução da retração com o tempo vale:

$$
\beta_{\mathrm{s}}\left(\mathrm{t}-\mathrm{t}_{\mathrm{s}}\right)=\left[\frac{\left(\mathrm{t}-\mathrm{t}_{\mathrm{s}}\right)}{0,035 \mathrm{~h}^{2}+\mathrm{t}-\mathrm{t}_{\mathrm{s}}}\right]^{0,5}
$$

com $\mathbf{h}$ igual a espessura equivalente, conforme definida anteriormente. 


\section{c) Processos Simplificados}

A determinação dos deslocamentos diferidos a partir das deformações requer maior esforço de cálculo, exigindo, em algumas situações, soluções numéricas mais complexas. Entretanto, existem vários processos mais simplificados para o cálculo desses deslocamentos. Alguns deles são comentados a seguir.

O método do módulo de elasticidade efetivo permite a determinação de deslocamentos que já englobam tanto a parcela imediata como a devida à fluência. Para isso, podem-se adotar as expressões utilizadas para a determinação dos deslocamentos imediatos, apenas substituindo-se o módulo de elasticidade do concreto por um módulo de elasticidade reduzido, dado por:

$$
\mathrm{E}_{\mathrm{c}, \mathrm{ef}}=\frac{\mathrm{E}_{\mathrm{c}}}{1+\phi_{\mathrm{t}}}
$$

sendo:

$\mathbf{E}_{\mathrm{c}, \mathrm{ef}} \quad$ o módulo de elasticidade efetivo do concreto;

$\mathbf{E}_{\mathbf{c}} \quad$ o módulo de elasticidade do concreto;

$\phi_{\mathrm{t}} \quad$ o coeficiente de fluência, conforme item 2.3.3a)

Um método empírico muito utilizado para o cálculo dos deslocamentos diferidos consiste em considerar os efeitos do tempo através da majoração do deslocamento imediato por um coeficiente multiplicador, ou seja:

$$
\mathrm{a}_{\mathrm{d}}=\lambda \cdot \mathrm{a}_{\mathrm{i}}
$$

sendo:

$\mathbf{a}_{\mathrm{d}} \quad$ o deslocamento diferido;

$\mathbf{a}_{\mathbf{i}} \quad$ o deslocamento imediato;

$\lambda \quad$ o coeficiente multiplicador dos deslocamentos imediatos.

Os primeiros coeficientes multiplicadores desenvolvidos com uma base experimental foram propostos por YU \& WINTER (1960). Segundo eles, esses multiplicadores variavam de caso para caso, e dependiam da duração da carga aplicada e das armaduras de compressão e de tração do elemento.

Com base nesses estudos, BRANSON (1971) sugeriu uma expressão para o cálculo dos multiplicadores, dada por: 


$$
\lambda=\frac{\mathrm{T}}{1+50 \rho^{\prime}}
$$

na qual:

$\lambda \quad$ é o coeficiente multiplicador dos deslocamentos imediatos;

T é um coeficiente compreendido entre 0 e 2, função da duração da carga;

$\rho$, é a taxa de armadura de compressão.

Esta expressão, por ser bastante simplificada, não leva em conta a influência de alguns fatores importantes.

Os ensaios de PAULSON et al. (1991), por exemplo, indicam que a influência da taxa de armadura de compressão, e os valores dos próprios deslocamentos finais, variam com a resistência do concreto à compressão. Para vigas ensaiadas sem armadura de compressão, quanto maior o $\mathbf{f}_{\mathbf{c k}}$, maior a superestimativa dos deslocamentos pela eq.(2.38). É que o aumento do $\mathbf{f}_{\mathbf{c k}}$ influiu significativamente na redução dos deslocamentos diferidos no tempo. Resultado semelhante, ainda que em escala bem menor, foi obtido para vigas com armaduras de compressão. Com isso, observou-se que, para resistências mais altas, a influência da armadura de compressão na redução desses deslocamentos não é tão efetiva como para resistência mais baixas. A solução apresentada por PAULSON et al. (1991) para refletir os efeitos tanto da resistência do concreto como da taxa de armadura de compressão nos deslocamentos diferidos no tempo, foi a introdução de fatores de correção no numerador e no denominador da eq.(2.38). Procedimento similar é proposto por SHERIF \& DILGER (1998).

Já os resultados de GRAHAM \& SCANLON (1986) mostram que, para lajes armadas em duas direções, os deslocamentos diferidos são maiores que os previstos pela eq.(2.38). O ACI 435.9R (1991) também chama atenção para esse fato. Algumas possíveis razões podem ser apontadas, como a maior retração desses elementos e a fissuração prematura provocada pelas ações de construção, fatores não considerados nessa expressão. Além disso, o próprio BRANSON (1971) comenta que a eq.(2.38) não apresenta bons resultados para elementos com baixas taxas de armadura, que é o caso de lajes. GRAHAM \& SCANLON (1986) sugerem, então, o aumento dos valores do multiplicador para as lajes armadas nas duas direções.

Um outro método para a determinação dos deslocamentos diferidos é o cálculo em separado das parcelas devidas à retração e à fluência. Para vigas e lajes armadas em uma direção, o ACI 435R (1995) fornece um procedimento deste tipo, baseado em BRANSON (1965, 1977), para o qual:

$$
\delta_{\mathrm{cr}}=\lambda_{\mathrm{c}}\left(\delta_{\mathrm{sus}}\right)
$$


e,

$$
\delta_{\mathrm{sh}}=\mathrm{k}_{\mathrm{sh}} \phi_{\mathrm{sh}} \ell^{2}=\mathrm{k}_{\mathrm{sh}}\left[\mathrm{A}_{\mathrm{sh}} \frac{\left(\varepsilon_{\mathrm{sh}}\right)_{\mathrm{t}}}{\mathrm{h}}\right] \ell^{2}
$$

na qual:

$\delta_{\text {cr }} \quad$ é o deslocamento devido à fluência;

$\delta_{\text {sh }} \quad$ é o deslocamento devido à retração;

$\delta_{\text {sus }} \quad$ é o deslocamento imediato devido às cargas de longa duração;

$\lambda_{\mathrm{c}} \quad$ é o coeficiente multiplicador do deslocamento devido às cargas de longa duração, dado por:

$$
\lambda_{\mathrm{c}}=\frac{0,85 \phi_{\mathrm{t}}}{1+50 \rho^{\prime}}
$$

$\phi_{\mathbf{t}} \quad$ é o coeficiente de fluência;

$\rho$ ' é a taxa de armadura de compressão;

$\mathbf{k}_{\text {sh }}$ é um coeficiente que leva em consideração as condições de apoio do elemento, cujos valores, em função das condições de apoio dos vãos, são:

$=0,50$ para vãos em balanço;

$=0,13$ para vãos simplesmente apoiados;

= 0,09 para vãos com uma extremidade contínua em elementos contínuos com vários vãos;

$=0,08$ para vãos com uma extremidade contínua em elementos contínuos com dois vãos;

$=0,07$ para vãos com ambas as extremidades contínuas;

$\phi_{\text {sh }} \quad$ é a curvatura devida à retração;

$\ell \quad$ é o vão do elemento;

$\mathbf{A}_{\text {sh }}$ é uma função das taxas de armadura de compressão e de tração, sendo:

$$
\begin{array}{ll}
A_{\text {sh }}=0,7\left(\rho-\rho^{\prime}\right)^{1 / 3}\left(\frac{\rho-\rho^{\prime}}{\rho}\right)^{1 / 2} & \text { para } \rho-\rho^{\prime} \leq 3 \% \\
A_{s h}=0,7 ?^{1 / 3} & \text { para } \rho^{\prime}=0 \\
A_{s h}=1,0 & \text { para } \rho-\rho^{\prime}>3 \%
\end{array}
$$

$\left(\varepsilon_{\mathrm{sh}}\right)_{\mathbf{t}} \quad$ é a deformação por retração livre.

h $\quad$ é a altura da seção transversal; 
Segundo FANELLA et al (1999), para valores médios, o coeficiente de fluência e a deformação por retração livre podem ser considerados iguais a 1,6 e $-400 \times 10^{-6}$, respectivamente. Entretanto, o ACI 209R (1992) fornece expressões para o cálculo desses parâmetros em função de diversos fatores como condições do ambiente e características do concreto, dentre outras.

Embora as eqs.(2.39) e (2.40) tenham sido determinadas para vigas e lajes armadas em uma direção, segundo o ACI 435R (1995), elas podem ser utilizadas para lajes armadas em duas direções.

Outros procedimentos para a determinação dos deslocamentos diferidos em elementos fletidos podem ser encontrados em GHALI \& FAVRE (1986), CLARKE et al. (1988) e GILBERT (2001), dentre outros. E os procedimentos recomendados por algumas normas serão apresentados no item 2.6.

\subsection{CONTROLE DOS DESLOCAMENTOS}

Para se garantir que uma estrutura mantenha suas condições de utilização em serviço, no que diz respeito tanto ao conforto dos usuários, quanto à segurança, à funcionalidade, à durabilidade e à aparência, deve-se verificar o estado limite de deslocamentos excessivos. E para evitar que esse estado limite seja atingido, deve-se fazer o controle dos deslocamentos.

O objetivo do controle dos deslocamentos é se garantir que uma estrutura ou um elemento estrutural, apesar de apresentar deslocamentos em relação à sua posição inicial, possa atender a critérios mínimos de aceitação, tanto do ponto de vista estrutural quanto estético. Para isso, podem ser utilizados dois procedimentos: ou o cálculo dos deslocamentos e posterior comparação com valores limites, ou a determinação de uma altura mínima que dispense o cálculo dos deslocamentos, mas garanta que os deslocamentos não causem danos à edificação.

\subsubsection{CÁLCULO DOS DESLOCAMENTOS}

Uma forma de se verificar o estado limite de deslocamentos excessivos é se calcular os deslocamentos em cada elemento, e compará-los com valores limites pré-definidos para cada tipo de situação.

A aplicação desse procedimento torna-se um pouco complicada, não só pela dificuldade de se considerarem diversos fatores de forma consistente, para que a estimativa 
dos deslocamentos possa fornecer bons resultados, mas também pelo estabelecimento de valores limites razoáveis para cada situação, uma vez que eles variam em função do tipo de edificação, da sensibilidade de aparelhos ou equipamentos que se apóiam no elemento estrutural, da presença ou não de paredes, do tipo de revestimento das paredes e dos forros e, ainda, da capacidade que esses elementos não estruturais vinculados à estrutura têm de absorver os deslocamentos, sem que haja perda da funcionalidade e da estética.

Em função dos efeitos que os deslocamentos podem causar nos elementos, estruturais ou não, de uma edificação, os valores limites podem ser separados em quatro grupos: a aceitabilidade sensorial, a interferência no uso da estrutura, os danos aos elementos não estruturais e os efeitos indesejáveis em elementos estruturais. Os valores usualmente empregados para todos esses casos são obtidos com base na experiência ao longo dos anos, e os resultados apresentados são, na maioria das vezes, satisfatórios.

\section{a) Aceitabilidade Sensorial}

A aceitabilidade sensorial está relacionada ao desconforto dos usuários ao perceberem deslocamentos excessivos em elementos visíveis e ao sentirem vibrações nos pisos. Essas sensações tendem a diminuir a confiança das pessoas na segurança da estrutura, mesmo quando não existem implicações desse tipo. Por isso, atenção especial deve ser dada a elementos que ficam aparentes na estrutura, nos quais os deslocamentos não devem ser perceptíveis.

Apesar de serem questões bastante subjetivas ou relacionadas ao uso da estrutura, alguns valores limites de deslocamentos relacionados à aceitabilidade sensorial são sugeridos por normas de cálculo de estruturas de concreto armado.

\section{b) Interferências no Uso das Estruturas}

As interferências no uso de uma estrutura se aplicam a casos bastante particulares em que os deslocamentos excessivos podem causar problemas, por exemplo, ao alinhamento de equipamentos sensíveis apoiados nos elementos estruturais, ao desenvolvimento de atividades previstas ou à drenagem de lajes de piso ou cobertura. Outro exemplo é o caso de vigas de apoio de pontes rolantes, cujos deslocamentos excessivos podem provocar problemas no deslizamento e dificuldades de controle de velocidade.

Apenas para alguns desses casos, as normas de cálculo sugerem valores limites para os deslocamentos. Entretanto, podem ser consideradas especificações particulares de equipamentos, fornecidas pelos próprios fabricantes. 


\section{c) Danos em Elementos não Estruturais}

Os danos em elementos não estruturais podem variar desde fissuras em paredes e problemas de funcionamento de portas e janelas, à quebra de elementos de vidro e rachaduras em forros. Isso ocorre porque os elementos não estruturais, devido à sua rigidez, podem não conseguir acompanhar a curvatura das vigas e lajes em que se apóiam.

As normas de cálculo fornecem alguns valores limites para os deslocamentos dos elementos estruturais, de acordo com o tipo de elemento não estrutural que neles se apóiem.

\section{d) Efeitos em Elementos Estruturais}

Os efeitos indesejáveis em elementos estruturais, causados por deslocamentos excessivos, podem ser bastante significativos, principalmente quando as hipóteses de cálculo adotadas e o comportamento previsto podem ser modificados. Nesses casos, é necessário se incorporar os deslocamentos ao modelo utilizado para a determinação dos esforços na estrutura.

\subsubsection{CRITÉRIOS DE ALTURAS MÍNIMAS}

Segundo os critérios de altura mínima, admite-se que o estado limite de deslocamentos excessivos está verificado se a altura da peça for superior a um determinado limite, que deve ser respeitado independentemente da altura mínima requerida pelo dimensionamento à flexão. Se esses critérios forem atendidos, o cálculo dos deslocamentos no elemento estará dispensado.

O valor da altura mínima de uma dada peça é função de diversos parâmetros. Além do comprimento do vão, da resistência do concreto e da tensão de escoamento do aço das armaduras, é necessário se definir se o elemento analisado está ligado a algum elemento não estrutural que possa sofrer dano com os deslocamentos. Há ainda a necessidade de se distinguir valores diferentes para elementos considerados lineares (vigas e lajes armadas em uma só direção) e elementos de superfície (lajes armadas nas duas direções).

Apesar de serem métodos mais simplificados, os critérios de altura mínima ainda são largamente utilizados por sua praticidade. Alguns deles são essencialmente empíricos e baseados na observação e na experiência adquirida ao longo dos anos para cada tipo de elemento estrutural; outros, mais recentes, já vêm propondo abordagens mais consistentes.

O ACI 318 (2002) apresenta valores tabelados de alturas mínimas para vigas e lajes armadas em uma direção, que são determinados em função das condições de apoio e do vão. Entretanto, a adoção destes valores de alturas mínimas não fornece condições para que o 
projetista possa estimar a ordem de grandeza dos deslocamentos que irão ocorrer no elemento. Com o intuito de solucionar esta questão, alguns trabalhos fornecem expressões mais complexas para a obtenção de alturas mínimas, que levam em consideração vários parâmetros além das condições de apoio, e do comprimento do vão, como as ações atuantes, o módulo de elasticidade do concreto e o deslocamento limite desejado.

RANGAN (1982), por exemplo, apresenta expressões de alturas mínimas para vigas e lajes armadas em uma direção, para elementos que apóiam ou não peças não estruturais que podem se danificar com deslocamentos excessivos. GILBERT (1985) estendeu o estudo de RANGAN (1982) para lajes armadas em duas direções.

Outras expressões para a determinação da altura mínima de elementos fletidos podem ser encontradas em GROSSMAN (1981), em HWANG \& CHANG (1996), entre outros.

\subsection{CONSIDERAÇÃO DAS AÇÕES}

Para o controle dos deslocamentos excessivos, é necessária a consideração das diversas ações a que estão submetidos os elementos estruturais.

\subsubsection{TIPOS DE AÇÕES}

As principais ações a que estão submetidas as edificações usuais são as permanentes, representadas por $\mathbf{g}$, e as variáveis, representadas por $\mathbf{q}$. As ações permanentes são aquelas que ocorrem com valores praticamente constantes durante a vida útil da edificação. Como exemplos, podem ser citados o peso próprio da estrutura e dos revestimentos. Já as ações variáveis, elas apresentam uma variação significativa da sua intensidade durante a vida útil da edificação, e, como exemplos, têm-se as ações acidentais definidas em função da utilização da estrutura e a ação do vento.

Vale ressaltar que, em alguns casos, as ações variáveis de construção exercem influência significativa para os deslocamentos finais, devendo ser consideradas. Isso se deve a dois fatores principais. O primeiro é a própria ordem de grandeza dessas ações, que podem valer até o dobro das ações permanentes. E o segundo é a fissuração prematura dos elementos, decorrente da aplicação de ações consideráveis a pequenas idades, quando os valores do módulo de elasticidade e da resistência à tração ainda são baixos. Além do aumento dos deslocamentos iniciais, as ações de construção podem influir nos 
deslocamentos ao longo do tempo, provocados, principalmente, pela fluência, que depende da idade do concreto quando do primeiro carregamento, como comentado anteriormente.

Assim, para edificações em que já se espera uma influência significativa para as ações de construção, recomenda-se que esse carregamento seja considerado tanto para o cálculo dos momentos de inércia efetivos quanto para a determinação dos próprios deslocamentos. Alguns procedimentos são sugeridos por GRUNDY \& KABAILA (1963), SBAROUNIS (1984), GRAHAM \& SCANLON (1985) e pelo ACI 435.9R (1991).

Entretanto, nas fases de concepção e elaboração de um projeto estrutural, nem sempre se conhece qual será o procedimento construtivo a ser empregado, com quantos dias será feita a desforma, e se materiais serão armazenados sobre os elementos estruturais, o que dificulta a consideração das ações devidas ao processo de execução da obra.

Nos casos em que as etapas de construção não são conhecidas, GRAHAM \& SCANLON (1985) sugerem a verificação dos deslocamentos excessivos de lajes considerando uma ação de construção padrão de pelo menos 2,3 vezes o valor do peso próprio.

\subsubsection{COMBINAÇÃO DE AÇÕES}

Algumas normas, como a NBR 6118 (2003), o CEB-FIP (1991), e o EUROCODE (1992) permitem que as ações permanentes e variáveis sejam combinadas em função da probabilidade que têm de atuarem simultaneamente durante um determinado período. Com isso, é possível se conhecerem os efeitos desfavoráveis que têm maior probabilidade de ocorrência na estrutura.

Para a verificação de estados limites de serviço, costuma-se definir três tipos de combinação de ações: quase-permanente, freqüente e rara.

Tanto na combinação quase-permanente quanto na combinação freqüente, as ações permanentes são consideradas com seus valores característicos totais $\mathbf{F}_{\mathbf{g}, \mathbf{k}}$, e as ações variáveis, com seus valores característicos reduzidos $\psi \mathbf{F}_{\mathbf{q}, \mathbf{k}}$, em função do tipo de ação e da utilização da estrutura. A diferença entre essas duas combinações está no valor do coeficiente redutor das ações variáveis.

$\mathrm{Na}$ combinação quase-permanente, todas as ações variáveis sofrem a mesma redução, sendo consideradas com seus valores quase-permanentes $\psi_{2} \mathbf{F}_{\mathbf{q}, \mathbf{k}}$, conforme a seguinte expressão:

$$
\mathrm{F}_{\mathrm{d}, \mathrm{ser}}=\sum_{\mathrm{i}=1}^{\mathrm{m}} \mathrm{F}_{\mathrm{gi}, \mathrm{k}}+\sum_{\mathrm{j}=1}^{\mathrm{n}} \Psi_{2 \mathrm{j}} \cdot \mathrm{F}_{\mathrm{qj}, \mathrm{k}}
$$


$\mathrm{Na}$ combinação freqüente, por outro lado, a ação variável principal $\mathbf{F}_{\mathbf{q} 1, \mathbf{k}}$ é considerada com um valor reduzido chamado de freqüente $\psi_{\mathbf{1}} \mathbf{F}_{\mathbf{q} 1 \mathbf{k}, \mathbf{k}}$, enquanto que as demais são tomadas com seus valores quase-permanentes $\psi_{2} \mathbf{F}_{\mathbf{q}, \mathbf{k}}$, ou seja:

$$
\mathrm{F}_{\mathrm{d}, \mathrm{ser}}=\sum_{\mathrm{i}=1}^{\mathrm{m}} \mathrm{F}_{\mathrm{gi}, \mathrm{k}}+\Psi_{1} \cdot \mathrm{F}_{\mathrm{q} 1, \mathrm{k}}+\sum_{\mathrm{j}=2}^{\mathrm{n}} \Psi_{2 \mathrm{j}} \cdot \mathrm{F}_{\mathrm{q} \mathrm{j}, \mathrm{k}}
$$

Já na combinação rara, as ações permanentes e a variável principal são consideradas com seus valores característicos totais. As demais ações variáveis são tomadas com seus valores freqüentes.

$$
\mathrm{F}_{\mathrm{d}, \mathrm{ser}}=\sum_{\mathrm{i}=1}^{\mathrm{m}} \mathrm{F}_{\mathrm{gi}, \mathrm{k}}+\mathrm{F}_{\mathrm{q} 1, \mathrm{k}}+\sum_{\mathrm{j}=2}^{\mathrm{n}} \Psi_{1 \mathrm{j}} \cdot \mathrm{F}_{\mathrm{qi}, \mathrm{k}}
$$

Nas eqs.(2.42) a (2.44), $\mathbf{F}_{\mathbf{d} \text {,ser }}$ é o valor de cálculo das ações para a combinação considerada e $\psi_{\mathrm{i}}$ é o coeficiente redutor das ações variáveis.

Para o estado limite de deslocamentos excessivos, a escolha da combinação a ser utilizada dependerá, além da norma de cálculo adotada, do tipo de verificação que está sendo realizada.

\subsection{RECOMENDAÇÕES NORMATIVAS}

São apresentadas a seguir as recomendações da NBR 6118 (2003), do ACI 318 (2002), do CEB-FIP (1991) e do EUROCODE 2 (1992), para a verificação dos deslocamentos em elementos fletidos. Por fim, faz-se um exemplo de cálculo, utilizando os procedimentos estudados.

\subsubsection{RECOMENDAÇÕES DA NBR 6118 (2003)}

De acordo com a NBR 6118 (2003), o controle dos deslocamentos excessivos em elementos fletidos deve ser feito através da comparação dos deslocamentos calculados com os valores limites indicados para algumas situações de projeto.

\section{a) Combinação de Ações}

Para as verificações relacionadas aos estados limites de serviço, a NBR 6118 (2003) considera os três tipos de combinação de ações: quase-permanente, freqüente e rara, já 
definidas no item 2.5.2. A escolha para cada caso depende do estado limite de serviço a ser verificado, das características e do uso da estrutura em questão e da natureza das ações.

Os valores dos coeficientes de redução das ações variáveis são fornecidos na Tabela 2.3.

Tabela 2.3 - Valores de $\psi_{1}$ e $\psi_{2}$, segundo a NBR 6118 (2003)

\begin{tabular}{|l|c|c|}
\hline \multicolumn{1}{|c|}{ Ações } & $\psi_{1}$ & $\psi_{2}$ \\
\hline $\begin{array}{l}\text { Ações acidentais em edifícios } \\
\text { Locais em que não há predominância de pesos de equipamentos que } \\
\text { permanecem fixos por longos períodos de tempo, nem de elevadas } \\
\text { concentrações de pessoas }\end{array}$ & 0,4 & 0,3 \\
$\begin{array}{l}\text { Locais em que há predominância de pesos de equipamentos que permanecem } \\
\text { fixos por longos períodos de tempo, ou de elevadas concentrações de pessoas } \\
\text { Bibliotecas, arquivos, oficinas e garagens }\end{array}$ & 0,6 & 0,4 \\
\hline $\begin{array}{l}\text { Vento } \\
\text { Pressão dinâmica do vento em estruturas em geral }\end{array}$ & 0,7 & 0,6 \\
\hline Temperatura & 0,3 & 0,0 \\
Variações uniformes de temperatura em relação à média anual local & 0,5 & 0,3 \\
\hline
\end{tabular}

Para a verificação dos deslocamentos, deve ser adotada a combinação quasepermanente, mas nos casos em que os deslocamentos excessivos são provocados pela ação do vento ou da temperatura, utiliza-se a combinação freqüente. Recomenda-se o uso da combinação freqüente também para a verificação de vibrações excessivas.

\section{b) Cálculo do Momento de Fissuração}

O momento de fissuração, segundo a NBR 6118 (2003) é dado por:

$$
\mathrm{M}_{\mathrm{r}}=\frac{\alpha \cdot \mathrm{f}_{\mathrm{ct}} \cdot \mathrm{I}_{\mathrm{c}}}{\mathrm{y}_{\mathrm{t}}}
$$

na qual:

$\alpha \quad$ é um coeficiente que leva em consideração a forma da seção transversal, e vale:

$\alpha=1,2$ para seções $\mathrm{T}$ ou duplo $\mathrm{T}$,

$\alpha=1,5$ para seções retangulares

I $\quad$ é o momento de inércia da seção bruta de concreto;

$\mathbf{y}_{\mathbf{t}}$ é a distância do centro de gravidade da seção à fibra mais tracionada;

$\mathbf{f}_{\text {ct }} \quad$ é a resistência à tração direta do concreto 
Os valores de $\mathbf{f}_{\mathrm{ct}}$ devem estar coerentes com o estado limite que se deseja verificar. Para deslocamentos excessivos, onde se deseja obter apenas uma boa estimativa do estágio de fissuração da peça, tem-se:

$$
\mathrm{f}_{\mathrm{ct}}=\mathrm{f}_{\mathrm{ctm}}=0,3 \cdot \mathrm{f}_{\mathrm{ck}}^{2 / 3}(\mathrm{em} \mathrm{MPa})
$$

sendo:

$\mathbf{f}_{\text {ctm }} \quad$ é a resistência média do concreto à tração;

$\mathbf{f}_{\text {ck }}$ é a resistência característica do concreto à compressão.

\section{c) Cálculo do Momento de Inércia Efetivo}

O momento de inércia efetivo é determinado com base na eq.(2.8) proposta por BRANSON (1965), aqui reescrita como:

$$
I_{e q}=\left(\frac{M_{r}}{M_{a}}\right)^{3} \cdot I_{c}+\left[1-\left(\frac{M_{r}}{M_{a}}\right)^{3}\right] \cdot I_{I I} \leq I_{c}
$$

sendo:

$\mathbf{M}_{\mathbf{r}} \quad$ o momento de fissuração, dado pela eq.(2.45);

$\mathbf{M}_{\mathbf{a}} \quad$ o momento máximo no elemento sob a condição de carregamento apropriada (quasepermanente ou freqüente);

I $\quad$ o momento de inércia da seção bruta de concreto no Estádio I, desprezando a influência da armadura;

III o momento de inércia da seção de concreto fissurada no Estádio II, como indicado no item 2.3.1a), desprezando a resistência do concreto à tração.

Para vigas contínuas, de acordo com a Prática Recomendada IBRACON (2003), deve-se utilizar uma média ponderada entre os valores de $\mathbf{I}_{\mathbf{e q}}$ das regiões de momento positivo e negativo em cada vão, com base no diagrama de momentos fletores (Figura 2.15). Assim,

$$
I_{e}=\frac{a_{1}}{\ell} \cdot I_{e, 1}+\frac{a_{v}}{\ell} \cdot I_{e, v}+\frac{a_{2}}{\ell} \cdot I_{e, 2}
$$

sendo:

$\mathbf{a}_{\mathrm{v}}$ o comprimento da região de momento positivo;

$\mathbf{a}_{1}, \mathbf{a}_{2}$ os comprimentos das regiões de momento negativo; 
$\ell \quad$ comprimento do vão, considerado como o vão livre mais a altura do elemento desde que esse valor não ultrapasse a distância entre eixos de apoio;

$\mathbf{I}_{\mathbf{e}, \mathbf{v}} \quad$ o momento de inércia efetivo na região de momento positivo, calculado para $\mathbf{M}_{\mathbf{v}}$;

$\mathbf{I}_{\mathrm{e}, 1}, \mathbf{I}_{\mathrm{e}, 2}$ os momentos de inércia efetivos nas regiões de momento negativo, calculados para $\mathbf{M}_{1}$ e $\mathbf{M}_{2}$, respectivamente;

$\mathbf{M}_{\mathbf{v}}$ o máximo momento fletor atuante no vão da viga contínua;

$\mathbf{M}_{1}, \mathbf{M}_{2}$ os momentos fletores atuantes nos apoios esquerdo e direito, respectivamente.

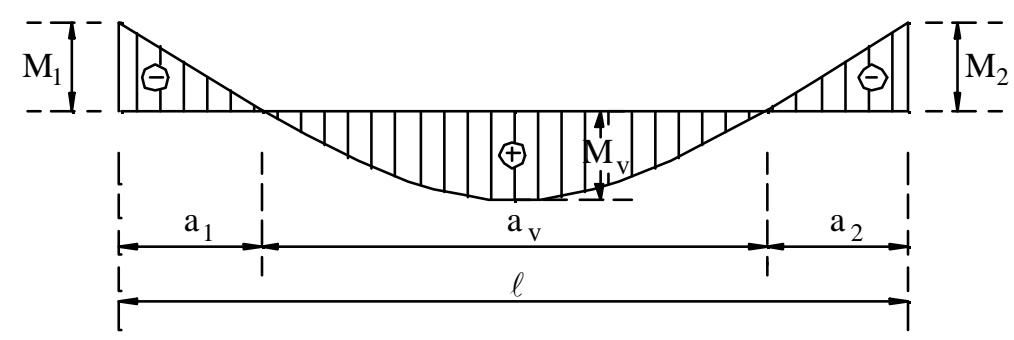

Figura 2.15 - Indicações para o cálculo de $\mathbf{I}_{\mathbf{e}}$ em vigas contínuas

Por simplificação, os valores de $\mathbf{a}_{1} / \ell$ e $\mathbf{a}_{2} / \ell$ podem ser considerados como 0,15 para vãos contínuos nas duas extremidades, recaindo-se na eq.(2.9).

\section{d) Cálculo do Módulo de Elasticidade do Concreto}

De acordo com a NBR 6118 (2003), quando não forem feitos ensaios para a determinação do módulo de elasticidade inicial ou tangente, pode ser utilizada a seguinte expressão:

$$
\mathrm{E}_{\mathrm{ci}}=5600 \cdot \sqrt{\mathrm{f}_{\mathrm{ck}}}
$$

na qual:

$\mathbf{E}_{\mathbf{c i}} \quad$ é o módulo de elasticidade inicial do concreto, em MPa;

$\mathbf{f}_{\text {ck }} \quad$ é a resistência característica do concreto à compressão, em MPa.

Para a verificação do estado limite de deformações excessivas, deve ser utilizado o módulo de elasticidade secante, dado por:

$$
\mathrm{E}_{\mathrm{cs}}=0,85 \cdot \mathrm{E}_{\mathrm{c}}=4760 \sqrt{\mathrm{f}_{\mathrm{ck}}}
$$




\section{e) Determinação do Deslocamento Imediato}

O deslocamento imediato pode ser obtido através de processos simplificados, assumindo-se um comportamento elástico e linear dos materiais, como mencionado no item 2.3.2, desde que os efeitos da presença das armaduras e a existência de fissuras ao longo do vão sejam levados em conta. Isto pode ser feito utilizando-se o momento de inércia efetivo nas eqs.(2.22) e (2.26).

\section{f) Determinação do Deslocamento Diferido}

O deslocamento diferido no tempo, tanto para vigas quanto para lajes, pode ser determinado a partir da multiplicação do deslocamento imediato pelo coeficiente abaixo:

$$
\alpha_{\mathrm{f}}=\frac{\Delta \xi}{1+50 \rho^{\prime}}
$$

sendo:

$$
\Delta \xi=\xi(\mathrm{t})-\xi\left(\mathrm{t}_{\mathrm{o}}\right)
$$

$\xi \quad$ um coeficiente compreendido entre 0 e 2, função da duração da carga, dado por:

$$
\begin{array}{ll}
\xi(t)=0,68 \cdot 0,996^{t} \cdot t^{0,32} & \text { se } t<70 \text { meses } \\
\xi(t)=2 & \text { se } t \geq 70 \text { meses }
\end{array}
$$

t o tempo, em meses, em que o valor do deslocamento é desejado;

$\mathbf{t}_{\mathbf{0}}$ o tempo, em meses, em que as ações de longa duração são aplicadas. Se essas ações forem aplicadas em idades diferentes, $\mathbf{t}_{\mathbf{0}}$ deve ser tomado como o valor médio dado por:

$$
\mathrm{t}_{\mathrm{o}}=\frac{\sum \mathrm{P}_{\mathrm{i}} \cdot \mathrm{t}_{\mathrm{o}, \mathrm{i}}}{\sum \mathrm{P}_{\mathrm{i}}}
$$

$\mathbf{P}_{\mathbf{i}} \quad$ a parcela da ação de longa duração;

$\mathbf{t}_{\mathbf{0}, \mathbf{i}} \quad$ o tempo, em meses, em que a parcela i da ação de longa duração é aplicada;

$\rho$, a taxa de armadura de compressão.

Para vigas contínuas, Prática Recomendada IBRACON (2003), sugere que o valor da taxa de armadura de compressão em cada vão seja calculado utilizando-se uma média ponderada entre os valores de $\rho$ ' das regiões de momento positivo e negativo, com base no 
diagrama de momentos (Figura 2.15), tal como proposto para a determinação do momento de inércia efetivo. Assim:

$$
\rho^{\prime}=\frac{\mathrm{a}_{1}}{\ell} \cdot \rho_{1}^{\prime}+\frac{\mathrm{a}_{\mathrm{v}}}{\ell} \cdot \rho_{\mathrm{v}}^{\prime}+\frac{\mathrm{a}_{2}}{\ell} \cdot \rho_{2}^{\prime}
$$

sendo:

$\rho_{\mathbf{v}} \quad$ a taxa de armadura de compressão na região de momento positivo, na seção de $\mathbf{M}_{\mathbf{v}}$;

$\rho{ }_{1}, \rho{ }_{2}$ as taxas de armadura de compressão nas regiões de momento negativo, nas seções de

$\mathbf{M}_{1}$ e $\mathbf{M}_{2}$, respectivamente.

\section{g) Comparação com Valores Limites de Deslocamentos}

Dependendo da natureza e da utilização da estrutura, os valores limites correspondentes a cada caso podem ser selecionados a partir da Tabela 2.4. Em alguns casos, esses valores se aplicam ao deslocamento total; em outros, apenas à parcela do deslocamento devida às ações variáveis. Existem situações onde o deslocamento a ser comparado é aquele ocorrido após um certo evento, como a construção de paredes ou de forros. Assim sendo, apesar de não estar claramente descrito na NBR 6118 (2003), esses deslocamentos podem ser calculados da seguinte forma:

- Deslocamento total:

$a_{t}=\left(1+\alpha_{f}\right) \cdot a_{i, g}+\Psi q$

- Deslocamento imediato devido às ações variáveis:

$a_{i, q}=a_{i, g+q}-a_{i, g}$

- Deslocamento incremental (que ocorre após construção de pisos, paredes, etc):

$a_{\text {inc }}=\alpha_{f} \cdot a_{i, g}+\left(1+\alpha_{f}\right) \cdot a_{i, \Psi q}$

ou, de outra forma:

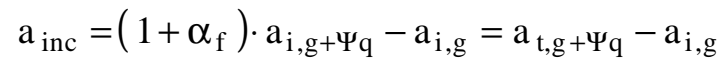

sendo:

$\mathbf{a}_{\mathbf{t}}$ deslocamento total;

$\mathbf{a}_{\text {inc }}$ deslocamento incremental; 
$\mathbf{a}_{\mathbf{i}, \mathbf{g}} \quad$ deslocamento imediato devido às ações permanentes;

$\mathbf{a}_{\mathbf{i}, \mathbf{q}}$ deslocamento imediato devido às ações variáveis;

$\mathbf{a}_{\mathbf{i}, \mathbf{g}+\psi \mathbf{q}}$ deslocamento imediato devido à ação total (combinação quase-permanente ou freqüente);

$\mathbf{a}_{\mathbf{t}, \mathbf{g}+\psi \mathbf{q}}$ deslocamento total devido à ação total (combinação quase-permanente ou freqüente).

Para todos os valores apresentados na Tabela 2.4 valem as seguintes observações gerais:

- Todos os valores limites de deslocamentos supõem elementos de vão $\ell$ suportados em ambas as extremidades por apoios que não se movem. Quando se tratar de balanços, o vão equivalente a ser considerado deve ser o dobro do comprimento do balanço.

- Para o caso de elementos de superfície, os limites prescritos consideram que o valor $\ell$ é o menor vão, exceto em casos de verificação de paredes e divisórias, onde interessa a direção na qual a parede ou divisória se desenvolve, limitando-se este valor a duas vezes o vão menor.

- Deslocamento total será obtido a partir da combinação das ações características, como indicado no item 2.6.1.a.

- Deslocamentos excessivos podem ser parcialmente compensados por contraflechas. 
Tabela 2.4 - Valores limites para os deslocamentos

\begin{tabular}{|c|c|c|c|}
\hline $\begin{array}{c}\text { Razões para } \\
\text { limitação dos } \\
\text { deslocamentos }\end{array}$ & Exemplos & Deslocamento limite & $\begin{array}{c}\text { Porção do } \\
\text { deslocamento a ser } \\
\text { considerado }\end{array}$ \\
\hline \multicolumn{4}{|c|}{ a) Aceitabilidade sensorial } \\
\hline Visual & $\begin{array}{l}\text { Deslocamentos em } \\
\text { elementos estruturais } \\
\text { visíveis }\end{array}$ & $\ell / 250$ & Deslocamento total \\
\hline Outros & $\begin{array}{l}\text { Vibrações do piso que } \\
\text { podem ser sentidas }\end{array}$ & $\ell / 350$ & $\begin{array}{l}\text { Deslocamentos devidos } \\
\text { à ação variável }\end{array}$ \\
\hline \multicolumn{4}{|l|}{ b) Uso da estrutura } \\
\hline $\begin{array}{l}\text { Superfícies que devem } \\
\text { drenar água }\end{array}$ & Coberturas e varandas & $\ell / 250^{1)}$ & Deslocamento total \\
\hline $\begin{array}{l}\text { Pavimentos que devem } \\
\text { permanecer planos }\end{array}$ & $\begin{array}{l}\text { Ginásios e pistas de } \\
\text { boliche }\end{array}$ & $\begin{array}{c}\ell / 350+\text { contraflecha }^{2)} \\
\ell / 600\end{array}$ & Deslocamento total \\
\hline $\begin{array}{l}\text { Elementos que } \\
\text { suportam } \\
\text { equipamentos sensíveis }\end{array}$ & Laboratórios & $\begin{array}{c}\text { De acordo com as } \\
\text { recomendações do } \\
\text { fabricante }\end{array}$ & $\begin{array}{l}\text { Deslocamentos } \\
\text { ocorridos após a } \\
\text { instalação do aparelho }\end{array}$ \\
\hline \multicolumn{4}{|c|}{ c) Efeitos em elementos não estruturais } \\
\hline Pontes rolantes & $\begin{array}{l}\text { Alvenaria e revestimentos } \\
\text { Divisórias leves } \\
\text { Movimentos laterais de } \\
\text { edifícios } \\
\text { Movimentos térmicos } \\
\text { verticais } \\
\text { Movimentos térmicos } \\
\text { horizontais } \\
\text { Revestimentos colados } \\
\text { Revestimentos com juntas } \\
\text { Desalinhamento dos } \\
\text { trilhos }\end{array}$ & $\begin{array}{c}\ell / 500^{3)} \text { ou } 10 \mathrm{~mm} \text { ou } \\
\theta=0,0017 \mathrm{rad}^{4)} \\
\ell / 250 \text { ou } 25 \mathrm{~mm} \\
\mathrm{H} / 2500 \text { ou } \mathrm{H}_{\mathrm{i}} / 1250^{5)} \\
\text { entre pavimentos }^{6)}\end{array}$ & $\begin{array}{l}\text { Deslocamentos } \\
\text { ocorridos após a } \\
\text { construção das paredes } \\
\text { Deslocamentos } \\
\text { ocorridos após a } \\
\text { instalação das } \\
\text { divisórias } \\
\text { Deslocamentos } \\
\text { provocados pela ação } \\
\text { do vento para } \\
\text { combinação freqüente } \\
\text { Deslocamentos } \\
\text { relativos provocados } \\
\text { por diferenças de } \\
\text { temperatura } \\
\text { Deslocamentos } \\
\text { relativos provocados } \\
\text { por diferenças de } \\
\text { temperatura } \\
\text { Deslocamentos } \\
\text { ocorridos após a } \\
\text { construção do forro } \\
\text { Deslocamentos } \\
\text { ocorridos após a } \\
\text { construção do forro } \\
\text { Deslocamentos } \\
\text { provocadospelas ações } \\
\text { de frenagem }\end{array}$ \\
\hline
\end{tabular}

1) As superfícies devem ser suficientemente inclinadas ou o deslocamento previsto compensado por contraflechas, de modo a não ocorrer acúmulo de água.

2) Os deslocamentos podem ser parcialmente compensados pela especificação de contraflechas. Entretanto, a atuação isolada da contraflecha não pode ocasionar um desvio do plano maior que $\ell / 350$. 
3) $\mathrm{O}$ vão $\ell$ deve ser tomado na direção na qual a parede ou a divisória se desenvolve.

4) $\theta$ é a rotação nos elementos que suportam paredes.

5) $\mathbf{H}$ é a altura total do edifício e $\mathbf{H}_{\mathbf{i}}$ o desnível entre dois pavimentos consecutivos.

6) Este limite aplica-se ao deslocamento lateral entre dois pavimentos consecutivos devido à atuação de ações horizontais. Não se devem incluir os deslocamentos devidos a deformações axiais nos pilares.

$\mathrm{O}$ valor $\ell$ refere-se à distância entre o pilar externo e o primeiro pilar interno.

\subsubsection{RECOMENDAÇÕES DO ACI 318 (2002)}

O ACI 318 (2002) permite a utilização de dois procedimentos para o controle dos deslocamentos. Se o elemento estrutural a ser analisado servir de apoio ou estiver fixado a elementos, estruturais ou não, que possam ser danificados por deslocamentos excessivos, deve-se fazer o cálculo dos deslocamentos e sua comparação com os valores limites. Caso contrário, pode-se utilizar diretamente as alturas mínimas fornecidas por este código, que a verificação dos deslocamentos é considerada satisfeita.

\section{a) Ações}

O ACI 318 (2002) não define nenhuma combinação de ações para a verificação dos deslocamentos. Apenas comenta que, para o cálculo de deslocamentos adicionais diferidos, deve-se utilizar a soma da ação permanente, com seu valor total, e de uma parcela da ação variável de longa duração, que não é definida. MACGREGOR (1992) sugere um valor próximo de $30 \%$.

\section{b) Alturas mínimas}

Para vigas e lajes armadas em uma direção, as alturas mínimas são apresentadas na Tabela 2.5. Essas alturas se aplicam a concretos com peso específico de aproximadamente $145 \mathrm{lblft}^{3}\left(22,8 \mathrm{kN} / \mathrm{m}^{3}\right)$, e para aços com tensão de escoamento de 60.000 psi (414 MPa). Para valores diferentes, deve-se fazer as seguintes correções:

- para concretos leves, com peso específico variando de 90 a $120 \mathrm{lb} / \mathrm{ft}^{3}$ (14 a 19 $\mathrm{kN} / \mathrm{m}^{3}$ ), os valores de altura mínima devem ser multiplicados por:

$$
\left(1,65-0,005 \mathrm{w}_{\mathrm{c}}\right) \geq 1,09
$$

onde $\mathbf{w}_{\mathbf{c}}$ é o peso específico do concreto, em $\mathrm{lb} / \mathrm{ft}^{3}$. Para valores de peso específico entre 120 e $145 \mathrm{lb} / \mathrm{ft}^{3}$ (19 e $23 \mathrm{kN} / \mathrm{m}^{3}$ ), não é especificada nenhuma correção, pois o valor do termo a ser multiplicado pela altura mínima é próximo de 1. 
- para valores de tensão de escoamento diferentes de 60.000 psi (414 MPa), deve-se multiplicar os valores de alturas mínimas por:

$$
\left(0,4+\frac{\mathrm{f}_{\mathrm{y}}}{100.000}\right)
$$

onde $\mathbf{f}_{\mathrm{y}}$ é a tensão de escoamento do aço, em psi.

Se essas situações ocorrerem simultaneamente, as duas correções devem ser feitas.

Tabela 2.5 - Alturas mín imas de vigas e lajes armadas em uma direção, segundo o

ACI 318 (2002)

\begin{tabular}{|c|c|c|c|c|}
\hline \multicolumn{5}{|c|}{ Altura Mínima, h } \\
\hline Condição de apoio & $\begin{array}{c}\text { Simplesmente } \\
\text { apoiada }\end{array}$ & $\begin{array}{c}\text { Uma extremidade } \\
\text { contínua }\end{array}$ & $\begin{array}{c}\text { Duas extremidades } \\
\text { contínuas }\end{array}$ & Balanço \\
\hline Elemento & $\begin{array}{c}\text { Elementos que não apóiem nem estejam fixados a outros elementos, estruturais } \\
\text { ou não, que possam ser danificados por deslocamentos excessivos }\end{array}$ & $\frac{\ell}{28}$ & $\frac{\ell}{10}$ \\
\hline Lajes maciças & $\frac{\ell}{20}$ & $\frac{\ell}{24}$ & $\frac{\ell}{21}$ & $\frac{\ell}{8}$ \\
\hline $\begin{array}{c}\text { Vigas ou lajes } \\
\text { nervuradas }\end{array}$ & $\frac{\ell}{16}$ & $\frac{\ell}{18,5}$ & & $\frac{\ell}{2}$ \\
\hline
\end{tabular}

Para lajes armadas em duas direções, apoiadas diretamente sobre os pilares e sem vigas entre os apoios, se a relação entre o maior e o menor vão for menor do que 2, as alturas mínimas são aquelas indicadas na Tabela 2.6. Contudo, os seguintes valores mínimos devem ser respeitados:

- para lajes sem capitéis, a altura não deve ser inferior a 5 in $(12,7 \mathrm{~cm})$;

- para lajes com capitéis, a altura não deve ser inferior a 4 in $(10,2 \mathrm{~cm})$.

Para lajes armadas em duas direções e apoiadas em vigas em todos os lados, a altura mínima é obtida da seguinte forma:

- $\quad$ para $\alpha_{m}$ menor ou igual a 0,2, pode-se utilizar os valores apresentados na Tabela 2.5.

- para $\alpha_{\mathrm{m}}$ maior do que 0,2 , mas menor do que 2 , a altura mínima é dada por:

$$
\mathrm{h}=\frac{\ell_{\mathrm{n}} \cdot\left(0,8+\frac{\mathrm{f}_{\mathrm{y}}}{200.000}\right)}{36+5 \cdot \beta \cdot\left(\alpha_{\mathrm{m}}-0,2\right)} \geq 5 \text { in }
$$


- para $\alpha_{\mathrm{m}}$ maior do que 2,0, a altura mínima é dada por:

$$
\mathrm{h}=\frac{\ell_{\mathrm{n}} \cdot\left(0,8+\frac{\mathrm{f}_{\mathrm{y}}}{200.000}\right)}{36+9 \cdot \beta} \geq 3,5 \mathrm{in}
$$

- para bordas descontínuas, a viga de borda deve ter uma relação de rigidez $\alpha$ maior do que 0,8 , ou a altura mínima dada pelas eqs.(2.55) e (2.56) devem ser aumentadas em pelo menos $10 \%$ no painel estudado.

sendo:

$\alpha \quad$ a razão da rigidez à flexão da viga pela rigidez à flexão de uma faixa da laje, limitada lateralmente pelas linhas centrais dos painéis adjacentes em cada lado da viga;

$\alpha_{\mathrm{m}} \quad$ o valor médio de $\alpha$ para todas as vigas de borda de um painel:

$\ell_{\mathbf{n}} \quad$ o comprimento do vão livre do maior lado da laje, medido de face a face das vigas, em in.;

$\mathbf{f}_{\mathbf{y}} \quad$ a tensão de escoamento do aço, em psi;

$\beta \quad$ a relação entre o maior vão livre pelo menor vão livre.

Tabela 2.6 - Alturas mínimas para lajes armadas em duas direções, segundo o

ACI 318 (2002)

\begin{tabular}{|c|c|c|c|c|c|c|}
\hline \multirow{3}{*}{$\begin{array}{c}\text { Tensão de } \\
\text { escoamento } \\
\mathbf{f}_{\mathbf{y}}(\mathbf{p s i})^{(1)}\end{array}$} & \multicolumn{3}{|c|}{ Sem capitéis } & \multicolumn{3}{|c|}{ Com capitéis } \\
\hline & \multicolumn{2}{|c|}{ Painéis externos } & \multirow{2}{*}{$\begin{array}{l}\text { Painéis } \\
\text { internos }\end{array}$} & \multicolumn{2}{|c|}{ Painéis externos } & \multirow{2}{*}{$\begin{array}{l}\text { Painéis } \\
\text { internos }\end{array}$} \\
\hline & $\begin{array}{l}\text { Sem vigas } \\
\text { de borda }\end{array}$ & $\begin{array}{l}\text { Com vigas } \\
\text { de borda }\end{array}$ & & $\begin{array}{l}\text { Sem vigas } \\
\text { de borda }\end{array}$ & $\begin{array}{l}\text { Com vigas } \\
\text { de borda }\end{array}$ & \\
\hline $\begin{array}{c}40.000 \\
(276 \mathrm{MPa})\end{array}$ & $\frac{\ell_{\mathrm{n}}}{33}$ & $\frac{\ell_{\mathrm{n}}}{36}$ & $\frac{\ell_{\mathrm{n}}}{36}$ & $\frac{\ell_{\mathrm{n}}}{36}$ & $\frac{\ell_{\mathrm{n}}}{40}$ & $\frac{\ell_{\mathrm{n}}}{40}$ \\
\hline $\begin{array}{c}60.000 \\
(414 \mathrm{MPa})\end{array}$ & $\frac{\ell_{\mathrm{n}}}{30}$ & $\frac{\ell_{\mathrm{n}}}{33}$ & $\frac{\ell_{\mathrm{n}}}{33}$ & $\frac{\ell_{\mathrm{n}}}{33}$ & $\frac{\ell_{\mathrm{n}}}{36}$ & $\frac{\ell_{\mathrm{n}}}{36}$ \\
\hline $\begin{array}{c}75.000 \\
(517 \mathrm{MPa})\end{array}$ & $\frac{\ell_{\mathrm{n}}}{28}$ & $\frac{\ell_{\mathrm{n}}}{31}$ & $\frac{\ell_{\mathrm{n}}}{31}$ & $\frac{\ell_{\mathrm{n}}}{31}$ & $\frac{\ell_{\mathrm{n}}}{34}$ & $\frac{\ell_{\mathrm{n}}}{34}$ \\
\hline
\end{tabular}

(1) Para tensões de escoamento entre os valores fornecidos na tabela, a altura mínima é obtida por interpolação linear.

(2) Para lajes com vigas nas bordas externas, o valor de $\alpha$ para a viga de borda deve ser maior do que 0,8 .

$\ell_{\mathrm{n}}$ é o comprimento do vão livre do maior lado, medido de face a face dos pilares, para lajes sem vigas. 


\section{c) Cálculo do Momento de Fissuração}

Como foi apresentado no item 2.3.1b), o momento de fissuração pode ser obtido a partir da eq.(2.6), aqui reescrita como:

$$
\mathrm{M}_{\mathrm{cr}}=\frac{\mathrm{f}_{\mathrm{r}} \cdot \mathrm{I}_{\mathrm{g}}}{\mathrm{y}_{\mathrm{t}}}
$$

na qual:

$\mathbf{M}_{\mathrm{cr}} \quad$ é o momento de fissuração;

I é o momento de inércia da seção bruta de concreto;

$\mathbf{y}_{\mathbf{t}}$ é a distância do centro de gravidade da seção à fibra mais tracionada;

$\mathbf{f}_{\mathbf{r}} \quad$ é o módulo de ruptura (em MPa), dado por:

$$
\mathrm{f}_{\mathrm{r}}=0,623 \cdot \sqrt{\mathrm{f}_{\mathrm{c}}{ }^{\prime}}(\mathrm{em} \mathrm{MPa})
$$

$\mathbf{f}_{\mathbf{c}}$, é a resistência do concreto à compressão (em MPa).

Vale ressaltar que a eq.(2.58) se aplica a concretos com peso específico da ordem de $145 \mathrm{lblft}^{3}\left(23 \mathrm{kN} / \mathrm{m}^{3}\right)$. Para concretos leves, é fornecida uma correção.

\section{d) Cálculo do Momento de Inércia Efetivo}

O momento de inércia efetivo, segundo o ACI 318 (2002), é determinado com base na expressão desenvolvida por BRANSON (1965), apresentada no item 2.3.1c), aqui reescrita como:

$$
I_{e}=\left(\frac{M_{c r}}{M_{a}}\right)^{3} \cdot I_{g}+\left[1-\left(\frac{M_{c r}}{M_{a}}\right)^{3}\right] \cdot I_{c r} \leq I_{g}
$$

na qual:

$\mathbf{M}_{\text {cr }} \quad$ é o momento de fissuração, dado pela eq.(2.57);

$\mathbf{M}_{\mathbf{a}}$ o momento máximo atuante no elemento, no estágio em que o deslocamento é calculado;

I o momento de inércia da seção bruta de concreto no Estádio I, desprezando a influência da armadura;

I o momento de inércia, no Estádio II, da seção de concreto homogeneizada, desprezando a resistência do concreto à tração. 
Para elementos contínuos, o ACI 318 sugere que se utilize a média simples dos valores obtidos a partir da eq.(2.59), calculados com os momentos máximos das regiões de momentos positivo e negativo. Se esses elementos apresentarem altura constante, é permitido o uso do momento de inércia efetivo calculado com o momento atuante na seção central de vãos simples ou contínuos, e com o momento atuante no apoio dos balanços.

\section{e) Cálculo do Módulo de Elasticidade do Concreto}

O módulo de elasticidade do concreto, com peso específico variando entre 90 a 155 $\mathrm{lb} / \mathrm{ft}^{3}$ (14 a $\left.24 \mathrm{kN} / \mathrm{m}^{3}\right)$, é calculado a partir da expressão:

$$
\mathrm{E}_{\mathrm{c}}=\mathrm{w}_{\mathrm{c}}{ }^{1,5} \cdot 33 \cdot \sqrt{\mathrm{f}_{\mathrm{c}}{ }^{\prime}} \quad(\mathrm{psi})
$$

na qual:

$\mathbf{w}_{\mathbf{c}} \quad$ é o peso específico do concreto, em $\mathrm{lb} / \mathrm{ft}^{3}$;

f é a resistência do concreto à compressão, em psi.

Para concretos de pesos específicos usuais, da ordem de $145 \mathrm{lb}_{\mathrm{lft}}{ }^{3}\left(23 \mathrm{kN} / \mathrm{m}^{3}\right)$, permite-se calcular o módulo de elasticidade apenas em função de $\mathbf{f}_{\mathbf{c}}$ ', segundo a seguinte expressão:

$$
\mathrm{E}_{\mathrm{c}}=4733 \sqrt{\mathrm{f}_{\mathrm{c}}{ }^{\prime}}(\mathrm{em} \mathrm{MPa})
$$

\section{f) Determinação do Deslocamento Imediato}

Segundo o ACI 318, os deslocamentos imediatos podem ser calculados a partir de métodos simplificados, como os apresentados no item 2.3.2, desde que se considere, de alguma forma, o efeito da fissuração e da armadura na rigidez à flexão do elemento.

Para elementos estruturais com altura da seção transversal constante ao longo do vão, a rigidez à flexão pode ser considerada a mesma para todas as seções e igual a $\mathbf{E}_{\mathbf{c}} \mathbf{I}_{\mathbf{g}}$, para os elementos não fissurados, e igual a $\mathbf{E}_{\mathbf{c}} \mathbf{I}_{\mathbf{e}}$, para os fissurados. Se a altura da seção transversal variar ao longo do vão, deve ser usado um método mais rigoroso para a determinação da rigidez à flexão.

\section{g) Determinação do Deslocamento Diferido}

Tanto para vigas quanto para lajes, a determinação do deslocamento diferido no tempo é feita a partir do produto do deslocamento imediato por um coeficiente multiplicador, dado por: 


$$
\lambda=\frac{\xi}{1+50 \cdot \rho^{\prime}}
$$

na qual:

$\xi \quad$ é o fator dependente da duração da ação, cujos valores são fornecidos na Tabela 2.7.

$\rho$ ' é a taxa de armadura de compressão na seção do meio do vão.

Tabela 2.7 - Valores do coeficiente $\xi$, segundo o ACI 318 (2002)

\begin{tabular}{|c|c|c|c|c|}
\hline Tempo (meses) & 3 & 6 & 12 & $\geq 60$ \\
\hline$\xi$ & 1,0 & 1,2 & 1,4 & 2,0 \\
\hline
\end{tabular}

\section{h) Comparação com Valores Limites de Deslocamento}

Os deslocamentos calculados de acordo com os itens anteriores devem respeitar os limites apresentados na Tabela 2.8.

Para o cálculo dos deslocamentos a serem comparados aos valores limites, apesar de não estar claramente descrito no ACI 318 (2002), podem ser utilizadas as seguintes expressões, de acordo com o ACI 435R (1995):

- deslocamento imediato devido às ações variáveis:

$$
a_{i, q}=a_{i, g+q}-a_{i, g}
$$

- deslocamento incremental (que ocorre após a construção dos elementos não estruturais):

$$
\mathrm{a}_{\text {inc }}=\mathrm{a}_{\mathrm{i}, \mathrm{q}}+\lambda \cdot \mathrm{a}_{\mathrm{i}, \mathrm{g}}+\lambda \cdot \mathrm{a}_{\mathrm{i}, \Psi \mathrm{q}}
$$

sendo:

$\mathbf{a}_{\mathbf{i}, \mathbf{g}} \quad$ deslocamento imediato devido às ações permanentes;

$\mathbf{a}_{\mathbf{i}, \mathbf{q}}$ deslocamento imediato devido às ações variáveis;

$\mathbf{a}_{\mathbf{i}, \mathbf{g}+\mathbf{q}}$ deslocamento imediato devido à ação total;

$\mathbf{a}_{\text {inc }}$ deslocamento incremental;

$\mathbf{a}_{\mathbf{i}, \mathbf{q}}$ deslocamento imediato devido à parcela da ação variável considerada de longa duração;

$\lambda \quad$ o coeficiente multiplicador dos deslocamentos imediatos, dado pela eq.(2.62). 
Tabela 2.8 - Valores dos deslocamentos limites, segundo o ACI 318 (2002)

\begin{tabular}{|l|l|c|}
\hline \multicolumn{1}{|c|}{ Tipo de elemento } & \multicolumn{1}{|c|}{$\begin{array}{c}\text { Deslocamento a ser } \\
\text { considerado }\end{array}$} & $\begin{array}{c}\text { Deslocamento } \\
\text { limite }\end{array}$ \\
\hline $\begin{array}{l}\text { Coberturas que não apóiem ou não estejam } \\
\text { fixadas a elementos não estruturais que podem } \\
\text { ser danificados por grandes deslocamentos }\end{array}$ & $\begin{array}{l}\text { Deslocamento imediato devido ação variável } \\
\text { àn }\end{array}$ & $\frac{\ell}{180}$ \\
\hline $\begin{array}{l}\text { Pisos que não apóiem ou não estejam fixados a } \\
\text { elementos não estruturais que podem ser } \\
\text { danificados por grandes deslocamentos }\end{array}$ & $\begin{array}{l}\text { Deslocamento imediato devido } \\
\text { ação variável }\end{array}$ & $\frac{\ell}{360}$ \\
\hline $\begin{array}{l}\text { Coberturas ou pisos que apóiem ou estejam } \\
\text { fixados a ele mentos não estruturais que podem } \\
\text { ser danificados por grandes deslocamentos }\end{array}$ & $\begin{array}{l}\text { Parcela do deslocamento total } \\
\text { que ocorre depois da instalação } \\
\text { dos elementos não estruturais (é } \\
\text { dado pelo deslocamento } \\
\text { diferido mais o deslocamento } \\
\text { imediato devido a qualquer } \\
\text { ação variável de longa duração) }\end{array}$ & $\frac{\ell}{480}$ \\
\hline $\begin{array}{l}\text { Coberturas ou pisos que apóiem ou estejam } \\
\text { fixados a elementos não estruturais que não são } \\
\text { danificados por grandes deslocamentos }\end{array}$ & $\frac{\ell}{240}$ \\
\hline
\end{tabular}

\subsubsection{RECOMENDAÇÕES DO CEB-FIP (1991)}

O Código Modelo do Comité Euro-International du Béton, CEB-FIP (1991), fornece recomendações tanto para o cálculo dos deslocamentos, como para o uso de um critério de altura mínima.

Vale ressaltar que as prescrições apresentadas neste item estão de acordo também com o FIB (1999).

\section{a) Combinação de Ações}

Para a verificação do estado limite de serviço, o CEB-FIP (1991) utiliza as combinações rara e freqüente de ações. Para o cálculo dos deslocamentos imediatos, é recomendada a combinação rara; já para os deslocamentos diferidos, a combinação a ser utilizada é a freqüente. É permitido, inclusive, que outras combinações de ações sejam utilizadas, desde que definidas diretamente entre o projetista e o cliente.

As combinações de ações são determinadas utilizando-se as expressões definidas no item 2.5.2, sendo os valores dos coeficientes de redução das ações variáveis apresentados na Tabela 2.9. 
Tabela 2.9 - Valores de $\psi_{1}$ e $\psi_{2}$, segundo o FIB (1999)

\begin{tabular}{|l|c|c|}
\hline \multicolumn{1}{|c|}{ Ações } & $\psi_{\mathbf{1}}$ & $\psi_{\mathbf{2}}$ \\
\hline Ações acidentais em edifícios & & \\
Residências & 0,4 & 0,2 \\
Escritórios e lojas de departamento & 0,8 & 0,5 \\
Estacionamento & 0,7 & 0,6 \\
\hline Ações devidas ao vento & $0,2-0,5$ & 0 \\
\hline Ações devidas a congelamento & $0,2-0,8$ & 0 \\
\hline
\end{tabular}

\section{b) Cálculo do Momento de Fissuração}

O momento de fissuração é calculado a partir da expressão:

$$
\mathrm{M}_{\mathrm{r}}=\frac{\mathrm{f}_{\mathrm{ctm}} \cdot \mathrm{I}_{1}}{\mathrm{y}_{\mathrm{t}}}
$$

na qual:

$\mathbf{y}_{\mathbf{t}} \quad$ é a distância do centro de gravidade da seção não fissurada à fibra mais tracionada;

I $_{1}$ é o momento de inércia da seção transversal não fissurada, homogeneizada;

$\mathbf{f}_{\text {ctm }}$ é a resistência média do concreto à tração, em MPa, dada por:

$\mathrm{f}_{\mathrm{ctm}}=0,30 \cdot \mathrm{f}_{\mathrm{ck}}^{2 / 3}$, para $\mathrm{f}_{\mathrm{ck}} \leq 50 \mathrm{MPa}$

$\mathrm{f}_{\mathrm{ctm}}=1,12 \cdot \mathrm{f}_{\mathrm{ck}}^{1 / 3}$, para $\mathrm{f}_{\mathrm{ck}}>50 \mathrm{MPa}$

$\mathbf{f}_{\text {ck }}$ é a resistência do concreto à compressão, em MPa.

\section{c) Cálculo do Módulo de Elasticidade do Concreto}

O módulo de elasticidade do concreto é dado por:

$E_{c}=\alpha_{E} \cdot\left[\frac{\left(f_{c k}+\Delta f\right)}{f_{c m o}}\right]^{1 / 3}$

na qual:

$\mathbf{E}_{\mathbf{c}} \quad$ é o módulo de elasticidade do concreto, na idade de 28 dias, em MPa;

$\mathbf{f}_{\mathrm{ck}} \quad$ é a resistência do concreto à compressão, em MPa;

$\Delta \mathbf{f}=8 \mathrm{MPa}$;

$\mathbf{f}_{\mathbf{c m o}}=10 \mathrm{MPa}$;

$\alpha_{\mathrm{E}}=2,15 \times 10^{4} \mathrm{MPa}$. 
Para análises elásticas de estruturas de concreto, deve-se utilizar o módulo de elasticidade secante igual a:

$$
\mathrm{E}_{\mathrm{cs}}=0,85 \cdot \mathrm{E}_{\mathrm{c}}
$$

\section{d) Determinação dos Deslocamentos a Partir da Curvatura Média}

Os deslocamentos imediatos ou adicionais podem ser calculados a partir da curvatura do elemento estrutural. Para isso, as seguintes hipóteses são consideradas:

- No estádio I, as seções planas permanecem planas após a deformação, e é válido o princípio da superposição de efeitos: ou seja, é assumida a linearidade do material;

- No estádio II, as seções planas permanecem planas após a deformação.

O CEB-FIP (1991), no item 3.6, fornece expressões para o cálculo das curvaturas médias, apresentadas a seguir e representadas na Figura 2.16.

$$
\begin{array}{ll}
\frac{1}{\mathrm{r}}=\frac{1}{\mathrm{r}_{1}} & \text { para o estádio I } \\
\frac{1}{\mathrm{r}}=\frac{1}{\mathrm{r}_{2}}-\frac{1}{\mathrm{r}_{\mathrm{ts}}}=\frac{1}{\mathrm{r}_{2}}-\left(\frac{1}{\mathrm{r}_{2 \mathrm{r}}}-\frac{1}{\mathrm{r}_{1 \mathrm{r}}}\right) \cdot \beta_{\mathrm{b}} \cdot\left(\frac{\mathrm{M}_{\mathrm{r}}}{\mathrm{M}}\right) \quad \text { para o estádio II } \\
\frac{1}{\mathrm{r}}=\frac{1}{\mathrm{r}_{\mathrm{y}}}-\left(\frac{1}{\mathrm{r}_{2 \mathrm{r}}}-\frac{1}{\mathrm{r}_{1 \mathrm{r}}}\right) \cdot \beta_{\mathrm{b}} \cdot\left(\frac{\mathrm{M}_{\mathrm{r}}}{\mathrm{M}}\right)+\left[\frac{\left(\mathrm{M}-\mathrm{M}_{\mathrm{y}}\right)}{2 \cdot \mathrm{K}_{\mathrm{III}}}\right] & \text { para } \mathrm{M} \geq \mathrm{M}_{\mathrm{y}}
\end{array}
$$

Sendo:

$$
\mathrm{K}_{\mathrm{III}}=\frac{\mathrm{M}_{\mathrm{u}}-\mathrm{M}_{\mathrm{y}}}{\frac{1}{\mathrm{r}_{\mathrm{u}}}-\frac{1}{\mathrm{r}_{\mathrm{y}}}}
$$

M

$\mathbf{M}_{\mathbf{y}}$

$\mathbf{M}_{\mathbf{u}}$

$\mathbf{M}_{\mathbf{r}}$

$\frac{1}{\mathrm{r}_{\mathrm{y}}}$ o momento fletor atuante na seção;

o momento fletor correspondente ao escoamento;

o momento fletor último;

o momento de fissuração, dado pela eq.(2.50);

a curvatura correspondente a $\mathbf{M}_{\mathbf{y}}$, calculada de acordo com a eq.(2.14); 
$\frac{1}{r_{u}} \quad$ a curvatura correspondente a $\mathbf{M}_{\mathbf{u}}$, calculada de acordo com a eq.(2.14);

$\frac{1}{\mathrm{r}_{1}}, \frac{1}{\mathrm{r}_{1 \mathrm{r}}} \quad$ as curvaturas, no estádio $\mathrm{I}$, correspondentes à atuação de $\mathbf{M}$ e $\mathbf{M}_{\mathbf{r}}$, respectivamente, calculadas de acordo com a eq.(2.20);

$\frac{1}{\mathrm{r}_{2}}, \frac{1}{\mathrm{r}_{2 \mathrm{r}}} \quad$ as curvaturas, no estádio II, correspondentes à atuação de $\mathbf{M}$ e $\mathbf{M}_{\mathbf{r}}$, respectivamente, calculadas de acordo com a eq.(2.21);

$\frac{1}{\mathrm{r}_{\mathrm{ts}}} \quad$ a curvatura correspondente à contribuição do concreto tracionado entre as fissuras, dada por:

$\frac{1}{\mathrm{r}_{\mathrm{ts}}}=\left(\frac{1}{\mathrm{r}_{2 \mathrm{r}}}-\frac{1}{\mathrm{r}_{1 \mathrm{r}}}\right) \cdot \beta_{\mathrm{b}} \cdot\left(\frac{\mathrm{M}_{\mathrm{r}}}{\mathrm{M}}\right)$

$\beta_{\mathrm{b}} \geq \beta_{1} \cdot \beta_{2} \quad$ um coeficiente que considera os efeitos da aderência e da duração do carregamento;

$\beta_{1} \quad$ o coeficiente que caracteriza a qualidade da aderência das barras da armadura, e assume os seguintes valores:

$\beta_{1}=1,0$ para barras de alta aderência,

$\beta_{1}=0,5$ para barras lisas;

$\beta_{2} \quad$ o coeficiente que representa a influência da duração da aplicação ou da repetição do carregamento, sendo:

$\beta_{2}=0,8$ para o primeiro carregamento,

$\beta_{2}=0,5$ para o carregamento de longa duração ou repetitivo.

Na Figura 2.16, a linha cheia representa a curvatura média. Já a linha tracejada entre os pontos A e B corresponde à situação do concreto sem fissuras, e submetido a um carregamento de curta duração. 


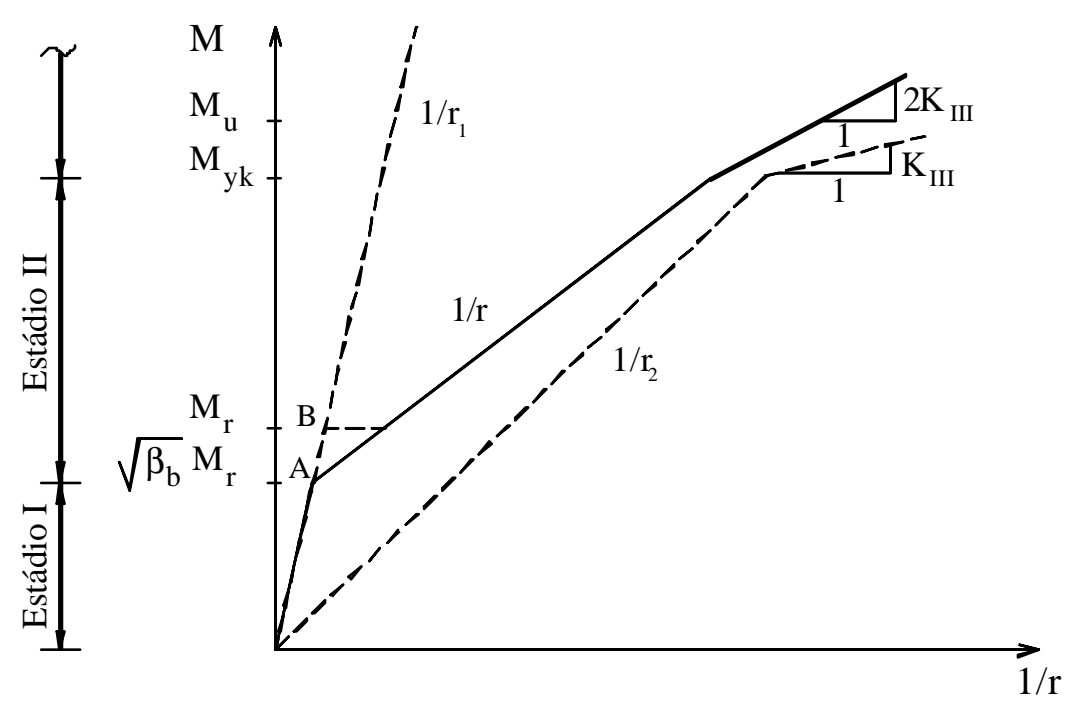

Figura 2.16 - Diagrama momento-curvatura para flexão simples (CEB-FIP, 1991)

O CEB-FIP (1991) indica que a curvatura média de um elemento, num tempo t qualquer após o instante $\mathbf{t}_{\mathbf{0}}$ da aplicação do carregamento, pode ser calculada a partir do somatório da curvatura inicial $\frac{1}{\mathrm{r}_{0}}$ com o incremento da curvatura devido à retração e à fluência $\Delta\left(\frac{1}{r}\right)$, ou seja:

$$
\left(\frac{1}{\mathrm{r}}\right)_{\mathrm{t}}=\frac{1}{\mathrm{r}_{0}}+\Delta\left(\frac{1}{\mathrm{r}}\right)
$$

sendo que a curvatura inicial e o incremento da curvatura podem ser calculados utilizando-se as eqs.(2.68) a (2.70), desde que os efeitos da retração e da fluência sejam considerados. No entanto, não faz nenhuma indicação de como isto deve ser feito.

A curvatura média no tempo $\mathbf{t}$ provocada pelas ações permanente $\mathbf{g}$ e pelas ações variáveis q é dada pela seguinte expressão:

$$
\left(\frac{1}{r}\right)_{(g+q)}=\left(\frac{1}{r}\right)_{(g)}+\left(\frac{1}{r_{0}}\right)_{(g+q)}-\left(\frac{1}{r_{o}}\right)_{(g)}
$$

na qual:

$$
\left(\frac{1}{r}\right)_{(\mathrm{g}+\mathrm{q})} \quad \text { é a curvatura no tempo } \mathbf{t} \text { devida à } \mathbf{g} \text { e } \mathbf{q} ;
$$




$$
\begin{array}{ll}
\left(\frac{1}{\mathrm{r}}\right)_{(\mathrm{g})} & \text { é a curvatura no tempo } \mathbf{t} \text { devida à } \mathbf{g} ; \\
\left(\frac{1}{\mathrm{r}_{\mathrm{o}}}\right)_{(\mathrm{g}+\mathrm{q})} & \text { é a curvatura imediata devida à } \mathbf{g} \text { e } \mathbf{q} ; \\
\left(\frac{1}{\mathrm{r}_{\mathrm{o}}}\right)_{(\mathrm{g})} & \text { é a curvatura imediata devida à } \mathbf{g} .
\end{array}
$$

\section{e) Processo Simplificado}

Para elementos estruturais de edifícios, é indicado um processo simplificado para a avaliação de deslocamentos diferidos no tempo, baseado em uma relação bilinear entre carga e deslocamento. Esses deslocamentos, calculados função do estado de fissuração dos elementos, são dados por:

$$
\begin{array}{ll}
a=(1+\phi) \cdot a_{c} & \text { para } M_{d}<M_{r} \\
a=\left(\frac{h}{d}\right)^{3} \cdot \eta \cdot\left(1-20 \cdot \rho_{c m}\right) \cdot a_{c} & \text { para } M_{d} \geq M_{r}
\end{array}
$$

sendo:

$\mathbf{M}_{\mathbf{r}} \quad$ o momento de fissuração, dado pela eq.(2.63);

$\mathbf{M}_{\mathbf{d}}$ o momento fletor no meio do vão da viga ou da laje, ou no apoio do balanço, sob combinação freqüente de ações;

$\phi \quad$ o coeficiente de fluência, calculado de acordo com o item 2.1.6.4.3b, do CEB-FIP (1991);

$\mathbf{a}_{\mathrm{c}} \quad$ o deslocamento elástico calculado com a rigidez $\mathbf{E}_{\mathbf{c}} \mathbf{I}_{\mathrm{g}}$ da seção bruta de concreto, desprezando a armadura;

$\rho_{\mathrm{cm}} \quad$ a taxa geométrica média da armadura de compressão;

$\rho_{\mathrm{tm}} \quad$ a taxa geométrica média da armadura de tração, (ver eq.(2.75));

$\eta \quad$ um fator de correção que inclui os efeitos da fissuração e da fluência (Tabela 2.10).

Tabela 2.10 - Fator de correção $\eta$ para determinação de deslocamentos, segundo o

CEB-FIP (1991)

\begin{tabular}{|c|c|c|c|c|c|c|c|}
\hline$\rho_{\text {tm }}(\boldsymbol{\%})$ & 0,15 & 0,20 & 0,30 & 0,50 & 0,75 & 1,00 & 1,50 \\
\hline$\eta$ & 10 & 8 & 6 & 4 & 3 & 2,5 & 2 \\
\hline
\end{tabular}


A taxa média da armadura de tração $\rho_{\text {tm }}$ é dada pela seguinte expressão:

$$
\rho_{\mathrm{tm}}=\frac{\mathrm{a}_{1}}{\ell} \cdot \rho_{1}+\frac{\mathrm{a}_{\mathrm{v}}}{\ell} \cdot \rho_{\mathrm{v}}+\frac{\mathrm{a}_{2}}{\ell} \cdot \rho_{2}
$$

na qual:

$\rho_{\mathrm{v}} \quad$ é a taxa de armadura de tração na seção de momento máximo;

$\rho_{1}, \rho_{2}$ são as axas de armadura de tração/compressão nos apoios esquerdo e direito, respectivamente;

$\mathbf{a}_{1}, \mathbf{a}_{2}$ são as distâncias dos apoios esquerdo e direito até o ponto de momento nulo, respectivamente;

$\mathbf{a}_{\mathbf{v}} \quad$ é o comprimento da região de momento positivo;

$\ell \quad$ é o comprimento do vão.

\section{f) Comparação com Valores Limites}

O CEB-FIP (1991) não estabelece valores para os deslocamentos limites a serem comparados com os deslocamentos calculados de acordo com os itens anteriores. Diz apenas que os valores limites para os deslocamentos devem ser estabelecidos pelo projetista em comum acordo com o cliente.

\section{g) Alturas Mínimas}

Para elementos fletidos de concreto armado sem força axial, o critério de altura mínima sugerido pelo CEB-FIP (1991) é dado pela:

$$
\frac{\ell}{\mathrm{d}} \leq \lambda_{\mathrm{o}} \cdot \mathrm{k}_{\mathrm{T}} \cdot \mathrm{k}_{\ell} \cdot\left(\frac{400}{\mathrm{f}_{\mathrm{yk}}}\right)
$$

na qual:

$\lambda_{\mathbf{0}}$ é um coeficiente que depende do tipo de sistema estrutural e do nível de tensão no concreto (Tabela 2.11);

$\mathbf{k}_{\mathbf{T}}=1,0$, para seções com a relação entre a largura da mesa e a largura da alma menor do que 3 ,

$=0,8$, para seções com a relação entre a largura da mesa e a largura da alma maior do que 3;

$\mathbf{k}_{\ell} \quad=\frac{7}{\ell} \leq 1$, com $\ell$ em metros;

$\mathbf{f}_{\mathbf{y k}}$ é a tensão de escoamento do aço da armadura, em MPa. 
Tabela 2.11 - Valores de $\lambda_{\mathbf{o}}$, segundo o CEB-FIP (1991)

\begin{tabular}{|l|c|c|}
\hline \multicolumn{1}{|c|}{ Sistema Estrutural } & $\begin{array}{c}\text { Concreto } \\
\text { altamente } \\
\text { tensionado }^{(\mathbf{1})}\end{array}$ & $\begin{array}{c}\text { Concreto } \\
\text { levemente } \\
\text { tensionado }^{(\mathbf{2})}\end{array}$ \\
\hline $\begin{array}{l}\text { 1. Vigas simplesmente apoiadas, e lajes armadas em uma } \\
\text { ou duas direções, simplesmente apoiadas }\end{array}$ & 18 & 25 \\
\hline $\begin{array}{l}\text { 2. Vão extremo de uma série de vãos contínuos, e lajes } \\
\text { armadas em duas direções com continuidade na direção do } \\
\text { maior vão }\end{array}$ & 23 & 32 \\
\hline $\begin{array}{l}\text { 3. Vão interno de viga ou de lajes armadas em uma ou em } \\
\text { duas direções }\end{array}$ & 25 & 35 \\
\hline $\begin{array}{l}\text { 4. Lajes apoiadas em pilares sem vigas, verificação } \\
\text { efetuada no maior vão }\end{array}$ & $21^{(3)}$ & $30^{(3)}$ \\
\hline 5. Balanços & 7 & 10 \\
\hline
\end{tabular}

(1) Elementos onde o concreto é considerado altamente tensionado são aqueles onde $\rho \geq \mathbf{1 , 5} \%$.

(2) Elementos onde o concreto é considerado levemente tensionado são aqueles onde $\rho \leq \mathbf{0 , 5} \%$.

Se a taxa de armadura é conhecida, valores de $\lambda_{0}$ para concretos entre levemente tensionados e altamente tensionados podem ser obtidos por interpolação, assumindo os valores correspondentes a $\rho=\mathbf{0 , 5 \%}$ para levemente tensionado, e a $\rho \mathbf{= 1 , 5 \%}$ para altamente tensionado.

(3) Esses valores devem ser verificados.

Já segundo o FIB (1999), para vãos menores que 5 m, a altura mínima pode ser determinada a partir da seguinte expressão:

$$
\frac{\alpha \cdot \ell}{\mathrm{h}} \leq\left\{\begin{array}{l}
25 \text { para vigas } \\
30 \text { para lajes }
\end{array}\right.
$$

na qual:

$\ell \quad$ é o vão do elemento;

h é a altura do elemento

$\alpha \quad$ é um coeficiente que depende do sistema estrutural, conforme a Tabela 2.12.

Tabela 2.12 - Valores de $\alpha$, segundo o FIB (1999)

\begin{tabular}{|l|c|}
\hline \multicolumn{1}{|c|}{ Sistema Estrutural } & $\alpha$ \\
\hline $\begin{array}{l}\text { Vigas simplesmente apoiadas, e lajes armadas em uma ou em duas direções, simplesmente } \\
\text { apoiadas }\end{array}$ & 1,0 \\
\hline $\begin{array}{l}\text { Vão extremo de uma série de vãos contínuos, e lajes armadas em duas direções com } \\
\text { continuidade na direção do maior vão }\end{array}$ & 0,8 \\
\hline Vão interno de viga ou de lajes armadas em uma ou em duas direções & 0,6 \\
\hline Balanços & 2,4 \\
\hline
\end{tabular}




\subsubsection{RECOMENDAÇÕES DO EUROCODE 2 (1992)}

O procedimento para a verificação dos deslocamentos segundo o EUROCODE 2 (1992) é basicamente o mesmo adotado pelo CEB-FIP (1991). Além de fornecer expressões para a determinação do deslocamento imediato em função da curvatura média, também é permitido o uso de um critério de altura mínima. O que distingue as recomendações dos dois códigos são as expressões para a obtenção de alguns parâmetros, e o cálculo do deslocamento diferido no tempo, que, no EUROCODE 2 (1992), é efetuado a partir das curvaturas devidas à fluência e à retração.

As recomendações apresentadas a seguir também estão de acordo com o EUROCODE FINAL DRAFT (2001).

\section{a) Combinação de Ações}

A única referência que se encontra para a combinação de ações a ser utilizada no cálculo dos deslocamentos é que, para edifícios, o uso da combinação quase-permanente é satisfatório, com os coeficientes de redução das ações variáveis da Tabela 2.13.

Tabela 2.13 - Coeficientes de redução das ações variáveis, segundo o EUROCODE 2 (1992)

\begin{tabular}{|l|c|c|}
\hline \multicolumn{1}{|c|}{ Ações } & $\psi_{\mathbf{1}}$ & $\psi_{\mathbf{2}}$ \\
\hline Ações acidentais em edifícios & & \\
Edifícios residenciais & 0,4 & 0,2 \\
Escritórios e lojas & 0,6 & 0,3 \\
Estacionamento & 0,7 & 0,6 \\
\hline Ações devidas ao vento & 0,2 & 0 \\
\hline Ações devidas a congelamento & 0,2 & 0,0 \\
\hline
\end{tabular}

\section{b) Cálculo do Momento de Fissuração}

O momento de fissuração é calculado utilizando-se a mesma expressão proposta pelo CEB-FIP (1991), apresentada no item 2.6.3b).

\section{c) Cálculo do Módulo de Elasticidade do Concreto}

O valor do módulo de elasticidade tangente inicial do concreto, na ausência de valores experimentais ou em casos onde não seja necessária uma grande precisão, pode ser calculado pela expressão: 


$$
\mathrm{E}_{\mathrm{cm}}=9500 \cdot\left(\mathrm{f}_{\mathrm{ck}}+8\right)^{1 / 3}
$$

na qual:

$\mathbf{E}_{\mathbf{c m}} \quad$ é o módulo de elasticidade tangente inicial do concreto, em MPa, definido a partir do diagrama tensão-deformação do concreto, para as tensões $\sigma_{\mathrm{c}}=0$ e $\sigma_{\mathrm{c}}=0,4 \mathrm{f}_{\mathrm{ck}}$;

$\mathbf{f}_{\mathrm{ck}} \quad$ é a resistência característica do concreto à compressão, em MPa.

\section{d) Determinação dos Deslocamentos Imediatos a Partir da Curvatura Média}

Segundo o EUROCODE 2 (1992), para elementos estruturais submetidos à flexão, a curvatura média pode ser escrita como:

$$
\frac{1}{\mathrm{r}}=\varsigma \cdot\left(\frac{1}{\mathrm{r}}\right)_{\mathrm{II}}+(1-\varsigma) \cdot\left(\frac{1}{\mathrm{r}}\right)_{\mathrm{I}}
$$

na qual:

$\left(\frac{1}{\mathrm{r}}\right)$ é a curvatura média da seção considerada;

$\left(\frac{1}{r}\right)_{\text {I }}$ é a curvatura da seção no estádio I, obtida pela eq.(2.20);

$\left(\frac{1}{\mathrm{r}}\right)_{\text {II }}$ é a curvatura da seção no estádio II, obtida pela eq.(2.21);

$\zeta \quad$ é um coeficiente de distribuição, dado por:

$$
\varsigma=1-\beta_{1} \cdot \beta_{2} \cdot\left(\frac{M_{c r}}{M}\right)^{2}
$$

$\beta_{1}$ é o coeficiente que considera as propriedades de aderência das barras da armadura, sendo:

$\beta_{1}=1 \quad$ para barras de alta aderência,

$\beta_{1}=0,5 \quad$ para barras lisas;

$\beta_{2}$ é um coeficiente que considera a duração e o número de ciclos do carregamento, sendo:

$\beta_{2}=1 \quad$ para carregamentos de curta duração,

$\beta_{2}=0,5 \quad$ para carregamentos de longa duração ou com muitos ciclos;

$\mathbf{M}_{\mathrm{cr}} \quad$ é o momento de fissuração;

M é o momento fletor atuante na seção fissurada considerada. 
Para seções não fissuradas, tem-se $\zeta=0$. Portanto, para o estádio I, a curvatura é dada por:

$$
\frac{1}{\mathrm{r}}=\left(\frac{1}{\mathrm{r}}\right)_{1}
$$

recaindo-se na eq.(2.68) do CEB-FIP (1991)

\section{e) Determinação dos Deslocamentos Diferidos a Partir da Curvatura Média}

Como mencionado anteriormente, o EUROCODE 2 (1992) fornece prescrições para a avaliação dos deslocamentos diferidos a partir das curvaturas devidas à fluência e à retração.

A curvatura devida à fluência pode ser obtida por meio da eq.(2.79), sendo $\beta_{2}=0,5$ e o módulo de elasticidade secante do concreto substituído pelo módulo de elasticidade efetivo, dado por:

$$
\mathrm{E}_{\mathrm{c}, \mathrm{ef}}=\frac{\mathrm{E}_{\mathrm{cm}}}{1+\phi}
$$

na qual:

$\mathbf{E}_{\mathbf{c}, \mathbf{e f}} \quad$ é o módulo de elasticidade efetivo do concreto, que considera os efeitos da fluência;

$\mathbf{E}_{\mathbf{c m}} \quad$ é o módulo de elasticidade tangente do concreto, dado pela eq.(2.78);

$\phi \quad$ é o coeficiente de fluência, cujos valores são apresentados na Tabela 2.14.

\begin{tabular}{|c|c|c|c|c|c|c|}
\hline \multirow{3}{*}{$\begin{array}{c}\text { Idade do concreto } \\
\text { quando do } \\
\text { carregamento inicial } \\
\mathbf{t}_{\mathrm{o}} \text { (dias) }\end{array}$} & \multicolumn{6}{|c|}{$2 A_{c} / u(m m)$} \\
\hline & 50 & 150 & 600 & 50 & 150 & 600 \\
\hline & \multicolumn{3}{|c|}{$\begin{array}{c}\text { Condição atmosférica seca } \\
(\mathrm{RH}=50 \%)\end{array}$} & \multicolumn{3}{|c|}{$\begin{array}{c}\text { Condição atmosférica úmida } \\
(\mathrm{RH}=80 \%)\end{array}$} \\
\hline 1 & 5,5 & 4,6 & 3,7 & 3,6 & 3,2 & 2,9 \\
\hline 7 & 3,9 & 3,1 & 2,6 & 2,6 & 2,3 & 2,0 \\
\hline 28 & 3,0 & 2,5 & 2,0 & 1,9 & 1,7 & 1,5 \\
\hline 90 & 2,4 & 2,0 & 1,6 & 1,5 & 1,4 & 1,2 \\
\hline 365 & 1,8 & 1,5 & 1,2 & 1,1 & 1,0 & 1,0 \\
\hline
\end{tabular}

Tabela 2.14 - Valores do coeficiente de fluência $\phi$, segundo o EUROCODE 2 (1992)

OBS: $\mathbf{A}_{\mathbf{c}}$ é a área de concreto da seção transversal, e $\mathbf{u}$ é o perímetro exposto de $\mathbf{A}_{\mathbf{c}}$.

A curvatura devida à retração é calculada a partir da seguinte expressão:

$$
\left(\frac{1}{r}\right)_{\mathrm{cs}}=\varepsilon_{\mathrm{cs}} \cdot \alpha_{\mathrm{e}, \mathrm{ef}} \cdot \frac{\mathrm{S}}{\mathrm{I}}
$$


na qual:

$\left(\frac{1}{r}\right)_{c s}$ é a curvatura devida à retração;

S é o momento estático da armadura em relação ao centróide da seção transversal;

I é o momento de inércia da seção transversal;

$\alpha_{\text {e,ef }} \quad$ é a razão modular efetiva, ou seja, a razão entre o módulo de elasticidade do aço e o módulo de elasticidade efetivo do concreto:

$$
\alpha_{\mathrm{e}, \mathrm{ef}}=\frac{\mathrm{E}_{\mathrm{s}}}{\mathrm{E}_{\mathrm{c}, \mathrm{ef}}}
$$

$\varepsilon_{\mathrm{cs}} \quad$ é deformação devida à retração livre, cujos valores são apresentados na Tabela 2.15.

Tabela 2.15 - Valores da deformação devida à retração livre, $\varepsilon_{\mathrm{cs}}$, em \%o, segundo o

EUROCODE 2 (1992)

\begin{tabular}{|c|c|c|c|}
\hline \multirow{2}{*}{$\begin{array}{c}\text { Localização do } \\
\text { elemento }\end{array}$} & $\begin{array}{c}\text { Umidade relativa } \\
(\boldsymbol{\%})\end{array}$ & $\leq 150$ & 600 \\
\hline Interno & 50 & $-0,60$ & 0,50 \\
\hline Externo & 80 & $-0,33$ & $-0,28$ \\
\hline
\end{tabular}

O momento estático $\mathbf{S}$ e o momento de inércia $\mathbf{I}$ da seção transversal devem ser calculados tanto para o estádio I quanto para o estádio II, com a curvatura final sendo calculada utilizando-se a eq.(2.79).

Os valores fornecidos nas Tabela 2.14 e Tabela 2.15 para o coeficiente de fluência e para a deformação por retração livre, respectivamente, devem ser usados em casos onde não seja necessária uma grande acuidade na determinação dos deslocamentos. No Apêndice 1 do EUROCODE 2 (1992), encontra-se um processo mais rigoroso para a determinação dos valores desses parâmetros.

\section{f) Comparação com Valores Limites de Deslocamentos}

O EUROCODE 2 (1992), assim como o CEB-FIP (1991), sugere que os valores limites dos deslocamentos devem ser definidos em comum acordo com o cliente. São feitas, entretanto, duas observações.

A primeira é que o deslocamento total de uma viga, laje ou balanço, calculado a partir da combinação de ações quase-permanente, pode prejudicar a aparência ou a funcionalidade da estrutura se exceder o limite de $\frac{\ell}{250}$. 
E a segunda, é que para não ocorrerem danos aos elementos, estruturais ou não, que se apóiam ou estão fixados em uma viga, laje ou balanço, o deslocamento incremental, definido no item 2.6.1g), não deve exceder $\frac{\ell}{500}$.

\section{g) Alturas Mínimas}

O critério de altura mínima fornecido pelo EUROCODE 2 (1992) é semelhante ao do CEB-FIP (1992), apresentado no item 2.6.3g) e dado pela eq.(2.76). A única diferença está nos valores do coeficiente $\mathbf{k}_{\ell}$, que, segundo o EUROCODE 2 (1992), são os seguintes:

$\mathbf{k}_{\ell} \quad=\frac{7}{\ell} \leq 1, \quad$ para vigas e lajes, exceto para lajes planas, que apóiam elementos não estruturais que possam ser danificados por deslocamentos excessivo;

$\mathbf{k}_{\ell} \quad=\frac{8,5}{\ell} \leq 1, \quad$ para lajes planas.

Nos dois casos, $\ell$ deve ser dado em metros.

\subsubsection{EXEMPLO DE CÁLCULO}

Para a viga representada na Figura 2.17, são calculados os deslocamentos imediatos e diferidos de acordo com cada uma das normas citadas anteriormente. Além disso, são fornecidos os valores dos principais parâmetros envolvidos no cálculo dos deslocamentos, é feita uma comparação com seus respectivos limites e são tecidos alguns comentários sobre os resultados obtidos.

\section{a) Dados}

Os dados necessários para a avaliação dos deslocamentos da viga em estudo são:

- $\mathrm{f}_{\mathrm{ck}}=30 \mathrm{MPa}$;

- $\quad$ Aço CA-50; $\mathrm{E}_{\mathrm{S}}=210000 \mathrm{MPa}$

- Ações permanente e variável : $g=12 \mathrm{kN} / \mathrm{m}$ e q $=4 \mathrm{kN} / \mathrm{m}$;

- Vão da viga $(\ell)=5,90 \mathrm{~m}$;

- Seção transversal: $b=15 \mathrm{~cm}$ e $\mathrm{h}=55 \mathrm{~cm}$;

- Área de aço da armadura de tração $=5,0 \mathrm{~cm}^{2}$ (4 $\left.\phi 12,5 \mathrm{~mm}\right)$;

- Área de aço da armadura de compressão $=1,6 \mathrm{~cm}^{2}(2$ ф $10 \mathrm{~mm})$;

- Diâmetro da armadura transversal =6,3 mm; 
- Cobrimento $=2,5 \mathrm{~cm}$;

- Idade do concreto quando da verificação dos deslocamentos: $t \geq 5$ anos.

- Idade do concreto quando da aplicação das ações:

- $\quad$ ação permanente: $t_{0}=28$ dias

- $\quad$ ação variável: $\quad \mathrm{t}_{0}=45$ dias

Vista Longitudinal

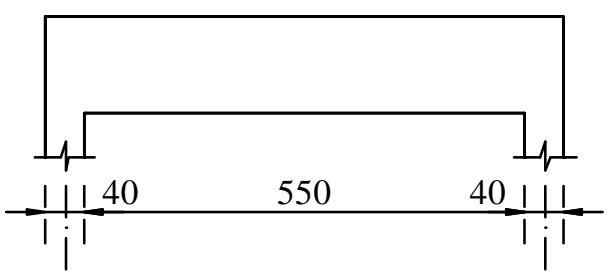

Sistema Estático e Carregamento
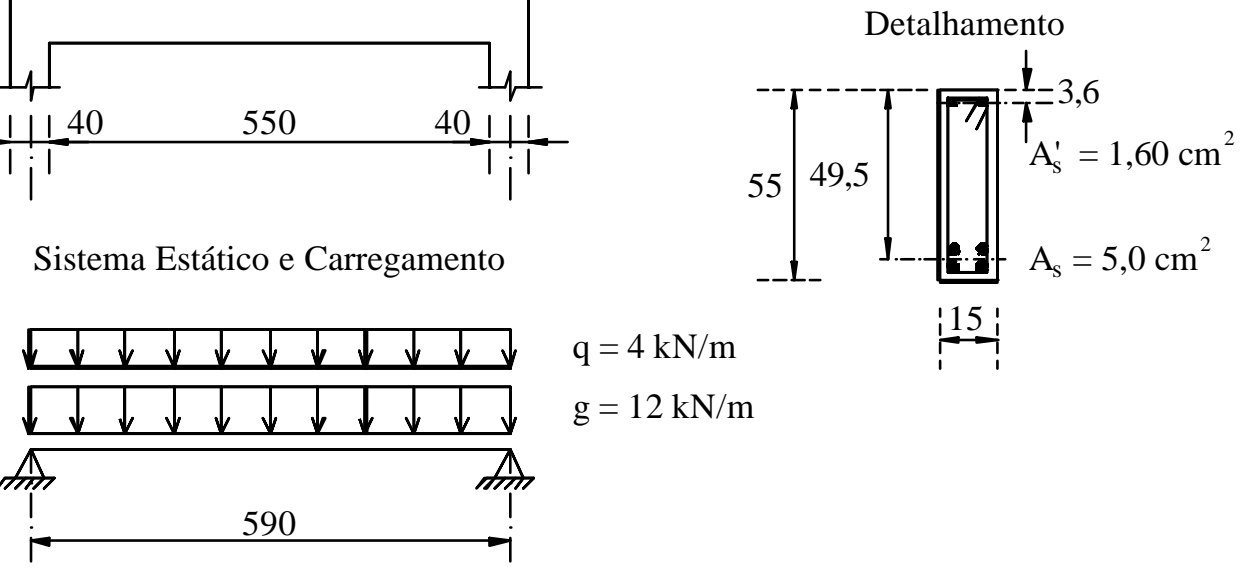

$\mathrm{q}=4 \mathrm{kN} / \mathrm{m}$

$\underset{i}{10 i}$

$\mathrm{g}=12 \mathrm{kN} / \mathrm{m}$

Figura 2.17 - Viga do exemplo

\section{b) Parâmetros Utilizados}

Os valores dos principais parâmetros envolvidos no cálculo dos deslocamentos são apresentados nas Tabela 2.16 a Tabela 2.19. Esses parâmetros foram determinados de acordo com as prescrições de cada uma das normas analisadas.

Apesar do ACI 318 (2002) não fornecer qual deve ser a parcela da ação variável a ser considerada no cálculo dos deslocamentos diferidos, foi adotado um valor igual a $30 \%$ da ação variável total, que, somada com a ação permanente, corresponde à combinação quasepermanente de ações recomendada pela NBR 6118 (2003). Isto foi feito para que os deslocamentos calculados de acordo com as recomendações destas normas pudessem ser comparados. 
Tabela 2.16 - Propriedades geométricas das seções transversais da viga

\begin{tabular}{|c|c|c|c|c|}
\hline \multirow{2}{*}{$\begin{array}{c}\text { Propriedades } \\
\text { Geométricas }\end{array}$} & \multicolumn{5}{|c|}{ Norma } \\
\cline { 2 - 5 } & NBR 6118 (2003) & ACI 318 (2002) & CEB-FIP (1991) & $\begin{array}{c}\text { EUROCODE 2 } \\
(1992)\end{array}$ \\
\hline $\mathrm{I}_{\mathrm{g}}\left(\mathrm{cm}^{4}\right)^{(1)}$ & 207969 & 207969 & 207969 & 207969 \\
\hline $\mathrm{I}_{1}\left(\mathrm{~cm}^{4}\right)^{(1)}$ & - & - & 228945 & 226370 \\
\hline $\mathrm{I}_{1}\left(\mathrm{~cm}^{4}\right)^{(2)}$ & - & - & - & 278786 \\
\hline $\mathrm{I}_{\mathrm{II}}\left(\mathrm{cm}^{4}\right)^{(1)}$ & 65600 & 65905 & 60935 & 55473 \\
\hline $\mathrm{I}_{\mathrm{II}}\left(\mathrm{cm}^{4}\right)^{(2)}$ & - & - & - & 149532 \\
\hline $\mathrm{I}_{\mathrm{e}}\left(\mathrm{cm}^{4}\right)^{(3)}$ & 101073 & 83036 & - & - \\
\hline $\mathrm{I}_{\mathrm{e}}\left(\mathrm{cm}^{4}\right)^{(4)}$ & 92252 & 80020 & - & - \\
\hline $\mathrm{I}_{\mathrm{e}}\left(\mathrm{cm}^{4}\right)^{(5)}$ & 80565 & 73132 & - & 142,7 \\
\hline $\mathrm{S}_{1}\left(\mathrm{~cm}^{3}\right)$ & - & - & - & 175,1 \\
\hline $\mathrm{S}_{2}\left(\mathrm{~cm}^{3}\right)$ & - & - & - & - \\
\hline$(1 / \mathrm{r})_{1 \mathrm{r}}$ & - & - & $3,786 \times 10^{-6}$ & - \\
\hline$(1 / \mathrm{r})_{2 \mathrm{r}}$ & - & - & $1,422 \times 10^{-5}$ & $7,068 \times 10^{-6}$ \\
\hline$(1 / \mathrm{r})_{\mathrm{cs} 1}$ & - & - & - & $1,617 \times 10^{-5}$ \\
\hline$(1 / \mathrm{r})_{\mathrm{cs} 2}$ & - & - & - & \\
\hline$(1) \mathrm{C}^{2}$ & & & & \\
\hline
\end{tabular}
(1) Calculado utilizando-se $\alpha_{\mathrm{e}}=\mathrm{E}_{\mathrm{s}} /\left(\mathrm{E}_{\mathrm{c}}\right.$ ou $\left.\mathrm{E}_{\mathrm{cs}}\right)$
(2) Calculado utilizando-se $\alpha_{\mathrm{e}}=\mathrm{E}_{\mathrm{s}} / \mathrm{E}_{\mathrm{c}, \mathrm{ef}}$
(3) Calculado considerando-se apenas as ações permanentes
(4) Calculado utilizando-se a combinação quase-permanente de ações
(5) Calculado utilizando-se a combinação rara de ações
(-) Não se aplica à norma em questão

Tabela 2.17 - Momentos fletores característicos para as combinações de ações estudadas, em kN.cm

\begin{tabular}{|c|c|c|c|c|}
\hline \multirow{2}{*}{$\begin{array}{c}\text { Combinação } \\
\text { de ações }\end{array}$} & NBR 6118 (2003) & ACI 318 (2002) & CEB-FIP (1991) & $\begin{array}{c}\text { EUROCODE 2 } \\
(1992)\end{array}$ \\
\cline { 2 - 5 } & 5222 & 5222 & 5222 & 5222 \\
\hline $\begin{array}{c}\text { Ações permanentes } \\
\text { Quase permanente } \\
\left(\psi_{2}=0,2\right) \\
\left(\psi_{2}=0,3\right)\end{array}$ & - & - & 5570 & 5570 \\
\hline $\begin{array}{c}\text { Freqüente } \\
\left(\psi_{1}=0,4\right)\end{array}$ & 5744 & 5744 & - & - \\
\hline Rara & 6962 & - & 5918 & 5918 \\
\hline
\end{tabular}

OBS: (-) Não se aplica à norma em questão 
Tabela 2.18 - Propriedades dos materiais e momento de fissuração

\begin{tabular}{|l|c|c|c|c|}
\hline \multirow{2}{*}{$\begin{array}{c}\text { Propriedades materiais } \\
\text { dos }\end{array}$} & NBR 6118 (2003) & ACI 318 (2002) & CEB-FIP (1991) & $\begin{array}{c}\text { EUROCODE 2 } \\
(1992)\end{array}$ \\
\cline { 2 - 5 } & - & 25924 & 33551 & 31939 \\
\hline $\mathrm{E}_{\mathrm{c}}(\mathrm{MPa})$ & 26072 & - & 28518 & - \\
\hline $\mathrm{E}_{\mathrm{cs}}(\mathrm{MPa})$ & - & - & - & 9125 \\
\hline $\mathrm{E}_{\mathrm{c}, \mathrm{ef}}(\mathrm{MPa})$ & 8,055 & 8,101 & 7,364 & $6,575^{(1)}$ \\
\hline$\alpha_{\mathrm{e}}$ & 2,90 & 3,41 & 2,90 & $23,013^{(2)}$ \\
\hline $\mathrm{f}_{\mathrm{ctm}}(\mathrm{MPa})$ & $3286^{(3)}$ & 2580 & 2472 & 2,90 \\
\hline $\mathrm{M}_{\mathrm{cr}}(\mathrm{kNcm})$ & & & & 2426 \\
\hline
\end{tabular}

(1) $\alpha_{\mathrm{e}}=\mathrm{E}_{\mathrm{s}} / \mathrm{E}_{\mathrm{cs}}$

(2) $\alpha_{e}=E_{s} / E_{c, e f}$

(3) $\alpha=1,5$

Tabela 2.19 - Parâmetros utilizados no cálculo dos deslocamentos diferidos

\begin{tabular}{|c|c|c|c|c|c|}
\hline \multirow{2}{*}{ Parâmetros } & \multicolumn{2}{|c|}{ Norma } & \multicolumn{2}{|c|}{ Norma } \\
\cline { 2 - 3 } \cline { 6 - 6 } & $\begin{array}{c}\text { NBR 6118 } \\
(2003)\end{array}$ & $\begin{array}{c}\text { ACI 318 } \\
(2002)\end{array}$ & Parâmetros & CEB-FIP (1991) & $\begin{array}{c}\text { EUROCODE 2 } \\
(1992)\end{array}$ \\
\hline$\xi(\mathrm{t})$ & 2,00 & 2,00 & $\eta$ & 3,32 & - \\
\hline$\xi\left(\mathrm{t}_{0}\right)$ & 0,67 & 0,67 & $\beta_{2}$ & - & 0,50 \\
\hline$\alpha_{\mathrm{f}}$ & 1,20 & - & $\phi$ & - & $2,5^{(1)}$ \\
\hline$\lambda(\mathrm{t})$ & - & 1,81 & $\varepsilon_{\mathrm{cs}}$ & - & $6,0 \times 10^{-4(1)}$ \\
\hline
\end{tabular}

(1) Para a determinação desses parâmetros foi considerado que a viga é interna, que a umidade relativa do ar é igual a $70 \%$

\section{c) Valores dos Deslocamentos}

Os deslocamentos calculados segundo as recomendações das normas em questão encontram-se nas Tabela 2.20 a Tabela 2.23.

Para o cálculo dos deslocamentos segundo o CEB-FIP (1991) e o EUROCODE 2 (1992), foi feita uma planilha para calcular a integração da curvatura ao longo do vão utilizando-se a regra do trapézio, como apresentado em BEEBY (1999).

Os deslocamentos diferidos de acordo com o CEB-FIP (1991) foram calculados empregando-se o processo simplificado apresentado no item 5.6.3.e. 
Tabela 2.20 - Deslocamentos calculados segundo a NBR 6118 (2003)

\begin{tabular}{|c|c|c|}
\hline & $\begin{array}{c}\text { Tipo de } \\
\text { Deslocamento }\end{array}$ & Deslocamentos (cm) \\
\hline \multirow{4}{*}{ 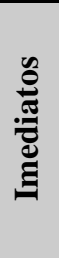 } & $a_{i, g}$ & 0,72 \\
\hline & $a_{i, g+q}$ & 1,20 \\
\hline & $a_{i, q}$ & 0,48 \\
\hline & $a_{i, g+0,3 q}$ & 0,87 \\
\hline \multirow{2}{*}{ 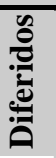 } & $a_{d, g}$ & 0,86 \\
\hline & $a_{d, g+0,3 q}$ & 1,04 \\
\hline ᄅे & $a_{t, g+0,3 q}$ & 1,91 \\
\hline$\dot{\Xi}$ & $\mathrm{a}_{\mathrm{inc}, \mathrm{g}+0,3 \mathrm{q}}$ & 1,19 \\
\hline
\end{tabular}

Tabela 2.21 - Deslocamentos calculados segundo o ACI 318 (2002)

\begin{tabular}{|c|c|c|}
\hline & $\begin{array}{c}\text { Tipo de } \\
\text { Deslocamento }\end{array}$ & $\begin{array}{c}\text { Deslocamentos } \\
(\mathrm{cm})\end{array}$ \\
\hline \multirow{5}{*}{ 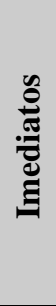 } & $a_{i, g}$ & 0,88 \\
\hline & $a_{i, g+q}$ & 1,33 \\
\hline & $a_{i, q}$ & 0,45 \\
\hline & $a_{i, g+0,3 q}$ & 0,99 \\
\hline & $a_{i, 0,3 q}$ & 0,11 \\
\hline \multirow{2}{*}{ 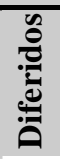 } & $a_{d, g}$ & 1,59 \\
\hline & $a_{d, 0,3 q}$ & 0,20 \\
\hline$\dot{\Xi}$ & $\mathrm{a}_{\text {inc, }, \mathrm{g}+0,3 \mathrm{q}}$ & 2,24 \\
\hline
\end{tabular}

Tabela 2.22 - Deslocamentos calculados segundo o CEB-FIP (1991)

\begin{tabular}{|c|c|c|}
\hline & $\begin{array}{c}\text { Tipo de } \\
\text { Deslocamento }\end{array}$ & $\begin{array}{c}\text { Deslocamentos } \\
\text { (cm) }\end{array}$ \\
\hline \multirow{2}{*}{ 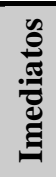 } & $a_{i, g}$ & 0,85 \\
\hline & $a_{i, g+q}$ & 1,25 \\
\hline$\dot{\ddot{\theta}}$ & $a_{d, g+0,4 q}$ & 1,34 \\
\hline$\dot{\vec{\theta}}$ & $\mathrm{a}_{\mathrm{t}, \mathrm{g}+0,4 \mathrm{q}}$ & 2,59 \\
\hline$\dot{\Xi}$ & $\mathrm{a}_{\text {inc, } g+0,4 \mathrm{q}}$ & 1,74 \\
\hline
\end{tabular}


Tabela 2.23 - Deslocamentos calculados segundo o EUROCODE 2 (1992)

\begin{tabular}{|c|c|c|}
\hline & $\begin{array}{c}\text { Tipo de } \\
\text { Deslocamento }\end{array}$ & $\begin{array}{c}\text { Deslocamentos } \\
\text { (cm) }\end{array}$ \\
\hline \multirow{2}{*}{ } & $a_{i, g}$ & 0,81 \\
\hline & $a_{i, g+0,2 q}$ & 0,90 \\
\hline$\dot{\vec{b}}$ & $a_{d, g+0,2 q}$ & 0,99 \\
\hline$\stackrel{\dot{\theta}}{\ddot{\varepsilon}}$ & $a_{t, g+0,2 q}$ & 1,89 \\
\hline$\dot{\mathscr{E}}$ & $\mathrm{a}_{\text {inc, }, \mathrm{g}+0,2 \mathrm{q}}$ & 1,08 \\
\hline
\end{tabular}

\section{d) Comparação com os Valores Limites}

Considerando-se que a viga em estudo faça parte de um edifício residencial e que não apóie nenhum equipamento sensível a deslocamentos, devem ser realizadas as verificações apresentadas a seguir.

- $\quad$ NBR 6118 (2003)

Tomando-se as indicações da Tabela 2.4, os limites de deslocamentos que devem ser verificados, segundo a NBR 6118 (2003), classificados de acordo com a razão pela qual a restrição é necessária, são os seguintes:

(A) Para atender aos requisitos relacionados à aceitabilidade sensorial

Visual: $\quad \mathrm{a}_{\mathrm{t}, \mathrm{g}+\Psi \mathrm{q}} \leq \frac{\ell}{250}=\frac{590}{250}=2,36 \mathrm{~cm}$

Vibrações: $\quad \mathrm{a}_{\mathrm{i}, \mathrm{q}} \leq \frac{\ell}{350}=\frac{590}{350}=1,69 \mathrm{~cm}$

(B) Para evitar efeitos em elementos não estruturais:

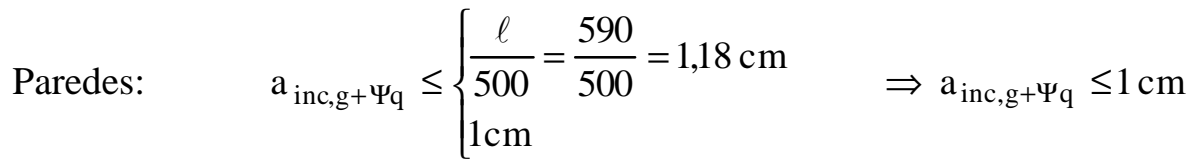

Na Tabela 2.24, estão relacionadas as verificações dos deslocamentos considerandose combinações quase-permanente de ações. 
Tabela 2.24 - Verificação dos deslocamentos, segundo a NBR 6118 (2003)

\begin{tabular}{|l|l|c|}
\hline Verificação & \multicolumn{1}{|c|}{ Comparação } & Aprovação \\
\hline Visual & $a_{\mathrm{t}, \mathrm{g}+0,3 \mathrm{q}}=1,91 \mathrm{~cm}<2,36 \mathrm{~cm}$ & Sim \\
\hline Vibração & $\mathrm{a}_{\mathrm{i}, \mathrm{q}}=0,48 \mathrm{~cm}<1,69 \mathrm{~cm}$ & Sim \\
\hline Efeito em elementos não estruturais & $\mathrm{a}_{\mathrm{inc}, \mathrm{g}+0,3 \mathrm{q}}=1,19 \mathrm{~cm}>1 \mathrm{~cm}$ & Não \\
\hline
\end{tabular}

- ACI $318(2002)$

Para o ACI 318 (2002), os deslocamentos calculados devem ser comparados aos deslocamentos admissíveis apresentados na Tabela 2.8. As verificações são indicadas na Tabela 2.25, sendo utilizados os seguintes limites:

(A) Considerando-se que a viga não apóie ou não esteja fixada a elementos não estruturais que podem ser danificados por grandes deslocamentos:

$$
\mathrm{a}_{\mathrm{i}, \mathrm{q}} \leq \frac{\ell}{360}=\frac{590}{360}=1,64 \mathrm{~cm}
$$

(B) Considerando-se que a viga apóie ou esteja fixada a elementos não estruturais que podem ser danificados por grandes deslocamentos:

$$
\mathrm{a}_{\text {inc, } \mathrm{g}+\Psi \mathrm{q}} \leq \frac{\ell}{480}=\frac{590}{480}=1,23 \mathrm{~cm}
$$

Tabela 2.25 - Verificação dos deslocamentos segundo o ACI 318, 2002

\begin{tabular}{|c|c|c|}
\hline Verificação & Comparação & Aprovação \\
\hline (A) & $a_{i, q}=0,45 \mathrm{~cm}<\frac{\ell}{360}=1,64 \mathrm{~cm}$ & Sim \\
\hline (B) & $a_{i n c, g+0,3 q}=2,21 \mathrm{~cm}>\frac{\ell}{480}=1,23 \mathrm{~cm}$ & Não \\
\hline
\end{tabular}

- EUROCODE 2 (1992)

Segundo o EUROCODE 2 (1992), os limites dos deslocamentos, classificados em função do objetivo que se deseja alcançar com a restrição, são os seguintes: 
(A) Para não prejudicar a aparência ou a funcionalidade da viga:

$$
\mathrm{a}_{\mathrm{t}, \mathrm{g}+0,2 \mathrm{q}} \leq \frac{\ell}{250}=\frac{590}{250}=2,36 \mathrm{~cm}
$$

(B) Para evitar danos nos elementos que se apóiam ou estão fixados na viga:

$$
\mathrm{a}_{\text {inc, } \mathrm{g}+0,2 \mathrm{q}} \leq \frac{\ell}{500}=\frac{590}{500}=1,18 \mathrm{~cm}
$$

$\mathrm{Na}$ Tabela 2.26, encontram-se as comparações desses limites com os deslocamentos calculados seguindo as recomendações do EUROCODE 2 (1992).

Tabela 2.26 - Verificação dos deslocamentos segundo o EUROCODE 2 (1992)

\begin{tabular}{|c|c|c|}
\hline Verificação & Comparação & Aprovação \\
\hline (A) & $a_{\mathrm{t}, \mathrm{g}+0,2 \mathrm{q}}=1,89 \mathrm{~cm}<\frac{\ell}{250}=2,36 \mathrm{~cm}$ & $\operatorname{Sim}$ \\
\hline (B) & $\mathrm{a}_{\mathrm{inc,g}+0,2 \mathrm{q}}=1,08 \mathrm{~cm}<\frac{\ell}{500}=1,18 \mathrm{~cm}$ & $\operatorname{Sim}$ \\
\hline
\end{tabular}

Como o CEB-FIP (1991) não fornece valores limites, os deslocamentos calculados segundo as recomendações deste código não foram verificados.

\section{e) Análise dos Resultados}

A partir dos deslocamentos calculados e da comparação com valores limites indicados pelas normas de cálculo estudadas, algumas observações podem ser feitas.

Comparando-se os resultados obtidos segundo a NBR 6118 (2003), Tabela 2.18, e segundo o ACI 318 (2002), Tabela 2.19, nota-se que os deslocamentos imediatos são bem próximos, mas os diferidos e incrementais do ACI 318 (2002) são maiores. Isto se deve ao fato de que, para este código, o fator $\xi$, utilizado na eq.(2.54) para o cálculo do coeficiente multiplicador dos deslocamentos imediatos $\lambda$, depende da duração total do carregamento, não considerando uma redução do seu valor em função da idade de aplicação do carregamento de longa duração, como recomenda a NBR 6118 (2003) na eq.(2.43).

Vale ressaltar que MACGREGOR (1992) apresenta um procedimento semelhante ao da NBR 6118 (2003), entretanto, NAWY (1996), FANELLA et al (1999) e o ACI 435 (1995) apresentam o cálculo do coeficiente multiplicador dos deslocamentos imediatos $\lambda$, em função da duração total do carregamento. 
Os deslocamentos calculados segundo o EUROCODE 2 (1992), indicados na Tabela 2.23, são os únicos que atendem aos limites estabelecidos em todas as verificações. De acordo com as Tabela 2.24 e Tabela 2.25, tanto para a NBR 6118 (2003) quanto para o ACI 318 (2002), a verificação dos deslocamentos incrementais não foi satisfeita. Comparando-se, então, os limites dessas verificações para os códigos em questão, observa-se que os dos EUROCODE 2 (1992) são menores, mantendo-se abaixo dos limites recomendados. Além disso, para a combinação de ações quase-permanente do EUROCODE 2 (1992), o coeficiente de redução das ações variáveis é menor $\left(\psi_{2}=0,20\right)$ que o da norma brasileira $\left(\psi_{2}=0,30\right)$.

Por fim, avaliando-se os deslocamentos calculados pelas quatro normas estudadas, observa-se que os valores obtidos de acordo com o CEB-FIP (1991) são os mais elevados. Isso acontece, principalmente, devido à utilização tanto da combinação rara de ações para o cálculo dos deslocamentos imediatos, quanto da combinação freqüente de ações para o cálculo dos deslocamentos diferid os, a partir do processo simplificado do item 2.6.3.e.

\subsection{CONSIDERAÇÕES FINAIS}

Vários são os fatores que contribuem para dificultar a previsão dos deslocamentos em uma estrutura em serviço, afastando os valores calculados daqueles que efetivamente ocorrerão.

Alguns desses fatores estão relacionados ao próprio cálculo dos deslocamentos, seja pelas incertezas na estimativa das ações, do nível de fissuração, do coeficiente de fluência e da deformação por retração, dentre outros, seja pelas dificuldades encontradas para a consideração desses parâmetros nos modelos adotados. Há também a questão da utilização de processos simplificados, que possuem limitações e podem fornecer subestimativas dos deslocamentos, em alguns casos. Como exemplos desses processos, podem ser citados o cálculo dos deslocamentos imediatos com a adoção do momento de inércia efetivo, e a obtenção dos deslocamentos diferidos a partir de um coeficiente multiplicador, já comentados anteriormente.

Outros fatores estão mais relacionados aos aspectos construtivos. Na maioria das vezes, não são conhecidos os processos de cura, as ações de construção, e as idades de desforma e de aplicação dos primeiros carregamentos, ambas cada vez mais reduzidas, para as estruturas executadas hoje em dia. Como todos ele s podem contribuir para a fissuração prematura dos elementos, os valores dos deslocamentos finais podem ser significativamente aumentados. 
Devem ser lembrados, ainda, os fatores relacionados às condições ambiente, especialmente as variações de temperatura e de umidade. Essas variações são de difícil estimativa e influem diretamente na retração, na fluência, e, conseqüentemente, nos deslocamentos diferidos.

Com todas essas questões, fica evidente a necessidade da atenção do projetista na adoção dos parâmetros envolvidos na análise dos deslocamentos. Inclusive, deve-se enfatizar a importância de se estudar a ocorrência de situações especiais na construção, que demandam avaliações ainda mais criteriosas.

Por fim, ressalta-se que o controle dos deslocamentos em elementos fletidos não atende a um critério absoluto. Além dos modelos bem definidos, da estimativa coerente dos parâmetros envolvidos, e da análise consistente dos resultados obtidos, também é necessário se considerarem os aspectos subjetivos, que dizem respeito, principalmente, à estética e ao conforto dos usuários. 


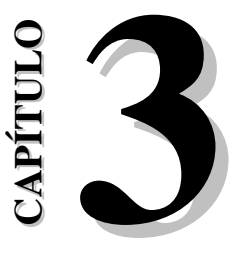

\section{DESLOCAMENTOS EM LAJES ISOLADAS}

\subsection{INTRODUÇÃO}

Neste capítulo apresenta-se o estudo realizado para as lajes isoladas. São apontadas suas características geométricas e de carregamento, bem como os parâmetros adotados para o cálculo dos seus deslocamentos imediatos, diferidos no tempo e totais. Foi utilizado o programa de análise estrutural ANPAV, desenvolvido por OLIVEIRA (2001), que é baseado no método dos elementos finitos, e permite o cálculo dos deslocamentos considerando o comportamento não linear do concreto. Assim, pode-se levar em conta a fissuração, a retração e a fluência, além da colaboração do concreto tracionado entre as fissuras para a rigidez à flexão dos elementos (tension stiffening).

Os resultados obtidos são comentados, e a influência de cada um dos parâmetros estudados é avaliada. Por fim, é apresentado um critério para a determinação de uma altura mínima, que dispensa o cálculo dos deslocamentos para a verificação do estado limite de deformações excessivas. Esse critério de altura mínima é realmente importante porque é o resultado da compilação de valores obtidos para mais de 5.500 lajes, processadas com todos os recursos para avaliação de efeitos não-lineares que um programa de análise sofisticado pode oferecer. Portanto, é um resultado de grande significado prático que, pelo número expressivo de casos estudados, confere uma boa confiabilidade ao procedimento de avaliação de deslocamentos para lajes isoladas. 


\subsection{CARACTERÍSTICAS DAS LAJES}

As lajes analisadas foram consideradas maciças, em concreto armado, e com os lados simplesmente apoiados ou engastados, sendo ambas as vinculações consideradas como perfeitamente rígidas. E foi adotado um cobrimento de $2,0 \mathrm{~cm}$. As principais características das lajes são apresentadas nos itens a seguir.

\subsubsection{TIPOS DE LAJES}

Em função das condições de apoio de cada lado, nas direções de menor ou maior vão, as lajes foram classificadas em nove tipos, como indicado na Figura 3.1.
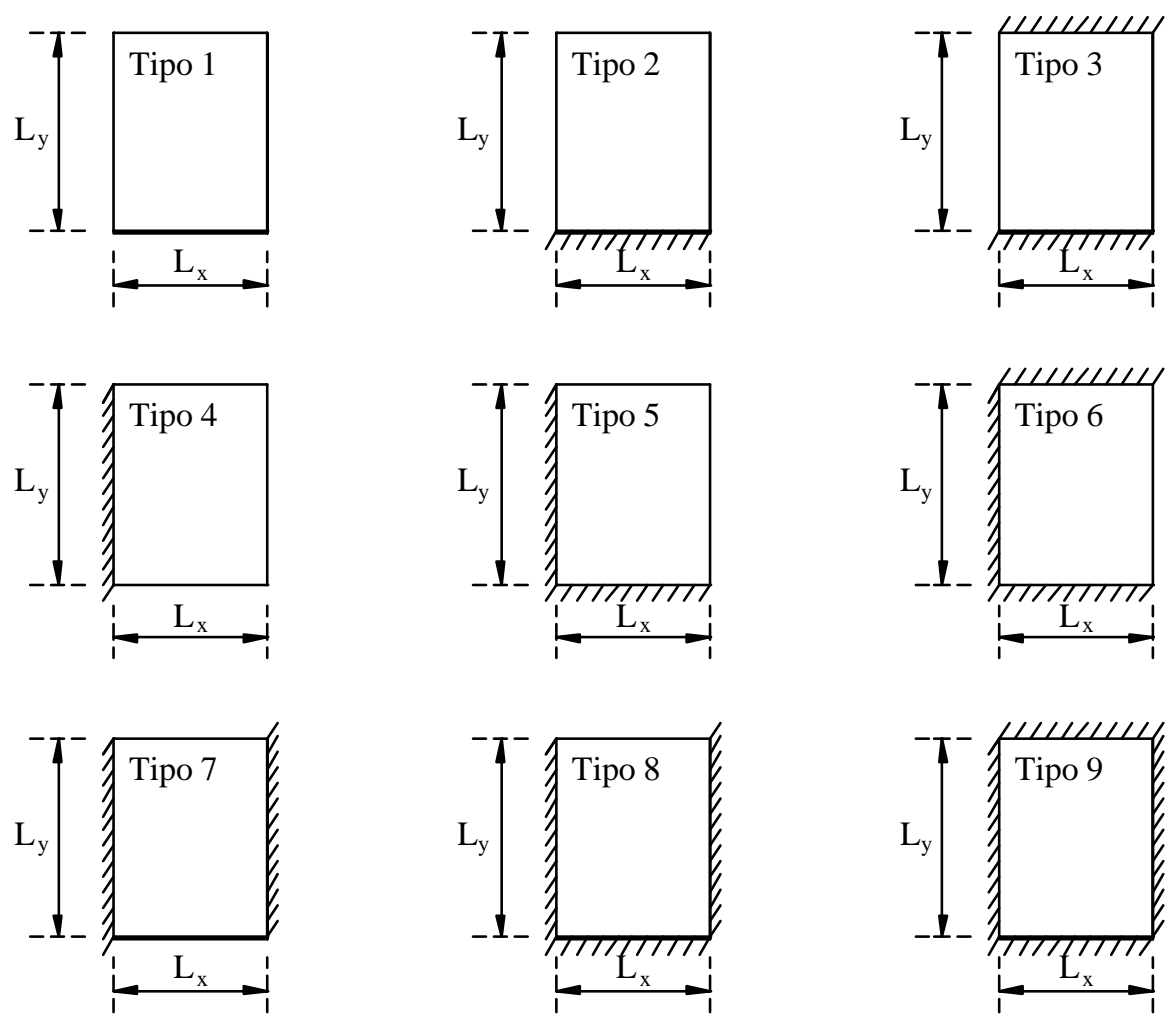

Legenda:

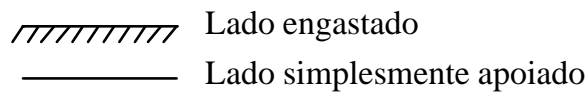

$$
\begin{array}{ll}
\mathrm{L}_{\mathrm{x}} & \text { Menor vão da laje } \\
\mathrm{L}_{\mathrm{y}} & \text { Maior vão da laje }
\end{array}
$$

Figura 3.1 - Tipos de lajes

\subsubsection{VÃOS DAS LAJES}

Buscando abranger os valores usuais de vãos de lajes utilizados em projetos estruturais, foram adotados os seguintes vãos: 
- Menor vão da laje $\left(\mathbf{L}_{\mathbf{x}}\right)-3,0 ; 4,0 ; 5,0$ e 6,0m,

- Maior vão da laje $\left(\mathbf{L}_{\mathbf{y}}\right)$ - em função do menor vão, respeitando as relações apresentadas na Tabela 3.1.

Tabela 3.1 - Relações entre os vãos das lajes

\begin{tabular}{|l|c|c|c|c|c|c|c|c|}
\hline $\mathbf{L}_{\mathbf{y}} / \mathbf{L}_{\mathbf{x}}$ & 1,0 & 1,2 & 1,4 & 1,6 & 1,8 & 2,0 & 3,0 & 4,0 \\
\hline
\end{tabular}

\subsubsection{CASOS DE CARREGAMENTO}

Com o intuito de avaliar a influência da relação entre as ações permanente e variável no valor dos deslocamentos, foram adotadas três situações de carregamento:

\section{a) Carregamento $\mathrm{C} 1$}

A ação permanente $\mathbf{g}_{1}$ e a ação variável $\mathbf{q}_{1}$ correspondem, respectivamente, a $80 \%$ e $20 \%$ da ação total $\mathbf{p}_{\mathbf{1}}$. Assim, têm-se as seguintes relações:

$$
\frac{\mathrm{g}_{1}}{\mathrm{p}_{1}}=0,80 \quad \frac{\mathrm{q}_{1}}{\mathrm{p}_{1}}=0,20 \quad \frac{\mathrm{q}_{1}}{\mathrm{~g}_{1}}=0,25
$$

\section{b) Carregamento C2}

Neste caso, a ação permanente $\mathbf{g}_{2}$ e a ação variável $\mathbf{q}_{2}$ correspondem, respectivamente, a $60 \%$ e $40 \%$ da ação total $\mathbf{p}_{2}$, igual a $\mathbf{p}_{1}$. Logo, obtêm-se:

$$
\begin{array}{lll}
\frac{\mathrm{g}_{2}}{\mathrm{p}_{2}}=0,60 & \frac{\mathrm{q}_{2}}{\mathrm{p}_{2}}=0,40 \quad \frac{\mathrm{q}_{2}}{\mathrm{~g}_{2}}=0,67
\end{array}
$$

\section{c) Carregamento C3}

Considera-se, agora, a ação permanente $\mathbf{g}_{3}$, igual $\mathbf{g}_{1}$, e a ação variável $\mathbf{q}_{3}$ correspondente ao dobro do valor de $\mathbf{q}_{1}$. Portanto, chega-se a:

$$
\begin{array}{lll}
\frac{\mathrm{g}_{3}}{\mathrm{p}_{3}}=0,67 & \frac{\mathrm{q}_{3}}{\mathrm{p}_{3}}=0,33 \quad \frac{\mathrm{q}_{3}}{\mathrm{~g}_{3}}=0,50
\end{array}
$$

Admitindo-se como ação permanente o peso próprio da laje somado às cargas de revestimento e peso de paredes que possam estar apoiadas sobre ela, adotados $1,50 \mathrm{kN} / \mathrm{m}^{2} \mathrm{e}$ $2,50 \mathrm{kN} / \mathrm{m}^{2}$, respectivamente, e obedecendo-se as relações entre as ações indicadas nos itens $\mathrm{a}, \mathrm{b}$ e c anteriores, montou-se a Tabela 3.2, com os valores do carregamento das lajes para diversas alturas consideradas. 
Tabela 3.2 - Carregamento das lajes

\begin{tabular}{|c|c|c|c|c|c|c|c|c|c|}
\hline \multirow{2}{*}{$\begin{array}{c}\text { h } \\
(\mathbf{c m})\end{array}$} & \multicolumn{2}{|c|}{ Carregamento $\mathbf{C 1}\left(\mathbf{k N} / \mathbf{m}^{2}\right)$} & \multicolumn{2}{|c|}{ Carregamento C2 $\left.\mathbf{( k N} \mathbf{m}^{2}\right)$} & \multicolumn{3}{|c|}{ Carregamento C3 $\left(\mathbf{k N} / \mathbf{m}^{2}\right)$} \\
\hline & $\mathbf{g}_{\mathbf{1}}$ & $\mathbf{q}_{\mathbf{1}}$ & $\mathbf{p}_{\mathbf{1}}$ & $\mathbf{g}_{\mathbf{2}}$ & $\mathbf{q}_{\mathbf{2}}$ & $\mathbf{p}_{\mathbf{2}}$ & $\mathbf{g}_{\mathbf{3}}$ & $\mathbf{q}_{\mathbf{3}}$ & $\mathbf{p}_{\mathbf{3}}$ \\
\hline 7 & 5,75 & 1,44 & 7,19 & 4,31 & 2,88 & 7,19 & 5,75 & 2,88 & 8,63 \\
\hline 8 & 6,00 & 1,50 & 7,50 & 4,50 & 3,00 & 7,50 & 6,00 & 3,00 & 9,00 \\
\hline 9 & 6,25 & 1,56 & 7,81 & 4,69 & 3,13 & 7,81 & 6,25 & 3,13 & 9,38 \\
\hline 10 & 6,50 & 1,63 & 8,13 & 4,88 & 3,25 & 8,13 & 6,50 & 3,25 & 9,75 \\
\hline 11 & 6,75 & 1,69 & 8,44 & 5,06 & 3,38 & 8,44 & 6,75 & 3,38 & 10,13 \\
\hline 12 & 7,00 & 1,75 & 8,75 & 5,25 & 3,50 & 8,75 & 7,00 & 3,50 & 10,50 \\
\hline 13 & 7,25 & 1,81 & 9,06 & 5,44 & 3,63 & 9,06 & 7,25 & 3,63 & 10,88 \\
\hline 14 & 7,50 & 1,88 & 9,38 & 5,63 & 3,75 & 9,38 & 7,50 & 3,75 & 11,25 \\
\hline 15 & 7,75 & 1,94 & 9,69 & 5,81 & 3,88 & 9,69 & 7,75 & 3,88 & 11,63 \\
\hline 16 & 8,00 & 2,00 & 10,00 & 6,00 & 4,00 & 10,00 & 8,00 & 4,00 & 12,00 \\
\hline 17 & 8,25 & 2,06 & 10,31 & 6,19 & 4,13 & 10,31 & 8,25 & 4,13 & 12,38 \\
\hline 18 & 8,50 & 2,13 & 10,63 & 6,38 & 4,25 & 10,63 & 8,50 & 4,25 & 12,75 \\
\hline 19 & 8,75 & 2,19 & 10,94 & 6,56 & 4,38 & 10,94 & 8,75 & 4,38 & 13,13 \\
\hline 20 & 9,00 & 2,25 & 11,25 & 6,75 & 4,50 & 11,25 & 9,00 & 4,50 & 13,50 \\
\hline 21 & 9,25 & 2,31 & 11,56 & 6,94 & 4,63 & 11,56 & 9,25 & 4,63 & 13,88 \\
\hline 22 & 9,50 & 2,38 & 11,88 & 7,13 & 4,75 & 11,88 & 9,50 & 4,75 & 14,25 \\
\hline 23 & 9,75 & 2,44 & 12,19 & 7,31 & 4,88 & 12,19 & 9,75 & 4,88 & 14,63 \\
\hline 24 & 10,00 & 2,50 & 12,50 & 7,50 & 5,00 & 12,50 & 10,00 & 5,00 & 15,00 \\
\hline 25 & 10,25 & 2,56 & 12,81 & 7,69 & 5,13 & 12,81 & 10,25 & 5,13 & 15,38 \\
\hline 26 & 10,50 & 2,63 & 13,13 & 7,88 & 5,25 & 13,13 & 10,50 & 5,25 & 15,75 \\
\hline 27 & 10,75 & 2,69 & 13,44 & 8,06 & 5,38 & 13,44 & 10,75 & 5,38 & 16,13 \\
\hline 28 & 11,00 & 2,75 & 13,75 & 8,25 & 5,50 & 13,75 & 11,00 & 5,50 & 16,50 \\
\hline 29 & 11,25 & 2,81 & 14,06 & 8,44 & 5,63 & 14,06 & 11,25 & 5,63 & 16,88 \\
\hline 30 & 11,50 & 2,88 & 14,38 & 8,63 & 5,75 & 14,38 & 11,50 & 5,75 & 17,25 \\
\hline
\end{tabular}

\subsection{PARÂMETROS ADOTADOS}

Para o cálculo dos deslocamentos, é necessário o conhecimento de parâmetros tais como as propriedades dos materiais, as condições do ambiente, a idade de aplicação das ações e suas combinações. A seguir são tecidos alguns comentários sobre eles.

\subsubsection{COMBINAÇÕES DAS AÇÕES}

A NBR 6118 (2003) recomenda que seja adotada a combinação quase-permanente de ações para a verificação do estado limite de deformações excessivas, e a Prática Recomendada IBRACON (2003) sugere que, nos casos onde os deslocamentos excessivos possam causar danos nos elementos de acabamento, deve ser utilizada uma combinação freqüente de ações. Assim, optou-se por calcular os deslocamentos utilizando-se essas duas combinações de ações. De acordo com o item 2.6.1.a, do capítulo 2, e considerando-se edifícios residenciais usuais, pode-se escrever: 
- Combinação quase permanente de ações:

$$
\mathrm{F}_{\mathrm{d}, \mathrm{ser}}=\mathrm{F}_{\mathrm{gk}}+0,3 \mathrm{~F}_{\mathrm{qk}}
$$

- Combinação freqüente de ações:

$$
\mathrm{F}_{\mathrm{d}, \mathrm{ser}}=\mathrm{F}_{\mathrm{gk}}+0,4 \mathrm{~F}_{\mathrm{qk}}
$$

sendo:

$\mathbf{F}_{\mathrm{d}, \text { ser }}$ a ação de serviço com seu valor de cálculo, calculada de acordo com a combinação de ações utilizada,

$\mathbf{F}_{\mathbf{g k}}$ as ações permanentes com seus valores característicos,

$\mathbf{F}_{\mathbf{q k}} \quad$ as ações variáveis com seus valores característicos.

\subsubsection{MATERIAIS}

O aço utilizado foi o CA-50, cujo módulo de deformação longitudinal pode ser considerado, segundo a NBR 6118 (2003), igual a 210 GPa. Para o concreto, foram adotados:

- $\quad$ Coeficiente de Poisson $(v)=0,20$

- Resistência característica à compressão $\left(\mathbf{f}_{\mathbf{c k}}\right)=25$ e $35 \mathrm{MPa}$;

Para esses valores de $\mathbf{f}_{\mathbf{c k}}$, o módulo de deformação tangente $\left(\mathbf{E}_{\mathbf{c i}}\right)$ e a resistência média do concreto à tração $\left(\mathbf{f}_{\mathbf{c t m}}\right)$ assumem, de acordo com a NBR 6118 (2003), os valores fornecidos na Tabela 3.3. Vale ressaltar que foi utilizado o módulo de deformação tangente e não o secante, pois os deslocamentos foram calculados a partir de uma análise não-linear.

Tabela 3.3 - Propriedades do concreto

\begin{tabular}{|c|c|c|}
\hline $\mathbf{f}_{\mathbf{c k}}(\mathbf{M P a})$ & $\mathbf{E}_{\mathbf{c i}}\left(\mathbf{k N} / \mathbf{c m}^{\mathbf{2}}\right)$ & $\mathbf{f}_{\mathrm{ctm}}\left(\mathbf{k N} / \mathrm{cm}^{\mathbf{2}}\right)$ \\
\hline 25 & 2800 & 0,256 \\
\hline 35 & 3313 & 0,321 \\
\hline
\end{tabular}

\subsubsection{CONDIÇÕES DO AMBIENTE}

Como foi mencionado no Capítulo 2, os deslocamentos diferidos no tempo dependem do comportamento do concreto com o tempo, ou seja, da retração e da fluência deste material. São fenômenos bastante influenciados pelas condições do ambiente, principalmente temperatura e umidade relativa. Assim, para a determinação dos deslocamentos, foram adotados a umidade relativa média $\mathbf{U}$ igual a $60 \%$ e a temperatura média $\mathbf{T}$ de $25^{\circ} \mathrm{C}$. 


\subsubsection{IDADE DE APLICAÇÃO DAS AÇÕES}

Os deslocamentos dependem também da idade $\mathbf{t}_{\mathbf{0}}$ de aplicação das ações permanentes e variáveis. Os valores adotados foram:

- para ações permanentes: $\mathbf{t}_{\mathbf{0}}=28$ dias

- para ações variáveis: $\mathbf{t}_{\mathbf{0}}=45$ dias

\subsection{CÁLCULO DOS DESLOCAMENTOS}

Além da definição dos parâmetros comentados no item anterior, o cálculo dos deslocamentos imediatos e os diferidos, a partir do programa ANPAV, requer a discretização das lajes em elementos finitos e o conhecimento das armaduras. Para maior clareza definemse os deslocamentos imediatos como sendo a parcela elástica-linear acrescida da parcela nãolinear devida à fissuração, se houver. Já os deslocamentos diferidos no tempo são calculados com as parcelas não-lineares devidas à retração e à fluência do concreto.

\subsubsection{DISCRETIZAÇÃO DAS LAJES}

Exceto para o tipo 5, a discretização das lajes foi feita de forma a se aproveitar o eixo ou os eixos de simetria, visando à simplificação da entrada de dados. Para as relações entre vãos compreendidas entre 1,0 e 2,0, foram adotados elementos finitos quadrados e de lado igual a um décimo do menor vão da laje. Já para relações entre vãos iguais a 3,0 e 4,0, embora também tenham sido utilizados elementos quadrados, tomou-se o comprimento do lado igual a um oitavo do menor vão da laje. A espessura da laje $\mathbf{h}$ foi discretizada em dez camadas.

Vale ressaltar que, com o intuito de se evitarem problemas causados por elementos muito pequenos, procurou-se adotar, como sugere OLIVEIRA (2001), relações $\mathbf{h}_{\mathbf{e q}} / \mathbf{h}$ maiores que 2,5, sendo:

$$
\mathrm{h}_{\mathrm{eq}}=\alpha_{\mathrm{h}} \cdot \sqrt{\mathrm{A}}
$$

na qual:

$\mathbf{h}_{\text {eq }}$ a altura equivalente;

A a área do elemento;

$\alpha_{\mathbf{R}} \quad=\sqrt{2}$ para elementos lineares

$=1$ para elementos quadrilate rais 


\subsubsection{DETERMINAÇÃO DAS ARMADURAS}

Os momentos fletores atuantes foram calculados a partir de uma análise elástica de cada um dos tipos de lajes apresentados na Figura 3.1, com as variações de vãos indicadas no item 3.2.2, e para as diversas alturas necessárias. Com esses momentos, foram determinadas as áreas de aço nas duas direções da laje, de acordo com as recomendações da NBR 6118 (2003).

\subsubsection{VALORES DOS DESLOCAMENTOS}

Utilizando-se as combinações de ações quase-permanente e freqüente nos modelos com todas as características anteriormente comentadas, o ANPAV pode fornecer os deslocamentos das diversas lajes correspondentes aos tipos apresentados na Figura 3.1 e com as variações de geometria indicadas no item 3.2.2.

Inicialmente, para a determinação dos deslocamentos imediatos, as lajes foram analisadas sem a consideração dos efeitos do tempo. Em seguida, tais efeitos foram levados em conta para a obtenção dos deslocamentos totais. Os deslocamentos diferidos foram determinados pela subtração dos deslocamentos imediatos dos totais. Vale ressaltar que o tempo $\mathbf{t}$ adotado para os efeitos de longa duração foi maior que seis anos ( $t>6$ anos).

Para cada laje, o ponto de partida do estudo foi a altura mínima necessária para resistir à flexão, respeitando limite inferior de $7 \mathrm{~cm}$ para lajes de piso, como recomenda a NBR 6118 (2003).

Já a determinação de uma altura mínima que não leve a laje a um estado limite de deformações excessivas foi feita pela comparação dos deslocamentos calculados com os limites das verific ações apresentados na Tabela 2.4 do capítulo 2. As referidas verificações são as seguintes:

\section{- Limites referentes à aceitabilidade sensorial:}

\section{- Visual : Verificação 1}

O deslocamento total devido à combinação de ações considerada deve respeitar o limite:

$$
a_{t, g+\psi q} \leq \frac{\ell}{250}
$$


- Vibrações : Verificação 2

O deslocamento imediato devido à ação variável total deve respeitar o limite:

$$
\mathrm{a}_{\mathrm{i}, \mathrm{q}} \leq \frac{\ell}{350}
$$

\section{- Limites devidos a efeitos nos elementos não estruturais:}

- $\quad$ Efeitos em paredes: Verificação 3

O deslocamento incremental, que ocorre após a construção dos elementos não estruturais, deve respeitar os seguintes limites:

$$
a_{\text {inc }} \leq\left\{\begin{array}{l}
\frac{\ell}{250} \\
10 \mathrm{~mm} \\
\theta=0,0017 \mathrm{rad}
\end{array}\right.
$$

Essas verificações foram feitas para deslocamentos determinados tanto com a combinação de ações quase-permanente quanto a freqüente. Assim, adotou-se a seguinte denominação:

- Verificação 1A: Verificação 1 para uma combinação quase-permanente de ações.

- Verificação 1B: Verificação 1 para uma combinação freqüente de ações.

- Verificação 2 : considerando-se apenas a carga variável total.

- Verificação 3A: Verificação 3 para uma combinação quase-permanente de ações.

- Verificação 3B: Verificação 3 para uma combinação freqüente de ações.

Quando uma altura adotada para a laje não satisfazia às condições anteriores, uma nova altura era processada, tendo seus deslocamentos calculados e verificados. Este procedimento foi repetido para cada laje dos diversos tipos estudados, até se chegar em uma altura que atendesse a todas as verificações.

Para ilustrar esse procedimento, são apresentados no Anexo A, os valores dos deslocamentos obtidos para alguns tipos de laje. Devido ao grande número de lajes analisadas, aproximadamente cinco mil e quinhentas, optou-se por não apresentar todos os valores de deslocamentos. Entretanto, todos os resultados serão dsponibilizados de uma maneira conveniente junto ao Departamento de Engenharia de Estruturas da EESC-USP. 


\subsection{ANÁLISE DOS RESULTADOS}

Com os deslocamentos obtidos seguindo-se os procedimentos mencionados no item anterior, fez-se uma avaliação da influência dos principais parâmetros envolvidos diretamente na determinação desses valores. Também foram elaboradas propostas para a determinação de um coeficiente multiplicador para os deslocamentos imediatos, e de uma altura mínima para as lajes que dispensa a verificação dos deslocamentos.

\subsubsection{INFLUÊNCIA DOS PARÂMETROS DE CÁLCULO}

Apresenta-se a seguir, uma síntese do estudo da influência dos principais parâmetros envolvidos no cálculo dos deslocamentos, com o intuito de facilitar o entendimento dos procedimentos propostos.

\section{a) Tipos de lajes}

Quanto mais lados engastados a laje apresentar, principalmente ao longo dos maiores vãos, menores serão seus deslocamentos. Esse comportamento pode ser observado na Figura 3.2, onde estão representados os deslocamentos totais médios para cada tipo de laje, anteriormente definidos no item 3.2.1 e ilustrados na Figura 3.1. Ressalta-se que esses deslocamentos totais médios correspondem à média aritmética dos deslocamentos totais devidos à combinação quase-permanente de ações, para cada tipo de laje. O mesmo comportamento foi observado para os demais deslocamentos e ações atuantes.

Observa-se que para as lajes que têm o mesmo tipo de vinculação ao longo do maior vão, os deslocamentos médios obtidos foram bastante semelhantes uns dos outros diferindo em, no máximo, $1,5 \%$. Isso demonstra a influência relativamente pequena que a presença de engastamentos ao longo dos vãos menores exerce sobre os deslocamentos das lajes.

Os deslocamentos das lajes dos tipos 1, 2 e 3, que não apresentam engastamentos nas extremidades dos vãos menores, foram, em média, $20 \%$ maiores que as lajes dos tipos 4, 5 e 6, que apresentam um dos maiores vãos engastados, e $48 \%$ maiores que as lajes dos tipos 7 , 8 e 9 , que apresentam os dois maiores vãos engastados. 


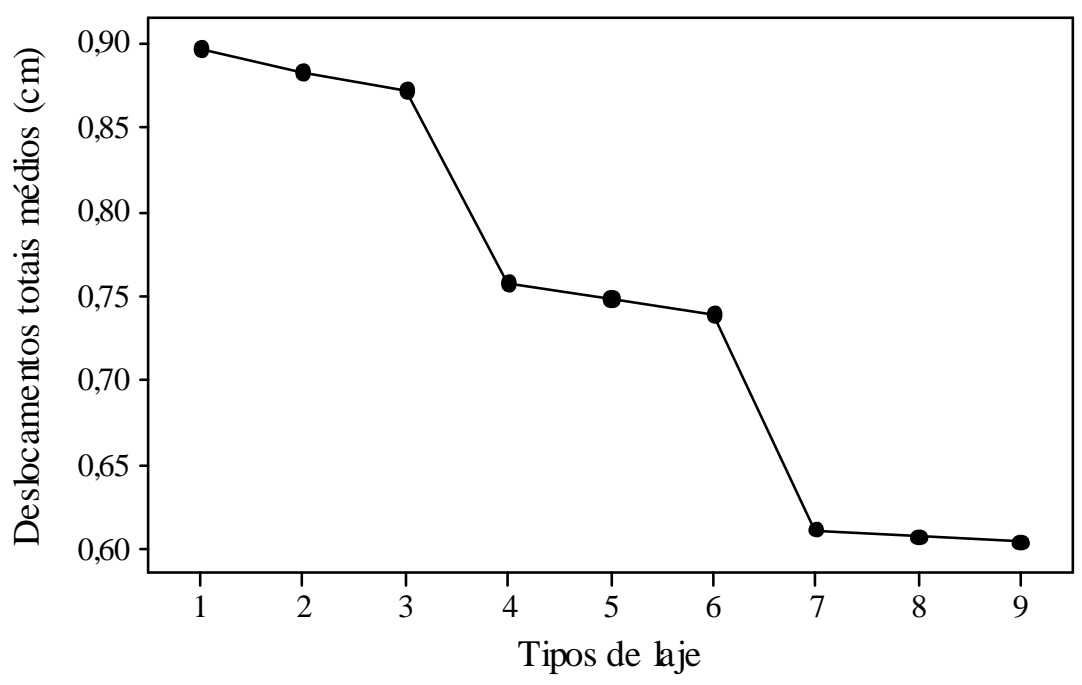

Figura 3.2 - Comparação entre as condições de apoio das lajes e seus deslocamentos médio

\section{b) Resistência à Compressão do Concreto}

Com o aumento da resistência característica à compressão do concreto $\mathbf{f}_{\mathrm{ck}}$, sabe-se que os valores dos deslocamentos tendem a diminuir, já que se aumenta o módulo de deformação longitudinal do concreto, e, consequentemente, a rigidez da laje.

Para o aumento do $\mathbf{f}_{\text {ck }}$ de $25 \mathrm{MPa}$ para $35 \mathrm{MPa}$, foi observada uma redução média diferente para os deslocamentos imediatos, diferidos no tempo, incrementais e totais.

Para os deslocamentos imediatos, essa redução ficou entre 15\%, para os deslocamentos devidos somente à ação permanente, e 20\%, para os deslocamentos devidos às combinações quase-permanente e freqüente de ações. Esses valores são inferiores aos obtidos para os deslocamentos diferidos, incrementais e totais, cuja redução foi de $25 \%$.

Essa menor redução dos deslocamentos imediatos, principalmente para os devidos à ação permanente, se justifica pelo fato de que, para esse nível de solicitação, o concreto ainda não apresenta fissuras, ou está pouco fissurado, o que resulta numa participação mais efetiva do concreto entre as fissuras. $O$ momento de inércia da seção transversal é praticamente igual ao da seção não fissurada, levando a um comportamento aproximadamente elástico. Assim sendo, a redução dos deslocamentos é inversamente proporcional ao aumento do valor módulo de elasticidade tangente do concreto, que para valores de $\mathbf{f}_{\text {ck }}$ iguais a 25 e $35 \mathrm{MPa}$; valem $28000 \mathrm{MPa}$ e $33130 \mathrm{MPa}$, respectivamente.

Ainda para os deslocamentos imediatos, com o crescimento no valor da ação atuante, atingindo os valores das combinações de ações quase-permanente ou freqüente, o concreto já se encontra em um nível de fissuração mais avançado, e o momento de inércia da seção 
transversal tem valor compreendido entre o da seção fissurada e o da seção totalmente fissurada. Assim, o aumento do $\mathbf{f}_{\text {ck }}$, que causa, além do acréscimo no módulo de elasticidade do concreto, o aumento do momento de fissuração do elemento, leva a valores mais elevados de momentos de inércia das seções transversais. Portanto, tem-se um aumento da rigidez do elemento, maior do que aquele que ocorre com a ação das ações permanentes.

Conforme já se mencionou, os deslocamentos diferidos no tempo diminuíram, em média, $25 \%$ com o aumento do $\mathbf{f}_{\mathbf{c k}}$. Essa maior redução desses deslocamentos foi decorrente não só do aumento da rigidez do elemento, como comentado anteriormente, mas também da diminuição da fluência do concreto relacionada ao aumento do $\mathbf{f}_{\text {ck }}$.

Finalmente, os deslocamentos totais apresentaram uma redução média da ordem de $22 \%$, portanto, intermediária à dos deslocamentos imediatos e diferidos.

\section{c) Casos de Carregamento}

Como já era esperado, os deslocamentos totais devidos ao carregamento $\mathrm{C} 1$ foram maiores que os devidos ao carregamento $\mathrm{C} 2$ e menores que os devidos ao carregamento $\mathrm{C} 3$.

Além disso, como as lajes em serviço apresentam poucas fissuras, as relações entre os valores obtidos para deslocamentos devidos às ações consideradas nos carregamentos $\mathrm{C} 1$, C2 e C3 guardam quase que a mesma proporção que as próprias ações desses carregamentos mantêm entre si. Assim, as relações entre os deslocamentos imediatos, diferidos e totais devidos às ações permanentes, às combinações de ações quase-permanentes e freqüente, e à ação total de cada caso de carregamento, são fornecidas na Tabela 3.4.

Tabela 3.4 - Relações entre os deslocamentos devidos às ações dos casos de carregamento

\begin{tabular}{|c|c|c|c|c|}
\hline $\begin{array}{c}\text { Relação entre os } \\
\text { Carregamentos }\end{array}$ & $\mathbf{g}$ & $\mathbf{g}+\mathbf{0 , 3 q}$ & $\mathbf{g}+\mathbf{0 , 4 q}$ & $\mathbf{g}+\mathbf{q}$ \\
\hline $\mathrm{C} 1 / \mathrm{C} 2$ & 1,33 & 1,19 & 1,16 & 1,00 \\
\hline $\mathrm{C} 1 / \mathrm{C} 3$ & 1,00 & 0,93 & 0,92 & 0,83 \\
\hline $\mathrm{C} 3 / \mathrm{C} 2$ & 1,33 & 1,28 & 1,26 & 1,20 \\
\hline
\end{tabular}

\subsubsection{RELAÇÃO ENTRE DESLOCAMENTOS DIFERIDOS E IMEDIATOS}

De posse dos deslocamentos diferidos e imediatos calculados pelo programa ANPAV para os diversos casos analisados, pode-se estudar os coeficientes multiplicadores dos deslocamentos imediatos a serem utilizados para a obtenção aproximada dos deslocamentos diferidos no tempo. Obviamente, esses multiplicadores são obtidos a partir da relação entre esses deslocamentos mencionados e possuem grande importância prática. 
Importante ressaltar que neste trabalho os referidos coeficientes serão chamados, por conveniência, de coeficientes multiplicadores dos deslocamentos imediatos.

Analisando-se os resultados referentes a cada caso de carregamento, pode-se observar que as condições de contorno e os vãos das lajes exerceram pouca influência nos valores médios do coeficiente, sendo a altura da laje seguida da resistência característica à compressão do concreto, $\mathbf{f}_{\text {ck }}$, os parâmetros de maior influência. Na Tabela 3.5, são apresentados os valores médios dos coeficientes obtidos para as diversas alturas de lajes, $\mathbf{f}_{\mathbf{c k}}$, e casos de carregamento.

Tabela 3.5 - Valores médios dos coeficientes multiplicadores dos deslocamentos imediatos

\begin{tabular}{|c|c|c|c|c|c|c|}
\hline \multirow{2}{*}{$\begin{array}{c}\mathbf{h} \\
(\mathbf{c m})\end{array}$} & \multicolumn{3}{|c|}{$\mathbf{f}_{\mathbf{c k}}=\mathbf{2 5} \mathbf{M p a}$} & \multicolumn{3}{c|}{$\mathbf{f}_{\text {ck }}=\mathbf{3 5} \mathbf{~ M p a}$} \\
\hline & $\mathrm{C} 1$ & $\mathrm{C} 2$ & $\mathrm{C} 3$ & $\mathrm{C} 1$ & $\mathrm{C} 2$ & $\mathrm{C} 3$ \\
\hline 7 & 2,60 & 2,53 & 2,59 & 2,21 & 2,18 & 2,21 \\
\hline 8 & 2,59 & 2,53 & 2,57 & 2,18 & 2,17 & 2,18 \\
\hline 9 & 2,52 & 2,50 & 2,50 & 2,14 & 2,15 & 2,13 \\
\hline 10 & 2,48 & 2,43 & 2,43 & 2,08 & 2,13 & 2,07 \\
\hline 11 & 2,45 & 2,42 & 2,42 & 2,06 & 2,08 & 2,04 \\
\hline 12 & 2,40 & 2,41 & 2,38 & 2,03 & 2,05 & 2,01 \\
\hline 13 & 2,36 & 2,37 & 2,35 & 2,01 & 2,04 & 2,00 \\
\hline 14 & 2,34 & 2,32 & 2,31 & 1,97 & 2,00 & 1,98 \\
\hline 15 & 2,30 & 2,30 & 2,28 & 1,94 & 1,97 & 1,94 \\
\hline 16 & 2,29 & 2,28 & 2,25 & 1,92 & 1,96 & 1,91 \\
\hline 17 & 2,28 & 2,24 & 2,24 & 1,91 & 1,92 & 1,88 \\
\hline 18 & 2,20 & 2,22 & 2,18 & 1,85 & 1,89 & 1,87 \\
\hline 19 & 2,18 & 2,19 & 2,16 & 1,81 & 1,88 & 1,81 \\
\hline 20 & 2,15 & 2,18 & 2,12 & 1,80 & 1,84 & 1,81 \\
\hline
\end{tabular}

Percebe-se que o aumento da altura da laje e do $\mathbf{f}_{\text {ck }}$ levaram à redução dos coeficientes, para um mesmo carregamento. Entretanto, sua variação entre os casos de carregamento, para uma mesma altura foi pouco significativa.

Representando os dados da Tabela 3.5, em um gráfico (Figura 3.3), notou-se um comportamento aproximadamente linear entre o valor do coeficiente e a altura da laje. Já os valores do $\mathbf{f}_{\text {ck }}$ produzem uma verdadeira translação nos gráficos. Assim, com os valores obtidos para todos os casos de lajes estudados, determinou-se a expressão a seguir para o coeficiente multiplicador em função da altura da laje e do $\mathbf{f}_{\mathrm{ck}}$ :

$$
\alpha_{\mathrm{f}, \mathrm{aj}}=3,7-0,36 \mathrm{f}_{\mathrm{ck}}-0,032 \mathrm{~h}
$$

sendo: 
$\alpha_{\mathrm{f}, \mathrm{aj}}$ relação entre deslocamentos diferidos e imediatos,

$\mathbf{f}_{\text {ck }}$ resistência característica à compressão do concreto, em $\mathrm{kN} / \mathrm{cm}^{2}$,

h altura da laje, em $\mathrm{cm}$.

Os valores fornecidos pela eq. (3.2) também são mostrados na Figura 3.3, evidenciando a boa concordância entre a equação proposta e os valores obtidos com a análise não-linear (programa ANPAV).

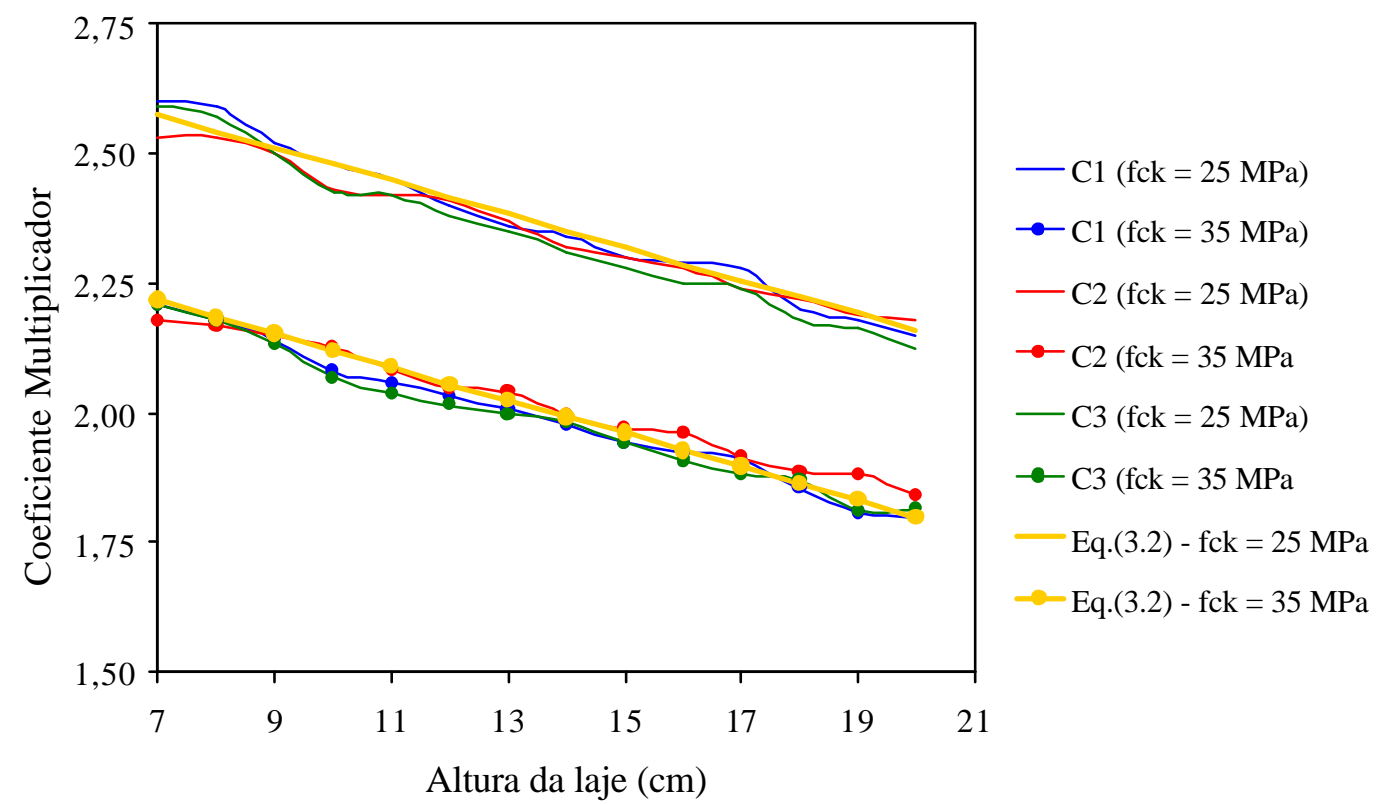

Figura 3.3 - Variação dos coeficientes multiplicadores dos deslocamentos imediatos em função da altura das lajes e do $\mathbf{f}_{\text {ck }}$

Vale ressaltar que a equação proposta para a determinação de coeficientes multiplicadores dos deslocamentos imediatos, eq.(3.2), só se aplica ao cálculo de deslocamentos diferidos em um tempo $\mathbf{t}$ maior ou igual a seis anos após o início da aplicação do carregamento, tempo que foi utilizado na análise das lajes.

Como exemplo, pode-se considerar uma laje submetida a um carregamento tal que a relação entre a ação variável e a ação permanente seja igual a 0,25 ; a idade de aplicação dessas ações seja igual a 45 e 28 dias, respectivamente; e que seja considerada uma combinação freqüente de ações.

Para essa situação, o valor do coeficiente multiplicador segundo a NBR 6118 (2003), dado pela eq.(2.50) do capítulo 2 , seria 1,33, independente da altura da laje e da resistência característica à compressão do concreto. Pode-se notar que esse valor é significativamente menor que os fornecidos na Figura 3.3. Isso vem a reforçar a posição de alguns pesquisadores, conforme comentado no item 2.3.3.c, de que o valor do coeficiente 
multiplicador dos deslocamentos imediatos, fornecido pelo ACI 318 (2002) e adaptado pela NBR 6118 (2003), tende a subestimar os deslocamentos diferidos para lajes armadas em duas direções.

A Tabela 3.6, apresentada pelo ACI 435R (1995), reúne algumas propostas de multiplicadores, segundo autores diversos.

Tabela 3.6 - Coeficientes multiplicadores dos deslocamentos imediatos para lajes armadas em duas direções, segundo o ACI 435R (1995).

\begin{tabular}{|l|c|c|c|c|}
\hline Fonte & Módulo de Ruptura & $\alpha_{\mathrm{f}}$ (fluência) & $\alpha_{\mathrm{f}}$ (retração) & $\alpha_{\mathrm{f}, \text { total }}$ \\
\hline SBAROUNIS (1984) & $\mathrm{f}_{\mathrm{r}}=0,623 \cdot \sqrt{\mathrm{f}_{\mathrm{c}}{ }^{\prime}}$ & 2,8 & 1,2 & 4,0 \\
\hline BRANSON (1977) & $\mathrm{f}_{\mathrm{r}}=0,623 \cdot \sqrt{\mathrm{f}_{\mathrm{c}}{ }^{\prime}}$ & 2,0 & 1,0 & 3,0 \\
\hline GRAHAM \& SCANLON & $\mathrm{f}_{\mathrm{r}}=0,623 \cdot \sqrt{\mathrm{f}_{\mathrm{c}}{ }^{\prime}}$ & 2,0 & 2,0 & 4,0 \\
$(1986)$ & $\mathrm{f}_{\mathrm{r}}=0,332 \cdot \sqrt{\mathrm{f}_{\mathrm{c}}{ }^{\prime}}$ & 1,5 & 1,0 & 2,5 \\
\hline ACI 318 (2002) & $\mathrm{f}_{\mathrm{r}}=0,623 \cdot \sqrt{\mathrm{f}_{\mathrm{c}}{ }^{\prime}}$ & \multicolumn{2}{|c|}{2,0} & 2,0 \\
\hline
\end{tabular}

Pode-se observar que o coeficiente multiplicador total, que considera tanto a fluência quanto a retração, tende a valores mais altos que aqueles propostos pelo ACI 318 (2002), cujos resultados não são considerados bons para as lajes armadas em duas direções. Mesmo pela segunda proposta de GRAHAM \& SCANLON (1986), na qual esse coeficiente é igual a 2,5, ele deve ser utilizado juntamente com a redução de quase $50 \%$ do módulo de ruptura do concreto, o que representa uma redução do momento de fissuração e, portanto, um aumento dos deslocamentos imediatos. As demais propostas admitem valores maiores que 3,0.

Entretanto, nenhum dos casos da Tabela 3.6 leva em consideração a influência do $\mathbf{f}_{\mathrm{ck}}$, parâmetro, como visto, importante na determinação dos deslocamentos diferidos. Os ensaios de PAULSON et al. (1991), embora realizados em vigas, indicaram que os valores dos deslocamentos finais realmente variam com a resistência do concreto à compressão. Para vigas ensaiadas sem armadura de compressão, como ocorre com as lajes, o aumento do $\mathbf{f}_{\text {ck }}$ levou à redução dos deslocamentos diferidos no tempo, e, conseqüentemente, dos coeficientes multiplicadores.

Desta forma, dentro dos limites dos parâmetros adotados neste trabalho, já mencionados nos itens iniciais deste capítulo, a expressão proposta para o cálculo do coeficiente multiplicador dos deslocamentos imediatos, eq.(3.2), está coerente com os resultados obtidos por alguns pesquisadores, e fornece uma boa estimativa para os deslocamentos diferidos em lajes armadas em duas direções. 


\subsubsection{CRITÉRIOS DE ALTURA MÍNIMA}

Com o intuito de simplificar a verificação do estado limite de deslocamentos excessivos, são propostos dois critérios de altura mínima. Segundo esses critérios, admite-se que o estado limite de deslocamentos excessivos estará indiretamente verificado se a altura do elemento estrutural for superior a um determinado limite, que deve ser respeitado independentemente da altura mínima requerida pelo dimensionamento à flexão. Dessa forma, o cálculo dos deslocamentos para o elemento em questão poderá ser dispensado.

\section{a) Critério com Base na Relação Menor Vão-Altura Mínima}

Bastante comuns na rotina de projetistas de estruturas, as relações menor vão - altura mínima de lajes são muito utilizadas tanto para o pré-dimensionamento da estrutura quanto para a verificação dos deslocamentos. Como foi visto no capítulo 2, relações desse tipo também são recomendadas por diversas normas. Assim, desde que bem calibradas, elas encontram grande utilização e dão uma boa idéia do comportamento das lajes quanto aos deslocamentos.

De posse das alturas mínimas das diversas lajes analisadas, alturas estas que garantiam que os deslocamentos satisfizessem os limites impostos pela NBR 6118 (2003), comentados no item 3.4.3, foram calculadas as relações vão-altura mínima das lajes, $\ell / \mathbf{h}_{\min }$.

A partir da avaliação dos resultados obtidos, observou-se que dos parâmetros envolvidos no cálculo das alturas mínimas das lajes, aqueles que mais afetaram as relações vão-altura mínima foram as relações entre os vãos, as condições de apoio do menor vão, a resistência característica do concreto à compressão, $\mathbf{f}_{\mathbf{c k}}$, e a verificação que se quer atender. Já os vãos das lajes, os carregamentos adotados e as combinações de ações exercem pouca influência nestes valores, levando a relações $\ell / \mathbf{h}_{\min }$ muito próximas entre si.

As lajes que têm as extremidades do menor vão simplesmente apoiadas, ou seja, as lajes dos tipos 1, 2 e 3 (Figura 3.1), apresentaram valores de $\ell / \mathbf{h}_{\min }$ bastante semelhantes. O mesmo comportamento foi apresentado pelo grupo de laje que têm o menor vão com uma extremidade engastada e outra apoiada, lajes dos tipos 4, 5 e 6, e pelo grupo de lajes que têm os maiores vãos engastamentos, lajes dos tipos 7, 8 e 9. Este comportamento é ilustrado nas Figura 3.4 e Fig ura 3.5, que apresentam os valores médios das relações vão-altura mínima para esses tipos de lajes, com $\mathbf{f}_{\text {ck }}$ de 25 e $35 \mathrm{MPa}$, e que satisfazem às verificações 1,2 e 3 . Pode-se observar que para o $\mathbf{f}_{\mathbf{c k}}$ de $35 \mathrm{MPa}$ as relações vão-altura mínima aumentam, em média, $14 \%$, quando comparadas com as do $\mathbf{f}_{\text {ck }}$ de $25 \mathrm{MPa}$. 


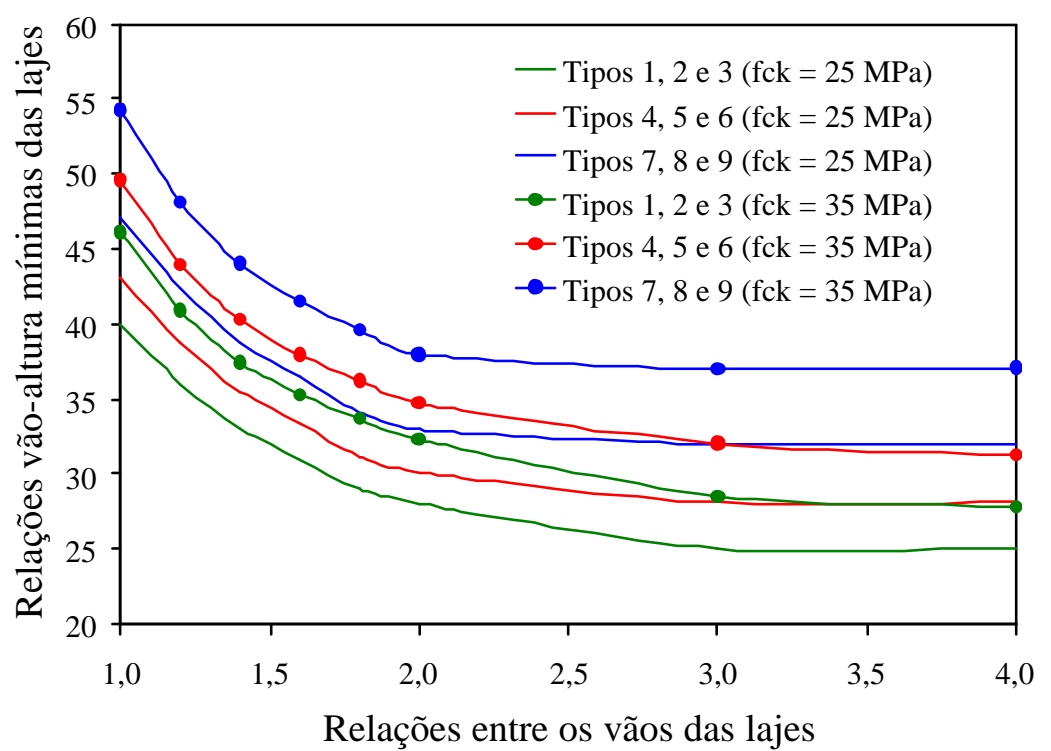

Figura 3.4 - Relações vão-altura mínima que satisfazem à verificação 1

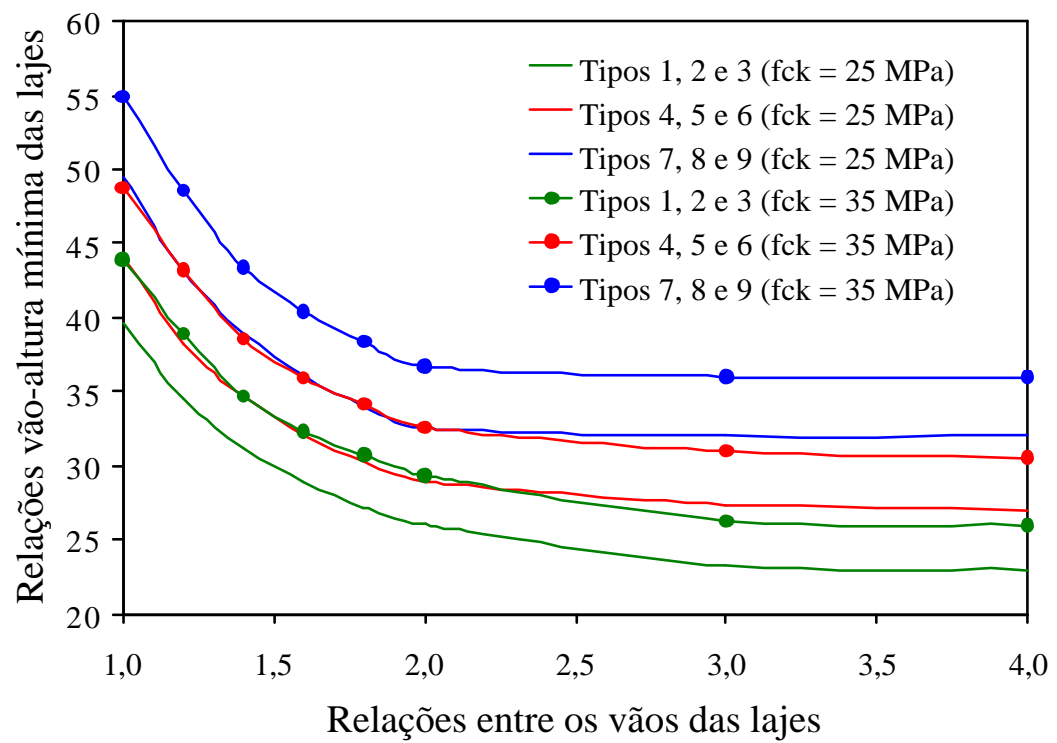

Figura 3.5 - Relações vão-altura mínima que satisfazem às verificações 2 e 3

Diante do exposto, chegou-se à seguinte expressão para a relação vão-altura mínima de laje:

$$
\frac{\mathrm{L}_{\mathrm{x}}}{\mathrm{h}_{\min }}=\frac{\beta}{\alpha}
$$

sendo: 
$\beta$ a relação vão-altura mínima para as lajes dos tipos 1,2 e 3, cujos valores são fornecidos pelas eqs.(3.4) e (3.5), e para o $\mathbf{f}_{\text {ck }}$ igual a $25 \mathrm{MPa}$, seus valores são apresentados na Tabela 3.7,

$\alpha \quad$ o coeficiente que leva em consideração as condições de apoio das lajes, corrigindo os valores do coeficiente $\beta$ para os demais tipos de lajes, e cujos valores são apresentados na Tabela 3.8,

$\mathbf{L}_{\mathbf{x}} \quad$ o menor vão da laje,

$\mathbf{h}_{\min } \quad$ a altura mínima da laje.

Tabela 3.7 - Valores de $\beta$ para o $\mathbf{f}_{\text {ck }}$ de $25 \mathrm{MPa}$

\begin{tabular}{|c|c|c|c|}
\hline \multirow{2}{*}{$\mathbf{L}_{\mathbf{y}}$} & \multicolumn{2}{|c|}{ Aceitabilidade Sensorial } & $\begin{array}{c}\text { Efeitos em elementos } \\
\text { não estruturais }\end{array}$ \\
\cline { 2 - 4 } & Visual & Vibrações & Efeito em paredes \\
\hline 1,0 & 40 & 39 & 39 \\
\hline 1,2 & 36 & 35 & 35 \\
\hline 1,4 & 33 & 31 & 31 \\
\hline 1,6 & 31 & 28 & 28 \\
\hline 1,8 & 29 & 26 & 26 \\
\hline 2,0 & 28 & 25 & 25 \\
\hline$>2,0$ & 25 & 22 & 22 \\
\hline
\end{tabular}

Tabela 3.8 - Valores do coeficiente $\alpha$

\begin{tabular}{|c|c|c|c|c|c|c|c|c|c|}
\hline \multirow{3}{*}{$\frac{\mathbf{L}_{\mathbf{y}}}{\mathbf{L}_{\mathbf{x}}}$} & \multicolumn{4}{|c|}{ Aceitabilidade Sensorial } & \multicolumn{3}{c|}{$\begin{array}{c}\text { Efeitos em elementos não } \\
\text { estruturais }\end{array}$} \\
\cline { 2 - 11 } & \multicolumn{3}{|c|}{ Visual } & \multicolumn{3}{c|}{ Vibrações } & \multicolumn{3}{c|}{ Efeito em paredes } \\
\cline { 2 - 11 } & Tipos & Tipos & Tipos & Tipos & Tipos & Tipos & Tipos & Tipos & Tipos \\
& 1,2 e 3 & 4,5 e 6 & 7,8 e 9 & 1,2 e 3 & 4,5 e 6 & 7,8 e 9 & 1,2 e 3 & 4,5 e 6 & 7,8 e 9 \\
\hline 1,0 a 2,0 & 1,00 & 0,93 & 0,84 & 1,00 & 0,90 & 0,80 & 1,00 & 0,90 & 0,80 \\
\hline$>2,0$ & 1,00 & 0,88 & 0,74 & 1,00 & 0,85 & 0,70 & 1,00 & 0,85 & 0,70 \\
\hline
\end{tabular}

Os valores de $\beta$ fornecidos na Tabela 3.7 valem para resistência característica do concreto à compressão igual a $25 \mathrm{MPa}$. Para valores diferentes de $\mathbf{f}_{\mathbf{c k}}$, os valores de $\beta$ podem ser determinados utilizando-se as expressões a seguir, respeitando-se sua variação com a relação entre os vãos das lajes.

Para a verificação de aceitabilidade sensorial com relação a aspectos visuais, tem-se:

$$
\beta=61+4,0 \cdot f_{c k}-42,7 \cdot\left(\frac{L_{y}}{L_{x}}\right)+13,2 \cdot\left(\frac{L_{y}}{L_{x}}\right)^{2}-1,36 \cdot\left(\frac{L_{y}}{L_{x}}\right)^{3}
$$


Para a verificação de aceitabilidade sensorial com relação a vibrações, e para a verificação dos efeitos em paredes, vale:

$$
\beta=67+3,5 \cdot f_{c k}-51,5 \cdot\left(\frac{L_{y}}{L_{x}}\right)+16,5 \cdot\left(\frac{L_{y}}{L_{x}}\right)^{2}-1,77 \cdot\left(\frac{L_{y}}{L_{x}}\right)^{3}
$$

sendo:

$\mathbf{f}_{\text {ck }}$ resistência característica à compressão do concreto, em $\mathrm{kN} / \mathrm{cm}^{2}$,

$\mathbf{L}_{\mathbf{x}} \quad$ o menor vão da laje, em $\mathrm{cm}$,

$\mathbf{L}_{\mathbf{y}}$ o maior vão da laje, em $\mathrm{cm}$.

Para as lajes com relação entre o maior e o menor vão superior a 2,0, para o cálculo de $\beta$ a partir das eqs.(3.4) e (3.5), deve-se utilizar o valor 3,0 para está relação.

Nas figuras a seguir, têm-se os valores das relações menor vão-altura mínima de todos os tipos de lajes, em função das relações entre os vãos das lajes e do $\mathbf{f}_{\mathbf{c k}}$. São apresentados os valores calculados a partir da eq.(3.3), com os coeficientes $\beta$ determinados de acordo com as eqs. (3.4) e (3.5), e os coeficientes $\alpha$ fornecidos pela Tabela 3.8. Têm-se, também, os valores médios obtidos com a análise não-linear (programa ANPAV).

Pode-se observar que os valores determinados a partir das equações propostas são bastante próximos dos fornecidos pela análise não-linear, principalmente, para relações entre os vãos das lajes entre 1,0 e 2,0, correspondentes às lajes armadas em duas direções. Embora, para relações entre os vãos das lajes maiores que 2,0, ou seja, para as lajes armadas em uma direção, os valores propostos sejam um pouco menores que os médios, a maior diferença foi aproximadamente $5 \%$.

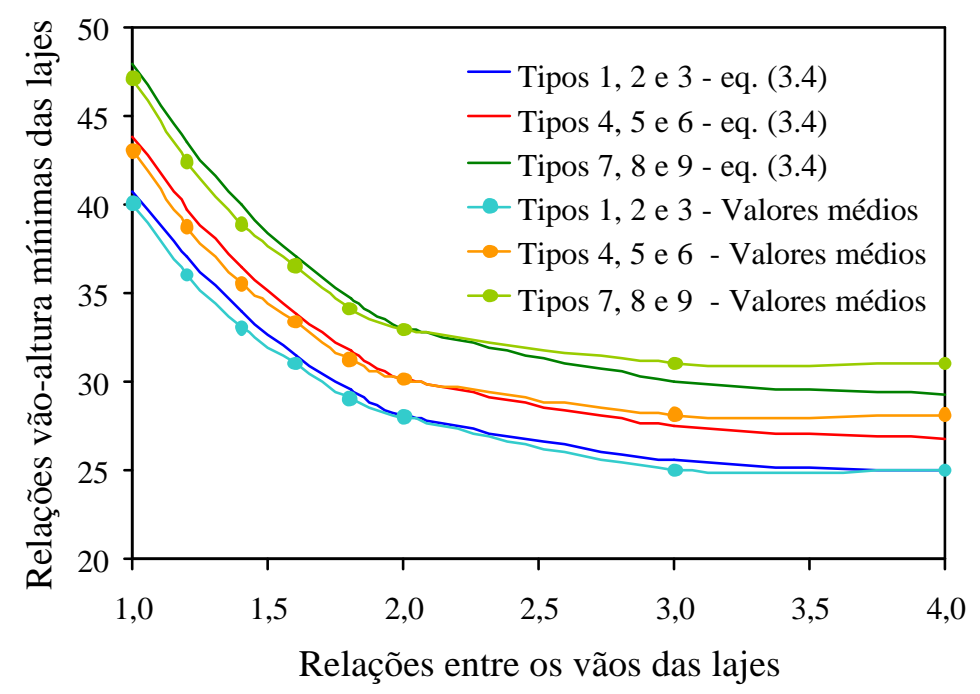

Figura 3.6 - Relações vão-altura mínima que satisfazem à verificação $1\left(f_{c k}=25 \mathrm{MPa}\right)$ 


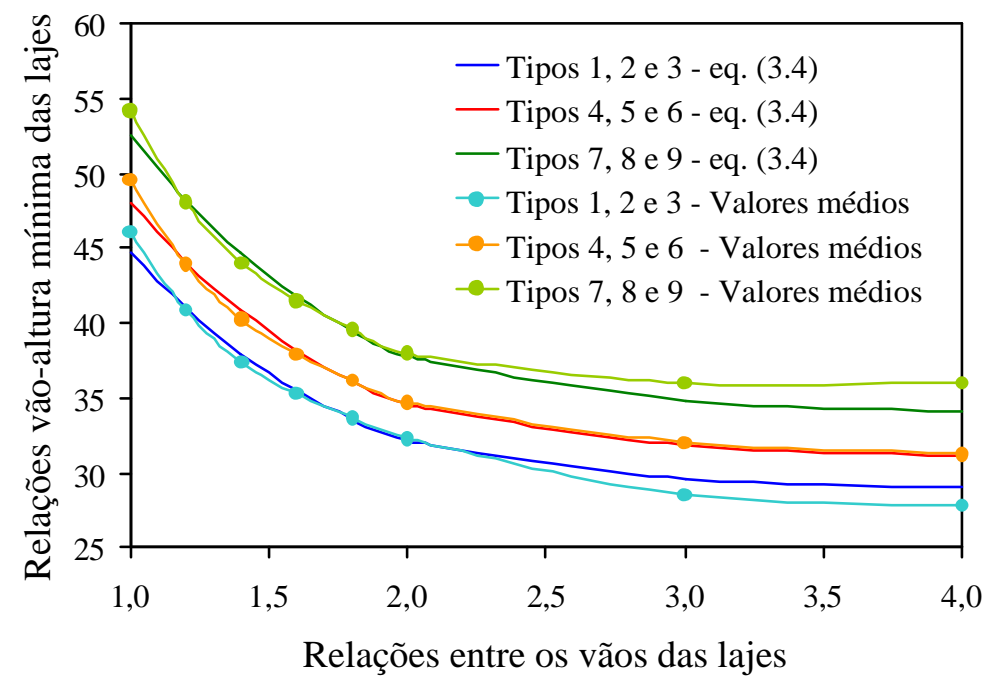

Figura 3.7 - Relações vão-altura mínima que satisfazem à verificação $1\left(f_{c k}=35 \mathrm{MPa}\right)$

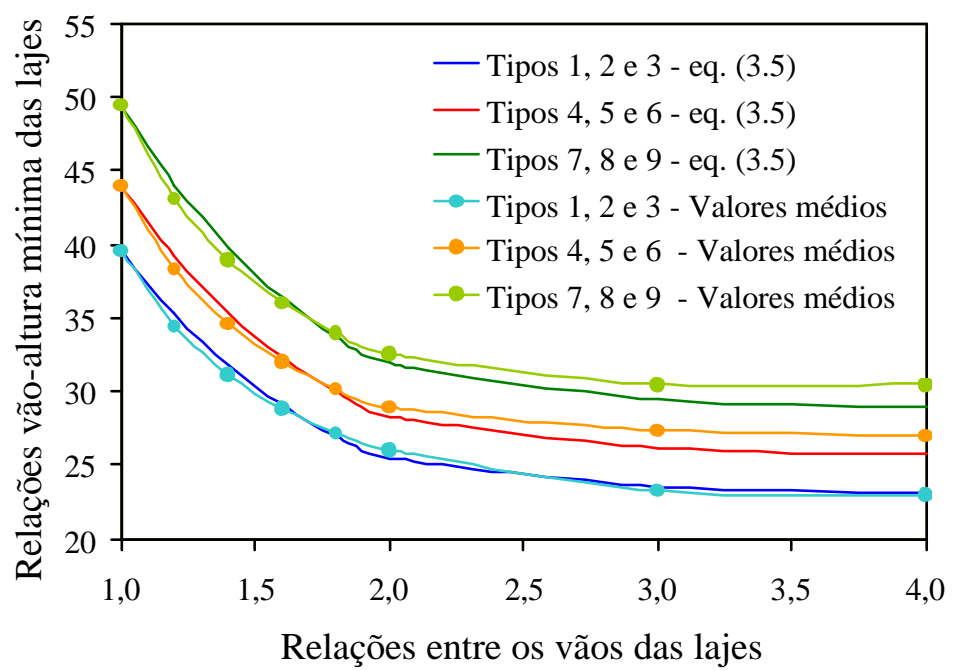

Figura 3.8 - Relações vão-altura mínima que satisfazem às verificações 2 e $3\left(\mathrm{f}_{\mathrm{ck}}=25 \mathrm{MPa}\right)$

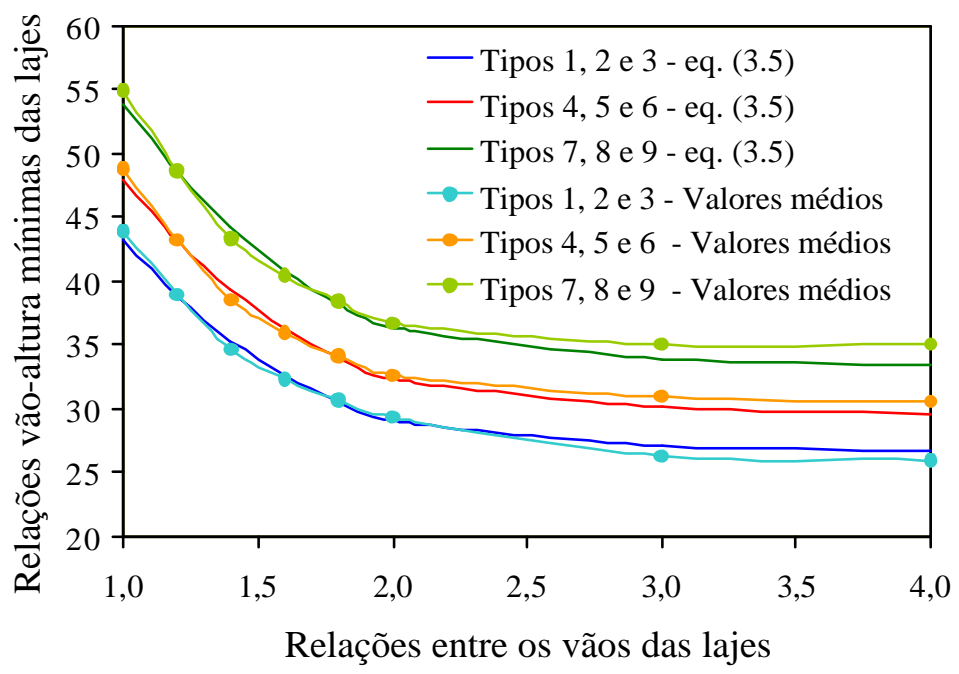

Figura 3.9 - Relações vão-altura mínima que satisfazem às verificações 2 e 3 ( $\left.\mathrm{f}_{\mathrm{ck}}=35 \mathrm{MPa}\right)$ 


\section{b) Expressão para o Cálculo da Altura Mínima}

No item anterior foi apresentada uma expressão para a determinação da relação entre o vão da laje e a altura mínima que esta deve possuir para que não venha a sofrer deslocamentos excessivos. Entretanto, tal expressão é simplificada já que foi determinada a partir dos valores médios obtidos para as lajes.

Para levar em conta os principais parâmetros que foram utilizados para a análise das lajes, comentados no início deste capítulo, fez-se uma regressão de variáveis múltiplas e obteve-se a seguinte expressão para o cálculo da altura mínima da laje:

$$
\mathrm{h}_{\min }=\eta_{0}+\eta_{1} \cdot \kappa+\eta_{2} \cdot \mathrm{f}_{\mathrm{ck}}+\eta_{3} \cdot \mathrm{L}_{\mathrm{x}}+\eta_{4} \cdot \mathrm{p}_{\mathrm{d}, \mathrm{ser}}+\eta_{5} \cdot \frac{\mathrm{L}_{\mathrm{y}}}{\mathrm{L}_{\mathrm{x}}} \geq 7 \mathrm{~cm}
$$

sendo:

$\mathbf{h}_{\text {min }}$ a altura mínima da laje, em $\mathrm{cm}$, a ser utilizada para dispensar o cálculo dos deslocamentos,

$\mathbf{f}_{\text {ck }}$ resistência característica à compressão do concreto, em $\mathrm{kN} / \mathrm{cm}^{2}$,

$\mathbf{L}_{\mathbf{x}} \quad$ o menor vão da laje, em cm,

$\mathbf{L}_{\mathbf{y}}$ o maior vão da laje, em cm,

$\mathbf{p}_{\mathbf{d}, \text { ser }}$ a ação de serviço estimada para a laje, correspondente a uma combinação de ações quase-permanente ou freqüente, em $\mathrm{kN} / \mathrm{cm}^{2}$. Para a verificação 2 , corresponde à relação entre a ação variável e a ação total $\left(\frac{\mathrm{q}}{\mathrm{p}}\right)$,

$\eta_{\mathrm{i}} \quad$ coeficientes que dependem do tipo de verificação e da combinação de ações adotada, cujos valores são fornecidos nas Tabela 3.9 e Tabela 3.10,

$\kappa \quad$ coeficiente que depende das condições de apoio das lajes, e, de acordo com a classificação apresentada no item 3.2.1, vale:

$\kappa=1$ para lajes do Tipo 1 ,

$\kappa=2$ para lajes do Tipo 2,

$\kappa=3$ para lajes do Tipo 3 ,

$\kappa=4$ para lajes do Tipo 4,

$\kappa=5$ para lajes do Tipo 5,

$\kappa=6$ para lajes do Tipo 6 ,

$\kappa=7$ para lajes do Tipo 7 ,

$\kappa=8$ para lajes do Tipo 8 ,

$\kappa=9$ para lajes do Tipo 9 . 


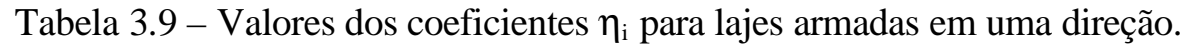

\begin{tabular}{|l|c|c|c|c|c|c|}
\hline Verificações e & \multicolumn{7}{|c|}{ Coeficientes $\eta$} \\
\cline { 2 - 7 } Combinação de ações & $\eta_{0}$ & $\eta_{1}$ & $\eta_{2}$ & $\eta_{3}$ & $\eta_{4}$ & $\eta_{5}$ \\
\hline Verificação 1A & $-0,50$ & $-0,40$ & $-1,30$ & 0,025 & 9480 & 0,48 \\
\hline Verificação 1B & $-0,60$ & $-0,40$ & $-1,30$ & 0,026 & 9080 & 0,50 \\
\hline Verificação 2 & 3,00 & $-0,45$ & $-1,70$ & 0,035 & 2,35 & 0,54 \\
\hline Verificação 3A & $-0,24$ & $-0,56$ & $-1,33$ & 0,027 & 9900 & 0,44 \\
\hline Verificação 3B & $-0,32$ & 0,56 & $-1,35$ & 0,028 & 9600 & 0,45 \\
\hline
\end{tabular}

Tabela 3.10 - Valores dos coeficientes $\eta_{i}$ para lajes armadas em duas direções.

\begin{tabular}{|l|c|c|c|c|c|c|}
\hline Verificações e & \multicolumn{7}{|c|}{ Coeficientes $\eta$} \\
\cline { 2 - 7 } Combinação de ações & $\eta_{0}$ & $\eta_{1}$ & $\eta_{2}$ & $\eta_{3}$ & $\eta_{4}$ & $\eta_{5}$ \\
\hline Verificação 1A & $-3,5$ & $-0,24$ & $-0,95$ & 0,019 & 8400 & 2,63 \\
\hline Verificação 1B & $-3,7$ & $-0,24$ & $-0,95$ & 0,019 & 8600 & 2,65 \\
\hline Verificação 2 & $-0,1$ & $-0,49$ & $-1,48$ & 0,030 & 1,42 & 3,50 \\
\hline Verificação 3A & $-4,2$ & $-0,33$ & $-1,00$ & 0,021 & 8850 & 2,93 \\
\hline Verificação 3B & $-4,3$ & $-0,33$ & $-1,05$ & 0,022 & 8620 & 2,95 \\
\hline
\end{tabular}

Para a estimativa da ação de serviço da laje, necessária para a determinação da altura mínima da laje, pode-se adotar, para o cálculo do peso próprio da laje, uma altura média, que em função do vão da laje, vale:

- $\mathrm{h}_{\text {média }}=8 \mathrm{~cm}$, para $\mathrm{L}_{\mathrm{x}}=3,0 \mathrm{~m}$,

- $\mathrm{h}_{\text {média }}=11 \mathrm{~cm}$, para $3,0 \mathrm{~m}<\mathrm{L}_{\mathrm{x}}=4,0 \mathrm{~m}$,

- $\mathrm{h}_{\text {média }}=13 \mathrm{~cm}$, para $4,0 \mathrm{~m}<\mathrm{L}_{\mathrm{x}}=5,0 \mathrm{~m}$,

- $\mathrm{h}_{\text {média }}=17 \mathrm{~cm}$, para $5,0 \mathrm{~m}<\mathrm{L}_{\mathrm{x}}=6,0 \mathrm{~m}$.

Nas figuras a seguir, têm-se os valores das alturas mínimas de alguns tipos de lajes, em função das relações entre os vãos das lajes. São apresentados os valores determinados a partir da eq.(3.6), e os obtidos com a análise não-linear, e pode-se observar que esses valores são muito próximos. 


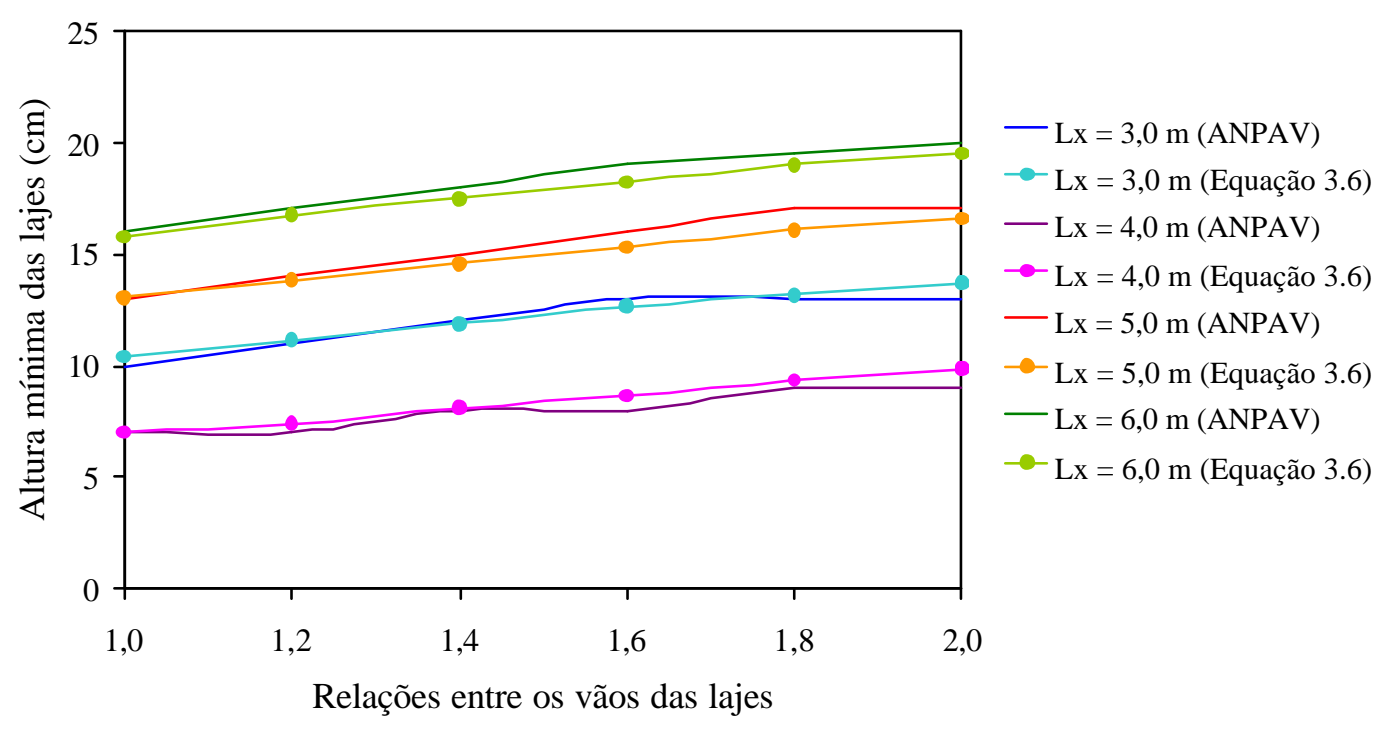

Figura 3.10 - Alturas mínimas de lajes do tipo 1, submetidas ao carregamento C1, e que satisfazem a verificação $1 \mathrm{~A}\left(\mathrm{f}_{\mathrm{ck}}=25 \mathrm{MPa}\right)$

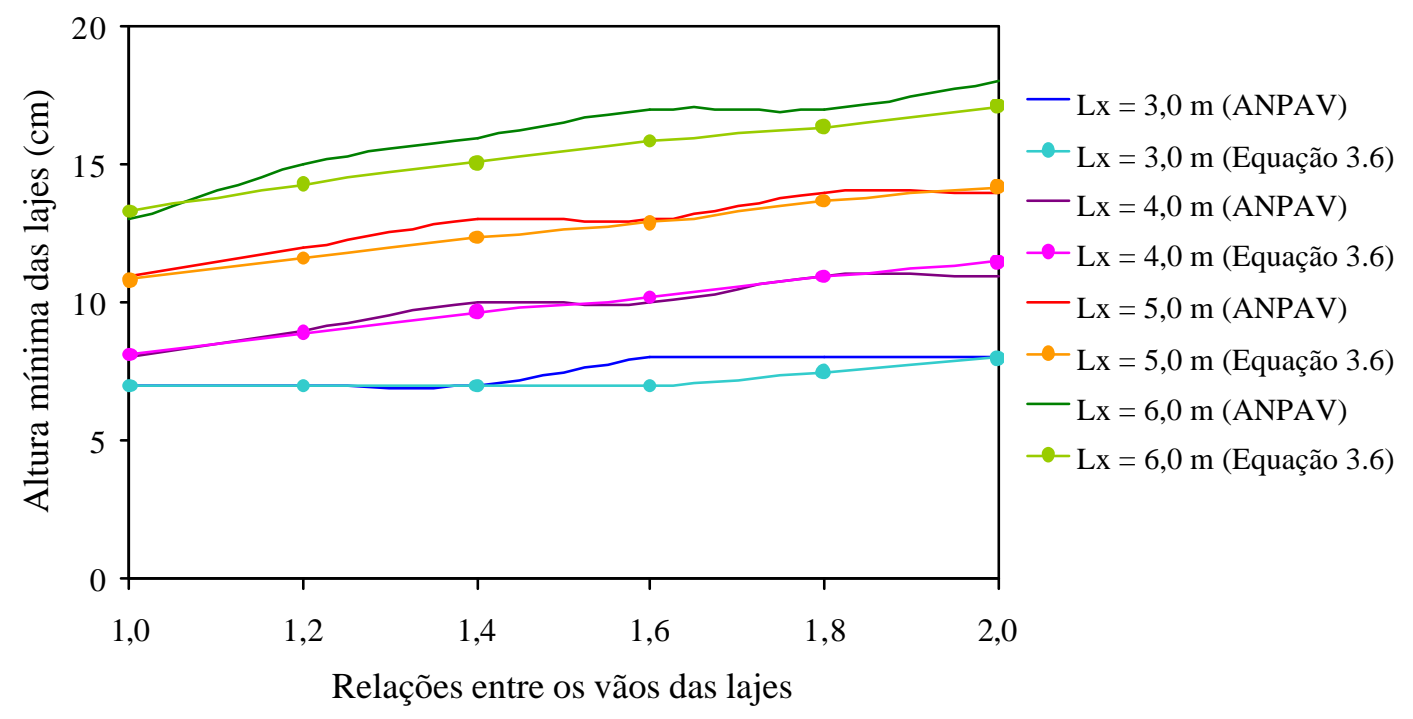

Figura 3.11 - Alturas mínimas de lajes do tipo 4, submetidas ao carregamento C1, e que satisfazem a verificação $1 \mathrm{~B}\left(\mathrm{f}_{\mathrm{ck}}=35 \mathrm{MPa}\right)$ 


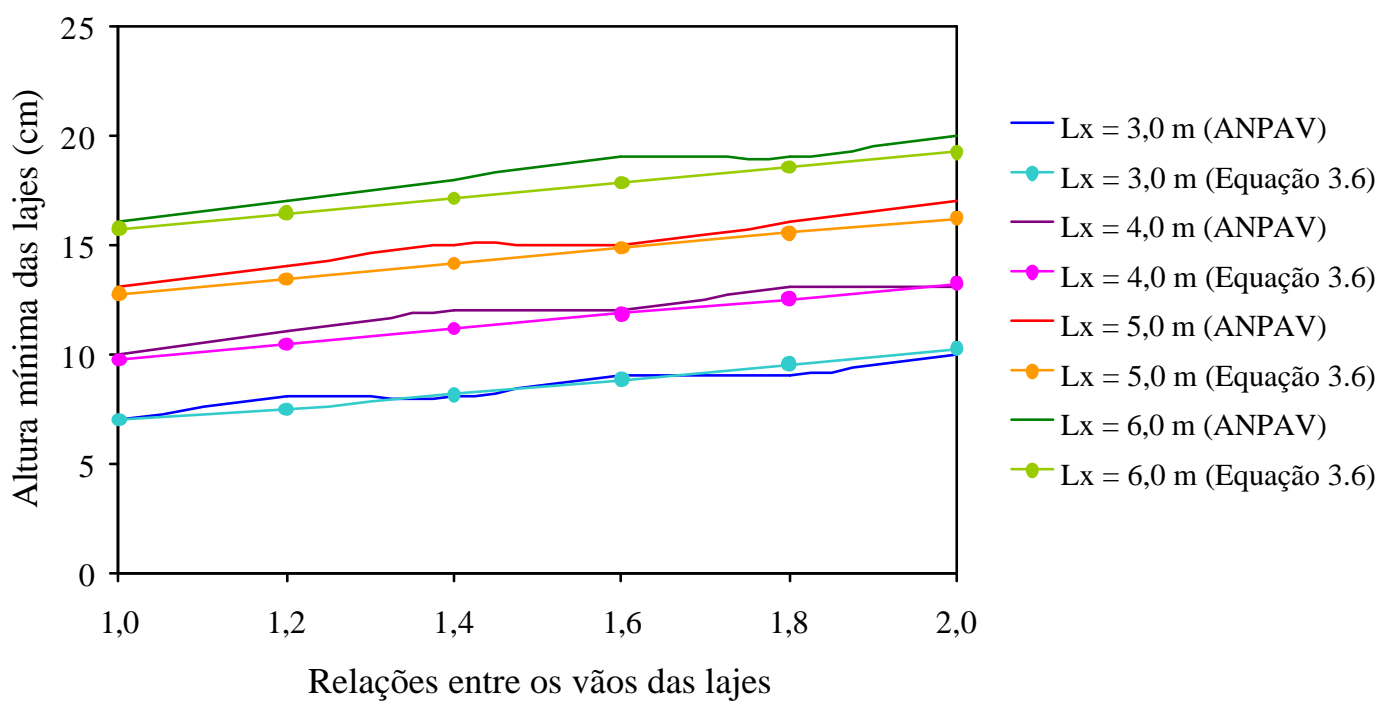

Figura 3.12 - Alturas mínimas de lajes do tipo 5, submetidas ao carregamento C3, e que satisfazem a verificação $2\left(\mathrm{f}_{\mathrm{ck}}=25 \mathrm{MPa}\right)$

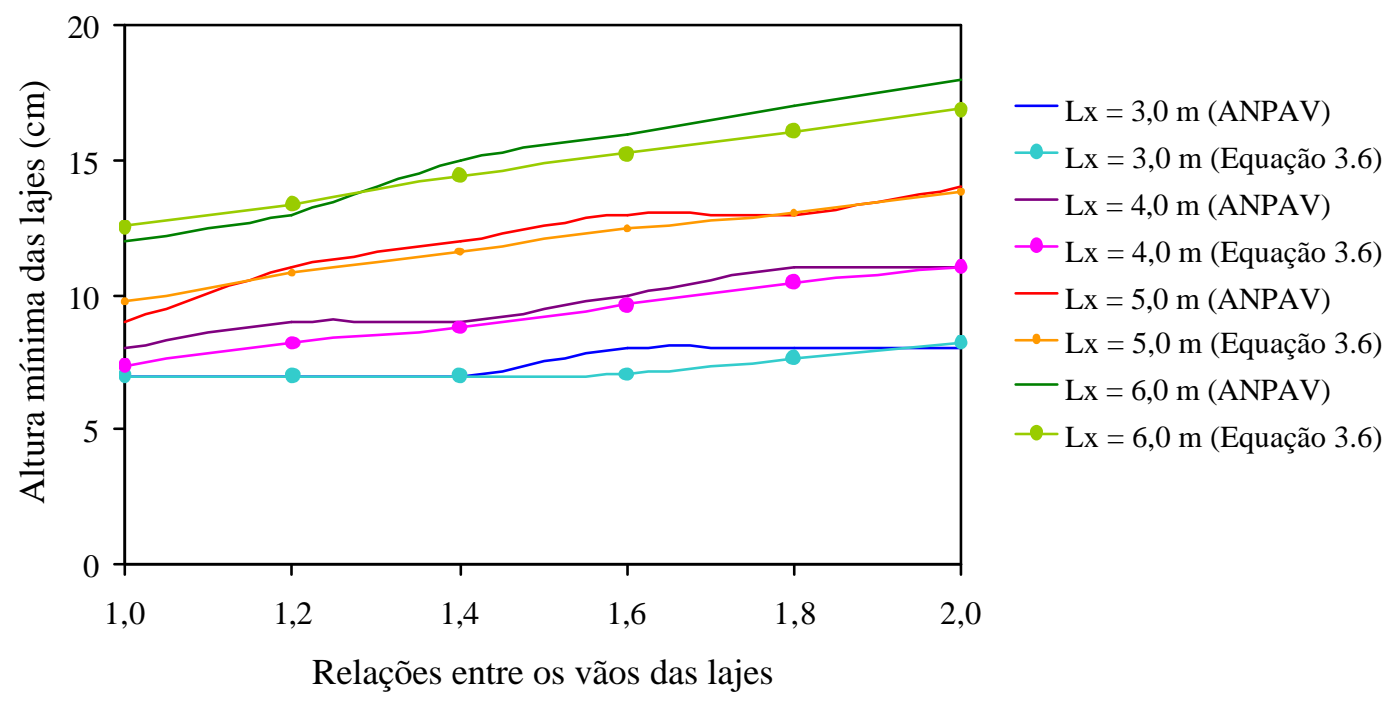

Figura 3.13 - Alturas mínimas de lajes do tipo 6, submetidas ao carregamento C2, e que satisfazem a verificação $3 \mathrm{~A}\left(\mathrm{f}_{\mathrm{ck}}=35 \mathrm{MPa}\right)$ 


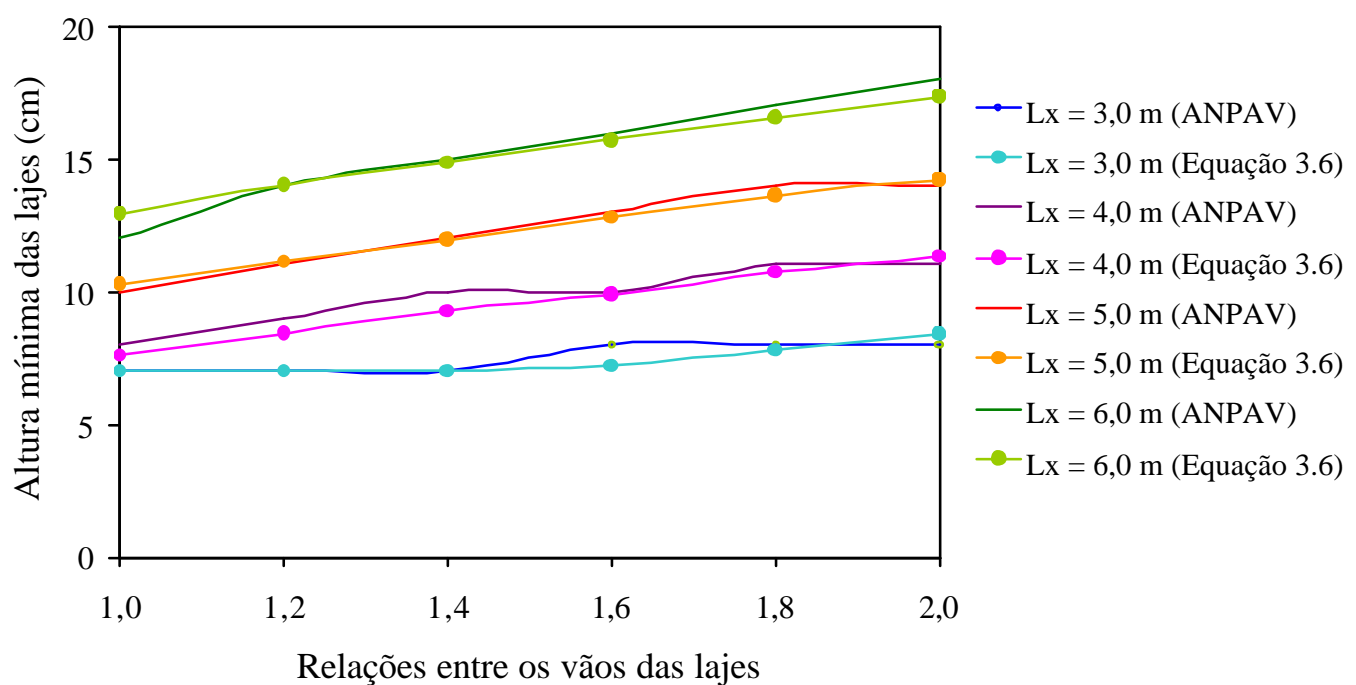

Figura 3.14 - Alturas mínimas de lajes do tipo 9, submetidas ao carregamento C3, e que satisfazem a verificação $3 \mathrm{~B}\left(\mathrm{f}_{\mathrm{ck}}=25 \mathrm{MPa}\right)$

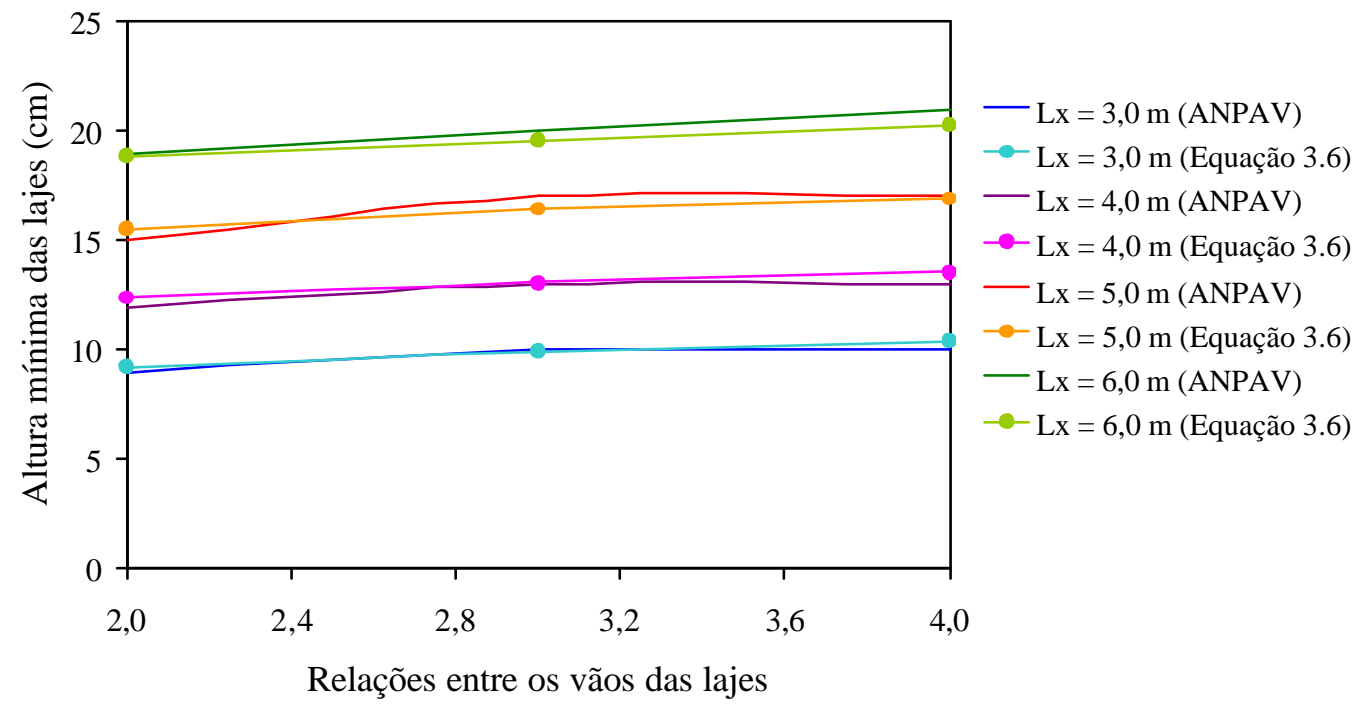

Figura 3.15 - Alturas mínimas de lajes do tipo 2, submetidas ao carregamento C2, e que satisfazem a verificação $1 \mathrm{~A}\left(\mathrm{f}_{\mathrm{ck}}=25 \mathrm{MPa}\right)$ 


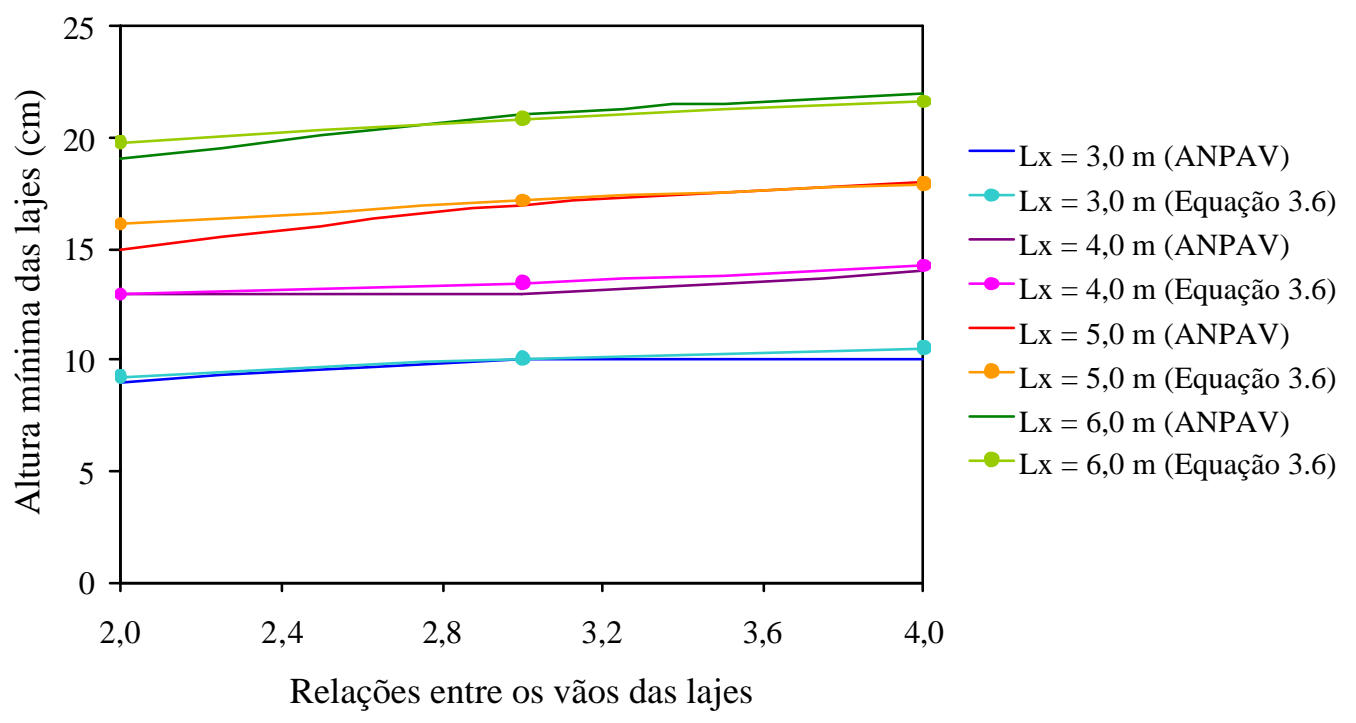

Figura 3.16 - Alturas mínimas de lajes do tipo 3, submetidas ao carregamento C3, e que satisfazem a verificação $1 \mathrm{~B}\left(\mathrm{f}_{\mathrm{ck}}=35 \mathrm{MPa}\right)$

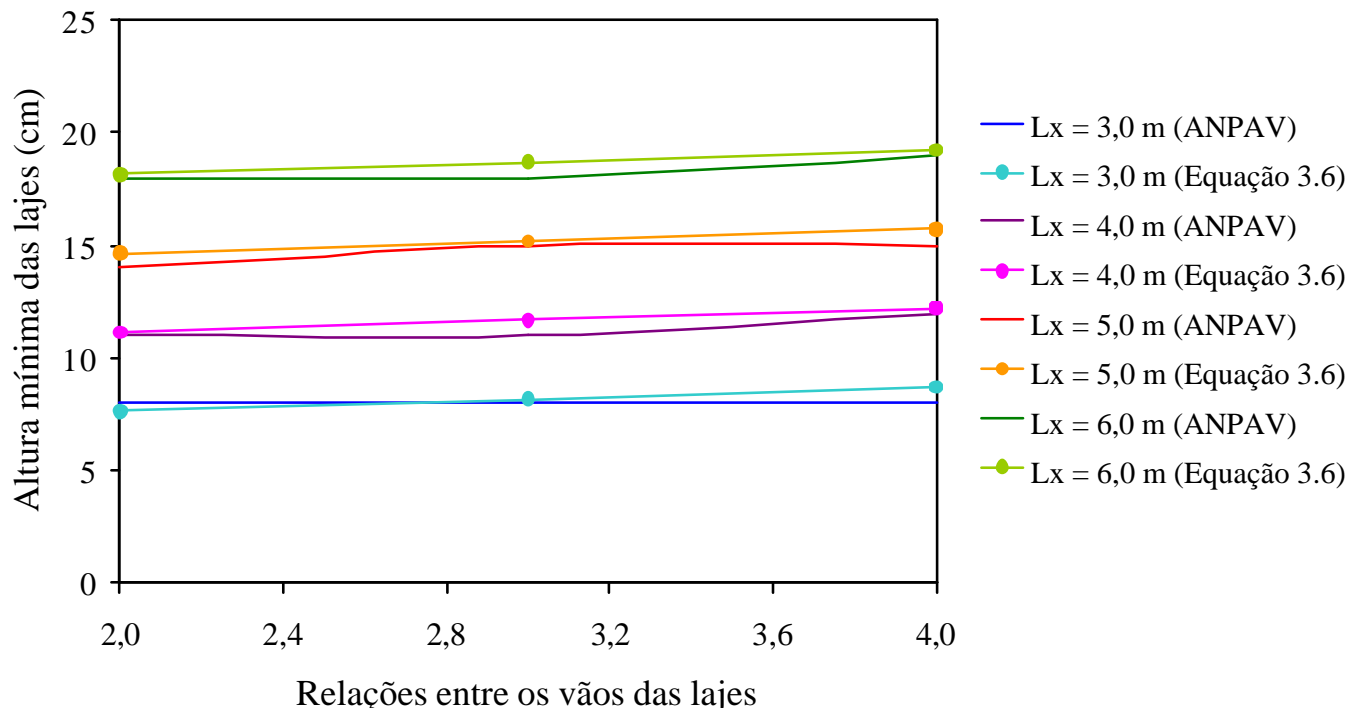

Figura 3.17 - Alturas mínimas de lajes do tipo 7, submetidas ao carregamento C1, e que satisfazem a verificação $2\left(f_{c k}=25 \mathrm{MPa}\right)$ 


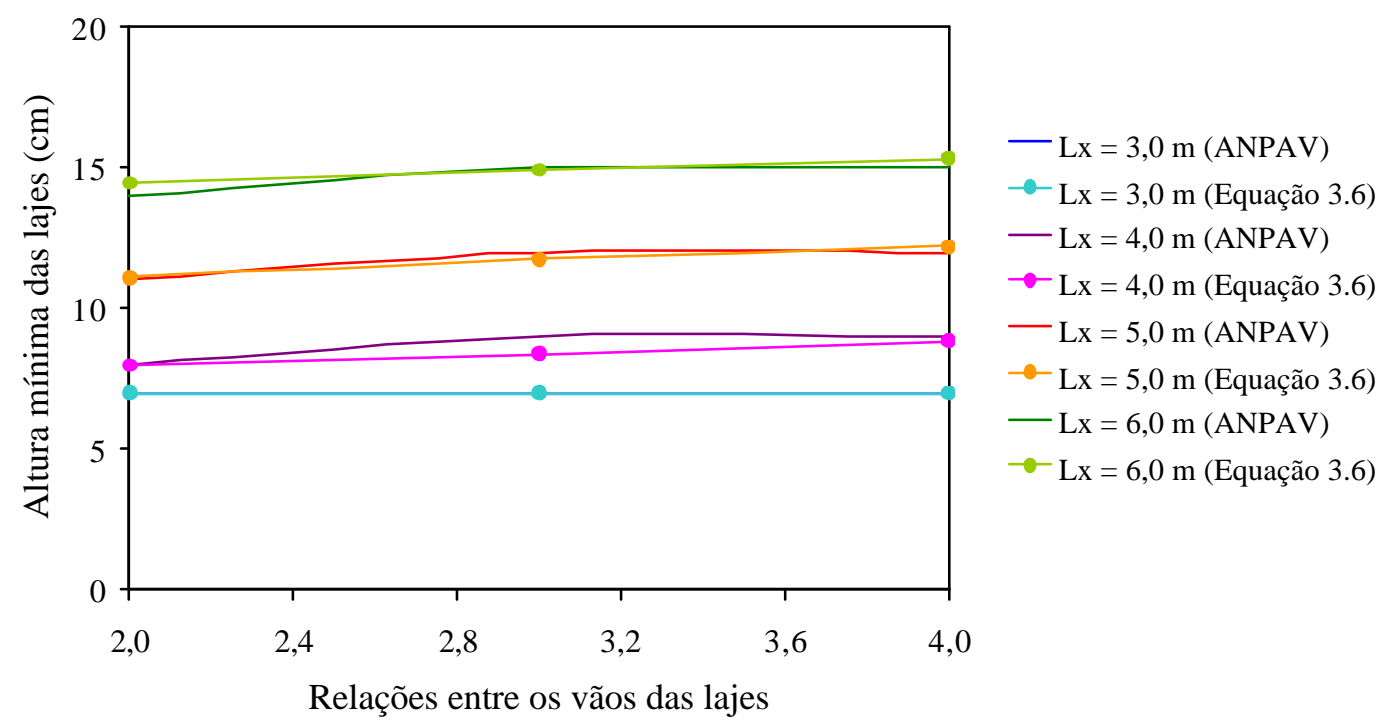

Figura 3.18 - Alturas mínimas de lajes do tipo 8, submetidas ao carregamento C2, e que satisfazem a verificação $3 \mathrm{~A}\left(\mathrm{f}_{\mathrm{ck}}=35 \mathrm{MPa}\right)$

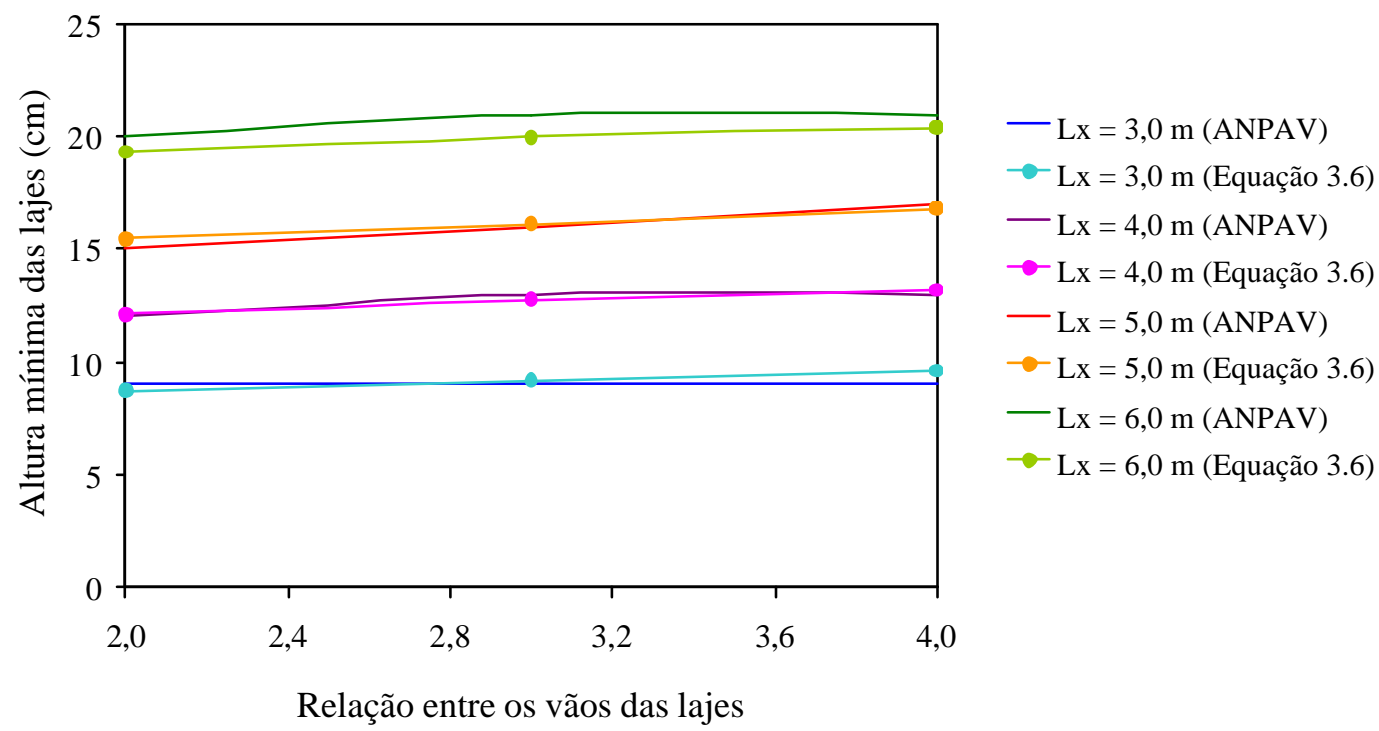

Figura 3.19 - Alturas mínimas de lajes do tipo 4, submetidas ao carregamento C2, e que satisfazem a verificação $3 \mathrm{~B}\left(\mathrm{f}_{\mathrm{ck}}=35 \mathrm{MPa}\right)$

Calculando-se a diferença entre os valores obtidos com a análise não-linear e os provenientes da eq. (3.6), tanto para lajes armadas em uma direção como para as armadas nas duas direções, pode-se notar que, a maioria das diferenças fica entre $-1 \mathrm{~cm}$ e $1 \mathrm{~cm}$, sendo $15 \%$ entre $-1 \mathrm{~cm}$ e $-0,5 \mathrm{~cm}, 60 \%$ entre $-0,5 \mathrm{~cm}$ e $0,5 \mathrm{~cm}$, e $15 \%$ entre $0,5 \mathrm{~cm}$ e $1 \mathrm{~cm}$. Para os $10 \%$ restantes, têm-se $5 \%$ dessas diferenças maiores que $-1 \mathrm{~cm}$ ou $1 \mathrm{~cm}$, como mostra a Figura 3.20. 


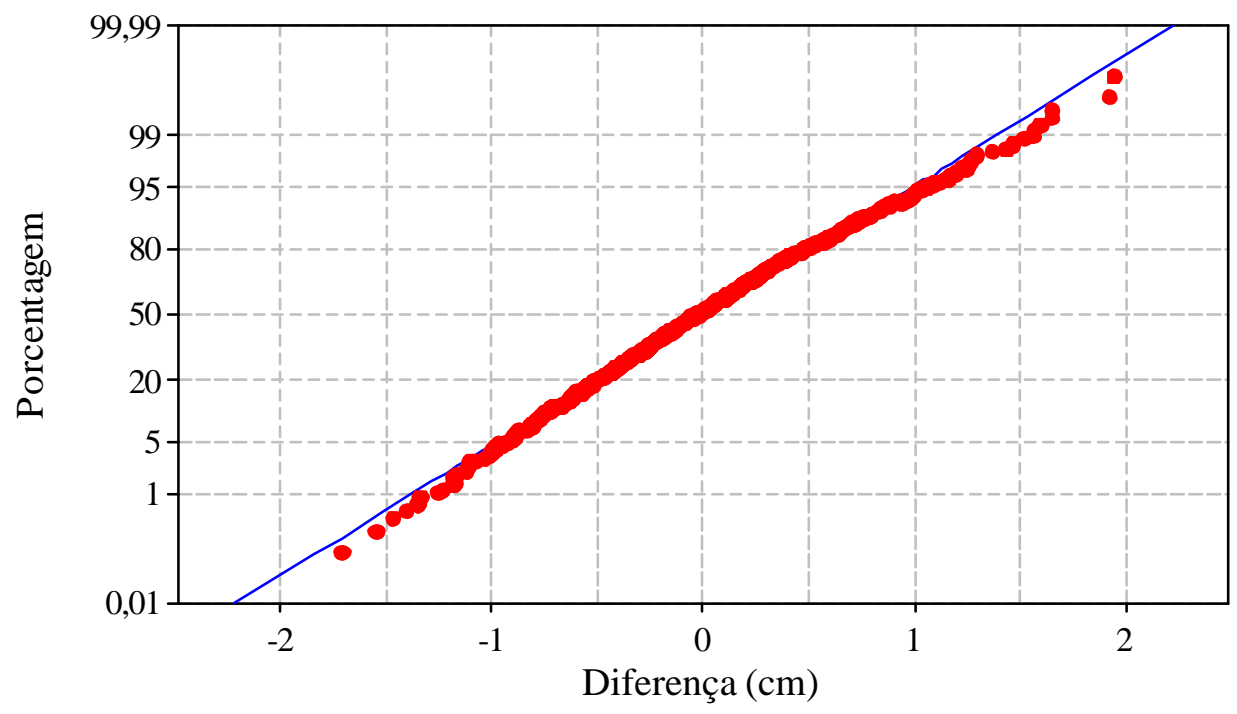

Figura 3.20 - Gráfico das porcentagens das diferenças entre os resultados da análise com o

$$
\text { ANPAV e da eq. (3.6) }
$$

As diferenças maiores que $1 \mathrm{~cm}$, que seriam os valores contra a segurança, corresponderam, em sua totalidade, aos valores de alturas menores que $7 \mathrm{~cm}$, fornecidos pela eq. (3.6). Entretanto, deve-se lembrar que, nas análises das lajes, a altura mínima foi limitada em $7 \mathrm{~cm}$ para respeitar a recomendação para lajes de pavimento da NBR 6118 (2003). Isto gerou esses valores mais altos para as diferenças, que, no entanto, se anulam com a adoção, nestes casos, da altura mínima igual a $7 \mathrm{~cm}$.

Vale ressaltar que podem ser adotadas alturas menores que as obtidas a partir das eqs. (3.3) e (3.6), porém, os deslocamentos devem ser calculados, e seus valores comparados com os limites impostos pela NBR 6118 (2003), já comentados anteriormente.

\section{c) Exemplos de Cálculo}

A seguir, são apresentados dois exemplos de determinação da altura mínima de lajes, utilizando-se as equações propostas nos itens anteriores.

\section{Exemplo 1}

Estudou-se uma laje do tipo 4 (Figura 3.1), com o menor e o maior vão iguais a $4,0 \mathrm{~m}$ e $12,0 \mathrm{~m}$, respectivamente. A resistência característica do concreto à compressão foi de $25 \mathrm{MPa}$, e seu carregamento foi composto pelas seguintes parcelas: 
- Ação devida ao peso do piso e revestimentos: $1,50 \mathrm{kN} / \mathrm{m}^{2}$;

- Ação devida ao peso das paredes: $2,50 \mathrm{kN} / \mathrm{m}^{2}$;

- Ação variável: $1,5 \mathrm{kN} / \mathrm{m}^{2}$.

Inicialmente, a altura mínima da laje foi calculada a partir da eq. (3.3). Como era uma laje do tipo 4 e armada em uma direção, e o $\mathbf{f}_{\text {ck }}$ era igual a $25 \mathrm{MPa}$, os coeficientes $\beta$ e $\alpha$ puderam ser obtidos diretamente das Tabela 3.7 e Tabela 3.8, respectivamente. Assim, para a verificação da aceitabilidade sensorial quanto a aspectos visuais (verificação 1), encontrou-se $\beta=25$ e $\alpha=0,88$. Portanto, pela eq. (3.3), obteve-se:

$$
\mathrm{h}_{\min }=\frac{\alpha \cdot \mathrm{L}_{\mathrm{x}}}{\beta}=\frac{0,88 \cdot 400}{25}=14 \mathrm{~cm}
$$

Para as verificações da aceitabilidade sensorial quanto às vibrações e do efeito dos deslocamentos nas paredes (verificações 2 e 3), os coeficientes $\beta$ e $\alpha$ foram $\mathfrak{2}$ e 0,85 , respectivamente, e a altura mínima foi igual a:

$$
\mathrm{h}_{\min }=\frac{\alpha \cdot \mathrm{L}_{\mathrm{x}}}{\beta}=\frac{0,85 \cdot 400}{22}=15,4 \mathrm{~cm}
$$

Desta forma, para satisfazer a verificação 1, a altura da laje precisou ser maior ou igual a $14 \mathrm{~cm}$. Já para satisfazer as verificações 2 e 3, a altura precisou ser maior ou igual a $15,4 \mathrm{~cm}$.

Em seguida, utilizou-se a eq. (3.6) para a determinação de $\mathbf{h}_{\mathbf{m i n}}$. Para a estimativa do peso próprio da laje, adotou-se uma altura média de $11 \mathrm{~cm}$, já que o menor vão foi igual a $4,0 \mathrm{~m}$.

Considerando o peso específico do concreto igual a $25 \mathrm{kN} / \mathrm{m}^{3}$, o peso próprio da laje ficou em $2,75 \mathrm{kN} / \mathrm{m}^{2}$. Assim, a ação permanente total foi de $6,75 \mathrm{kN} / \mathrm{m}^{2}$, e calculou-se as seguintes ações de serviço:

- Combinação quase-permanente:

$$
\mathrm{p}_{\mathrm{d}, \mathrm{ser}}=\mathrm{g}+0,3 \mathrm{q}=6,75+0,3 \cdot 1,50=7,2 \mathrm{kN} / \mathrm{m}^{2}=0,00072 \mathrm{kN} / \mathrm{cm}^{2}
$$

- Combinação freqüente:

$$
\mathrm{p}_{\mathrm{d}, \mathrm{ser}}=\mathrm{g}+0,4 \mathrm{q}=6,75+0,4 \cdot 1,50=7,35 \mathrm{kN} / \mathrm{m}^{2}=0,000735 \mathrm{kN} / \mathrm{cm}^{2}
$$


Para a verificação 1, considerando-se a combinação quase-permanente de ações, e a partir dos coeficientes $\eta$ dados da Tabela 3.9, a eq. (3.6) pode ser escrita da seguinte forma:

$$
\mathrm{h}_{\min }=-0,50-0,40 \cdot \kappa-1,30 \cdot \mathrm{f}_{\mathrm{ck}}+0,025 \cdot \mathrm{L}_{\mathrm{x}}+9480 \cdot \mathrm{p}_{\mathrm{d}, \mathrm{ser}}+0,48 \cdot \frac{\mathrm{L}_{\mathrm{y}}}{\mathrm{L}_{\mathrm{x}}}
$$

para a qual o coeficiente $\kappa$ foi 4 , já que se tratava de uma laje do tipo 4. Portanto

$$
\begin{gathered}
\mathrm{h}_{\text {min-verlA }}=-0,50-0,40 \cdot 4-1,30 \cdot 2,5+0,025 \cdot 400+9480 \cdot 0,00072+0,48 \cdot 3 \\
\mathrm{~h}_{\text {min-verlA }}=12,9 \mathrm{~cm}
\end{gathered}
$$

De maneira similar, para a verificação 1 , considerando-se a combinação freqüente de ações, a eq. (3.6), resultou em:

$$
\begin{gathered}
\mathrm{h}_{\text {min-verlB }}=-0,60-0,40 \cdot 4-1,30 \cdot 2,5+0,026 \cdot 400+9080 \cdot 0,000735+0,50 \cdot 3 \\
\mathrm{~h}_{\min -\mathrm{ver} 1 \mathrm{~B}}=13,1 \mathrm{~cm}
\end{gathered}
$$

Logo, para a verificação 1, tanto para a combinação quase-permanente quanto freqüente, a altura mínima obtida a partir da eq. (3.6), foi, aproximadamente, igual a $13 \mathrm{~cm}$.

Para a verificação 2, a eq. (3.6) forneceu:

$$
\mathrm{h}_{\min -\text { ver } 2}=3,0-0,45 \cdot 4-1,70 \cdot 2,5+0,035 \cdot 400+2,35 \cdot 0,18+0,54 \cdot 3=13 \mathrm{~cm}
$$

lembrando que, neste caso, entra-se na eq. (3.6) com a razão entre a ação variável e ação total, em vez da ação de serviço, $\mathbf{p}_{\mathbf{d}, \text { ser }}$.

Para a verificação 3, considerando-se mais uma vez as combinações quasepermanente e freqüente de ações e os coeficientes $\eta$ fornecidos na Tabela 3.9, a eq. (3.6) levou a:

$$
\begin{gathered}
\mathrm{h}_{\text {min-ver3A }}=-0,24-0,56 \cdot 4-1,33 \cdot 2,5+0,027 \cdot 400+9900 \cdot 0,00072+0,44 \cdot 3 \\
\mathrm{~h}_{\min -\mathrm{ver} 3 \mathrm{~A}}=13,4 \mathrm{~cm} \\
\mathrm{~h}_{\min -\mathrm{ver} 3 \mathrm{~B}}=-0,32-0,56 \cdot 4-1,35 \cdot 2,5+0,028 \cdot 400+9600 \cdot 0,000735+0,45 \cdot 3 \\
\mathrm{~h}_{\min -\mathrm{ver} 3 \mathrm{~B}}=13,7 \mathrm{~cm}
\end{gathered}
$$

Diante dos resultados obtidos, pode-se observar que o uso da eq. (3.6) resultou em alturas mínimas menores que as obtidas utilizando-se a eq. (3.3). Isto ocorreu, principalmente, devido ao fato de que, para a obtenção da eq. (3.3), foram considerados os 
valores médios das relações menor vão - altura mínima, enquanto que para a eq. (3.6), foram levadas em conta as alturas mínimas de todas as lajes analisadas.

Para se comprovar que os valores de alturas mínimas obtidos com a eq. (3.6), não levaram a laje a um estado de deslocamentos excessivos, foi feita uma análise da laje com o programa ANPAV. Para isso, considerou-se uma altura mínima igual a $13 \mathrm{~cm}$ para todas as verificações dos deslocamentos, e os carregamentos foram ajustados em função da altura adotada. Os deslocamentos obtidos foram apresentados na Tabela 3.11.

Tabela 3.11 - Deslocamentos da laje do exemplo 1, para $\mathrm{h}=13 \mathrm{~cm}$ (ANPAV)

\begin{tabular}{|l|c|c|c|c|c|}
\hline \multirow{2}{*}{ Ações } & \multicolumn{4}{|c|}{ Deslocamentos (cm) } & $\begin{array}{c}\text { Relação entre os } \\
\text { desls. diferidos e } \\
\text { imediatos }\end{array}$ \\
\cline { 2 - 6 } & Imediatos & Totais & Diferidos & Incrementais & 2,35 \\
\hline Permanente & 0,20 & 0,67 & 0,47 & - & 2,40 \\
\hline Quase-permanente & 0,25 & 0,85 & 0,60 & 0,65 & 2,42 \\
\hline Freqüente & 0,28 & 0,96 & 0,68 & 0,76 & 2,40 \\
\hline Total & 0,47 & 1,60 & 1,13 & - & 2,44 \\
\hline Variável & 0,27 & 0,93 & 0,66 & - & - \\
\hline
\end{tabular}

Para um vão de 4,0 m, os limites dos deslocamentos para as verificações 1, 2 e 3, foram, respectivamente:

$$
\begin{aligned}
& \mathrm{a}_{\mathrm{t}, \mathrm{g}+\psi \mathrm{q}} \leq \frac{\ell}{250} \leq \frac{400}{250} \leq 1,6 \mathrm{~cm} \\
& \mathrm{a}_{\mathrm{i}, \mathrm{q}} \leq \frac{\ell}{350} \leq \frac{400}{350} \leq 1,14 \mathrm{~cm} \\
& \mathrm{a}_{\mathrm{inc}} \leq\left\{\begin{array}{l}
\frac{\ell}{250}=\frac{400}{250}=1,6 \mathrm{~cm} \\
1,0 \mathrm{~cm}
\end{array} \Rightarrow \mathrm{a}_{\mathrm{inc}} \leq 1,0 \mathrm{~cm}\right.
\end{aligned}
$$

Observa-se, assim, que os deslocamentos obtidos atendem a todas as verificações. Os deslocamentos totais e incrementais devidos às combinações quase-permanente e freqüente foram menores que $1,6 \mathrm{~cm}$ e $1,0 \mathrm{~cm}$, respectivamente, e o deslocamento imediato devido à ação variável foi menor que $1,14 \mathrm{~cm}$.

$\mathrm{Na}$ Tabela 3.11, foram colocadas também as relações entre os deslocamentos diferidos e imediatos resultantes da análise não-linear. Pode-se notar que essas relações variaram entre 2,35 e 2,44 , com um valor médio de 2,4 . Pela eq. (3.2), proposta para o 
cálculo do coeficiente multiplicador dos deslocamentos imediatos para o cálculo dos deslocamentos diferidos, obteve-se:

$$
\alpha_{\mathrm{f}, \mathrm{aj}}=3,7-0,36 \mathrm{f}_{\mathrm{ck}}-0,032 \mathrm{~h}=3,7-0,36 \cdot 2,5-0,032 \cdot 13=2,38
$$

Observa-se, então, que o valor fornecido pela eq. (3.2) de 2,38 é bastante próximo dos valores obtidos com a análise não-linear (ANPAV).

\section{Exemplo 2}

Estudou-se em seguida uma laje do tipo 7 (Figura 3.1), para a qual o menor vão foi igual a $5,0 \mathrm{~m}$ e a relação entre os vãos foi igual a 1,4. As ações foram iguais às do exemplo 1, e o $\mathbf{f}_{\text {ck }}$ foi de $35 \mathrm{MPa}$.

Para o cálculo das alturas mínimas pela eq. (3.3), foi necessário utilizar as eqs. (3.4) e (3.5) para o cálculo do coeficiente $\beta$, já que o $\mathbf{f}_{\mathbf{c k}}$ foi diferente de $25 \mathrm{MPa}$. Logo, para a verificação 1 , calculou-se:

$$
\beta=61+4,0 \cdot 3,5-42,7 \cdot(1,4)+13,2 \cdot(1,4)^{2}-1,36 \cdot(1,4)^{3}=37,4
$$

Para as verificações 2 e 3 , o coeficiente $\beta$ foi:

$$
\beta=67+3,5 \cdot 3,5-51,5 \cdot(1,4)+16,5 \cdot(1,4)^{2}-1,77 \cdot(1,4)^{3}=34,6
$$

Para laje do tipo 7, e pela Tabela 3.8, os coeficientes $\alpha$ para a verificação 1 e para as verificações 2 e 3 , foram 0,84 e 0,80 , respectivamente.

Assim, pela eq.(3.3), as alturas mínimas que atenderam às verificações 1, 2 e 3, foram iguais a:

$$
\mathrm{h}_{\text {min-verl }}=\frac{\alpha \cdot \mathrm{L}_{\mathrm{x}}}{\beta}=\frac{0,84 \cdot 500}{37,4}=11,2 \mathrm{~cm}
$$

e,

$$
\mathrm{h}_{\min -\mathrm{ver} 2 \mathrm{e} 3}=\frac{\alpha \cdot \mathrm{L}_{\mathrm{x}}}{\beta}=\frac{0,80 \cdot 500}{34,6}=11,6 \mathrm{~cm}
$$

Como o menor vão da laje foi igual a 5,0 m, pode-se considerar uma altura média de $13 \mathrm{~cm}$ para o cálculo do peso próprio da laje, definindo-se, assim, o carregamento para o cálculo da altura mínima a partir da eq. (3.6). 
Para essa altura de $13 \mathrm{~cm}$, o peso próprio ficou em $3,25 \mathrm{kN} / \mathrm{m}^{2}$, que levou a ações permanentes, variáveis e totais iguais a $7,25 \mathrm{kN} / \mathrm{m}^{2}, 1,50 \mathrm{kN} / \mathrm{m}^{2}$ e $8,75 \mathrm{kN} / \mathrm{m}^{2}$, respectivamente. Com esses valores de ações, calculou-se as seguintes ações de serviços:

- Combinação quase-permanente:

$$
\mathrm{p}_{\mathrm{d}, \mathrm{ser}}=\mathrm{g}+0,3 \mathrm{q}=7,25+0,3 \cdot 1,5=7,70 \mathrm{kN} / \mathrm{m}^{2}=0,000770 \mathrm{kN} / \mathrm{cm}^{2}
$$

- Combinação freqüente:

$$
\mathrm{p}_{\mathrm{d}, \mathrm{ser}}=\mathrm{g}+0,4 \mathrm{q}=7,25+0,4 \cdot 2,0=7,85 \mathrm{kN} / \mathrm{m}^{2}=0,000785 \mathrm{kN} / \mathrm{cm}^{2}
$$

Da mesma forma que no exemplo 1, com os coeficientes $\eta$ dados da Tabela 3.10, a eq. (3.6), para as verificações 1 e 3, com combinações quase-permanente e freqüente de ações, e para a verificação 2 , pode ser escrita da seguinte forma:

$$
\begin{aligned}
& \mathrm{h}_{\text {min-verlA }}=-3,5-0,24 \cdot 7-0,95 \cdot 3,5+0,019 \cdot 500+8400 \cdot 0,000770+2,63 \cdot 1,4 \\
& \mathrm{~h}_{\text {min- verlA }}=11,1 \mathrm{~cm} \\
& \mathrm{~h}_{\text {min-verlB }}=-3,7-0,24 \cdot 7-0,95 \cdot 3,5+0,019 \cdot 500+8600 \cdot 0,000785+2,65 \cdot 1,4 \\
& \mathrm{~h}_{\text {min-verlB }}=11,3 \mathrm{~cm} \\
& \mathrm{~h}_{\min -\text { ver } 2}=-0,1-0,49 \cdot 7-1,48 \cdot 3,5+0,030 \cdot 500+1,42 \cdot 0,17+3,50 \cdot 1,4=11,4 \mathrm{~cm} \\
& \mathrm{~h}_{\text {min-ver3A }}=-4,2-0,33 \cdot 7-1,00 \cdot 3,5+0,021 \cdot 500+8850 \cdot 0,000770+2,93 \cdot 1,4 \\
& \mathrm{~h}_{\text {min-verlA }}=11,4 \mathrm{~cm} \\
& \mathrm{~h}_{\min -\mathrm{ver} 3 \mathrm{~B}}=-4,3-0,33 \cdot 7-1,05 \cdot 3,5+0,022 \cdot 500+8600 \cdot 0,000785+2,95 \cdot 1,4 \\
& \mathrm{~h}_{\text {min-verlB }}=11,6 \mathrm{~cm}
\end{aligned}
$$

Neste exemplo, pode-se notar que os resultados fornecidos pelas eqs. (3.3) e (3.6) foram bastante semelhantes. Embora a eq.(3.3) tenha sido obtida a partir de valores médios das relações menor vão - altura da laje, para as lajes armadas nas duas direções, os valores do coeficiente $\beta$ resultantes das eqs. (3.4) e (3.5) foram muito próximos dos valores obtidos com a análise não-linear. Esse comportamento, que pode ser observado da Figura 3.6 a Figura 3.9, é o que leva ao bom resultado da eq. (3.3) em comparação com o da eq. (3.6)

Adotando-se a altura mínima igual a $11 \mathrm{~cm}$, foi feita a análise da laje com o programa ANPAV, corrigindo-se carregamento em função dessa altura adotada. Os 
deslocamentos obtidos foram apresentados na Tabela 3.12. Já os limites dos deslocamentos para as verificações 1, 2 e 3, para o menor vão igual a 5,0 m, foram, respectivamente:

$$
\begin{aligned}
& \mathrm{a}_{\mathrm{t}, \mathrm{g}+\psi \mathrm{q}} \leq \frac{\ell}{250} \leq \frac{500}{250} \leq 2,0 \mathrm{~cm} \\
& \mathrm{a}_{\mathrm{i}, \mathrm{q}} \leq \frac{\ell}{350} \leq \frac{500}{350} \leq 1,43 \mathrm{~cm} \\
& \mathrm{a}_{\mathrm{inc}} \leq\left\{\begin{array}{l}
\frac{\ell}{250}=\frac{500}{250}=2,0 \mathrm{~cm} \\
1,0 \mathrm{~cm}
\end{array} \Rightarrow \mathrm{a}_{\text {inc }} \leq 1,0 \mathrm{~cm}\right.
\end{aligned}
$$

Tabela 3.12 - Deslocamentos da laje do exemplo 2, para $\mathrm{h}=11 \mathrm{~cm}($ ANPAV)

\begin{tabular}{|l|c|c|c|c|c|}
\hline \multirow{2}{*}{ Ações } & \multicolumn{4}{|c|}{ Deslocamentos (cm) } & $\begin{array}{c}\text { Relação entre os } \\
\text { desls. diferidos e } \\
\text { imediatos }\end{array}$ \\
\cline { 2 - 6 } & Imediatos & Totais & Diferidos & Incrementais & 2,16 \\
\hline Permanente & 0,31 & 0,98 & 0,67 & - & 2,18 \\
\hline Quase-permanente & 0,38 & 1,21 & 0,83 & 0,90 & 2,19 \\
\hline Freqüente & 0,42 & 1,34 & 0,92 & 1,03 & 2,24 \\
\hline Total & 0,59 & 1,91 & 1,32 & - & 2,32 \\
\hline Variável & 0,28 & 0,93 & 0,65 & - & \\
\hline
\end{tabular}

A altura mínima de $11 \mathrm{~cm}$ satisfez às verificações 1 e 2 , já que os deslocamentos totais devidos às combinações quase-permanente e freqüente foram menores que o limite de $2,0 \mathrm{~cm}$, e o deslocamento devido à ação variável foi menor que $1,43 \mathrm{~cm}$.

Já para a verificação 3A, o deslocamento incremental devido à combinação quasepermanente, igual a $0,90 \mathrm{~cm}$, também foi menor que o limite de $1,0 \mathrm{~cm}$. No entanto, para a verificação 3B, o deslocamento incremental de $1,03 \mathrm{~cm}$ foi um pouco maior que o limite de $1,0 \mathrm{~cm}$. Como a diferença foi pouco significativa, pode-se admitir que a altura de $11 \mathrm{~cm}$ satisfez a todas as verificações.

De qualquer forma, como para a verificação 3B a altura mínima obtida foide $11,6 \mathrm{~cm}$, tanto pela eq. (3.3), quanto pela eq. (3.6), esse valor poderia ter sido aproximado para $12 \mathrm{~cm}$, e, com certeza, essa verificação também estaria satisfeita.

As relações entre os deslocamentos diferidos e imediatos, obtidas a partir da análise não-linear, foram apresentadas na Tabela 3.12. Pela eq. (3.2), obteve-se: 


$$
\alpha_{\mathrm{f}, \mathrm{aj}}=3,7-0,36 \mathrm{f}_{\mathrm{ck}}-0,032 \mathrm{~h}=3,7-0,36 \cdot 3,5-0,032 \cdot 11=2,09
$$

Novamente, a relação entre os deslocamentos diferidos e imediatos obtida com a eq. (3.2), foi próxima das resultantes da análise não-linear.

Diante dos resultados desses exemplos, pode-se ter uma idéia da boa aproximação que os métodos simplificados propostos podem oferecer tanto para a determinação da altura mínima de lajes quanto para o cálculo de coeficientes multiplicadores dos deslocamentos imediatos. 


\section{DESLOCAMENTOS EM VIGAS ISOLADAS}

\subsection{INTRODUÇÃO}

Neste capítulo é apresentado o estudo dos deslocamentos de vigas, a partir de uma análise não-linear, novamente utilizando-se o programa ANPAV. Inicialmente, são apontados os modelos e as popriedades das vigas, bem como os principais parâmetros adotados para o cálculo desses deslocamentos. De acordo com os resultados obtidos, avaliase a influência da cada parâmetro na magnitude dos deslocamentos, comenta-se o comportamento dos deslocamentos diferidos e estuda-se um coeficiente multiplicador para os deslocamentos imediatos, e, por fim, propõe-se um critério para a determinação da altura mínima de vigas que verifica o estado limite de deformações excessivas.

\subsection{CARACTERÍSTICAS DAS VIGAS}

Os tipos de vigas que fizeram parte deste estudo, bem como suas propriedades geométricas e seus carregamentos são comentadas nos itens a seguir.

\subsubsection{TIPOS E PROPRIEDADES DAS VIGAS}

Foram estudados três tipos de vigas em concreto armado apoiadas em pilares: um vão (Figura 4.1a), dois vãos de comprimentos iguais (Figura 4.1b) e dois vãos de comprimentos diferentes (Figura 4.1c). O cobrimento adotado foi igual a $3,0 \mathrm{~cm}$. 


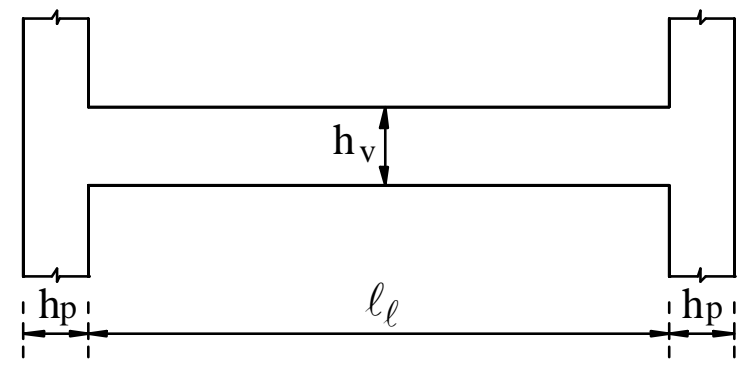

a) Esquema para viga com um único vão

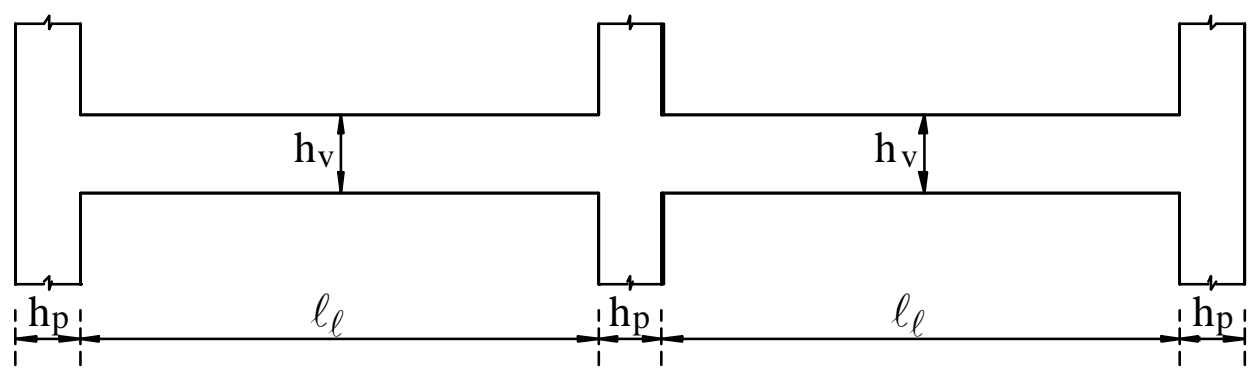

b) Esquema para viga com dois vãos de mesmo comprimento

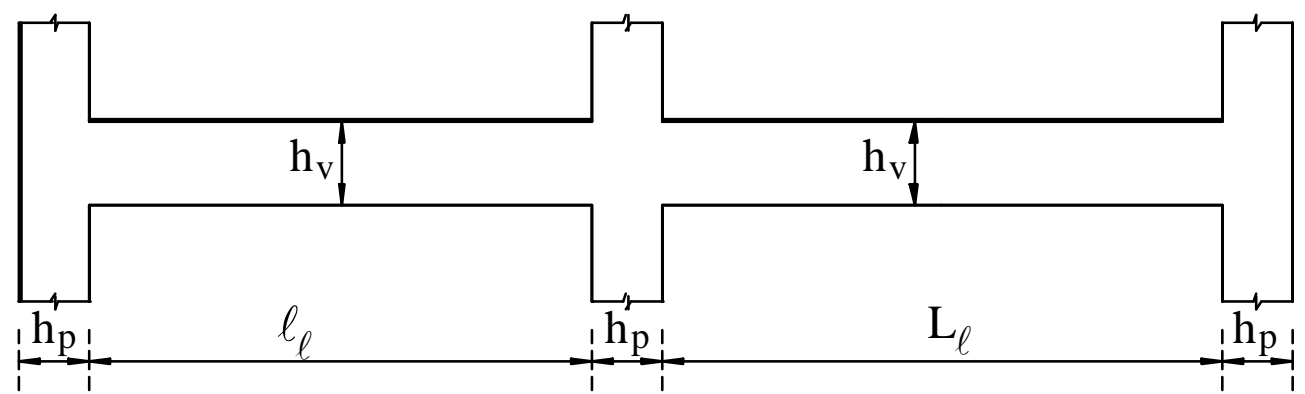

c) Esquema para viga com dois vãos de comprimentos diferentes

Figura 4.1 - Representação esquemática das vigas

Para abranger situações usuais em projetos estruturais, foram consideradas algumas variações nas propriedades geométricas das vigas. Com base nos esquemas representados na Figura 4.1, foram adotados:

- Largura da seção transversal da viga (b): 14 e 20 cm;

- Comprimentos dos vãos efetivos da viga $\left(\ell_{\mathbf{e f}}\right): 3,0 ; 5,0$ e 7,0 m;

- Dimensão da seção transversal do pilar, paralela ao eixo da viga $\left(\mathbf{h}_{\mathbf{p}}\right): 20,50,70$ e $100 \mathrm{~cm}$;

- Dimensão da seção transversal do pilar, perpendicular ao eixo da viga $\left(\mathbf{b}_{\mathbf{p}}\right): 20 \mathrm{~cm}$;

- Comprimento do pilar - pé direito - $\left(\ell_{\mathbf{p}}\right): 3,0 \mathrm{~m}$.

- Área da armadura de compressão (A' $\left.\mathbf{A}^{\prime}\right): 15 \%$ e $30 \%$ da área da armadura de tração $\left(\mathbf{A}_{\mathbf{S}}\right)$. 


\subsubsection{CARREGAMENTO DAS VIGAS}

Para considerar a influência da relação entre as ações permanentes e variáveis no valor dos deslocamentos, foram adotados os mesmos procedimentos utilizados no estudo das lajes do Capítulo 3.

Foram estudados três casos de carregamento, aqui também chamados de $\mathrm{C} 1, \mathrm{C} 2 \mathrm{e}$ C3. Para C1, a ação permanente e a ação variável corresponderam a $80 \%$ e $20 \%$ da ação total, respectivamente. Para $\mathrm{C} 2$, manteve-se ação total, e a ação variável foi tomada igual ao dobro da correspondente de $\mathrm{C} 1$. Já para $\mathrm{C} 3$, a ação permanente foi adotada igual à de $\mathrm{C} 1$, com a ação variável igual à de $\mathrm{C} 2$. Na Tabela 4.1, relações entre as ações de cada caso de carregamento são resumidas.

Tabela 4.1 - Relações entre as ações dos casos de carregamento

\begin{tabular}{|c|c|c|c|}
\hline $\begin{array}{c}\text { Relações entre } \\
\text { as ações }\end{array}$ & $\mathbf{C 1}$ & $\mathbf{C 2}$ & $\mathbf{C 3}$ \\
\hline$\frac{\mathbf{g}}{\mathbf{p}}$ & 0,80 & 0,60 & 0,67 \\
\hline$\frac{\mathbf{q}}{\mathbf{p}}$ & 0,20 & 0,40 & 0,33 \\
\hline$\underline{\mathbf{q}}$ & 0,25 & 0,67 & 0,50 \\
\hline
\end{tabular}

Para a composição da ação total atuante no carregamento 1, e a partir dela a dos demais carregamentos, foram utilizadas as seguintes parcelas de carregamento:

- peso próprio da viga;

- peso próprio de parede ou de qualquer outro elemento de vedação que possa estar apoiado sobre a viga igual a $5 \mathrm{kN} / \mathrm{m}$;

- reação de apoio de lajes:

Admitiu-se que as vigas apóiam faixas de lajes de 2,0 m de largura, como indicado na Figura 4.2, sendo a ação total atuante na laje igual a $10 \mathrm{kN} / \mathrm{m}^{2}$. Dessa forma, a reação adotada foi de $40 \mathrm{kN} / \mathrm{m}$.

Uma vez definida a ação total do caso de carregamento 1, as dos demais casos foram determinadas a partir das relações fornecidas na Tabela 4.1. Os valores finais para todos os casos de carregamento, para diversas as seções transversais de vigas, encontram-se na Tabela 4.2. 


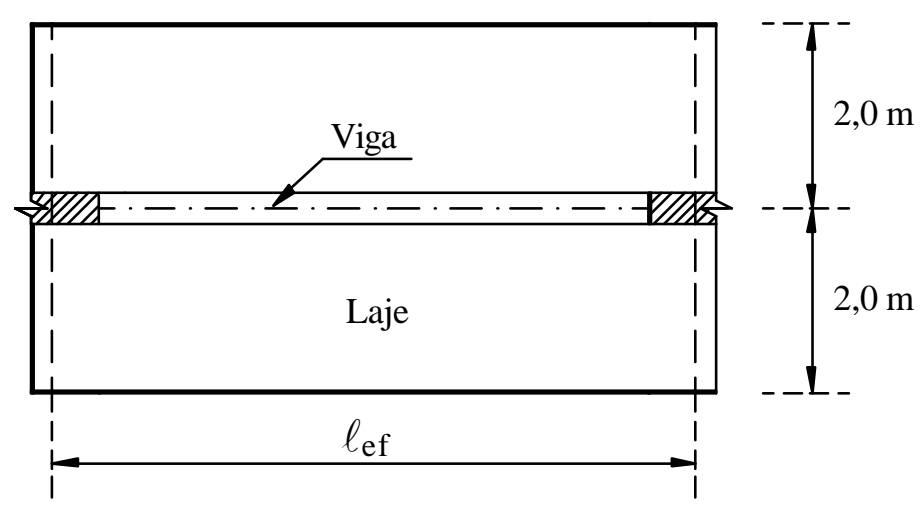

Figura 4.2 - Faixas de laje que se apóiam nas vigas

Tabela 4.2 - Valores das ações permanentes, variáveis e totais para os casos de carregamento

\begin{tabular}{|c|c|c|c|c|c|c|c|c|c|c|c|c|}
\hline \multirow{2}{*}{$\begin{array}{c}b_{\mathrm{v}} \\
(\mathrm{cm}) \\
\end{array}$} & \multirow{2}{*}{$\begin{array}{l}\mathbf{h}_{\mathrm{v}} \\
(\mathbf{c m})\end{array}$} & \multirow{2}{*}{$\begin{array}{c}\text { Peso } \\
\text { da viga } \\
(\mathrm{kN} / \mathrm{m})\end{array}$} & \multirow{2}{*}{$\begin{array}{c}\text { Peso } \\
\text { da parede } \\
(\mathrm{kN} / \mathrm{m})\end{array}$} & \multirow{2}{*}{$\begin{array}{c}\text { Reação } \\
\text { da laje } \\
(\mathrm{kN} / \mathrm{m})\end{array}$} & \multicolumn{5}{|c|}{$\begin{array}{c}\text { Carregamentos C } 1 \text { e C2 } \\
(\mathrm{kN} / \mathrm{m})\end{array}$} & \multicolumn{3}{|c|}{$\begin{array}{c}\text { Carregamento C3 } \\
(\mathrm{kN} / \mathrm{m})\end{array}$} \\
\hline & & & & & $p_{1}=p_{2}$ & $\mathrm{~g}_{1}$ & $q_{1}$ & $g_{2}$ & $q_{2}$ & $\mathbf{p}_{3}$ & $g_{3}$ & $q_{3}$ \\
\hline 14 & 25 & 0.875 & 5.0 & 40.0 & 45.88 & 36.70 & 9.18 & 27.53 & 18.35 & 55.05 & 36,70 & 18.35 \\
\hline 14 & 30 & 1,050 & 5,0 & 40,0 & 46,05 & 36,84 & 9.21 & 27.63 & 18.42 & 55.26 & 36,84 & 18.42 \\
\hline 14 & 35 & 1.225 & 5.0 & 40.0 & 46.23 & 36.98 & 9.25 & 27.74 & 18.49 & 55.47 & 36.98 & 18.49 \\
\hline 14 & 40 & 1.400 & 5,0 & 40,0 & 46.40 & 37.12 & 9.28 & 27.84 & 18.56 & 55.68 & 37,12 & 18.56 \\
\hline 14 & 45 & 1,575 & 5,0 & 40,0 & 46,58 & 37,26 & 9,32 & 27,95 & 18,63 & 55,89 & 37,26 & 18,63 \\
\hline 14 & 50 & 1.750 & 5.0 & 40,0 & 46.75 & 37.40 & 9.35 & 28.05 & 18.70 & 56,10 & 37.40 & 18.70 \\
\hline 14 & 55 & 1,925 & 5,0 & 40,0 & 46,93 & 37.54 & 9.39 & 28,16 & 18,77 & 56,31 & 37,54 & 18,77 \\
\hline 14 & 60 & 2,100 & 5,0 & 40,0 & 47.10 & 37.68 & 9,42 & 28,26 & 18,84 & 56.52 & 37.68 & 18,84 \\
\hline 14 & 65 & 2.275 & 5.0 & 40.0 & 47.28 & 37.82 & 9.46 & 28.37 & 18.91 & 56.73 & 37.82 & 18.91 \\
\hline 14 & 70 & 2.450 & 5.0 & 40,0 & 47.45 & 37.96 & 9.49 & 28.47 & 18.98 & 56.94 & 37.96 & 18.98 \\
\hline 14 & 75 & 2.625 & 50 & & 47.63 & 38.10 & 9.53 & 28.58 & 19.05 & 57.15 & 38.10 & 19.05 \\
\hline 14 & 80 & 2,800 & 5,0 & 40,0 & 47,80 & 38,24 & 9,56 & 28,68 & 19,12 & 57,36 & 38,24 & 19,12 \\
\hline 14 & 85 & 2,975 & 5,0 & 40,0 & 47,98 & 38,38 & 9,60 & 28,79 & 19,19 & 57,57 & 38,38 & 19,19 \\
\hline 14 & 90 & 3,150 & 5,0 & 40,0 & 48,15 & 38.52 & 9.63 & 28,89 & 19.26 & 57.78 & 38,52 & 19.26 \\
\hline 14 & 95 & 3,325 & 5,0 & 40,0 & 48.33 & 38.66 & 9.67 & 29.00 & 19.33 & 57.99 & 38,66 & 19.33 \\
\hline 14 & 100 & 3.500 & 5,0 & 40,0 & 48.50 & 38.80 & 9.70 & 29.10 & 19.40 & 58.20 & 38.80 & 19.40 \\
\hline 20 & 25 & 1,250 & 5,1 & 40,0 & 46,25 & 37.00 & 9.25 & 27.75 & 18,50 & 55,50 & 37,00 & 18,50 \\
\hline 20 & 30 & 1,500 & 5,0 & 40,0 & 46.50 & 37.20 & 9.30 & 27.90 & 18.60 & 55.80 & 37.20 & 18,60 \\
\hline 20 & 35 & 1.750 & 5.0 & 40.0 & 46.75 & 37.40 & 9.35 & 28.05 & 18.70 & 56.10 & 37.40 & 18.70 \\
\hline 20 & 40 & 2,000 & 5,0 & 40,0 & 47,00 & 37,60 & 9,40 & 28,20 & 18,80 & 56,40 & 37,60 & 18,80 \\
\hline 20 & 45 & 2.250 & 5,0 & 40.0 & 47.25 & 37.80 & 9.45 & 28.35 & 18.90 & 56,70 & 37.80 & 18.90 \\
\hline 20 & 50 & 2,500 & 5,0 & 40,0 & 47.50 & 38,00 & 9,50 & 28,50 & 19.00 & 57.00 & 38,00 & 19.00 \\
\hline 20 & 55 & 2,750 & 5,0 & 40,0 & 47.75 & 38.20 & 9.55 & 28,65 & 19.10 & 57,30 & 38,20 & 19,10 \\
\hline 20 & 60 & 3,000 & 5,0 & 40,0 & 48.00 & 38.40 & 9.60 & 28.80 & 19.20 & 57.60 & 38,40 & 19.20 \\
\hline 20 & 65 & 3,250 & 5.0 & 40,0 & 48.25 & 38.60 & 9.65 & 28.95 & 19.30 & 57.90 & 38,60 & 19.30 \\
\hline 20 & 70 & 3,500 & 5. & 40,0 & 48.50 & 38.80 & 9,70 & 29.10 & 19.40 & 58.20 & 38,80 & 19,40 \\
\hline 20 & 75 & 3.750 & 5. & & 48.75 & 39.00 & 9.75 & 29,25 & 19.50 & 58.50 & 39,00 & 19.50 \\
\hline 20 & 80 & 4,000 & 5, & & 49,00 & 39,20 & 9,80 & 29,40 & 19,60 & 58,80 & 39,20 & 19,60 \\
\hline 20 & 85 & 4,250 & 5. & & 49.25 & 39.40 & 9.85 & 29.55 & 19.70 & 59.10 & 39.40 & 19.70 \\
\hline 20 & 90 & 4,500 & 5,0 & 40,0 & 49.50 & 39.60 & 9.90 & 29.70 & 19.80 & 59.40 & 39,60 & 19.80 \\
\hline 20 & 95 & 4,750 & 5,0 & 40,0 & 49,75 & 39.80 & 9.95 & 29.85 & 19.90 & 59,70 & 39,80 & 19,90 \\
\hline 20 & 100 & 5,000 & 5,0 & 40,0 & 50,00 & 40,00 & 10,00 & 30,00 & 20,00 & 60,00 & 40,00 & 20,00 \\
\hline
\end{tabular}




\subsection{PARÂMETROS ADOTADOS}

Procurou-se adotar os mesmos parâmetros de cálculo utilizados no estudo das lajes, os quais são reapresentados resumidamente a seguir.

\subsubsection{COMBINAÇÕES DE AÇÕES}

Como comentado no item 3.3.1 do capítulo 3, foram utilizadas, considerando-se edifícios residenciais:

- a combinação de ações quase permanente, para a qual vale:

$$
\mathrm{F}_{\mathrm{d}, \mathrm{ser}}=\mathrm{F}_{\mathrm{gk}}+0,3 \mathrm{~F}_{\mathrm{qk}}
$$

- a combinação freqüente de ações, para a qual tem-se:

$$
\mathrm{F}_{\mathrm{d}, \mathrm{ser}}=\mathrm{F}_{\mathrm{gk}}+0,4 \mathrm{~F}_{\mathrm{qk}}
$$

\subsubsection{MATERIAIS}

Foram utilizados aço CA-50 e concreto com coeficiente de Poisson igual a 0,20 e resistência característica à compressão de 25 e $35 \mathrm{MPa}$.

\subsubsection{CONDIÇÕES AMBIENTAIS}

Para a determinação dos deslocamentos diferidos no tempo, considerou-se a umidade relativa média igual a $60 \%$ e a temperatura média de $25^{\circ} \mathrm{C}$.

\subsubsection{IDADE DE APLICAÇÃO DAS AÇÕES}

A idade de aplicação das ações foi tomada igual a 28 dias para as ações permanentes, e a 45 dias para as ações variáveis.

\subsection{CÁLCULO E VERIFICAÇÃO DOS DESLOCAMENTOS}

Para a realização da análise não-linear das vigas, utilizando-se o programa ANPAV, foi necessário o conhecimento prévio de suas armaduras e a sua discretização em elementos finitos, assim como foi feito para as lajes. 


\subsubsection{DISCRETIZAÇÃO}

As vigas foram consideradas apoiadas em pilares com tramos inferiores e superiores engastados nas extremidades, e seus vãos foram divididos em vinte elementos. Para vigas de um vão, esse esquema é ilustrado na Figura 4.3.

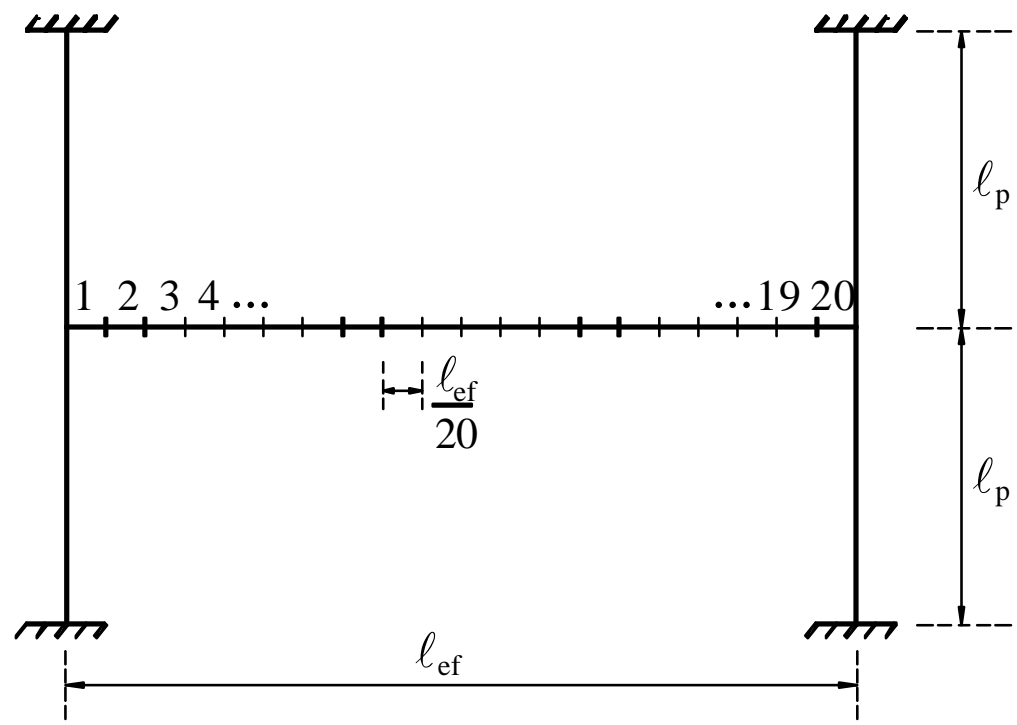

Figura 4.3 - Discretização de uma viga de um vão

\subsubsection{DETERMINAÇÃO DAS ARMADURAS}

Inicialmente, assim como para as lajes, os esforços solicitantes de cada viga foram determinados a partir de uma análise elástica. E as áreas de aço foram determinadas de acordo com as recomendações da NBR 6118 (2003), respeitando-se as armaduras mínimas por ela definida.

\subsubsection{VALORES DOS DESLOCAMENTOS}

O procedimento adotado no cálculo dos deslocamentos das vigas foi igual ao das lajes. Primeiramente, para a determinação dos deslocamentos imediatos, as vigas foram analisadas sem a consideração dos efeitos do tempo. Em seguida, tal efeito foi levado em conta para a obtenção dos deslocamentos totais.

Para cada viga, os deslocamentos foram calculados, a princípio, para a altura mínima necessária para resistir à flexão, e, comparados com os valores limites impostos pela NBR 6118 (2003), de acordo com as verificações apresentadas no item 3.4.3 do Capítulo 3. Quando tais verificações não eram satisfeitas, uma nova altura era adotada, e os 
deslocamentos eram novamente calculados e verificados. Este procedimento foi repetido até a obtenção de uma altura para a qual os deslocamentos fossem menores que os limites da NBR 6118 (2003). Foram utilizados valores de alturas múltiplos de $5 \mathrm{~cm}$.

\subsection{ANÁLISE DOS RESULTADOS}

A partir da análise dos resultados obtidos, pode-se avaliar a influência de alguns parâmetros no valor dos deslocamentos e desenvolver uma proposta para a determinação de uma altura mínima para vigas que satisfaz o estado limite de deformações excessivas.

\subsubsection{INFLUÊNCIA DOS PARÂMETROS DE CÁLCULO}

A seguir, comenta-se como cada um dos parâmetros envolvidos no cálculo dos deslocamentos afeta seus valores finais.

\section{a) Dimensão dos Pilares}

Para iniciar a análise da influência da dimensão dos pilares nos deslocamentos, foram tomadas vigas com vão de 3,0 m, largura igual a $14 \mathrm{~cm}$ e altura igual à altura mínima requerida pela flexão. Os pilares de apoio tinham seções transversais de $20 \times 20 \mathrm{~cm}$. Com essas propriedades, os deslocamentos foram calculados para os três casos de carregamento e verificados, como comentado anteriormente, ncrementando-se os valores das alturas das vigas até a obtenção de um valor para o qual as verificações dos deslocamentos fossem satisfeitas. Em seguida, esse procedimento foi repetido, mantendo-se as características geométricas das vigas, alterando-se apenas os valores da dimensão do pilar na direção do eixo da viga, aqui chamada de altura da seção transversal do pilar. Feito isto, todo o processo foi reiniciado considerando dessa vez vigas com largura de $20 \mathrm{~cm}$. A metodologia foi ainda repetida para as vigas com vãos de 5 e $7 \mathrm{~m}$. Vale ressaltar que, para esta análise foram utilizadas somente vigas com um vão.

A partir da avaliação dos resultados obtidos, pode-se constatar que as vigas, independente do vão, apresentaram, aproximadamente, o mesmo percentual de redução dos deslocamentos com o aumento da seção do pilar, para todos os casos de carregamento considerados. Analisando-se separadamente cada tipo de deslocamento; imediatos, diferidos, totais e incrementais; nota-se que houve uma pequena diferença neste percentual. A redução dos deslocamentos imediatos foi um pouco superior à dos deslocamentos totais, assim como a redução destes foi um pouco superior a dos deslocamentos diferidos e incrementais Esses 
últimos tiveram, praticamente, o mesmo percentual de redução. Uma observação direta desses resultados pode ser feita a partir de gráficos como o da Figura 4.4, que apresenta a redução média dos deslocamentos, para uma viga de 7,0 m de vão, e seção transversal de $14 \times 70 \mathrm{~cm}$, com base nos deslocamentos obtidos para o pilar de seção transversal inicial de $20 \times 20 \mathrm{~cm}$.

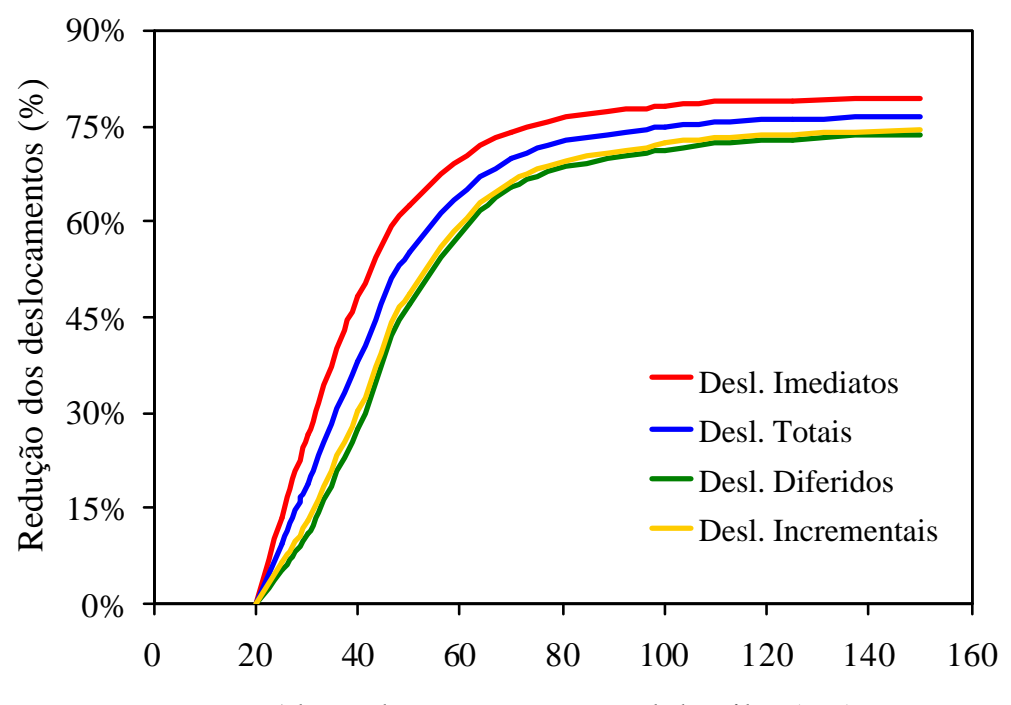

Altura da seção transversal do pilar (cm)

Figura 4.4 - Redução dos deslocamentos em função do aumento da seção transversal do pilar

Pode-se observar que, à medida que se aumentou a altura da seção transversal dos pilares, os deslocamentos sofreram um decréscimo significativo até certo valor de altura da seção transversal do pilar, a partir da qual os deslocamentos praticamente não se alteraram. O valor dessa dimensão limite variou em função das dimensões das vigas, como mostrado nas Figura 4.5, Figura 4.6 e Figura 4.7. Pode-se observar que, para vigas com vão de 3,0 m e seção transversal de $14 \times 30 \mathrm{~cm}$, a dimensão limite do pilar foi $40 \mathrm{~cm}$ (Figura 4.5). Para vigas com vão de 5,0 m e seção transversal de $14 \times 50 \mathrm{~cm}$, esse limite foi de $55 \mathrm{~cm}$. Já para as vigas com vão de 7,0 m e seção transversal de $14 \times 70 \mathrm{~cm}$, encontrou-se $70 \mathrm{~cm}$. Vale ressaltar que esses valores foram praticamente iguais para todos os carregamentos estudados. 


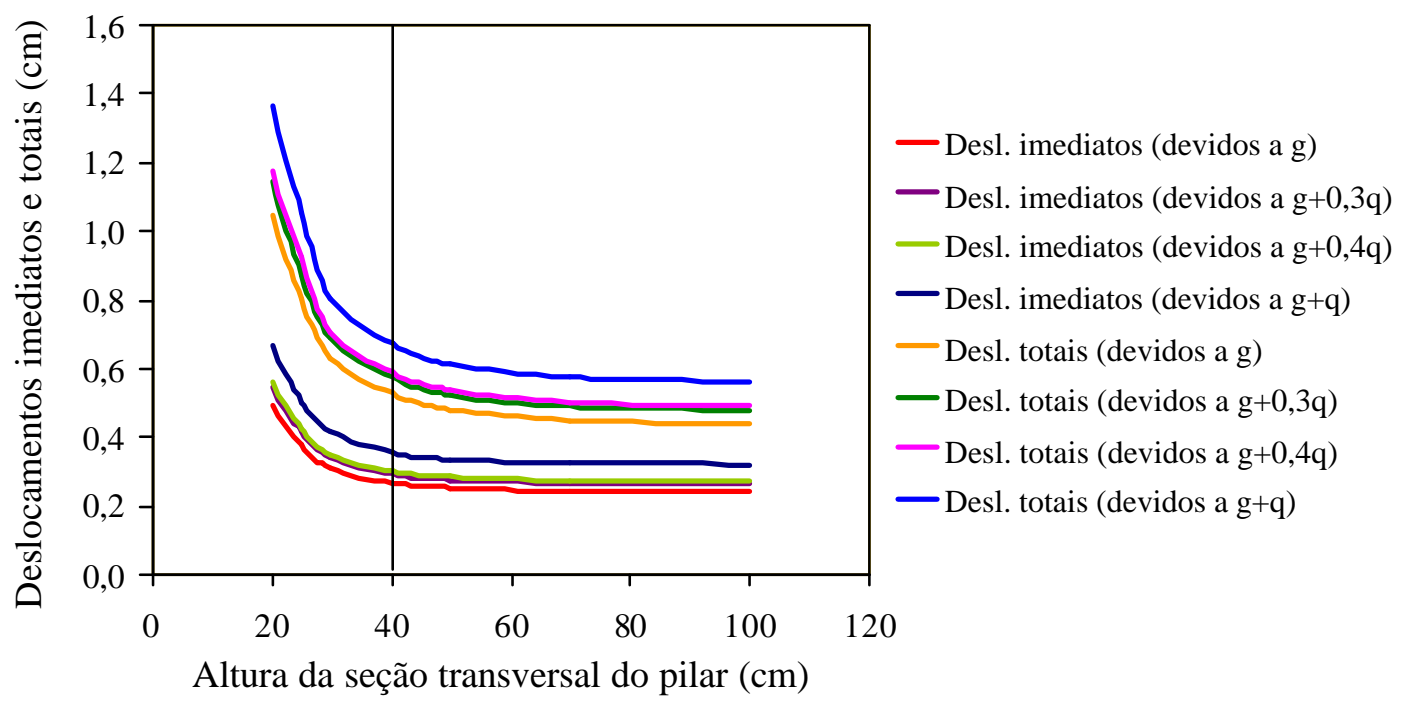

Figura 4.5 - Valores dos deslocamentos em função da altura da seção transversal do pilar $\left(\ell_{\text {viga }}=3,0 \mathrm{~m}\right.$ e seção transversal de $\left.14 \times 30 \mathrm{~cm}\right)$

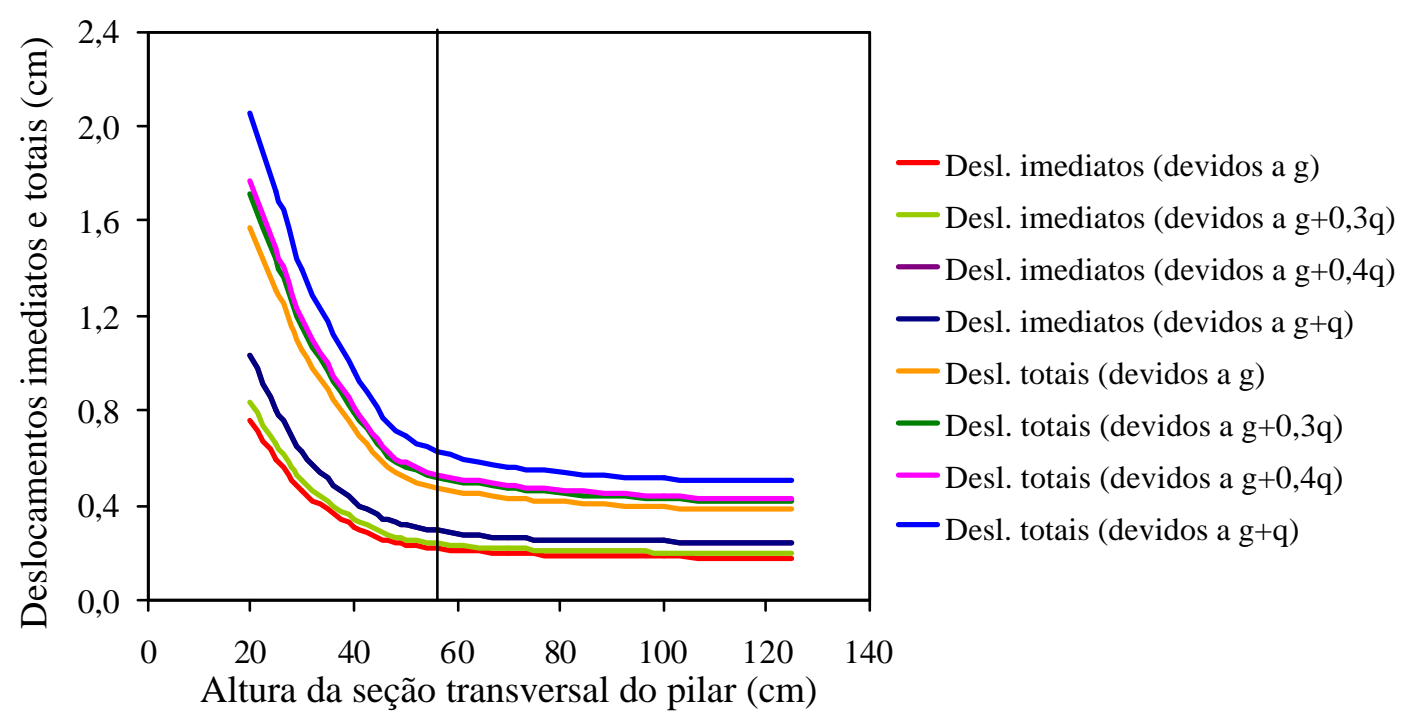

Figura 4.6 - Valores dos deslocamentos em função da altura da seção transversal do pilar

$$
\left(\ell_{\text {viga }}=5,0 \mathrm{~m} \text { e seção transversal de } 14 \times 50 \mathrm{~cm}\right)
$$




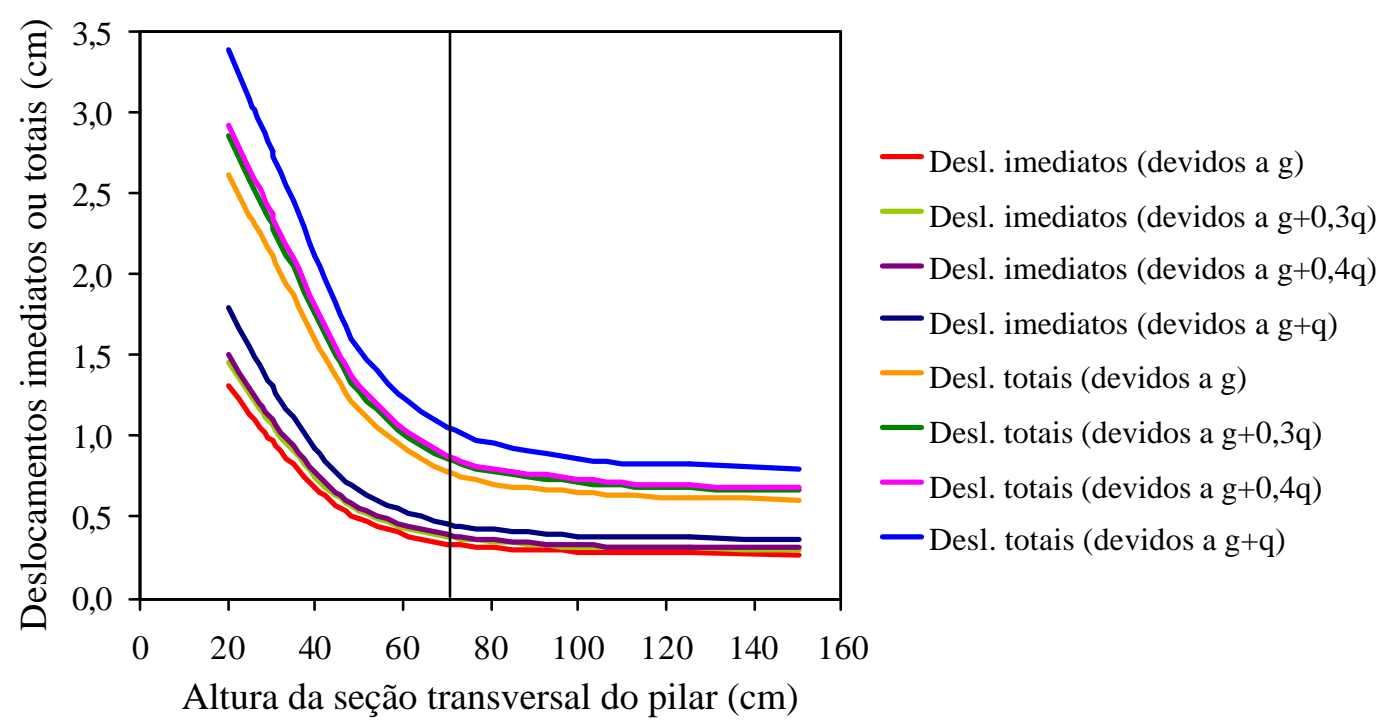

Figura 4.7 - Valores dos deslocamentos em função da altura da seção transversal do pilar

$$
\left(\ell_{\text {viga }}=7,0 \mathrm{~m} \text { e seção transversal de } 14 \times 70 \mathrm{~cm}\right)
$$

Para essas vigas, tomando-se as dimensões limites dos pilares, têm-se:

- Para a viga com vão de $3,0 \mathrm{~m}$ :

$$
\begin{aligned}
& \mathrm{R}_{\mathrm{v}}=\frac{\mathrm{I}_{\mathrm{v}}}{\ell_{\mathrm{v}}}=\frac{\frac{14 \cdot 30^{3}}{12}}{300}=105 \mathrm{~cm}^{3} \\
& \mathrm{R}_{\mathrm{p}}=\frac{\mathrm{I}_{\mathrm{p}}}{\ell_{\mathrm{p}}}=\frac{\frac{20 \cdot 40^{3}}{12}}{300}=356 \mathrm{~cm}^{3} \\
& \frac{\mathrm{R}_{\mathrm{v}}}{\mathrm{R}_{\mathrm{p}}}=\frac{105}{356}=0,29
\end{aligned}
$$

- Para a viga com vão de 5,0 m:

$$
\begin{aligned}
& \mathrm{R}_{\mathrm{v}}=\frac{\mathrm{I}_{\mathrm{v}}}{\ell_{\mathrm{v}}}=\frac{\frac{14 \cdot 50^{3}}{12}}{500}=292 \mathrm{~cm}^{3} \\
& \mathrm{R}_{\mathrm{p}}=\frac{\mathrm{I}_{\mathrm{p}}}{\ell_{\mathrm{p}}}=\frac{\frac{20 \cdot 55^{3}}{12}}{300}=924 \mathrm{~cm}^{3} \\
& \frac{\mathrm{R}_{\mathrm{v}}}{\mathrm{R}_{\mathrm{p}}}=\frac{292}{924}=0,32
\end{aligned}
$$


- Para a viga com vão de $7,0 \mathrm{~m}$ :

$$
\begin{aligned}
& \mathrm{R}_{\mathrm{v}}=\frac{\mathrm{I}_{\mathrm{v}}}{\ell_{\mathrm{v}}}=\frac{\frac{14 \cdot 70^{3}}{12}}{700}=572 \mathrm{~cm}^{3} \\
& \mathrm{R}_{\mathrm{p}}=\frac{\mathrm{I}_{\mathrm{p}}}{\ell_{\mathrm{p}}}=\frac{\frac{20 \cdot 70^{3}}{12}}{300}=1906 \mathrm{~cm}^{3} \\
& \frac{\mathrm{R}_{\mathrm{v}}}{\mathrm{R}_{\mathrm{p}}}=\frac{572}{1906}=0,30
\end{aligned}
$$

nas quais:

$\mathbf{R}_{\mathbf{v}} \quad$ é a rigidez da viga, dada pela razão entre o momento de inércia da viga e seu vão efetivo,

I é o momento de inércia da seção bruta de concreto da viga,

$\ell_{\mathbf{v}} \quad$ é o vão da viga.

$\mathbf{R}_{\mathbf{p}} \quad$ é a rigidez do pilar, dada pela razão entre o momento de inércia do pilar e seu comprimento,

I é o momento de inércia da seção bruta de concreto do pilar,

$\ell_{\mathbf{p}} \quad$ é o comprimento do pilar.

Desta forma, pode-se perceber que as vigas que apresentaram relação entre sua rigidez e a rigidez dos seus pilares de apoio da ordem de 0,30, o aumento da dimensão do pilar na direção do eixo da viga não leva a redução significativa dos deslocamentos das vigas.

Embora os resultados apresentados tenham sido de vigas com a largura da seção transversal igual a $14 \mathrm{~cm}$, o mesmo comportamento foi observado para as vigas com a largura de $20 \mathrm{~cm}$.

\section{b) Aumento da Largura da Viga}

O aumento da largura da viga de 14 para $20 \mathrm{~cm}$, mantidas constantes as demais propriedades geométricas, também levou a uma redução dos deslocamentos. Essa redução variou, principalmente, em função do tipo do deslocamento, da altura da viga e da resistência característica do concreto a compressão, $\mathbf{f}_{\text {ck }}$, como pode ser visto na Figura 4.8. Os casos de carregamento e os vãos adotados tiveram pouca influência sobre esse resultado. 


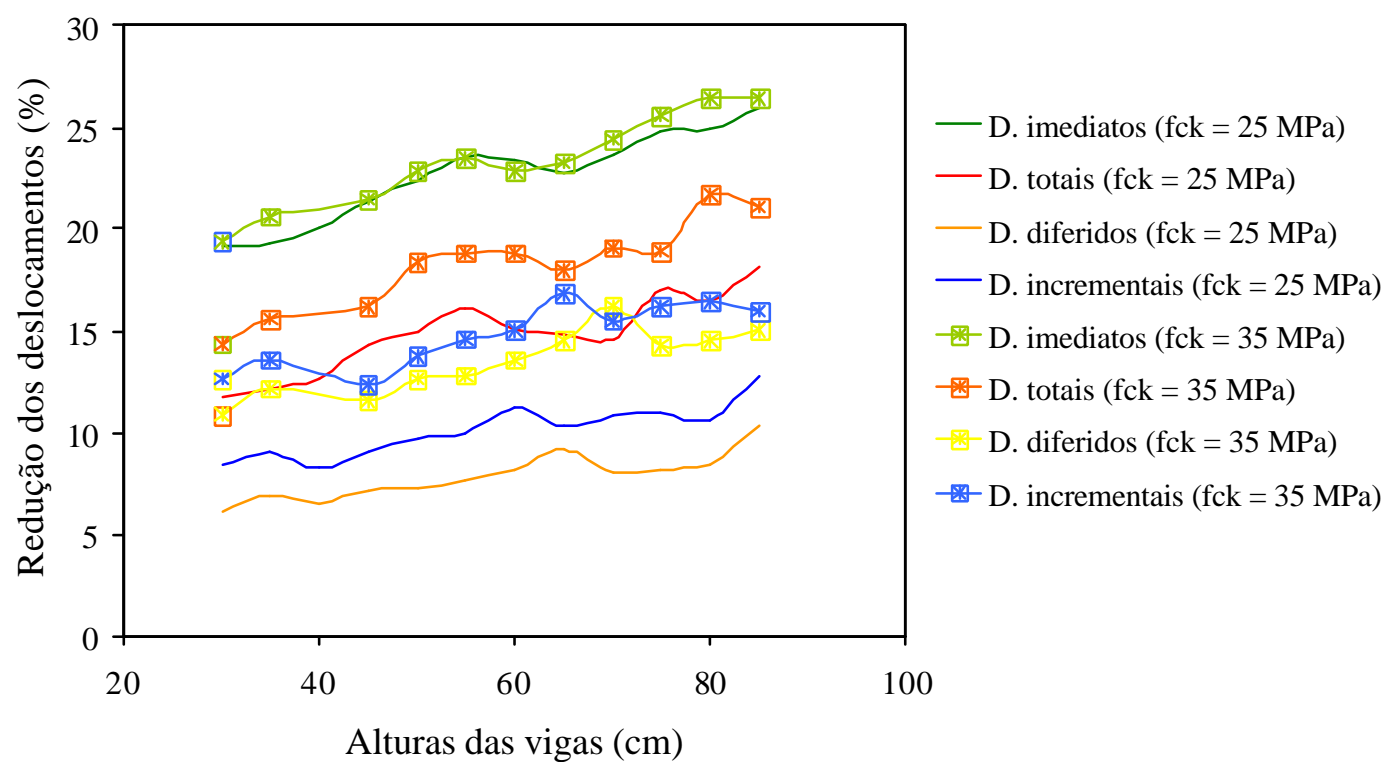

Figura 4.8 - Redução dos deslocamentos devido ao aumento da largura da viga

Pode-se observar que os deslocamentos imediatos sofreram as maiores reduções, tanto para o $\mathbf{f}_{\mathbf{c k}}$ de $25 \mathrm{MPa}$ quanto para o de $35 \mathrm{MPa}$. As reduções encontradas nos dois casos apresentaram valores bastante próximos, sendo que para o $\mathbf{f}_{\text {ck }}$ de $35 \mathrm{MPa}$, as reduções foram, em média, 4,5\% superiores.

Para o $\mathbf{f}_{\text {ck }}$ de $25 \mathrm{MPa}$, comparando-se as reduções dos deslocamentos imediatos com as reduções que ocorreram nos demais tipos de deslocamentos, constatou-se que estas últimas foram $35 \%, 55 \%$ e $65 \%$ menores que as primeiras, para os deslocamentos totais, incrementais e diferidos, respectivamente.

Já para o $\mathbf{f}_{\text {ck }}$ de $35 \mathrm{MPa}$, as reduções dos deslocamentos totais, incrementais e diferidos foram $22 \%, 37 \%$ e $43 \%$, respectivamente, menores que a dos deslocamentos imediatos. Portanto, superiores às do $\mathbf{f}_{\mathrm{ck}}$ de $25 \mathrm{MPa}$. Entretanto, este fato pode estar sendo influenciado, também, pelo efeito do aumento do $\mathbf{f}_{\text {ck }}$, que leva ao decréscimo dos deslocamentos diferidos e, conseqüentemente, à diminuição dos deslocamentos totais e incrementais.

\section{c) Armadura de Compressão}

Para a avaliação da influência da armadura de compressão, as vigas foram analisadas em três situações: só com a armadura de tração; com armadura de compressão correspondente a 15\% da armadura de tração; e com armadura de compressão correspondente a $30 \%$ da armadura de tração. 
Comparando-se os resultados obtidos, observou-se que as reduções dos deslocamentos não variaram em função dos casos de carregamento considerados, apresentando diferenças de no máximo 1\%. A mesma conclusão pode ser obtida variando-se o vão e a largura da viga. A altura da viga também exerceu pequena influência, como se nota pelas retas praticamente horizontais mostradas da Figura 4.9 a Figura 4.12. Nesses gráficos são apresentadas as reduções dos deslocamentos quando se compara valores obtidos com armadura de compressão, $15 \%$ ou $30 \%$ da armadura de tração, com casos para os quais existia apenas armadura de tração $\mathrm{A}_{\mathrm{s}}$.

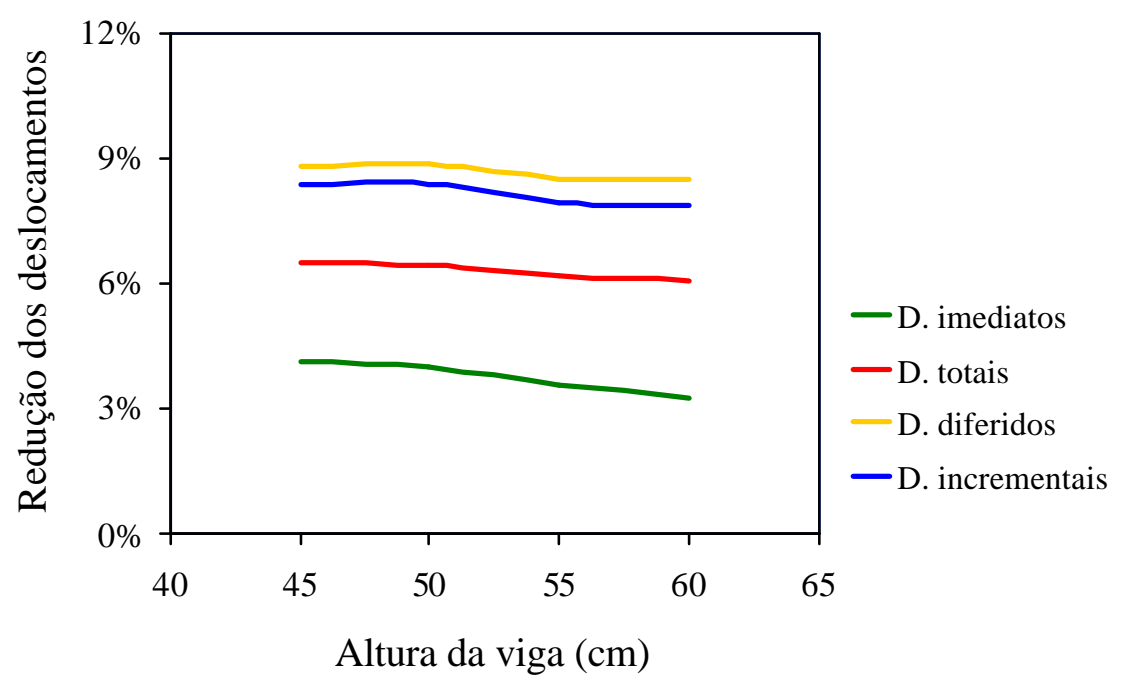

Figura 4.9 - Redução dos deslocamentos para a armadura de compressão igual a $15 \%$ de $\mathrm{A}_{\mathrm{s}}$ $\left(\mathrm{f}_{\mathrm{ck}}=25 \mathrm{MPa}\right)$

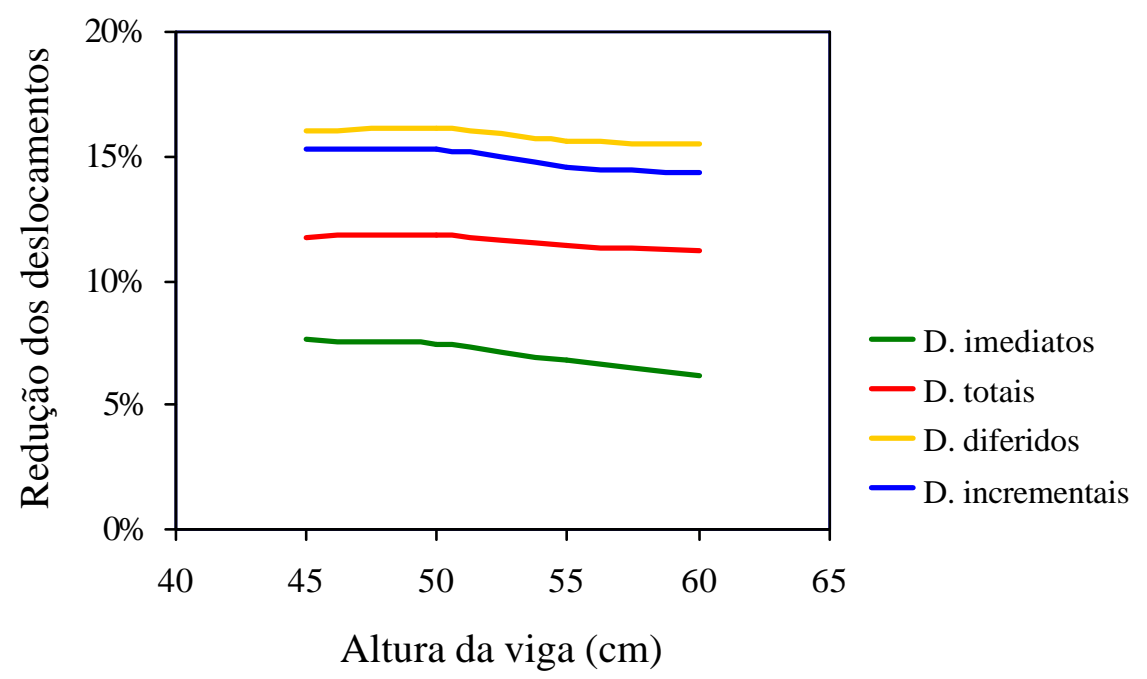

Figura 4.10 - Redução dos deslocamentos para a armadura de compressão igual $30 \%$ de $\mathrm{A}_{s}$

$$
\left(\mathrm{f}_{\mathrm{ck}}=25 \mathrm{MPa}\right)
$$




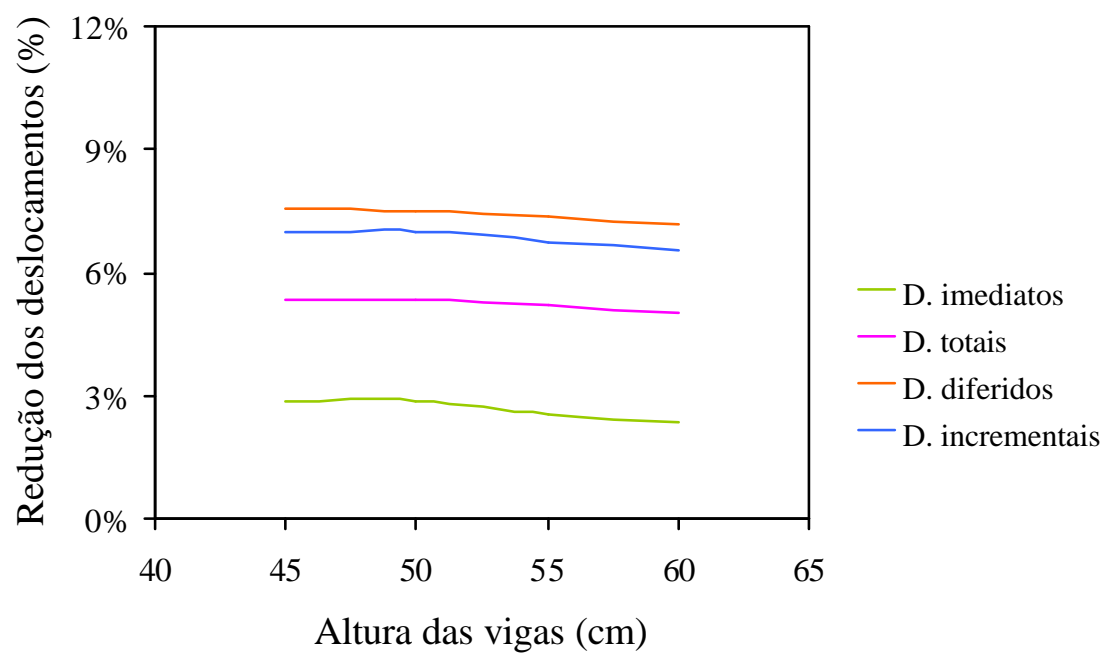

Figura 4.11 - Redução dos deslocamentos devido à armadura de compressão igual a 15\% de $\mathrm{A}_{\mathrm{s}}\left(\mathrm{f}_{\mathrm{ck}}=35 \mathrm{MPa}\right)$

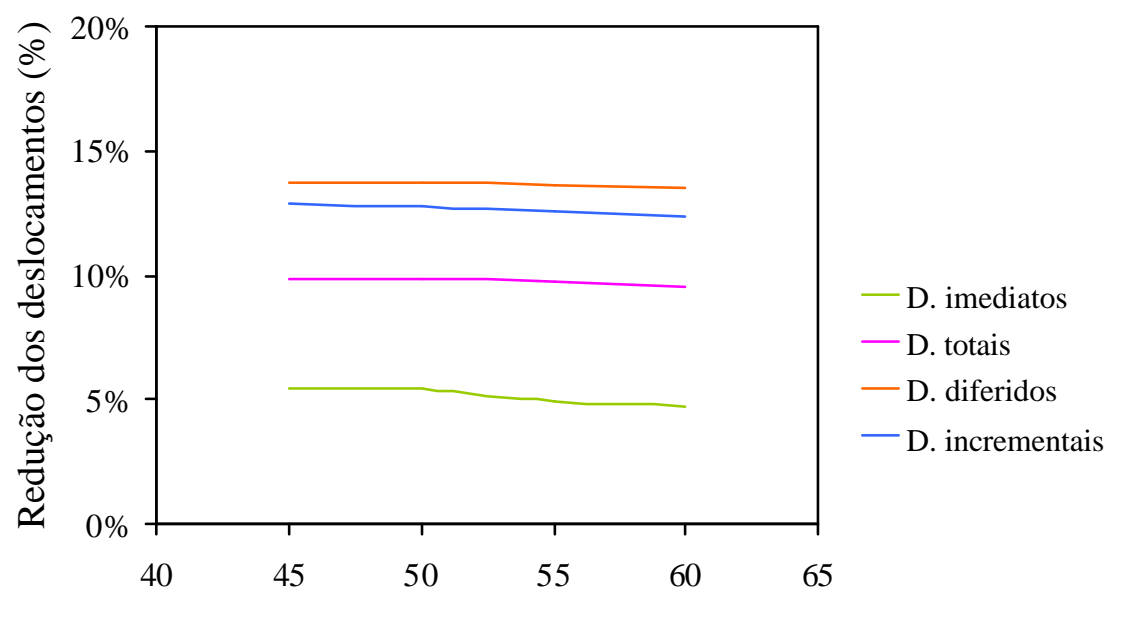

Altura das vigas $(\mathrm{cm})$

Figura 4.12 - Redução dos deslocamentos devido à armadura de compressão igual a 30\% de

$$
\mathrm{A}_{\mathrm{s}}\left(\mathrm{f}_{\mathrm{ck}}=35 \mathrm{MPa}\right)
$$

Pode-se constatar que os deslocamentos diferidos foram os que apresentaram os maiores decréscimos, já que a armadura de compressão colabora na diminuição da curvatura causada pela retração, como exposto no item 2.2.3 do capítulo 2. Estes deslocamentos sofreram uma redução média de aproximadamente 9 e $16 \%$, para o $\mathbf{f}_{\text {ck }}$ de $25 \mathrm{MPa}$, e de $8 \%$ e $14 \%$, para o $\mathbf{f}_{\text {ck }}$ de $35 \mathrm{MPa}$, considerando-se armaduras de compressão iguais a $15 \%$ e $30 \%$ da armadura de tração, respectivamente. 
Pode-se notar, também, que para as vigas com $\mathbf{f}_{\mathbf{c k}}$ de $35 \mathrm{MPa}$, as reduções de todos os deslocamentos foram inferiores às do $\mathbf{f}_{\mathrm{ck}}$ de $25 \mathrm{MPa}$. Portanto, confirma-se a conclusão de PAULSON et al. (1991), que observaram, a partir de dados experimentais, que para resistências mais altas, a influência da armadura de compressão na redução dos deslocamentos não é tão efetiva como para resistência mais baixas, conforme comentado no item 2.3.3.c do capítulo 2.

\section{d) Resistência Característica do Concreto à Compressão}

Para as vigas, a magnitude da redução dos deslocamentos devido ao aumento da resistência característica do concreto à compressão, $\mathbf{f}_{\text {ck }}$, variou em função do tipo de deslocamento e da rigidez dos pilares de apoio. Observou-se que para pilares de apoio com alturas da seção transversal menores que a altura limite, comentada no item 4.5.1.a, ou seja, para relações entre a rigidez da viga e rigidez do pilar maiores que 0,30 , a redução média foi de $21 \%$ para os deslocamentos imediatos, de $25 \%$ para os deslocamentos totais e de $27 \%$ para os deslocamentos diferidos e incrementais.

No caso pilares de apoio com alturas de seção transversal maiores que altura limite, ou seja, para relações entre as rigidezes da viga e do pilar menores que 0,30 , a redução dos deslocamentos foi um pouco inferior, sendo de $18 \%$ para os deslocamentos imediatos, de $22 \%$ para os totais, e de $24 \%$ para os diferidos e incrementais.

Vale lembrar que, conforme comentado no item 4.5.1.a, chama-se de altura limite aquela a partir da qual a redução dos deslocamentos com o aumento desta dimensão do pilar praticamente não se altera.

\section{e) Casos de Carregamento}

Analisando-se os deslocamentos devidos aos casos de carregamento adotados, observou-se que a diferença entre eles só apresentou variação significativa com relação à combinação de ações à qual a viga está submetida, não sendo, portanto, influenciada pelas propriedades das vigas e dos materiais.

Foram comparados, inicialmente, os deslocamentos devidos a $\mathrm{C} 1$ e $\mathrm{C} 2$, lembrandose que para ambos a ação total $\mathbf{p}$ tem o mesmo valor e que as ações permanentes $\mathbf{g}$ correspondem a $80 \%$ e $60 \%$ de p, respectivamente. Observou-se que os deslocamentos imediatos, totais e diferidos causados pelas ações permanentes, combinações quasepermanente e freqüente de ações de C2 foram, em média, 31\%, 20\% e 18\% menores que os de $\mathrm{C} 1$, respectivamente, embora as relações entre essas ações, para esses casos de 
carregamento, sejam de $25 \%, 16 \%$ e $14 \%$. Percebe-se, portanto, que a redução dos deslocamentos foi um pouco maior que a redução das ações nos carregamentos.

A seguir foram analisados os carregamentos $\mathrm{C} 1$ e $\mathrm{C} 3$, nos quais as ações permanentes $\mathbf{g}$ eram iguais e as ações variáveis $\mathbf{q}$ e totais $\mathbf{p}$ de $\mathrm{C} 3$ eram $100 \%$ e $20 \%$ maiores que as de $\mathrm{C} 1$, respectivamente. Percebeu-se que os deslocamentos apresentaram uma pequena diferença entre si, sendo os deslocamentos de $\mathrm{C} 1$ em torno de $7 \%$ menores que os respectivos de C3. Nota-se que, apesar das ações variáveis terem dobrado de valor para C3, os deslocamentos não sofreram uma variação muito significativa.

Por fim, comparam-se os carregamentos C2 e C3, para os quais as ações variáveis $\mathbf{q}$ eram iguais e as ações permanentes $\mathbf{g}$ e totais $\mathbf{p}$ de $\mathrm{C} 3$ eram $33 \%$ e $20 \%$ maiores que as de $\mathrm{C} 2$, respectivamente. Notou-se que os deslocamentos devidos a C2 foram menores que os devidos a C3, como esperado, mas essa redução apresentou diferenças entre os tipos de deslocamentos e ações atuantes. Os deslocamentos imediatos devidos a C2 apresentaram reduções maiores que as dos deslocamentos totais e diferidos. Para as ações permanentes, combinações quase-permanente e freqüente de ações, as reduções médias foram, respectivamente, $39 \%, 31 \%$ e $28 \%$ para os deslocamentos imediatos; $31 \%$, $22 \%$ e $20 \%$ para os deslocamentos totais; e $24 \%, 15 \%$ e $13 \%$ para os deslocamentos diferidos.

Percebeu-se, como esperado, que os deslocamentos são mais influenciados por mudanças nas ações permanentes que nas ações variáveis.

\section{f) Vãos Adjacentes}

Comparou-se os deslocamentos do maior vão das vigas com dois vãos, iguais ou não, com aqueles das vigas com um vão e pilares de apoio com seção transversal de $20 \times 20 \mathrm{~cm}$, observou-se que houve uma redução dos deslocamentos com a presença do vão adjacente, maior ou menor, em função da relação entre o maior e o menor vão das vigas e do tipo de deslocamento, como pode ser visto na Figura 4.13. O decréscimo dos deslocamentos foi máximo para relação entre os vãos igual a um, e para relações maiores que 1,50, seu valor sofreu alterações muito pouco significativas. 


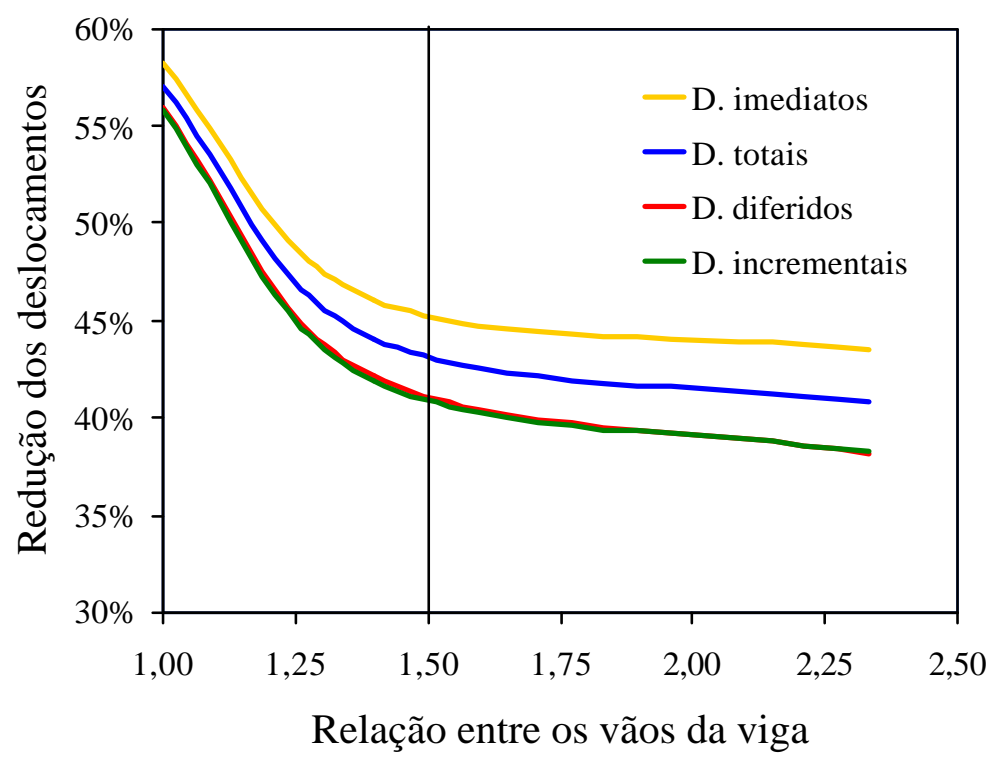

Figura 4.13 - Redução dos deslocamentos em função da relação entre o maior e o menor vão da viga

\subsubsection{COEFICIENTE MULTIPLICADOR DOS DESLOCAMENTOS IMEDIATOS}

De posse de todos os deslocamentos diferidos e imediatos, pode-se estudar os coeficientes multiplicadores dos deslocamentos imediatos que permitem obter-se os deslocamentos diferidos.

Apenas os casos de carregamento adotados exerceram pouca influência nos valores dos coeficientes multiplicadores. Por outro lado, foram as propriedades da seção transversal, $\mathrm{o}$ vão das vigas, a resistência característica do concreto à compressão $\mathbf{f}_{\mathrm{ck}} \mathrm{e}$ a armadura de compressão; os parâmetros que mais influenciaram tais coeficientes. A Figura 4.14 e a Figura 4.15 ilustram esse comportamento, apresentando os resultados obtidos para vigas com vão efetivo de $7 \mathrm{~m}$.

Pode-se observar que o aumento da altura da seção transversal da viga provocou o acréscimo nos valores dos coeficientes multiplicadores Já os aumentos do $\mathbf{f}_{\mathrm{ck}}$ e da taxa de armadura de compressão provocaram um decréscimo nestes coefic ientes, o que, aliás, já era esperado. É que o aumento destes parâmetros tende a acarretar uma redução dos deslocamentos diferidos, já que promovem a diminuição da retração e da fluência do concreto, conforme comentado anteriormente. 


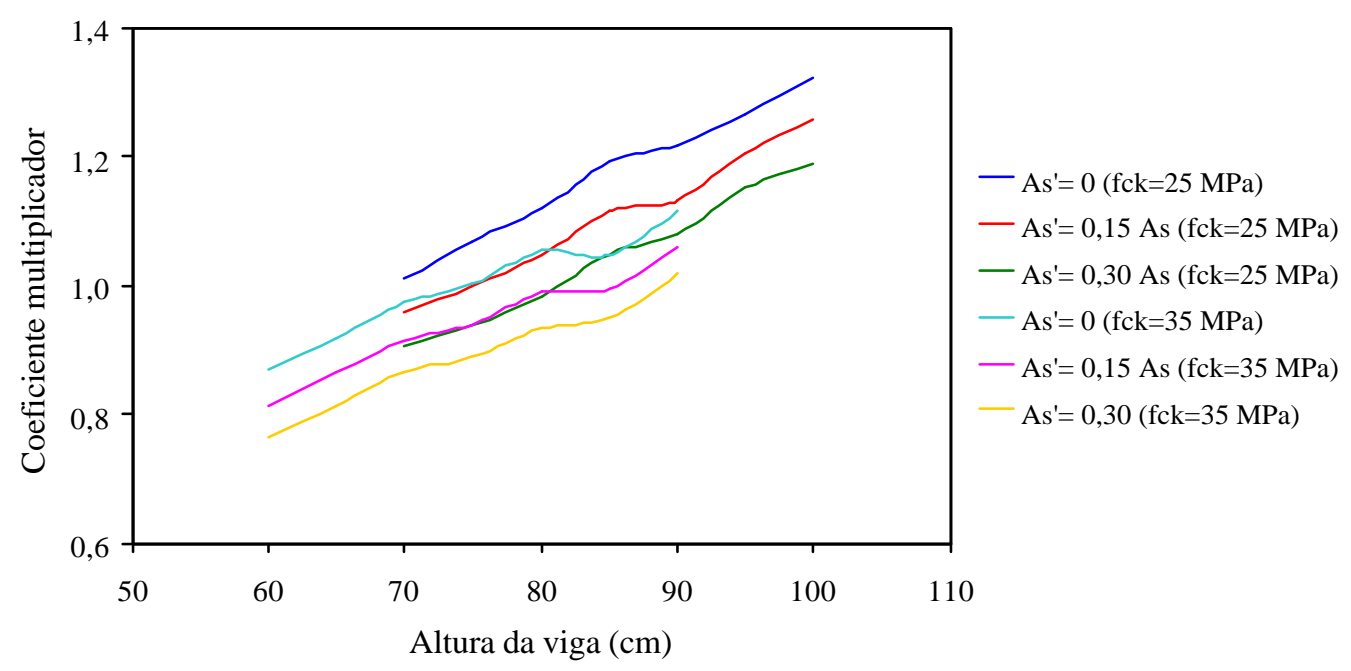

Figura 4.14 - Coeficientes multiplicadores em função da altura da viga, da armadura de compressão e do $\mathbf{f}_{\mathrm{ck}}\left(\ell_{\text {viga }}=7,0 \mathrm{~m} \mathrm{e} \mathrm{b}=14 \mathrm{~cm}\right)$

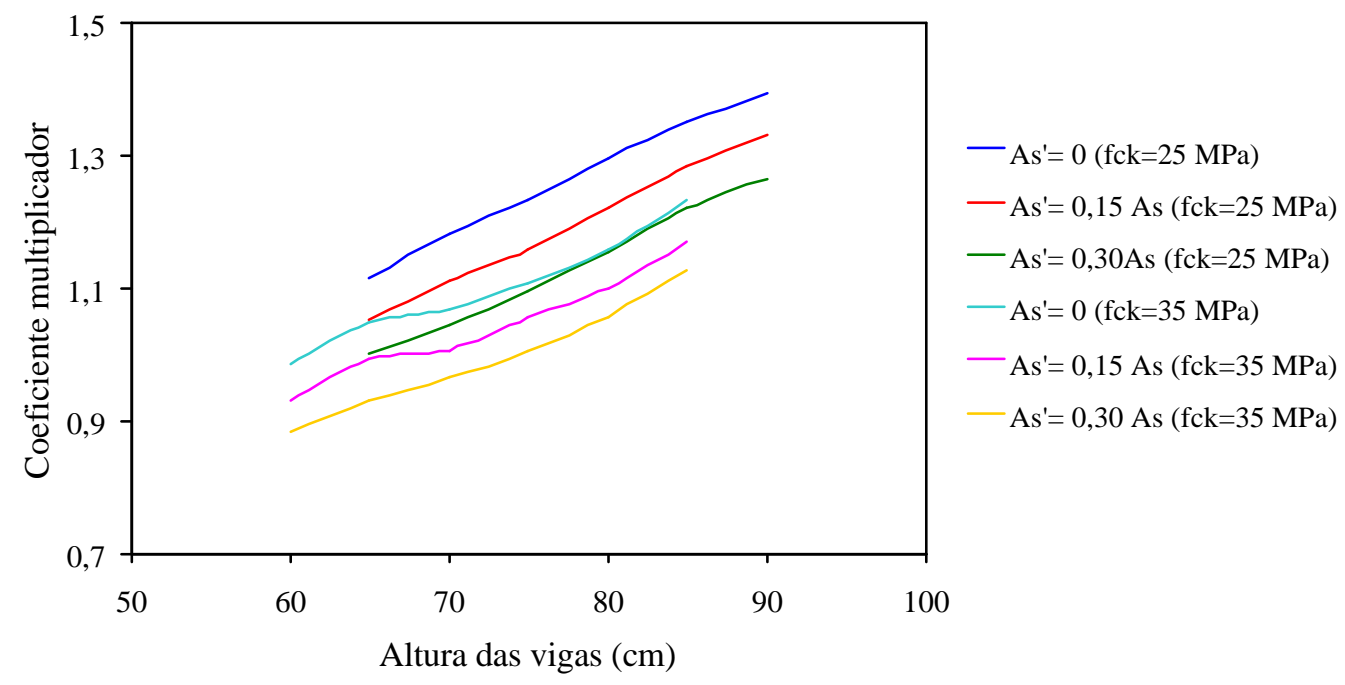

Figura 4.15 - Coeficientes multiplicadores em função da altura da viga, da armadura de

$$
\text { compressão e do } \mathbf{f}_{\mathrm{ck}}\left(\ell_{\mathrm{viga}}=7,0 \mathrm{~m} \mathrm{e} \mathrm{b}=20 \mathrm{~cm}\right)
$$

Como o coeficiente multiplicador dos deslocamentos imediatos mostrou uma tendência de variação aproximadamente linear em função desses parâmetros, buscou-se, a partir de uma regressão linear de múltiplas variáveis, uma expressão para representá-lo. Com isso, chegou-se a:

$$
\alpha_{f, a j}=1,65-0,085 \cdot f_{c k}-0,0014 \cdot \ell_{\text {ef }}-0,38 \cdot \frac{A_{s}^{\prime}}{A_{s}}+0,023 \cdot b+0,00006 \cdot h^{2}
$$

na qual:

$\alpha_{\mathrm{f}, \mathrm{aj}} \quad$ é o coeficiente multiplicador dos deslocamentos imediatos, 
f é a resistência característica à compressão do concreto, em $\mathrm{kN} / \mathrm{cm}^{2}$,

$\ell_{\mathbf{e f}} \quad$ é o vão efetivo da viga, em cm,

As' é a área de aço da armadura de compressão, em $\mathrm{cm}^{2}$,

A é a área de aço da armadura de tração, $\mathrm{em} \mathrm{cm}^{2}$,

b é a largura da seção transversal da viga, em cm,

h é a altura da seção transversal da viga, em $\mathrm{cm}$.

Com o intuito de mostrar a boa concordância dos valores fornecidos pela eq. (4.1) com os obtidos a partir da análise não-linear através do programa ANPAV, foram traçados os gráficos da Figura 4.16 a Figura 4.19. Para esses exemplos, foram tomadas, novamente, as vigas com $7 \mathrm{~m}$ de vão efetivo.

Para efeito de comparação também com o valor do coefic iente multiplicador dado pela NBR 6118 (2003), de acordo com a eq.(2.50) do capítulo 2, tomou-se uma viga submetida, a um carregamento tal que a relação entre a ação permanente e a ação variável fosse igual a 0,25, sendo a idade de aplicação dessas ações iguais a 28 e 45 dias, respectivamente, e considerando a taxa geométrica da armadura de tração igual a 0,01. Para uma combinação freqüente de ações, o coeficiente multiplicador fornecido pela expressão da NBR 6118 (2003) foi igual a 1,33, se a viga não tiver armadura de compressão; igual a 1,24, se a armadura de compressão for igual a $15 \%$ da armadura de tração; e igual a 1,16, se a armadura de compressão for igual a 30\% da armadura de tração. Note-se que esses valores são independentes das propriedades da seção transversal da viga e da resistência característica do concreto à compressão. Esses resultados também foram acrescentados aos gráficos da Figura 4.16 a Figura 4.19.

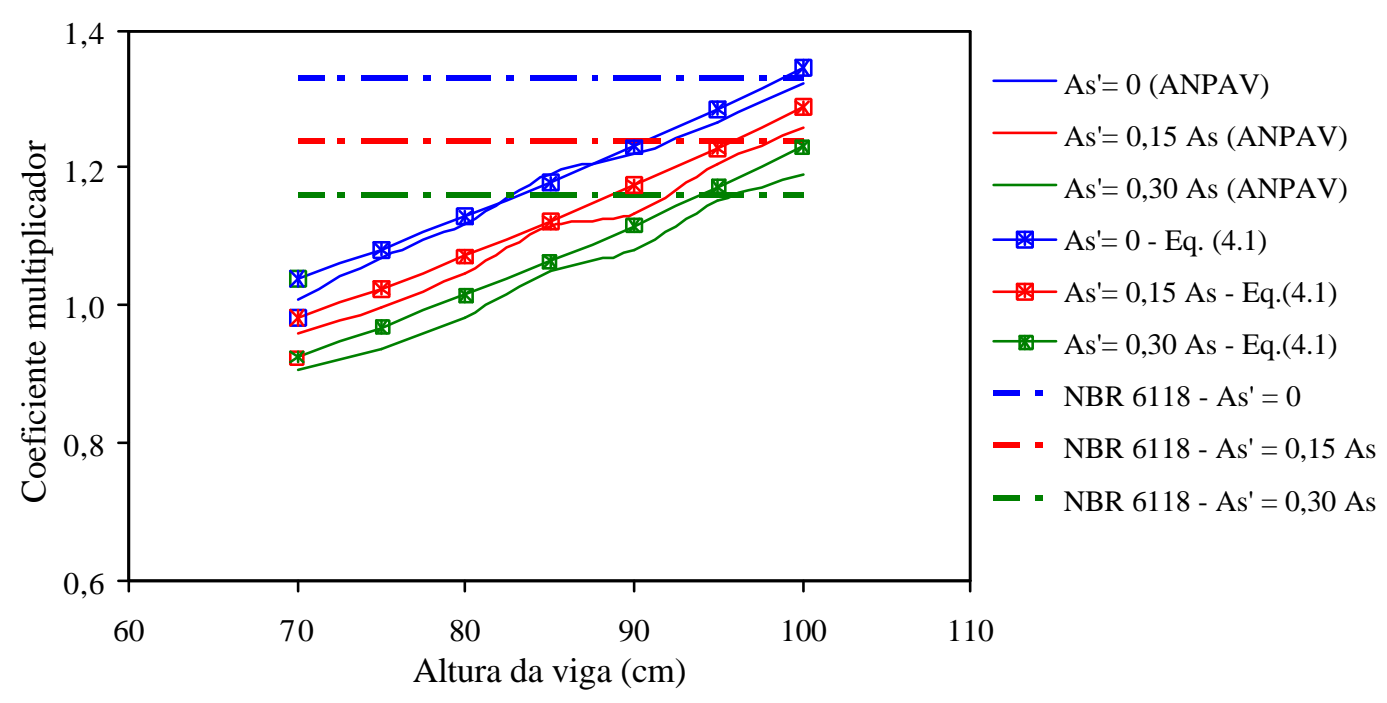

Figura 4.16 - Coeficientes multiplicadores obtidos pelo programa ANPAV, pela eq. (4.1) e

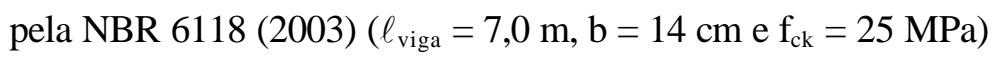




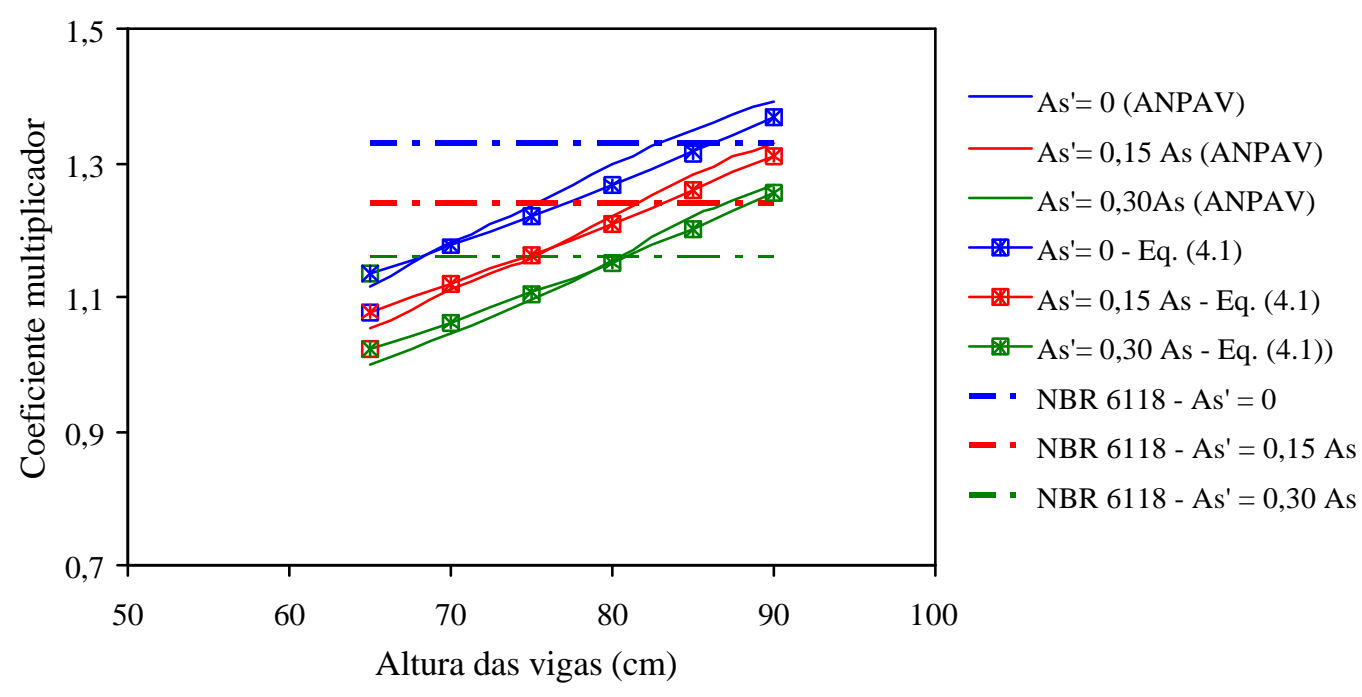

Figura 4.17 - Coeficientes multiplicadores obtidos pelo programa ANPAV, pela eq. (4.1) e pela NBR $6118(2003)\left(\ell_{\text {viga }}=7,0 \mathrm{~m}, \mathrm{~b}=20 \mathrm{~cm} \mathrm{e}_{\mathrm{ck}}=25 \mathrm{MPa}\right)$

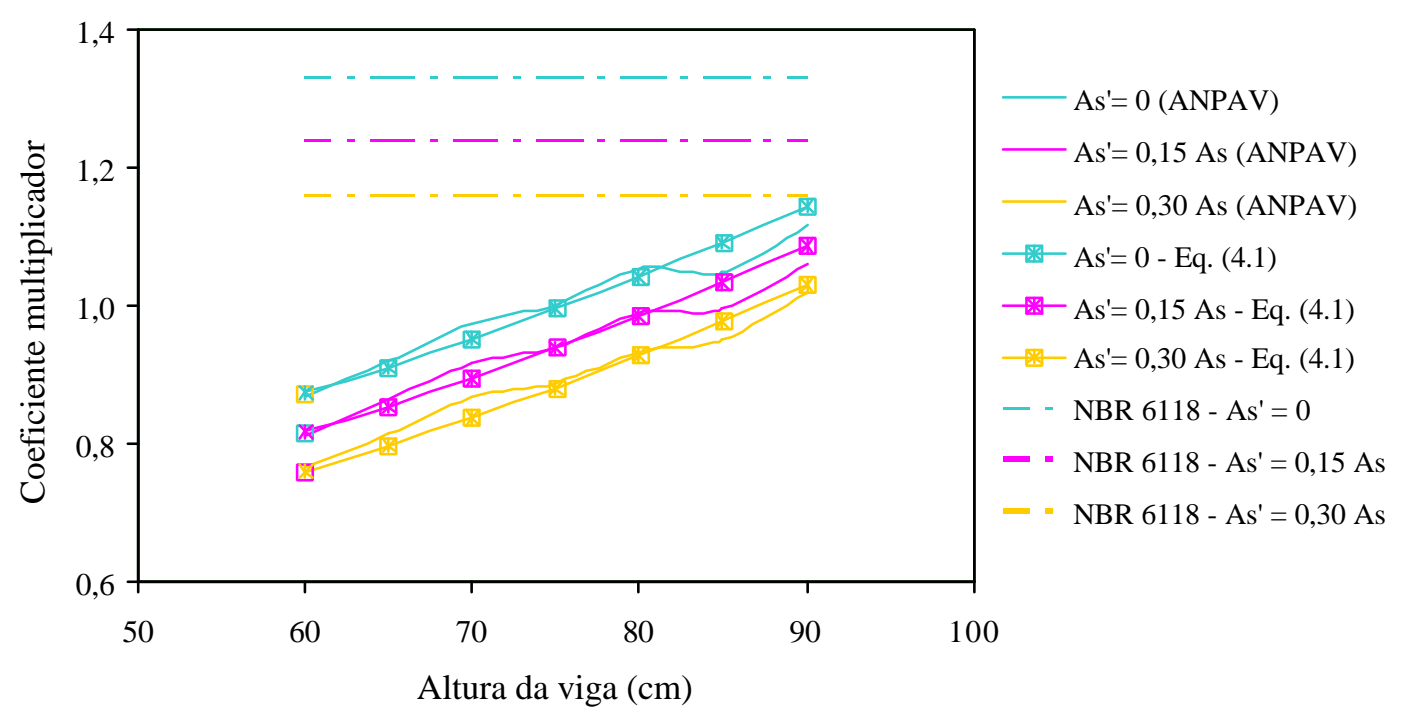

Figura 4.18 - Coeficientes multiplicadores obtidos pelo programa ANPAV, pela eq. (4.1) e

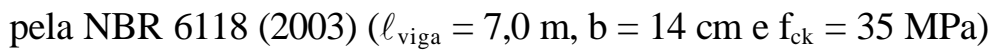




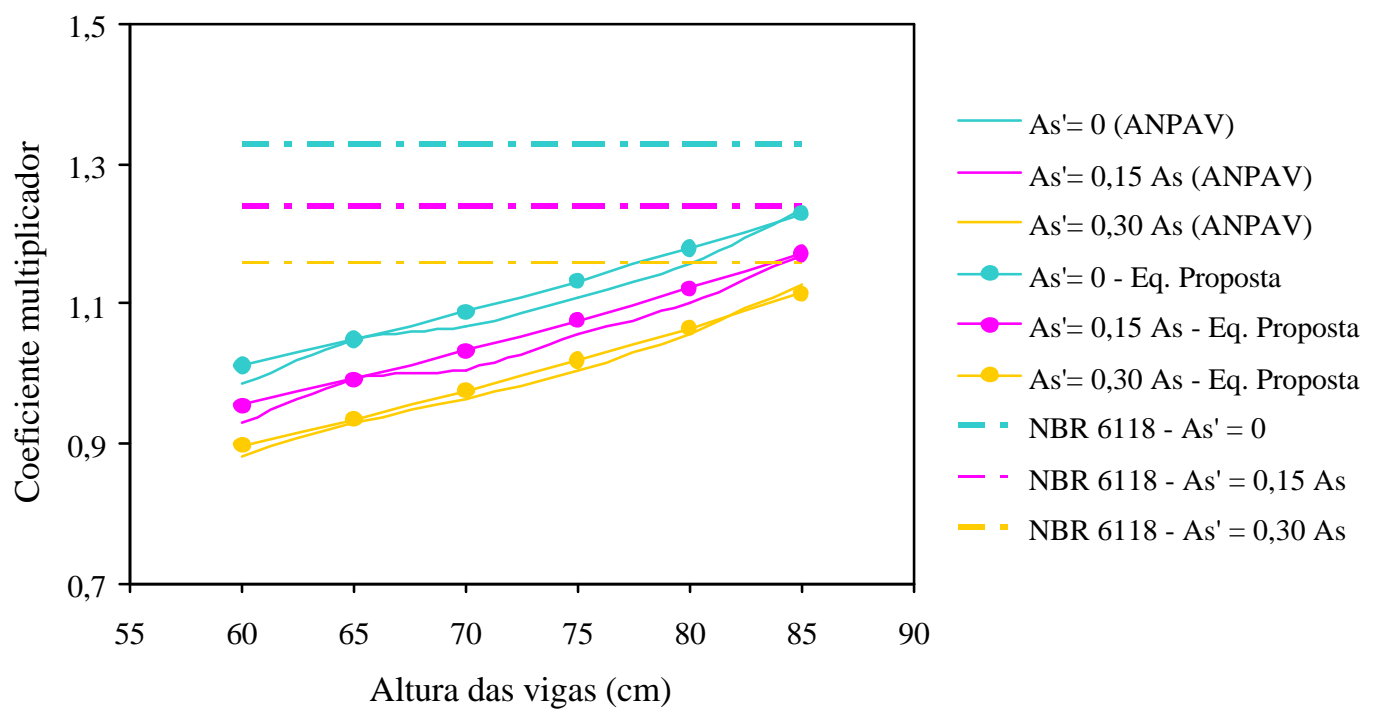

Figura 4.19 - Coeficientes multiplicadores obtidos pelo programa ANPAV, pela eq. (4.1) e pela NBR 6118 (2003) $\left(\ell_{\text {viga }}=7,0 \mathrm{~m}, \mathrm{~b}=20 \mathrm{~cm} \mathrm{e}_{\mathrm{ck}}=35 \mathrm{MPa}\right)$

Por esses gráficos observa-se a coerência dos resultados fornecidos pela eq. (4.1) com os da análise não-linear. Além disso, percebe-se que os valores fornecidos pelo procedimento recomendado pela NBR 6118 (2003) tende a superestimar os coeficientes multiplicadores dos deslocamentos imediatos, principalmente para o $\mathbf{f}_{\mathrm{ck}}$ de $35 \mathrm{MPa}$.

\subsubsection{ALTURAS MÍNIMAS}

Assim como para as lajes, são propostas expressões para o cálculo de alturas mínimas das vigas que garantem a verificação do estado limite de deslocamentos excessivos, e dispensam o cálculo dos deslocamentos, desde que a altura do elemento estrutural seja superior a um determinado limite. Esta altura mínima deve ser respeitada independentemente da altura mínima requerida pelo dimensionamento à flexão.

Também de forma semelhante ao que foi adotado para as lajes, foram consideradas as seguintes verificações, cujos limites são apresentados no item 3.4.3, do Capítulo 3:

- Verificação 1A: Verificação de aceitabilidade sensorial com relação a aspectos visuais, considerando-se a combinação quase-permanente de ações.

- Verificação 1B: Verificação de aceitabilidade sensorial com relação a aspectos visuais, considerando-se a combinação freqüente de ações.

- Verificação 2: Verificação de aceitabilidade sensorial com relação a vibrações, considerando-se apenas a carga variável total. 
- Verificação 3A: Verificação dos efeitos dos deslocamentos nas paredes, considerando-se a combinação quase-permanente de ações.

- Verificação 3B: Verificação dos efeitos dos deslocamentos nas paredes, considerando-se a combinação frequiente de ações.

\section{a) Relação Vão-Altura Mínima}

A partir das alturas mínimas das vigas, determinadas como exposto no item 4.4.3, foram calculadas as suas relações vão-altura mínima, $\ell / \mathbf{h}_{\text {min. }}$.

Pela avaliação dos valores obtidos, para as vigas com um vão, pode-se observar que tanto as propriedades geométricas das vigas e dos pilares de apoio, como a resistência característica do concreto à compressão, $\mathbf{f}_{\mathrm{ck}}$, afetaram significativamente essas relações. Já os casos de carregamento adotados exerceram pouca influência nesses valores, levando a relações $\ell / \mathbf{h}_{\min }$ muito próximas uma das outras.

Quanto às combinações de ações adotadas, notou-se que os valores das relações $\ell / \mathbf{h}_{\min }$ encontrados são praticamente iguais, tanto para a verificação da aceitabilidade sensorial relativa ao aspecto visual, com as combinações quase-permanente e freqüente de ações (Verificações 1A e 1B), quanto para essa verificação relativa às vibrações (Verificação 2). Também para as verificações do efeito dos deslocamentos nas paredes (Verificações 3A e 3B), as combinações quase permanente e freqüente de ações levaram a valores de relações $\ell / \mathbf{h}_{\min }$ bastante próximos.

Da Figura 4.20 a Figura 4.22, têm-se, para vigas de um vão, a variação da relação $\ell / \mathbf{h}_{\min }$ em função das propriedades geométricas das vigas e dos pilares e também do $\mathbf{f}_{\text {ck. }}$. As relações apresentadas satisfazem à verificação do efeito dos deslocamentos em paredes para a combinação quase-permanente de ações (Verificação 3A).

Pode-se notar que, para as vigas com vão efetivo igual a 3,0, 5,0 e 7,0m, as relações $\ell / \mathbf{h}_{\text {min }}$ tendem a um valor constante, a partir das alturas de seções transversais de pilares de 40, 50 e $70 \mathrm{~cm}$, respectivamente. Essas alturas de pilares são praticamente iguais àquelas comentadas no item 4.5.1.a, a partir das quais o aumento desta dimensão do pilar pouco afeta os valores dos deslocamentos das vigas. Desta forma, pode-se considerar que, para valores da relação entre o vão efetivo da viga e a altura da seção do pilar menores que aproximadamente 10 , as relações $\ell / \mathbf{h}_{\min }$ assumem valores constantes. 


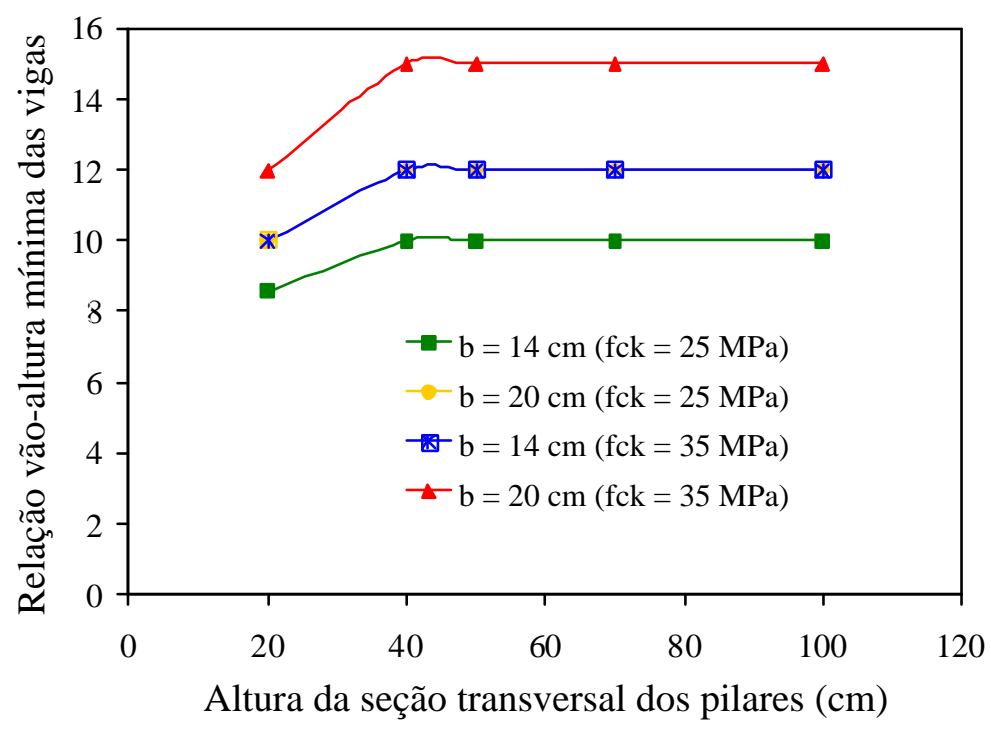

Figura 4.20 - Relação vão-altura-mínima das vigas em função da altura seção dos pilares de apoio $\left(\ell_{\text {viga }}=3,0 \mathrm{~m}\right)$

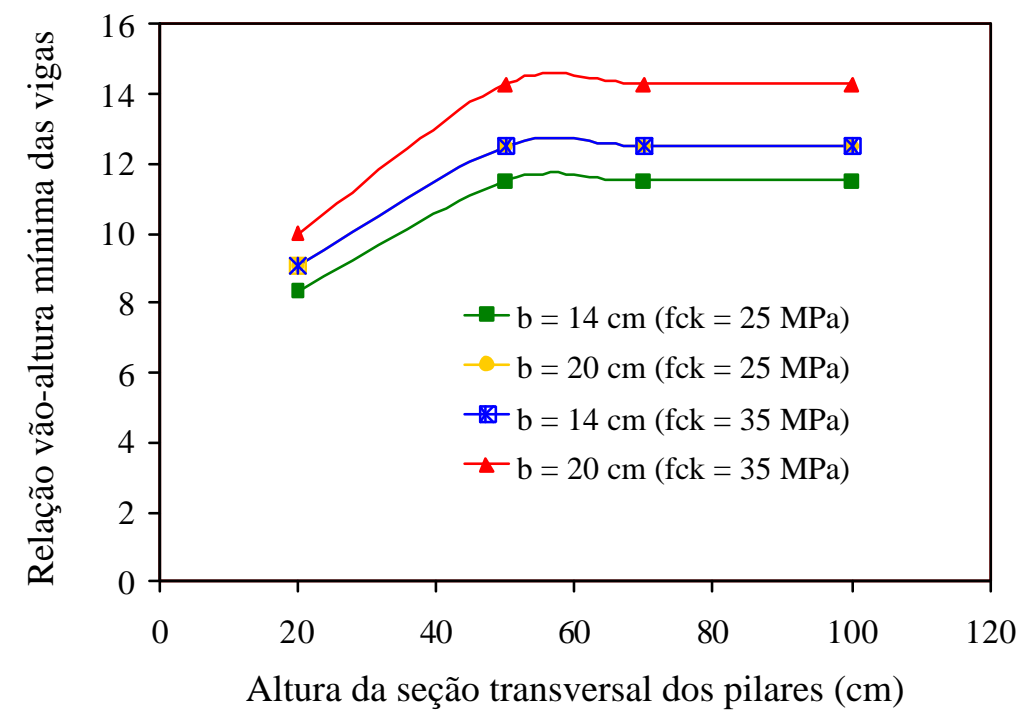

Figura 4.21 - Relação vão-altura-mínima das vigas em função da altura da seção dos pilares de apoio $\left(\ell_{\text {viga }}=5,0 \mathrm{~m}\right)$ 


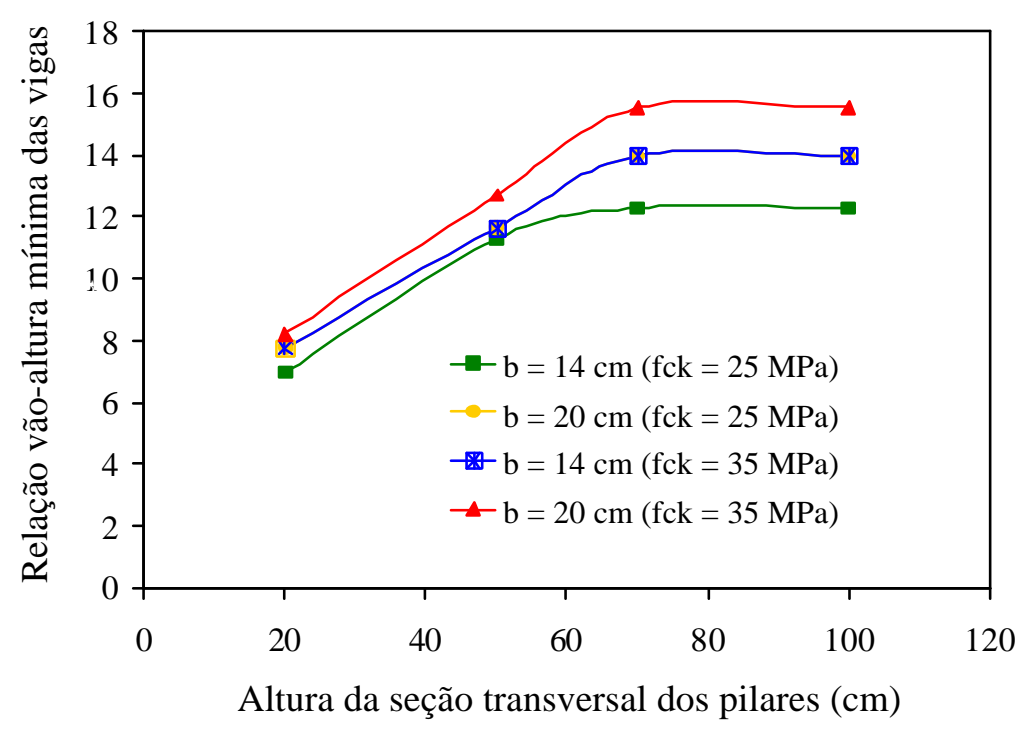

Figura 4.22 - Relação vão-altura-mínima das vigas em função da altura da seção dos pilares

$$
\text { de apoio }\left(\ell_{\text {viga }}=7,0 \mathrm{~m}\right)
$$

A partir dos valores das relações vão-altura mínima de todas as vigas de um vão estudadas, e de acordo com as observações anteriores, foi determinada a seguinte expressão para o cálculo dessas relações:

$$
\frac{\ell_{\text {ef }}}{\mathrm{h}_{\min }}=\beta
$$

na qual:

$\ell_{\mathbf{f f}} \quad$ é o vão efetivo da viga, em $\mathrm{cm}$,

$\mathbf{h}_{\min }$ é a altura mínima da viga, em $\mathrm{cm}$, que satisfaz as verificações dos deslocamentos apresentadas no item 3.4.3, do Capítulo 3,

$\beta \quad$ é uma função que depende das propriedades geométricas da viga e dos pilares, da resistência característica do concreto à compressão e do tipo de verificação que se deseja realizar. Para verificações de aceitabilidade sensorial tem-se:

$$
\beta=6,0+1,4 \cdot \mathrm{f}_{\mathrm{ck}}+0,005 \cdot \ell_{\mathrm{ef}}+0,21 \cdot \mathrm{b}-0,009 \cdot \mathrm{h}_{\mathrm{p}}-0,25 \cdot \frac{\ell_{\mathrm{ef}}}{\mathrm{h}_{\mathrm{p}}}
$$

Para a verificação do efeito dos deslocamentos em paredes obtém-se:

$$
\beta=5,7+1,35 \cdot \mathrm{f}_{\mathrm{ck}}+0,005 \cdot \ell_{\mathrm{ef}}+0,18 \cdot \mathrm{b}-0,007 \cdot \mathrm{h}_{\mathrm{p}}-0,26 \cdot \frac{\ell_{\mathrm{ef}}}{\mathrm{h}_{\mathrm{p}}}
$$


nas quais:

$\mathbf{f}_{\text {ck }}$ é a resistência característica do concreto à compressão, em kN/cm²,

b é a largura da seção transversal da viga, em cm,

$\mathbf{h}_{\mathbf{p}} \quad$ é a altura da seção transversal do pilar, em $\mathrm{cm}$.

Uma comparação dos resultados fornecidos pela eq. (4.2) com aqueles obtidos na análise das vigas é apresentada nas Figura 4.23 e Figura 4.24, para uma viga com vão efetivo de 7,0 m, e cujas relações $\ell / \mathbf{h}_{\min }$ satisfazem à verificação do efeito dos deslocamentos em paredes. Pode-se notar que os resultados são relativamente próximos. Os valores fornecidos pela eq. (4.2) apresentaram, em média, uma diferença da ordem de $\pm 10 \%$ em relação aos valores encontrados a partir do programa ANPAV.

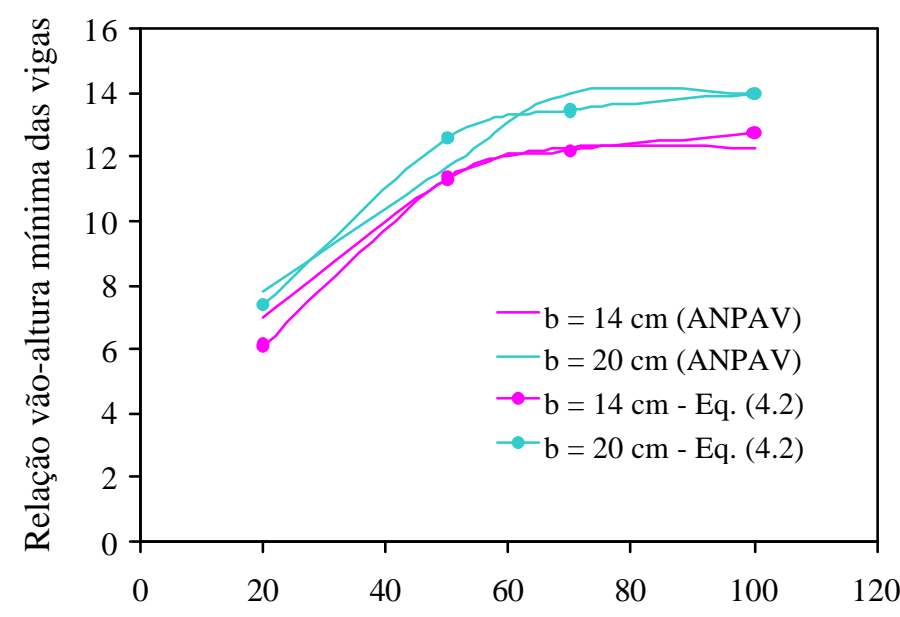

Altura da seção transversal dos pilares $(\mathrm{cm})$

Figura 4.23 - Relações $\ell / \mathbf{h}_{\text {min }}$ para vigas com $\ell_{\mathrm{ef}}=7,0 \mathrm{~m} \mathrm{e} \mathrm{f}_{\mathrm{ck}}=25 \mathrm{MPa}$

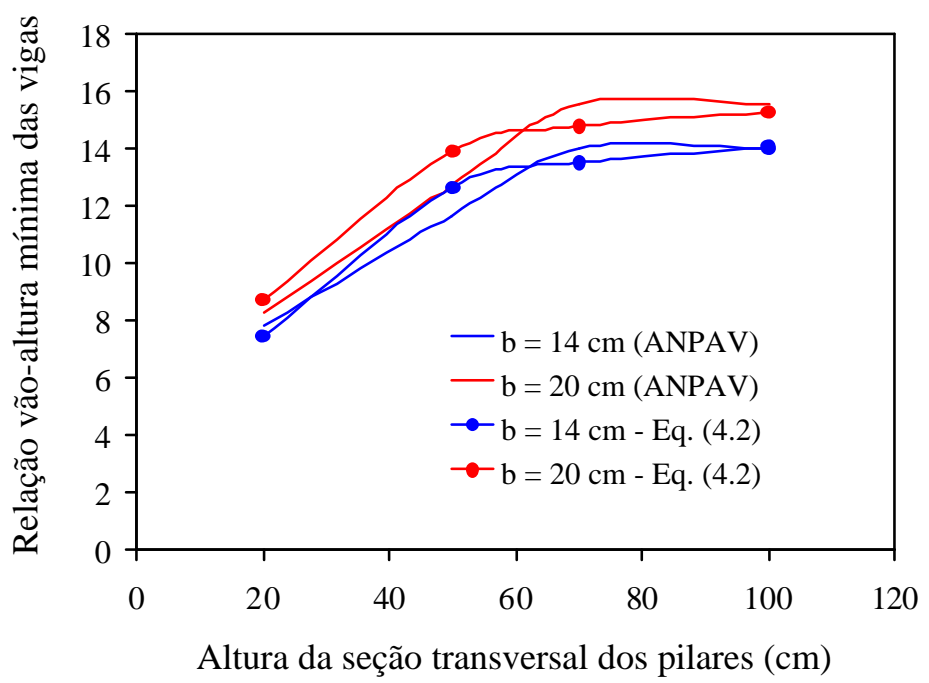

Figura 4.24 - Relações $\ell / \mathbf{h}_{\text {min }}$ para vigas com $\ell_{\text {ef }}=7,0 \mathrm{~m} \mathrm{e}_{\mathrm{ck}}=35 \mathrm{MPa}$ 
Nas figuras apresentadas a seguir, são dados alguns valores de alturas mínimas, obtidos a partir das relações vão-altura mínimas de vigas fornecidas pela eq. (4.2), que satisfazem às verificações de aceitabilidade sensorial e efeito dos deslocamentos em paredes, verificações 1,2 e 3, de acordo com o item 3.4.3, do Capítulo 3. Foram consideradas vigas com vãos efetivos de 4,0, 5,0, 6,0 e 7,0 m, largura da seção transversal iguais a 14 e $20 \mathrm{~cm}$, e resistência característica do concreto à compressão de $25 \mathrm{MPa}$.

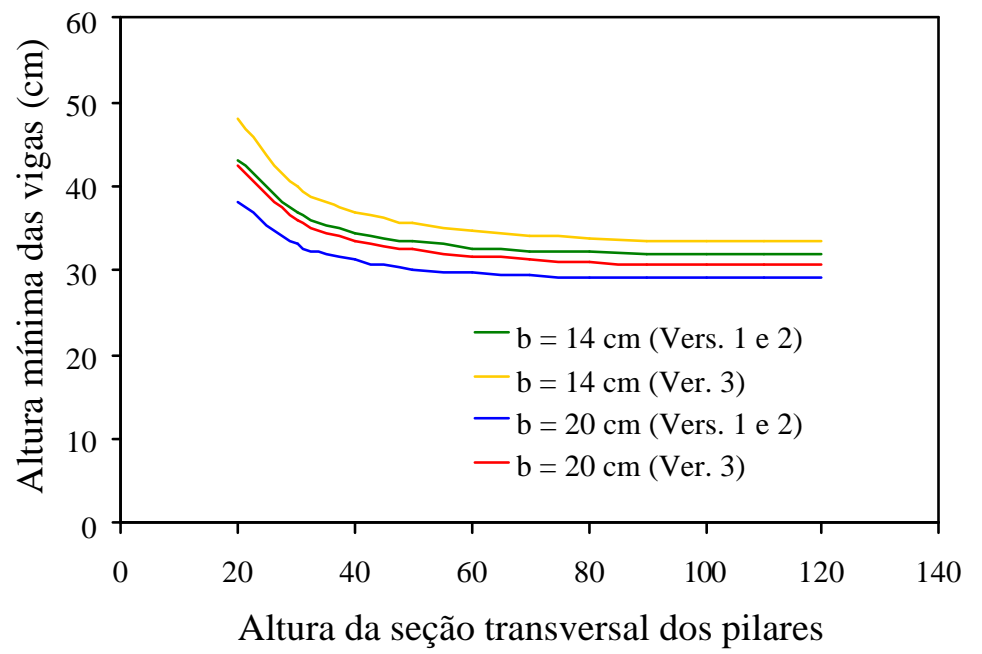

Figura 4.25 - Alturas mínimas de vigas com $\ell_{\mathrm{ef}}=4,0 \mathrm{~m} \mathrm{e}_{\mathrm{ck}}=25 \mathrm{MPa}$

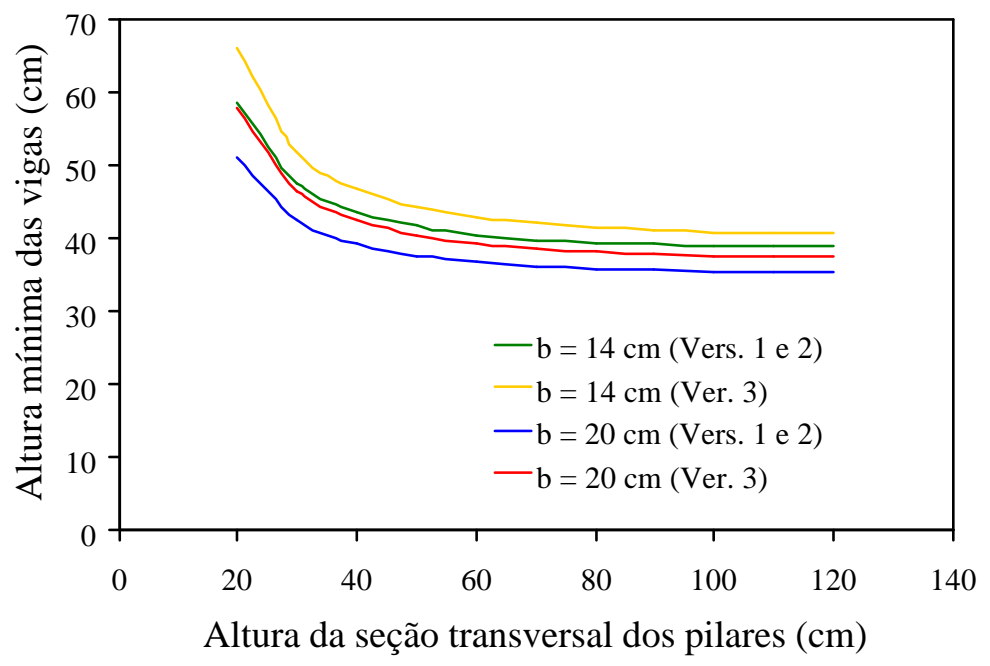

Figura 4.26 - Alturas mínimas de vigas com $\ell_{\text {ef }}=5,0 \mathrm{~m} \mathrm{e}_{\mathrm{ck}}=25 \mathrm{MPa}$ 


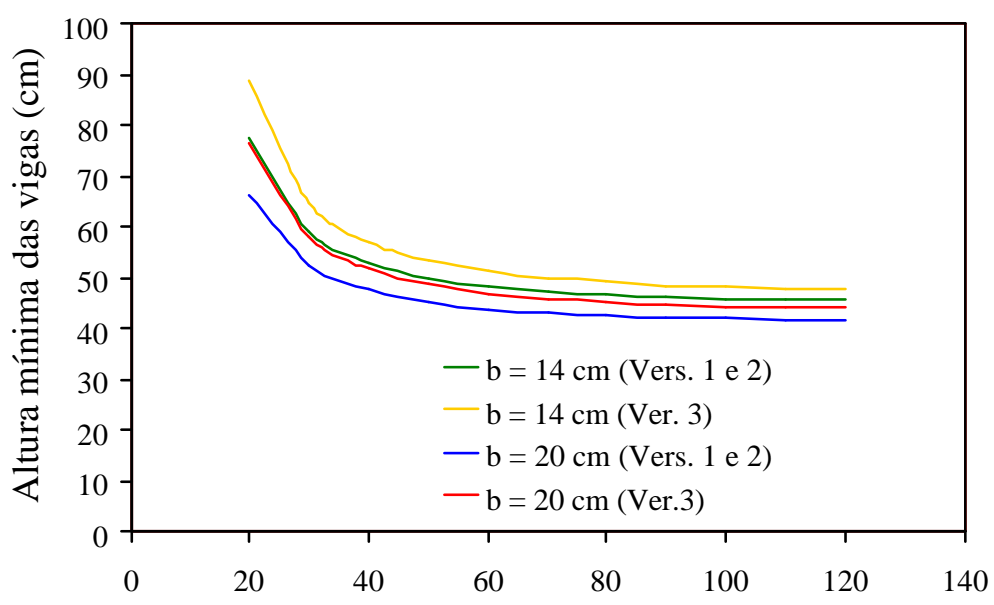

Altura da seção transversal dos pilares $(\mathrm{cm})$

Figura 4.27 - Alturas mínimas de vigas com $\ell_{\mathrm{ef}}=6,0 \mathrm{~m} \mathrm{e}_{\mathrm{ck}}=25 \mathrm{MPa}$

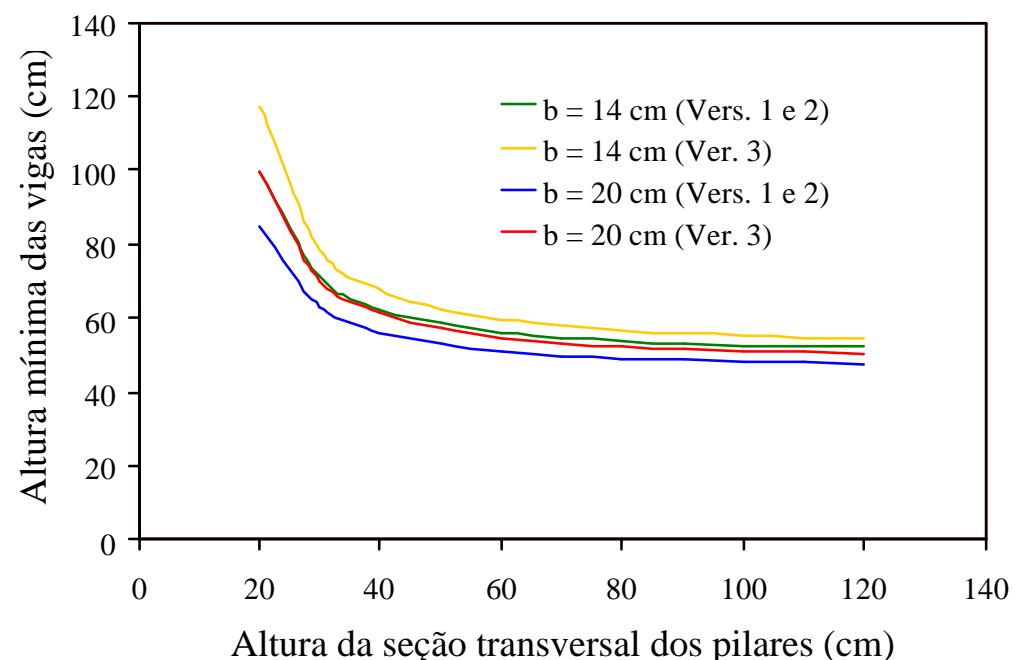

Figura 4.28 - Alturas mínimas de vigas com $\ell_{\mathrm{ef}}=7,0 \mathrm{~m} \mathrm{e}_{\mathrm{ck}}=25 \mathrm{MPa}$

A variação das alturas mínimas das vigas dadas pela eq. (4.2), em relação aos seus vãos, está representada nas Figura 4.29 e Figura 4.30, para vigas com a largura da seção transversal igual a $14 \mathrm{~cm}$ e altura da seção transversal do pilar igual a 20 e $70 \mathrm{~cm}$. 


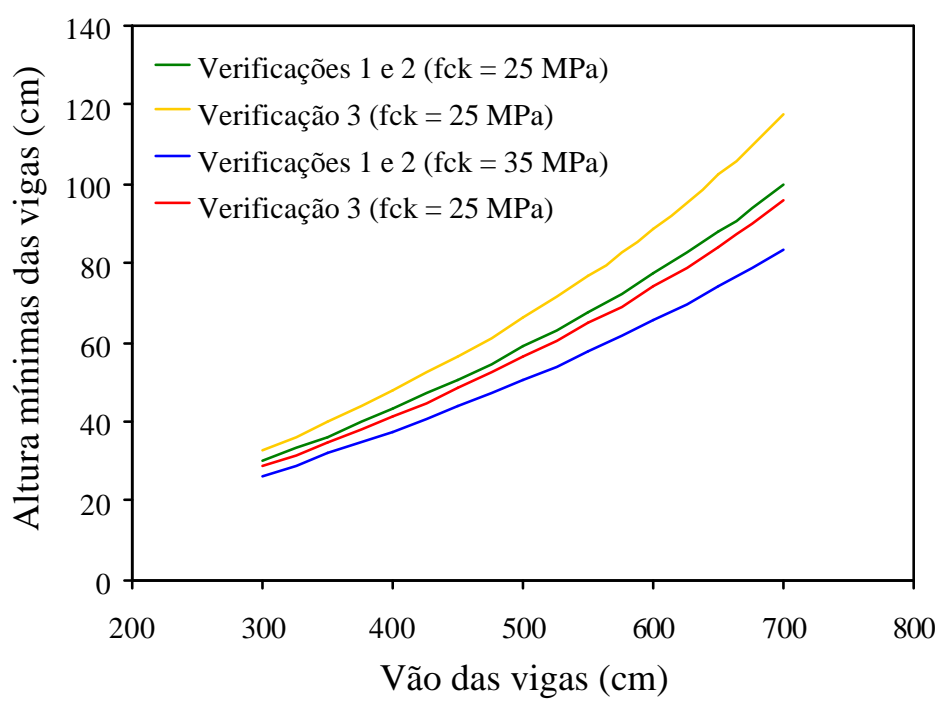

Figura 4.29 - Alturas mínimas das vigas em função de seus vãos $\left(b=14 \mathrm{~cm}\right.$ e $\left.h_{p}=20 \mathrm{~cm}\right)$

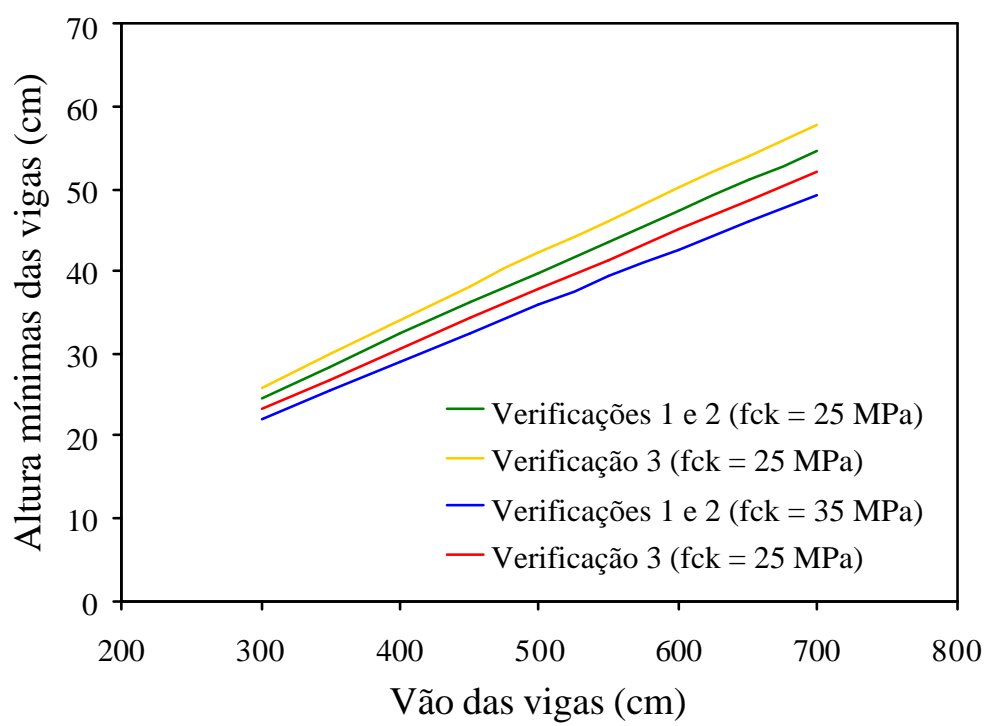

Figura 4.30 - Alturas mínimas das vigas em função de seus vãos $\left(b=14 \mathrm{~cm}\right.$ e $\left.h_{p}=70 \mathrm{~cm}\right)$

Com base nos resultados obtidos e com o intuito de simplificar a obtenção da altura mínima das vigas pode-se, de maneira aproximada, adotar o valor de $\beta$ na eq. (4.2) de acordo com a Tabela 4.3. 
Tabela 4.3 - Valores simplificados de $\beta$ para a eq. (4.2)

\begin{tabular}{|l|c|c|c|}
\hline \multicolumn{2}{|c|}{ Condições } & \multicolumn{2}{c|}{ Valores de $\beta$} \\
\cline { 3 - 4 } & $\begin{array}{c}\text { Verificações da } \\
\text { Aceitabilidade Sensorial }\end{array}$ & $\begin{array}{c}\text { Verificação do Efeito dos } \\
\text { Deslocamentos em Paredes }\end{array}$ \\
\hline \multirow{2}{*}{$\frac{\ell_{\mathrm{ef}}}{\mathrm{h}_{\mathrm{p}}}>10$} & $\mathrm{~b}<20 \mathrm{~cm}$ & 8 & 7 \\
\cline { 2 - 4 } & $\mathrm{b} \geq 20 \mathrm{~cm}$ & 10 & 8 \\
\hline$\frac{\ell_{\mathrm{ef}}}{\mathrm{h}_{\mathrm{p}}} \leq 10$ & $\mathrm{~b}<20 \mathrm{~cm}$ & 12 & 10 \\
\cline { 2 - 4 } & $\mathrm{b} \geq 20 \mathrm{~cm}$ & 13 & 11 \\
\hline
\end{tabular}

\section{b) Expressão para o Cálculo da Altura Mínima}

Buscando-se considerar todos os parâmetros que foram utilizados no estudo das vigas e comentados neste capítulo, fez-se uma análise de regressão de múltiplas variáveis e obteve-se a seguinte expressão para a determinação da altura mínima das vigas de um vão que satisfaz a verificação de aceitabilidade sensorial quanto aos aspectos visuais e de vibrações:

$$
\begin{aligned}
\mathrm{h}_{\min }= & -25-5,13 \cdot \mathrm{f}_{\mathrm{ck}}+47,4 \cdot \mathrm{F}_{\mathrm{d}, \mathrm{est}}+0,049 \cdot \ell_{\mathrm{ef}}-0,97 \cdot \mathrm{b}+2,06 \cdot \mathrm{h}_{\mathrm{p}}+ \\
& +0,0215 \cdot \mathrm{R}_{\mathrm{p}}+2,81 \cdot \frac{\ell_{\mathrm{ef}}}{\mathrm{R}_{\mathrm{p}}}-0,0274 \cdot \mathrm{h}_{\mathrm{p}}{ }^{2}
\end{aligned}
$$

Já para a verificação dos efeitos dos deslocamentos em paredes, encontrou-se:

$$
\begin{aligned}
\mathrm{h}_{\min }= & -55,5-8,0 \cdot \mathrm{f}_{\mathrm{ck}}+53,7 \cdot \mathrm{F}_{\mathrm{d}, \text { est }}+0,083 \cdot \ell_{\mathrm{ef}}-0,81 \cdot \mathrm{b}+2,74 \cdot \mathrm{h}_{\mathrm{p}}+ \\
& +0,028 \cdot \mathrm{R}_{\mathrm{p}}+4,1 \cdot \frac{\ell_{\mathrm{ef}}}{\mathrm{R}_{\mathrm{p}}}-0,036 \cdot \mathrm{h}_{\mathrm{p}}{ }^{2}
\end{aligned}
$$

sendo:

$\mathbf{h}_{\text {min }}$ é a altura mínima da viga que satisfaz as verificações dos deslocamentos, em cm,

$\mathbf{f}_{\text {ck }}$ é a resistência característica do concreto à compressão, em $\mathrm{kN} / \mathrm{cm}^{2}$,

$\mathbf{F}_{\text {d,est }}$ é a ação de serviço estimada, em $\mathrm{kN} / \mathrm{cm}$,

$\ell_{\mathbf{e f}} \quad$ é o vão efetivo da viga, em cm,

b é a largura da seção transversal da viga, em cm,

$\mathbf{h}_{\mathbf{p}} \quad$ é a altura da seção transversal do pilar, em $\mathrm{cm}$.

$\mathbf{R}_{\mathbf{p}} \quad$ é a rigidez do menor pilar de apoio, dada pela relação entre o momento de inércia do pilar e seu comprimento, $\mathrm{em}^{3}$. 
Caso o pilar de apoio termine no nível da viga, ou seja, não exista tramo superior, a rigidez $\mathbf{R}_{\mathrm{p}}$, do menor pilar deve ser dividida por 2 .

Para a estimativa da ação de serviço, pode-se adotar uma altura média igual a um décimo do vão efetivo da viga, para o cálculo do peso próprio. Pode-se, também, considerar a ação de serviço igual a $0,40 \mathrm{kN} / \mathrm{cm}$, para vigas com situações de carregamento semelhantes às deste trabalho.

Devido à pequena variabilidade da altura mínima das vigas com vão de 3,0 $\mathrm{m}$, as eqs. (4.5) e (4.6) não apresentam bons resultados para esse caso. Entretanto, para os outros vãos adotados, essas equações levam a valores de alturas mínimas muito próximas dos valores obtidos a partir da análise não-linear das vigas, como pode ser visto nas figuras a seguir.

Da Figura 4.31 a Figura 4.34, são apresentadas as alturas mínimas que satisfazem as verificações referentes à aceitabilidade sensorial, para vigas de 5,0 e 7,0 m, com larguras da seção transversal iguais a 14 e $20 \mathrm{~cm}$, resistências características do concreto à compressão de 25 e $35 \mathrm{MPa}$, e submetidas ao carregamento C3. Pode-se observar que os valores fornecidos pela eq. (4.5) são muito próximos dos valores obtidos com o programa ANPAV.

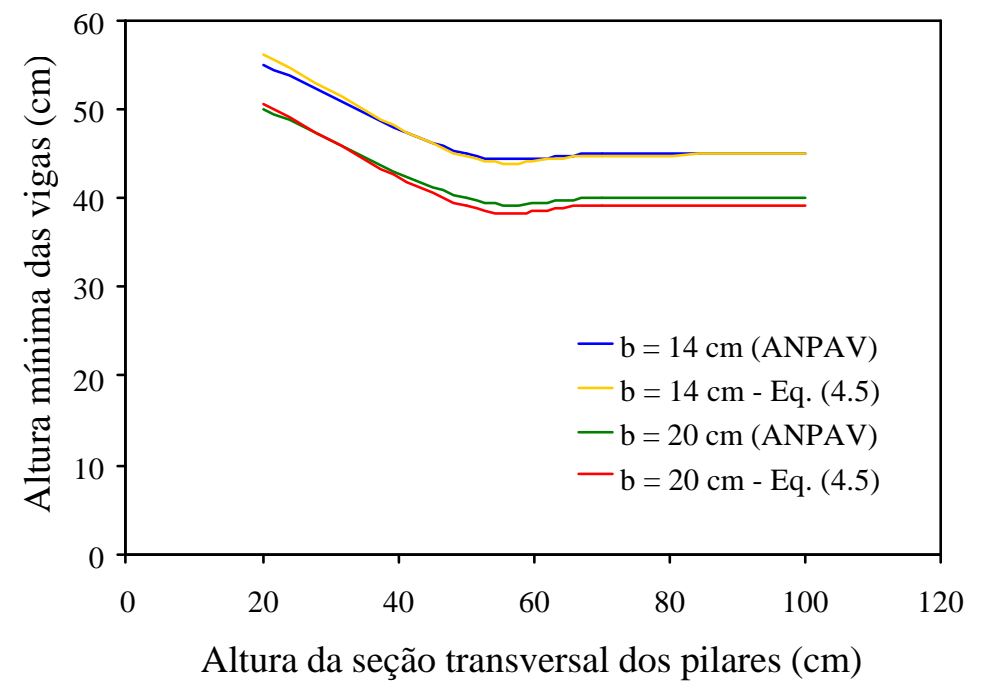

Figura 4.31 - Altura mínima das vigas em função da altura da seção dos pilares (para vigas com $\ell_{\text {ef }}=5,0 \mathrm{~m} \mathrm{e}_{\mathrm{ck}}=25 \mathrm{MPa}$ ) 


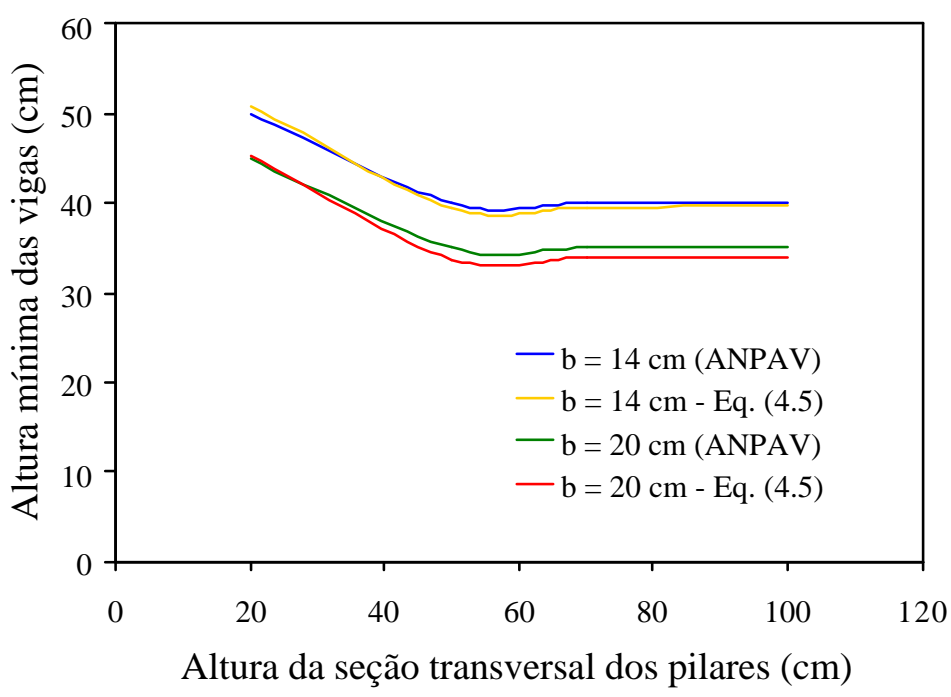

Figura 4.32 - Altura mínima das vigas em função da altura da seção dos pilares (para vigas com $\ell_{\mathrm{ef}}=5,0 \mathrm{~m} \mathrm{e}_{\mathrm{ck}}=35 \mathrm{MPa}$ )

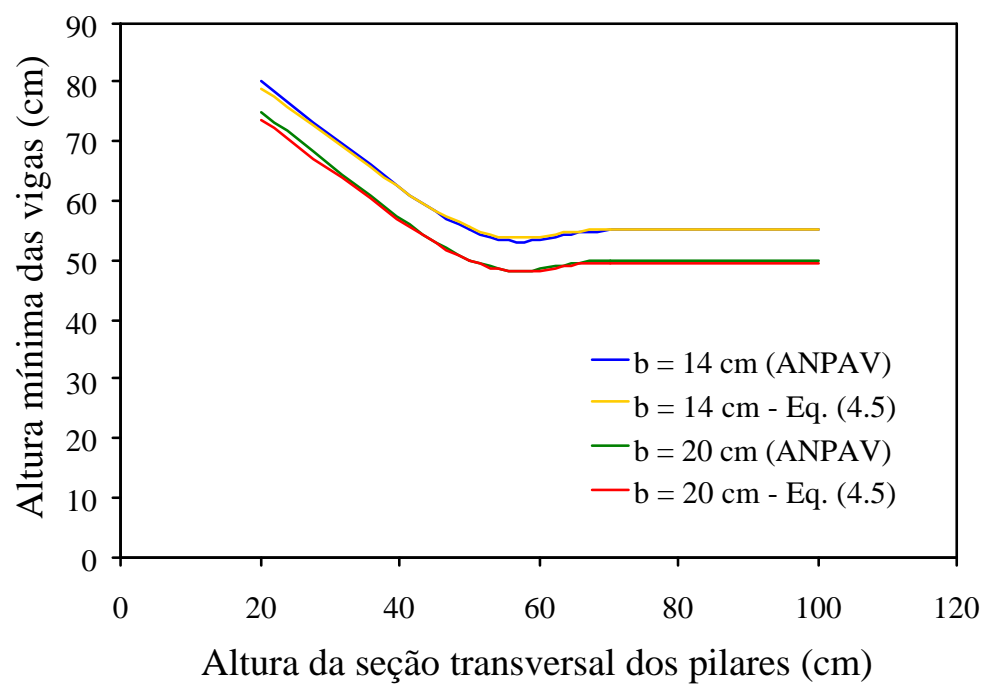

Figura 4.33 - Altura mínima das vigas em função da altura da seção dos pilares (para vigas com $\ell_{\text {ef }}=7,0 \mathrm{~m} \mathrm{e}_{\mathrm{ck}}=25 \mathrm{MPa}$ ) 


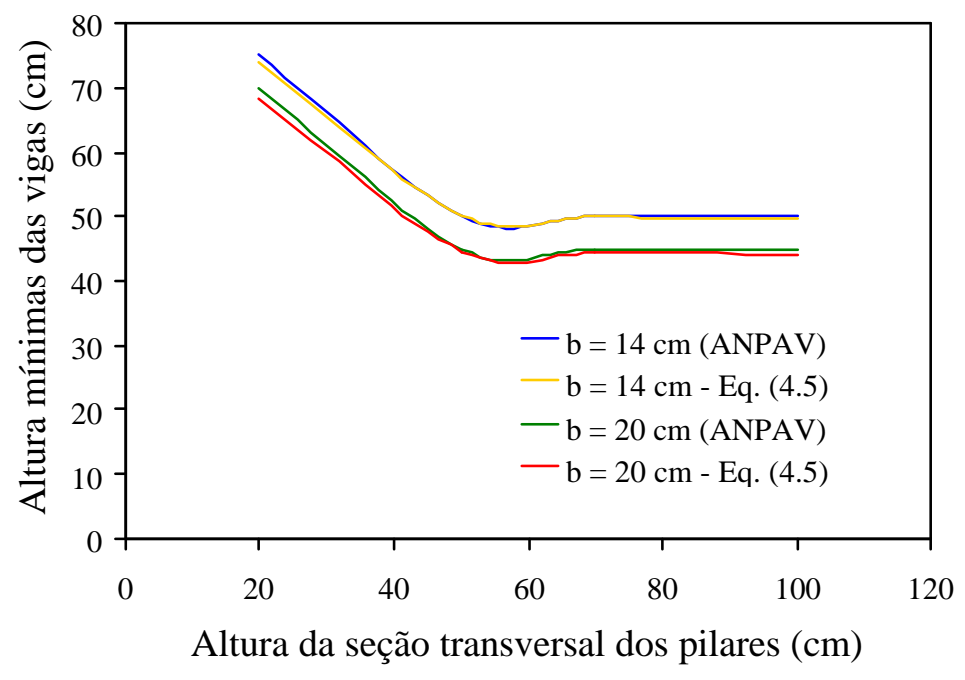

Figura 4.34 - Altura mínima das vigas em função da altura da seção dos pilares (para vigas com $\ell_{\text {ef }}=7,0 \mathrm{~m} \mathrm{e}_{\mathrm{ck}}=35 \mathrm{MPa}$ )

Da Figura 4.35 a Figura 4.38, têm-se as alturas mínimas que satisfazem à verificação do efeito dos deslocamentos em paredes, para vigas submetidas às mesmas condições anteriores, ou seja, vãos de 5,0 e 7,0 m, larguras da seção transversal iguais a 14 e 20 cm, $\mathbf{f}_{\text {ck }}$ de 25 e $35 \mathrm{MPa}$ e submetidas ao carregamento C3. Pode-se notar que a eq. (4.6) também fornece valores próximos dos obtidos pelo programa ANPAV.

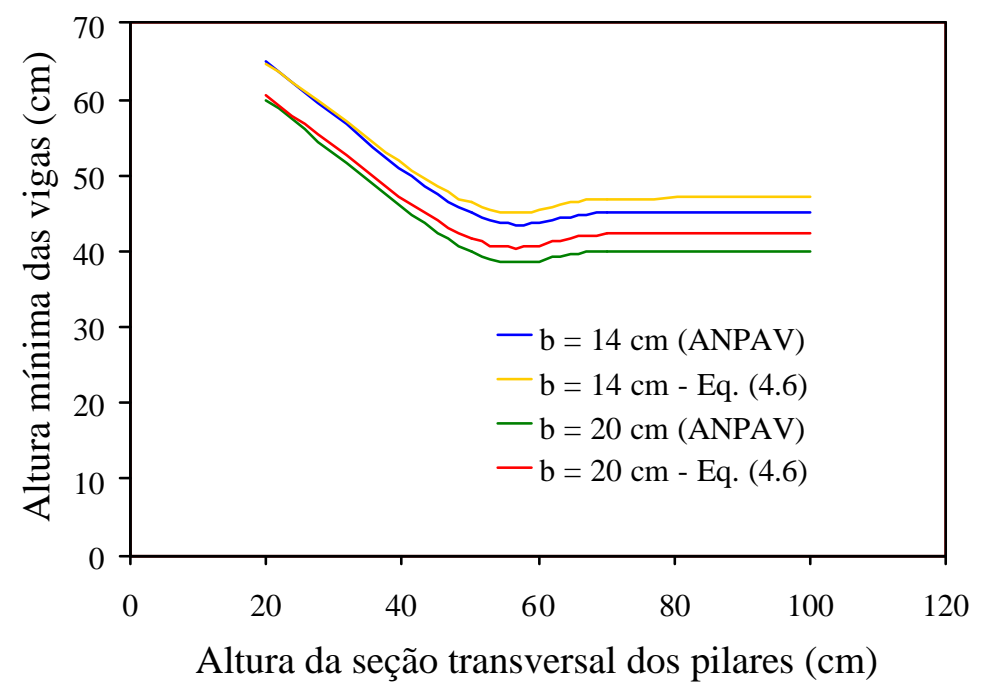

Figura 4.35 - Altura mínima das vigas em função da altura da seção dos pilares (para vigas com $\ell_{\text {ef }}=5,0 \mathrm{~m} \mathrm{e}_{\mathrm{ck}}=25 \mathrm{MPa}$ ) 


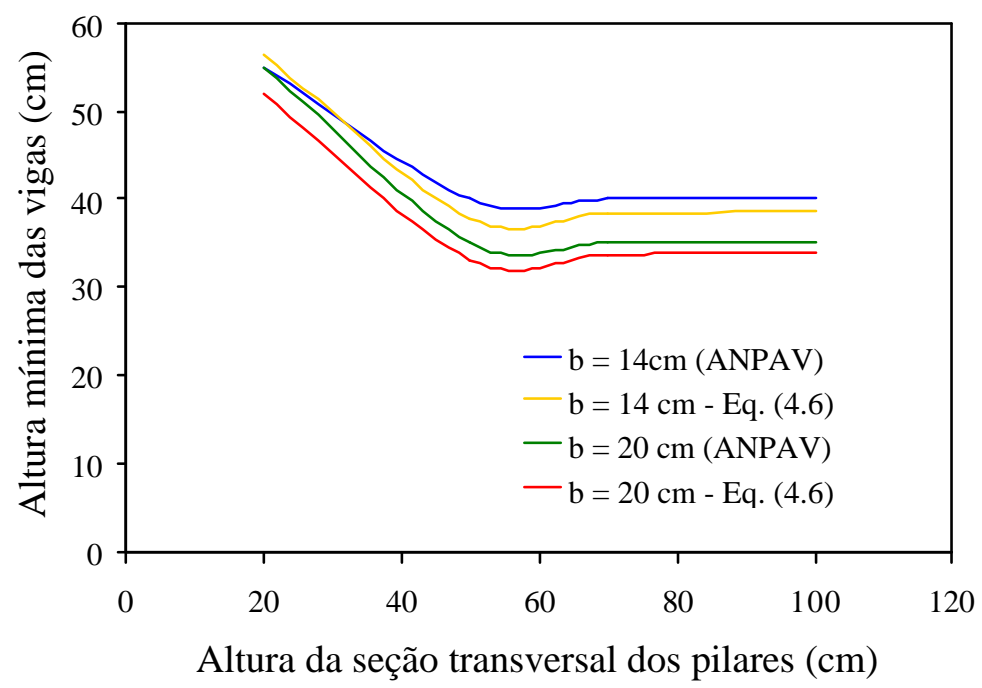

Figura 4.36 - Altura mínima das vigas em função da altura da seção dos pilares (para vigas com $\ell_{\text {ef }}=5,0 \mathrm{~m} \mathrm{e}_{\mathrm{ck}}=35 \mathrm{MPa}$ )

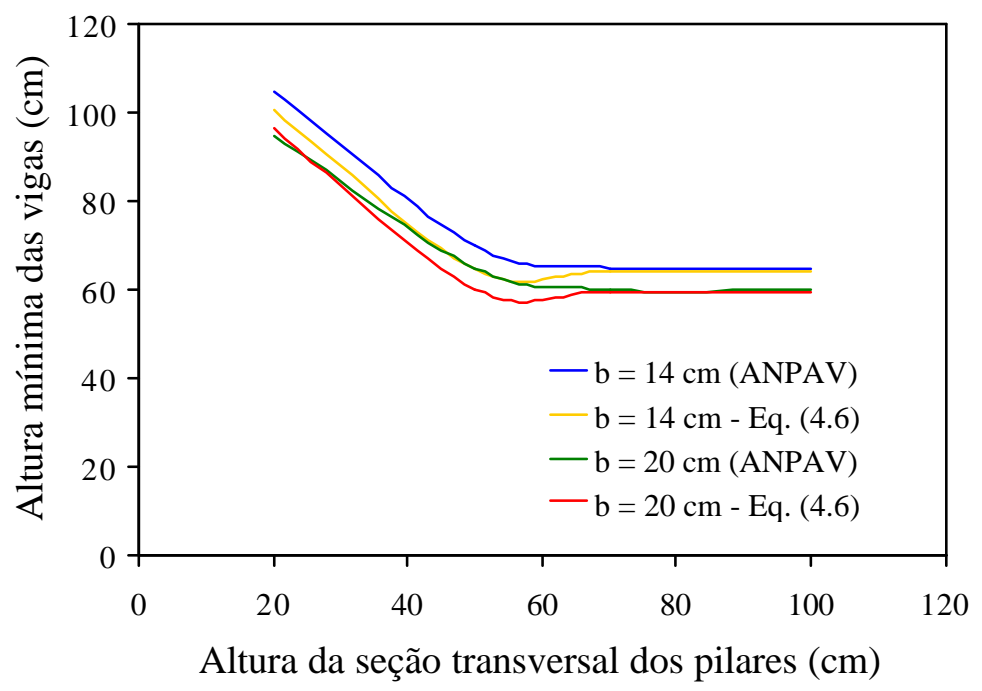

Figura 4.37 - Altura mínima das vigas em função da altura da seção dos pilares (para vigas com $\ell_{\text {ef }}=7,0 \mathrm{~m} \mathrm{e}_{\mathrm{ck}}=25 \mathrm{MPa}$ ) 


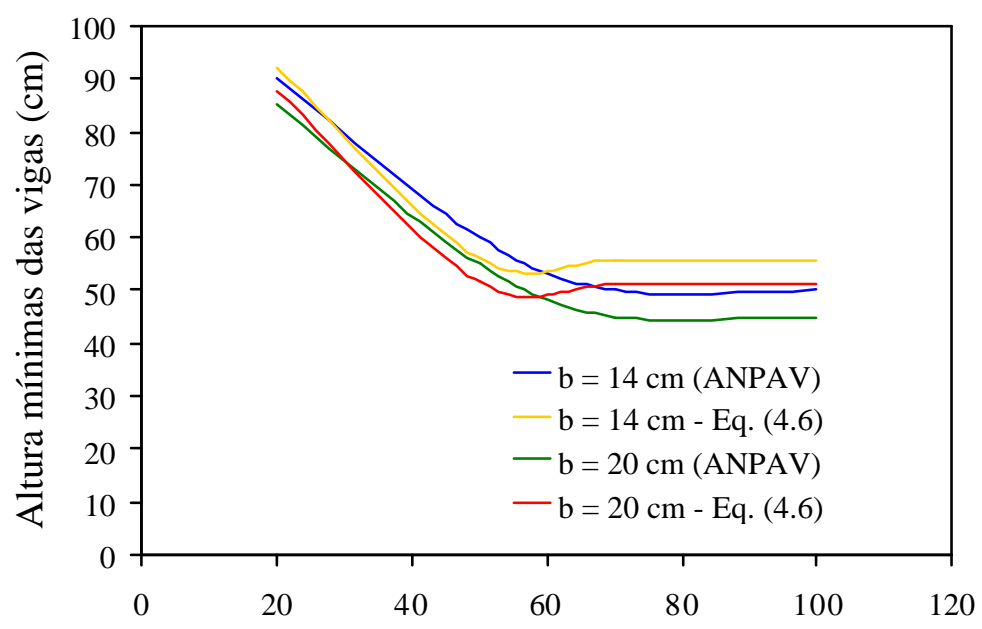

Altura da seção transversal dos pilares $(\mathrm{cm})$

Figura 4.38 - Altura mínima das vigas em função da altura da seção dos pilares

$$
\text { (para vigas com } \ell_{\text {ef }}=7,0 \mathrm{~m} \mathrm{e}_{\mathrm{ck}}=25 \mathrm{MPa} \text { ) }
$$

Considerando-se agora vigas com largura da seção transversal igual a 14 e $20 \mathrm{~cm}$, pilares de apoio com seção transversal de $20 \times 20 \mathrm{~cm}$ e $20 \times 70 \mathrm{~cm}, \mathbf{f}_{\text {ck }}$ de $25 \mathrm{MPa}$ e submetidas a uma ação de serviço de $0,4 \mathrm{kN} / \mathrm{cm}$, os valores de alturas mínimas das vigas, fornecidos pelas eqs. (4.5) e (4.6), que satisfazem as verificações de aceitabilidade sensorial e efeito em paredes estão representados na Figura 4.39.

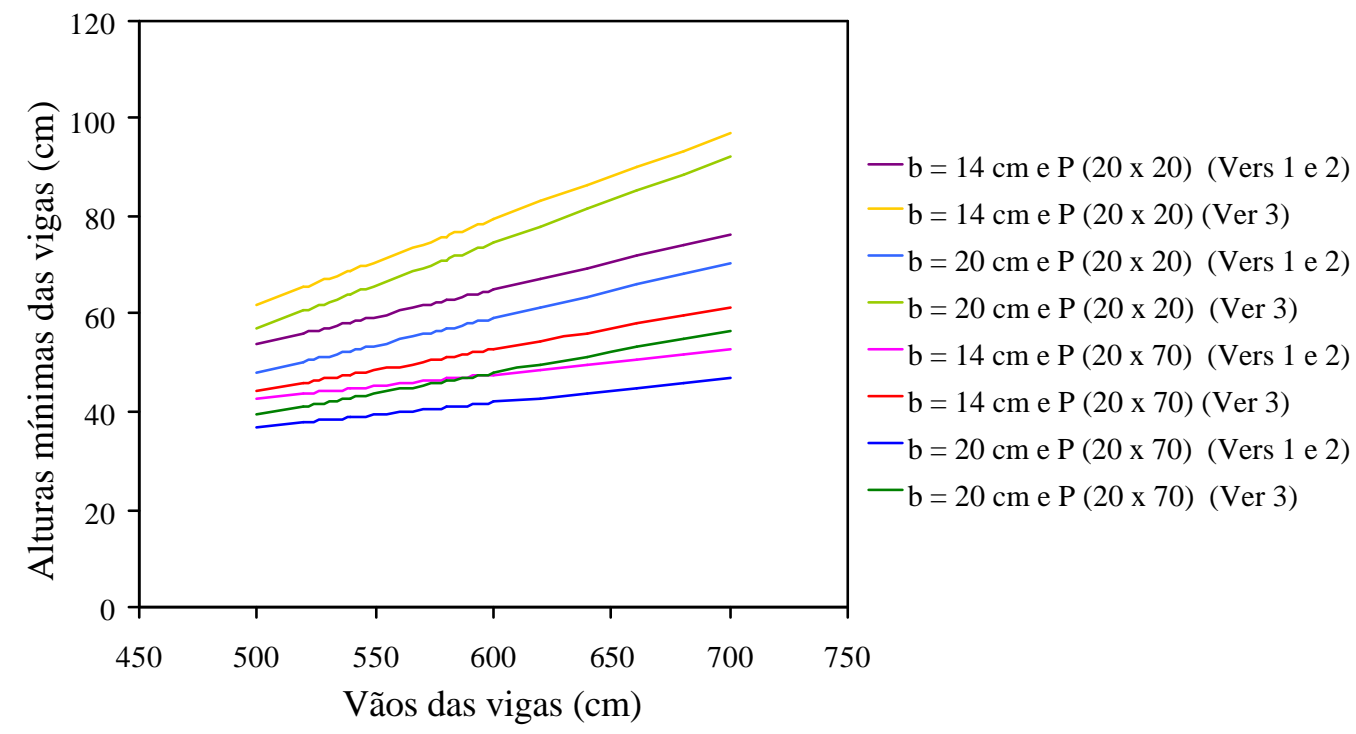

Figura 4.39 - Alturas mínimas de vigas para alguns vãos efetivos 


\section{c) Exemplo de Cálculo}

Para a viga da Figura 4.40, a largura da seção transversal é igual a $15 \mathrm{~cm}$ e a resistência característica do concreto à compressão é igual a $25 \mathrm{MPa}$. Os pilares de apoio têm seção transversal de $20 \times 50 \mathrm{~cm}$ e comprimentos inferior e superior iguais a $3,0 \mathrm{~m}$.

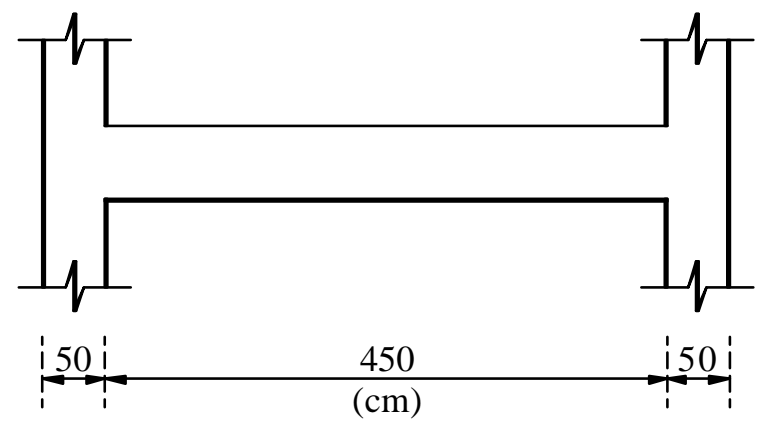

Figura 4.40 - Viga do exemplo de cálculo de altura mínima

Inicialmente, determinou-se a altura mínima para a viga que atendesse às verificações de aceitabilidade sensorial quanto a aspectos visuais e de vibrações, utilizandose a eq. (4.2). Considerando como vão efetivo a distância de eixo a eixo de apoio, e igual a $5,0 \mathrm{~m}$, o coeficiente $\beta$, dado pela eq.(4.3), vale:

$$
\beta=6,0+1,4 \cdot 2,5+0,005 \cdot 500+0,21 \cdot 15-0,009 \cdot 50-0,25 \cdot \frac{500}{50}=12,2
$$

Logo, a altura mínima foi igual a:

$$
\mathrm{h}_{\min }=\frac{\ell_{\mathrm{ef}}}{\beta}=\frac{500}{12,2}=41 \mathrm{~cm}
$$

Como a relação entre o vão efetivo da viga e a altura da seção transversal do pilar foi igual a 10 e a base da viga é menor que $20 \mathrm{~cm}$, o valor de $\beta$, dado pela Tabela 4.3, foi igual a 12. Portanto, obteve-se a altura mínima de:

$$
\mathrm{h}_{\min }=\frac{\ell_{\mathrm{ef}}}{\beta}=\frac{500}{12}=41,7 \mathrm{~cm}
$$

Calculando-se a altura mínima pela eq. (4.5), e adotando-se a carga de serviço igual a $0,40 \mathrm{kN} / \mathrm{cm}$, obteve-se: 


$$
\begin{aligned}
\mathrm{h}_{\min }= & -25-5,13 \cdot 2,5+47,4 \cdot 0,40+0,049 \cdot 500-0,97 \cdot 15+2,06 \cdot 50+ \\
& +0,0215 \cdot 694,44+2,81 \cdot \frac{500}{694,44}-0,0274 \cdot 50^{2}=42,5 \mathrm{~cm}
\end{aligned}
$$

Pode-se observar que as alturas mínimas determinadas a partir dos três procedimentos propostos foram bastante próximas. Considerando-se um valor múltiplo de 5 $\mathrm{cm}$, adotou-se a altura mínima que atendesse às verificações de aceitabilidade sensorial igual a $45 \mathrm{~cm}$.

A altura mínima para satisfazer à verificação do efeito dos deslocamentos em paredes pode ser determinada da mesma forma. Primeiramente, utilizou-se a eq. (4.2), com o coeficiente $\beta$ dado por:

$$
\beta=5,7+1,35 \cdot 2,5+0,005 \cdot 500+0,18 \cdot 15-0,007 \cdot 50-0,26 \cdot \frac{500}{50}=11,3
$$

Assim, calculou-se a altura mínima igual a:

$$
\mathrm{h}_{\min }=\frac{\ell_{\mathrm{ef}}}{\beta}=\frac{500}{11,3}=44,2 \mathrm{~cm}
$$

Neste caso, o coeficiente $\beta$ dado pela Tabela 4.3, foi igual a 10, e a altura mínima resultou:

$$
\mathrm{h}_{\min }=\frac{\ell_{\mathrm{ef}}}{\beta}=\frac{500}{10}=50 \mathrm{~cm}
$$

Já pela a eq. (4.6), obteve-se a altura mínima igual a:

$$
\begin{aligned}
\mathrm{h}_{\min }= & -55,5-8,0 \cdot 2,5+53,7 \cdot 0,40+0,083 \cdot 500-0,81 \cdot 15+2,74 \cdot 50+ \\
& +0,028 \cdot 694,44+4,1 \cdot \frac{500}{694,44}-0,036 \cdot 50^{2}=44,7 \mathrm{~cm}
\end{aligned}
$$

Novamente, pode-se notar que os valores de alturas mínimas determinadas a partir dos três procedimentos propostos ficaram próximos. Apenas o valor obtido com a utilização do coeficiente $\beta$ dado pela Tabela 4.3, que é o procedimento mais simplificado, foi um pouco maior. 
Assim, para a verificação dos efeitos dos deslocamentos em paredes, também se pode adotar a altura mínima igual a $45 \mathrm{~cm}$.

Com a finalidade de se verific ar o resultado obtido, a viga foi resolvida utilizando-se o programa ANPAV. Para o dimensionamento das armaduras foi considerada uma carga total $25 \%$ maior que a ação de serviço adotada para o cálculo da altura mínima. Os deslocamentos obtidos foram apresentados na Tabela 4.4.

Tabela 4.4 - Deslocamentos calculados com o programa ANPAV

\begin{tabular}{|c|c|c|c|c|}
\hline \multirow{2}{*}{ Ação } & \multicolumn{3}{|c|}{ Deslocamentos (cm) } & $\begin{array}{c}\text { Relação entre os } \\
\text { deslocamentos diferidos } \\
\text { e imediatos }\end{array}$ \\
\cline { 2 - 5 } & Imediatos & Totais & Diferidos & \begin{tabular}{c}
1,17 \\
\hline De serviço
\end{tabular} \\
\hline Total & 0,41 & 0,89 & 0,48 & 1,16 \\
\hline
\end{tabular}

Sendo o vão efetivo da viga igual a $5,0 \mathrm{~m}$, os limites dos deslocamentos para as verificações 1,2 e 3 , foram, respectivamente:

$$
\begin{aligned}
& \mathrm{a}_{\mathrm{t}, \mathrm{g}+\psi \mathrm{q}} \leq \frac{\ell}{250} \leq \frac{500}{250} \leq 2,0 \mathrm{~cm} \\
& \mathrm{a}_{\mathrm{i}, \mathrm{q}} \leq \frac{\ell}{350} \leq \frac{500}{350} \leq 1,43 \mathrm{~cm} \\
& \mathrm{a}_{\mathrm{inc}} \leq\left\{\begin{array}{l}
\frac{\ell}{250}=\frac{500}{250}=2,0 \mathrm{~cm} \\
1,0 \mathrm{~cm}
\end{array} \Rightarrow \mathrm{a}_{\text {inc }} \leq 1,0 \mathrm{~cm}\right.
\end{aligned}
$$

Embora não tenham sido calculados os deslocamentos incrementais e os devidos à ação variável, pode-se perceber que a altura mínima de $45 \mathrm{~cm}$ satisfez às três verificações, já que o deslocamento total devido à ação de serviço, igual a $0,89 \mathrm{~cm}$, foi menor que todos os limites dessas verificações.

A Tabela 4.4 fornece também as relações entre os deslocamentos diferidos e imediatos resultantes da análise com o programa ANPAV, iguais a 1,17 e 1,16, para as ações de serviço e totais, respectivamente. Pela eq. (4.1), proposta para o cálculo do coeficiente multiplicador dos deslocamentos imediatos para o cálculo dos deslocamentos diferidos, obteve-se:

$$
\alpha_{\mathrm{f}, \mathrm{aj}}=1,65-0,085 \cdot 2,5-0,0014 \cdot 500+0,023 \cdot 15+0,00006 \cdot 45^{2}=1,20
$$


Pode-se observar que o valor fornecido pela eq. (4.1) foi bastante próximo do obtido com o programa ANPAV.

Assim, diante dos resultados desse exemplo, novamente, pode-se ter uma idéia da boa aproximação que os métodos simplificados propostos oferecerem. 


\section{DESLOCAMENTOS EM PAVIMENTOS}

\subsection{INTRODUÇÃO}

Neste capítulo é apresentado o estudo dos deslocamentos de alguns pavimentos de edifícios residenciais, com lajes maciças apoiadas em vigas. Os deslocamentos imediatos foram calculados a partir de uma análise linear, utilizando-se o programa LASER, desenvolvido no SET-EESC-USP por RAMALHO (1990), e de uma análise não-linear, com o programa ANPAV, também desenvolvido no SET-EESC-USP por OLIVEIRA (2001), com o qual também foram calculados os deslocamentos totais.

Inicialmente, são comentados os principais parâmetros considerados no cálculo dos deslocamentos, comuns a todos os pavimentos. Em seguida, são apresentadas as características de cada um dos pavimentos analisados, bem como seus deslocamentos. Fazse, então, uma comparação entre os deslocamentos devidos aos dois tipos de análise, ressaltando-se a relação entre os deslocamentos imediatos, obtidos a partir da análise elástica, com os deslocamentos imediatos e diferidos fornecidos pela análise não-linear. Por fim, para algumas lajes e vigas de cada pavimento, são calculadas suas alturas mínimas utilizando-se os procedimentos propostos nos Capítulos 3 e 4, e o resultado obtido é comparado com os valores adotados no projeto.

\subsection{CONSIDERAÇÕES GERAIS}

Comentam-se a seguir, o procedimento adotado para a análise dos pavimentos com os programas supracitados. 
De posse das propriedades dos elementos estruturais e dos materiais utilizados, fornecidos no projeto estrutural dos pavimentos, inicialmente, foi realizada a análise linear com o programa LASER. Para isso, foi feita a discretização dos pavimentos, onde as lajes foram discretizadas em elementos quadrilaterais e as vigas em elementos lineares.

As ações devidas ao peso do piso e do revestimento das lajes e a ação variável foram lançadas sobre as lajes, e todas as paredes existentes sobre vigas ou lajes foram consideradas através de cargas nodais localizadas corretamente nas posições onde se encontravam nesses elementos. Dessa forma, procurou-se evitar o inconveniente de se trabalhar com cargas linearmente distribuídas que poderiam levar a distorções nos resultados obtidos, especialmente para as lajes.

Vale ressaltar que para essa análise linear foi considerado o módulo de elasticidade secante do concreto.

Assim, foram calculados os deslocamentos imediatos, utilizando-se as combinações quase-permanente e freqüiente de ações, com os seguintes coeficientes de redução das ações variáveis:

- Combinação quase permanente de ações:

$$
\mathrm{F}_{\mathrm{d}, \mathrm{ser}}=\mathrm{F}_{\mathrm{gk}}+0,3 \mathrm{~F}_{\mathrm{qk}}
$$

- Combinação freqüiente de ações:

$$
\mathrm{F}_{\mathrm{d}, \mathrm{ser}}=\mathrm{F}_{\mathrm{gk}}+0,4 \mathrm{~F}_{\mathrm{qk}}
$$

sendo:

$\mathbf{F}_{\text {d,ser }}$ a ação de serviço com seu valor de cálculo, calculada de acordo com a combinação de ações utilizada,

$\mathbf{F}_{\mathbf{g k}}$ as ações permanentes com seus valores característicos,

$\mathbf{F}_{\mathbf{q k}}$ as ações variáveis com seus valores característicos.

Para realização da análise não-linear dos pavimentos com o programa ANPAV, além dos dados utilizados na análise linear, foram consideradas as áreas de aço de flexão de todos os elementos estruturais, também fornecidas no projeto estrutural.

Para a análise não-linear foi considerado o módulo de elasticidade tangente do concreto.

De posse desses dados foram calculados os deslocamentos imediatos e totais devido às combinações quase-permanente e freqüente de ações, utilizando-se o programa ANPAV 
Para o cálculo dos deslocamentos totais, foram adotados, além das combinações de ações apresentadas anteriormente, a umidade relativa igual a $60 \%$, a temperatura de $25{ }^{\circ} \mathrm{C} \mathrm{e}$ as idades de aplicação das ações permanentes e variáveis iguais a 28 e 45 dias, respectivamente. Esses valores correspondem às mesmas condições dos estudos das lajes e vigas isoladas.

\subsection{PAVIMENTO 1}

Nas Figuras 5.1 e 5.2 são apresentadas as plantas da arquitetura e dos eixos dos elementos estruturais do primeiro pavimento analisado.

As lajes têm a altura igual a $9 \mathrm{~cm}$ e todas as vigas têm seção transversal de $12 \times 60 \mathrm{~cm}$, com exceção da viga $\mathrm{V} 3$, que tem $12 \times 40 \mathrm{~cm}$.

A carga uniformemente distribuída sobre a laje foi constituída, além do peso próprio, por uma parcela igual a $1,0 \mathrm{kN} / \mathrm{m}^{2}$, correspondente ao peso do piso e do revestimento, e uma ação variável de $1,5 \mathrm{kN} / \mathrm{m}^{2}$.

Neste pavimento foram utilizados aço CA - 50 e concreto com resistência característica à compressão de $20 \mathrm{MPa}$.
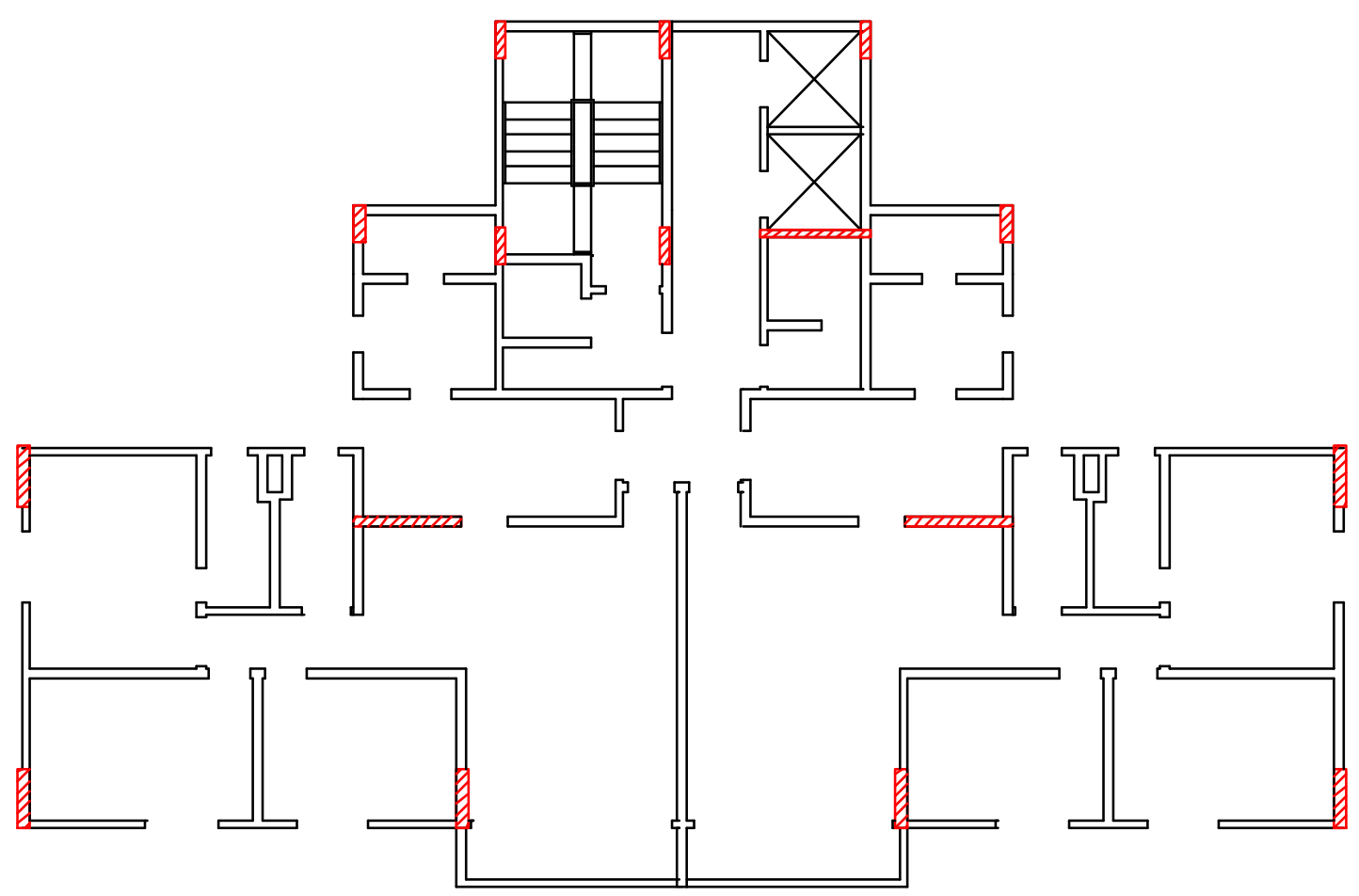

Figura 5.1 - Planta arquitetura do pavimento 1 


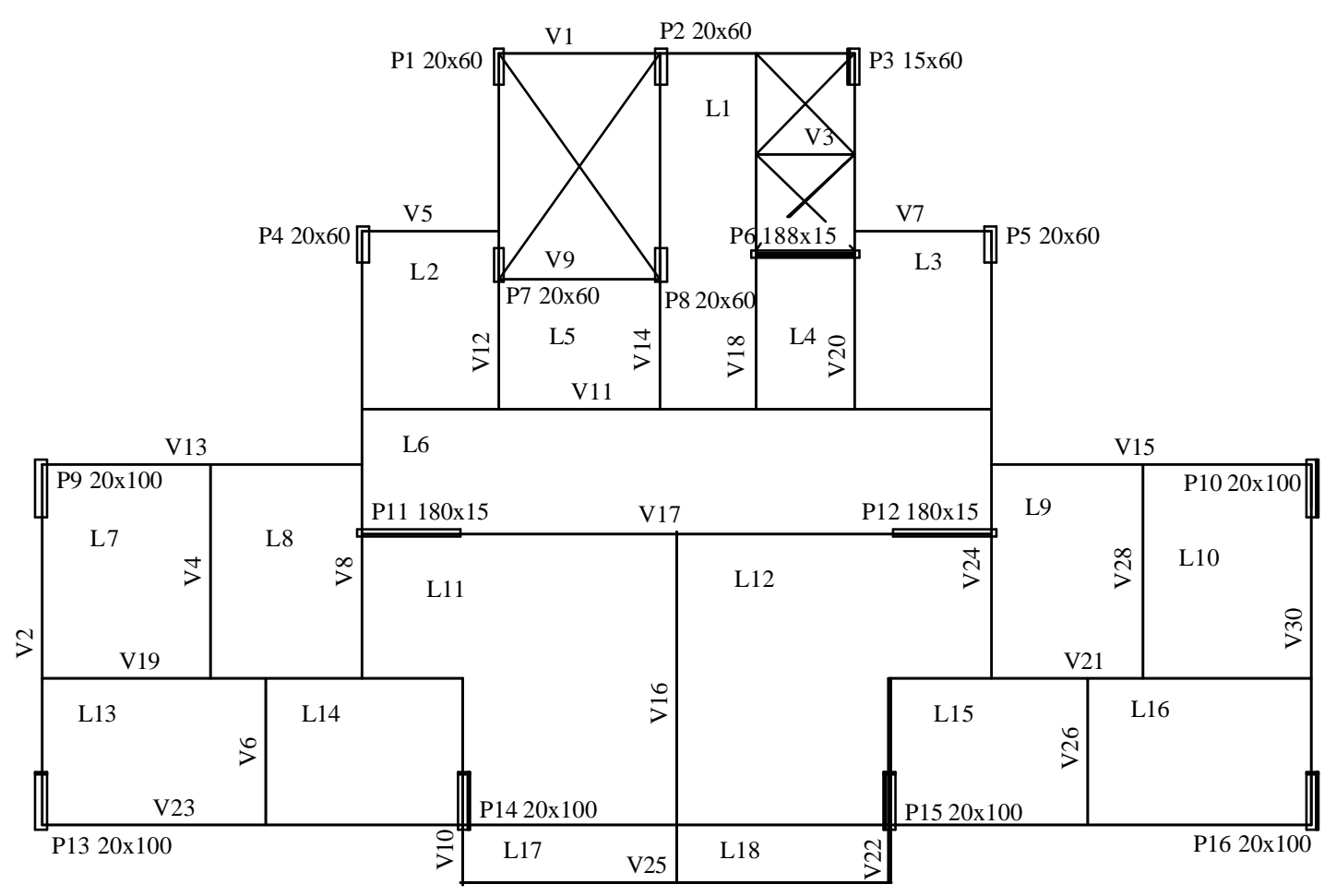

Figura 5.2 - Eixos dos elementos estruturais

\subsubsection{VALORES DOS DESLOCAMENTOS}

Para as combinações quase-permanente e freqüente de ações foram determinados os deslocamentos imediatos com o programa LASER, e com o programa ANPAV foram calculados os deslocamentos imediatos, levando-se em conta a influência da fissuração, e os deslocamentos totais, considerando-se o efeito da fluência e da retração do concreto.

Os deslocamentos imediatos, obtidos a partir das análises linear e não-linear, e os deslocamentos totais, obtidos evidentemente apenas com a análise não-linear, são apresentados nas figuras seguintes, nas quais são representados por linhas de mesmo deslocamento cujo valor aparece anotado. Nestas figuras, M e m correspondem, respectivamente, aos deslocamentos mínimo e máximo que ocorrem no pavimento. Ressaltase que, devido à referência adotada, os valores negativos correspondem aos deslocamentos no sentido do carregamento colocado, ou seja, para baixo. 


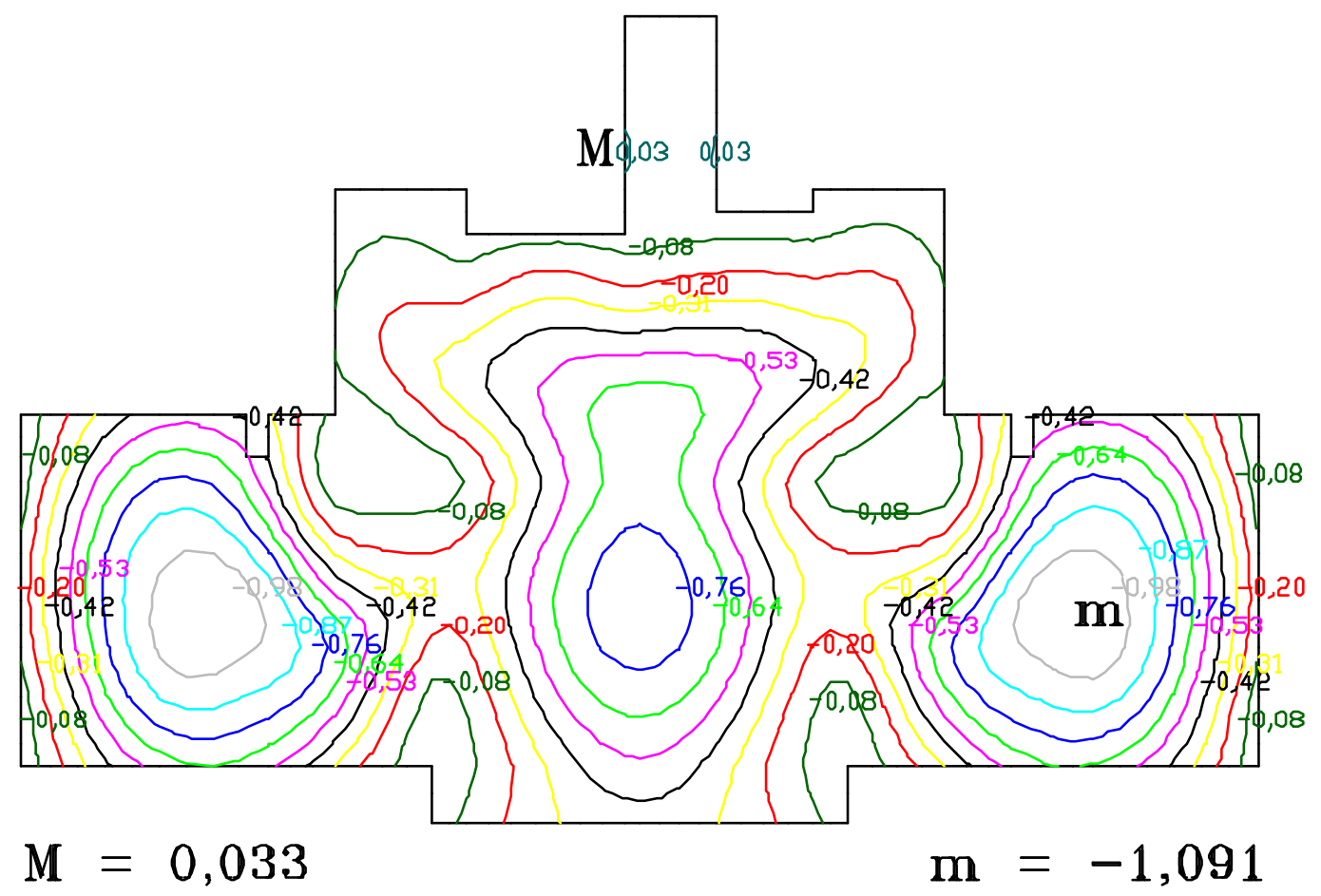

Figura 5.3 - Deslocamentos imediatos obtidos a partir da análise linear (Combinação quase-permanente)

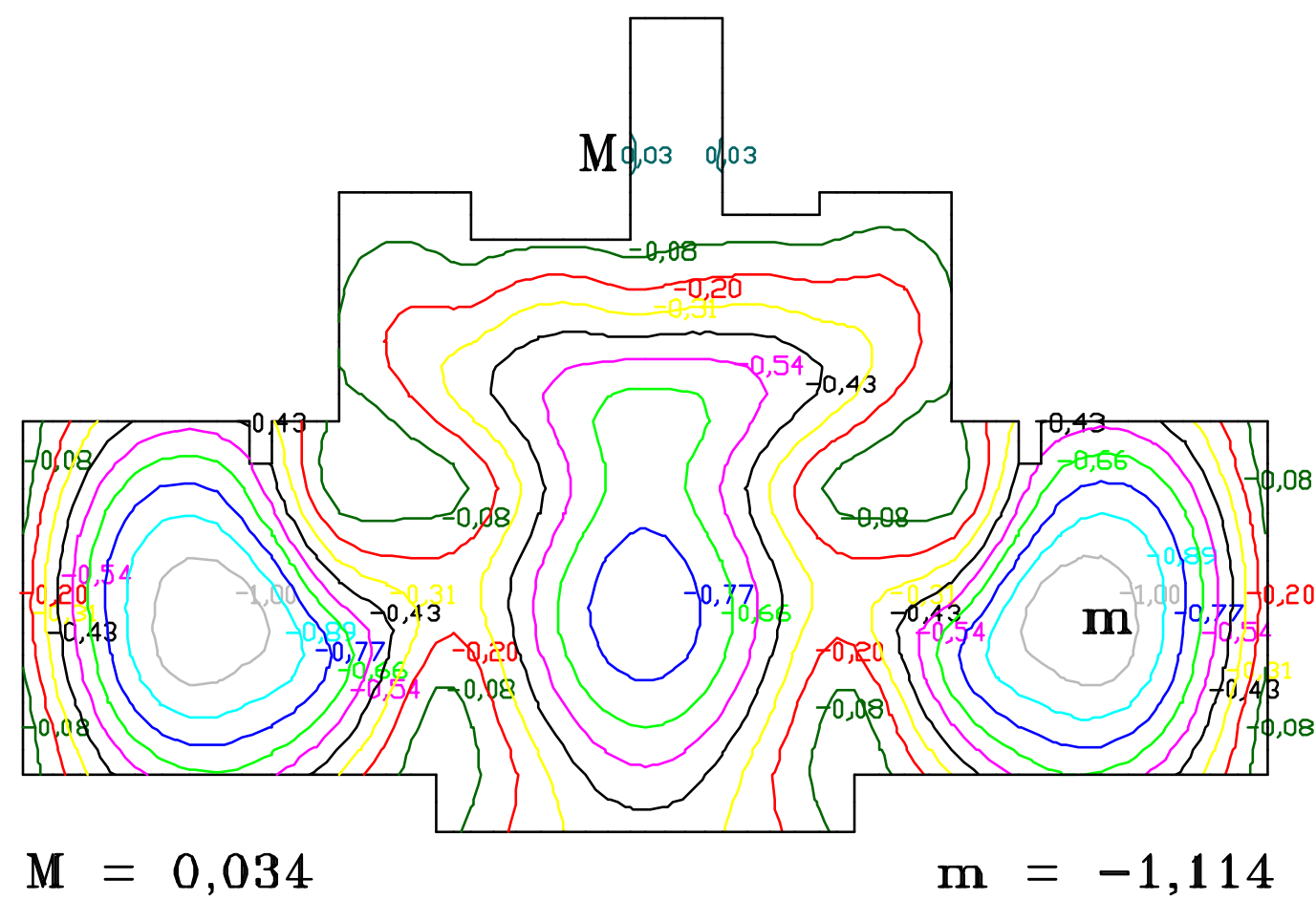

Figura 5.4 - Deslocamentos imediatos obtidos a partir da análise linear (Combinação freqüente) 


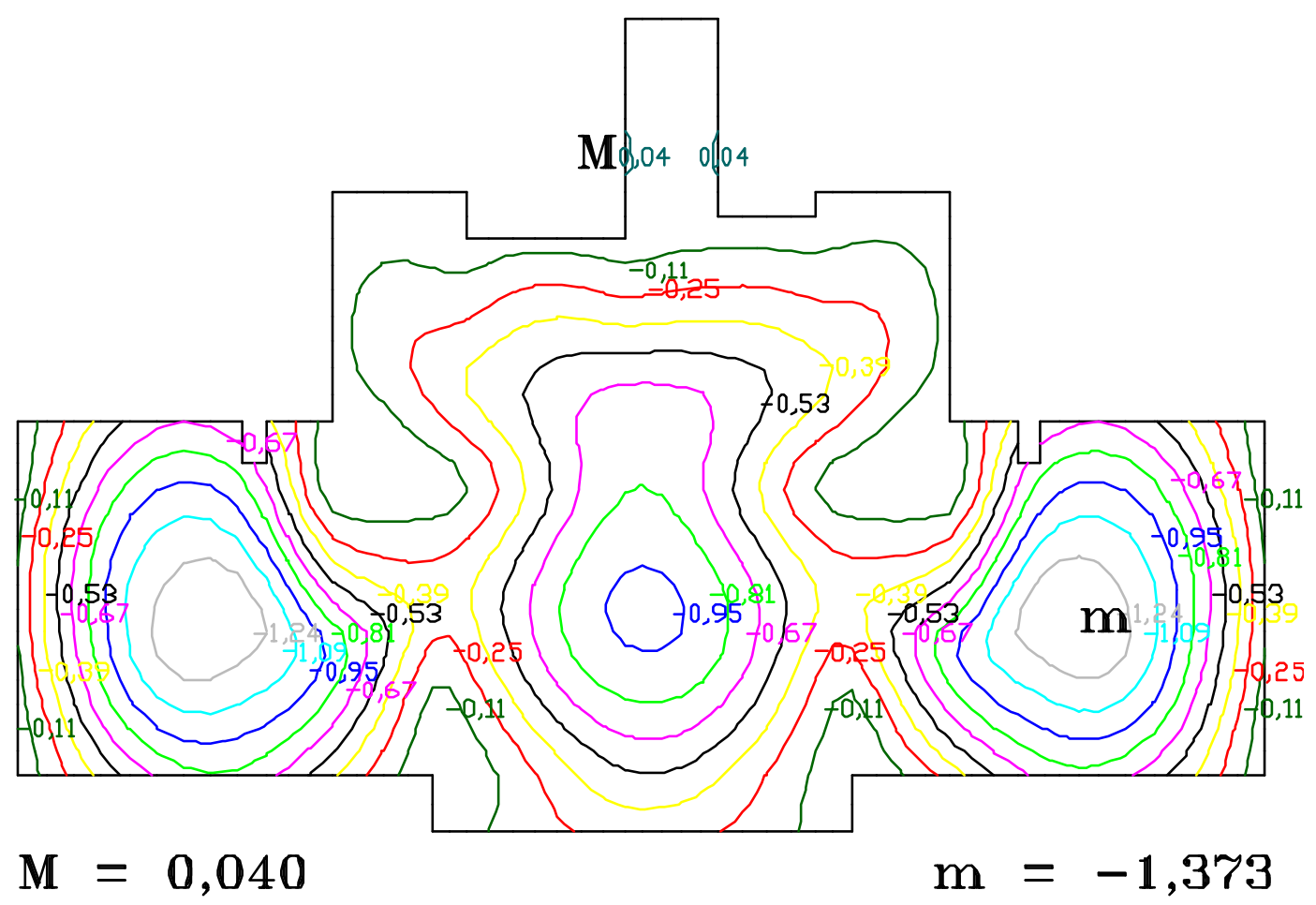

Figura 5.5 - Deslocamentos imediatos obtidos a partir da análise não-linear (Combinação quase-permanente)

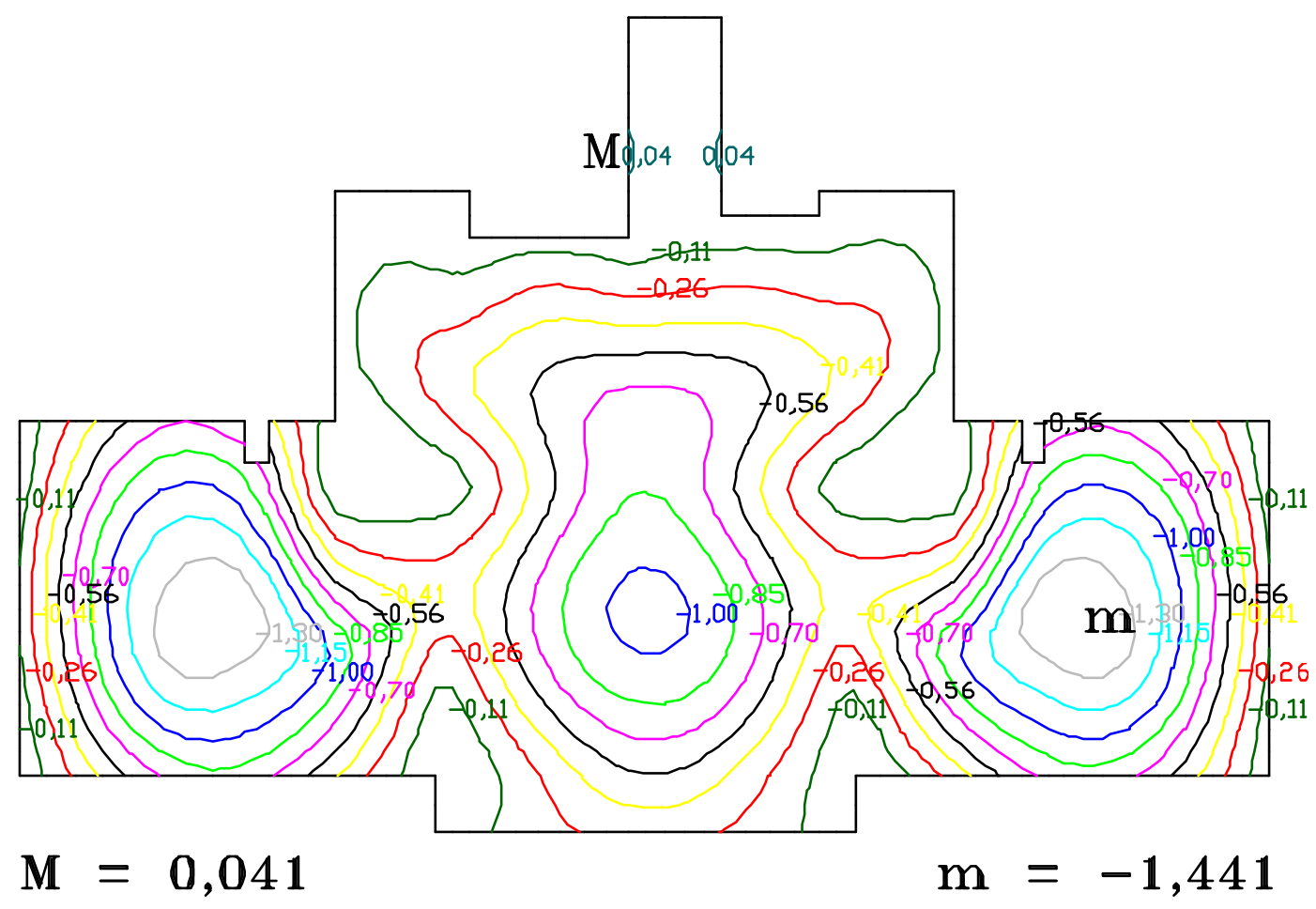

Figura 5.6 - Deslocamentos imediatos obtidos a partir da análise não-linear (Combinação freqüente) 


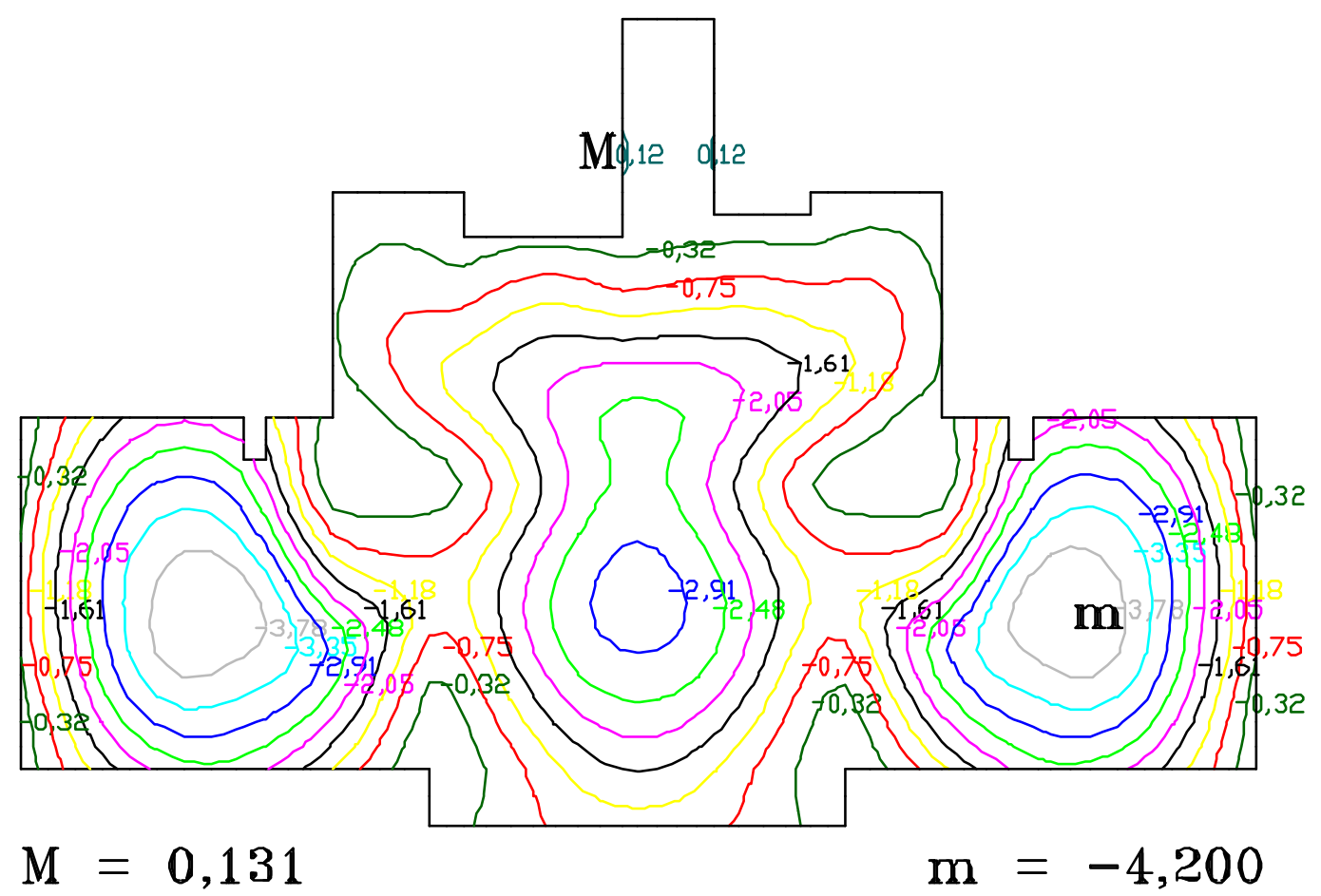

Figura 5.7 - Deslocamentos totais obtidos a partir da análise não-linear (Combinação quase-permanente)

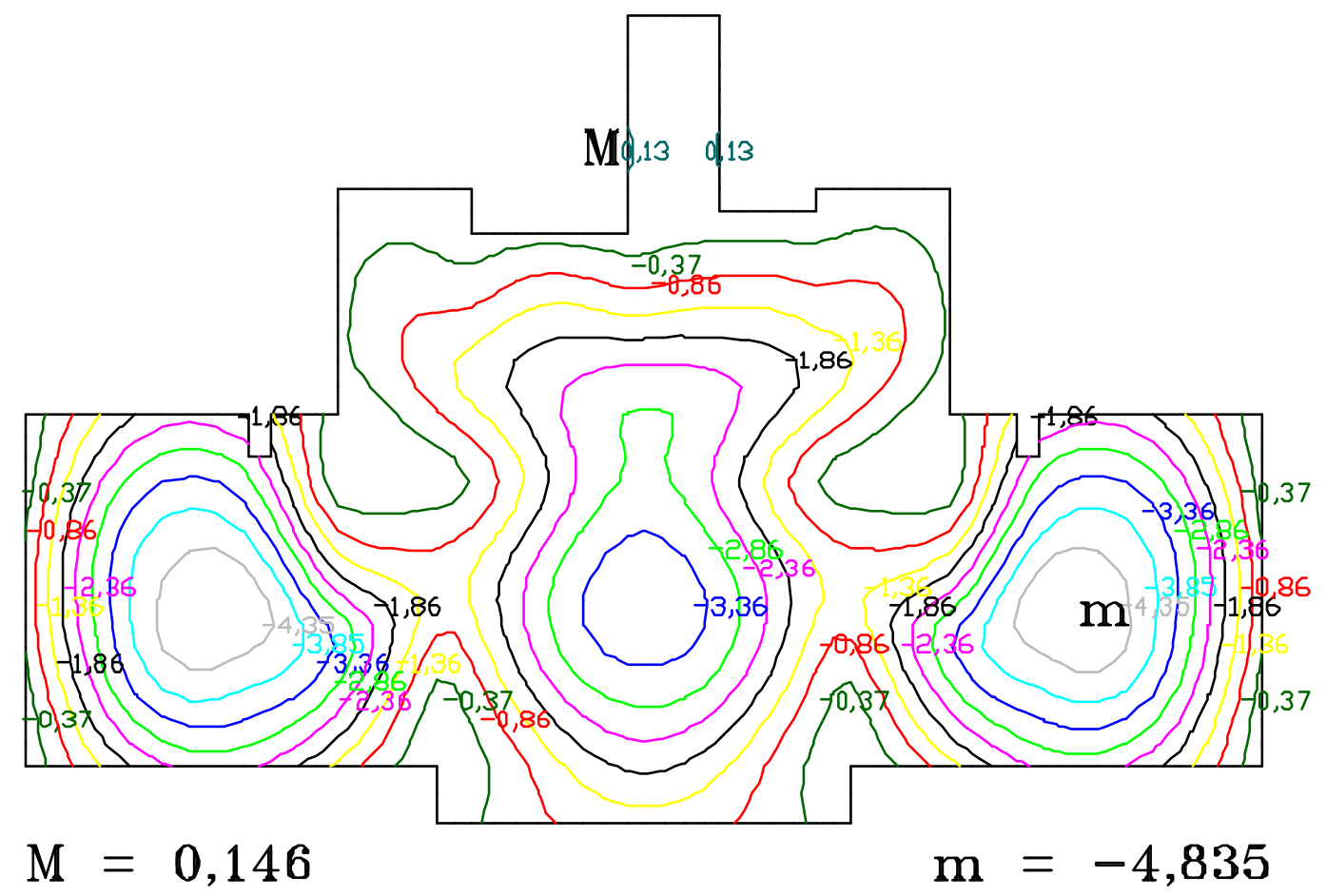

Figura 5.8 - Deslocamentos totais obtidos a partir da análise não-linear (Combinação frequiente) 


\subsubsection{ANÁLISE DOS RESULTADOS}

Faz-se a seguir uma comparação entre os deslocamentos resultantes das análises linear e não-linear.

\section{a) Deslocamentos Imediatos}

Comparando-se os deslocamentos imediatos obtidos com os programas LASER e ANPAV, notou-se que nas regiões onde os níveis dos esforços eram mais baixos, os deslocamentos não-lineares foram bastante próximos e até menores que os lineares.

Para níveis mais elevados de esforços, os deslocamentos imediatos resultantes da análise não-linear, e devidos às combinações quase-permanente e freqüente, foram respectivamente $26 \%$ e $30 \%$, maiores, em média, que os correspondentes obtidos da análise linear.

Este comportamento já era esperado, pois nos elementos que apresentam nenhuma ou poucas fissuras, a consideração da colaboração da armadura na sua rigidez, como permite o programa ANPAV, reduz os deslocamentos, em comparação com a análise com o programa LASER, que considera apenas a seção de concreto no cálculo da rigidez.

Já para as regiões mais fissuradas, a consideração da seção bruta de concreto no cálculo da rigidez, como faz o programa LASER, leva a uma maior rigidez dos elementos, e, consequentemente, a menores deslocamentos.

A partir dos deslocamentos ilustrados da Figura 5.3 à Figura 5.8, e organizados na Tabela 5.1 pelos valores das curvas de deslocamentos equivalentes, observou-se tal comportamento. As relações médias entre os deslocamentos imediatos não-lineares e os lineares foram 1,27 e 1,31, respectivamente para as combinações quase-permanente e freqüente de ações, valores estes bastante próximos das médias do pavimento, comentadas anteriormente.

Tabela 5.1 - Deslocamentos imediatos do pavimento 1 devidos às análises lineares e não-lineares, em cm

\begin{tabular}{|c|c|c|c|c|c|}
\hline \multicolumn{2}{|c|}{ Análise Linear (LASER) } & \multicolumn{2}{c|}{ Análise Não Linear (ANPAV) } & \multicolumn{2}{c|}{$\begin{array}{c}\text { Relação entre os deslocamentos } \\
\text { não lineares e lineares }\end{array}$} \\
\hline O. Permanente & Frequente & O. Permanente & Frequente & O. Permanente & Frequente \\
\hline$-0,08$ & $-0,08$ & $-0,11$ & $-0,11$ & 1,38 & 1,38 \\
\hline$-0,20$ & $-0,20$ & $-0,25$ & $-0,26$ & 1,25 & 1,30 \\
\hline$-0,31$ & $-0,31$ & $-0,39$ & $-0,41$ & 1,26 & 1,32 \\
\hline$-0,42$ & $-0,42$ & $-0,53$ & $-0,56$ & 1,26 & 1,33 \\
\hline$-0,53$ & $-0,54$ & $-0,67$ & $-0,70$ & 1,26 & 1,30 \\
\hline$-0,64$ & $-0,66$ & $-0,81$ & $-0,85$ & 1,27 & 1,29 \\
\hline$-0,76$ & $-0,77$ & $-0,95$ & $-1,00$ & 1,25 & 1,30 \\
\hline$-0,87$ & $-0,89$ & $-1,09$ & $-1,15$ & 1,25 & 1,29 \\
\hline$-0,98$ & $-1,00$ & $-1,24$ & $-1,30$ & 1,27 & 1,30 \\
\hline
\end{tabular}


Para representar essa situação nas vigas são apresentados, da Figura 5.9 a Figura 5.11, os deslocamentos imediatos das vigas V2, V13 e V19.

Como a viga V2 foi submetida a esforços mais baixos, notou-se que os valores dos deslocamentos imediatos lineares e não-lineares foram bem próximos.

Já as vigas V13 e V19, que inham um maior grau de fissuração, apresentaram deslocamentos imediatos não-lineares maiores que os lineares. Na região central dos vãos, onde se tem os maiores esforços, os deslocamentos imediatos obtidos com o programa ANPAV, para a combinação quase-permanente de ações, foram, em média, $28 \%$ e $25 \%$ maiores que os fornecidos pelo programa LASER, respectivamente para as vigas V13 e V19. Já para a combinação freqüente de ações, esses deslocamentos diferiram em $32 \%$ e $28 \%$, respectivamente. Esses valores são fornecidos nas Tabelas 5.2 e 5.3.

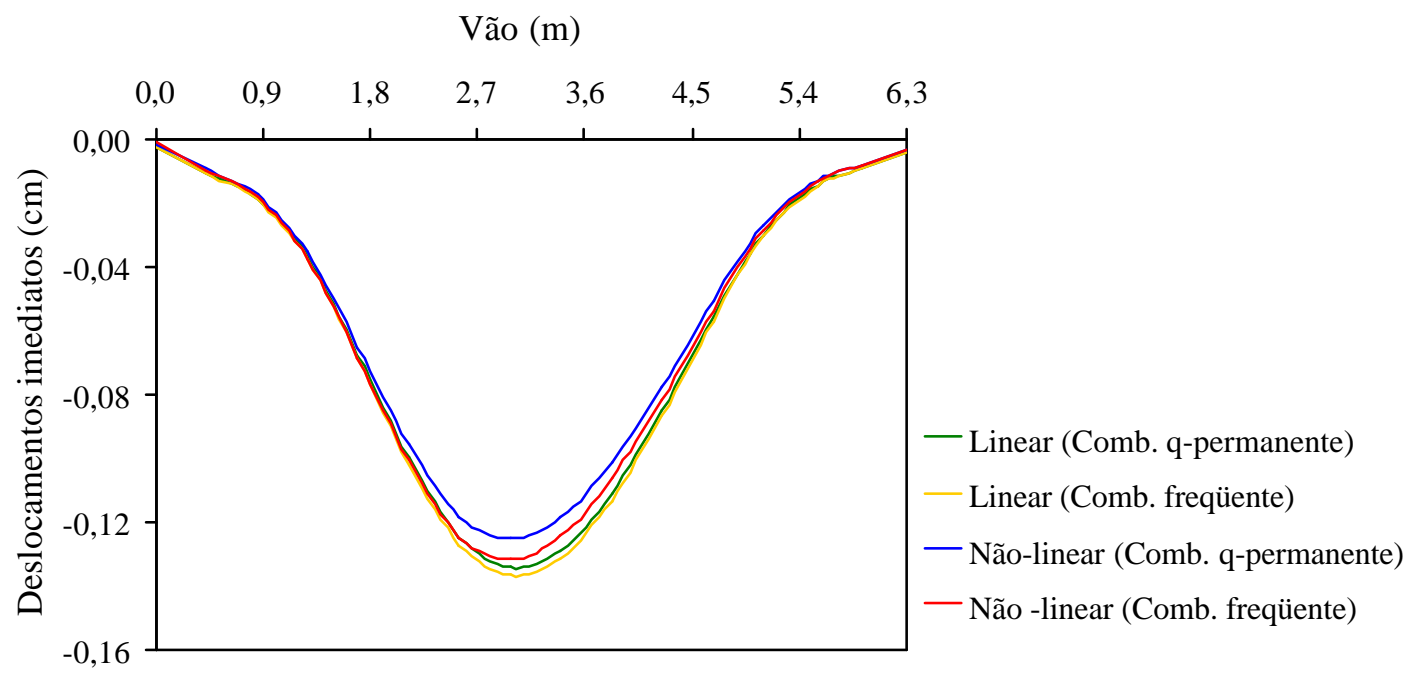

Figura 5.9 - Deslocamentos imediatos da viga V2

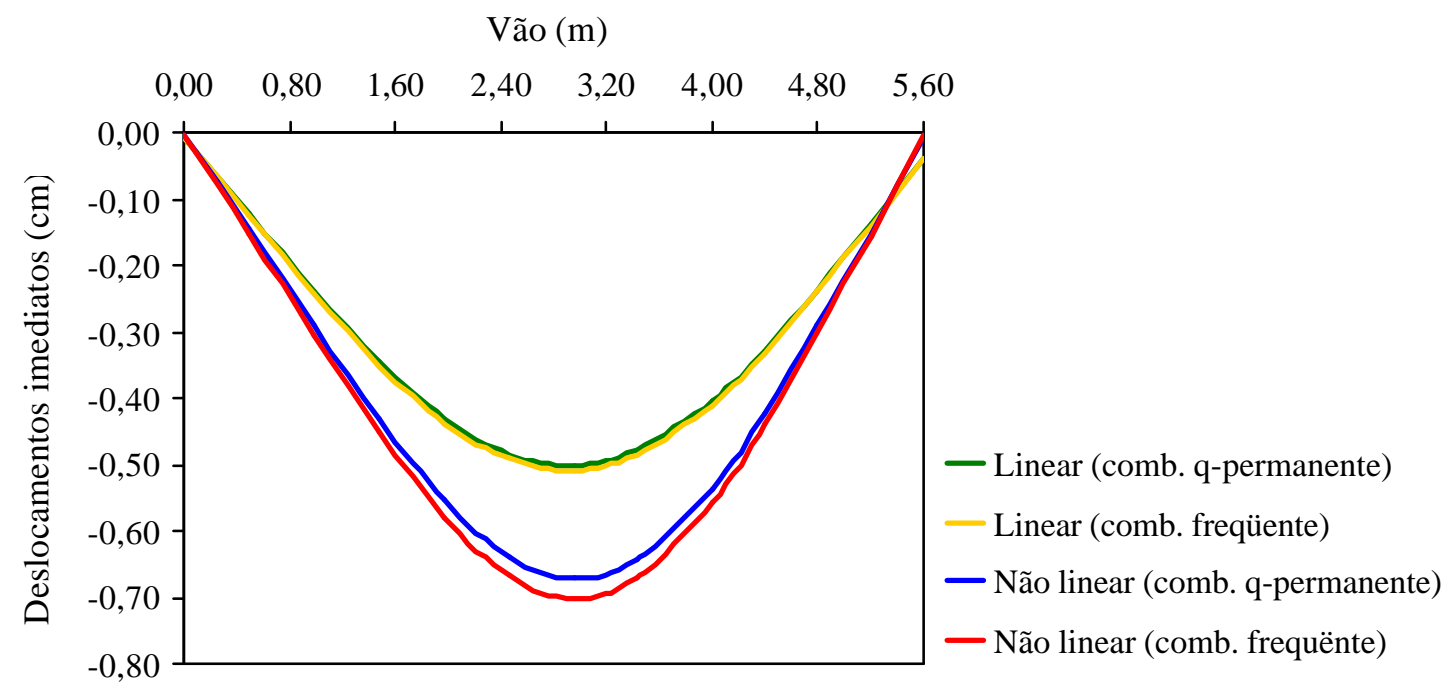

Figura 5.10 - Deslocamentos imediatos da viga V13 


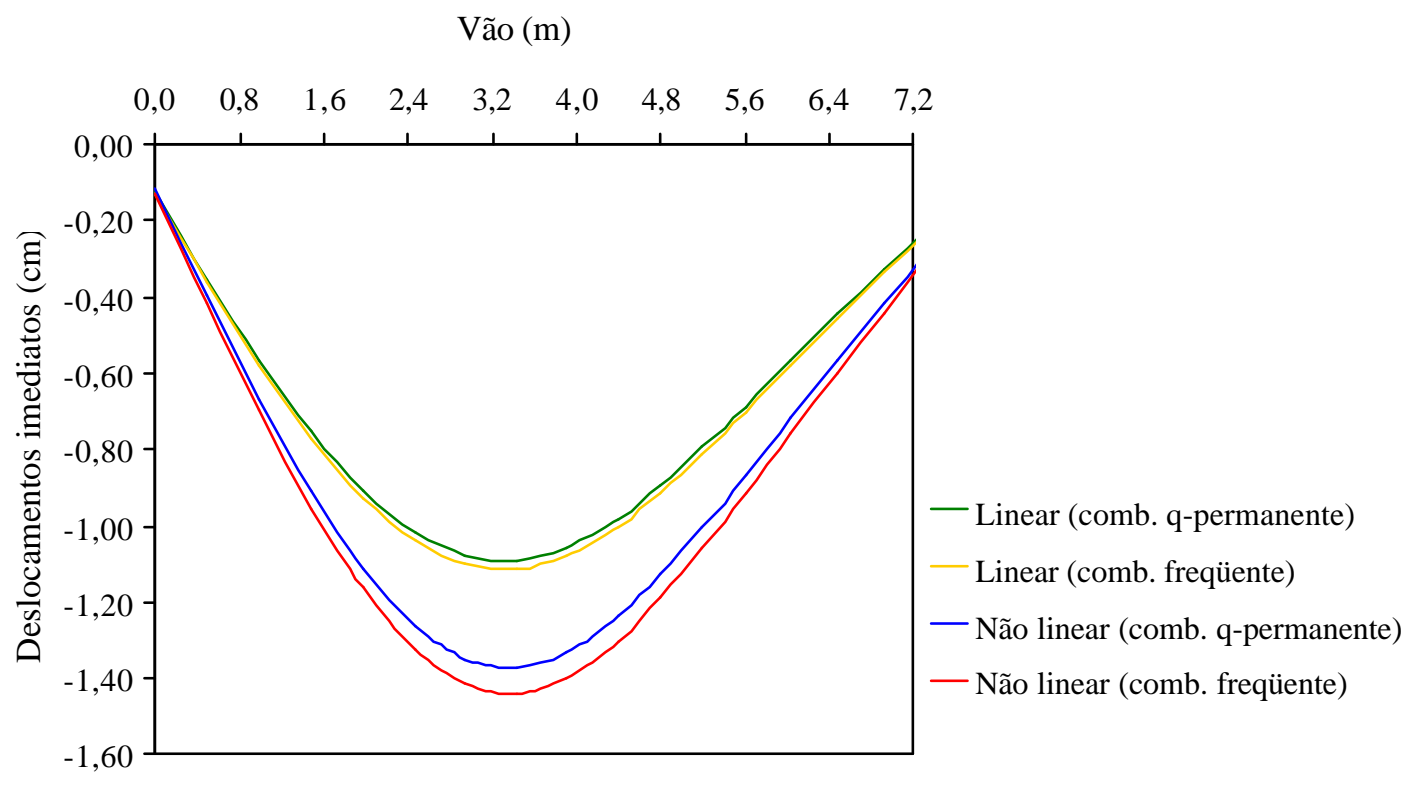

Figura 5.11 - Deslocamentos imediatos da viga V19

Tabela 5.2 - Deslocamentos imediatos da viga V13, em cm

\begin{tabular}{|c|c|c|c|c|c|c|}
\hline \multirow{2}{*}{$\begin{array}{c}\text { Vão } \\
(\mathbf{m})\end{array}$} & \multicolumn{2}{|c|}{ Análise Linear (LASER) } & \multicolumn{2}{c|}{ Análise Não Linear (ANPAV) } & \multicolumn{2}{c|}{$\begin{array}{c}\text { Relação entre os deslocamentos } \\
\text { não lineares e lineares }\end{array}$} \\
\cline { 2 - 7 } & Q-Permanente & Frequente & O-Permanente & Frequente & O-Permanente & Frequente \\
\hline 0,000 & $-0,004$ & $-0,004$ & $-0,004$ & $-0,004$ & 0,84 & 0,79 \\
\hline 0,492 & $-0,120$ & $-0,122$ & $-0,144$ & $-0,151$ & 1,20 & 1,24 \\
\hline 0,983 & $-0,238$ & $-0,241$ & $-0,290$ & $-0,304$ & 1,22 & 1,26 \\
\hline 1,475 & $-0,344$ & $-0,349$ & $-0,430$ & $-0,450$ & 1,25 & 1,29 \\
\hline 1,967 & $-0,429$ & $-0,436$ & $-0,553$ & $-0,578$ & 1,29 & 1,33 \\
\hline 2,458 & $-0,483$ & $-0,490$ & $-0,639$ & $-0,668$ & 1,32 & 1,36 \\
\hline 2,950 & $-0,500$ & $-0,507$ & $-0,671$ & $-0,701$ & 1,34 & 1,38 \\
\hline 3,425 & $-0,477$ & $-0,484$ & $-0,642$ & $-0,670$ & 1,34 & 1,38 \\
\hline 4,000 & $-0,403$ & $-0,409$ & $-0,534$ & $-0,557$ & 1,32 & 1,36 \\
\hline 4,400 & $-0,327$ & $-0,331$ & $-0,422$ & $-0,439$ & 1,29 & 1,33 \\
\hline 4,800 & $-0,236$ & $-0,238$ & $-0,290$ & $-0,301$ & 1,23 & 1,26 \\
\hline 5,200 & $-0,137$ & $-0,138$ & $-0,149$ & $-0,153$ & 1,09 & 1,11 \\
\hline 5,600 & $-0,037$ & $-0,036$ & $-0,007$ & $-0,004$ & 0,18 & 0,10 \\
\hline
\end{tabular}


Tabela 5.3 - Deslocamentos imediatos da viga V19, em $\mathrm{cm}$

\begin{tabular}{|c|c|c|c|c|c|c|}
\hline \multirow{2}{*}{$\begin{array}{c}\text { Vão } \\
(\mathbf{m})\end{array}$} & \multicolumn{2}{|c|}{ Análise Linear (LASER) } & \multicolumn{2}{c|}{ Análise Não Linear (ANPAV) } & \multicolumn{2}{c|}{$\begin{array}{c}\text { Relação entre os deslocamentos } \\
\text { não lineares e lineares }\end{array}$} \\
\cline { 2 - 7 } & O-Permanente & Frequente & O-Permanente & Frequente & O-Permanente & Frequente \\
\hline 0,000 & $-0,125$ & $-0,127$ & $-0,118$ & $-0,125$ & 0,95 & 0,98 \\
\hline 0,492 & $-0,352$ & $-0,360$ & $-0,398$ & $-0,418$ & 1,13 & 1,16 \\
\hline 0,983 & $-0,566$ & $-0,578$ & $-0,666$ & $-0,698$ & 1,18 & 1,21 \\
\hline 1,475 & $-0,754$ & $-0,770$ & $-0,909$ & $-0,952$ & 1,20 & 1,24 \\
\hline 1,967 & $-0,907$ & $-0,926$ & $-1,111$ & $-1,164$ & 1,22 & 1,26 \\
\hline 2,458 & $-1,017$ & $-1,038$ & $-1,261$ & $-1,322$ & 1,24 & 1,27 \\
\hline 2,950 & $-1,078$ & $-1,101$ & $-1,350$ & $-1,416$ & 1,25 & 1,29 \\
\hline 3,425 & $-1,090$ & $-1,113$ & $-1,371$ & $-1,440$ & 1,26 & 1,29 \\
\hline 3,900 & $-1,057$ & $-1,080$ & $-1,334$ & $-1,402$ & 1,26 & 1,30 \\
\hline 4,400 & $-0,981$ & $-1,001$ & $-1,237$ & $-1,302$ & 1,26 & 1,30 \\
\hline 4,800 & $-0,895$ & $-0,914$ & $-1,129$ & $-1,188$ & 1,26 & 1,30 \\
\hline 5,200 & $-0,795$ & $-0,812$ & $-1,004$ & $-1,057$ & 1,26 & 1,30 \\
\hline 5,600 & $-0,686$ & $-0,701$ & $-0,870$ & $-0,916$ & 1,27 & 1,31 \\
\hline 6,038 & $-0,564$ & $-0,577$ & $-0,719$ & $-0,757$ & 1,27 & 1,31 \\
\hline 6,475 & $-0,444$ & $-0,455$ & $-0,568$ & $-0,598$ & 1,28 & 1,32 \\
\hline 6,913 & $-0,329$ & $-0,337$ & $-0,418$ & $-0,440$ & 1,27 & 1,30 \\
\hline 7,350 & $-0,220$ & $-0,226$ & $-0,271$ & $-0,285$ & 1,23 & 1,26 \\
\hline & & & & $-M e ́ d i a$ & 1,25 & $\mathbf{1 , 2 8}$ \\
\hline
\end{tabular}

Para o pavimento analisado, constatou-se, então, que a consideração da fissuração a partir do programa ANPAV gerou deslocamentos imediatos, em média, $26 \%$ e $30 \%$ maiores que os deslocamentos imediatos lineares, respectivamente para as combinações quase-permanente e freqüente de ações.

\section{b) Deslocamentos Diferidos}

De posse dos deslocamentos totais e imediatos do pavimento, fornecidos pelo programa ANPAV, os deslocamentos diferidos foram calculados a partir da subtração dos deslocamentos imediatos dos deslocamentos totais.

Determinando-se as relações entre os deslocamentos diferidos e imediatos obtidos com o programa ANPAV, foram encontrados valores médios iguais a 2,0 e 2,4, para as combinações quase-permanente e freqüente de ações, respectivamente.

As relações médias entre os deslocamentos diferidos fornecidos pelo programa ANPAV e os deslocamentos imediatos obtidos com o programa LASER foram iguais de 2,6 e 3,1, respectivamente para as combinações quase-permanente e freqüente.

De maneira simplificada, esses valores podem ser verificados, tomando-se as linhas de mesmo deslocamento apresentadas da Figura 5.3 a Figura 5.8. Os deslocamentos imediatos e diferidos e as relações entre eles são fornecidas na Tabela 5.4. 
Tabela 5.4 - Relações entre os deslocamentos diferidos e imediatos do pavimento 1

\begin{tabular}{|c|c|c|c|c|c|c|c|c|c|}
\hline \multicolumn{4}{|c|}{ Deslocamentos Imediatos (cm) } & \multirow{2}{*}{\multicolumn{2}{|c|}{$\begin{array}{c}\text { Desl Diferidos } \\
(\mathrm{cm})\end{array}$}} & \multirow{2}{*}{\multicolumn{2}{|c|}{$\begin{array}{c}\text { Relação entre } \\
\text { deslocamentos } \\
\text { diferidos e imediatos* } \\
\end{array}$}} & \multirow{2}{*}{\multicolumn{2}{|c|}{$\begin{array}{c}\text { Relação entre } \\
\text { deslocamentos } \\
\text { diferidos e imediatos** }\end{array}$}} \\
\hline \multicolumn{2}{|c|}{$\overline{\text { LASER }}$} & \multicolumn{2}{|c|}{ ANPAV } & & & & & & \\
\hline (1) & (2) & (1) & (2) & (1) & (2) & (1) & (2) & (1) & (2) \\
\hline$-0,08$ & $-0,08$ & $-0,11$ & $-0,11$ & $-0,21$ & $-0,26$ & 2,63 & 3,25 & 1,91 & 2,36 \\
\hline$-0,20$ & $-0,20$ & $-0,25$ & $-0,26$ & $-0,50$ & $-0,60$ & 2,50 & 3,00 & 2,00 & 2,31 \\
\hline$-0,31$ & $-0,31$ & $-0,39$ & $-0,41$ & $-0,79$ & $-0,95$ & 2,55 & 3,06 & 2,03 & 2,32 \\
\hline$-0,42$ & $-0,42$ & $-0,53$ & $-0,56$ & $-1,08$ & $-1,30$ & 2,57 & 3,10 & 2,04 & 2,32 \\
\hline$-0,53$ & $-0,54$ & $-0,67$ & $-0,70$ & $-1,38$ & $-1,66$ & 2,60 & 3,07 & 2,06 & 2,37 \\
\hline$-0,64$ & $-0,66$ & $-0,81$ & $-0,85$ & $-1,67$ & $-2,01$ & 2,61 & 3,05 & 2,06 & 2,36 \\
\hline$-0,76$ & $-0,77$ & $-0,95$ & $-1,00$ & $-1,96$ & $-2,36$ & 2,58 & 3,06 & 2,06 & 2,36 \\
\hline$-0,87$ & $-0,89$ & $-1,09$ & $-1,15$ & $-2,26$ & $-2,70$ & 2,60 & 3,03 & 2,07 & 2,35 \\
\hline$-0,98$ & $-1,00$ & $-1,24$ & $-1,30$ & $-2,54$ & $-3,05$ & 2,59 & 3,05 & 2,05 & 2,35 \\
\hline & & & & & Média & 2,58 & 3,08 & 2,03 & 2,34 \\
\hline
\end{tabular}

(1) Deslocamentos devidos à combinação quase-permanente

(2) Deslocamentos devidos à combinação freqüente

* Relação entre os deslocamentos diferidos e os deslocamentos imediatos obtidos com o programa LASER

** Relação entre os deslocamentos diferidos e os deslocamentos imediatos obtidos com o programa ANPAV

Observou-se que a relação média entre os deslocamentos diferidos e imediatos nãolineares do pavimento, para qualquer combinação de ações, foi maior que 2. Mais uma vez, foram encontrados valores que confirmam que o coeficiente multiplicador dos deslocamentos imediatos, recomendado pela NBR 6118 (2003) subestima os deslocamentos diferidos de lajes, conforme comentado no capítulo 3.

A partir da análise dos deslocamentos das vigas foram observados valores de relações médias entre os deslocamentos diferidos e imediatos bastante próximos dos do pavimento.

Para representar o comportamento dos deslocamentos diferidos das vigas foram tomaram as vigas V13 e V19, cujos deslocamentos são apresentados nas Figuras 5.12 e 5.13. Os valores desses deslocamentos e das relações entre eles são fornecidos nas Tabelas $5.5 \mathrm{e}$ 5.6.

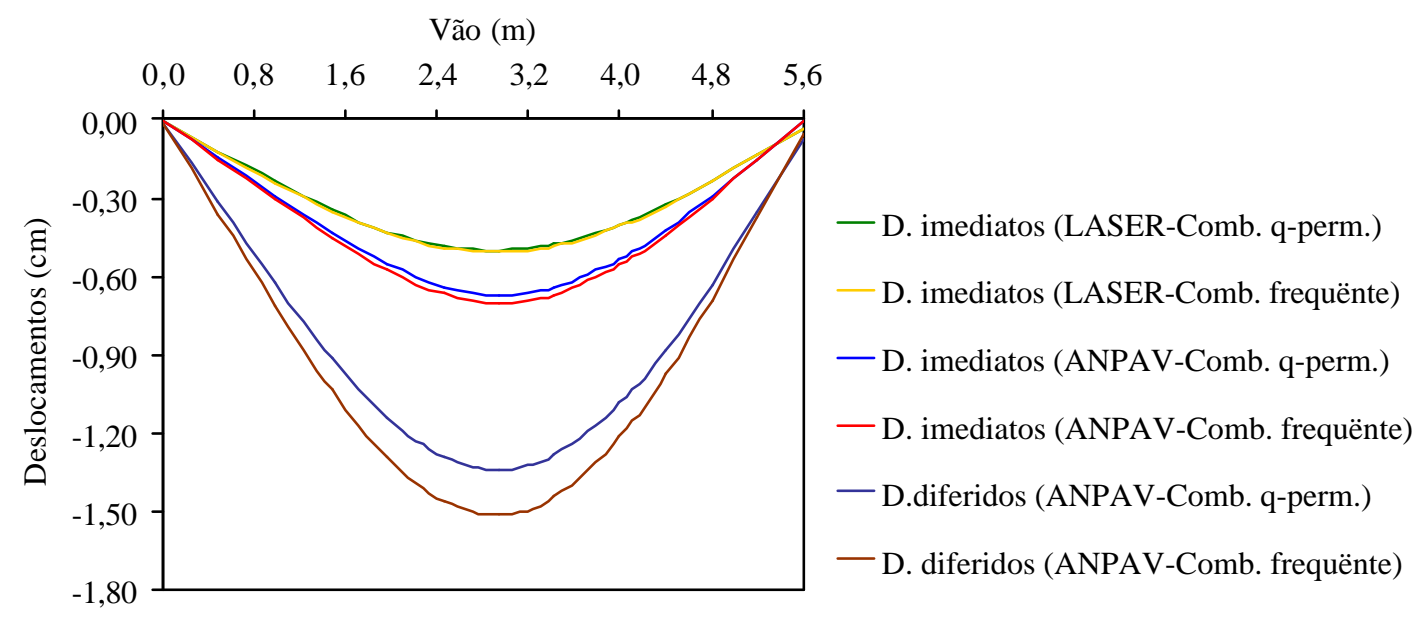

Figura 5.12 - Deslocamentos imediatos e diferidos da viga V13 


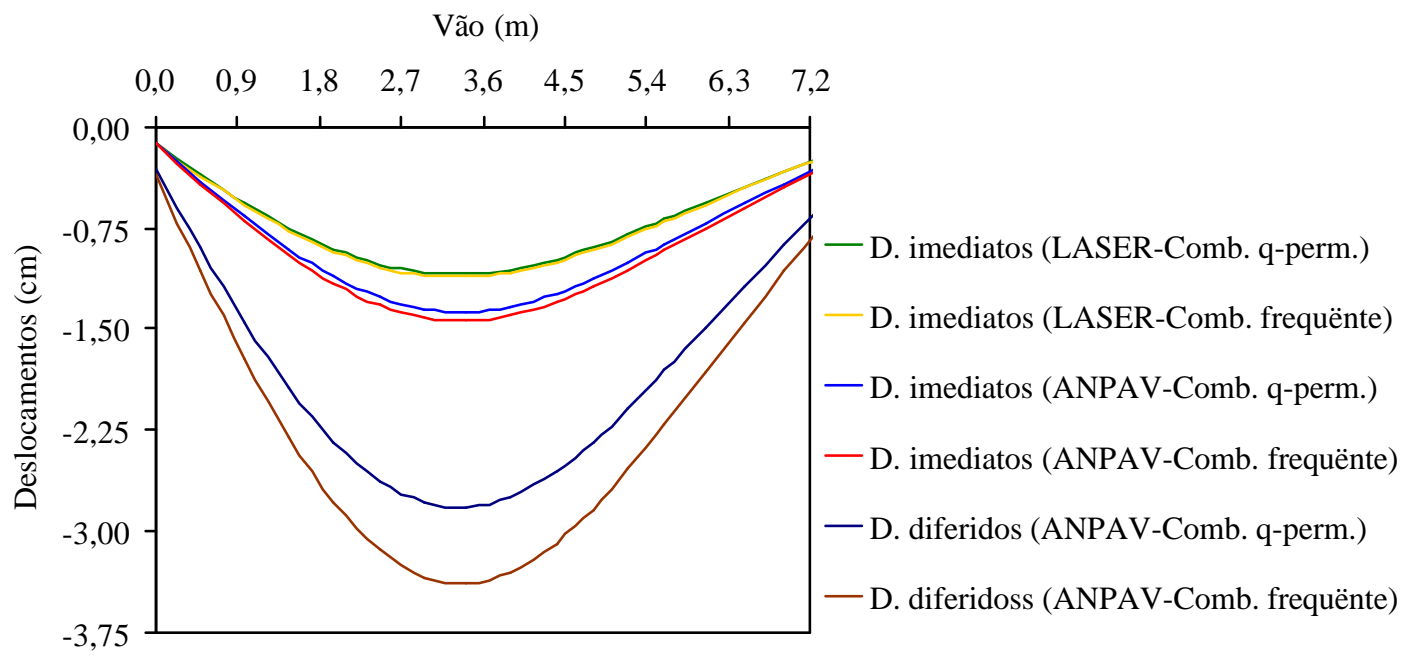

Figura 5.13 - Deslocamentos imediatos e diferidos da viga V19

Para essas vigas, as relações médias entre os deslocamentos diferidos e os deslocamentos imediatos lineares e não-lineares foram bastante próximas das obtidas para o pavimento como um todo, como pode ser visto nas Tabelas 5.4, 5.5 e 5.6. Exceto a relação média entre os deslocamentos diferidos e os imediatos lineares da viga V13, para a combinação freqüente, que foi um pouco menor.

Tabela 5.5 - Relações entre os deslocamentos diferidos e imediatos da viga V13

\begin{tabular}{|c|c|c|c|c|c|c|c|c|c|c|}
\hline \multirow{3}{*}{$\begin{array}{l}\text { Vão } \\
\text { (m) }\end{array}$} & \multicolumn{4}{|c|}{ Deslocamentos Imediatos (cm) } & \multirow{2}{*}{\multicolumn{2}{|c|}{$\begin{array}{c}\text { Desl Diferidos } \\
(\mathrm{cm})\end{array}$}} & \multirow{2}{*}{\multicolumn{2}{|c|}{$\begin{array}{c}\text { Relação entre } \\
\text { deslocamentos } \\
\text { diferidos e imediatos* }\end{array}$}} & \multirow{2}{*}{\multicolumn{2}{|c|}{$\begin{array}{c}\text { Relação entre } \\
\text { deslocamentos } \\
\text { diferidos e imediatos** }\end{array}$}} \\
\hline & \multicolumn{2}{|c|}{ LASER } & \multicolumn{2}{|c|}{ ANPAV } & & & & & & \\
\hline & (1) & (2) & (1) & (2) & (1) & (2) & (1) & (2) & (1) & (2) \\
\hline 0,00 & $-0,004$ & $-0,004$ & $-0,004$ & $-0,004$ & $-0,012$ & $-0,012$ & 2,70 & 2,82 & 3,21 & 3,55 \\
\hline 0,49 & $-0,120$ & $-0,122$ & $-0,144$ & $-0,151$ & $-0,317$ & $-0,360$ & 2,64 & 2,94 & 2,20 & 2,38 \\
\hline 0,98 & $-0,238$ & $-0,241$ & $-0,290$ & $-0,304$ & $-0,628$ & $-0,713$ & 2,64 & 2,96 & 2,16 & 2,35 \\
\hline 1,48 & $-0,344$ & $-0,349$ & $-0,430$ & $-0,450$ & $-0,913$ & $-1,036$ & 2,65 & 2,97 & 2,12 & 2,30 \\
\hline 1,97 & $-0,429$ & $-0,436$ & $-0,553$ & $-0,578$ & $-1,142$ & $-1,296$ & 2,66 & 2,97 & 2,07 & 2,24 \\
\hline 2,46 & $-0,483$ & $-0,490$ & $-0,639$ & $-0,668$ & $-1,291$ & $-1,462$ & 2,67 & 2,98 & 2,02 & 2,19 \\
\hline 2,95 & $-0,500$ & $-0,507$ & $-0,671$ & $-0,701$ & $-1,340$ & $-1,515$ & 2,68 & 2,99 & 2,00 & 2,16 \\
\hline 3,43 & $-0,477$ & $-0,484$ & $-0,642$ & $-0,670$ & $-1,283$ & $-1,445$ & 2,69 & 2,99 & 2,00 & 2,16 \\
\hline 4,00 & $-0,403$ & $-0,409$ & $-0,534$ & $-0,557$ & $-1,087$ & $-1,215$ & 2,69 & 2,98 & 2,03 & 2,18 \\
\hline 4,40 & $-0,327$ & $-0,331$ & $-0,422$ & $-0,439$ & $-0,881$ & $-0,977$ & 2,69 & 2,95 & 2,09 & 2,23 \\
\hline 4,80 & $-0,236$ & $-0,238$ & $-0,290$ & $-0,301$ & $-0,632$ & $-0,690$ & 2,68 & 2,90 & 2,18 & 2,29 \\
\hline 5,20 & $-0,137$ & $-0,138$ & $-0,149$ & $-0,153$ & $-0,358$ & $-0,375$ & 2,62 & 2,72 & 2,40 & 2,44 \\
\hline 5,60 & $-0,037$ & $-0,036$ & $-0,007$ & $-0,004$ & $-0,077$ & $-0,052$ & 2,10 & 1,42 & 11,90 & 14,53 \\
\hline & & & & & & Média & 2,62 & 2,81 & 2,12 & 2,37 \\
\hline
\end{tabular}

(1) Deslocamentos devidos à combinação quase-permanente

(2) Deslocamentos devidos à combinação freqüente

* Relação entre os deslocamentos diferidos e os deslocamentos imediatos obtidos com o programa LASER

** Relação entre os deslocamentos diferidos e os deslocamentos imediatos obtidos com o programa ANPAV 
Tabela 5.6 - Relações entre os deslocamentos diferidos e imediatos da viga V19

\begin{tabular}{|c|c|c|c|c|c|c|c|c|c|c|}
\hline \multirow{3}{*}{$\begin{array}{l}\text { Vão } \\
\text { (m) }\end{array}$} & \multicolumn{4}{|c|}{ Deslocamentos Imediatos (cm) } & \multirow{2}{*}{\multicolumn{2}{|c|}{$\begin{array}{c}\text { Desl Diferidos } \\
(\mathrm{cm})\end{array}$}} & \multirow{2}{*}{\multicolumn{2}{|c|}{$\begin{array}{c}\text { Relação entre } \\
\text { deslocamentos } \\
\text { diferidos e imediatos* }\end{array}$}} & \multirow{2}{*}{\multicolumn{2}{|c|}{$\begin{array}{c}\text { Relação entre } \\
\text { deslocamentos } \\
\text { diferidos e imediatos** }\end{array}$}} \\
\hline & \multicolumn{2}{|c|}{ LASER } & \multicolumn{2}{|c|}{ ANPAV } & & & & & & \\
\hline & (1) & (2) & (1) & (2) & (1) & (2) & (1) & (2) & (1) & (2) \\
\hline 0,00 & $-0,125$ & $-0,127$ & $-0,118$ & $-0,125$ & $-0,305$ & $-0,356$ & 2,44 & 2,80 & 2,58 & 2,85 \\
\hline 0,49 & $-0,352$ & $-0,360$ & $-0,398$ & $-0,418$ & $-0,896$ & $-1,062$ & 2,54 & 2,95 & 2,25 & 2,54 \\
\hline 0,98 & $-0,566$ & $-0,578$ & $-0,666$ & $-0,698$ & $-1,450$ & $-1,727$ & 2,56 & 2,99 & 2,18 & 2,47 \\
\hline 1,48 & $-0,754$ & $-0,770$ & $-0,909$ & $-0,952$ & $-1,941$ & $-2,314$ & 2,57 & 3,00 & 2,14 & 2,43 \\
\hline 1,97 & $-0,907$ & $-0,926$ & $-1,111$ & $-1,164$ & $-2,339$ & $-2,793$ & 2,58 & 3,02 & 2,11 & 2,40 \\
\hline 2,46 & $-1,017$ & $-1,038$ & $-1,261$ & $-1,322$ & $-2,627$ & $-3,141$ & 2,58 & 3,03 & 2,08 & 2,38 \\
\hline 2,95 & $-1,078$ & $-1,101$ & $-1,350$ & $-1,416$ & $-2,791$ & $-3,344$ & 2,59 & 3,04 & 2,07 & 2,36 \\
\hline 3,43 & $-1,090$ & $-1,113$ & $-1,371$ & $-1,440$ & $-2,826$ & $-3,394$ & 2,59 & 3,05 & 2,06 & 2,36 \\
\hline 3,90 & $-1,057$ & $-1,080$ & $-1,334$ & $-1,402$ & $-2,749$ & $-3,309$ & 2,60 & 3,06 & 2,06 & 2,36 \\
\hline 4,40 & $\begin{array}{l}-0,981 \\
\end{array}$ & $-1,001$ & $-1,237$ & $-1,302$ & $-2,558$ & $-3,090$ & 2,61 & 3,09 & 2,07 & 2,37 \\
\hline 4,80 & $-0,895$ & $-0,914$ & $-1,129$ & $-1,188$ & $-2,343$ & $-2,838$ & 2,62 & 3,10 & 2,08 & 2,39 \\
\hline 5,20 & $-0,795$ & $-0,812$ & $-1,004$ & $-1,057$ & $-2,089$ & $-2,538$ & 2,63 & 3,13 & 2,08 & 2,40 \\
\hline 5,60 & $-0,686$ & $-0,701$ & $-0,870$ & $-0,916$ & $-1,810$ & $-2,207$ & 2,64 & 3,15 & 2,08 & 2,41 \\
\hline 6,04 & $-0,564$ & $-0,577$ & $-0,719$ & $-0,757$ & $-1,492$ & $-1,828$ & 2,65 & 3,17 & 2,08 & 2,41 \\
\hline 6,48 & $-0,444$ & $-0,455$ & $-0,568$ & $-0,598$ & $-1,175$ & $-1,445$ & 2,64 & 3,18 & 2,07 & 2,42 \\
\hline 6,91 & $-0,329$ & $-0,337$ & $-0,418$ & $-0,440$ & $-0,863$ & $-1,066$ & 2,62 & 3,16 & 2,07 & 2,42 \\
\hline 7,35 & $-0,220$ & $-0,226$ & $-0,271$ & $-0,285$ & $-0,563$ & $-0,698$ & 2,56 & 3,08 & 2,08 & 2,45 \\
\hline & & & & & & Média & 2,59 & 3,06 & 2,12 & 2,44 \\
\hline
\end{tabular}

(1) Deslocamentos devidos à combinação quase-permanente

(2) Deslocamentos devidos à combinação freqüiente

* Relação entre os deslocamentos diferidos e os deslocamentos imediatos obtidos com o programa LASER

** Relação entre os deslocamentos diferidos e os deslocamentos imediatos obtidos com o programa ANPAV

Com base nos valores das relações entre os deslocamentos diferidos e imediatos comentadas anteriormente, notou-se que os deslocamentos diferidos obtidos com o programa ANPAV, foram aproximadamente $100 \%$ e $140 \%$ maiores que os deslocamentos imediatos fornecidos por este programa, para as combinações quase-permanente e freqüente de ações, respectivamente. Isto levou a coeficientes multiplicadores dos deslocamentos imediatos iguais a 2,0 e 2,4 .

Já em função das relações entre os deslocamentos diferidos obtidos com o programa ANPAV e os imediatos fornecidos pelo programa LASER, percebeu-se que os deslocamentos diferidos foram em torno de $160 \%$ e $200 \%$ maiores que os deslocamentos imediatos lineares, respectivamente para as combinações quase-permanente e freqüiente de ações.

\subsubsection{ALTURAS MÍNIMAS}

Utilizando-se os procedimentos propostos nos Capítulos 3 e 4 para a determinação de alturas mínimas para lajes e vigas, respectivamente, foram determinadas tais alturas para alguns desses elementos do pavimento em estudo, e os resultados obtidos foram comparados com os adotados no projeto. 


\section{a) Alturas Mínimas das Lajes}

Para o cálculo das alturas mínimas das lajes, foi utilizado o procedimento apresentado no item 3.5.3a, segundo o qual, a altura mínima pode ser obtida a partir da eq.(3.3), aqui repetida:

$$
\frac{\mathrm{L}_{\mathrm{x}}}{\mathrm{h}_{\min }}=\frac{\beta}{\alpha}
$$

na qual:

$\mathbf{L}_{\mathbf{x}} \quad$ é o menor vão da laje,

$\mathbf{h}_{\text {min }}$ é a altura mínima da laje,

$\beta \quad$ é a relação vão-altura mínima para as lajes dos tipos 1,2 e 3, cujos valores são fornecidos pelas eqs.(3.4) e (3.5),

$\alpha \quad$ é o coeficiente que leva em consideração as condições de apoio das lajes, corrigindo os valores de $\beta$ para os demais tipos de lajes, cujos valores são dados na Tabela 3.8.

Em função das condições de apoio de seus lados, as lajes foram classificadas em tipos de acordo com a Figura 3.1 do Capítulo 3. Com o engastamento definido a partir da existência de lajes adjacentes.

\section{- $\quad$ Laje L7}

De acordo com a estrutura do pavimento, mostrada na Figura 5.2, foram obtidas as seguintes características para a laje L7:

- Tipo 5

- $\mathrm{L}_{\mathrm{x}}=295 \mathrm{~cm}$

- $\mathrm{L}_{\mathrm{y}}=375 \mathrm{~cm}$

Para as lajes do tipo 5, segundo a Tabela 3.8, o coeficiente $\alpha$ foi igual a 0,93 , para a verificação da aceitabilidade sensorial quanto a aspectos visuais (verificação 1). Já para as verificações de aceitabilidade sensorial relativa a vibrações (verificação 2) e dos efeitos dos deslocamentos nas paredes (verificação 3), o coeficiente $\alpha$ foi igual a 0,90.

Sendo o $\mathbf{f}_{\text {ck }}$ igual a $20 \mathrm{MPa}$, e a relação entre os vãos das lajes igual a $\frac{L_{y}}{L_{x}}=\frac{375}{295}=1,27$, utilizando-se as eqs.(3.4) e (3.5), foram obtidos os seguintes valores de $\beta$ :

$$
\beta_{\text {ver. } 1}=61+4,0 \cdot 2,0-42,7 \cdot(1,27)+13,2 \cdot(1,27)^{2}-1,36 \cdot(1,27)^{3}=33,3
$$




$$
\beta_{\text {ver. } 2 \text { e } 3}=67+3,5 \cdot 2,0-51,5 \cdot(1,27)+16,5 \cdot(1,27)^{2}-1,77 \cdot(1,27)^{3}=31,6
$$

Logo, a partir da eq.(3.3), para satisfazer a verificação 1, a altura mínima da laje L7 foi igual a:

$$
\mathrm{h}_{\text {min,ver.1 }}=\frac{\alpha \mathrm{L}_{\mathrm{x}}}{\beta}=\frac{0,93 \cdot 295}{33,3}=8,2 \mathrm{~cm}
$$

E, para satisfazer as verificações 2 e 3 , encontrou-se:

$$
\mathrm{h}_{\min , \mathrm{ver} .2 \mathrm{e} 3}=\frac{\alpha \mathrm{L}_{\mathrm{x}}}{\beta}=\frac{0,90 \cdot 295}{31,6}=8,4 \mathrm{~cm}
$$

Observou-se, então, que para satisfazer às verificações do estado limite de deformações excessivas, a laje $\mathrm{L} 7$ deveria apresentar uma altura maior que $8,4 \mathrm{~cm}$. Como no projeto foi adotada uma altura de $9 \mathrm{~cm}$ para esta laje, esse estado limite foi verificado.

\section{- Laje L11}

Para o cálculo da altura mínima da laje L11, foi considerada uma laje retangular, com as seguintes características:

- Tipo 8 (não foi considerado o engastamento no lado apoiado na viga V23)

- $\mathrm{L}_{\mathrm{x}}=460 \mathrm{~cm}$

- $\mathrm{L}_{\mathrm{y}}=510 \mathrm{~cm}$

Pela Tabela 3.8, para a verificação da aceitabilidade sensorial quanto a aspectos visuais, o coeficiente $\alpha$ foi igual a 0,84 , e para as verificações de aceitabilidade sensorial relativa a vibrações e dos efeitos dos deslocamentos nas paredes, o coeficiente $\alpha$ foi igual a 0,80. E, a partir das eqs.(3.4) e (3.5), foram calculados os seguintes valores de $\beta$ :

$$
\begin{aligned}
& \beta_{\text {ver. } 1}=61+4,0 \cdot 2,0-42,7 \cdot\left(\frac{510}{460}\right)+13,2 \cdot\left(\frac{510}{460}\right)^{2}-1,36 \cdot\left(\frac{510}{460}\right)^{3}=36,0 \\
& \beta_{\text {ver. } 2 \text { e } 3}=67+3,5 \cdot 2,0-51,5 \cdot\left(\frac{510}{460}\right)+16,5 \cdot\left(\frac{510}{460}\right)^{2}-1,77 \cdot\left(\frac{510}{460}\right)^{3}=34,8
\end{aligned}
$$

E, portanto, para satisfazer as verificações supracitadas, foram encontradas as seguintes alturas mínimas:

$$
\mathrm{h}_{\text {min, ver. } 1}=\frac{\alpha \mathrm{L}_{\mathrm{x}}}{\beta}=\frac{0,84 \cdot 460}{36,0}=10,7 \mathrm{~cm}
$$


e,

$$
\mathrm{h}_{\text {min,ver.2 e } 3}=\frac{\alpha \mathrm{L}_{\mathrm{x}}}{\beta}=\frac{0,80 \cdot 460}{34,8}=10,6 \mathrm{~cm}
$$

Logo, para atender às verificações do estado limite de deformações excessivas, a laje L11 deveria ter uma altura superior a $10,7 \mathrm{~cm}$. No projeto, foi considerada uma altura igual a $9 \mathrm{~cm}$. Constatou-se, assim, que para esta laje seria necessário o cálculo dos deslocamentos e sua comparação com os valores limites fornecidos pela NBR 6118 (2003), apresentados na Tabela 2.4 do Capítulo 2, para a verificação desse estado limite de serviço.

\section{b) Alturas Mínimas das Vigas}

Para a determinação das alturas mínimas das vigas, foi adotado o procedimento apresentado no item 4.5.3a, segundo o qual, a altura mínima é dada pela eq.(4.2), ou seja:

$$
\frac{\ell_{\mathrm{ef}}}{\mathrm{h}_{\min }}=\beta
$$

sendo:

$\ell_{\mathbf{e f}} \quad \mathrm{o}$ vão efetivo da viga, em cm,

$\mathbf{h}_{\min }$ a altura mínima da viga, em $\mathrm{cm}$, que satisfaz as verificações dos deslocamentos apresentadas no item 3.4.3, do Capítulo 3,

$\beta \quad$ uma função que depende das propriedades geométricas da viga e dos pilares, da resistência característica do concreto à compressão e do tipo de verificação que se deseja realizar; e é calculada a partir das eqs.(4.3) e (4.4).

\section{- Viga V9}

Foram consideradas as seguintes características para o cálculo da altura mínima da viga V9:

- $\ell_{\mathrm{ef}}=282,5 \mathrm{~cm}$

- $\mathrm{b}=12 \mathrm{~cm}$

- $\mathrm{h}_{\mathrm{p}}=20 \mathrm{~cm}$

Para as verificações de aceitabilidade sensorial (verificações 1 e 2), foi calculado o seguinte valor para $\beta$ :

$$
\beta_{\text {ver. } 1 \mathrm{e} 2}=6,0+1,4 \cdot 2,0+0,005 \cdot 282,5+0,21 \cdot 12-0,009 \cdot 20-0,25 \cdot \frac{282,5}{20}=9,0
$$


E, para a verificação dos efeitos dos deslocamentos nas paredes (verificação 3), encontrou-se:

$$
\beta_{\mathrm{ver} .3}=5,7+1,35 \cdot 2,0+0,005 \cdot 282,5+0,18 \cdot 12-0,007 \cdot 20-0,26 \cdot \frac{282,5}{20}=8,2
$$

De acordo com a eq.(4.2), as alturas mínimas que atendem essas verificações foram iguais a:

$$
\mathrm{h}_{\text {min,ver. } 1 \mathrm{e} 2}=\frac{\ell_{\mathrm{ef}}}{\beta}=\frac{282,5}{9,0}=31,4 \mathrm{~cm}
$$

e,

$$
\mathrm{h}_{\text {min, ver. } 3}=\frac{\ell_{\mathrm{ef}}}{\beta}=\frac{282,5}{8,2}=34,5 \mathrm{~cm}
$$

Observou-se, então, que para satisfazer as verificações de aceitabilidade sensorial, a altura da viga deveria ser superior a 31,4 cm. Já para atender à verificação dos efeitos dos deslocamentos nas paredes, a altura deveria ser maior que $34,5 \mathrm{~cm}$. Portanto, como foi adotada uma altura igual a $60 \mathrm{~cm}$, as verificações do estado limite de deformações excessivas foram atendidas.

\section{- Viga V2}

Para a viga V2, foram tomadas as características a seguir.

- $\ell_{\mathrm{ef}}=550 \mathrm{~cm}$

- $\mathrm{b}=12 \mathrm{~cm}$

- $\mathrm{h}_{\mathrm{p}}=100 \mathrm{~cm}$

E, utilizando-se as eqs.(4.3) e (4.4), foram obtidos os seguintes valores de $\beta$ :

$$
\begin{aligned}
& \beta_{\text {ver. } 1 \text { e } 2}=6,0+1,4 \cdot 2,0+0,005 \cdot 550+0,21 \cdot 12-0,009 \cdot 100-0,25 \cdot \frac{550}{100}=11,8 \\
& \beta_{\text {ver. } 3}=5,7+1,35 \cdot 2,0+0,005 \cdot 550+0,18 \cdot 12-0,007 \cdot 100-0,26 \cdot \frac{550}{100}=11,2
\end{aligned}
$$

Para atender as verificações de aceitabilidade sensorial, a altura mínima obtida foi igual a: 
$\mathrm{h}_{\text {min,ver.1e } 2}=\frac{\ell_{\text {ef }}}{\beta}=\frac{550}{11,8}=46,6 \mathrm{~cm}$

E para satisfazer a verificação dos efeitos dos deslocamentos nas paredes, obteve-se:

$\mathrm{h}_{\text {min,ver. } 3}=\frac{\ell_{\text {ef }}}{\beta}=\frac{550}{11,2}=49,1 \mathrm{~cm}$

Notou-se, de acordo com esse resultado, que a altura da viga V2 deveria ser superior a $49 \mathrm{~cm}$ para atender às verificações do estado limite de deformações excessivas, o que ocorreu, já que no projeto foi considerada, para esta viga, uma altura de $60 \mathrm{~cm}$.

\subsection{PAVIMENTO 2}

As plantas de arquitetura e de forma do pavimento tipo do segundo edifício analisado são apresentadas nas Figuras 5.14 e 5.15, respectivamente.

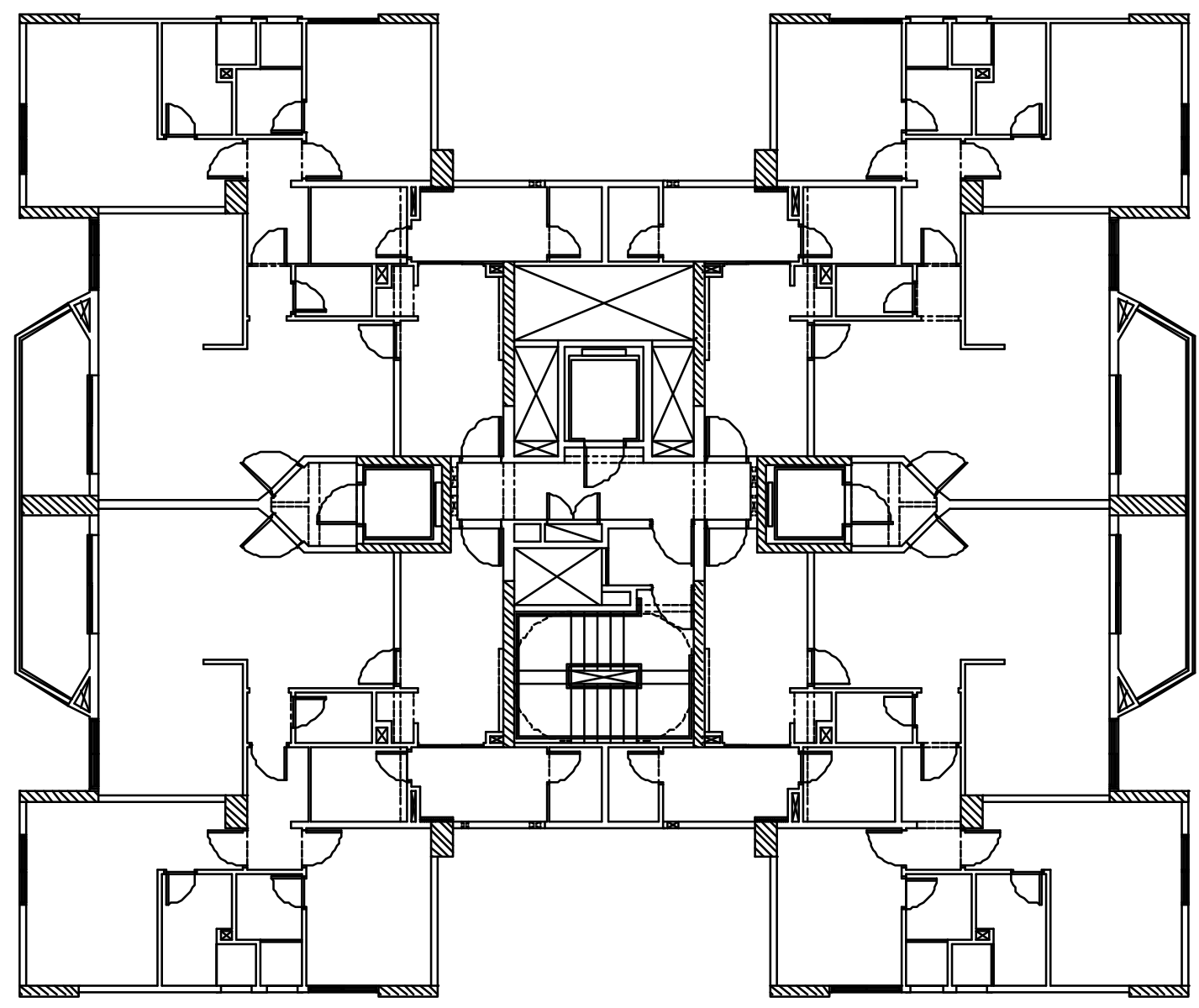

Figura 5.14 - Planta de arquitetura do pavimento 2 


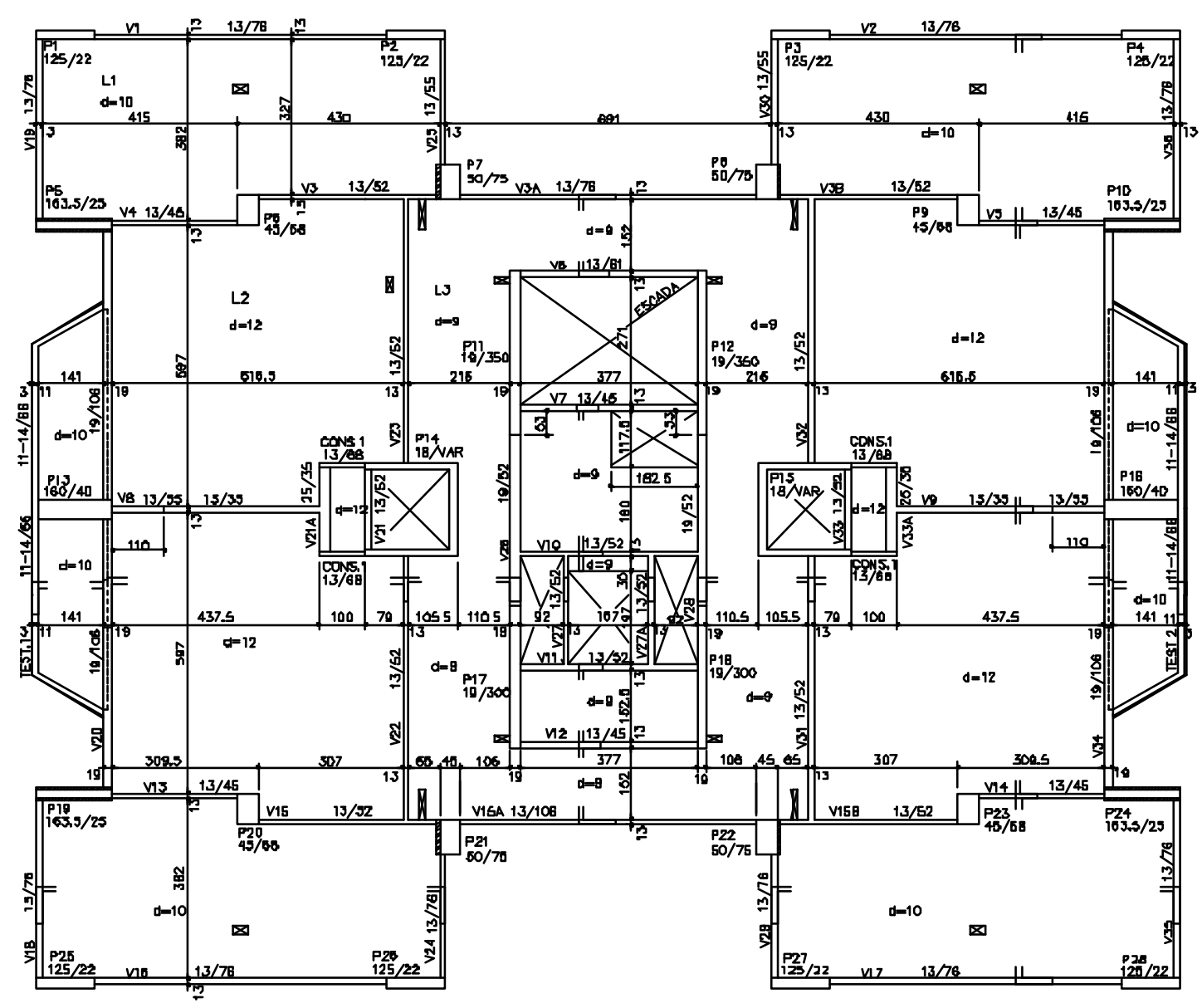

Figura 5.15 - Planta de forma do pavimento 2

Neste pavimento, também foram utilizados aço CA - 50 e concreto com resistência característica à compressão de $20 \mathrm{MPa}$.

O carregamento das lajes consistiu de uma parcela igual a $1,0 \mathrm{kN} / \mathrm{m}^{2}$, correspondente ao peso do piso e do revestimento, e uma ação variável de $1,5 \mathrm{kN} / \mathrm{m}^{2}$.

\subsubsection{VALORES DOS DESLOCAMENTOS}

De maneira análoga ao exemplo anterior, foram calculados os deslocamentos imediatos com os programas LASER e ANPAV, e os deslocamentos totais com o último. Os valores desses deslocamentos, para a combinação quase-permanente de ações, são ilustrados da Figura 5.16 a 5.18, novamente a partir de curvas de mesmos deslocamentos. Para a combinação freqüente de ações os valores dos deslocamentos das curvas correspondentes são apresentados na Tabela 5.7. 


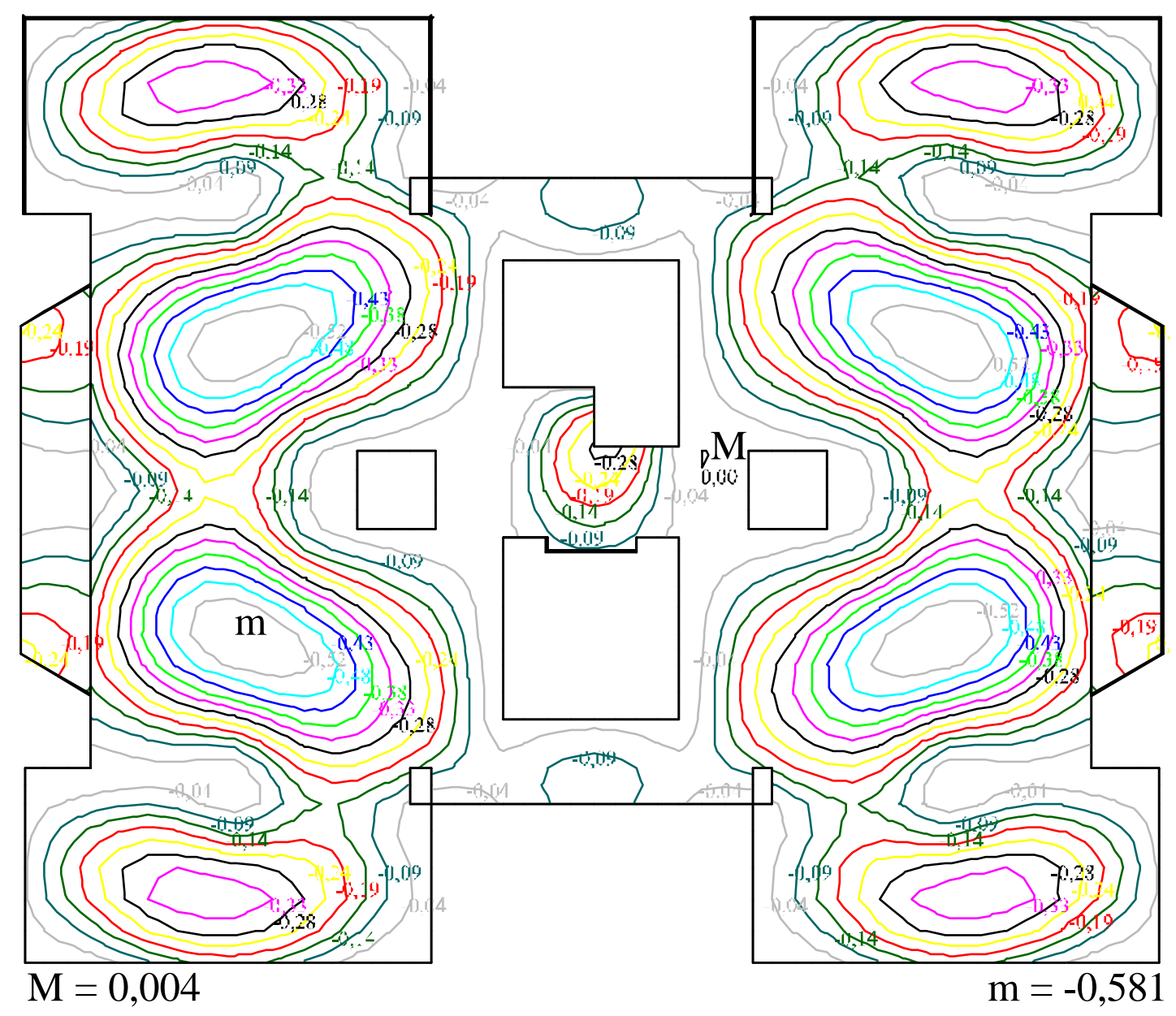

Figura 5.16 - Deslocamentos imediatos obtidos a partir da análise linear (Combinação quase-permanente) 


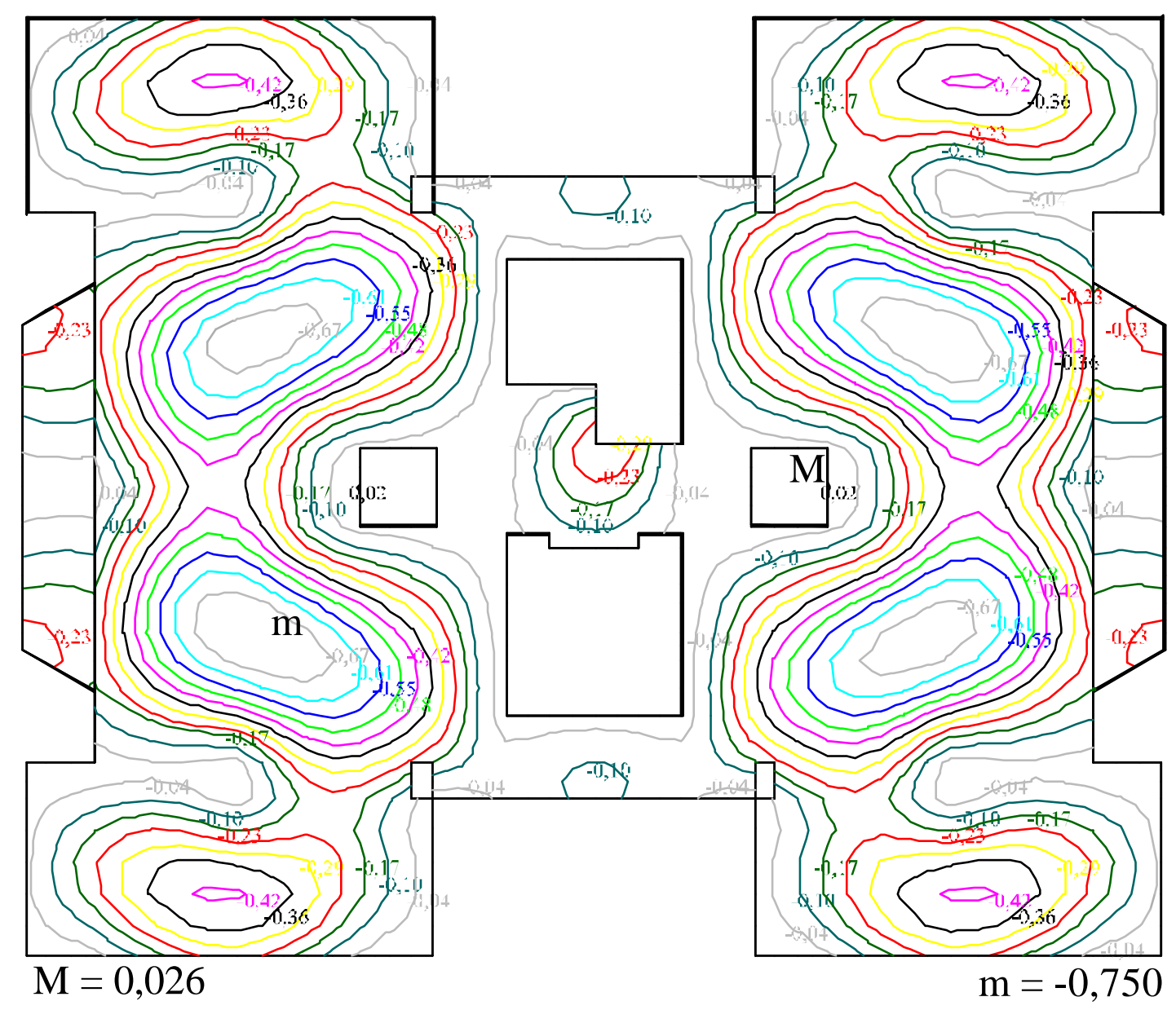

Figura 5.17 - Deslocamentos imediatos obtidos a partir da análise não-linear (Combinação quase-permanente) 


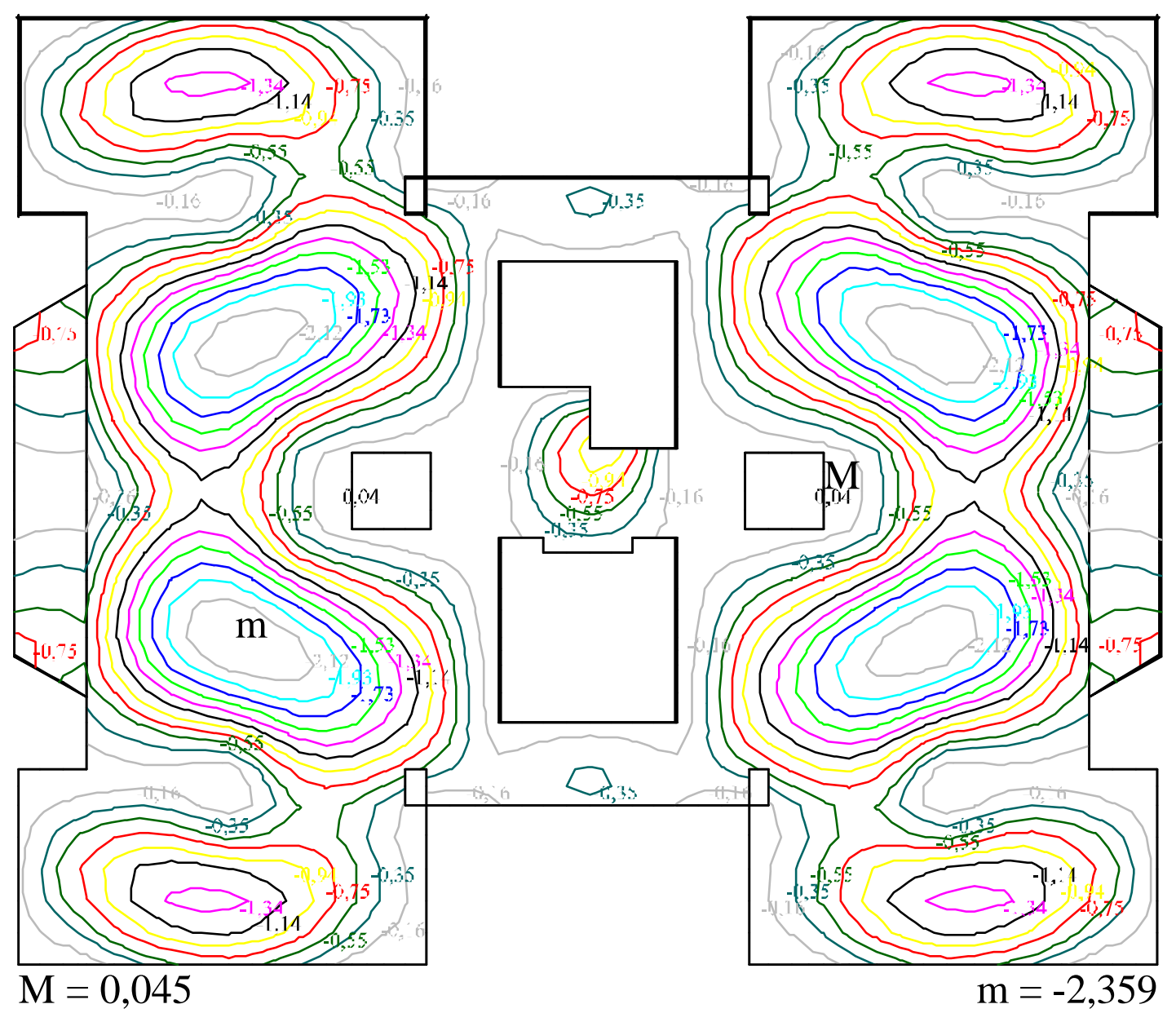

Figura 5.18 - Deslocamentos totais obtidos a partir da análise não-linear (Combinação quase-permanente)

Tabela 5.7 - Deslocamentos do pavimento 2, em $\mathrm{cm}$

\begin{tabular}{|c|c|c|c|c|c|}
\hline \multicolumn{3}{|c|}{ Deslocamentos Imediatos } & \multicolumn{2}{c|}{ Deslocamentos Totais } \\
\hline$(\mathbf{1})$ & $(\mathbf{2})$ & $(\mathbf{1})$ & $\mathbf{( 2 )}$ & $(\mathbf{1})$ & $(\mathbf{2})$ \\
\hline 0,04 & 0,05 & 0,04 & 0,04 & 0,16 & 0,16 \\
\hline 0,09 & 0,09 & 0,10 & 0,11 & 0,35 & 0,36 \\
\hline 0,14 & 0,14 & 0,17 & 0,17 & 0,55 & 0,57 \\
\hline 0,19 & 0,19 & 0,23 & 0,24 & 0,75 & 0,77 \\
\hline 0,24 & 0,24 & 0,29 & 0,31 & 0,94 & 0,97 \\
\hline 0,28 & 0,29 & 0,36 & 0,37 & 1,14 & 1,18 \\
\hline 0,33 & 0,34 & 0,42 & 0,44 & 1,34 & 1,38 \\
\hline 0,38 & 0,39 & 0,48 & 0,50 & 1,53 & 1,58 \\
\hline 0,43 & 0,44 & 0,55 & 0,57 & 1,73 & 1,79 \\
\hline 0,48 & 0,49 & 0,61 & 0,64 & 1,93 & 1,99 \\
\hline 0,52 & 0,54 & 0,67 & 0,70 & 2,12 & 2,19 \\
\hline $\mathbf{0 , 5 8 1}$ & $\mathbf{0 , 5 9 5}$ & $\mathbf{0 , 7 5 0}$ & $\mathbf{0 , 7 7 9}$ & $\mathbf{2 , 3 5 9}$ & $\mathbf{2 , 4 3 7}$ \\
\hline
\end{tabular}

(1) Deslocamentos devidos à combinação quase-permanente

(2) Deslocamentos devidos à combinação freqüiente 
$\mathrm{Na}$ última linha da Tabela 5.7, os valores em negrito correspondem aos deslocamentos máximos ocorridos no pavimento.

\subsubsection{ANÁLISE DOS RESULTADOS}

De posse dos deslocamentos fornecidos tanto pelo procedimento elástico quanto pelo não-linear foram feitas algumas comparações entre os resultados obtidos, apresentadas a seguir.

\section{a) Deslocamentos Imediatos}

A partir dos deslocamentos imediatos calculados com as análises não-linear (programa ANPAV) e linear (programa LASER), foram determinadas as relações entre esses deslocamentos. Considerando-se apenas as regiões mais fissuradas, foi observado que aqueles determinados com análise não-linear foram em torno de $24 \%$ e $28 \%$ maiores que os obtidos da análise linear, respectivamente para as combinações quase-permanente e freqüente de ações.

Para as curvas de deslocamentos do pavimento, mostradas anteriormente, foram calculadas as relações entre os deslocamentos imediatos correspondentes, e os resultados são dados na Tabela 5.8. Notou-se que os valores são bem próximos da média obtida para o pavimento.

Tabela 5.8 - Deslocamentos imediatos do pavimento 2 devidos às análises lineares e não-lineares, em cm

\begin{tabular}{|c|c|c|c|c|c|}
\hline \multicolumn{2}{|c|}{ Análise Linear (LASER) } & \multicolumn{2}{c|}{ Análise Não Linear (ANPAV) } & $\begin{array}{c}\text { Relação entre os deslocamentos } \\
\text { não lineares e lineares }\end{array}$ \\
\hline Q. Permanente & Frequente & Q. Permanente & Frequente & Q. Permanente & Frequente \\
\hline 0,04 & 0,05 & 0,04 & 0,04 & 1,00 & 0,80 \\
\hline 0,09 & 0,09 & 0,10 & 0,11 & 1,11 & 1,22 \\
\hline 0,14 & 0,14 & 0,17 & 0,17 & 1,21 & 1,21 \\
\hline 0,19 & 0,19 & 0,23 & 0,24 & 1,21 & 1,26 \\
\hline 0,24 & 0,24 & 0,29 & 0,31 & 1,21 & 1,29 \\
\hline 0,28 & 0,29 & 0,36 & 0,37 & 1,29 & 1,28 \\
\hline 0,33 & 0,34 & 0,42 & 0,44 & 1,27 & 1,29 \\
\hline 0,38 & 0,39 & 0,48 & 0,50 & 1,26 & 1,28 \\
\hline 0,43 & 0,44 & 0,55 & 0,57 & 1,28 & 1,30 \\
\hline 0,48 & 0,49 & 0,61 & 0,64 & 1,27 & 1,31 \\
\hline 0,52 & 0,54 & 0,67 & 0,70 & 1,29 & 1,30 \\
\hline
\end{tabular}

Para representar o comportamento das vigas foram tomadas V1 e V20, cujos deslocamentos imediatos estão representados nas Figuras 5.20 e 5.19, respectivamente. 
No primeiro vão da viga V20, os deslocamentos imediatos devidos aos dois tipos de análise foram bastante próximos, sendo que os obtidos com a análise não-linear foram um pouco menores, devido à consideração da colaboração da armadura na rigidez da viga feita por esta análise. Já para o segundo vão, os deslocamentos imediatos devidos à análise nãolinear apresentaram valores maiores que os lineares, pois o concreto já havia fissurado. Considerando apenas a região fissurada deste vão, a relação média entre os deslocamentos imediatos não-lineares e lineares foi igual a 1,23 e 1,28, respectivamente para as combinações quase-permanente e freqüente de ações. Ou seja, a consideração da fissuração no cálculo dos deslocamentos imediatos levou a deslocamentos imediatos $23 \%$ e $28 \%$ maiores que os lineares. Todos os valores das relações entre os deslocamentos imediatos da viga V20 são fornecidos na Tabela 5.9

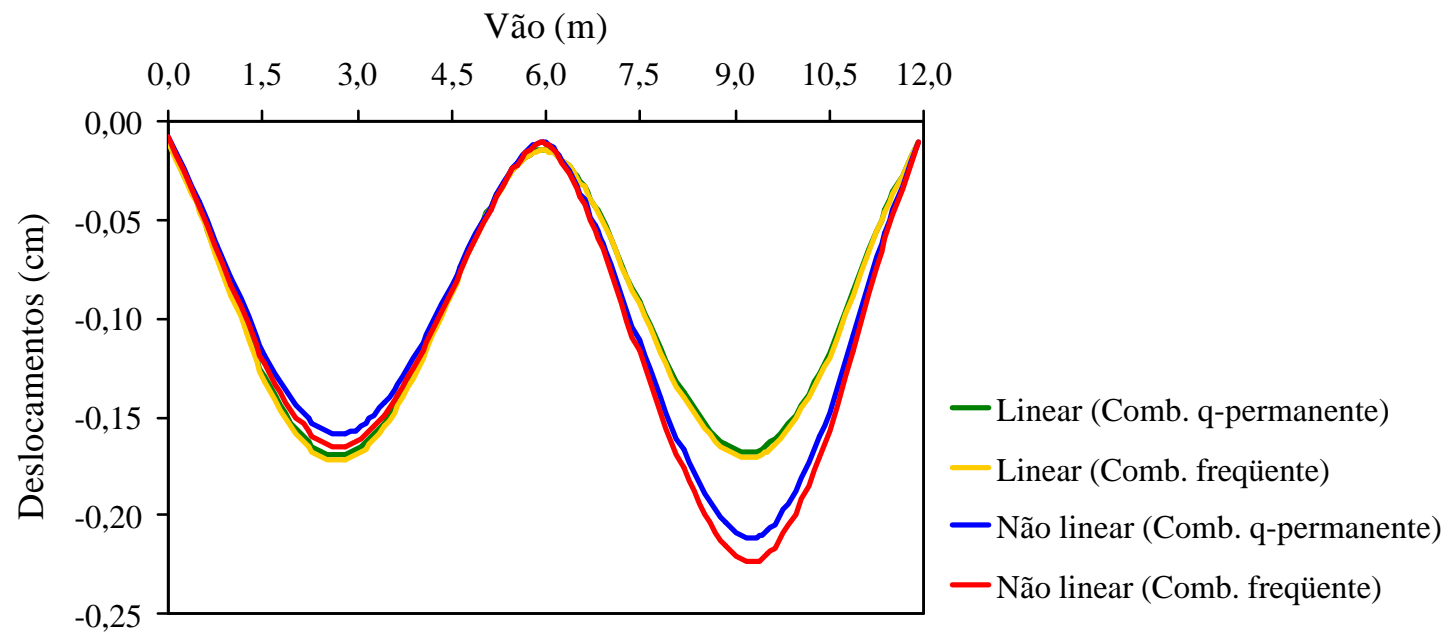

Figura 5.19 - Deslocamentos imediatos da viga V20

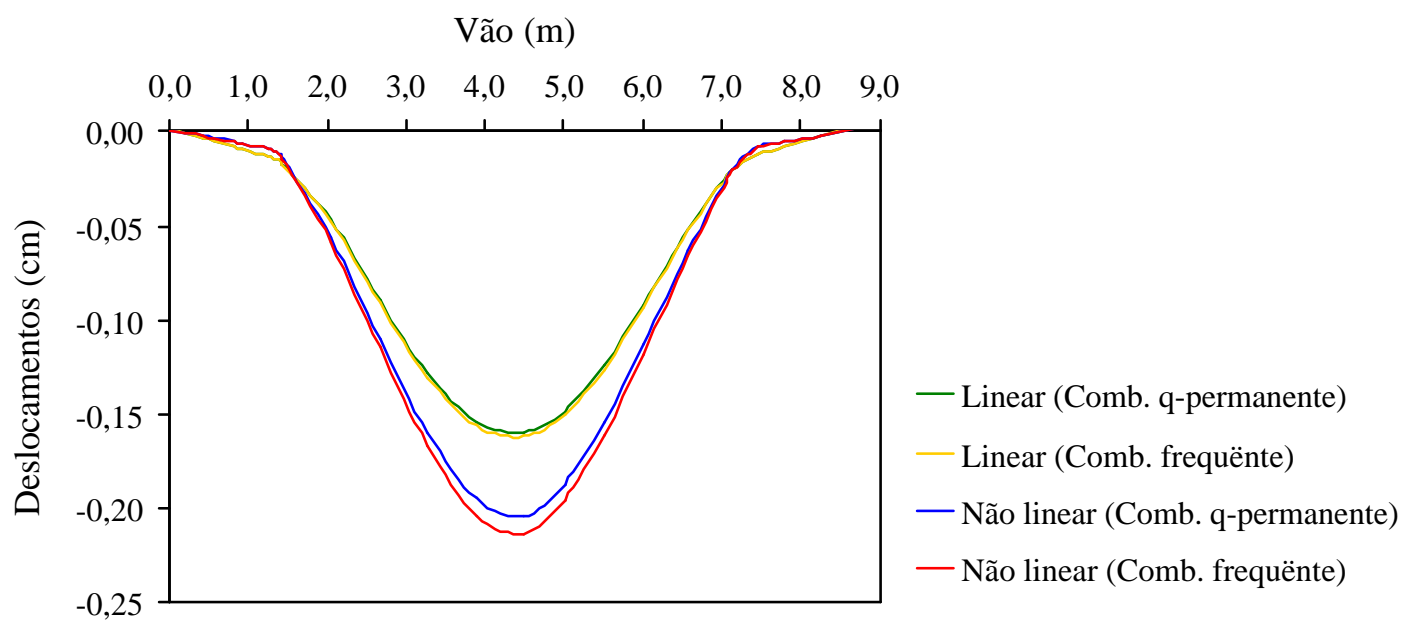

Figura 5.20 - Deslocamentos imediatos da viga V1 
Tabela 5.9 - Deslocamentos imediatos da viga V20, em $\mathrm{cm}$

\begin{tabular}{|c|c|c|c|c|c|c|}
\hline \multirow{2}{*}{$\begin{array}{c}\text { Vão } \\
(\mathbf{m})\end{array}$} & \multicolumn{2}{|c|}{ Análise Linear (LASER) } & \multicolumn{2}{c|}{ Análise Não Linear (ANPAV) } & \multicolumn{2}{c|}{$\begin{array}{c}\text { Relação entre os deslocamentos } \\
\text { não lineares e lineares }\end{array}$} \\
\cline { 2 - 7 } & Q-Permanente & Frequente & Q-Permanente & Frequente & Q-Permanente & Frequente \\
\hline 0,00 & $-0,010$ & $-0,011$ & $-0,008$ & $-0,008$ & 0,77 & 0,77 \\
\hline 0,51 & $-0,045$ & $-0,046$ & $-0,041$ & $-0,043$ & 0,91 & 0,93 \\
\hline 1,01 & $-0,087$ & $-0,089$ & $-0,080$ & $-0,083$ & 0,92 & 0,94 \\
\hline 1,55 & $-0,130$ & $-0,132$ & $-0,119$ & $-0,123$ & 0,91 & 0,94 \\
\hline 2,22 & $-0,163$ & $-0,165$ & $-0,150$ & $-0,157$ & 0,93 & 0,95 \\
\hline 2,83 & $-0,169$ & $-0,171$ & $-0,158$ & $-0,165$ & 0,94 & 0,96 \\
\hline 3,43 & $-0,153$ & $-0,155$ & $-0,143$ & $-0,149$ & 0,94 & 0,96 \\
\hline 4,04 & $-0,119$ & $-0,121$ & $-0,112$ & $-0,117$ & 0,95 & 0,97 \\
\hline 4,64 & $-0,076$ & $-0,077$ & $-0,074$ & $-0,077$ & 0,98 & 0,99 \\
\hline 5,12 & $-0,043$ & $-0,044$ & $-0,043$ & $-0,045$ & 1,00 & 1,02 \\
\hline 5,54 & $-0,023$ & $-0,023$ & $-0,021$ & $-0,022$ & 0,94 & 0,95 \\
\hline 5,95 & $-0,015$ & $-0,015$ & $-0,011$ & $-0,011$ & 0,73 & 0,73 \\
\hline 6,37 & $-0,023$ & $-0,023$ & $-0,026$ & $-0,026$ & 1,12 & 1,14 \\
\hline 6,78 & $-0,043$ & $-0,044$ & $-0,053$ & $-0,056$ & 1,23 & 1,27 \\
\hline 7,48 & $-0,091$ & $-0,093$ & $-0,111$ & $-0,117$ & 1,22 & 1,26 \\
\hline 8,17 & $-0,137$ & $-0,139$ & $-0,167$ & $-0,176$ & 1,22 & 1,26 \\
\hline 8,85 & $-0,164$ & $-0,167$ & $-0,204$ & $-0,215$ & 1,24 & 1,29 \\
\hline 9,53 & $-0,164$ & $-0,167$ & $-0,207$ & $-0,220$ & 1,26 & 1,32 \\
\hline 10,35 & $-0,128$ & $-0,130$ & $-0,160$ & $-0,170$ & 1,26 & 1,31 \\
\hline 10,88 & $-0,086$ & $-0,088$ & $-0,109$ & $-0,116$ & 1,26 & 1,32 \\
\hline 11,39 & $-0,045$ & $-0,046$ & $-0,057$ & $-0,060$ & 1,26 & 1,31 \\
\hline 11,89 & $-0,010$ & $-0,011$ & $-0,010$ & $-0,010$ & 0,98 & 0,97 \\
\hline & & & & - Média & $\mathbf{1 , 2 3}$ & $\mathbf{1 , 2 8}$ \\
\hline
\end{tabular}

Para a viga V1, as relações médias entre os deslocamentos imediatos não-lineares e lineares, para as combinações quase-permanente e freqüente de ações, foram iguais a 1,24 e 1,28, respectivamente. Esses valores, computados considerando-se a região fissurada, são dados na Tabela 5.10.

Assim, para este pavimento, observou-se que os deslocamentos imediatos nãolineares foram em torno de $24 \%$ e $28 \%$ maiores que os correspondentes obtidos com a análise linear, para as combinações quase-permanente e freqüente de ações, respectivamente. 
Tabela 5.10 - Deslocamentos imediatos da viga V1, em $\mathrm{cm}$

\begin{tabular}{|c|c|c|c|c|c|c|}
\hline \multirow{2}{*}{$\begin{array}{c}\text { Vão } \\
(\mathbf{m})\end{array}$} & \multicolumn{2}{|c|}{ Análise Linear (LASER) } & \multicolumn{2}{c|}{ Análise Não Linear (ANPAV) } & \multicolumn{2}{c|}{$\begin{array}{c}\text { Relação entre os deslocamentos } \\
\text { não lineares e lineares }\end{array}$} \\
\cline { 2 - 7 } & Q-Permanente & Frequente & Q-Permanente & Frequente & Q-Permanente & Frequente \\
\hline 0,00 & 0,001 & 0,001 & 0,001 & 0,001 & 0,68 & 0,68 \\
\hline 0,43 & $-0,004$ & $-0,004$ & $-0,002$ & $-0,002$ & 0,68 & 0,69 \\
\hline 0,93 & $-0,009$ & $-0,010$ & $-0,006$ & $-0,006$ & 0,68 & 0,68 \\
\hline 1,25 & $-0,013$ & $-0,013$ & $-0,009$ & $-0,009$ & 0,68 & 0,68 \\
\hline 1,44 & $-0,017$ & $-0,017$ & $-0,014$ & $-0,014$ & 0,82 & 0,82 \\
\hline 2,05 & $-0,047$ & $-0,048$ & $-0,057$ & $-0,059$ & 1,20 & 1,23 \\
\hline 2,66 & $-0,089$ & $-0,091$ & $-0,110$ & $-0,115$ & 1,23 & 1,26 \\
\hline 3,28 & $-0,128$ & $-0,130$ & $-0,159$ & $-0,166$ & 1,24 & 1,27 \\
\hline 3,89 & $-0,154$ & $-0,156$ & $-0,195$ & $-0,204$ & 1,27 & 1,31 \\
\hline 4,50 & $-0,159$ & $-0,162$ & $-0,204$ & $-0,213$ & 1,28 & 1,32 \\
\hline 5,00 & $-0,148$ & $-0,150$ & $-0,187$ & $-0,195$ & 1,26 & 1,30 \\
\hline 5,51 & $-0,124$ & $-0,126$ & $-0,154$ & $-0,161$ & 1,24 & 1,28 \\
\hline 6,01 & $-0,091$ & $-0,093$ & $-0,113$ & $-0,118$ & 1,24 & 1,27 \\
\hline 6,58 & $-0,052$ & $-0,053$ & $-0,064$ & $-0,066$ & 1,23 & 1,26 \\
\hline 7,14 & $-0,021$ & $-0,021$ & $-0,020$ & $-0,021$ & 0,99 & 1,00 \\
\hline 7,46 & $-0,012$ & $-0,012$ & $-0,008$ & $-0,008$ & 0,68 & 0,69 \\
\hline 7,80 & $-0,008$ & $-0,008$ & $-0,006$ & $-0,006$ & 0,69 & 0,69 \\
\hline 8,26 & $-0,003$ & $-0,003$ & $-0,002$ & $-0,002$ & 0,69 & 0,69 \\
\hline 8,71 & 0,002 & 0,002 & 0,002 & 0,002 & 0,68 & 0,68 \\
\hline & & & & Média & $\mathbf{1 , 2 4}$ & $\mathbf{1 , 2 8}$ \\
\hline
\end{tabular}

\section{b) Deslocamentos Diferidos}

Da mesma maneira que para o pavimento 1 , os deslocamentos diferidos foram calculados pela subtração dos deslocamentos imediatos dos deslocamentos totais, ambos calculados com o programa ANPAV.

Para as combinações quase-permanente e freqüente de ações, as relações entre os deslocamentos diferidos e imediatos foram bastante próximas.

Comparando-se os deslocamentos diferidos e os imediatos fornecidos pela análise linear, constatou-se que os diferidos foram aproximadamente $180 \%$ maiores que os imediatos. Com relação aos deslocamentos imediatos provenientes da análise não-linear, os deslocamentos diferidos foram $130 \%$ maiores. Essas porcentagens entre os deslocamentos diferidos e imediatos foram obtidas tanto com a combinação quase-permanente quanto com a combinação freqüente de ações.

Esses valores podem ser verificados a partir dos deslocamentos correspondentes às curvas apresentadas nas Figuras 5.16, 5.17 e 5.18 e também fornecidos na Tabela 5.7. Calculando-se as relações entre os deslocamentos diferidos e imediatos foram encontrados valores bem próximos da média do pavimento, como pode ser visto na Tabela 5.11. 
Tabela 5.11 - Relações entre os deslocamentos diferidos e imediatos do pavimento 2

\begin{tabular}{|c|c|c|c|c|c|c|c|c|c|}
\hline \multicolumn{4}{|c|}{ Deslocamentos Imediatos (cm) } & \multirow{2}{*}{\multicolumn{2}{|c|}{$\begin{array}{c}\text { Desl Diferidos } \\
(\mathrm{cm})\end{array}$}} & \multirow{2}{*}{\multicolumn{2}{|c|}{$\begin{array}{c}\text { Relação entre } \\
\text { deslocamentos } \\
\text { diferidos e imediatos* }\end{array}$}} & \multirow{2}{*}{\multicolumn{2}{|c|}{$\begin{array}{c}\text { Relação entre } \\
\text { deslocamentos } \\
\text { diferidos e imediatos** }\end{array}$}} \\
\hline \multicolumn{2}{|c|}{ LASER } & \multicolumn{2}{|c|}{ ANPAV } & & & & & & \\
\hline$(1)$ & (2) & (1) & $(2)$ & (1) & $(2)$ & (1) & $(2)$ & (1) & $(2)$ \\
\hline 0,04 & 0,05 & 0,04 & 0,04 & 0,12 & 0,12 & 3,00 & 2,40 & 3,00 & 3,00 \\
\hline 0,09 & 0,09 & 0,10 & 0,11 & 0,25 & 0,25 & 2,78 & 2,78 & 2,50 & 2,27 \\
\hline 0,14 & 0,14 & 0,17 & 0,17 & 0,38 & 0,40 & 2,71 & 2,86 & 2,24 & 2,35 \\
\hline 0,19 & 0,19 & 0,23 & 0,24 & 0,52 & 0,53 & 2,74 & 2,79 & 2,26 & 2,21 \\
\hline 0,24 & 0,24 & 0,29 & 0,31 & 0,65 & 0,66 & 2,71 & 2,75 & 2,24 & 2,13 \\
\hline 0,28 & 0,29 & 0,36 & 0,37 & 0,78 & 0,81 & 2,79 & 2,79 & 2,17 & 2,19 \\
\hline 0,33 & 0,34 & 0,42 & 0,44 & 0,92 & 0,94 & 2,79 & 2,76 & 2,19 & 2,14 \\
\hline 0,38 & 0,39 & 0,48 & 0,50 & 1,05 & 1,08 & 2,76 & 2,77 & 2,19 & 2,16 \\
\hline 0,43 & 0,44 & 0,55 & 0,57 & 1,18 & 1,22 & 2,74 & 2,77 & 2,15 & 2,14 \\
\hline 0,48 & 0,49 & 0,61 & 0,64 & 1,32 & 1,35 & 2,75 & 2,76 & 2,16 & 2,11 \\
\hline 0,52 & 0,54 & 0,67 & 0,70 & 1,45 & 1,49 & 2,79 & 2,76 & 2,16 & 2,13 \\
\hline & & & & & Média & 2,78 & 2,74 & 2,30 & 2,26 \\
\hline
\end{tabular}

(1) Deslocamentos devidos à combinação quase-permanente

(2) Deslocamentos devidos à combinação frequiente

* Relação entre os deslocamentos diferidos e os deslocamentos imediatos obtidos com o programa LASER

** Relação entre os deslocamentos diferidos e os deslocamentos imediatos obtidos com o programa ANPAV

Nas Figuras 5.21 e 5.22 são apresentados os deslocamentos imediatos e diferidos das vigas V20 e V1, respectivamente.

Para a viga V20, considerando-se a região fissurada do centro do segundo vão, a relação média entre os deslocamentos diferidos e imediatos lineares foi igual a 2,72 e 2,86, respectivamente para as combinações quase-permanente e freqüente de ações. Considerandose os deslocamentos imediatos não-lineares, essas relações foram iguais a 2,22 e 2,25. Os valores dessas relações são dados na Tabela 5.12.

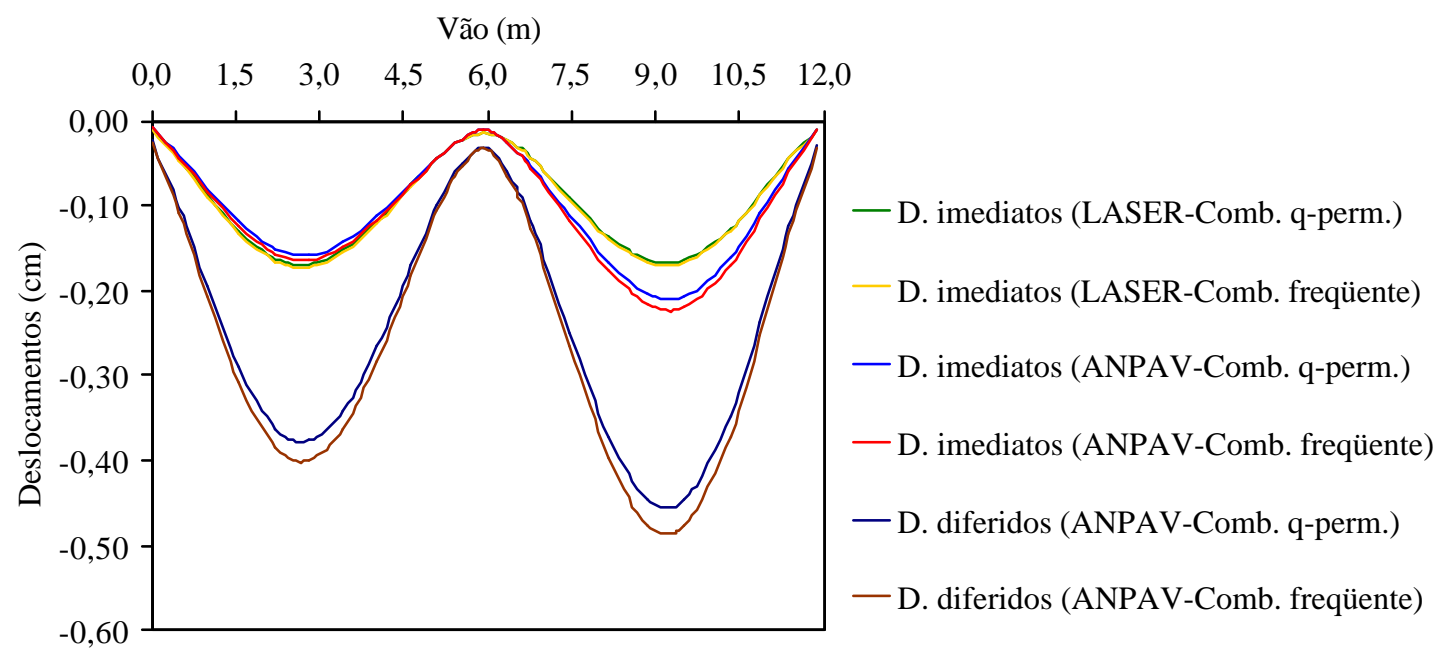

Figura 5.21 - Deslocamentos imediatos e diferidos da viga V20 
Vão (m)

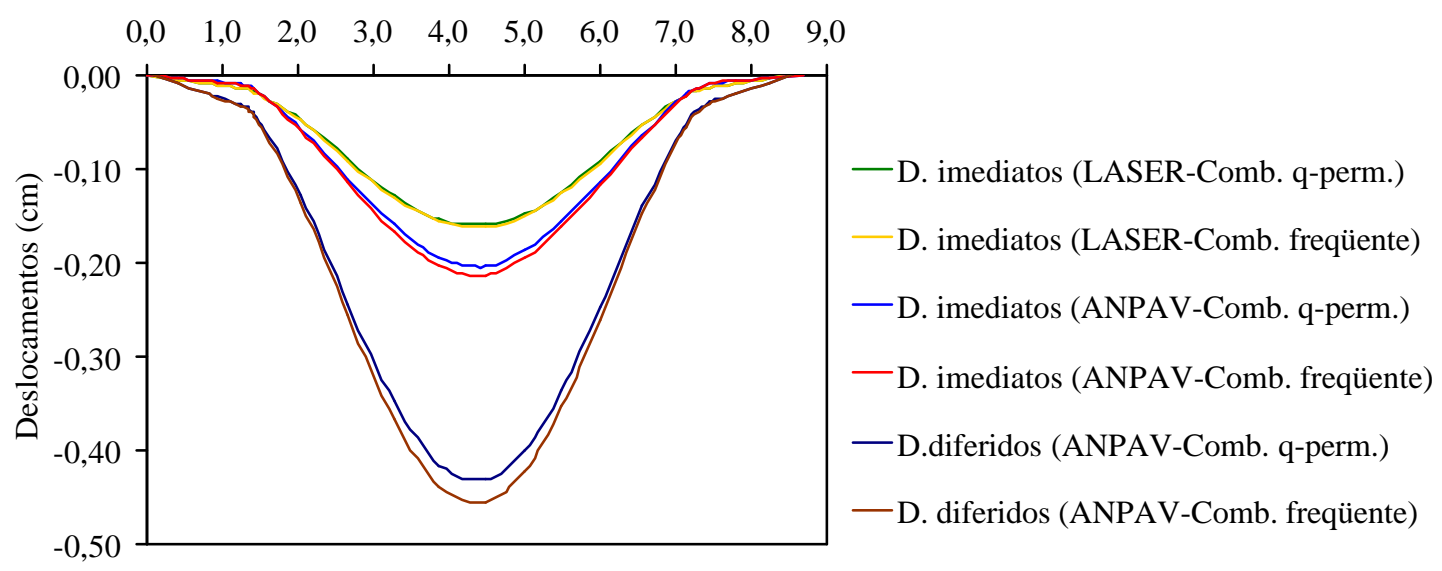

Figura 5.22 - Deslocamentos imediatos e diferidos da viga V1

As relações entre os deslocamentos diferidos e imediatos da viga V1 são dadas na Tabela 5.13. Observou-se que os valores também foram bem próximos da média do pavimento.

Tabela 5.12 - Relações entre os deslocamentos diferidos e imediatos da viga V20

\begin{tabular}{|c|c|c|c|c|c|c|c|c|c|c|}
\hline \multirow{3}{*}{$\begin{array}{l}\text { Vão } \\
\text { (m) }\end{array}$} & \multicolumn{4}{|c|}{ Deslocamentos Imediatos (cm) } & \multirow{2}{*}{\multicolumn{2}{|c|}{$\begin{array}{c}\text { Desl Diferidos } \\
(\mathrm{cm})\end{array}$}} & \multirow{2}{*}{\multicolumn{2}{|c|}{$\begin{array}{c}\text { Relação entre } \\
\text { deslocamentos } \\
\text { diferidos e imediatos* }\end{array}$}} & \multirow{2}{*}{\multicolumn{2}{|c|}{$\begin{array}{c}\text { Relação entre } \\
\text { deslocamentos } \\
\text { diferidos e imediatos* }\end{array}$}} \\
\hline & \multicolumn{2}{|c|}{ LASER } & \multicolumn{2}{|c|}{ ANPAV } & & & & & & \\
\hline & (1) & (2) & (1) & (2) & (1) & (2) & (1) & $(2)$ & (1) & $(2)$ \\
\hline 0,00 & $-0,010$ & $-0,011$ & $-0,008$ & $-0,008$ & $-0,024$ & $-0,025$ & 2,27 & 2,33 & 2,94 & 3,03 \\
\hline 0,51 & $-0,045$ & $-0,046$ & $-0,041$ & $-0,043$ & $-0,102$ & $-0,109$ & 2,25 & 2,35 & 2,47 & 2,52 \\
\hline 1,01 & $-0,087$ & $-0,089$ & $-0,080$ & $-0,083$ & $-0,195$ & $-0,208$ & 2,24 & 2,34 & 2,45 & 2,49 \\
\hline 1,55 & $-0,130$ & $-0,132$ & $-0,119$ & $-0,123$ & $-0,289$ & $-0,307$ & 2,23 & 2,33 & 2,44 & 2,49 \\
\hline 2,22 & $-0,163$ & $-0,165$ & $-0,150$ & $-0,157$ & $-0,362$ & $-0,385$ & 2,23 & 2,33 & 2,41 & 2,46 \\
\hline 2,83 & $-0,169$ & $-0,171$ & $-0,158$ & $-0,165$ & $-0,376$ & $-0,400$ & 2,23 & 2,33 & 2,38 & 2,42 \\
\hline 3,43 & $-0,153$ & $-0,155$ & $-0,143$ & $-0,149$ & $-0,340$ & $-0,361$ & 2,23 & 2,33 & 2,38 & 2,43 \\
\hline 4,04 & $-0,119$ & $-0,121$ & $-0,112$ & $-0,117$ & $-0,266$ & $-0,282$ & 2,24 & 2,34 & 2,36 & 2,42 \\
\hline 4,64 & $-0,076$ & $-0,077$ & $-0,074$ & $-0,077$ & $-0,171$ & $-0,182$ & 2,26 & 2,36 & 2,32 & 2,38 \\
\hline 5,12 & $-0,043$ & $-0,044$ & $-0,043$ & $-0,045$ & $-0,099$ & $-0,105$ & 2,28 & 2,38 & 2,29 & 2,34 \\
\hline 5,54 & $-0,023$ & $-0,023$ & $-0,021$ & $-0,022$ & $-0,052$ & $-0,055$ & 2,27 & 2,35 & 2,41 & 2,47 \\
\hline 5,95 & $-0,015$ & $-0,015$ & $-0,011$ & $-0,011$ & $-0,032$ & $-0,033$ & 2,16 & 2,21 & 2,96 & 3,02 \\
\hline 6,37 & $-0,023$ & $-0,023$ & $-0,026$ & $-0,026$ & $-0,061$ & $-0,065$ & 2,69 & 2,80 & 2,39 & 2,46 \\
\hline 6,78 & $-0,043$ & $-0,044$ & $-0,053$ & $-0,056$ & $-0,119$ & $-0,127$ & 2,75 & 2,88 & 2,23 & 2,27 \\
\hline 7,48 & $-0,091$ & $-0,093$ & $-0,111$ & $-0,117$ & $-0,249$ & $-0,265$ & 2,73 & 2,86 & 2,24 & 2,27 \\
\hline 8,17 & $-0,137$ & $-0,139$ & $-0,167$ & $-0,176$ & $-0,372$ & $-0,396$ & 2,72 & 2,85 & 2,23 & 2,26 \\
\hline 8,85 & $-0,164$ & $-0,167$ & $-0,204$ & $-0,215$ & $-0,445$ & $-0,475$ & 2,72 & 2,85 & 2,19 & 2,21 \\
\hline 9,53 & $-0,164$ & $-0,167$ & $-0,207$ & $-0,220$ & $-0,447$ & $-0,477$ & 2,72 & 2,85 & 2,15 & 2,17 \\
\hline 10,35 & $-0,128$ & $-0,130$ & $-0,160$ & $-0,170$ & $-0,346$ & $-0,370$ & 2,72 & 2,86 & 2,16 & 2,17 \\
\hline 10,88 & $-0,086$ & $-0,088$ & $-0,109$ & $-0,116$ & $-0,236$ & $-0,253$ & 2,73 & 2,88 & 2,16 & 2,19 \\
\hline 11,39 & $-0,045$ & $-0,046$ & $-0,057$ & $-0,060$ & $-0,124$ & $-0,133$ & 2,75 & 2,91 & 2,19 & 2,22 \\
\hline 11,89 & $-0,010$ & $-0,011$ & $-0,010$ & $-0,010$ & $-0,029$ & $-0,031$ & 2,76 & 2,89 & 2,82 & 2,98 \\
\hline & & & & & & Média & 2,72 & 2,86 & 2,22 & 2,25 \\
\hline
\end{tabular}


Tabela 5.13 - Relações entre os deslocamentos diferidos e imediatos da viga V1

\begin{tabular}{|c|c|c|c|c|c|c|c|c|c|c|}
\hline \multirow{3}{*}{$\begin{array}{l}\text { Vão } \\
\text { (m) }\end{array}$} & \multicolumn{4}{|c|}{ Deslocamentos Imediatos (cm) } & \multirow{2}{*}{\multicolumn{2}{|c|}{$\begin{array}{c}\text { Desl Diferidos } \\
(\mathbf{c m})\end{array}$}} & \multirow{2}{*}{\multicolumn{2}{|c|}{$\begin{array}{c}\text { Relação entre } \\
\text { deslocamentos } \\
\text { diferidos e imediatos* }\end{array}$}} & \multirow{2}{*}{\multicolumn{2}{|c|}{$\begin{array}{c}\text { Relação entre } \\
\text { deslocamentos } \\
\text { diferidos e imediatos** }\end{array}$}} \\
\hline & \multicolumn{2}{|c|}{ LASER } & \multicolumn{2}{|c|}{ ANPAV } & & & & & & \\
\hline & (1) & (2) & (1) & (2) & (1) & (2) & (1) & (2) & (1) & (2) \\
\hline 0,00 & 0,001 & 0,001 & 0,001 & 0,001 & 0,003 & 0,003 & 2,23 & 2,29 & 3,29 & 3,36 \\
\hline 0,43 & $-0,004$ & $-0,004$ & $-0,002$ & $-0,002$ & $-0,008$ & $-0,009$ & 2,41 & 2,48 & 3,53 & 3,62 \\
\hline 0,93 & $-0,009$ & $-0,010$ & $-0,006$ & $-0,006$ & $-0,022$ & $-0,023$ & 2,37 & 2,44 & 3,49 & 3,58 \\
\hline 1,25 & $-0,013$ & $-0,013$ & $-0,009$ & $-0,009$ & $-0,031$ & $-0,032$ & 2,37 & 2,44 & 3,48 & 3,57 \\
\hline 1,44 & $-0,017$ & $-0,017$ & $-0,014$ & $-0,014$ & $-0,042$ & $-0,044$ & 2,45 & 2,53 & 2,99 & 3,06 \\
\hline 2,05 & $-0,047$ & $-0,048$ & $-0,057$ & $-0,059$ & $-0,128$ & $-0,135$ & 2,72 & 2,82 & 2,26 & 2,29 \\
\hline 2,66 & $-0,089$ & $-0,091$ & $-0,110$ & $-0,115$ & $-0,244$ & $-0,257$ & 2,73 & 2,83 & 2,21 & 2,24 \\
\hline 3,28 & $-0,128$ & $-0,130$ & $-0,159$ & $-0,166$ & $-0,349$ & $-0,368$ & 2,72 & 2,82 & 2,19 & 2,21 \\
\hline 3,89 & $-0,154$ & $-0,156$ & $-0,195$ & $-0,204$ & $-0,417$ & $-0,440$ & 2,71 & 2,82 & 2,14 & 2,16 \\
\hline 4,50 & $-0,159$ & $-0,162$ & $-0,204$ & $-0,213$ & $-0,432$ & $-0,456$ & 2,71 & 2,82 & 2,12 & 2,14 \\
\hline 5,00 & $-0,148$ & $-0,150$ & $-0,187$ & $-0,195$ & $-0,401$ & $-0,423$ & 2,71 & 2,81 & 2,15 & 2,17 \\
\hline 5,51 & $-0,124$ & $-0,126$ & $-0,154$ & $-0,161$ & $-0,336$ & $-0,355$ & 2,71 & 2,81 & 2,18 & 2,21 \\
\hline 6,01 & $-0,091$ & $-0,093$ & $-0,113$ & $-0,118$ & $-0,248$ & $-0,262$ & 2,72 & 2,82 & 2,20 & 2,22 \\
\hline 6,58 & $-0,052$ & $-0,053$ & $-0,064$ & $-0,066$ & $-0,140$ & $-0,147$ & 2,70 & 2,81 & 2,20 & 2,23 \\
\hline 7,14 & $-0,021$ & $-0,021$ & $-0,020$ & $-0,021$ & $-0,052$ & $-0,054$ & 2,52 & 2,60 & 2,54 & 2,60 \\
\hline 7,46 & $-0,012$ & $-0,012$ & $-0,008$ & $-0,008$ & $-0,028$ & $-0,030$ & 2,34 & 2,41 & 3,42 & 3,52 \\
\hline 7,80 & $-0,008$ & $-0,008$ & $-0,006$ & $-0,006$ & $-0,019$ & $-0,020$ & 2,35 & 2,43 & 3,43 & 3,53 \\
\hline 8,26 & $-0,003$ & $-0,003$ & $-0,002$ & $-0,002$ & $-0,007$ & $-0,007$ & 2,41 & 2,48 & 3,51 & 3,60 \\
\hline 8,71 & 0,002 & 0,002 & 0,002 & 0,002 & 0,005 & 0,006 & 2,22 & 2,30 & 3,26 & 3,36 \\
\hline & & & & & & Média & 2,71 & 2,82 & 2,17 & 2,20 \\
\hline
\end{tabular}

Diante do exposto anteriormente, notou-se que para os deslocamentos diferidos obtidos com o programa ANPAV, foram aproximadamente $130 \%$ maiores que os deslocamentos imediatos fornecidos por este programa, tanto para a combinação quasepermanente de ações quanto para a freqüente. Desta forma, o coeficiente multiplicador dos deslocamentos imediatos foi igual a 2,3.

Com relação aos deslocamentos imediatos lineares fornecidos pelo programa LASER, os deslocamentos diferidos obtidos com o programa ANPAV foram, em média, $180 \%$ maiores, para as duas combinações de ações consideradas.

\subsubsection{ALTURAS MÍNIMAS}

São apresentados a seguir, o cálculo das alturas mínimas de algumas lajes e vigas, alturas estas que satisfazem o estado limite de deformações excessivas.

Para o cálculo dessas alturas mínimas de lajes e vigas, de maneira similar ao pavimento anterior, foram utilizadas as eqs.(3.3) e (4.2), respectivamente.

\section{a) Alturas Mínimas das Lajes}

Para este pavimento foram calculadas as alturas mínimas das seguintes lajes: 


\section{- Laje L1}

Para a laje L1, de acordo com a Figura 5.15, foram obtidas as seguintes propriedades:

- Tipo 4

- $\mathrm{L}_{\mathrm{x}}=395 \mathrm{~cm}$

- $\mathrm{L}_{\mathrm{y}}=858 \mathrm{~cm}$

Pela Tabela 3.8, para a verificação da aceitabilidade sensorial quanto a aspectos visuais, o coeficiente $\alpha$ foi igual a 0,88 , e para as verificações de aceitabilidade sensorial relativa a vibrações e dos efeitos dos deslocamentos nas paredes, o coeficiente $\alpha$ foi igual a 0,85. E, de acordo com as eqs.(3.4) e (3.5), foram calculados os seguintes valores de $\beta$ :

$$
\begin{aligned}
& \beta_{\text {ver. } 1}=61+4,0 \cdot 2,0-42,7 \cdot(3,0)+13,2 \cdot(3,0)^{2}-1,36 \cdot(3,0)^{3}=23,0 \\
& \beta_{\text {ver. } 2 \mathrm{e} 3}=67+3,5 \cdot 2,0-51,5 \cdot(3,0)+16,5 \cdot(3,0)^{2}-1,77 \cdot(3,0)^{3}=20,2
\end{aligned}
$$

Vale lembrar que, como a relação entre os vãos foi maior que 2,0, nas eqs.(3.4) e (3.5), essa relação foi considerada igual a 3,0, conforme recomendado no Capítulo 3.

Com esses valores de $\alpha$ e $\beta$, foram encontradas as seguintes alturas mínimas que satisfazem as verificações do estado limite de deformações excessivas:

$$
\mathrm{h}_{\text {min,ver. } 1}=\frac{\alpha \mathrm{L}_{\mathrm{x}}}{\beta}=\frac{0,88 \cdot 395}{23,0}=15,1 \mathrm{~cm}
$$

$\mathrm{e}$,

$$
\mathrm{h}_{\text {min, ver.2e } 3}=\frac{\alpha \mathrm{L}_{\mathrm{x}}}{\beta}=\frac{0,85 \cdot 395}{20,2}=16,6 \mathrm{~cm}
$$

De acordo com esses resultados, observou-se que, para atender às verificações do estado limite de deformações excessivas, a laje L1 deveria ter uma altura superior a 16,6 cm, o que não ocorreu, já que a laje foi projetada com uma altura igual a $10 \mathrm{~cm}$. Foi constatado, assim, que essa laje pode apresentar problemas devidos a deslocamentos excessivos, sendo necessário, então, para essa verificação, o cálculo dos deslocamentos da laje L1 e a comparação com os limites fornecidos pela NBR 6118 (2003).

\section{- Laje L2}

Para a laje L2, foram consideradas as seguintes características: 
- Tipo 6 (não foi considerado o engastamento no lado apoiado na viga V20)

- $\mathrm{L}_{\mathrm{x}}=632,5 \mathrm{~cm}$

- $\mathrm{L}_{\mathrm{y}}=652 \mathrm{~cm}$

Pela Tabela 3.8, para a verificação da aceitabilidade sensorial relativa a aspectos visuais, e para as verificações de aceitabilidade sensorial relativa a vibrações e dos efeitos dos deslocamentos nas paredes, os valores do coeficiente $\alpha$ foram 0,93 e 0,90, respectivamente. E, de acordo com as eqs.(3.4) e (3.5), foram obtidos os seguintes valores de $\beta$ :

$$
\begin{aligned}
& \beta_{\text {ver. } 1}=61+4,0 \cdot 2,0-42,7 \cdot\left(\frac{652}{632,5}\right)+13,2 \cdot\left(\frac{652}{632,5}\right)^{2}-1,36 \cdot\left(\frac{652}{632,5}\right)^{3}=37,5 \\
& \beta_{\text {ver. } 2 \text { e } 3}=67+3,5 \cdot 2,0-51,5 \cdot\left(\frac{652}{632,5}\right)+16,5 \cdot\left(\frac{652}{632,5}\right)^{2}-1,77 \cdot\left(\frac{652}{632,5}\right)^{3}=36,5
\end{aligned}
$$

Portanto, foram encontradas as seguintes alturas mínimas para a laje L2:

$$
\mathrm{h}_{\text {min,ver. } 1}=\frac{\alpha \mathrm{L}_{\mathrm{x}}}{\beta}=\frac{0,93 \cdot 632,5}{37,5}=15,7 \mathrm{~cm}
$$

e,

$$
\mathrm{h}_{\min , v e r .2 \mathrm{e} 3}=\frac{\alpha \mathrm{L}_{\mathrm{x}}}{\beta}=\frac{0,90 \cdot 632,5}{36,5}=15,6 \mathrm{~cm}
$$

Constatou-se, assim, que para atender às verificações do estado limite de deformações excessivas, seria necessária uma altura superior a $15,7 \mathrm{~cm}$. Como no projeto foi considerada uma altura igual a $12 \mathrm{~cm}$, a laje L2 também pode apresentar problemas devidos a deslocamentos excessivos.

\section{b) Alturas Mínimas das Vigas}

Para este pavimento foram calculadas as alturas mínimas das seguintes vigas:

\section{- Viga V1}

Foram consideradas as seguintes características para o cálculo da altura mínima da viga V1:

- $\ell_{\mathrm{ef}}=746 \mathrm{~cm}$

- $\mathrm{b}=13 \mathrm{~cm}$

- $\mathrm{h}_{\mathrm{p}}=125 \mathrm{~cm}$ 
Para as verificações de aceitabilidade sensorial, foi calculado o seguinte valor para $\beta$ :

$$
\beta_{\text {ver. } 1 \text { e } 2}=6,0+1,4 \cdot 2,0+0,005 \cdot 746+0,21 \cdot 13-0,009 \cdot 125-0,25 \cdot \frac{746}{125}=12,6
$$

E, para a verificação dos efeitos dos deslocamentos nas paredes (verificação 3), encontrou-se:

$$
\beta_{\text {ver. } 3}=5,7+1,35 \cdot 2,0+0,005 \cdot 746+0,18 \cdot 13-0,007 \cdot 125-0,26 \cdot \frac{746}{125}=12,0
$$

De acordo com a eq.(4.2), as alturas mínimas que atendem essas verificações foram iguais a:

$$
\mathrm{h}_{\text {min,ver. } 1 \mathrm{e} 2}=\frac{\ell_{\text {ef }}}{\beta}=\frac{746}{12,6}=59,0 \mathrm{~cm}
$$

e,

$$
\mathrm{h}_{\text {min,ver. } 3}=\frac{\ell_{\mathrm{ef}}}{\beta}=\frac{746}{12,0}=61,9 \mathrm{~cm}
$$

Percebeu-se, então, que para satisfazer as verificações tanto de aceitabilidade sensorial quanto de efeitos dos deslocamentos nas paredes, a altura da viga deveria ser superior a $62 \mathrm{~cm}$. Portanto, como no projeto foi adotada uma altura igual a $76 \mathrm{~cm}$, essas verificações do estado limite de deformações excessivas foram atendidas.

\section{- Viga V19}

Para a viga V19, foram tomadas as características a seguir.

- $\ell_{\mathrm{ef}}=404 \mathrm{~cm}$

- $\mathrm{b}=13 \mathrm{~cm}$

- $\mathrm{h}_{\mathrm{p}}=22 \mathrm{~cm}$

E, utilizando-se as eqs.(4.3) e (4.4), foram obtidos os seguintes valores de $\beta$ :

$$
\begin{aligned}
& \beta_{\text {ver. } 1 \mathrm{e} 2}=6,0+1,4 \cdot 2,0+0,005 \cdot 404+0,21 \cdot 13-0,009 \cdot 22-0,25 \cdot \frac{404}{22}=8,8 \\
& \beta_{\text {ver. } 3}=5,7+1,35 \cdot 2,0+0,005 \cdot 404+0,18 \cdot 13-0,007 \cdot 22-0,26 \cdot \frac{404}{22}=7,8
\end{aligned}
$$


Para atender as verificações de aceitabilidade sensorial, a altura mínima obtida foi igual a:

$$
\mathrm{h}_{\min , \text { ver.1e } 2}=\frac{\ell_{\mathrm{ef}}}{\beta}=\frac{404}{8,8}=46,1 \mathrm{~cm}
$$

E para satisfazer a verificação dos efeitos dos deslocamentos nas paredes, obteve-se:

$$
\mathrm{h}_{\min , \text { ver. } 3}=\frac{\ell_{\text {ef }}}{\beta}=\frac{404}{7,8}=51,6 \mathrm{~cm}
$$

Observou-se, então, que a altura da viga V19 deveria ser superior a 51,6 cm para atender as verificações do estado limite de deformações excessivas, o que ocorreu, já que no projeto foi considerada, para esta viga, uma altura de $76 \mathrm{~cm}$.

\subsection{PAVIMENTO 3}

Nas Figuras 5.23 e 5.24 têm-se as plantas se arquitetura e de forma de mais um pavimento analisado.

Para este pavimento, foram utilizados concreto com resistência característica à compressão de $25 \mathrm{MPa}$ e aço CA - 50.

A altura de todas as lajes é igual a $9 \mathrm{~cm}$, e o carregamento também foi constituído de uma parcela igual a $1,0 \mathrm{kN} / \mathrm{m}^{2}$, correspondente ao peso do piso e do revestimento, e uma ação variável de $1,5 \mathrm{kN} / \mathrm{m}^{2}$

\subsubsection{VALORES DOS DESLOCAMENTOS}

Mais uma vez, após o cálculo dos deslocamentos imediatos com os programas LASER e ANPAV, e dos deslocamentos totais, evidentemente, apenas com o programa ANPAV, foram traçadas as curvas de mesmo deslocamento, para as combinações quasepermanente e freqüente de ações, e para cada tipo de deslocamentos, conforme ilustrado da Figura 5.25 a Figura 5.30.

Vale observar que nestas figuras o pavimento sofreu um giro de $90^{\circ}$ em relação à planta de forma da Figura 5.24. 


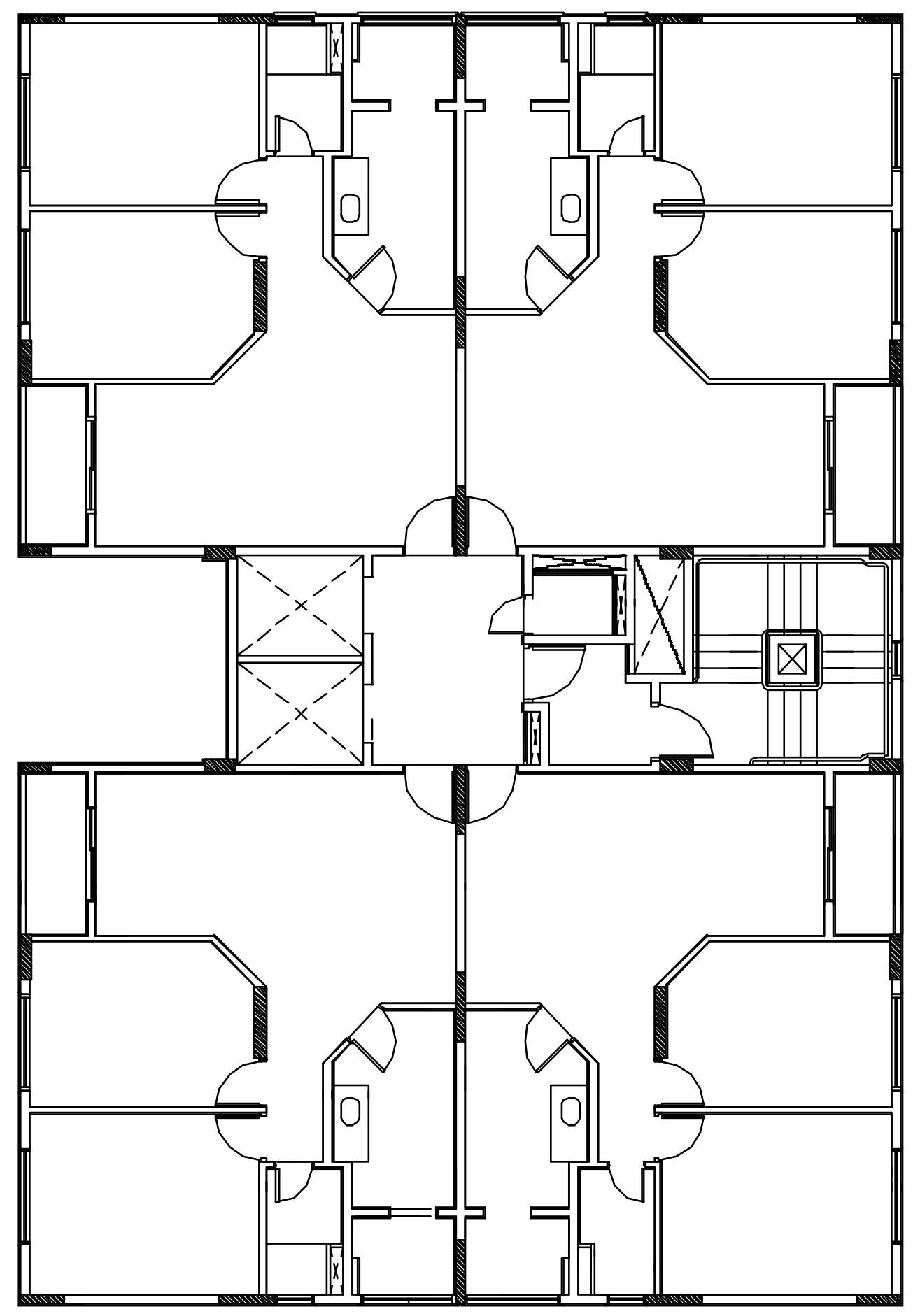

Figura 5.23 - Planta de arquitetura do pavimento 3 


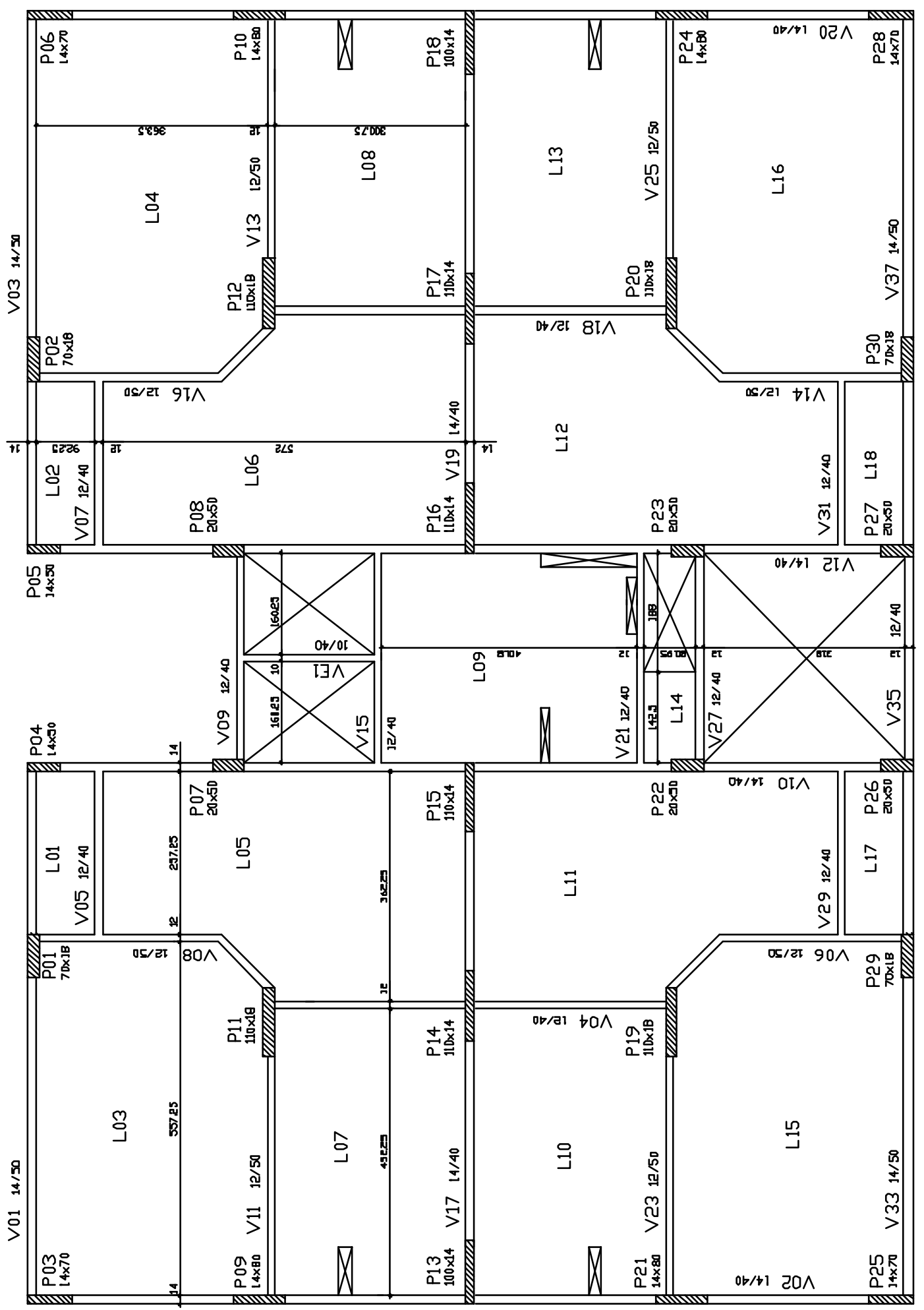

Figura 5.24 - Planta de forma do pavimento 3 


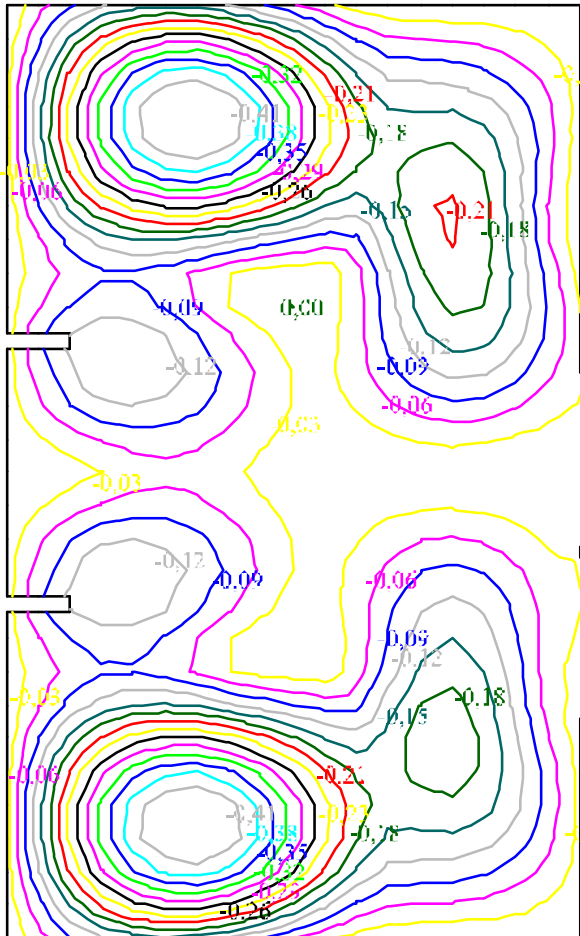

$\mathrm{M}=-0,004$

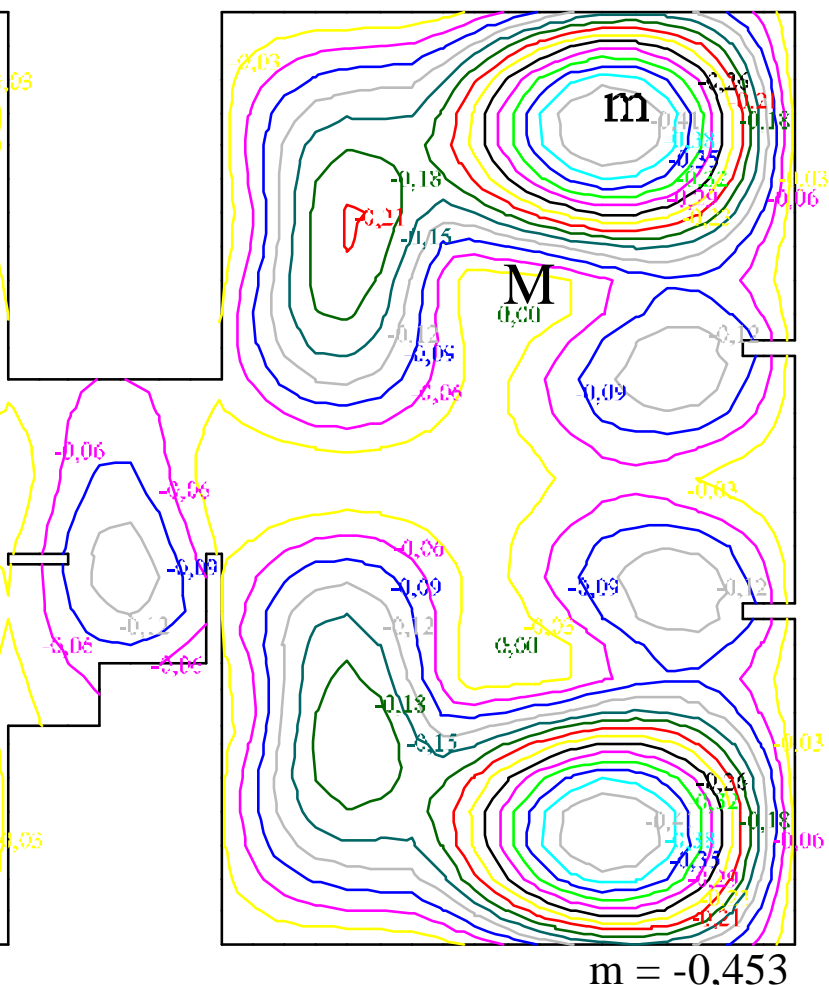

$\mathrm{m}=-0,453$

Figura 5.25 - Deslocamentos imediatos obtidos a partir da análise linear (Combinação quase-permanente)
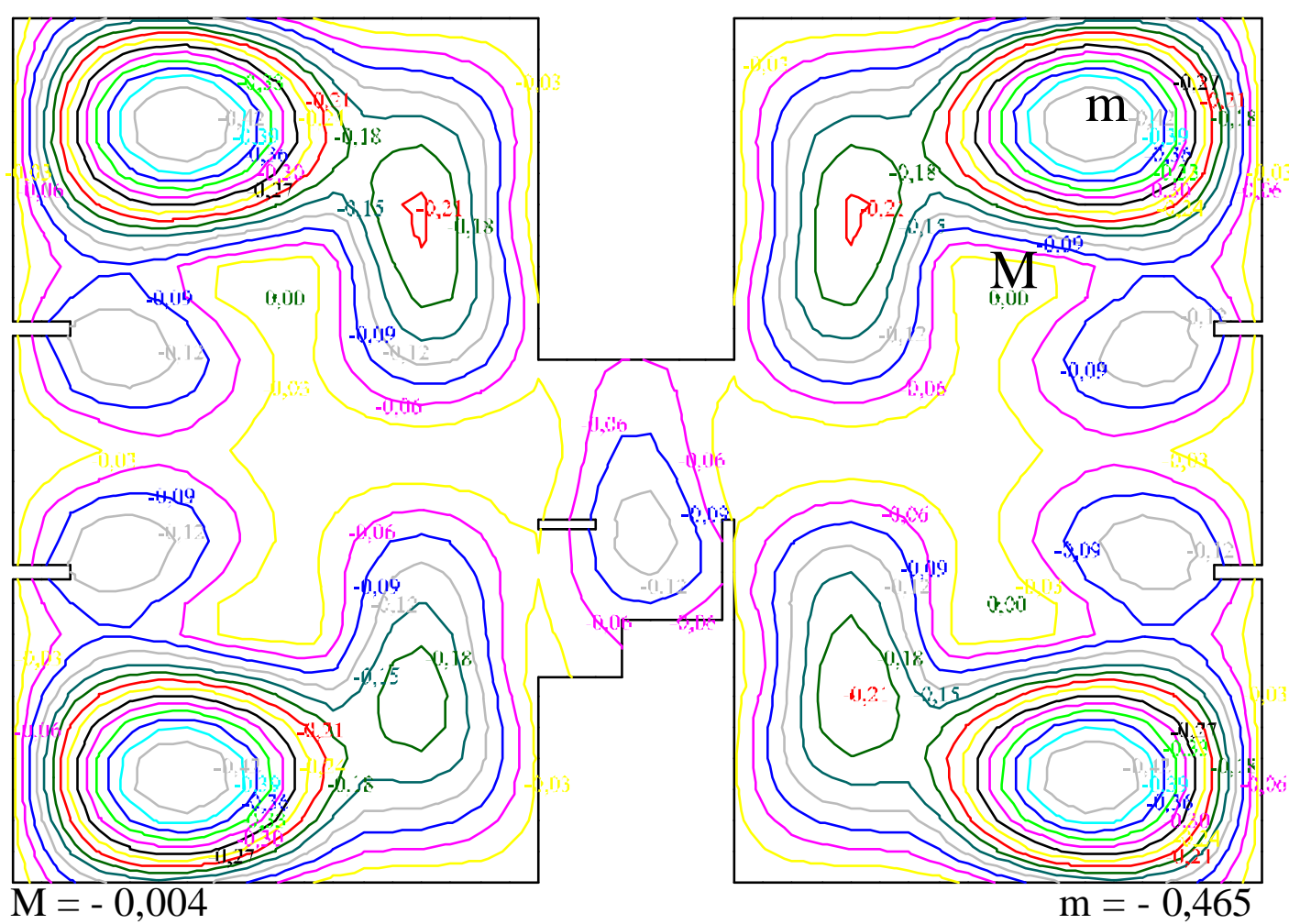

Figura 5.26 - Deslocamentos imediatos obtidos a partir da análise linear (Combinação frequiente) 


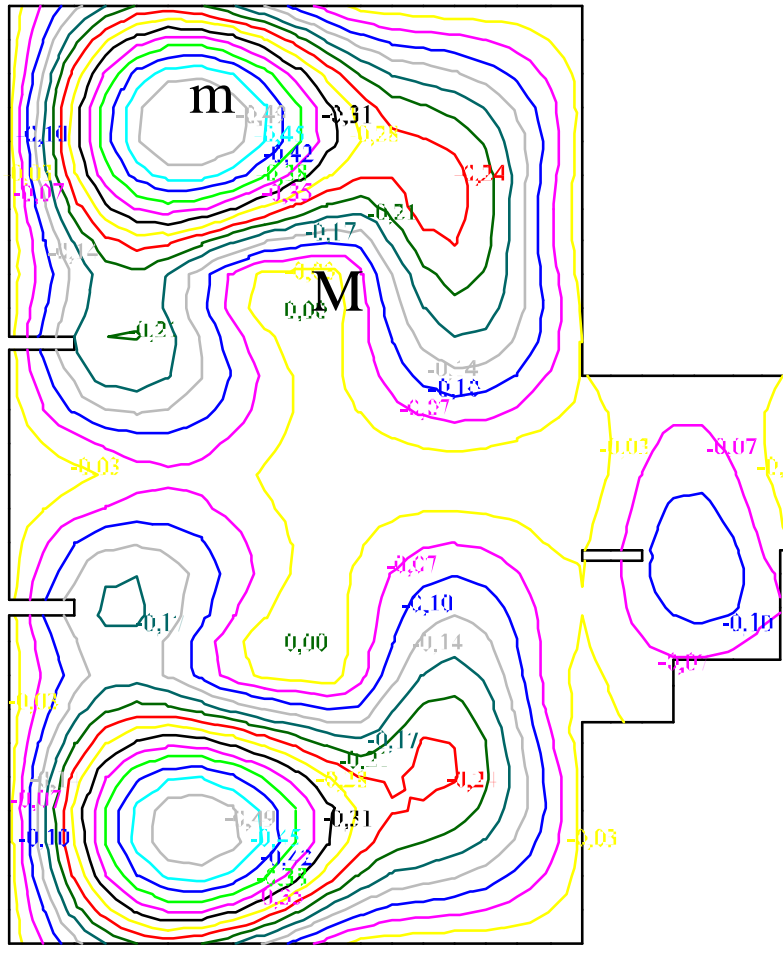

$\mathrm{M}=0,005$

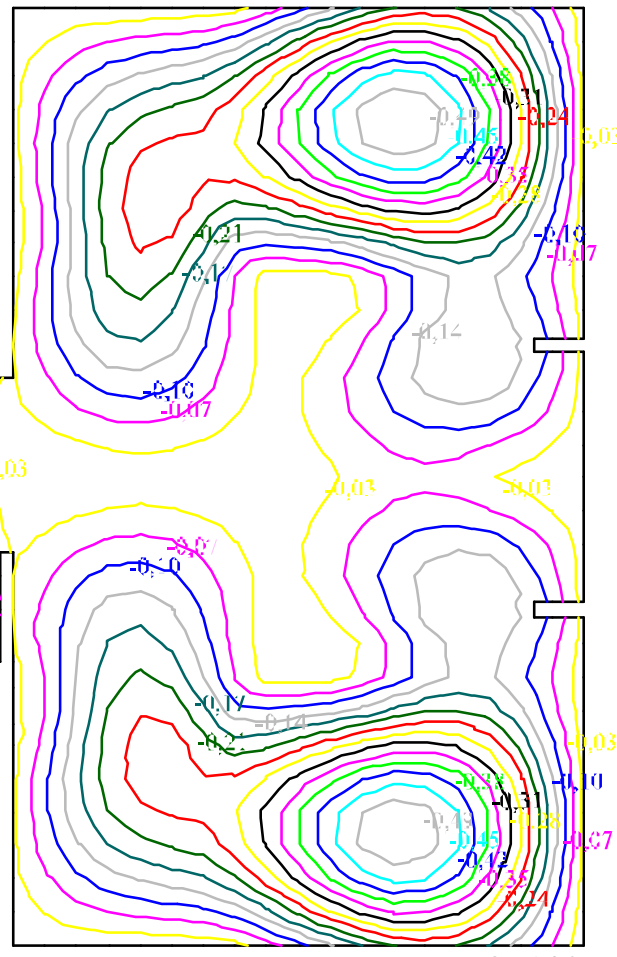

$\mathrm{m}=-0,542$

Figura 5.27 - Deslocamentos imediatos obtidos a partir da análise não-linear (Combinação quase-permanente)

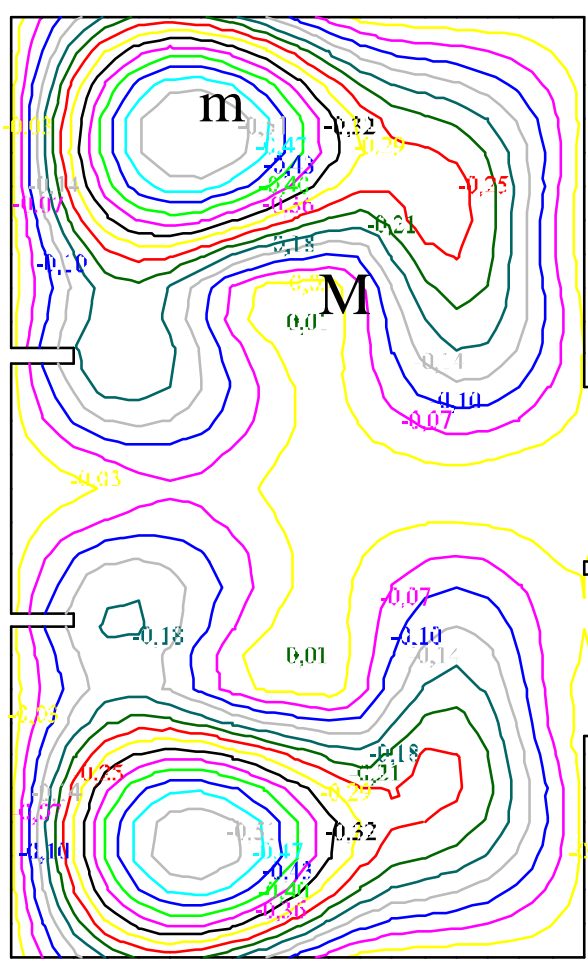

$\mathrm{M}=0,006$

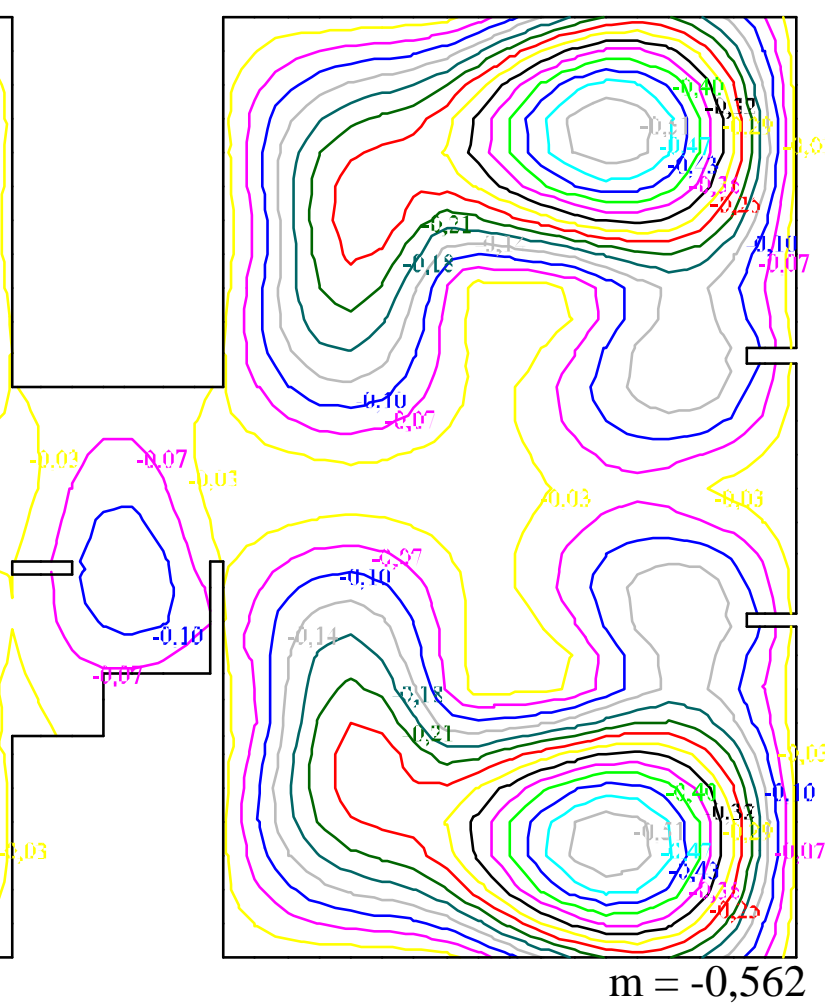

$\mathrm{m}=-0,562$

Figura 5.28 - Deslocamentos imediatos obtidos a partir da análise não-linear (Combinação freqüente) 

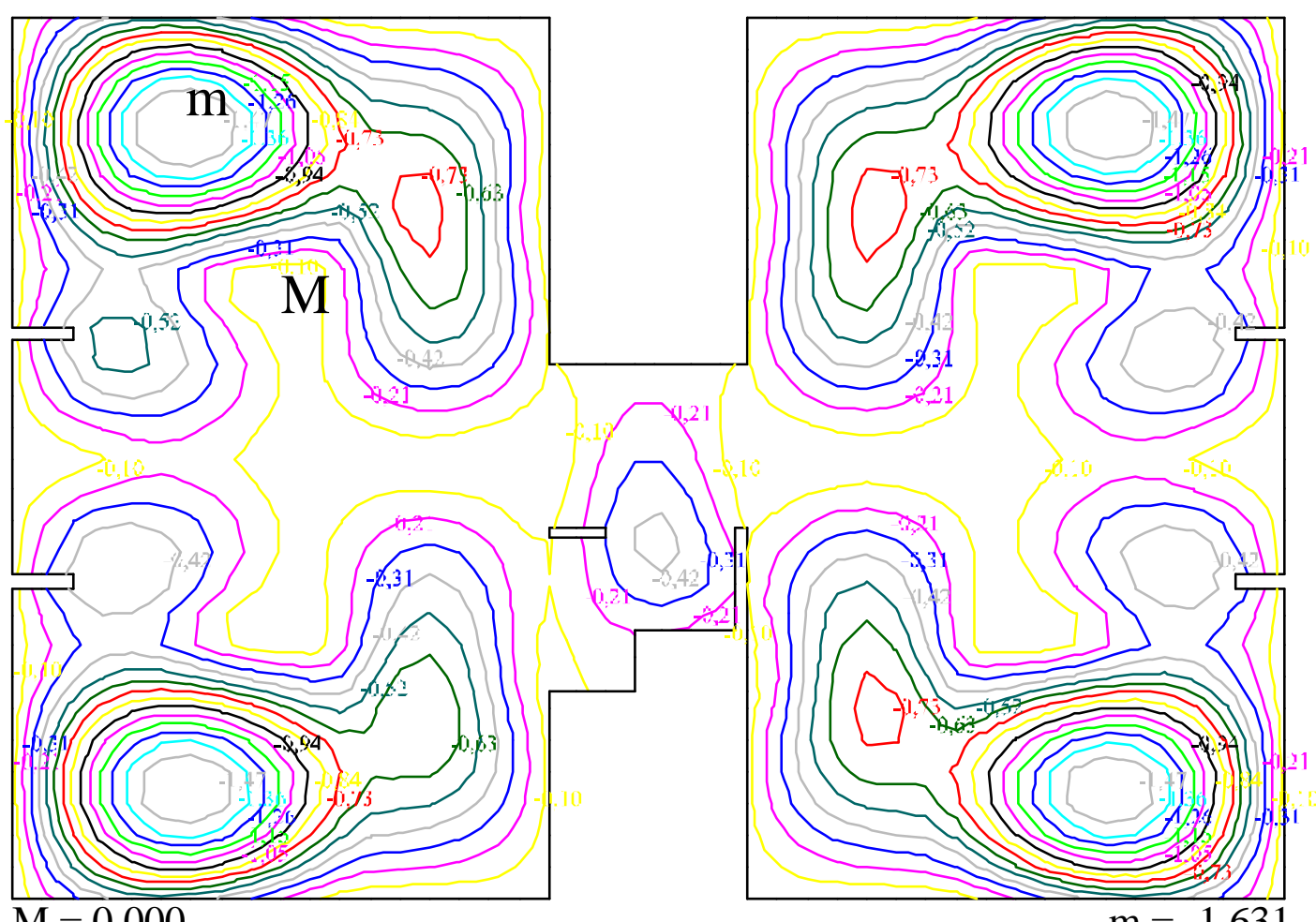

$\mathrm{M}=0,000$

$m=-1,631$

Figura 5.29 - Deslocamentos totais obtidos a partir da análise não-linear (Combinação quase-permanente)

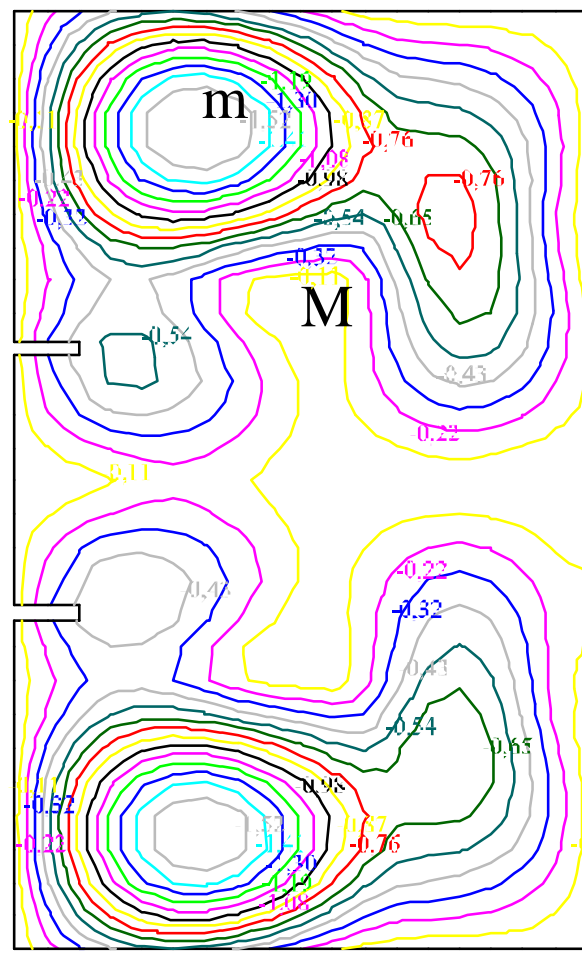

$\mathrm{M}=0,002$

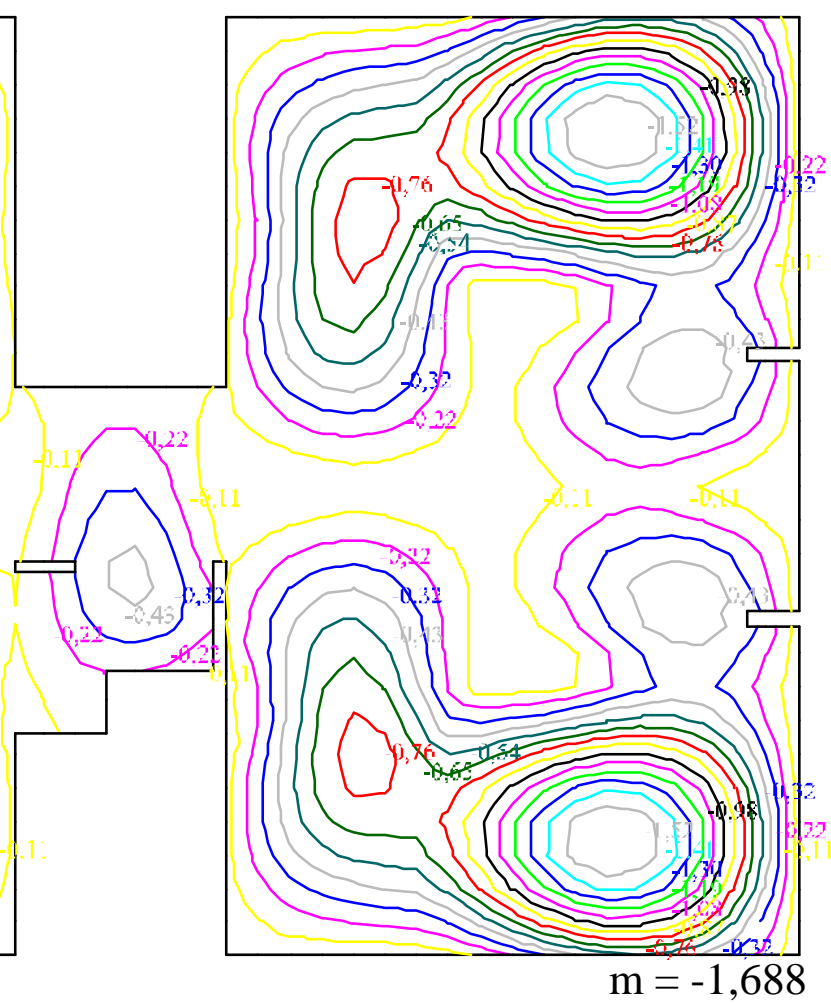

Figura 5.30 - Deslocamentos totais obtidos a partir da análise não-linear (Combinação freqüente) 


\subsubsection{ANÁLISE DOS RESULTADOS}

A seguir são comentadas algumas comparações entre os deslocamentos calculados com o programa LASER e ANPAV.

\section{a) Deslocamentos Imediatos}

Para este pavimento, os valores médios das relações entre os deslocamentos imediatos calculados com os programas ANPAV e LASER foram bastante próximos para as duas combinações de ações consideradas.

Considerando-se as curvas de deslocamentos mostradas da Figura 5.25 a Figura 5.28, e apresentados na Tabela 5.14, observou-se que as relações entre os deslocamentos imediatos não-lineares e os lineares foram menores que as obtidas nos pavimentos apresentados nos itens anteriores. Os valores médios desta relação para as combinações quase-permanente e freqüente de ações foram iguais a 1,18 e 1,20, respectivamente. Desta forma, constatou-se que os deslocamentos imediatos provenientes da análise não-linear foram aproximadamente $20 \%$ maiores que os deslocamentos imediatos lineares.

Tabela 5.14 - Deslocamentos imediatos do pavimento 3 devidos às análises lineares e não-lineares, em cm

\begin{tabular}{|c|c|c|c|c|c|}
\hline \multicolumn{2}{|c|}{ Análise Linear (LASER) } & \multicolumn{2}{c|}{ Análise Não Linear (ANPAV) } & $\begin{array}{c}\text { Relação entre os deslocamentos } \\
\text { não lineares e lineares }\end{array}$ \\
\hline Q. Permanente & Frequente & Q. Permanente & Frequente & Q. Permanente & Frequente \\
\hline 0,03 & 0,03 & 0,03 & 0,03 & 1,00 & 1,00 \\
\hline 0,06 & 0,06 & 0,07 & 0,07 & 1,17 & 1,17 \\
\hline 0,09 & 0,09 & 0,10 & 0,10 & 1,11 & 1,11 \\
\hline 0,12 & 0,12 & 0,14 & 0,14 & 1,17 & 1,17 \\
\hline 0,15 & 0,15 & 0,17 & 0,18 & 1,16 & 1,17 \\
\hline 0,18 & 0,18 & 0,21 & 0,21 & 1,17 & 1,17 \\
\hline 0,21 & 0,21 & 0,24 & 0,25 & 1,16 & 1,19 \\
\hline 0,23 & 0,24 & 0,28 & 0,29 & 1,20 & 1,21 \\
\hline 0,26 & 0,27 & 0,31 & 0,32 & 1,19 & 1,19 \\
\hline 0,29 & 0,30 & 0,35 & 0,36 & 1,19 & 1,20 \\
\hline 0,32 & 0,33 & 0,38 & 0,40 & 1,19 & 1,21 \\
\hline 0,35 & 0,36 & 0,42 & 0,43 & 1,20 & 1,20 \\
\hline 0,38 & 0,39 & 0,45 & 0,47 & 1,18 & 1,21 \\
\hline 0,41 & 0,42 & 0,49 & 0,51 & 1,20 & 1,21 \\
\hline & & & Média & $\mathbf{1 , 1 8}$ & $\mathbf{1 , 2 0}$ \\
\hline
\end{tabular}

Analisando-se os deslocamentos imediatos das vigas verificou-se, para as regiões de maiores momentos fletores, onde o concreto já apresentava fissuras, que a relação média entre os deslocamentos imediatos não-lineares e os lineares foi aproximadamente 1,32, valor um pouco superior à média do pavimento. 
Na Figura 5.31 são ilustrados os deslocamentos imediatos da viga V1, cujos valores são fornecidos na Tabela 5.15. Observou-se que no primeiro vão, considerando-se apenas a região de maiores momentos fletores, os valores médios das relações entre os deslocamentos imediatos não-lineares e os lineares foram 1,30 e 1,34, respectivamente para as combinações quase-permanente e freqüente de ações.

Percebe u-se, também, que para o segundo vão da viga V1, os deslocamentos devidos à análise com o programa ANPAV foram menores que aqueles obtidos com o programa LASER. Conforme comentado anteriormente, este fato se deve à consideração da colaboração da armadura na determinação da rigidez do ele mento, permitida pelo programa ANPAV.

Ainda para ilustrar o comportamento das vigas, na Figura 5.32 têm-se os deslocamentos imediatos da viga V16. Novamente, considerando-se apenas a região de maiores momentos fletores, as relações entre os deslocamentos imediatos não-lineares e os lineares apresentaram valores médios iguais a 1,33 e 1,36, para as combinações quasepermanente e freqüente de ações, respectivamente. Na Tabela 5.16 são fornecidos tais valores.

Para o pavimento em estudo observou-se, então, que os deslocamentos imediatos fornecidos pela análise não-linear com o programa ANPAV foram aproximadamente $20 \%$ maiores que os da análise linear com o programa LASER. E considerando-se somente as vigas, essa diferença foi de $30 \%$.

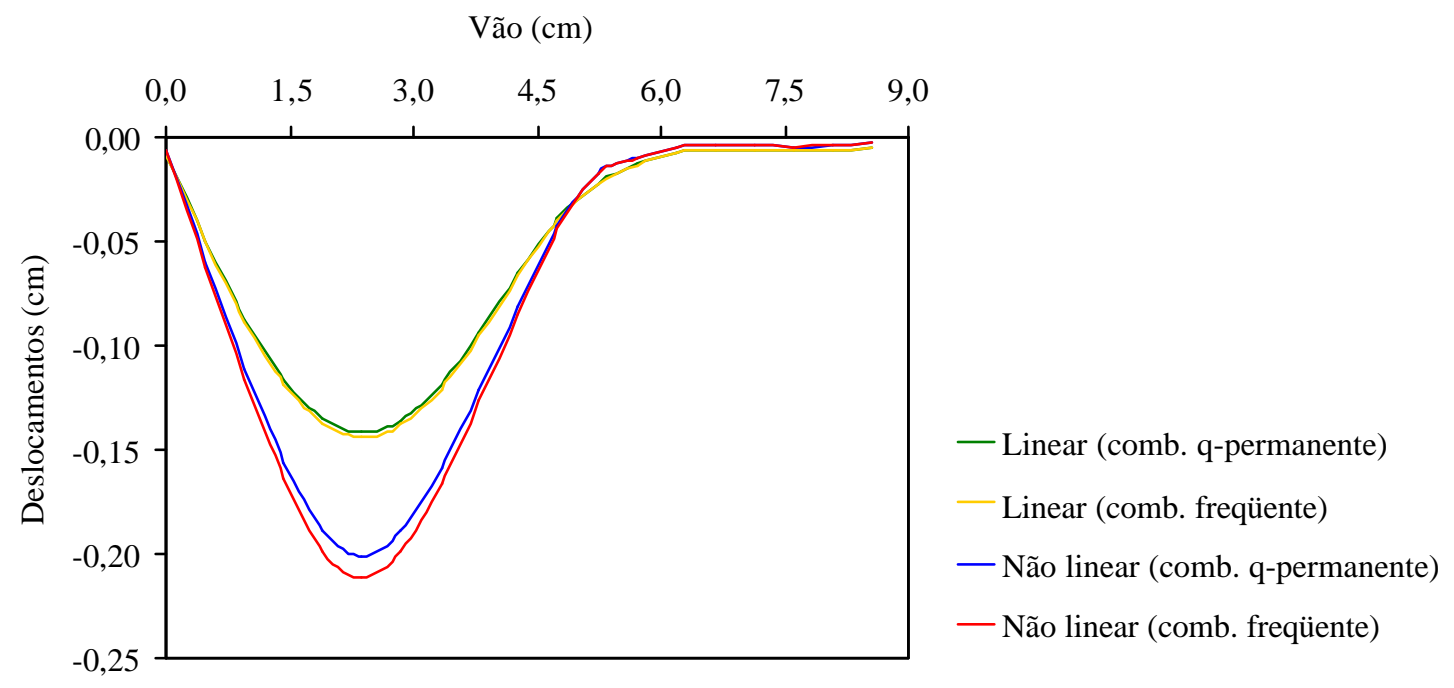

Figura 5.31 - Deslocamentos imediatos da viga V1 
Tabela 5.15 - Deslocamentos imediatos da viga V1, em cm

\begin{tabular}{|c|c|c|c|c|c|c|}
\hline \multirow{2}{*}{$\begin{array}{c}\text { Vão } \\
(\mathbf{m})\end{array}$} & \multicolumn{2}{|c|}{ Análise Linear (LASER) } & \multicolumn{2}{c|}{ Análise Não Linear (ANPAV) } & \multicolumn{2}{c|}{$\begin{array}{c}\text { Relação entre os deslocamentos } \\
\text { não lineares e lineares }\end{array}$} \\
\cline { 2 - 7 } & Q-Permanente & Frequente & Q-Permanente & Frequente & Q-Permanente & Frequente \\
\hline 0,00 & $-0,008$ & $-0,009$ & $-0,006$ & $-0,006$ & 0,75 & 0,75 \\
\hline 0,47 & $-0,050$ & $-0,051$ & $-0,060$ & $-0,063$ & 1,20 & 1,24 \\
\hline 0,95 & $-0,087$ & $-0,089$ & $-0,111$ & $-0,116$ & 1,27 & 1,31 \\
\hline 1,42 & $-0,116$ & $-0,118$ & $-0,156$ & $-0,164$ & 1,34 & 1,39 \\
\hline 1,90 & $-0,135$ & $-0,137$ & $-0,189$ & $-0,199$ & 1,40 & 1,45 \\
\hline 2,37 & $-0,142$ & $-0,144$ & $-0,201$ & $-0,211$ & 1,42 & 1,47 \\
\hline 2,85 & $-0,136$ & $-0,138$ & $-0,188$ & $-0,198$ & 1,39 & 1,44 \\
\hline 3,32 & $-0,119$ & $-0,121$ & $-0,158$ & $-0,166$ & 1,34 & 1,38 \\
\hline 3,80 & $-0,094$ & $-0,095$ & $-0,121$ & $-0,127$ & 1,29 & 1,33 \\
\hline 4,27 & $-0,065$ & $-0,066$ & $-0,081$ & $-0,085$ & 1,24 & 1,28 \\
\hline 4,74 & $-0,039$ & $-0,040$ & $-0,043$ & $-0,044$ & 1,09 & 1,11 \\
\hline 5,22 & $-0,022$ & $-0,023$ & $-0,017$ & $-0,018$ & 0,78 & 0,78 \\
\hline 5,69 & $-0,013$ & $-0,013$ & $-0,010$ & $-0,010$ & 0,77 & 0,77 \\
\hline 6,17 & $-0,007$ & $-0,007$ & $-0,005$ & $-0,005$ & 0,73 & 0,73 \\
\hline 6,64 & $-0,006$ & $-0,006$ & $-0,004$ & $-0,004$ & 0,67 & 0,67 \\
\hline 7,12 & $-0,006$ & $-0,006$ & $-0,004$ & $-0,004$ & 0,65 & 0,65 \\
\hline 7,59 & $-0,007$ & $-0,007$ & $-0,005$ & $-0,005$ & 0,66 & 0,65 \\
\hline 8,07 & $-0,007$ & $-0,007$ & $-0,004$ & $-0,004$ & 0,66 & 0,66 \\
\hline 8,54 & $-0,005$ & $-0,005$ & $-0,003$ & $-0,003$ & 0,65 & 0,65 \\
\hline & & & & $-M e ́ d i a$ & 1,30 & $\mathbf{1 , 3 4}$ \\
\hline
\end{tabular}

Vão (m)

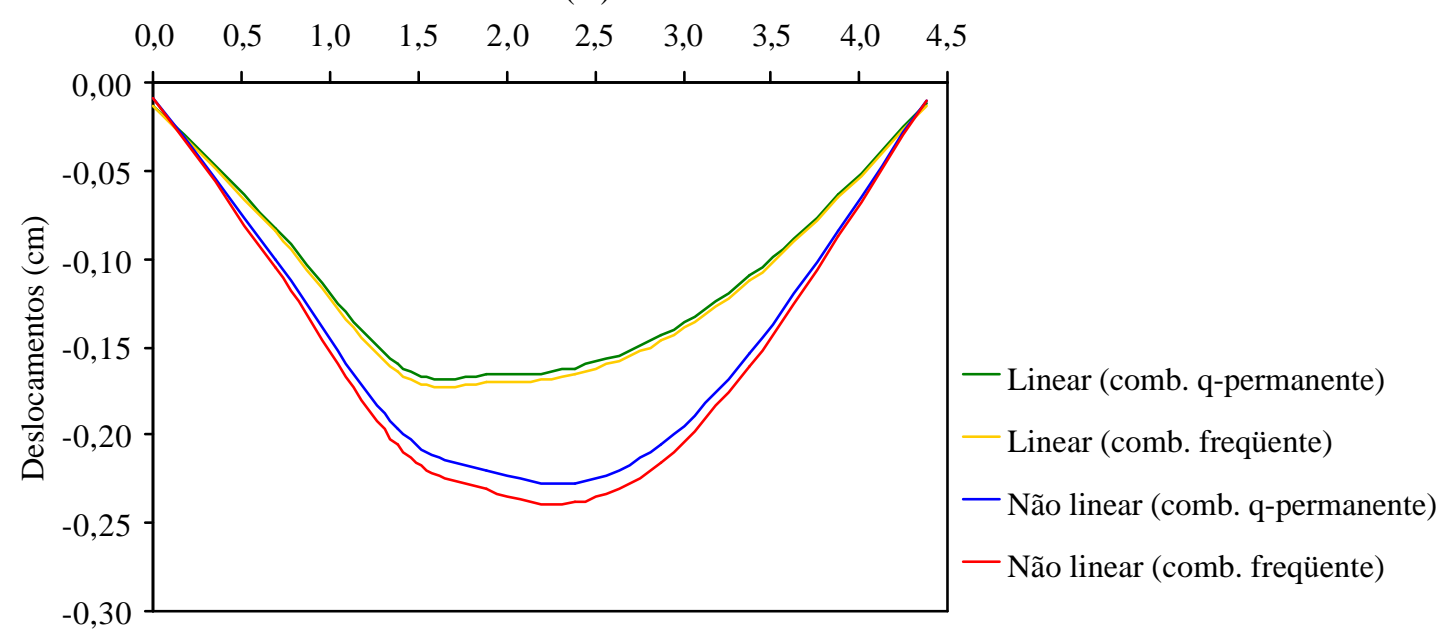

Figura 5.32 - Deslocamentos imediatos da viga V16 
Tabela 5.16 - Deslocamentos imediatos da viga V16, em cm

\begin{tabular}{|c|c|c|c|c|c|c|}
\hline \multirow{2}{*}{$\begin{array}{c}\text { Vão } \\
(\mathbf{m})\end{array}$} & \multicolumn{2}{|c|}{ Análise Linear (LASER) } & \multicolumn{2}{c|}{ Análise Não Linear (ANPAV) } & \multicolumn{2}{c|}{$\begin{array}{c}\text { Relação entre os deslocamentos } \\
\text { não lineares e lineares }\end{array}$} \\
\cline { 2 - 7 } & Q-Permanente & Frequente & Q-Permanente & Frequente & Q-Permanente & Frequente \\
\hline 0,00 & $-0,013$ & $-0,013$ & $-0,009$ & $-0,009$ & 0,67 & 0,66 \\
\hline 0,69 & $-0,083$ & $-0,085$ & $-0,101$ & $-0,105$ & 1,22 & 1,24 \\
\hline 1,38 & $-0,160$ & $-0,164$ & $-0,197$ & $-0,206$ & 1,23 & 1,25 \\
\hline 1,88 & $-0,166$ & $-0,171$ & $-0,220$ & $-0,231$ & 1,32 & 1,35 \\
\hline 2,38 & $-0,162$ & $-0,166$ & $-0,227$ & $-0,238$ & 1,40 & 1,44 \\
\hline 2,88 & $-0,143$ & $-0,147$ & $-0,205$ & $-0,215$ & 1,43 & 1,46 \\
\hline 3,38 & $-0,110$ & $-0,113$ & $-0,153$ & $-0,161$ & 1,39 & 1,42 \\
\hline 3,88 & $-0,065$ & $-0,066$ & $-0,084$ & $-0,088$ & 1,30 & 1,33 \\
\hline 4,38 & $-0,013$ & $-0,013$ & $-0,010$ & $-0,010$ & 0,80 & 0,81 \\
\hline
\end{tabular}

\section{b) Deslocamentos Diferidos}

Comparando-se os deslocamentos diferidos e imediatos do pavimento, percebeu-se que os deslocamentos diferidos foram aproximadamente $10 \%$ e $100 \%$ maiores que os deslocamentos imediatos provenientes da análise linear e da análise não-linear, respectivamente.

Não foi constatada diferença significativa nesses valores para as combinações quasepermanente e freqüente de ações, como pode ser visto na Tabela 5.17, onde, considerando-se as curvas de deslocamentos das Figuras 5.25 a 5.30, são expostas as relações entre esses deslocamentos.

Tabela 5.17 - Relações entre os deslocamentos diferidos e imediatos do pavimento 3

\begin{tabular}{|c|c|c|c|c|c|c|c|c|c|}
\hline \multicolumn{4}{|c|}{ Deslocamentos Imediatos (cm) } & \multirow{2}{*}{\multicolumn{2}{|c|}{$\begin{array}{c}\text { Desl Diferidos } \\
(\mathrm{cm})\end{array}$}} & \multirow{2}{*}{\multicolumn{2}{|c|}{$\begin{array}{c}\text { Relação entre } \\
\text { deslocamentos } \\
\text { diferidos e imediatos* }\end{array}$}} & \multirow{2}{*}{\multicolumn{2}{|c|}{$\begin{array}{c}\text { Relação entre } \\
\text { deslocamentos } \\
\text { diferidos e imediatos } * *\end{array}$}} \\
\hline \multicolumn{2}{|c|}{ LASER } & \multicolumn{2}{|c|}{ ANPAV } & & & & & & \\
\hline (1) & $(2)$ & (1) & (2) & (1) & (2) & (1) & (2) & (1) & (2) \\
\hline 0,03 & 0,03 & 0,03 & 0,03 & 0,07 & 0,08 & 2,33 & 2,67 & 2,33 & 2,67 \\
\hline 0,06 & 0,06 & 0,07 & 0,07 & 0,14 & 0,15 & 2,33 & 2,50 & 2,00 & 2,14 \\
\hline 0,09 & 0,09 & 0,10 & 0,10 & 0,21 & 0,22 & 2,33 & 2,44 & 2,10 & 2,20 \\
\hline 0,12 & 0,12 & 0,14 & 0,14 & 0,28 & 0,29 & 2,33 & 2,42 & 2,00 & 2,07 \\
\hline 0,15 & 0,15 & 0,17 & 0,18 & 0,35 & 0,36 & 2,33 & 2,40 & 2,06 & 2,00 \\
\hline 0,18 & 0,18 & 0,21 & 0,21 & 0,42 & 0,44 & 2,33 & 2,44 & 2,00 & 2,10 \\
\hline 0,21 & 0,21 & 0,24 & 0,25 & 0,49 & 0,51 & 2,33 & 2,43 & 2,04 & 2,04 \\
\hline 0,23 & 0,24 & 0,28 & 0,29 & 0,57 & 0,59 & 2,46 & 2,44 & 2,05 & 2,05 \\
\hline 0,26 & 0,27 & 0,31 & 0,32 & 0,63 & 0,66 & 2,42 & 2,44 & 2,03 & 2,06 \\
\hline 0,29 & 0,30 & 0,35 & 0,36 & 0,70 & 0,72 & 2,41 & 2,40 & 2,00 & 2,00 \\
\hline 0,32 & 0,33 & 0,38 & 0,40 & 0,77 & 0,79 & 2,41 & 2,39 & 2,03 & 1,98 \\
\hline 0,35 & 0,36 & 0,42 & 0,43 & 0,84 & 0,87 & 2,40 & 2,42 & 2,00 & 2,02 \\
\hline 0,38 & 0,39 & 0,45 & 0,47 & 0,91 & 0,94 & 2,39 & 2,41 & 2,02 & 2,00 \\
\hline 0,41 & 0,42 & 0,49 & 0,51 & 0,98 & 1,01 & 2,39 & 2,40 & 2,00 & 1,98 \\
\hline & & & & & Média & 2,37 & 2,44 & 2,05 & 2,09 \\
\hline
\end{tabular}


Para as vigas, considerando-se as regiões de maiores momentos fletores, e, consequentemente, deslocamentos mais significativos, verificou-se que os deslocamentos diferidos foram $140 \%$ e $80 \%$ maiores que os deslocamentos imediatos provenientes da análise linear e da análise não-linear, respectivamente.

Observou-se que a relação média entre os deslocamentos diferidos e deslocamentos os imediatos lineares, para as vigas, foi igual à do pavimento, sendo que para os deslocamentos imediatos não-lineares, essa relação foi um pouco menor que a média do pavimento.

Novamente para representar esse comportamento das vigas, nas Figuras 5.33 e 5.34 são apresentados os deslocamentos imediatos e diferidos das vigas V1 e V16, e seus valores, juntamente com as relações entre eles, são dados nas Tabelas 5.18 e 5.19 .

Para a viga V1, a relação média entre os deslocamentos diferidos e os imediatos lineares foi aproximadamente 2,31, para as duas combinações de ações. Já para a viga V16, essa relação foi igual a 2,36.

Considerando-se agora a relação entre os deslocamentos diferidos e imediatos nãolineares, tanto para a viga V1 quanto para a viga V16, foi verificada uma relação média de 1,76 .

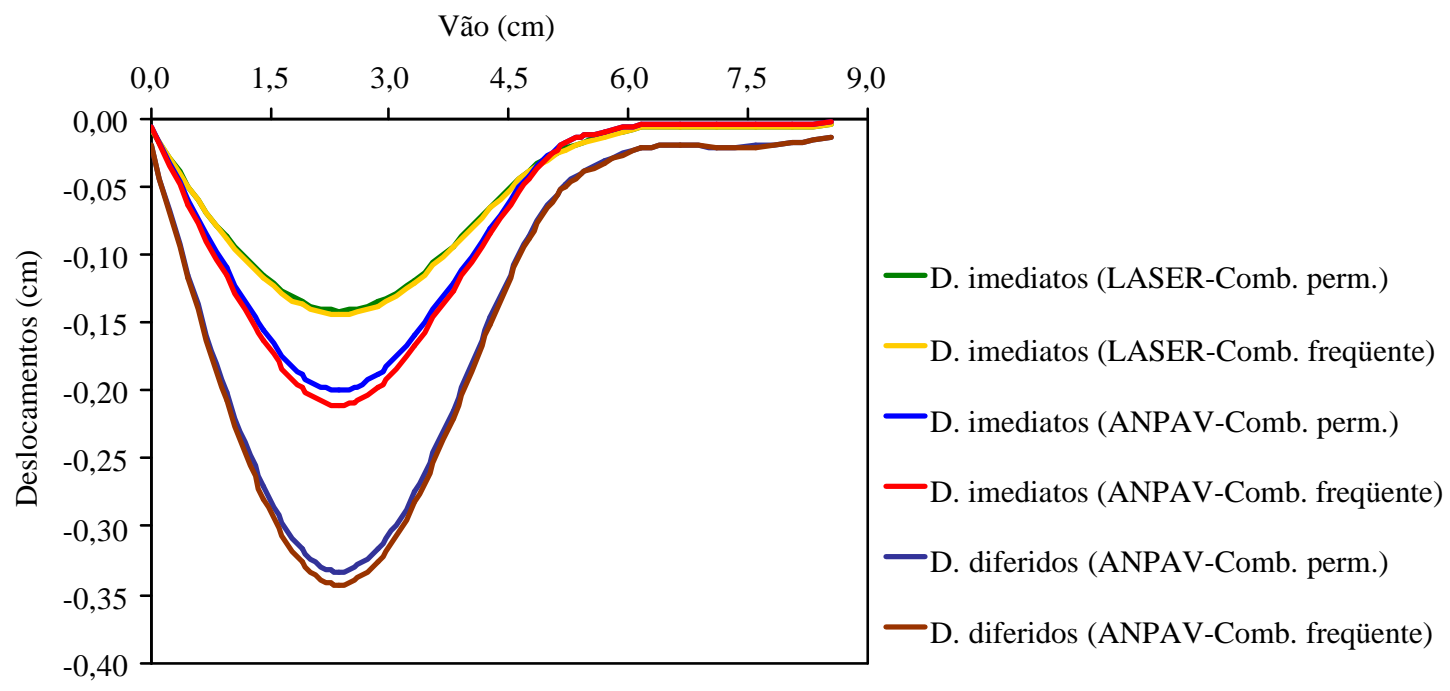

Figura 5.33 - Deslocamentos da viga V1 
Tabela 5.18 - Relações entre os deslocamentos diferidos e imediatos da viga V1

\begin{tabular}{|c|c|c|c|c|c|c|c|c|c|c|}
\hline \multirow{3}{*}{$\begin{array}{l}\text { Vão } \\
\text { (m) }\end{array}$} & \multicolumn{4}{|c|}{ Deslocamentos Imediatos (cm) } & \multirow{2}{*}{\multicolumn{2}{|c|}{$\begin{array}{c}\text { Desl Diferidos } \\
(\mathrm{cm})\end{array}$}} & \multirow{2}{*}{\multicolumn{2}{|c|}{$\begin{array}{c}\text { Relação entre } \\
\text { deslocamentos } \\
\text { diferidos e imediatos* }\end{array}$}} & \multirow{2}{*}{\multicolumn{2}{|c|}{$\begin{array}{c}\text { Relação entre } \\
\text { deslocamentos } \\
\text { diferidos e imediatos** }\end{array}$}} \\
\hline & \multicolumn{2}{|c|}{ LASER } & \multicolumn{2}{|c|}{ ANPAV } & & & & & & \\
\hline & (1) & $(2)$ & (1) & (2) & (1) & $(2)$ & (1) & (2) & (1) & $(2)$ \\
\hline 0,00 & $-0,008$ & $-0,009$ & $-0,006$ & $-0,006$ & $-0,020$ & $-0,021$ & 2,42 & 2,43 & 3,23 & 3,24 \\
\hline 0,47 & $-0,050$ & $-0,051$ & $-0,060$ & $-0,063$ & $-0,115$ & $-0,118$ & 2,30 & 2,33 & 1,92 & 1,88 \\
\hline 0,95 & $-0,087$ & $-0,089$ & $-0,111$ & $-0,116$ & $-0,201$ & $-0,207$ & 2,31 & 2,34 & 1,82 & 1,78 \\
\hline 1,42 & $-0,116$ & $-0,118$ & $-0,156$ & $-0,164$ & $-0,271$ & $-0,279$ & 2,33 & 2,36 & 1,74 & 1,70 \\
\hline 1,90 & $-0,135$ & $-0,137$ & $-0,189$ & $-0,199$ & $-0,317$ & $-0,327$ & 2,35 & 2,38 & 1,68 & 1,64 \\
\hline 2,37 & $-0,142$ & $-0,144$ & $-0,201$ & $-0,211$ & $-0,333$ & $-0,343$ & 2,35 & 2,38 & 1,66 & 1,62 \\
\hline 2,85 & $-0,136$ & $-0,138$ & $-0,188$ & $-0,198$ & $-0,317$ & $-0,326$ & 2,34 & 2,37 & 1,68 & 1,65 \\
\hline 3,32 & $-0,119$ & $-0,121$ & $-0,158$ & $-0,166$ & $-0,275$ & $-0,282$ & 2,32 & 2,34 & 1,73 & 1,70 \\
\hline 3,80 & $-0,094$ & $-0,095$ & $-0,121$ & $-0,127$ & $-0,214$ & $-0,220$ & 2,29 & 2,31 & 1,77 & 1,74 \\
\hline 4,27 & $-0,065$ & $-0,066$ & $-0,081$ & $-0,085$ & $-0,147$ & $-0,151$ & 2,26 & 2,28 & 1,82 & 1,78 \\
\hline 4,74 & $-0,039$ & $-0,040$ & $-0,043$ & $-0,044$ & $-0,086$ & $-0,088$ & 2,20 & 2,21 & 2,01 & 1,98 \\
\hline 5,22 & $-0,022$ & $-0,023$ & $-0,017$ & $-0,018$ & $-0,049$ & $-0,050$ & 2,17 & 2,17 & 2,78 & 2,78 \\
\hline 5,69 & $-0,013$ & $-0,013$ & $-0,010$ & $-0,010$ & $-0,032$ & $-0,033$ & 2,48 & 2,49 & 3,23 & 3,23 \\
\hline 6,17 & $-0,007$ & $-0,007$ & $-0,005$ & $-0,005$ & $-0,022$ & $-0,022$ & 3,11 & 3,13 & 4,27 & 4,29 \\
\hline 6,64 & $-0,006$ & $-0,006$ & $-0,004$ & $-0,004$ & $-0,020$ & $-0,020$ & 3,42 & 3,44 & 5,10 & 5,16 \\
\hline 7,12 & $-0,006$ & $-0,006$ & $-0,004$ & $-0,004$ & $-0,021$ & $-0,021$ & 3,21 & 3,24 & 4,93 & 4,99 \\
\hline 7,59 & $-0,007$ & $-0,007$ & $-0,005$ & $-0,005$ & $-0,021$ & $-0,021$ & 2,97 & 2,99 & 4,52 & 4,56 \\
\hline 8,07 & $-0,007$ & $-0,007$ & $-0,004$ & $-0,004$ & $-0,018$ & $-0,018$ & 2,81 & 2,83 & 4,24 & 4,27 \\
\hline 8,54 & $-0,005$ & $-0,005$ & $-0,003$ & $-0,003$ & $-0,013$ & $-0,013$ & 2,72 & 2,72 & 4,15 & 4,21 \\
\hline & & & & & & Média & 2,30 & 2,33 & 1,78 & 1,75 \\
\hline
\end{tabular}

Vão (m)

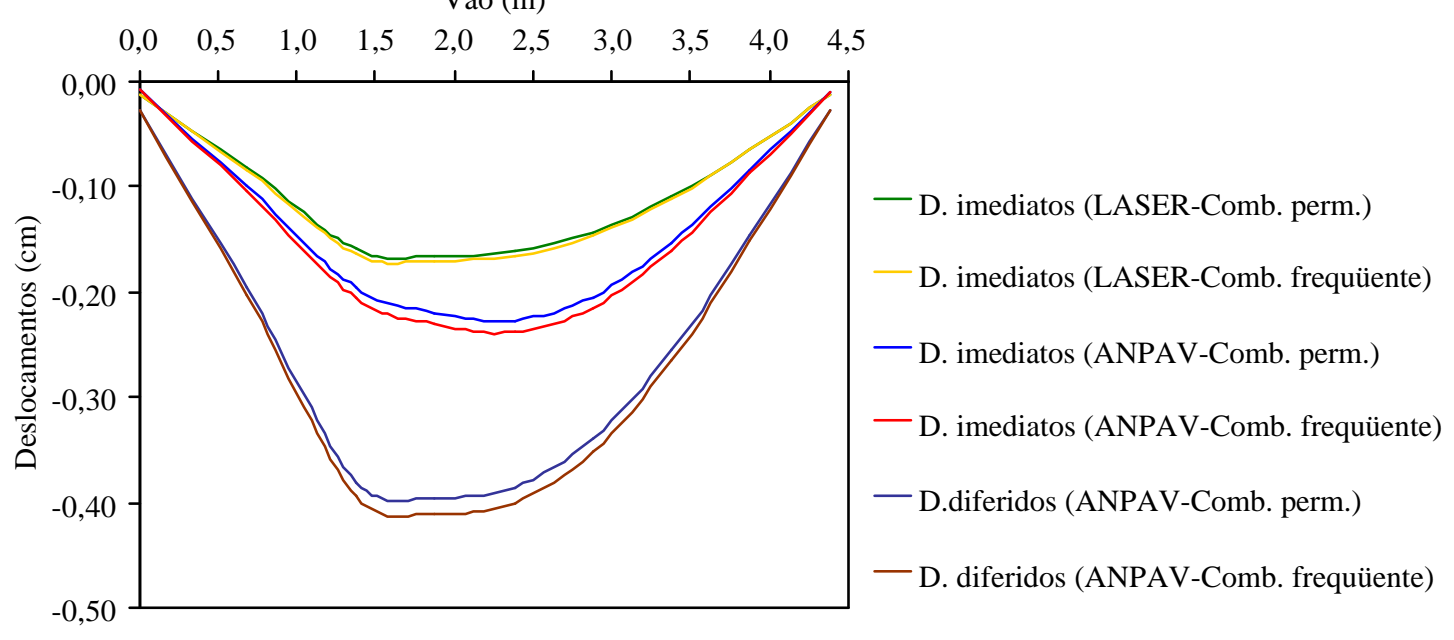

Figura 5.34 - Deslocamentos da viga V16 
Tabela 5.19 - Relações entre os deslocamentos diferidos e imediatos da viga V16

\begin{tabular}{|c|c|c|c|c|c|c|c|c|c|c|}
\hline \multirow{3}{*}{$\begin{array}{l}\text { Vão } \\
\text { (m) }\end{array}$} & \multicolumn{4}{|c|}{ Deslocamentos Imediatos (cm) } & \multirow{2}{*}{\multicolumn{2}{|c|}{$\begin{array}{l}\text { Desl Diferidos } \\
(\mathrm{cm})\end{array}$}} & \multirow{2}{*}{\multicolumn{2}{|c|}{$\begin{array}{c}\text { Relação entre } \\
\text { deslocamentos } \\
\text { diferidos e imediatos* }\end{array}$}} & \multirow{2}{*}{\multicolumn{2}{|c|}{$\begin{array}{c}\text { Relação entre } \\
\text { deslocamentos } \\
\text { diferidos e imediatos** }\end{array}$}} \\
\hline & \multicolumn{2}{|c|}{ LASER } & \multicolumn{2}{|c|}{ ANPAV } & & & & & & \\
\hline & (1) & (2) & (1) & (2) & (1) & $(2)$ & (1) & $(2)$ & (1) & $(2)$ \\
\hline 0,00 & $-0,013$ & $-0,013$ & $-0,009$ & $-0,009$ & $-0,028$ & $-0,029$ & 2,15 & 2,14 & 3,22 & 3,24 \\
\hline 0,69 & $-0,083$ & $-0,085$ & $-0,101$ & $-0,105$ & $-0,196$ & $-0,204$ & 2,37 & 2,40 & 1,95 & 1,93 \\
\hline 1,38 & $-0,160$ & $-0,164$ & $-0,197$ & $-0,206$ & $-0,380$ & $-0,394$ & 2,38 & 2,40 & 1,93 & 1,91 \\
\hline 1,88 & $-0,166$ & $-0,171$ & $-0,220$ & $-0,231$ & $-0,395$ & $-0,411$ & 2,38 & 2,41 & 1,80 & 1,78 \\
\hline 2,38 & $-0,162$ & $-0,166$ & $-0,227$ & $-0,238$ & $-0,385$ & $-0,400$ & 2,38 & 2,41 & 1,70 & 1,68 \\
\hline 2,88 & $-0,143$ & $-0,147$ & $-0,205$ & $-0,215$ & $-0,339$ & $-0,352$ & 2,37 & 2,40 & 1,66 & 1,64 \\
\hline 3,38 & $-0,110$ & $-0,113$ & $-0,153$ & $-0,161$ & $-0,256$ & $-0,266$ & 2,33 & 2,36 & 1,67 & 1,65 \\
\hline 3,88 & $-0,065$ & $-0,066$ & $-0,084$ & $-0,088$ & $-0,146$ & $-0,151$ & 2,27 & 2,29 & 1,74 & 1,72 \\
\hline 4,38 & $-0,013$ & $-0,013$ & $-0,010$ & $-0,010$ & $-0,028$ & $-0,028$ & 2,15 & 2,16 & 2,69 & 2,69 \\
\hline & & & & & & Média & 2,35 & 2,38 & 1,78 & 1,76 \\
\hline
\end{tabular}

Baseado nos resultados apresentados para o pavimento 3, notou-se que tanto para a combinação quase-permanente de ações quanto para a freqüente, os deslocamentos diferidos obtidos com o programa ANPAV, foram aproximadamente $100 \%$ maiores que os deslocamentos imediatos fornecidos por este programa. Desta forma, o coeficiente multiplicador dos deslocamentos imediatos foi igual a 2,0.

Considerando-se apenas as vigas, os deslocamentos diferidos foram em torno de $80 \%$ maiores que os deslocamentos não-lineares.

Com relação aos deslocamentos imediatos lineares fornecidos pelo programa LASER, os deslocamentos diferidos obtidos com o programa ANPAV foram, em média, $140 \%$ maiores, tanto para todo o pavimento quanto para as vigas.

\subsubsection{ALTURAS MÍNIMAS}

São apresentadas a seguir, a altura mínima de algumas lajes e vigas que satisfazem o estado limite de deformações excessivas.

\section{a) Alturas Mínimas das Lajes}

Para este pavimento foram calculadas as alturas mínimas das seguintes lajes:

\section{- Laje L03}

Para a laje L03, de acordo com a Figura 5.24, foram obtidas as seguintes propriedades:

- Tipo 5

- $\mathrm{L}_{\mathrm{x}}=376,5 \mathrm{~cm}$

- $\mathrm{L}_{\mathrm{y}}=570,25 \mathrm{~cm}$ 
Pela Tabela 3.8, para a verificação da aceitabilidade sensorial quanto a aspectos visuais, o coeficiente $\alpha$ foi igual a 0,93 , e para as verificações de aceitabilidade sensorial relativa a vibrações e dos efeitos dos deslocamentos nas paredes, o coeficiente $\alpha$ foi igual a 0,90. E os valores de $\beta$, calculados a partir das eqs.(3.4) e (3.5), foram iguais a:

$$
\begin{aligned}
& \beta_{\text {ver. } 1}=61+4,0 \cdot 2,5-42,7 \cdot\left(\frac{570,25}{376,5}\right)+13,2 \cdot\left(\frac{570,25}{376,5}\right)^{2}-1,36 \cdot\left(\frac{570,25}{376,5}\right)^{3}=31,9 \\
& \beta_{\text {ver. } 2 \text { e } 3}=67+3,5 \cdot 2,5-51,5 \cdot\left(\frac{570,25}{376,5}\right)+16,5 \cdot\left(\frac{570,25}{376,5}\right)^{2}-1,77 \cdot\left(\frac{570,25}{376,5}\right)^{3}=29,4
\end{aligned}
$$

Utilizando-se esses valores de $\alpha$ e $\beta$, foram encontradas as seguintes alturas mínimas que satisfazem as verificações do estado limite de deformações excessivas:

$$
\mathrm{h}_{\min , \text { ver. } 1}=\frac{\alpha \mathrm{L}_{\mathrm{x}}}{\beta}=\frac{0,93 \cdot 376,5}{31,9}=11 \mathrm{~cm}
$$

e,

$$
\mathrm{h}_{\min , \text { ver.2e } 3}=\frac{\alpha \mathrm{L}_{\mathrm{x}}}{\beta}=\frac{0,90 \cdot 376,5}{29,4}=11,5 \mathrm{~cm}
$$

De acordo com esses resultados, observou-se que, para atender às verificações do estado limite de deformações excessivas, a laje L03 deveria ter uma altura superior a $11,5 \mathrm{~cm}$, o que não ocorreu, já que a laje foi projetada com uma altura igual a $9 \mathrm{~cm}$. Assim, para se verificar se a laje não vai apresentar problemas devidos a deslocamentos excessivos, seria necessário o cálculo dos deslocamentos e sua comparação com os valores limites fornecidos pela NBR 6118 (2003).

\section{- $\quad$ Laje L07}

Para a laje L07, as características utilizadas no cálculo da altura mínima foram as seguintes:

- $\quad$ Tipo 8

- $\mathrm{L}_{\mathrm{x}}=313,75 \mathrm{~cm}$

- $\mathrm{L}_{\mathrm{y}}=465,25 \mathrm{~cm}$

Pela Tabela 3.8, para a verificação da aceitabilidade sensorial relativa a aspectos visuais, e para as verificações de aceitabilidade sensorial relativa a vibrações e dos efeitos dos deslocamentos nas paredes, os valores do coeficiente $\alpha$ foram 0,84 e 0,80 , respectivamente. E, de acordo com as eqs.(3.4) e (3.5), foram obtidos os seguintes valores de $\beta$ : 


$$
\begin{aligned}
& \beta_{\text {ver. } 1}=61+4,0 \cdot 2,5-42,7 \cdot\left(\frac{465,25}{313,75}\right)+13,2 \cdot\left(\frac{465,25}{313,75}\right)^{2}-1,36 \cdot\left(\frac{465,25}{313,75}\right)^{3}=32,2 \\
& \beta_{\text {ver.2 } 33}=67+3,5 \cdot 2,5-51,5 \cdot\left(\frac{465,25}{313,75}\right)+16,5 \cdot\left(\frac{465,25}{313,75}\right)^{2}-1,77 \cdot\left(\frac{465,25}{313,75}\right)^{3}=29,9
\end{aligned}
$$

Foram calculadas, então, as seguintes alturas mínimas que satisfazem as verificações supracitadas:

$$
\mathrm{h}_{\text {min,ver. } 1}=\frac{\alpha \mathrm{L}_{\mathrm{x}}}{\beta}=\frac{0,84 \cdot 313,75}{32,2}=8,2 \mathrm{~cm}
$$

e,

$$
\mathrm{h}_{\text {min,ver.2 } \mathrm{e} 3}=\frac{\alpha \mathrm{L}_{\mathrm{x}}}{\beta}=\frac{0,80 \cdot 313,75}{29,9}=8,4 \mathrm{~cm}
$$

Observou-se, assim, que as verificações do estado limite de deformações excessivas foram atendidas para a laje L07, uma vez que, para isso, seria necessária uma altura superior a $8,4 \mathrm{~cm}$, e no projeto foi adotada uma altura igual a $9 \mathrm{~cm}$.

\section{b) Alturas Mínimas das Vigas}

Para este pavimento, foi calculada a altura mínima da viga V09, que possui as seguintes características:

- $\ell_{\mathrm{ef}}=338,5 \mathrm{~cm}$

- $\mathrm{b}=12 \mathrm{~cm}$

- $\mathrm{h}_{\mathrm{p}}=20 \mathrm{~cm}$

Para as verificações de aceitabilidade sensorial, foi calculado o seguinte valor para $\beta$ :

$$
\beta_{\text {ver. } 1 \mathrm{e} 2}=6,0+1,4 \cdot 2,5+0,005 \cdot 338,5+0,21 \cdot 12-0,009 \cdot 20-0,25 \cdot \frac{338,5}{20}=9,3
$$

E, para a verificação dos efeitos dos deslocamentos nas paredes, encontrou-se:

$$
\beta_{\text {ver. } 3}=5,7+1,35 \cdot 2,5+0,005 \cdot 338,5+0,18 \cdot 12-0,007 \cdot 20-0,26 \cdot \frac{338,5}{20}=8,4
$$

De acordo com a eq.(4.2), as alturas mínimas que atendem essas verificações foram iguais a: 


$$
\mathrm{h}_{\text {min,ver.1e } 2}=\frac{\ell_{\mathrm{ef}}}{\beta}=\frac{338,5}{9,3}=36,4 \mathrm{~cm}
$$

$\mathrm{e}$,

$$
\mathrm{h}_{\text {min, ver. } 3}=\frac{\ell_{\mathrm{ef}}}{\beta}=\frac{338,5}{8,4}=40,4 \mathrm{~cm}
$$

Percebeu-se, então, que para satisfazer as verificações mencionadas, a altura da viga deveria ser superior a $40 \mathrm{~cm}$. Como a altura adotada no projeto foi igual a esta, pode-se considerar que as verificações do estado limite de deformações excessivas foram atendidas.

\subsection{PAVIMENTO 4}

Para o pavimento, cujas plantas de arquitetura e de forma são apresentadas nas Figuras 5.35 e 5.36, foram utilizados concreto com resistência característica à compressão de $25 \mathrm{MPa}$ e aço CA -50.

O carregamento das lajes foi constituído de uma parcela igual a $1,0 \mathrm{kN} / \mathrm{m}^{2}$, correspondente ao peso do piso e do revestimento, e uma ação variável de $2,0 \mathrm{kN} / \mathrm{m}^{2}$.

\subsubsection{VALORES DOS DESLOCAMENTOS}

Da mesma forma que para os pavimentos apresentados anteriormente, foram determinados os deslocamentos imediatos com o programa LASER, e com o programa ANPAV foram calculados os deslocamentos imediatos, levando-se em conta a influência da fissuração, e os deslocamentos totais, considerando-se o efeito da fluência e da retração do concreto. Foram consideradas as combinações quase-permanente e freqüente de ações

Os deslocamentos imediatos, obtidos a partir das análises linear e não-linear, e os deslocamentos totais, são apresentados esquematicamente nas figuras seguintes, por linhas de mesmo deslocamento cujo valor aparece anotado. Vale lembrar que nestas figuras, $\mathbf{M}$ e $\mathbf{m}$ correspondem, respectivamente, aos deslocamentos mínimo e máximo que ocorrem no pavimento. Os valores negativos correspondem aos deslocamentos no sentido do carregamento colocado, ou seja, para baixo. 


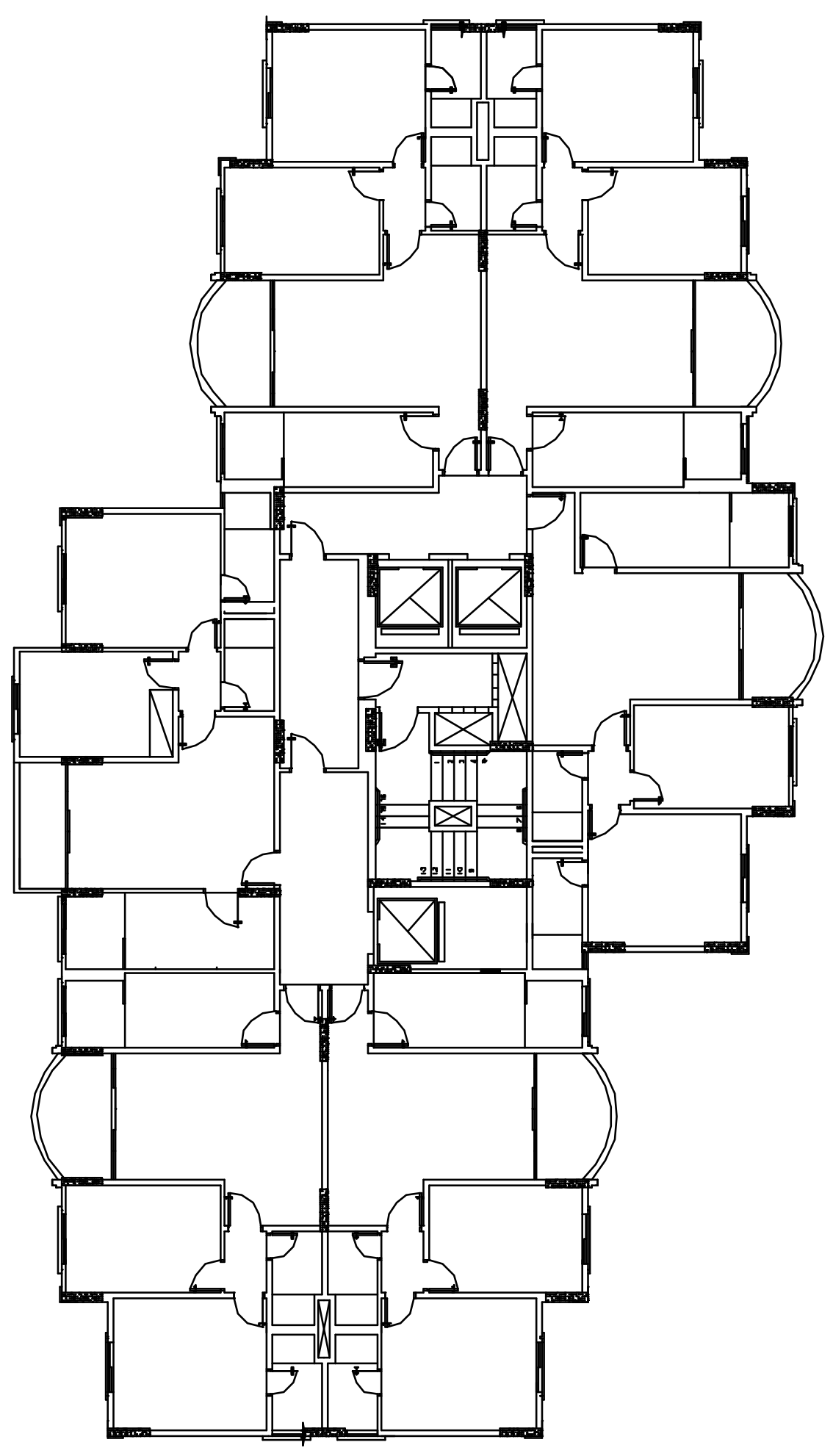

Figura 5.35 - Planta de arquitetura do pavimento 4 


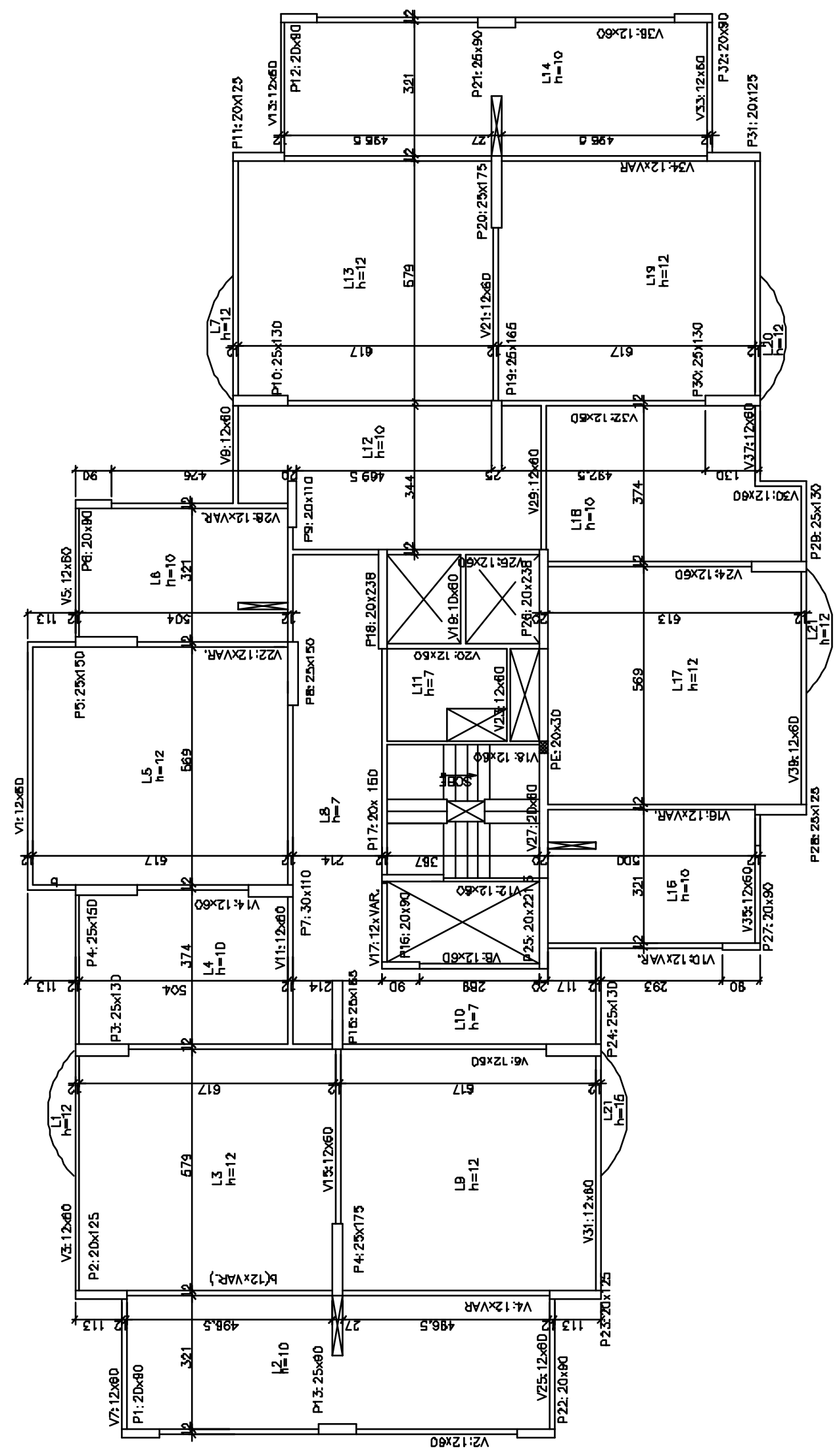

Figura 5.36 - Planta de forma do pavimento 4 


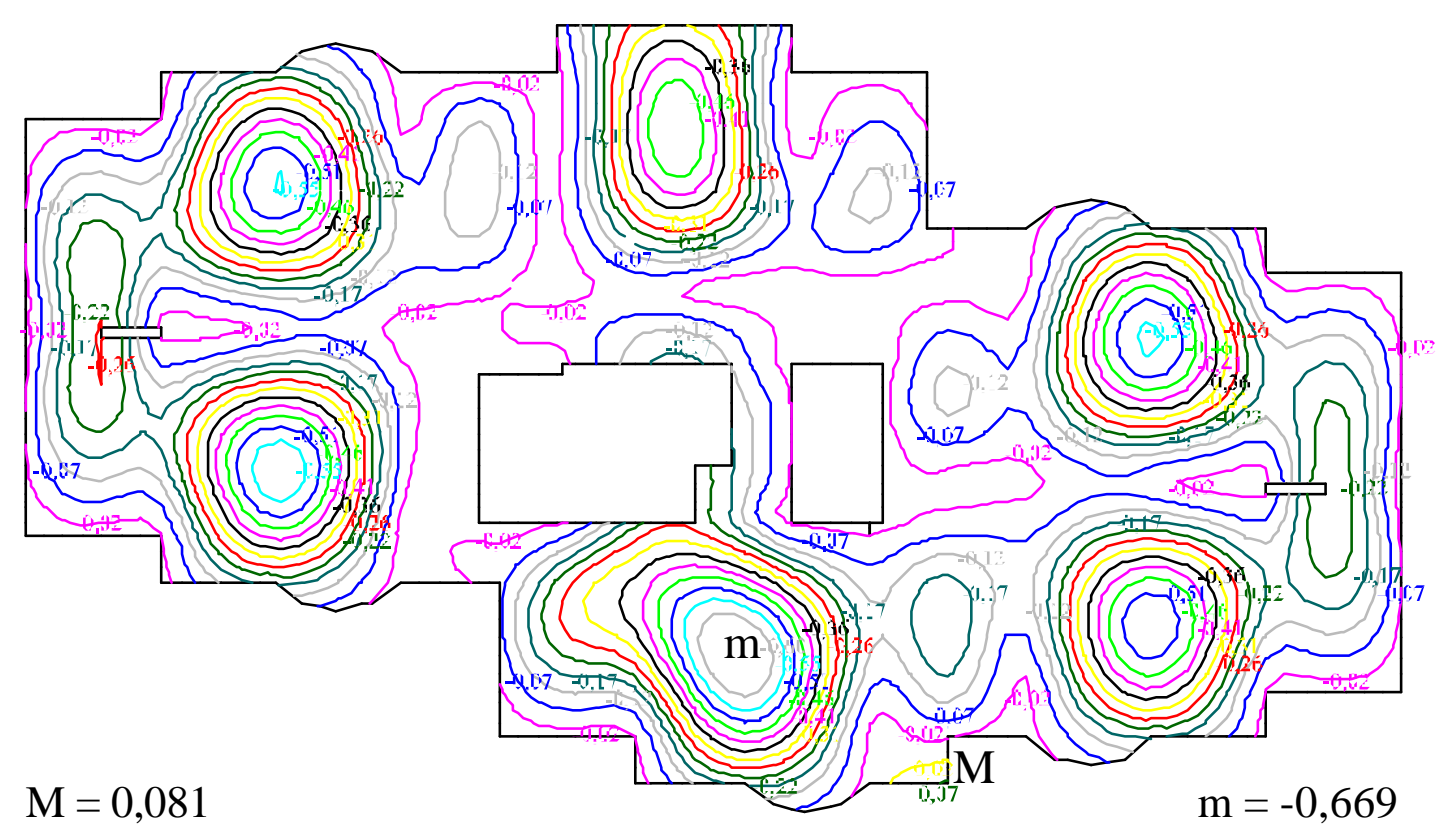

Figura 5.37 - Deslocamentos imediatos obtidos a partir da análise linear (Combinação quase-permanente)

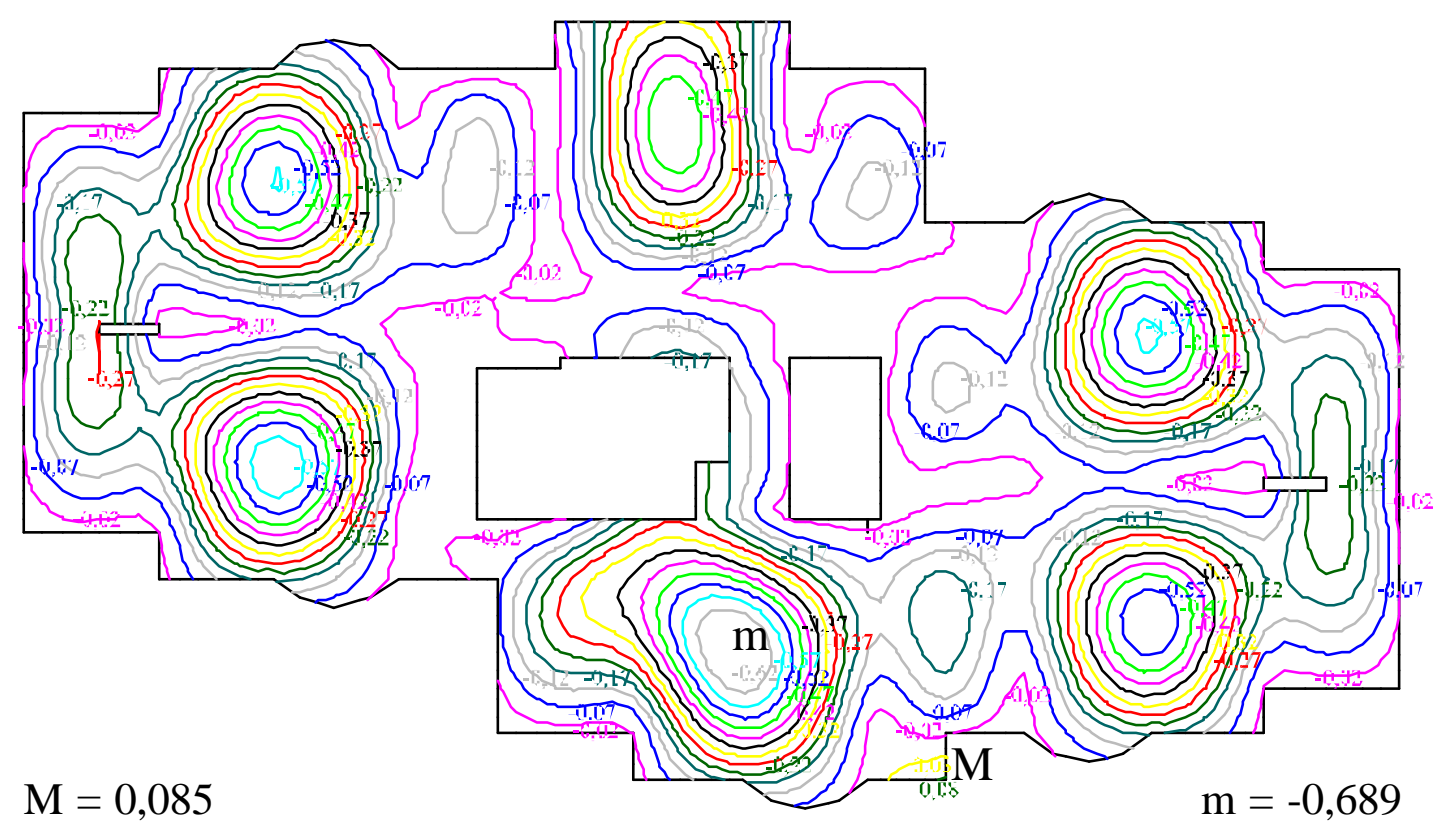

Figura 5.38 - Deslocamentos imediatos obtidos a partir da análise linear (Combinação freqüente) 


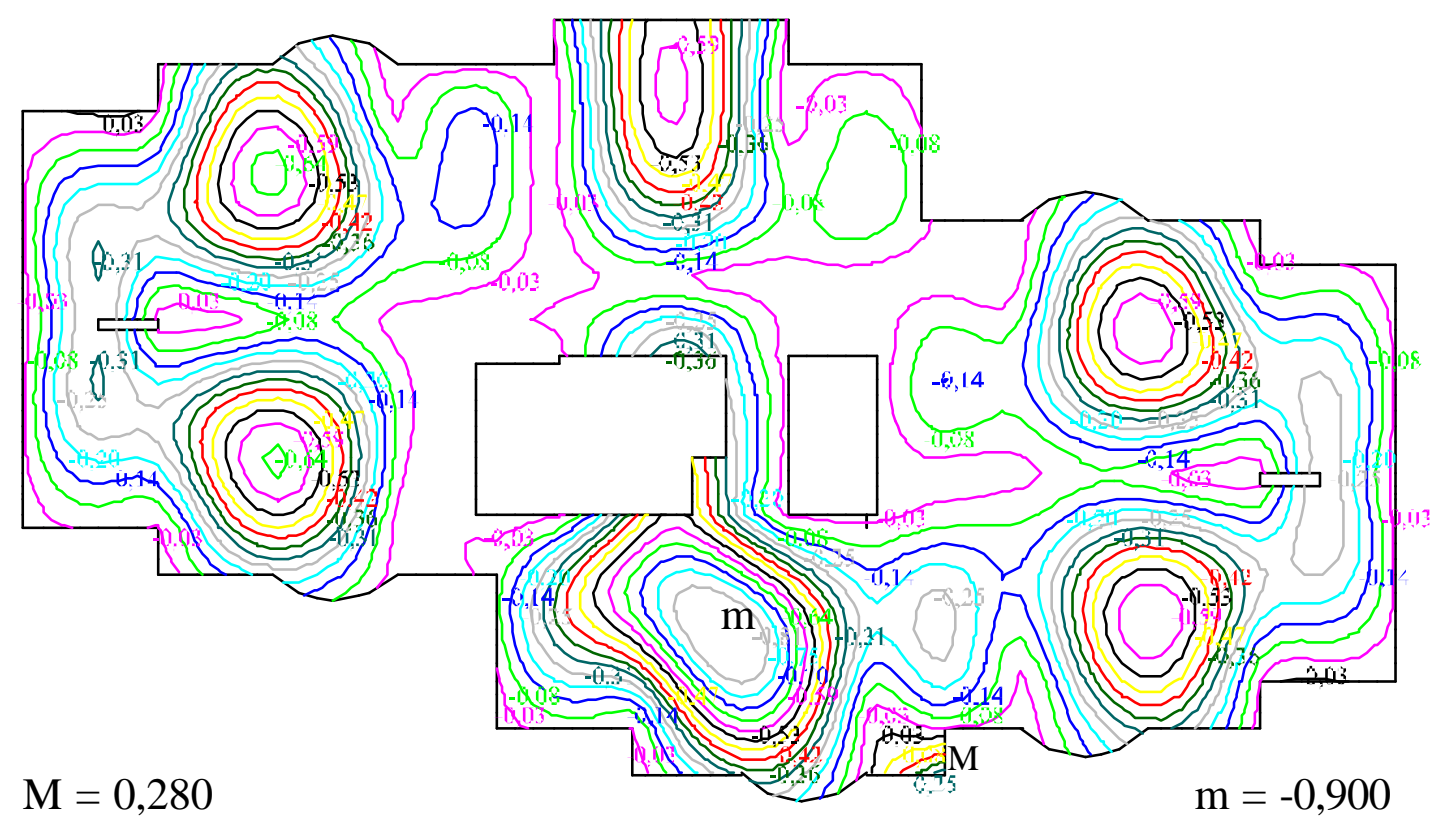

Figura 5.39 - Deslocamentos imediatos obtidos a partir da análise não-linear (Combinação quase-permanente)

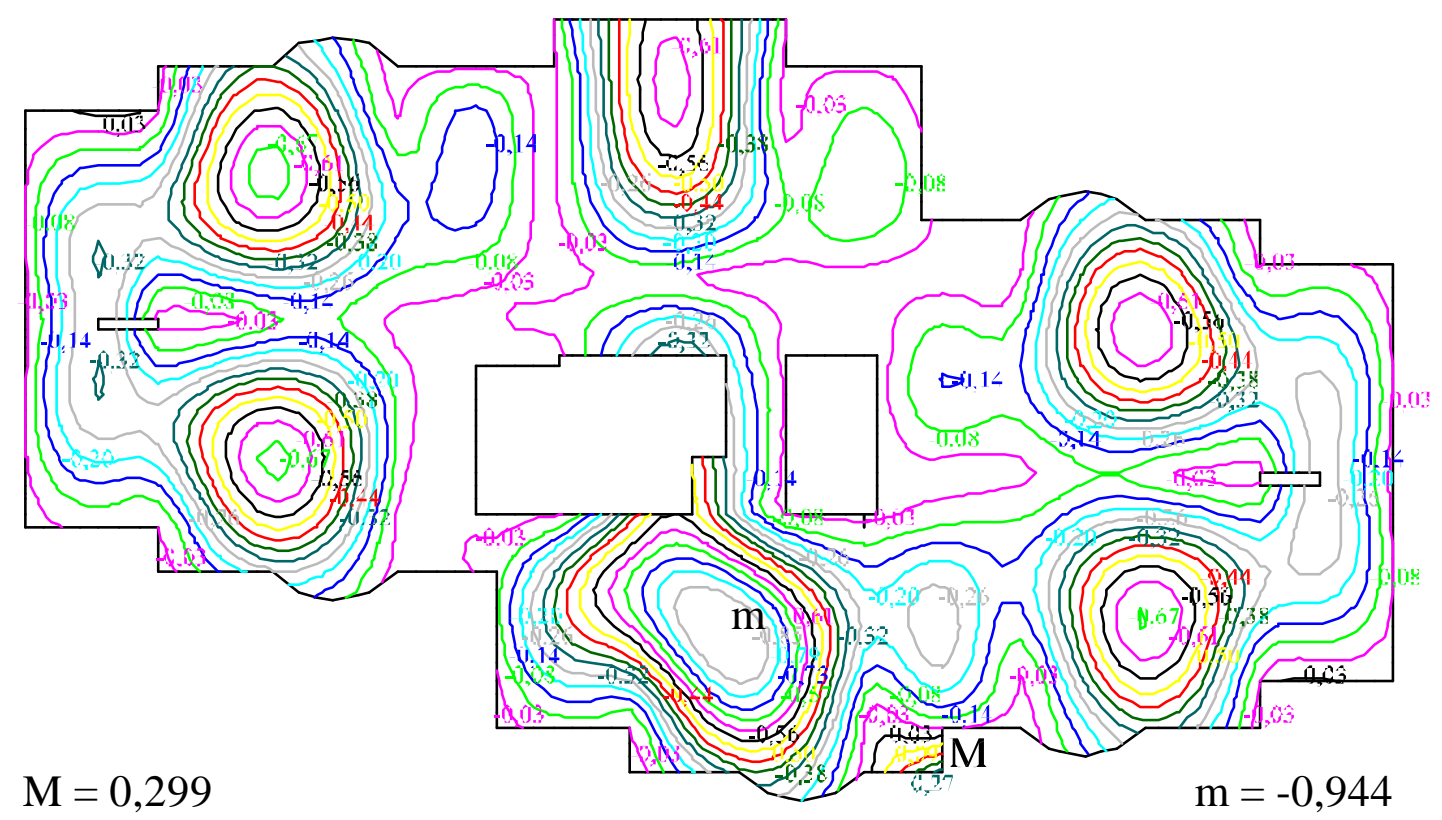

Figura 5.40 - Deslocamentos imediatos obtidos a partir da análise não-linear (Combinação freqüente) 


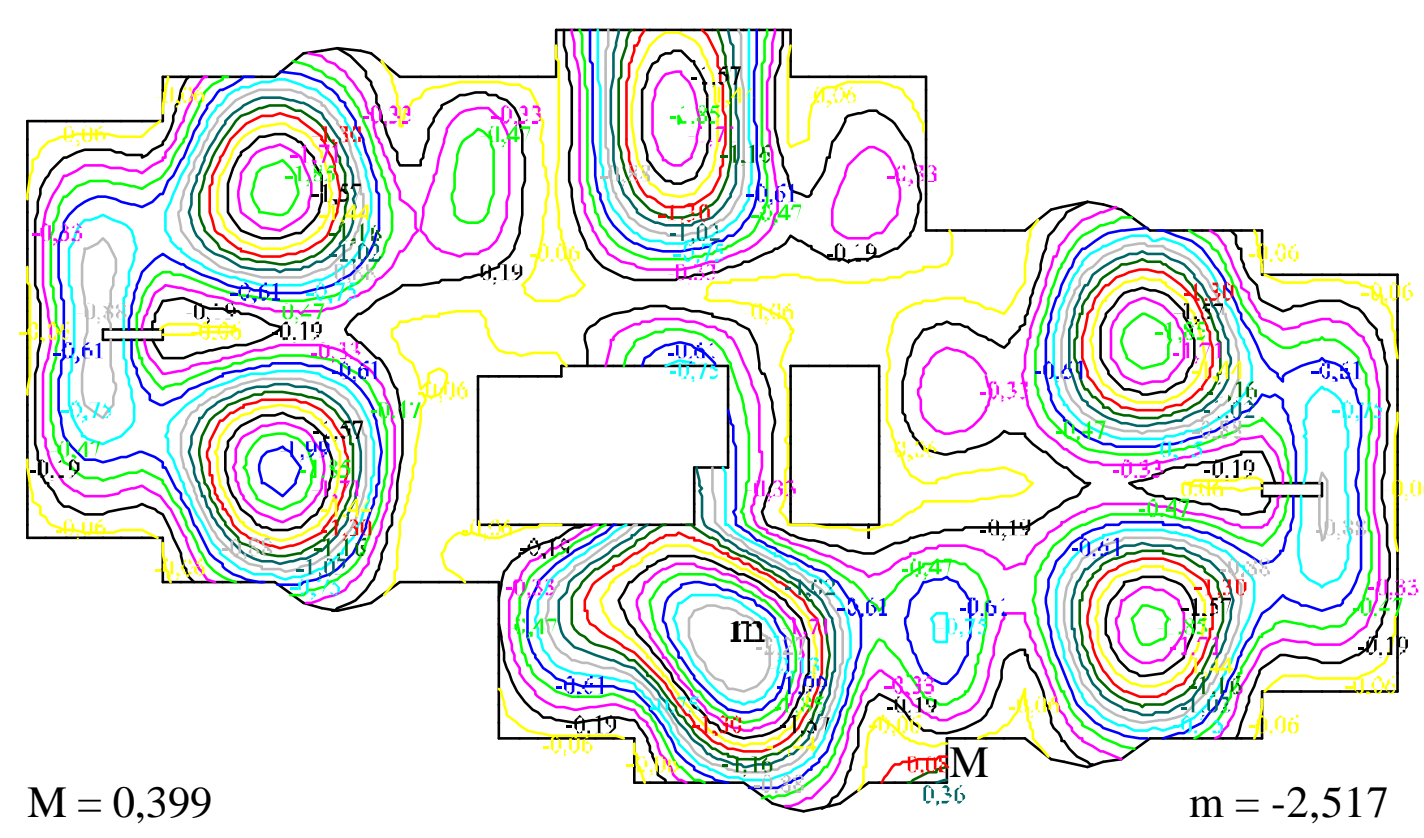

Figura 5.41 - Deslocamentos totais obtidos a partir da análise não-linear (Combinação quase-permanente)

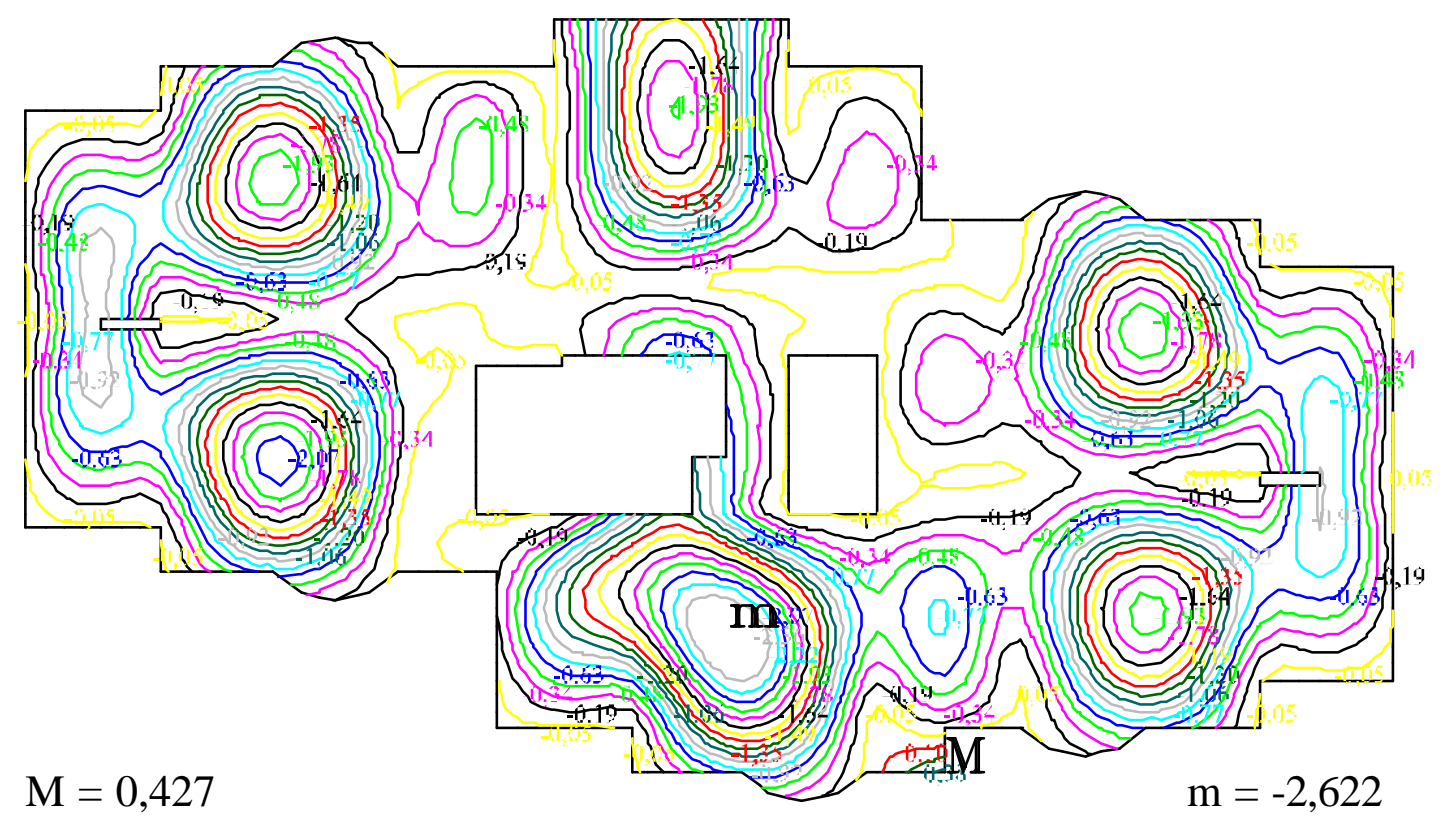

Figura 5.42 - Deslocamentos totais obtidos a partir da análise não-linear (Combinação frequente) 


\subsubsection{ANÁLISE DOS RESULTADOS}

Os deslocamentos resultantes das análises linear e não-linear são comentados a seguir.

\section{a) Deslocamentos Imediatos}

Comparando-se os deslocamentos imediatos provenientes da análise não-linear com os deslocamentos imediatos da análise linear, notou-se que estes últimos foram aproximadamente $20 \%$ maiores que os primeiros, para as duas combinações de ações utilizadas.

Este comportamento pode ser evidenciado tomando-se as curvas de deslocamentos mostradas da Figura 5.37 a Figura 5.40. Comparando-se os deslocamentos das curvas correspondentes, cujos valores são fornecidos na Tabela 5.20, observou-se que as relações médias entre os deslocamentos imediatos não-lineares e os lineares foram iguais a 1,16 e 1,18, para as combinações quase-permanente e freqüente de ações foram, respectivamente.

Tabela 5.20 - Deslocamentos imediatos do pavimento 4 devidos às análises lineares e não-lineares, em cm

\begin{tabular}{|c|c|c|c|c|c|}
\hline \multicolumn{2}{|c|}{ Análise Linear (LASER) } & \multicolumn{2}{c|}{ Análise Não Linear (ANPAV) } & $\begin{array}{c}\text { Relação entre os deslocamentos } \\
\text { não lineares e lineares }\end{array}$ \\
\hline Q. Permanente & Frequente & Q. Permanente & Frequente & Q. Permanente & Frequente \\
\hline 0,02 & 0,02 & 0,03 & 0,03 & 1,50 & 1,50 \\
\hline 0,07 & 0,07 & 0,08 & 0,08 & 1,14 & 1,14 \\
\hline 0,12 & 0,12 & 0,14 & 0,14 & 1,17 & 1,17 \\
\hline 0,17 & 0,17 & 0,20 & 0,20 & 1,18 & 1,18 \\
\hline 0,22 & 0,22 & 0,25 & 0,26 & 1,14 & 1,18 \\
\hline 0,26 & 0,27 & 0,31 & 0,32 & 1,19 & 1,19 \\
\hline 0,31 & 0,32 & 0,36 & 0,38 & 1,16 & 1,19 \\
\hline 0,36 & 0,37 & 0,42 & 0,44 & 1,17 & 1,19 \\
\hline 0,41 & 0,42 & 0,47 & 0,50 & 1,15 & 1,19 \\
\hline 0,46 & 0,47 & 0,53 & 0,56 & 1,15 & 1,19 \\
\hline 0,51 & 0,52 & 0,59 & 0,61 & 1,16 & 1,17 \\
\hline & & & Média & $\mathbf{1 , 1 6}$ & $\mathbf{1 , 1 8}$ \\
\hline
\end{tabular}

Considerando-se apenas os deslocamentos imediatos das vigas, verificou-se que nas regiões de maiores momentos fletores, os deslocamentos imediatos não-lineares foram em torno de trinta $30 \%$ maiores que os deslocamentos imediatos lineares.

Para representar esse comportamento das vigas tomou-se a viga V1, cujos deslocamentos imediatos lineares e não-lineares estão ilustrados na Figura 5.43, e as relações entre esses deslocamentos são dadas Tabela 5.21. Percebeu-se que, novamente analisando-se apenas a região de maiores momentos fletores, os valores médios das relações entre os 
deslocamentos imediatos não-lineares e os lineares foram 1,26 e 1,31, respectivamente para as combinações quase-permanente e freqüente de ações. Ou seja, os deslocamentos imediatos não-lineares foram $26 \%$ e $31 \%$ maiores que os deslocamentos imediatos lineares para as duas combinações de ações utilizadas. Observou-se que estas relações foram bastante próximas da relação média para as vigas do pavimento, igual a 1,30.

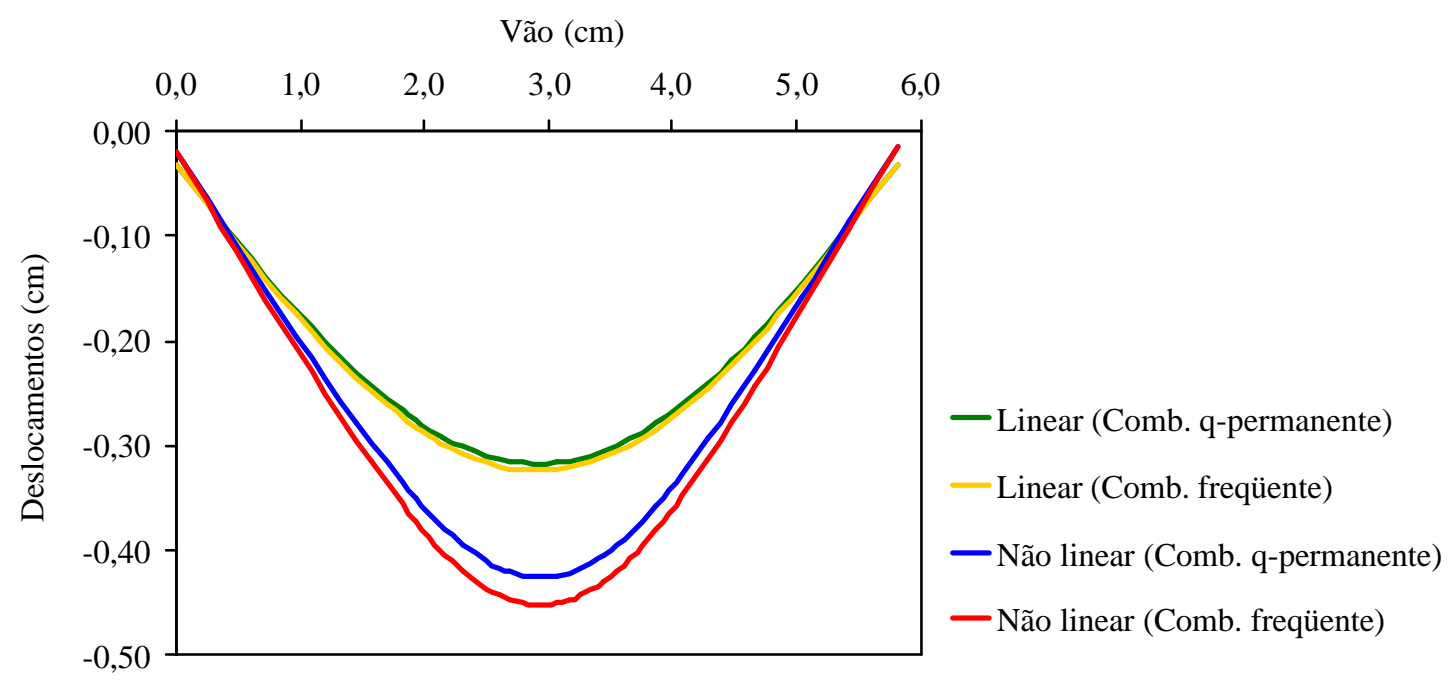

Figura 5.43 - Deslocamentos imediatos da viga V1

Tabela 5.21 - Deslocamentos imediatos da viga V1, em $\mathrm{cm}$

\begin{tabular}{|c|c|c|c|c|c|c|}
\hline \multirow{2}{*}{$\begin{array}{c}\text { Vão } \\
(\mathbf{m})\end{array}$} & \multicolumn{2}{|c|}{ Análise Linear (LASER) } & \multicolumn{2}{c|}{ Análise Não Linear (ANPAV) } & \multicolumn{2}{c|}{$\begin{array}{c}\text { Relação entre os deslocamentos } \\
\text { não lineares e lineares }\end{array}$} \\
\cline { 2 - 7 } & Q-Permanente & Frequente & Q-Permanente & Frequente & Q-Permanente & Frequente \\
\hline 0,00 & $-0,032$ & $-0,032$ & $-0,019$ & $-0,019$ & 0,58 & 0,59 \\
\hline 0,48 & $-0,104$ & $-0,106$ & $-0,108$ & $-0,114$ & 1,04 & 1,08 \\
\hline 0,97 & $-0,172$ & $-0,175$ & $-0,195$ & $-0,207$ & 1,14 & 1,18 \\
\hline 1,45 & $-0,231$ & $-0,236$ & $-0,278$ & $-0,295$ & 1,20 & 1,25 \\
\hline 1,93 & $-0,277$ & $-0,283$ & $-0,351$ & $-0,373$ & 1,27 & 1,32 \\
\hline 2,31 & $-0,302$ & $-0,308$ & $-0,396$ & $-0,420$ & 1,31 & 1,36 \\
\hline 2,69 & $-0,315$ & $-0,322$ & $-0,421$ & $-0,447$ & 1,34 & 1,39 \\
\hline 3,07 & $-0,317$ & $-0,323$ & $-0,425$ & $-0,451$ & 1,34 & 1,40 \\
\hline 3,45 & $-0,305$ & $-0,312$ & $-0,405$ & $-0,430$ & 1,33 & 1,38 \\
\hline 3,87 & $-0,279$ & $-0,285$ & $-0,359$ & $-0,381$ & 1,28 & 1,34 \\
\hline 4,29 & $-0,241$ & $-0,245$ & $-0,294$ & $-0,313$ & 1,22 & 1,28 \\
\hline 4,67 & $-0,196$ & $-0,200$ & $-0,229$ & $-0,243$ & 1,17 & 1,21 \\
\hline 5,05 & $-0,145$ & $-0,148$ & $-0,160$ & $-0,169$ & 1,10 & 1,14 \\
\hline 5,43 & $-0,090$ & $-0,092$ & $-0,088$ & $-0,093$ & 0,98 & 1,01 \\
\hline 5,81 & $-0,033$ & $-0,033$ & $-0,015$ & $-0,015$ & 0,47 & 0,46 \\
\hline & & & & Média & $\mathbf{1 , 2 6}$ & $\mathbf{1 , 3 1}$ \\
\hline
\end{tabular}




\section{b) Deslocamentos Diferidos}

Pela comparação dos deslocamentos diferidos com os deslocamentos imediatos provenientes das duas análises, constatou-se que os deslocamentos diferidos foram aproximadamente $130 \%$ e $100 \%$ maiores que os deslocamentos imediatos provenientes da análise linear e da análise não-linear, respectivamente.

Para demonstrar esse comportamento, foram consideradas as curvas de deslocamentos mostradas da Figura 5.37 a Figura 5.42. Comparando-se os deslocamentos das curvas correspondentes, notou que a média das relações entre os deslocamentos diferidos e os imediatos lineares foram iguais a 2,25 e 2,34, para as combinações quase-permanente e freqüiente de ações, respectivamente. Em relação aos deslocamentos imediatos não-lineares esses valores foram iguais a 1,94 e 1,99, respectivamente.

Tabela 5.22 - Relações entre os deslocamentos diferidos e imediatos do pavimento 4

\begin{tabular}{|c|c|c|c|c|c|c|c|c|c|}
\hline \multicolumn{4}{|c|}{ Deslocamentos Imediatos } & \multirow{2}{*}{\multicolumn{2}{|c|}{$\begin{array}{c}\text { Desl Diferidos } \\
(\mathrm{cm})\end{array}$}} & \multirow{2}{*}{\multicolumn{2}{|c|}{$\begin{array}{c}\text { Relação entre } \\
\text { deslocamentos } \\
\text { diferidos e imediatos* }\end{array}$}} & \multirow{2}{*}{\multicolumn{2}{|c|}{$\begin{array}{c}\text { Relação entre } \\
\text { deslocamentos } \\
\text { diferidos e imediatos*** }\end{array}$}} \\
\hline \multicolumn{2}{|c|}{ LASER } & \multicolumn{2}{|c|}{ ANPAV } & & & & & & \\
\hline (1) & (2) & (1) & (2) & (1) & $(2)$ & (1) & $(2)$ & (1) & $(2)$ \\
\hline 0,07 & 0,07 & 0,08 & 0,08 & 0,16 & 0,16 & 2,29 & 2,29 & 2,00 & 2,00 \\
\hline 0,12 & 0,12 & 0,14 & 0,14 & 0,27 & 0,28 & 2,25 & 2,33 & 1,93 & 2,00 \\
\hline 0,17 & 0,17 & 0,20 & 0,20 & 0,38 & 0,39 & 2,24 & 2,29 & 1,90 & 1,95 \\
\hline 0,22 & 0,22 & 0,25 & 0,26 & 0,49 & 0,51 & 2,23 & 2,32 & 1,96 & 1,96 \\
\hline 0,26 & 0,27 & 0,31 & 0,32 & 0,61 & 0,63 & 2,35 & 2,33 & 1,97 & 1,97 \\
\hline 0,31 & 0,32 & 0,36 & 0,38 & 0,70 & 0,76 & 2,26 & 2,38 & 1,94 & 2,00 \\
\hline 0,36 & 0,37 & 0,42 & 0,44 & 0,80 & 0,87 & 2,22 & 2,35 & 1,90 & 1,98 \\
\hline 0,41 & 0,42 & 0,47 & 0,50 & 0,94 & 1,00 & 2,29 & 2,38 & 2,00 & 2,00 \\
\hline 0,46 & 0,47 & 0,53 & 0,56 & 0,96 & 1,11 & 2,09 & 2,36 & 1,81 & 1,98 \\
\hline 0,51 & 0,52 & 0,59 & 0,61 & 1,17 & 1,23 & 2,29 & 2,37 & 1,98 & 2,02 \\
\hline & & & & & Média & 2,25 & 2,34 & 1,94 & 1,99 \\
\hline
\end{tabular}

Analisando-se os deslocamentos imediatos das vigas, novamente considerando-se as regiões com maior grau de fissuração, verificou-se que os deslocamentos diferidos foram, em média, $130 \%$ e $85 \%$ maiores que os deslocamentos imediatos lineares e não-lineares, respectivamente.

Para as vigas, assim como para o pavimento 3, a relação média entre os deslocamentos diferidos e os imediatos lineares foi igual à do pavimento. Entretanto, essa relação calculada para os deslocamentos imediatos não-lineares, foi um pouco menor que a média do pavimento.

Na Figura 5.44 e na Tabela 5.23 são apresentados os deslocamentos imediatos e diferidos da viga $\mathrm{V} 1$, onde podem ser observadas as relações entre esses deslocamentos, ratificando o comportamento comentado. 


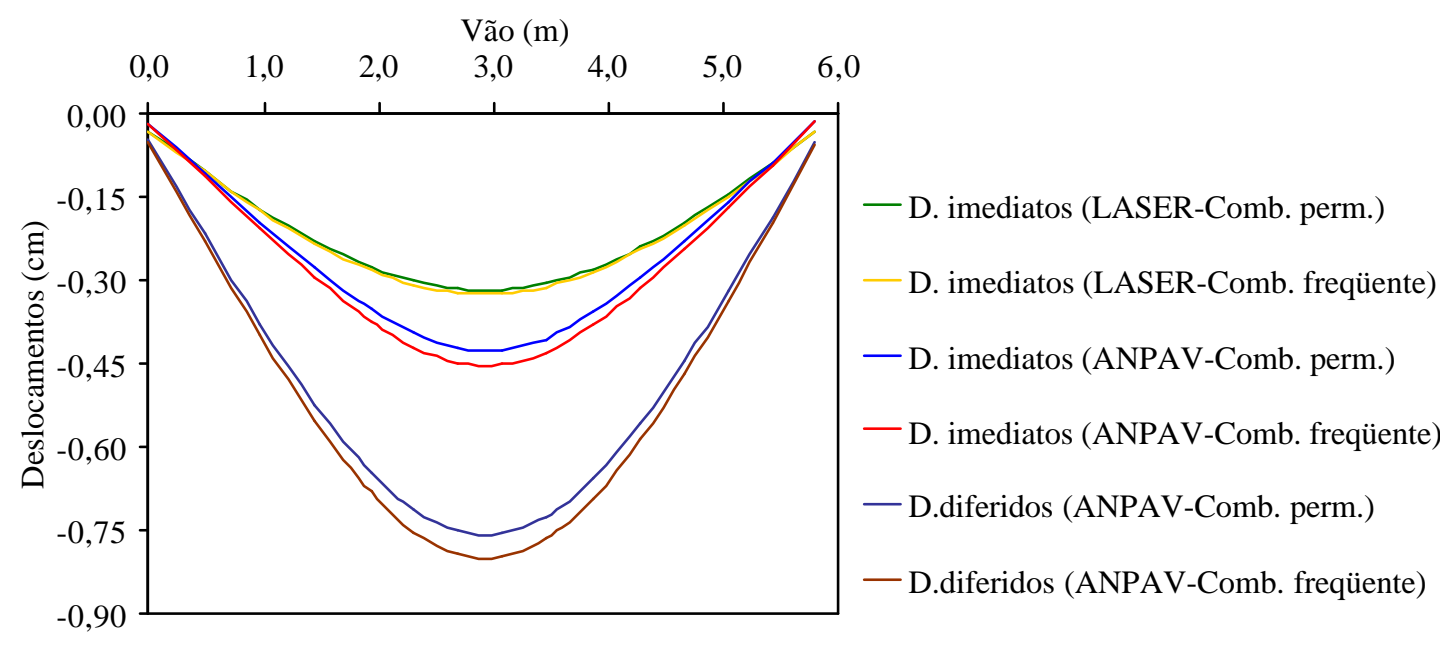

Figura 5.44 - Deslocamentos da viga V1

Tabela 5.23 - Relações entre os deslocamentos diferidos e imediatos da viga V1

\begin{tabular}{|c|c|c|c|c|c|c|c|c|c|c|}
\hline \multirow{3}{*}{$\begin{array}{l}\text { Vão } \\
\text { (m) }\end{array}$} & \multicolumn{4}{|c|}{ Deslocamentos Imediatos (cm) } & \multirow{2}{*}{\multicolumn{2}{|c|}{$\begin{array}{c}\text { Desl Diferidos } \\
(\mathrm{cm})\end{array}$}} & \multirow{2}{*}{\multicolumn{2}{|c|}{$\begin{array}{c}\text { Relação entre } \\
\text { deslocamentos } \\
\text { diferidos e imediatos* }\end{array}$}} & \multirow{2}{*}{\multicolumn{2}{|c|}{$\begin{array}{c}\text { Relação entre } \\
\text { deslocamentos } \\
\text { diferidos e imediatos** }\end{array}$}} \\
\hline & \multicolumn{2}{|c|}{ LASER } & \multicolumn{2}{|c|}{ ANPAV } & & & & & & \\
\hline & (1) & (2) & (1) & (2) & (1) & (2) & (1) & (2) & (1) & (2) \\
\hline 0,00 & $-0,032$ & $-0,032$ & $-0,019$ & $-0,019$ & $-0,050$ & $-0,051$ & 1,56 & 1,58 & 2,67 & 2,67 \\
\hline 0,48 & $-0,104$ & $-0,106$ & $-0,108$ & $-0,114$ & $-0,217$ & $-0,229$ & 2,09 & 2,15 & 2,01 & 2,00 \\
\hline 0,97 & $-0,172$ & $-0,175$ & $-0,195$ & $-0,207$ & $-0,378$ & $-0,399$ & 2,20 & 2,27 & 1,93 & 1,93 \\
\hline 1,45 & $-0,231$ & $-0,236$ & $-0,278$ & $-0,295$ & $-0,524$ & $-0,553$ & 2,27 & 2,35 & 1,88 & 1,88 \\
\hline 1,93 & $-0,277$ & $-0,283$ & $-0,351$ & $-0,373$ & $-0,644$ & $-0,680$ & 2,33 & 2,41 & 1,83 & 1,82 \\
\hline 2,31 & $-0,302$ & $-0,308$ & $-0,396$ & $-0,420$ & $-0,712$ & $-0,751$ & 2,36 & 2,44 & 1,80 & 1,79 \\
\hline 2,69 & $-0,315$ & $-0,322$ & $-0,421$ & $-0,447$ & $-0,750$ & $-0,791$ & 2,38 & 2,46 & 1,78 & 1,77 \\
\hline 3,07 & $-0,317$ & $-0,323$ & $-0,425$ & $-0,451$ & $-0,755$ & $-0,796$ & 2,38 & 2,46 & 1,78 & 1,76 \\
\hline 3,45 & $-0,305$ & $-0,312$ & $-0,405$ & $-0,430$ & $-0,725$ & $-0,765$ & 2,38 & 2,45 & 1,79 & 1,78 \\
\hline 3,87 & $-0,279$ & $-0,285$ & $-0,359$ & $-0,381$ & $-0,657$ & $-0,692$ & 2,35 & 2,43 & 1,83 & 1,81 \\
\hline 4,29 & $-0,241$ & $-0,245$ & $-0,294$ & $-0,313$ & $-0,555$ & $-0,585$ & 2,31 & 2,38 & 1,89 & 1,87 \\
\hline 4,67 & $-0,196$ & $-0,200$ & $-0,229$ & $-0,243$ & $-0,444$ & $-0,467$ & 2,26 & 2,33 & 1,94 & 1,92 \\
\hline 5,05 & $-0,145$ & $-0,148$ & $-0,160$ & $-0,169$ & $-0,320$ & $-0,336$ & 2,20 & 2,27 & 2,00 & 1,99 \\
\hline 5,43 & $-0,090$ & $-0,092$ & $-0,088$ & $-0,093$ & $-0,189$ & $-0,198$ & 2,10 & 2,15 & 2,14 & 2,13 \\
\hline 5,81 & $-0,033$ & $-0,033$ & $-0,015$ & $-0,015$ & $-0,054$ & $-0,056$ & 1,66 & 1,68 & 3,53 & 3,62 \\
\hline & & & & & & Média & 2,32 & 2,40 & 1,85 & 1,83 \\
\hline
\end{tabular}

Assim, para este pavimento, os deslocamentos diferidos foram aproximadamente $100 \%$ maiores que os deslocamentos imediatos obtidos com o programa ANPAV, para as duas combinações de ações utilizadas. Portanto, o coeficiente multiplicador dos deslocamentos imediatos foi igual a 2,0. E, com relação aos deslocamentos imediatos lineares fornecidos pelo programa LASER, os deslocamentos diferidos obtidos com o programa ANPAV foram, em média, $140 \%$ maiores, também para as duas combinações de ações consideradas. 


\subsubsection{ALTURAS MÍNIMAS}

Utilizando-se as eqs.(3.3) e (4.2), foram calculadas as alturas mínimas de algumas lajes e vigas, apresentadas a seguir.

\section{a) Alturas Mínimas das Lajes}

Para este pavimento foram calculadas as alturas mínimas das lajes L2 e L3, apresentadas a seguir.

\section{- Laje L2}

Para a laje L2, de acordo com a Figura 5.36, foram obtidas as seguintes propriedades:

- Tipo 4

- $\mathrm{L}_{\mathrm{x}}=333 \mathrm{~cm}$

- $\mathrm{L}_{\mathrm{y}}=1032 \mathrm{~cm}$

Pela Tabela 3.8, para a verificação da aceitabilidade sensorial quanto a aspectos visuais, o coeficiente $\alpha$ foi igual a 0,88 , e para as verificações de aceitabilidade sensorial relativa a vibrações e dos efeitos dos deslocamentos nas paredes, o coeficiente $\alpha$ foi igual a 0,85 . E, a partir das eqs.(3.4) e (3.5), foram calculados os seguintes valores de $\beta$ :

$$
\begin{aligned}
& \beta_{\text {ver. } 1}=61+4,0 \cdot 2,5-42,7 \cdot(3,0)+13,2 \cdot(3,0)^{2}-1,36 \cdot(3,0)^{3}=25 \\
& \beta_{\text {ver. } 2 \text { e } 3}=67+3,5 \cdot 2,5-51,5 \cdot(3,0)+16,5 \cdot(3,0)^{2}-1,77 \cdot(3,0)^{3}=22
\end{aligned}
$$

Vale ressaltar que, como a relação entre os vãos foi maior que 2,0, nas eqs.(3.4) e (3.5), essa relação foi considerada igual a 3,0, conforme recomendado no Capítulo 3.

Com esses valores de $\alpha$ e $\beta$, foram encontradas as seguintes alturas mínimas que satisfazem as verificações do estado limite de deformações excessivas:

$$
\mathrm{h}_{\min , \text { ver. } 1}=\frac{\alpha \mathrm{L}_{\mathrm{x}}}{\beta}=\frac{0,88 \cdot 333}{25}=11,7 \mathrm{~cm}
$$

e,

$$
\mathrm{h}_{\text {min,ver.2 } \mathrm{e} 3}=\frac{\alpha \mathrm{L}_{\mathrm{x}}}{\beta}=\frac{0,85 \cdot 333}{22}=12,9 \mathrm{~cm}
$$

Percebeu-se, assim, que para atender às verificações do estado limite de deformações excessivas, a laje L2 deveria ter uma altura superior a 12,9 cm. Entretanto, no projeto foi 
adotada uma altura de $10 \mathrm{~cm}$, inferior à mínima requerida. Assim, para essa laje seria necessário o cálculo dos deslocamentos e a comparação com os limites fornecidos pela NBR 6118 (2003), para se verificar esse estado limite.

\section{- Laje L3}

Para a laje L3, foram consideradas as seguintes características:

- $\quad$ Tipo 8

- $\mathrm{L}_{\mathrm{x}}=591 \mathrm{~cm}$

- $\mathrm{L}_{\mathrm{y}}=629 \mathrm{~cm}$

Pela Tabela 3.8, para a verificação da aceitabilidade sensorial relativa a aspectos visuais, e para as verificações de aceitabilidade sensorial relativa a vibrações e dos efeitos dos deslocamentos nas paredes, os valores do coeficiente $\alpha$ foram 0,84 e 0,80, respectivamente. E, de acordo com as eqs.(3.4) e (3.5), foram obtidos os seguintes valores de $\beta$ :

$$
\begin{aligned}
& \beta_{\text {ver. } 1}=61+4,0 \cdot 2,5-42,7 \cdot\left(\frac{629}{591}\right)+13,2 \cdot\left(\frac{629}{591}\right)^{2}-1,36 \cdot\left(\frac{629}{591}\right)^{3}=38,9 \\
& \beta_{\text {ver.2 } 33}=67+3,5 \cdot 2,5-51,5 \cdot\left(\frac{629}{591}\right)+16,5 \cdot\left(\frac{629}{591}\right)^{2}-1,77 \cdot\left(\frac{629}{591}\right)^{3}=37,5
\end{aligned}
$$

Portanto, foram obtidas as seguintes alturas mínimas:

$$
\mathrm{h}_{\min , \text { ver. } 1}=\frac{\alpha \mathrm{L}_{\mathrm{x}}}{\beta}=\frac{0,84 \cdot 591}{38,9}=12,8 \mathrm{~cm}
$$

e,

$$
\mathrm{h}_{\text {min,ver.2 } \mathrm{e} 3}=\frac{\alpha \mathrm{L}_{\mathrm{x}}}{\beta}=\frac{0,80 \cdot 591}{37,5}=12,6 \mathrm{~cm}
$$

Assim, para atender às verificações do estado limite de deformações excessivas, a altura da laje L3 deveria ser superior a $12,8 \mathrm{~cm}$. No projeto foi considerada uma altura igual a $12 \mathrm{~cm}$, valor bastante próximo do mínimo. Para esse caso também, seria necessário o cálculo dos deslocamentos da laje, e a comparação com os valores limites recomendados pela NBR 6118 (2003).

\section{b) Alturas Mínimas das Vigas}

Para este pavimento foram calculadas as alturas mínimas das seguintes vigas: 


\section{- Viga V7}

Foram consideradas as seguintes características para o cálculo da altura mínima da viga V7:

- $\ell_{\mathrm{ef}}=333 \mathrm{~cm}$

- $\mathrm{b}=12 \mathrm{~cm}$

- $\mathrm{h}_{\mathrm{p}}=20 \mathrm{~cm}$

Para as verificações de aceitabilidade sensorial, foi calculado o seguinte valor para $\beta$ :

$$
\beta_{\text {ver. } 1 \mathrm{e} 2}=6,0+1,4 \cdot 2,5+0,005 \cdot 333+0,21 \cdot 12-0,009 \cdot 20-0,25 \cdot \frac{333}{20}=9,3
$$

E, para a verificação dos efeitos dos deslocamentos nas paredes, encontrou-se:

$$
\beta_{\text {ver. } 3}=5,7+1,35 \cdot 2,5+0,005 \cdot 333+0,18 \cdot 12-0,007 \cdot 20-0,26 \cdot \frac{333}{20}=8,4
$$

De acordo com a eq.(4.2), foram obtidas as seguintes alturas mínimas:

$$
\mathrm{h}_{\min , \text { ver. } 1 \mathrm{e} 2}=\frac{\ell_{\mathrm{ef}}}{\beta}=\frac{333}{9,3}=35,6 \mathrm{~cm}
$$

$\mathrm{e}$,

$$
\mathrm{h}_{\text {min, ver. } 3}=\frac{\ell_{\text {ef }}}{\beta}=\frac{333}{8,4}=39,5 \mathrm{~cm}
$$

Observou-se, então, que para satisfazer as verificações do estado limite de deformações excessivas, a altura da viga deveria ser superior a $39,5 \mathrm{~cm}$. Portanto, como no projeto foi adotada uma altura igual a $60 \mathrm{~cm}$, essas verificações foram atendidas.

\section{- Viga V15}

Para a viga V15, foram tomadas as características a seguir.

- $\ell_{\mathrm{ef}}=586 \mathrm{~cm}$

- $\mathrm{b}=12 \mathrm{~cm}$

- $\mathrm{h}_{\mathrm{p}}=165 \mathrm{~cm}$

E, utilizando-se as eqs.(4.3) e (4.4), foram obtidos os seguintes valores de $\beta$ :

$$
\beta_{\text {ver. } 1 \mathrm{e} 2}=6,0+1,4 \cdot 2,5+0,005 \cdot 586+0,21 \cdot 12-0,009 \cdot 165-0,25 \cdot \frac{586}{165}=12,6
$$




$$
\beta_{\mathrm{ver} .3}=5,7+1,35 \cdot 2,5+0,005 \cdot 586+0,18 \cdot 12-0,007 \cdot 165-0,26 \cdot \frac{586}{165}=12,1
$$

E, para atender as verificações do estado limite de deformações excessivas, as alturas mínimas obtidas foram iguais a:

$$
\mathrm{h}_{\text {min, ver.1 e } 2}=\frac{\ell_{\text {ef }}}{\beta}=\frac{586}{12,6}=46,6 \mathrm{~cm}
$$

e,

$$
\mathrm{h}_{\text {min, ver. } 3}=\frac{\ell_{\text {ef }}}{\beta}=\frac{586}{12,1}=48,5 \mathrm{~cm}
$$

Observou-se, então, que para a viga V15, sua altura deveria ser superior a 48,5 cm para que fossem atendidas as verificações do estado limite de deformações excessivas. Como no projeto foi adotada uma altura de $60 \mathrm{~cm}$, pode-se concluir que essas verificações foram satisfeitas.

\subsection{CONSIDERAÇÕES FINAIS}

Em função do exposto neste capítulo, algumas considerações podem ser feitas sobre o estudo dos deslocamentos de pavimentos a partir de análises lineares e não-lineares.

\subsubsection{VALORES DOS DESLOCAMENTOS}

Considerando-se os deslocamentos dos pavimentos como um todo, tomando-se todas as vigas e lajes, notou-se que, para os pavimentos 1 e 2 , os deslocamentos imediatos provenientes da análise não-linear com o programa ANPAV foram aproximadamente $25 \% \mathrm{e}$ $30 \%$ maiores que os deslocamentos imediatos fornecidos pela análise linear com o programa LASER, respectivamente para as combinações quase-permanente e freqüente de ações. Essas mesmas proporções foram observadas entre os deslocamentos imediatos das vigas nas suas regiões mais fissuradas. A resistência à compressão do concreto, $\mathbf{f}_{\mathrm{ck}}$, utilizado nesses pavimentos foi igual a $20 \mathrm{MPa}$.

Já para os pavimentos 3 e 4, cujo concreto tinha uma resistência à compressão de $25 \mathrm{MPa}$, os deslocamentos imediatos não-lineares foram em torno de $20 \%$ maiores que os deslocamentos imediatos lineares, para as duas combinações de ações utilizadas. Nas regiões fissuradas das vigas essa proporção foi de $30 \%$. 
Percebeu-se, então, que o aumento do $\mathbf{f}_{\mathrm{ck}}$ diminuiu a diferença entre os deslocamentos imediatos lineares e não-lineares do pavimento, mas praticamente não a alterou para as vigas.

Comparando-se os deslocamentos diferidos com os deslocamentos imediatos lineares do pavimento e das vigas, constatou-se que os deslocamentos diferidos foram em torno de $180 \%$ e $140 \%$ maiores que os deslocamentos imediatos lineares, respectivamente para os pavimentos 1 e 2 e para os pavimentos 3 e 4 .

E comparando-se os deslocamentos diferidos com os deslocamentos imediatos nãolineares, observou-se que para o pavimento como um todo, os deslocamentos diferidos foram $140 \%$ maiores que os imediatos, para os pavimentos 1 e 2 , e $100 \%$, maiores que estes, para os pavimentos 3 e 4. Já os deslocamentos diferidos das vigas desses dois últimos pavimentos foram, em média, 80 \% maiores que os deslocamentos imediatos não-lineares.

Verificou-se que os deslocamentos diferidos dos pavimentos analisados foram sempre maiores que $100 \%$ que os deslocamentos imediatos lineares. Isto mostra que os coeficientes multiplicadores dos deslocamentos imediatos para o cálculo dos deslocamentos diferidos seriam, nestes casos, maiores que 2 , ratificando a subestimativa dos deslocamentos diferidos das lajes pelo coeficiente multiplicador da NBR 6118 (2003), que pode ser, no máximo, igual a 2, conforme apresentado no capítulo 3.

De acordo com o comentado anteriormente, é necessário que já se conheçam as armaduras dos elementos estruturais que compõem o pavimento, para que se possa realizar uma análise não-linear. Isto implica na necessidade de uma análise prévia, normalmente feita utilizando-se comportamento linear ou com a introdução das não-linearidades dos materiais feita a partir de processos simplificados. Desta forma, percebe-se que o cálculo de uma estrutura através de um procedimento não-linear corresponde a uma etapa adicional aos procedimentos de análises utilizados correntemente, levando a um maior tempo a ser investido na análise da estrutura.

Assim, no que diz respeito ao cálculo dos deslocamentos, acredita-se ser mais simples e eficiente a resolução da estrutura a partir de uma análise linear, corrigindo-se posteriormente os deslocamentos imediatos obtidos de forma a se levar em conta os efeitos da fissuração, da fluência e da retração. Essa metodologia é a recomendada pela NBR 6118 (2003), através da utilização do momento efetivo de inércia para a consideração da fissuração e de coeficientes multiplicadores dos deslocamentos imediatos para a consideração da fluência e da retração.

Com os resultados obtidos para os pavimentos analisados neste trabalho, constatouse que, de uma maneira geral, os deslocamentos imediatos não-lineares foram 
aproximadamente $30 \%$ maiores que os lineares. Desta forma, para pavimentos de edifícios residenciais que apresentem níveis de carregamento e comprimentos de vãos usuais, semelhantes aos dos pavimentos analisados neste capítulo, pode-se sugerir majorar os deslocamentos lineares em $30 \%$ para a consideração do efeito da fissuração, tanto para a combinação de ações quase-permanente quanto para a freqüente.

Para a obtenção dos deslocamentos diferidos no tempo, que dependem da fluência e da retração do concreto, para edifícios residenciais em condições semelhantes às dos pavimentos estudados, sugere-se a majoração de $180 \%$ dos deslocamentos imediatos lineares, para concretos com $\mathbf{f}_{\text {ck }}$ de $20 \mathrm{MPa}$, e a majoração de $140 \%$ destes deslocamentos, para concretos com $\mathbf{f}_{\text {ck }}$ de $25 \mathrm{MPa}$.

Para concreto com $\mathbf{f}_{\text {ck }}$ diferentes dos considerados aqui, sugere-se que um estudo semelhante ao desenvolvido neste trabalho seja realizado com o intuito de se determinarem os coeficientes multiplicadores dos deslocamentos imediatos para a determinação dos deslocamentos diferidos.

\subsubsection{VALORES DAS ALTURAS MÍNIMAS}

Pela comparação das alturas de lajes e vigas adotadas nos projetos dos pavimentos estudados com as alturas mínimas calculadas utilizando-se os procedimentos propostos nos Capítulos 3 e 4, foram constatados alguns aspectos comentados a seguir.

Para as lajes, observou-se que, na maioria dos casos analisados, as alturas adotadas no projeto foram menores que os valores das alturas mínimas calculadas. Desta forma, para a verificação do estado limite de deformações excessivas, seria necessário o cálculo dos deslocamentos desses elementos e sua comparação com os valores limites fornecidos pela NBR 6118 (2003).

Já para as vigas, as alturas consideradas no projeto foram maiores que as alturas mínimas calculadas, atendendo, assim, às verificações de aceitabilidade sensorial e de efeitos dos deslocamentos nas paredes.

Vale ressaltar que na elaboração dos critérios para o cálculo das alturas mínimas de lajes e vigas, propostos neste trabalho, foram consideradas as recomendações da NBR 6118 (2003), que apresenta novas prescrições relativas à durabilidade das estruturas, levando a utilização de cobrimentos maiores que os anteriormente usados, e limites mais rígidos para os deslocamentos na verificação do estado limite de deformações excessivas. Como conseqüência, as vigas e lajes, principalmente estas últimas, têm necessitado de alturas maiores que as requeridas pela versão anterior da NBR 6118 (2003), considerada nos projetos dos pavimentos estudados neste capítulo. 


\section{CONCLUSÕES}

\subsection{INTRODUÇÃO}

Neste capítulo, são apresentadas as principais conclusões e algumas considerações finais sobre os estudos realizados neste trabalho. Também são sugeridas novas pesquisas sobre deslocamentos em pavimentos de concreto armado.

\subsection{CÁLCULO DOS DESLOCAMENTOS}

No capítulo 2, foram apresentados os conceitos e parâmetros envolvidos no cálculo dos deslocamentos em elementos fletidos. Além disso, foram comentadas as recomendações das seguintes normas de projeto de concreto estrutural: NBR 6118 (2003), ACI 318 (2002), CEB-FIP (1991) e sua atualização BULLETIN FIB (1999), e EUROCODE 2 (1992) e seu projeto de revisão EUROCODE FINAL DRAFT (1999).

Verificou-se a existência de vários processos mais rigorosos, que levam em consideração diversos parâmetros para o cálculo dos deslocamentos, como o recomendado pelo CEB-FIP (1991) para o cálculo dos deslocamentos devidos à fluência e à retração do concreto apresentado no item 2.3.3. Entretanto, tais procedimentos necessitam de recursos computacionais mais sofisticados para sua utilização, que levam a um maior tempo gasto para o cálculo dos deslocamentos. Por outro lado, constatou-se, também, a existência de processos simplificados, tanto para os deslocamentos imediatos quanto para os deslocamentos diferidos, que consideram de forma mais ou menos aproximada os fatores que influenciam os deslocamentos. 
Pode-se observar, também, que vários fatores que afetam os deslocamentos são difíceis de serem mensurados, principalmente devido à grande variabilidade dos parâmetros que influenciam tais fatores. Pode-se citar, por exemplo, a fluência do concreto que afeta diretamente os deslocamentos diferidos. Ela é influenciada pela umidade relativa do ar, temperatura, idade de aplicação das cargas e materiais constituintes do concreto, dentre outros. Esses parâmetros variam bastante de obra para obra, tornando menos precisa a sua avaliação. Percebeu-se, então, que vários são os fatores que contribuem para dificultar a previsão dos deslocamentos em uma estrutura, afastando os valores calc ulados daqueles que efetivamente ocorrerão.

Com relação às recomendações normativas, observou-se que o CEB-FIP (1991) e EUROCODE 2 (1992) apresentam procedimentos análogos para o cálculo dos deslocamentos imediatos e diferidos, realizados a partir da relação momento-curvatura das seções transversais. O CEB-FIP (1991) fornece também um processo simplificado para o cálculo dos deslocamentos diferidos, através da majoração dos deslocamentos imediatos por um coeficiente que depende do nível de fissuração e da fluência.

Já as recomendações da NBR 6118 (2003) são bastante semelhantes às do ACI 318 (2002). Para a consideração da fissuração no cálculo dos deslocamentos imediatos, ambas recomendam a utilização do momento efetivo de inércia, desenvolvido por BRANSON (1965). Além disso, prescrevem a utilização de um coeficiente que deve ser multiplicado pelos deslocamentos imediatos para a obtenção dos deslocamentos diferidos. $\mathrm{O}$ cálculo deste coeficiente, entretanto, apresenta algumas diferenças. Segundo o ACI 318 (2002), ele depende da duração total do carregamento, não considerando uma redução do seu valor em função da idade de aplicação do carregamento de longa duração, como recomenda a NBR 6118 (2003). Desta forma, os deslocamentos diferidos obtidos segundo o procedimento do ACI 318 (2002) são maiores que os fornecidos pela NBR 6118 (2003), como pode ser visto, o exemplo de cálculo apresentado no capítulo 2.

Dentro dessa ótica, e considerando-se os resultados obtidos nos estudos das lajes e vigas isoladas, sugere-se não reduzir o coeficiente multiplicador dos deslocamentos imediatos em função da idade de aplicação das ações. Espera-se com isso minimizar a subestimativa dos deslocamentos diferidos.

\subsection{DESLOCAMENTOS EM LAJES ISOLADAS}

No capítulo 3, foram apresentados as características e os parâmetros adotados no estudo das lajes isoladas. Com base nos deslocamentos obtidos pela análise de mais de 5500 
lajes com o programa ANPAV, desenvolvido no SET-EESC-USP por OLIVEIRA (2001), foi possível:

- Avaliar a influência dos parâmetros envolvidos nesta análise;

- Avaliar o procedimento da NBR 6118 (2003) para o cálculo dos deslocamentos diferidos;

- Desenvolver uma expressão para o cálculo do coeficiente multiplicador dos deslocamentos imediatos;

- Desenvolver algumas propostas para o cálculo de uma altura mínima para lajes que, se adotada, satisfaz as verificações do estado limite de deformações excessivas.

As principais conclusões são apresentadas sucintamente nos parágrafos a seguir.

A existência de engastamento ao longo dos lados maiores da laje reduziu significativamente os deslocamentos em comparação com lajes simplesmente apoiadas. Para as lajes que tinham apenas um dos maiores lados engastado, observou-se uma redução média dos deslocamentos de $17 \%$. Já para lajes com os dois maiores lados engastados essa redução foi de $32 \%$.

Por outro lado, observou-se que a existência de engastamentos ao longo do menor vão das lajes exerceu pouca influência nos valores dos deslocamentos.

O aumento da resistência característica do concreto à compressão causou uma redução dos deslocamentos, cuja intensidade dependeu do tipo de deslocamento se considerou. Essa redução ocorreu, principalmente, devido ao aumento do módulo de elasticidade de concreto, e do conseqüente aumento da rigidez do elemento, causado pelo acréscimo no valor do $\mathbf{f}_{\mathrm{ck}}$.

Para níveis de carregamento relativamente baixos, os deslocamentos imediatos sofreram uma redução inversamente proporcional ao acréscimo no valor do módulo de elasticidade devido ao aumento do $\mathbf{f}_{\text {ck }}$. Nessas condições, o concreto ainda não apresenta va fissuras, ou estava pouco fissurado, resultando em uma participação mais efetiva do concreto entre as fissuras. Assim, o momento de inércia da seção transversal foi praticamente igual ao da seção não fissurada, e o comportamento pode ser considerado praticamente elástico.

Já os deslocamentos diferidos, incrementais e totais apresentaram uma redução um pouco maior que a dos deslocamentos imediatos, pois, além do acréscimo na rigidez do elemento, o aumento do $\mathbf{f}_{\mathrm{ck}}$ causou ainda a diminuição da fluência do concreto.

Quando se compararam deslocamentos obtidos para os diversos casos de carregamento adotados, verificou-se que, devido ao baixo nível de fissuração usualmente 
atingido pelas lajes, as relações entre esses deslocamentos resultantes foram praticamente as mesmas existentes entre as ações desses casos de carregamento.

A partir da determinação das relações entre os deslocamentos diferidos e imediatos, que foram chamadas de coeficientes multiplicadores dos deslocamentos imediatos, notou-se que a altura de laje e o $\mathbf{f}_{\text {ck }}$ influenciaram de forma significativa seus valores. Assim, foi proposta uma expressão para o cálculo dessas relações, que leva em consideração esses dois parâmetros.

Comparando-se os resultados obtidos com o programa ANPAV e os fornecidos pela expressão proposta para o cálculo dos coeficientes multiplicadores dos deslocamentos imediatos, observou-se uma boa concordância entre esses valores. Já a comparação desses valores com os fornecidos pe lo procedimento proposto pela NBR 6118 (2003) indic ou que este último levou a uma considerável subestimativa desses coeficientes e, consequentemente, dos deslocamentos diferidos.

Por fim, a partir dos valores de alturas mínimas das lajes obtidas com o programa ANPAV, foram apresentadas duas propostas para a determinação dessa altura mínima de lajes, que atende às verificações do estado limite de deformação excessiva.

Pela primeira proposta, a altura mínima é determinada a partir da relação menor vãoaltura mínima da laje, eq. (3.3), e é função da verificação de se deseja fazer, dos vãos da laje, do $\mathbf{f}_{\mathbf{c k}}$ e das condições de apoio. Os valores fornecidos por esta expressão foram comparados com os obtidos pela análise com o programa ANPAV e se mostraram bastante próximos, principalmente, para as relações entre o maior e o menor vão das lajes situadas entre 1,0 e 2,0 .

A segunda proposta apresenta uma expressão para a altura mínima de lajes, eq. (3.6), que leva em consideração os principais parâmetros adotados para o cálculo dos deslocamentos. Por isso, sua aplicação é um pouco mais trabalhosa que a da proposta baseada na relação menor vão-altura mínima da laje. Entretanto, seus resultados foram ainda mais próximos daqueles obtidos com o programa ANPAV.

Foram feitos exemplos de cálculo para os quais as alturas mínimas das lajes foram determinadas a partir das expressões propostas. Seus resultados foram comparados e verificou-se que, em alguns casos, as alturas mínimas determinadas a partir da eq. (3.6) foram um pouco menores que os fornecidos pela eq.(3.3), mas não apresentaram diferenças significativas.

Com a altura mínima definida, os deslocamentos das lajes foram determinados com o programa ANPAV, e os resultados foram comparados com os valores limites impostos 
pela NBR 6118 (2003). Constatou-se, então, que a altura mínima obtida a partir dos procedimentos propostos atendeu a todas as verificações, confirmando a sua eficácia.

Recomenda-se, então, a utilização da proposta para a determinação da altura mínima a partir da relação menor vão-altura mínima da laje, eq.(3.3), por ser de simples execução e depender apenas da resistência característica do concreto à compressão $\mathbf{f}_{\mathbf{c k}}$, do tipo de vinculação e dos vãos da laje.

Vale ressaltar que esses critérios de altura mínima são realmente importantes porque são o resultado da análise de valores obtidos para mais 5.500 lajes, processadas com todos os recursos para avaliação de efeitos não-lineares que um programa de análise sofisticado pode oferecer. Portanto, é um resultado representativo do comportamento das lajes e de grande significado prático que, pelo número expressivo de casos estudados, confere uma boa confiabilidade ao procedimento de avaliação de deslocamentos para lajes isoladas.

\subsection{DESLOCAMENTOS EM VIGAS ISOLADAS}

No capítulo 4, foram apresentados as características e os parâmetros adotados no estudo das vigas isoladas. As principais conclusões são apresentadas a seguir.

Observou-se que com o aumento da altura da seção transversal dos pilares de apoio, dimensão segundo o eixo da viga, os deslocamentos, independentemente do vão, da largura e dos casos de carregamentos adotados, apresentaram, aproximadamente, o mesmo percentual de redução. Constatou-se também que a redução dos deslocamentos imediatos foi um pouco superior à dos deslocamentos totais, assim como a redução destes foi um pouco superior a dos deslocamentos diferidos e incrementais.

Notou-se, entretanto, que à medida que se aumentou a dimensão dos pilares, os deslocamentos sofreram um decréscimo significativo até certo valor de altura da seção transversal do pilar a partir da qual os deslocamentos praticamente não se alteraram. Desta forma, constatou-se que, para as vigas que apresentaram relação entre sua rigidez e a rigidez dos seus pilares de apoio da ordem de 0,30, o aumento da dimensão do pilar na direção do eixo da viga não levou a redução significativa dos deslocamentos das vigas.

A presença de armadura de compressão nas vigas causou uma redução dos deslocamentos, que foi maior para os deslocamentos diferidos. Isto se deve, principalmente, ao fato desta armadura também colaborar na diminuição da curvatura causada pela retração do concreto. Verificou-se, também, que para as vigas com $\mathbf{f}_{\text {ck }}$ de $35 \mathrm{MPa}$, as reduções de todos os deslocamentos foram inferiores as das vigas com $\mathbf{f}_{\text {ck }}$ de $25 \mathrm{MPa}$. Constatou-se, então, que para concretos com resistências características à compressão mais elevadas, a 
influência da armadura de compressão na redução dos deslocamentos não é tão efetiva como para resistência mais baixas.

Com o aumento do $\mathbf{f}_{\mathrm{ck}}$, notou-se que a redução dos deslocamentos variou em função da rigidez dos pilares de apoio. Para relações entre a rigidez da viga e a rigidez do pilar maiores que 0,30 , a redução média foi de $21 \%$ para os deslocamentos imediatos, de $25 \%$ para os deslocamentos totais e de $27 \%$ para os deslocamentos diferidos e incrementais. Já para relações entre essas rigidezes menores que 0,30 , a redução dos deslocamentos foi um pouco inferior, sendo de $18 \%$ para os deslocamentos imediatos, de $22 \%$ para os totais, e de $24 \%$ para os diferidos e incrementais.

Para as vigas com dois vãos, observou-se que os deslocamentos do maior vão, quando comparados com os de uma viga com um único vão e pilares de apoio com seção transversal de $20 \times 20 \mathrm{~cm}$, sofreram uma redução significativa. Essa redução dos deslocamentos com a presença do vão adjacente foi maior ou menor em função da relação entre o maior e o menor vão das vigas. O decréscimo dos deslocamentos foi máximo para relação entre os vãos igual a um e para relações maiores que 1,50, seu valor sofreu alterações muito pouco significativas.

Assim como para as lajes, foram determinadas as relações entre os deslocamentos diferidos e imediatos, definindo-se os chamados coeficientes multiplicadores dos deslocamentos imediatos. Com os resultados obtidos foi possível o desenvolvimento de uma expressão para o cálculo desses coeficientes, que leva em consideração as propriedades geométricas das vigas, as armaduras de tração e de compressão e o $\mathbf{f}_{\text {ck. }}$.

Comparando-se os resultados obtidos com o programa ANPAV e os fornecidos pela expressão proposta, observou-se que eles são bastante próximos. Entretanto, quando comparados com o procedimento proposto pela NBR 6118 (2003), notou-se que os valores são bem diferentes. Ficou constatado que o coeficiente multiplicador dos deslocamentos imediatos proposto pela Norma tende a superestimar os coeficientes multiplicadores dos deslocamentos imediatos, principalmente, para valores de $\mathbf{f}_{\text {ck }}$ mais elevados.

Percebeu-se, então, que o procedimento da NBR 6118 (2003) para a determinação dos deslocamentos diferidos a partir de coeficientes multiplicadores dos deslocamentos imediatos, pode não apresentar bons resultados tanto para lajes quanto para vigas. Para as primeiras geralmente leva a uma subestimativa dos deslocamentos diferidos, sendo que para as vigas pode levar a uma superestimativa desses deslocamentos.

Finalmente, a partir dos valores de alturas mínimas das vigas obtidas com o programa ANPAV, também foram apresentadas duas propostas para a determinação dessa 
altura mínima que, se adotadas, atendem ao estado limite de deformação excessiva sem a necessidade do cálculo dos deslocamentos.

Pela primeira proposta, a altura mínima é determinada a partir da relação vão- altura mínima da viga, eq. (4.2), e é função da verificação de se deseja fazer, das propriedades geométricas das vigas e dos pilares de apoio e do $\mathbf{f}_{\text {ck }}$.

Comparados com os valores das relações vão-altura mínima das vigas obtidos pela análise com o programa ANPAV, os valores fornecidos por esta expressão foram relativamente próximos.

Foram propostas ainda duas outras expressões para o cálculo da altura mínima de vigas, eq. (4.5) e eq. (4.6). Uma foi desenvolvida para as verificações referentes à aceitabilidade sensorial e a outra para a verificação dos efeitos dos deslocamentos em paredes.

Vale ressaltar que essas expressões não apresentaram bons resultados para vigas com vãos de 3,0 m, devido à pequena variabilidade das alturas mínimas dessas vigas com os parâmetros adotados nos cálculos. Entretanto, para os outros vãos adotados, os valores obtidos foram muito próximos dos valores fornecidos pela análise com o programa ANPAV.

Por fim, foi feito um exemplo de cálculo para os quais as alturas mínimas das vigas foram determinadas a partir das expressões propostas. Com a altura mínima definida, os deslocamentos das vigas foram determinados com o programa ANPAV, e os resultados foram comparados com os valores limites impostos pela NBR 6118 (2003). Novamente, observou-se que a altura mínima obtida a partir dos procedimentos propostos satisfaz a todas as verificações com relativa precisão.

\subsection{DESLOCAMENTOS EM PAVIMENTOS}

Para a realização de uma análise não-linear é necessário que se conheçam as armaduras dos elementos estruturais que compõem o pavimento. Isto implica na necessidade de uma análise prévia, normalmente feita utilizando-se comportamento linear ou com a introdução das não-linearidades dos materiais feita a partir de processos simplificados. Desta forma, constatou-se que o cálculo de uma estrutura através de um procedimento não-linear corresponde a uma etapa adicional aos procedimentos de análises utilizados correntemente, levando a um maior tempo a ser investido na análise da estrutura.

Assim, para o cálculo dos deslocamentos, acredita-se ser mais simples e eficiente a resolução da estrutura a partir de uma análise linear, corrigindo-se posteriormente os deslocamentos lineares obtidos de forma a se levar em conta os efeitos da fissuração, da 
fluência e da retração. Essa metodologia é a recomendada pela NBR 6118 (2003), através da utilização do momento efetivo de inércia para a consideração da fissuração e de coeficientes multiplicadores dos deslocamentos imediatos para a consideração da fluência e da retração.

De uma maneira geral, para os pavimentos analisados, observou-se que os deslocamentos imediatos não-lineares foram aproximadamente $30 \%$ maiores que os lineares. Assim, para pavimentos de edifícios residenciais com características semelhantes às dos pavimentos estudados, sugere-se majorar os deslocamentos lineares em $30 \%$ para a consideração do efeito da fissuração, tanto para a combinação de ações quase-permanente quanto para a freqüente.

Já para a obtenção dos deslocamentos diferidos no tempo sugere-se a majoração de $180 \%$ dos deslocamentos imediatos lineares, para concretos com $\mathbf{f}_{\text {ck }}$ de $20 \mathrm{MPa}$, e a majoração de $140 \%$ destes deslocamentos, para concretos com $\mathbf{f}_{\text {ck }}$ de $25 \mathrm{MPa}$.

Com relação às alturas mínimas obtidas da aplicação dos critérios propostos neste trabalho, observou-se que para a maioria das lajes analisados, as alturas adotadas no projeto foram menores que os valores das alturas mínimas calculadas. E para as vigas, as alturas consideradas no projeto foram maiores que as alturas mínimas. Constatou-se, assim, que em função das novas prescrições da NBR 6118 (2003) para a verificação do estado limite de deformações excessivas e para a garantia da durabilidade das estruturas, as vigas e lajes, principalmente estas últimas, têm necessitado de alturas maiores que as requeridas pela versão anterior da NBR 6118 (2003).

\subsection{SUGESTÕES PARA NOVAS PESQUISAS}

Como comentado anteriormente, o cálculo dos deslocamentos diferidos a partir da utilização do coeficiente multiplicador dos deslocamentos imediatos recomendado pela NBR 6118 (2003) pode levar a uma superestimativa desses deslocamentos para vigas, e também a sua subestimativa para as lajes. Desta forma, julga-se conveniente a realização de pesquisas experimentais para a determinação dos deslocamentos diferidos no tempo, de forma que se possa ratificar esse comportamento e melhorar as expressões propostas para $\mathrm{o}$ cálculo dos coeficientes multiplicadores dos deslocamentos imediatos.

Durante a construção de uma edificação, as cargas atuantes nos pavimentos podem ultrapassar os valores previstos no projeto. E a aplicação dessas ações consideráveis a pequenas idades, quando os valores do módulo de elasticidade e da resistência à tração do concreto ainda são baixos, pode acarretar uma fissuração prematura com o conseqüente aumento dos deslocamentos imediatos. Além disso, sabe-se que a fluência depende da idade 
do concreto quando do primeiro carregamento. Assim, a aplicação dessas cargas de construção pode aumentar não só os deslocamentos imediatos, mas também os deslocamentos diferidos.

Neste contexto, sugere-se um estudo visando a determinação das cargas que usualmente ocorrem nas estruturas durante a sua execução, com a medição local dos deslocamentos para que se possa definir, por exemplo, com qual nível de carregamento devem ser calculados os deslocamentos imediatos.

Conforme comentado no capítulo 2, para elementos com momentos atuantes muito próximos do momento de fissuração, e com taxas de armadura muito baixas, a utilização do momento efetivo de inércia pode levar a uma subestimativa dos deslocamentos. Assim, sugere-se que um estudo semelhante ao desenvolvido neste trabalho seja realizado com o intuito de se avaliarem os resultados da utilização do momento efetivo de inércia para a consideração da fissuração dos elementos, principalmente para lajes. 


\section{ANEXO A}

\section{A.1 ASPECTOS GERAIS}

Para as verificações dos deslocamentos fornecidos ms tabelas a seguir, valem as seguintes observações:

- $\quad \mathbf{1}^{\mathbf{a}}$. Verificação: Verificação da aceitabilidade sensorial quanto ao aspecto visual.

- Na primeira coluna de status, tem-se essa verificação para os deslocamentos determinados a partir da combinação quase-permanente de ações.

- Na segunda coluna de status, tem-se essa verificação para os deslocamentos determinados a partir da combinação freqüente de ações.

- $\quad \mathbf{2}^{\mathbf{a}}$. Verificação: Verificação da aceitabilidade sensorial relativa às vibrações.

- 3a. Verificação: Verificação dos efeitos dos deslocamentos em elementos não estruturais

- Na primeira coluna de status, tem-se essa verificação para os deslocamentos determinados a partir da combinação quase-permanente de ações.

- Na segunda coluna de status, tem-se essa verificação para os deslocamentos determinados a partir da combinação freqüente de ações.

\section{A.2 VALORES DOS DESLOCAMENTOS DAS LAJES}

A seguir são apresentados os deslocamentos calculados para alguns tipos de lajes. 


\begin{tabular}{|c|c|c|c|c|c|c|c|c|c|c|c|c|c|c|c|c|c|c|c|c|c|c|c|c|}
\hline \multicolumn{25}{|c|}{$\begin{array}{l}\mathrm{f}_{\mathrm{ck}}=25 \mathrm{Mpa} \\
\text { TIPO } 1\end{array}$} \\
\hline \multirow{2}{*}{$L y / L x$} & \multirow{2}{*}{$\begin{array}{c}\text { h } \\
(\mathrm{cm})\end{array}$} & \multicolumn{5}{|c|}{ Deslocamentos Imediatos (cm) } & \multicolumn{4}{|c|}{ Deslocamentos Totais (cm) } & \multicolumn{4}{|c|}{ Deslocamentos Diferidos (cm) } & \multicolumn{2}{|c|}{ D. Incrementais } & \multicolumn{3}{|c|}{ 1a Verficação } & \multicolumn{2}{|c|}{ 2a Verficação } & \multicolumn{3}{|c|}{ 3a Verficação } \\
\hline & & $\overline{a_{i g}}$ & & & $a_{i, g+a}$ & $\overline{a .9}$ & $\overline{\mathrm{at}_{\mathrm{tg}} \mathrm{g}}$ & & $a_{t, q+0,49}$ & a., & $\mathrm{a}_{\mathrm{d}}$ & & $a_{d, q 0.49}$ & $a_{d, g+q}$ & $a_{\text {inc, },+0,3.3}$ & & Limite & Status & Status & Limite & Status & 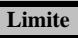 & Status & Status \\
\hline$\overline{1,0}$ & 7,0 & 0,228 & 56 & 263 & 2,301 & 2,073 & 0,797 & 85 & 0,927 & 3,031 & 0,569 & 0,629 & 0,665 & 0,730 & 0,658 & 0,699 & 1,200 & $\mathrm{Ok}$ & $\mathrm{Ok}$ & 0,857 & N.G. & 0,600 & N.G. & N.G. \\
\hline 1,0 & 8,0 & 0,159 & 71 & 175 & 0,199 & 0,040 & 0,549 & $\overline{590}$ & 0,603 & 0,686 & 0,389 & 0,419 & 0,428 & 0,487 & 0,430 & 0,444 & 1,200 & $\mathrm{Ok}$ & $\mathrm{Ok}$ & 0,857 & $\mathrm{Ok}$ & 0,600 & $\mathrm{Ok}$ & $\mathrm{Ok}$ \\
\hline & $\overline{9,0}$ & & & & & & & & & & & & & & & & & & & & & & & \\
\hline .2 & $8, \overline{0}$ & 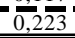 & 0,244 & 0,260 & $1,-\infty$ & 0,98 & $\overline{0,766}$ & $\overline{0}, \overline{83}$ & $\overline{059}$ & 3,185 & $=0$. & $=\frac{5}{05}$ & $\overline{0}, \overline{599}$ & $1, \overline{98}$ & $\overline{0,607}$ & -0 & & $\overline{\mathrm{Ok}}$ & $\overline{\mathrm{k}}$ & $\overline{0} \overline{8}$ & $\bar{v}($ & & N.G. & 8 \\
\hline$\overline{1,2}$ & $\overline{\overline{9,0}}$ & $\overline{0,162}$ & 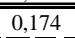 & 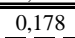 & 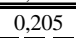 & $0,0,043$ & $0,0,553$ & $0,0,594$ & $0,0,608$ & $0,0,696$ & $0,0,39$ & $=0,420$ & (20,430 & 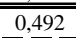 & $\overline{0.4 .4}$ & $0,0,446$ & $\overline{1,200}$ & $\overline{\mathrm{O \textrm {Ok }}}$ & 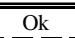 & 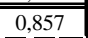 & $\overline{\overline{\mathrm{OKk}}}$ & 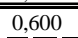 & $\overline{\overline{\mathrm{Ok}}}$ & $\overline{\overline{\mathrm{OKk}}}$ \\
\hline 1,4 & $\overline{8}, \overline{0}$ & $\overline{0,31}$ & $\overline{0}, 4$ & $\overline{0}, \overline{45} 5$ & $5, \overline{21}$ & $\overline{4,886}$ & $\overline{1,056}$ & $\overline{1}, \overline{783}$ & $\overline{1}, \overline{88} \overline{1}$ & $-3, \overline{6} 4 \overline{3}$ & $\overline{0,739}$ & & & $-\overline{-1, \overline{5} 61}$ & & $1, \overline{5} 6 \overline{3}$ & & N.G. & $\overline{\mathrm{N}} . \overline{\mathrm{G}}$. & & $\overline{\text { N.G. }}$ & $\overline{0}, \overline{600}$ & N.G. & $\bar{N} . \bar{G}$. \\
\hline 1,4 & 9,0 & 0,204 & 0,226 & 0,235 & 0,308 & 0,104 & 0,686 & 0,744 & 0,764 & 1,641 & 0,482 & 0,519 & 0,529 & 1,333 & 0,540 & 0,560 & 1,200 & Ok & $\mathrm{Ok}$ & 0,857 & Ok & 0,600 & Ok & $\mathrm{Ok}$ \\
\hline 1,6 & $\overline{8}, 0$ & 0,491 & 1,3 & $\overline{1}, \overline{935}$ & $3,33 \overline{3}$ & 2,843 & $\overline{1,734}$ & 2,418 & $\overline{2}, \overline{579}$ & $3, \overline{83} 8$ & 1,244 & 1,080 & 0,645 & $\overline{0}, \overline{50} \overline{-}$ & $\overline{1,927}$ & $-2,089$ & 1,200 & N.G. & $\overline{\mathrm{N}} . \overline{\mathrm{G}}$. & 0,857 & N.G. & 0,600 & N.G. & $\overline{\mathrm{N}} \cdot \overline{\mathrm{G}}$. \\
\hline 1,6 & 9,0 & 0,261 & 0,301 & 0,314 & 1,403 & 1,143 & 0,832 & 0,952 & 1,001 & 2,130 & 0,572 & 0,651 & \begin{tabular}{l|l}
0,686 \\
\end{tabular} & 0,727 & 0,691 & 0,740 & 1,200 & $\mathrm{Ok}$ & $\mathrm{Ok}$ & 0,857 & N.G. & 0,600 & N.G. & N.G. \\
\hline 1,6 & 10,0 & 0,180 & & 0,206 & 0,2 & $-0,082$ & 0,601 & 0,650 & & 0,831 & 0,4 & & & 0,569 & & & 1,200 & Ok & Ok & & Ok & & $\mathrm{Ok}$ & $\mathrm{Ok}$ \\
\hline & 9.0 & 0.324 & 0.387 & 0.420 & 2.432 & 2.107 & 1.005 & 1.173 & 1.497 & $2.55 \overline{7}$ & 0.681 & 0.786 & 1.077 & -0.126 & 0.848 & -1.172 & 1.200 & $-\overline{\mathrm{Ok}}=$ & $\bar{N} . \bar{G}$. & 0.857 & $\bar{N} . \bar{G}$. & 0.600 & N.G. & $\overline{\mathrm{N}} . \overline{\mathrm{G}}$. \\
\hline 1,8 & $\begin{array}{c}10,0 \\
\end{array}$ & 0,210 & $0,0,240$ & $0,0,254$ & 0,329 & 0,119 & 0,673 & 0,756 & $0,0,792$ & 1,019 & 0,463 & 0,516 & 0,538 & $\begin{array}{c}0,690 \\
\end{array}$ & $\begin{array}{l}0,546 \\
\end{array}$ & $\begin{array}{c}0,582 \\
\end{array}$ & 1,200 & $\overline{\mathrm{OK}}$ & $\begin{array}{l}\mathrm{OK} \\
\end{array}$ & 0,857 & Ok & 0,600 & $\overline{\mathrm{Ok}}$ & OKk \\
\hline & 11,0 & 0,1 & & & & & & 0,5 & & & & & & & & & 1,200 & & OK & & Ok & & Ok & \\
\hline 10 & 9,0 & 0,392 & 0,506 & 0,652 & 3,403 & 3,012 & 1,169 & 1,554 & 1,666 & $-2,656$ & 0,7 & 1,048 & 1,014 & $-0,748$ & 1,162 & $-1,274$ & 1,200 & $-\mathrm{N.G}$. & $\overline{\mathrm{N}} . \bar{G}$. & 0,857 & N.G. & 0,600 & N.G. & $\overline{\mathrm{N}} \cdot \overline{\mathrm{G}}$ \\
\hline 2,0 & $\begin{array}{l}10,0 \\
\end{array}$ & 0,247 & & 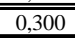 & 0,440 & 0,193 & 0,759 & 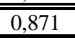 & $0,0,903$ & 01,392 & $\overline{0.5,5}$ & $\overline{0.0,5}$ & 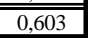 & 0,952 & $=$ & 0,656 & 1,200 & $\overline{\mathrm{O \textrm {Ok }}}$ & $\begin{array}{l}\mathrm{Ok} \\
\end{array}$ & $\begin{array}{c}0,857 \\
\end{array}$ & $\begin{array}{l}\mathrm{Ok} \\
\end{array}$ & 0 & $\begin{array}{l}\text { N.G.G. } \\
\end{array}$ & 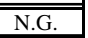 \\
\hline- & 11,0 & 0,171 & & 0,202 & 0,262 & 0,091 & 0,560 & 0,606 & 0,6 & 0,794 & 0,3 & 0,41 & 0,43 & 0,532 & & & 1,200 & $\overline{\mathrm{Ok}}$ & $\overline{\mathrm{Ok}}$ & & $\overline{\mathrm{Ok}}$ & & $\overline{\mathrm{Ok}}$ & \\
\hline 30 & $\overline{10,0}$ & $\overline{0,402}$ & $\overline{0}, 4$ & $\overline{0}, \overline{515}$ & $-\overline{5}, \overline{0}$ & $\overline{1,098}$ & 1,070 & $\overline{1}, 231$ & $-1,306$ & $-1,726$ & $\overline{0,6}$ & $=074$ & $\overline{0}, \overline{911}$ & $\overline{0}, \overline{22} 6$ & $-\frac{-8}{08}$ & $-\overline{904}$ & $=1,200$ & $-{ }_{\text {N.G. }}$ & $\overline{\mathrm{N}} . \overline{\mathrm{G}}$. & $\overline{0}, \overline{8 .}$ & N.G. & $\overline{0}, \overline{600}$ & N.G. & $\overline{\mathrm{N}} . \overline{\mathrm{G}}$. \\
\hline 3,0 & 11,0 & 0,253 & 0,309 & 0,325 & 0,451 & 0,198 & 0,706 & 0,814 & 0,874 & 1,166 & 0,453 & 0,505 & 0,549 & 0,715 & $\begin{array}{c}0,561 \\
\end{array}$ & 0,621 & 1,200 & Ok & Ok & 0,857 & Ok & 0,600 & $\begin{array}{l}\mathrm{Ok} \\
\end{array}$ & N.G. \\
\hline 4,0 & $\begin{array}{ll}11,0 \\
\end{array}$ & 0,318 & 0,399 & 0,430 & 0,631 & 0,312 & 0,793 & 0,952 & 1,002 & 1,357 & 0,475 & 0,553 & 0,572 & 0,726 & 0,634 & 0,683 & 1,200 & $\mathrm{Ok}$ & $\mathrm{Ok}$ & 0,8 & $\mathrm{O}$ & 0,600 & N.G. & N.G. \\
\hline 4,0 & 12,0 & 0,198 & 0,240 & 0,267 & 0,400 & 0,203 & 0,546 & 0,668 & 0,693 & 0,972 & 0,349 & 0,428 & 0,426 & 0,572 & 0,471 & 0,495 & 1,200 & $\mathrm{Ok}$ & Ok & 0,857 & $\mathrm{Ok}$ & 0,600 & $\mathrm{Ok}$ & $\mathrm{Ok}$ \\
\hline
\end{tabular}




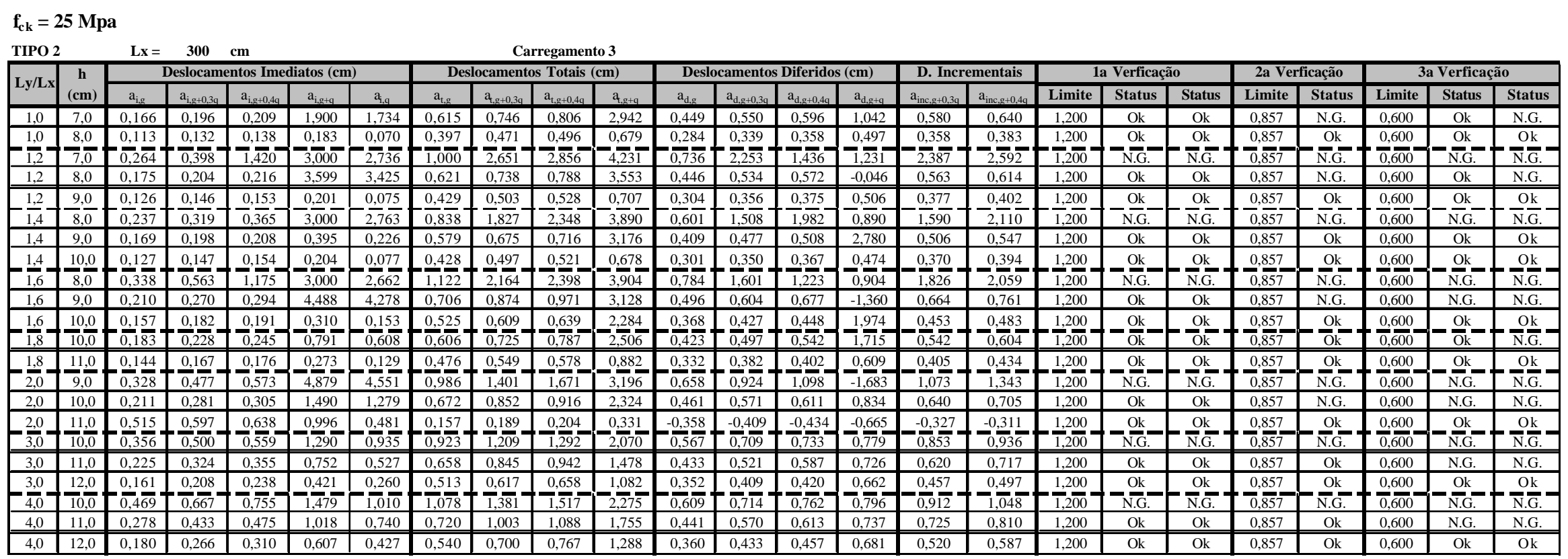


$\mathrm{f}_{\mathrm{ck}}=25 \mathrm{Mpa}$

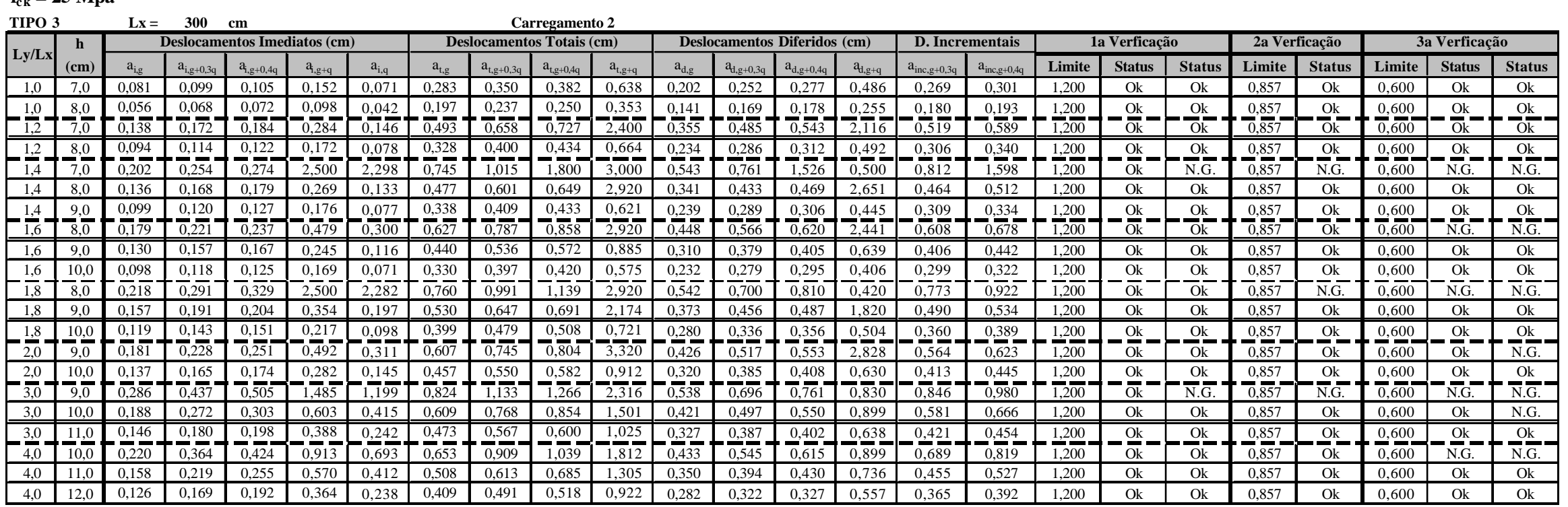




\begin{tabular}{|c|c|c|c|c|c|c|c|c|c|c|c|c|c|c|c|c|c|c|c|c|c|c|c|c|}
\hline \multicolumn{25}{|c|}{$\begin{array}{l}\mathrm{f}_{\mathrm{ck}}=25 \mathrm{Mpa} \\
\mathrm{TIPO}^{\mathrm{L}} \quad \mathrm{Lx}=400 \mathrm{~cm}\end{array}$} \\
\hline & \multirow{2}{*}{$\begin{array}{c}\mathbf{h} \\
(\mathrm{cm})\end{array}$} & \multicolumn{5}{|c|}{$\begin{array}{c}\mathrm{Lx}=\quad 400 \mathrm{~cm} \\
\text { Destocamentos Imediatos }(\mathrm{cm})\end{array}$} & \multicolumn{4}{|c|}{$\begin{array}{c}\text { Carregamento } 2 \\
\text { nentos Totais (cm) }\end{array}$} & \multicolumn{4}{|c|}{ Deslocamentos Diferidos (cm) } & \multirow{2}{*}{\multicolumn{2}{|c|}{ D. Incrementais }} & \multicolumn{3}{|c|}{ 1a Verficação } & \multicolumn{2}{|c|}{ 2a Verficação } & \multicolumn{3}{|c|}{ a Verficaç. } \\
\hline & & & & & & $a_{.9}$. & & & & & & $a_{d, 8+0,3}$ & $\mathrm{a}_{\mathrm{d}+2+0,4 \mathrm{a}}$ & & & & \begin{tabular}{|l|} 
Limite \\
\end{tabular} & \begin{tabular}{|l|l|} 
Status \\
\end{tabular} & Status & Limite & Status & Limite & Status & Status \\
\hline & & 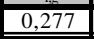 & 0358 & 0.417 & 3.100 & 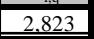 & -1 & 770 & 7300 & $4=0$ & 0.57 & 5010 & 6000 & & 7 & 7.023 & 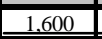 & & & & & & & \\
\hline$\overline{1,0}$ & 9,0 & \begin{tabular}{|l|l|}
0,197 \\
\end{tabular} & 0,242 & 0.257 & 3.000 & 2,803 & $\begin{array}{l}.849 \\
.849\end{array}$ & 0.908 & 0.973 & 4.150 & $\begin{array}{ll}0.652 \\
0.652 \\
\end{array}$ & 0.666 & $\begin{array}{ll}0,716 \\
0.76\end{array}$ & $\frac{1,150}{1,150}$ & 0,711 & 0.776 & .600 & Ok & & 1,143 & N.G. & 800 & 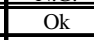 & $\mathrm{O \textrm {Ok }}$ \\
\hline & $10,0$. & 0,14 & & & -0.268 & 27 & 50 & 0,6 & & -0.940 & 0345 & $\frac{0,429}{2}$ & 0,458 & 0,6 & -0.463. & 0.502 & $1,600-$ & - & 5 & & 5 & & 2 & \\
\hline & $\begin{array}{ll}\frac{9,0}{10,0} \\
10\end{array}$ & & & $\frac{253}{253}$ & $\begin{array}{l}3,000 \\
3.000 \\
\end{array}$ & $\begin{array}{ll}2, / 41 \\
2.810\end{array}$ & & & & & & & & & & 00 & & k k & 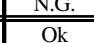 & & $\frac{\text { N.G. }}{N G \text {. }}$ & & $\mathrm{k}$ & Ok \\
\hline & 11,0 & 0,145 & 0,179 & 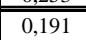 & $\begin{array}{ll}.3000 \\
0,285\end{array}$ & $\frac{2.810}{0,139}$ & 0,483 & $\frac{21}{04}$ & & $\frac{2.080}{1,011}$ & $\frac{31}{38}$ & $\begin{array}{ll}0.580 \\
0,425\end{array}$ & $\frac{154}{154}$ & $\frac{2.58}{0,72}$ & $0,0.459$ & 0,000 & $1 \frac{1.000}{1,600}$ & $\frac{\mathrm{OK}}{\mathrm{Ok}}$ & $\frac{\mathrm{OK}}{\mathrm{O \textrm {k }}}$ & & D., & & $\frac{\partial \mathrm{K}}{\mathrm{ok}}$ & $\frac{\mathrm{OK}}{\mathrm{Ok}}$ \\
\hline & & & & & 3.000 & & & & & & & & & 2.5 & & & & & & & & & & \\
\hline$\frac{1,4}{1 .}$ & 11,0 & & & $\overline{\underline{0.2}}$ & $\overline{0.4 .}$ & $\overline{\underline{0,2}}$ & & & & & & & & & & & 1,6 & $\mathrm{Ok}$ & & & $\mathrm{Ok}$ & & Ok & $\overline{\mathrm{OK}}$ \\
\hline & & & & & $=2$ & 0,130 & & & & & & & & $\overline{0.7}$ & -2 & - & $1,0,000-1$ & - & - & & $=-$ & & Oي & $\overline{\mathrm{OOk}}$ \\
\hline & & & & & & -5 & & & & & & & & & & & -1 & $\overline{0-1}$ & -- & & & & $\overline{\mathrm{Ok}}$ & \\
\hline & 12,0.0 & & & $-2-$ &,- 357 & 0,208 & -7 & 0,63 & & $-5,300$ & $-0,-344$ & 0.4 & & \begin{tabular}{|l|}
4,943 \\
-9
\end{tabular} & $=0,-881$. & $10,-1$ & 1,6000 & Ok & - & & OK & & Ok & $=-\frac{1}{2}$ \\
\hline & $\overline{11}, \overline{0}$ & & & & 3.000 & $2,79 \overline{0}$ & & & & 6. & $-\overline{-5}$ & & & $-3, \overline{00}$ & 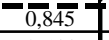 & -1 & & $-\overline{0}=$ & -i & & & & $5-$ & $\bar{x} \bar{c}$ \\
\hline 1,8 & 12,0 & & & 0.220 & 0,471 & 0,311 & & $0.0,704$ & & 6,360 & & & & & 0,5 & & & $=$ & 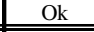 & & Ok & & Ok & Ook \\
\hline , & 13,0 & & & 0,1 & 0,292 & 0,1 & & & & -2 & & & & 0,8 & & 0, & $1 ., 6$ & & & & -3 & & -- & $-\underline{-1}$ \\
\hline 2,0 & 11,0 & & & 0,3 & 3,000 & & & & & & & & & & & & & & & & & & & G. \\
\hline & 12,0 & & 0,2 & 0,244 & 0,662 & 0,4 & 0,56 & 0,7 & & 6,360 & 0,3 & 0,53 & 0,62 & 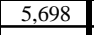 & 0,58 & 0,699 & & & & & & & Ok & $\bar{~} \bar{k}$ \\
\hline & $\frac{13,0}{10} \mathrm{t}$ & $0, \overline{81}$ & $=\frac{0,167}{0,259}-$ & $\frac{0.182}{0.30}$ & $-\frac{0.350}{3000}$ & 0.218 & $0,0,28$ & $\frac{0,558}{0.42}$ & 1 & -6.660 & $\frac{0.29}{0,42}$ & $\frac{0,35}{0.58}$ & $\frac{0.423}{0.790-}-1$ & $\frac{6,310}{360}$ & $\frac{0.426}{0661}$ & 0.472 & $\frac{1.600}{1.600}-$ & $-\frac{O k}{O k}-$ & k & $\frac{1,14}{1,14}$ & $\frac{\mathrm{Ok}}{\mathrm{S}}$ & & $\frac{\text { okk- }}{0 \mathrm{k}}$ & $\frac{\mathrm{k}}{\mathrm{G}}$ \\
\hline & 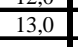 & & & 0.193 & 0,00 & $\frac{0.421}{0.421}$ & & & & 6.660 & & 0.4 & 0,4 & & 4 & 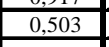 & & Ok & & 111 & $\overline{O k}$ & & $\frac{\pi}{0 k}$ & \\
\hline & & $\overline{0,11}$ & & & & & & & & & & & & & & & & & & & & & & \\
\hline & $\frac{1}{12.0}$ & $\overline{0,184}$ & $\overline{0.288}$ & $0, \overline{371}-1$ & -3.000 & 2.816 & if & & & $6.360^{\circ}$ & $-\frac{0.427}{0.42}$ & 0,706 & 73 & 3,360 & $-0,810^{-}$ & $1,76 \mathrm{~T}$ & $1,600-7$ & $-\frac{\pi}{\mathrm{Ok}}-$ & N.G. & 3 & N.G. & & $-\frac{1 . G}{N .6}$ & $\bar{N} \cdot \bar{G}$. \\
\hline 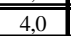 & 13,0 & \begin{tabular}{|l|l|}
0,141 \\
\end{tabular} & 0,183 & 0,2000 & 0,561 & 0,420 & 0 & & $\frac{1,2}{0,2}$ & 6,660 & & $\begin{array}{l}0.413 \\
\end{array}$ & & & & & & & $\overline{\bar{c}}$ & & $\overline{\mathrm{Ok \textrm {k }}}$ & & Ok & \\
\hline 4 & \begin{tabular}{|l|}
14,0 \\
\end{tabular} & \begin{tabular}{|c|}
0,116 \\
\end{tabular} & \begin{tabular}{|l|}
0,146 \\
\end{tabular} & \begin{tabular}{|l|l|}
0,157 \\
\end{tabular} & $\begin{array}{l}0,402 \\
0,402\end{array}$ & \begin{tabular}{|l|}
0,287 \\
\end{tabular} & 0,370 & 0,471 & 0,511 & 6,900 & \begin{tabular}{|l|}
0,255 \\
\end{tabular} & \begin{tabular}{|l|}
0,115 \\
0,325
\end{tabular} & \begin{tabular}{|l|}
0,354 \\
\end{tabular} & $\begin{array}{l}6,498 \\
\end{array}$ & 0,355 & 0,395 & 1,600 & Ok & JK & 1,143 & $\mathrm{Ok}$ & 0,800 & $\mathrm{Ok}$ & $\mathrm{Ok}$ \\
\hline
\end{tabular}




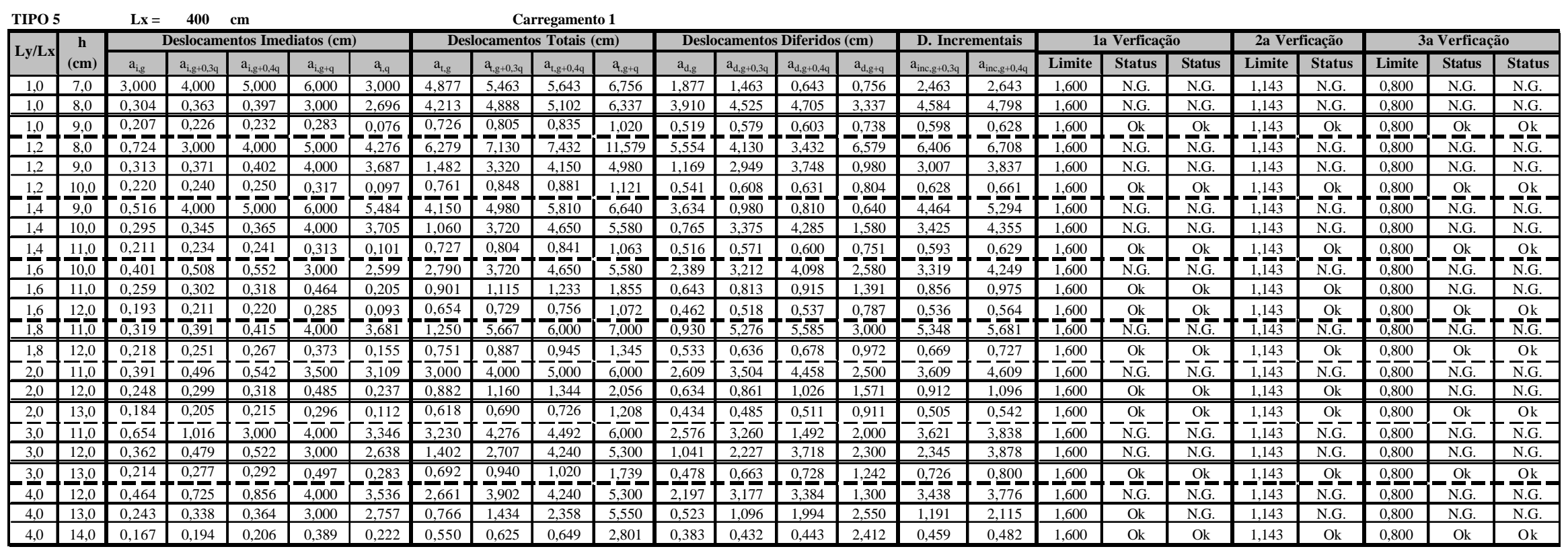


$\mathrm{f}_{\mathrm{ck}}=35 \mathrm{Mpa}$

\begin{tabular}{|c|c|c|c|c|c|c|c|c|c|c|c|c|c|c|c|c|c|c|c|c|c|c|c|c|}
\hline \multirow{3}{*}{$y / L x$} & \multirow{2}{*}{\begin{tabular}{|c|}
$\mathbf{h}$ \\
$(\mathrm{cm})$ \\
\end{tabular}} & \multicolumn{5}{|c|}{ os (cm) } & \multicolumn{4}{|c|}{ nentos Totais (cm) } & \multicolumn{4}{|c|}{ 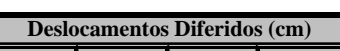 } & \multicolumn{2}{|c|}{ D. Incrementais } & \multicolumn{3}{|c|}{ 1a Verficaçãa } & \multicolumn{2}{|c|}{ 2a Verficação } & \multicolumn{3}{|c|}{ 3a Verficação } \\
\hline & & & & & & & & & & & & & & & & & & 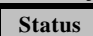 & Status & Limite & Status & ite & $\begin{array}{l}\text { Status } \\
\end{array}$ & $\overline{\text { Status }}$ \\
\hline & & & & & & & & & & & & & & & & & & & & & & & & \\
\hline & & & & & & & & & & & & & & & & & & & & & & & & \\
\hline & $: 0$ & $\overline{74}$ & $=-1+2>$ & $\overline{0} \overline{313}$ & & - & & $1.0^{\circ}$ & & & & & & & & & & $c$ & & & & & $\mathrm{~N}$ & \\
\hline & $\overline{9,0}$ & 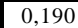 & 209 & 0,215 & & 0,064 & & 0,662 & & 843 & & & & & & & & & & & & & & \\
\hline & & & & & & & & & & & & & & & & & & & & & & & & \\
\hline & $\overline{9.1}(-2)$ & 260 & $\overline{0.28} \mathrm{~S}$ & $\overline{0.29}$ & & $\overline{0,1}$ & & & & & & & & & & & & & & & & & & \\
\hline & 10,0 & 0,188 & $0,206-$ & 0,212 & $-0,250-6$ & $-0,062$ & $-\frac{0,589}{-12}$ & $0.651-t$ & $-3,-1$ & $-0,813$ & 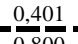 & $=-\frac{1}{2}-\frac{1}{2}$. & 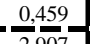 & $=$ & $=$ & $-30-2$ & $-1,0$, & -1 & $=-5+2+3$ & -3 & $-3+2+$ & & $-1 \quad-$ & \\
\hline & & & & & & 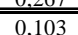 & & & & & & & & & & & & & & & & & & \\
\hline & $\overline{10}, \overline{0}$ & $0, \overline{277}$ & $\overline{0,321}]$ & $0, \overline{338}$ & 0,499 & 0,222 & $\overline{0,}$, & 2,790 & $3, \overline{3} 20$ & 4,65 & 653 & 2,4 & 3,382 & & & $3, \overline{4} 4 \overline{3}$ & & $\mathrm{~N}$. & & & & & N.G. & \\
\hline & & 0,203 & 0.224 & 0,231 & 0,291 & $-\frac{0,088}{2}$ & $-0,632$ & $0,704-1$ & 0,733 & $-1,111$ & 0,030 . & $=0,479$ & . $30020-1$ & 0.820 & $\frac{0.501 .51}{-1}$ & -.530 & $-\frac{1,600}{-1}-$ & $-\frac{O k}{6}-$ & OK & $\frac{1}{1}, 14$ & 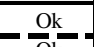 & & 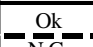 & \\
\hline & $0,0,0>0$ & ,.321 & & & & 0,35 & & & & & & & & & & & & & & & & & & \\
\hline & -5 & & -7 & 0.805 & 3.000 & $-2,463$ & -2 & 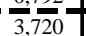 & & $=-8$ & 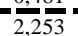 & & & & & - & - & - & & & 然. & & & \\
\hline & 11,0 & 0,297 & 0,368 & 0,409 & 0,694 & 0,397 & 0, & 1,2 & (566 & 2,65 & 0,600 & & & 1,963 & 0, & 1,269 & & Ok & & 1,1 & UK & & N.G. & \\
\hline & 2,0 & $\frac{0,204}{0,53}$ & $\frac{0,228}{0.42-}-$ & t.239- & $-0,360-$ & $-0,156$ & 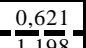 & $\frac{0.698}{3}$ & 0,726 & $-1,294$ & $-\frac{0,417}{0.45}$ & $=\frac{0,470}{25}$. & (14) & 0.0934 & $-\frac{0.494}{26,7}$. & -0.522 & $-\frac{1,600}{1},-1-1$ & $-\frac{0 k}{-}-$ & $\frac{\mathrm{Ok}}{\mathrm{N} G}$ & 1,143 & $-\frac{\mathrm{Ok}}{\mathrm{N} G \mathrm{~s}}$. & $0,800-$ & $-\frac{O k}{N-}$ & \\
\hline & & & & & tont & & & & & & & & & & & & $1,1,600$ & Ok & Ok & $1,14$. & Ok & 8000 & $\overline{\overline{\mathrm{ok}}}$ & \\
\hline
\end{tabular}

$\mathrm{f}_{\mathrm{ck}}=35 \mathrm{Mpa}$

\begin{tabular}{|c|c|c|c|c|c|c|c|c|c|c|c|c|c|c|c|c|c|c|c|c|c|c|c|c|}
\hline \multirow{3}{*}{$\begin{array}{l}\text { TIPO } 7 \\
\text { Ly/Lx }\end{array}$} & \multirow{3}{*}{$\begin{array}{c}\mathrm{h} \\
(\mathrm{cm})\end{array}$} & \multirow{2}{*}{\multicolumn{5}{|c|}{$\begin{array}{ll}L x & =\quad 500 \quad \mathrm{~cm} \\
\text { Deslocamentos Imediatos } \mathrm{C}\end{array}$}} & \multirow{2}{*}{\multicolumn{4}{|c|}{$\begin{array}{r}\text { Carregamento } 3 \\
\text { locamentos Totais }(\mathrm{cm})\end{array}$}} & \multirow{2}{*}{\multicolumn{4}{|c|}{ Desti }} & \multirow{2}{*}{\multicolumn{2}{|c|}{ D. Inc }} & \multirow{2}{*}{\multicolumn{3}{|c|}{ 1a Verficação }} & \multirow{2}{*}{\multicolumn{3}{|c|}{ 2a Verficação }} & & \\
\hline & & & & & & & & & & & & & & & & & & & & & & \multicolumn{3}{|c|}{ 3a Verficação } \\
\hline & & $a_{i, g}$ & $a_{i, 9+0,3}$ & $a_{i, s+0,0}$ & $a_{1, g+}$ & $a_{i, 9}$ & $a_{L_{2 g}}$ & $a_{1,0}$ & $a_{\mathrm{tat}}$ & $a_{t, g+t}$ & $a_{\mathrm{d}, g}$ & & & $a_{\mathrm{d}, g+a}$ & & $a_{\text {ancesentent }}$ & Limite & \begin{tabular}{|l|} 
Status \\
\end{tabular} & \begin{tabular}{|l|} 
Status \\
\end{tabular} & \begin{tabular}{|l|} 
Limite \\
\end{tabular} & Status & Limite & Status & \begin{tabular}{|l|} 
Stati \\
\end{tabular} \\
\hline & & $\overline{\underline{0.33}}$ & & 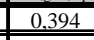 & & 3.697 & 0.969 & 1.269 & 10.03 & 5.580 & 0.666 & & & 1.580 & 0.9 & 1.054 & 2.000 & 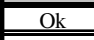 & $\mathrm{OK}$ & & & 1.000 & $\mathrm{Ok}$ & $\mathrm{N.C}$ \\
\hline & 11,0 & $\overline{0,27}$ & $\frac{0,269}{0,347}$ & $0, \overline{38}$ & $-\frac{0,44}{0.000}$ & $\frac{0,201}{3,722}$ & $\frac{0,690}{0.878}$ & $\frac{0,845}{1,178}$ & $-\frac{0,903}{33}$ & $\frac{0,919}{6,000}$ & $-0,467$. & & $\frac{0,619}{0,053}$ & $\frac{0,496}{2000}$ & $-\frac{0,622}{0,901}$ & $-0, \frac{680}{0.056}$. & $\frac{2,000}{2000}$ & $-\frac{\mathrm{Ok}}{\mathrm{Ok}}-$ & 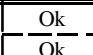 & $1, \frac{1429}{120}$ & $\begin{array}{ll}\mathrm{Ok} \\
\mathrm{N}\end{array}$ & 1,000 & - & $\frac{\mathrm{Ok}}{\mathrm{O}}$ \\
\hline & $\frac{12,0}{12,0}$ & 0.209 & 0.256 & 0.27 & 0.438 & -0.229 & 0,64 & 0.808 & 0,862 & $-1,383$ & 0.432. & & 0.59 & 0.9 & 0.59 & 0.654 & 2,000 & & Ok & & & 1,000 & ok & \\
\hline & $\frac{12}{12,0}$ & $\frac{0,236}{0,260}$ & 0,344 & & $\begin{array}{l}0, \overline{6} 4 \\
4,00 \\
4.00\end{array}$ & $-\frac{0,406}{3.740} f$ & $0.8 \overline{0}$ & $0.0,979$ & $\begin{array}{l}-\overline{1}, 134 \\
-3,180 \\
3\end{array}$ & $-\frac{2,25 \overline{4}}{5,300}$ & $=0.0 .57$. & $=0,0,940$ & 2, & $\frac{1}{1,30}$ & $\overline{1,025}$ & $2 ., 920$ & $\frac{2,000}{2,000}$ & & $\bar{N} . \bar{G}$ & & & -7 & S.G. & \\
\hline & 13.0 & $\overline{0.19}$ & $\overline{0.2}$ & 0.265 & $\overline{0.51}$ & -0.318 & $\overline{\overline{0.600}}$ & 0,792 & $0,0.878$ & 1.703 & -0.409. & 0,544 & 0,613 & $1,1,190$ & 0.597 & 0.683 & 2,000 & - $\mathrm{Ok}$ & Okㅡ. & & & 1,000 & Ok- & OF \\
\hline & $\overline{1} 3 \overline{0}$ & $=\frac{0.200}{0.212}$ & $\frac{0202}{0.272}$ & $0 \overline{310}$ & 4000 & $\frac{0.490}{3.788}$ & $\overline{0}, 6 \overline{3}$. & $=\frac{0.000}{0.940}-1$ & $-\frac{1}{4} 60$ & $-\frac{200}{6.660}$ & $-\frac{0.451}{0.451}$ & $-\frac{16}{0668}$ & 5150 & $266-$ & $-\frac{1}{072}$ & 20 & $20-1$ & $-\overline{0 k}$ & - & $\overline{409}$ & $G$ & 1000 & ok & $\bar{N} \bar{c}$ \\
\hline & & & & & & & & 0 & \begin{tabular}{|l|}
0,710 \\
0,710
\end{tabular} & & $-0,323$ & & & & & & 2,000 & - Ok & Ok & 1,429 & ok- & $\frac{1,000}{1,000}$ & Ok & \\
\hline & 13,0 & 0,211 & 0,266 & 0.298 & $-4,000$ & $-3,789$ & 0.643 & 0,885 & 1,083 & 6.660 & 0,432 & $0,10-$ & 0,785 & 2.660 & 0,674 & 0,872 & 2,000 & $-\frac{\mathrm{m}}{\mathrm{Ok}}$ & - & 1,429 & $=-$ & 1,000 & $-\frac{\pi}{\mathrm{O}}-$ & -2 \\
\hline$-\frac{10}{40}-$ & $\frac{14,0}{130}$ & $-\frac{0,160}{02}$ & $\frac{0.203}{0265}$ & $\frac{0.221}{0299}$ & $-0,5440$ & $-\frac{0,382}{3790}$ & $\frac{0.480}{0.64}$ & $\frac{0.621}{0.82}-1$ & $-0,699-1$ & $-\frac{1,718}{660}$ & $-\frac{0,321}{0.41}$. & $=\frac{0,418}{0.64}$ & $\frac{0,479}{4}-1$ & $\frac{1}{2}, \frac{177}{660}$ & $=$ & -0.540 & $=\frac{2,000}{2000}-$ & $-\frac{\mathrm{Ok}}{\mathrm{Ok}}-$ & $-\frac{O k}{N} \frac{k}{G}$. & $\frac{1,429}{149}$ & $-\frac{O k}{N G^{-}}$ & $\frac{1,000}{1000}$ & $-\frac{O k}{O k}-$ & $\frac{\mathrm{Ok}}{\mathrm{N}} \frac{\mathrm{G}}{\mathrm{G}}$ \\
\hline & 14,0 & 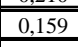 & 0.203 & 0,220 & ,, 000 & 3.841 & $\begin{array}{l}0.478 \\
0.47\end{array}$ & 0.619 & 0.059 & $\frac{6.900}{6.900}$ & 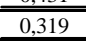 & 0.416 & 0.479 & 2,906 & 0,460 & 0.540 & 2,0000 & Ok & Ok & 1,429 & N.G. & 000 & 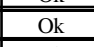 & Ok \\
\hline & 15,0 & 0,129 & 0,156 & 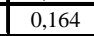 & $\overline{0,260}$ & 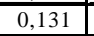 & 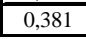 & 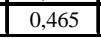 & 048 & & & & & & & 0250 & 2000 & 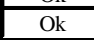 & 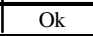 & 10 & & 0 & 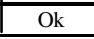 & 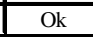 \\
\hline
\end{tabular}


$\mathrm{f}_{\mathrm{ck}}=35 \mathrm{Mpa}$

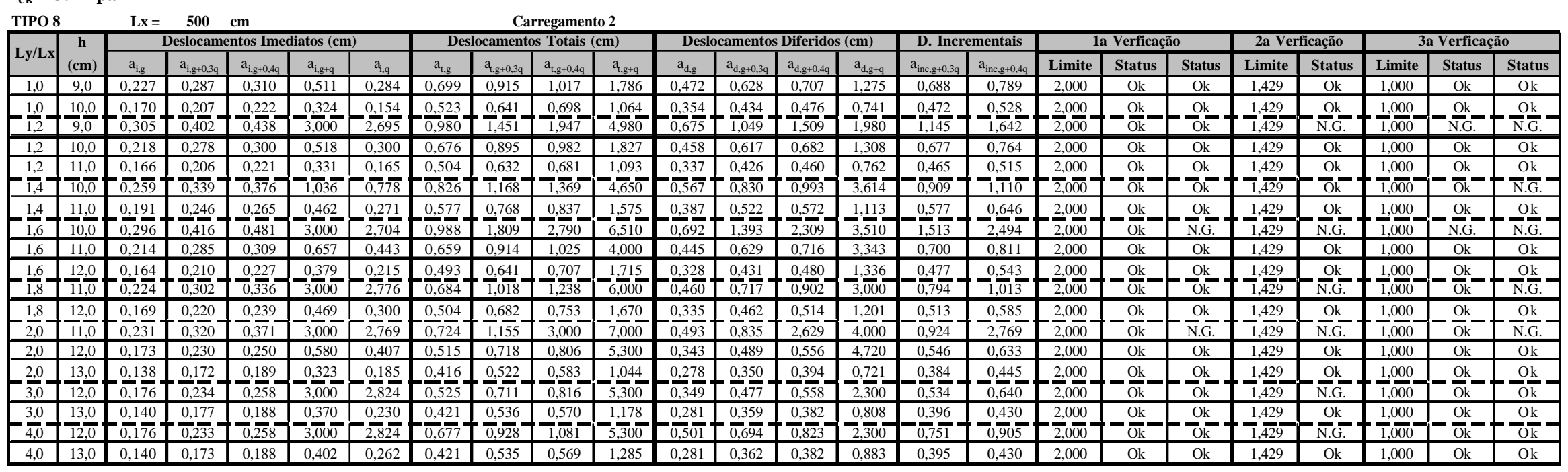




\begin{tabular}{|c|c|c|c|c|c|c|c|c|c|c|c|c|c|c|c|c|c|c|c|c|c|c|c|c|}
\hline \multicolumn{25}{|c|}{$\begin{array}{l}\mathrm{f}_{\mathrm{ck}}=35 \mathrm{Mpa} \\
\text { TIPO } 9 \quad \mathrm{Lx}=600 \quad \mathrm{~cm}\end{array}$} \\
\hline & \multirow{2}{*}{\begin{tabular}{c|}
$\mathbf{h}$ \\
$(\mathrm{cm})$ \\
\end{tabular}} & & \multicolumn{4}{|c|}{$\frac{600 \quad \mathrm{~cm}}{\text { eslocamentos Imediatos (cm) }}$} & \multicolumn{4}{|c|}{$\frac{\text { Carregamento } 1}{\text { nentos Totais (cm) }}$} & \multicolumn{4}{|c|}{ Deslocamentos Diferid } & \multicolumn{2}{|c|}{ D. Incrementais } & \multicolumn{3}{|c|}{ 1a Verficação } & \multicolumn{2}{|c|}{ 2a Verficação } & \multicolumn{3}{|c|}{ 3a Verficação } \\
\hline & & $\frac{a_{i, g}}{g_{2}}$ & & & & a. & $a_{t g}$ & & & & & & & & & & Limite & Status & Status & Limite & Status & imite & Status & $\begin{array}{l}\text { Status } \\
\end{array}$ \\
\hline & \begin{tabular}{l|l}
9,0 \\
\end{tabular} & 0.43 & & & $\overline{07}$ & & 3230 & $17^{2}$ & & & & & & 1810 & & & 2,400 & $\begin{array}{ll}\text { N.G. } \\
\Omega\left({ }^{k}\right.\end{array}$ & & & & & $\begin{array}{l}\text { N.G. } \\
\text { NG. }\end{array}$ & \\
\hline & 10,0 & & & & & 03 & & & & & & & & & & & & \begin{tabular}{|l|l|} 
Ok \\
\end{tabular} & Ok & & (5) & & N.G. & \\
\hline & 11,0 & 0,310 & $0,0,350-$ & 0,359 & $-0,4$ & $0 ., 127$ & 0.991. & $=-1,109$ & & $=1.494-$ & & $\frac{0,2}{2}$ & $11-$ & 1,058 & & $\frac{5}{7}$ & - & - - - & $\bar{T}$ & & ok- & 000 & Ok_ & $\mathrm{Ok}$ \\
\hline & $\frac{11,0}{12,0}$ & & & $\frac{0.083}{0.408}$ & & & & & & & & & & & & & & & & & & & & \\
\hline & $1.0 t$ & & & & & $=\frac{1}{3,250}$ & & $\frac{1}{6}$. & & 8.00 & & & & & & & & & & & N.G. & & & $\bar{N} \bar{G}-$ \\
\hline & 10 & 75 & $\overline{0.5}$ & & & 0.482 & 501 & 3.180 & & 5,300 & & & & 4.34 & 2.70 & $\underline{\underline{5}}$ & 2.4 & $\begin{array}{ll}\text { N.G. } \\
\end{array}$ & $\frac{1.0 .6}{N . G}$ & & 0 & & $\begin{array}{ll}\text { N.G. } \\
\end{array}$ & N.G. \\
\hline & $.13,0$ & $-\ldots$ & 0,3 & 0,415 & - & 0,216 & $-1,1,2,-1$ & 1,293 & & $-1,8$ & & & & $1,2 \underline{28}$ & 0,0 & 1,000 & 2,4 & - ok_ & $\mathrm{O}$ & & Ok & 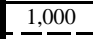 & ok_. & - \\
\hline & 12,0 & & & $0, \overline{939}$ & 4,000 & & 3,180 & 4,240 & & & & & & 2,36 & & & & & & & & & & $\bar{N} \bar{c}$ \\
\hline & \begin{tabular}{l|l|l|l|l|l}
13,0 \\
\end{tabular} & $\begin{array}{l}0,431 \\
\end{array}$ & & & & & 1,445 & & & & & & & & & & & Ok & & & $\mathrm{Ol}$ & & N.G. & N.G. \\
\hline-7 & $\frac{14,0}{130} t$ & $t-\overline{05} \overline{5}$ & $-\frac{0,36}{0.6}$ & $\frac{0,388}{0.75}$ & -5000 & $-\frac{0,2}{44}$ & $\frac{1,031}{3,30}$ & $-\frac{1,202}{440}$ & $\frac{1}{5}, 263$ & $-\frac{1,764}{6660}$ & & $\frac{1}{3} \overline{65}$ & & -16 & $-\frac{106}{390}$ & -5 & 240 & $-1-1$ & $\overline{\mathrm{N}} \bar{G}$ & & $\bar{N} \bar{G}^{-}$ & & $\mathrm{G}^{-}$ & $\bar{N} \bar{G}$. \\
\hline & $\begin{array}{ll}14,0 \\
\end{array}$ & 0.371 & \begin{tabular}{|l|}
0.44 \\
\end{tabular} & 0.461 & 0,73 & 0.365 & 1.218 & 1.59 & & $\frac{1.06}{3.06}$ & & & & 2,33 & & & & N. & & & & & N.C & N.G. \\
\hline & & & & & & & & & & & & & & & & & & & & & & & & \\
\hline & 13,0 & $\overline{0,654}$ & $\overline{0}, \overline{924}$ & $i . \overline{064}$ & & & $=1$ & & & 77 & & & & & & & & & & & 5 & & & \\
\hline & \begin{tabular}{l|l|}
14,0 &
\end{tabular} & 0,420 & \begin{tabular}{|l|l|} 
\\
\end{tabular} & 0.576 & 1,10 & & 1,505 & 4,60 & 5,75 & 6,90 & 1.0 & 4,0 & & 5,79 & 4,1 & $5,3$. & 2,40 & 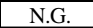 & & & $\overline{\mathrm{Ok}}$ & & N.G & G. \\
\hline & & & & & & & & & & & & & & & & & & & & & & & & \\
\hline & $=$ & & -7 & 4,918 & 500 & & & & & -7 & & & & & & & $5-$ & & & & -5 & & & \\
\hline & 15,0 & \begin{tabular}{|l|l|}
0,331 \\
\end{tabular} & $\overline{0.407}$ & $\overline{0.468}$ & $\begin{array}{l}1,057 \\
\end{array}$ & 0,726 & 1,060 & 555 & $\begin{array}{l}4.680 \\
\end{array}$ & 5,850 & 0,72 & 8 & & 4,793 & 1,224 & 49 & 2.44 & ok & & & Ok & & $\overline{\mathrm{N} . \mathrm{G} .}$ & \\
\hline & $.16,0$ & 0,260 & $-0,300$ & 0,309 & - 0.502 & 0,242 & $-0,797$ & $.0,906$ & 0.961_. & -1.563 & $=0,537$. & $=0,-606$. & $0.0,52$ & 1,061 & -0.646. & 0,701 & $\frac{2,400}{2}-$ & - k﹎ & Ok & 1,71 & $x=-1$ & 1,000 & 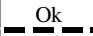 & \\
\hline & 壁, & (0.04 & & $\frac{253}{153}$ & & & 1.079 & & & $\frac{2,200}{5,850}$ & & & & & & & 2,40 & N.G & & 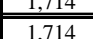 & N.G. & & N.G. & \\
\hline & 16,0 & 0,260 & 0,301 & 0,310 & 0,669 & \begin{tabular}{|l|l|}
0,409 \\
\end{tabular} & 0,808 & 0,924 & \begin{tabular}{ll|}
0,978 \\
\end{tabular} & 2,109 & 0,547 & 0,022 & & 1,440 & 0,664 & 0,718 & 2,400 & & & $\overline{1.714}$ & $\mathrm{Ok}$ & .000 & & \\
\hline
\end{tabular}




\begin{tabular}{|c|c|c|c|c|c|c|c|c|c|c|c|c|c|c|c|c|c|c|c|c|c|c|c|c|c|}
\hline \multirow{2}{*}{\begin{tabular}{|l|}
$\begin{array}{l}\text { b viga } \\
(\mathrm{cm})\end{array}$ \\
\end{tabular}} & \multirow{2}{*}{$\begin{array}{l}\text { hriga } \\
\text { (cm) }\end{array}$} & \multirow{2}{*}{\begin{tabular}{|l}
$\begin{array}{l}\text { holur } \\
\text { (cm }\end{array}$ \\
\end{tabular}} & \multicolumn{5}{|c|}{ Deslocamentos Imediatos (cm) } & \multicolumn{4}{|c|}{ Deslocamentos Totais (cm) } & \multicolumn{4}{|c|}{ Deslocamentos Diferidos (cm) } & \multicolumn{2}{|c|}{ D. Incrementais } & \multicolumn{3}{|c|}{$1^{\text {a Verficacãão }}$} & \multicolumn{2}{|c|}{$2^{a}$ Verfícaẵo } & \multicolumn{3}{|c|}{$3^{\text {a Verfícação }}$} \\
\hline & & & $a_{i g}$ & $\frac{a_{i 20+3}}{3}$ & 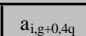 & $\mathrm{a}_{\mathrm{i} ; \mathrm{q}+\mathrm{a}}$ & a.q. & $\overline{a, g}$ & $\overline{a_{1},+0,0,3 q}$ & $a_{1,8+0,49}$ & $a_{\mathrm{lg}+9}$ & $\overline{a_{1, g}}$ & $\mathrm{atg}_{\mathrm{g}+0.3 \mathrm{ac}}$ & $a_{a_{d, p}+0,4 q_{9}}$ & $a_{1, p+q}$ & $\overline{a_{\text {anc: } 9+30,39}}$ & $a_{\text {inceg } 20.49}$ & \begin{tabular}{|l|} 
Limite \\
\end{tabular} & Status & Status & & & \begin{tabular}{|l|} 
Limite \\
\end{tabular} & \begin{tabular}{|l|} 
Status \\
\end{tabular} & $\overline{\text { Status }}$ \\
\hline & 20 & 20 & & & & & & & & & & & & & & & & \begin{tabular}{|l|l}
1,200 \\
\end{tabular} & $\begin{array}{ll}\text { N.G. } \\
\text { N. }\end{array}$ & $\begin{array}{ll}\text { N.G. } \\
\end{array}$ & & $\begin{array}{ll}\text { N.G. } \\
\end{array}$ & $\begin{array}{ll}0,600 \\
\end{array}$ & \begin{tabular}{|l|l|} 
N.G. \\
\end{tabular} & \\
\hline 14 & 25 & 20 & $\begin{array}{ll}0.492 \\
\end{array}$ & $\begin{array}{ll}0.545 \\
\end{array}$ & 0.561 & 0,666 & 0.173 & $\begin{array}{ll}1.049 \\
\end{array}$ & $\frac{1.143}{0.057}$ & \begin{tabular}{|l|l|l|l|}
094 \\
\end{tabular} & 1.366 & 0.557 & 0.599 & 0,613 & 0,700 & $\begin{array}{ll}0.651 \\
\end{array}$ & 0.682 & \begin{tabular}{|l|}
1.200 \\
\end{tabular} & $\mathrm{ok}$ & $\mathrm{OK}$ & $\begin{array}{ll}0.857 \\
\end{array}$ & $\mathrm{Ok}$ & 0,600 & $\begin{array}{ll}. G . \\
\end{array}$ & N.G. \\
\hline 14 & 30 & 20 & 0.367 & $\begin{array}{ll}0.404 \\
0.404\end{array}$ & 0.416 & 0.498 & 0.130 & 0.861 & 0.957 & 0.984 & 1.150 & 0.494 & 0.553 & 0.568 & 0.652 & 0.589 & 0.617 & \begin{tabular}{l|l|l}
1.200 \\
1
\end{tabular} & Ok & Ok & $\begin{array}{ll}0.857 \\
\end{array}$ & $\mathrm{Ok}$ & 0,600 & Ok & \\
\hline$=\frac{14}{14}-$ & 35. & $-\frac{20}{50}-$ & 0.273 & -0.301. & -0.310. & $\underline{0.368}$ & 0.094 & -0.680 & 0.744 & $-0.766-$ & 0.211 & 0,407 & -0.443 & -0.456 & -0.543 & $-0.471-$ & -0.493 & 1,200 & $-\frac{O k}{N G}-$ & $-\frac{O k}{N G}$. & $\frac{0.857}{0.857-}$ & $-\mathrm{OK}-$ & $-0.600-$ & $-\frac{O k}{N G}$ & $\frac{\mathrm{O} k}{\mathrm{~N}}$ \\
\hline$-\frac{14}{14}$ & $\frac{25}{20}$ & $-\frac{50}{70}$ & 0.258 & 0,283 & 0,291 & 0,344 & 0,087 & 0,502 & 0.0 .546 & $-0,562$ & 0,650 & 0,244 & 0.264 & 0,270 & $-0,306$ & 0,289 & $0,0,304$ & $-1,200$ & $\frac{\mathrm{k}}{\mathrm{N}}$ & $\frac{\mathrm{O} k}{\mathrm{O}} \mathrm{k}$ & 0.857 & $-\mathrm{Ok}$ & $\begin{array}{ll}0,600 \\
-0,6-1\end{array}$ & 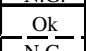 & $\frac{\mathrm{O}}{\mathrm{O}} \mathrm{k}$ \\
\hline & 25 & 70 & 0.249 & \begin{tabular}{l|l|l}
0,273 \\
\end{tabular} & 0,282 & 0,333 & 0,084 & 0,476 & 0,520 & $\begin{array}{lll}0,534 \\
\end{array}$ & 0,619 & 0,228 & 0,246 & 0.252 & \begin{tabular}{|l}
0.285 \\
\end{tabular} & 0,271 & 0.285 & $\frac{1,200}{1,200}$ & ok & $\mathrm{OK}$ & 0.857 & $\mathrm{Ok}$ & 0,600 & $\mathrm{Ok}$ & 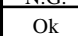 \\
\hline$\overline{14}$ & 20 & $100-$ & & & & & & & & & & & & & & & & 1.200 & N.G. & N.G. & -1 & N.G.- & 0.600 & N.G. & $\bar{c}$ \\
\hline 14 & 25 & 100 & $\begin{array}{ll}0,246 \\
\end{array}$ & \begin{tabular}{|c|}
0,270 \\
\end{tabular} & \begin{tabular}{|l|l|}
0,278 \\
\end{tabular} & 0,329 & 0,084 & \begin{tabular}{|l|l|}
0,467 \\
\end{tabular} & 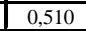 & \begin{tabular}{|l|l|l|}
0,24 \\
\end{tabular} & 0,608 & 0,221 & 0 & \begin{tabular}{|l|l|l}
0,246 \\
\end{tabular} & 0,278 & 0,264 & 0,278 & \begin{tabular}{|l|l|}
1,200 \\
\end{tabular} & Ok & $\mathrm{Ok}$ & 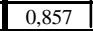 & Ok & \begin{tabular}{|l|l|}
$0,600 \mid$ \\
\end{tabular} & Ok & $\mathrm{Ok}$ \\
\hline 20 & & 20 & 0,684 & 0,755 & 0.781 & 0,940 & 0.256 & 1,561 & 1,703 & 1,750 & 2,055 & 0,877 & 0.948 & 0.969 & 1,115 & & 1.066 & \begin{tabular}{|l|l|}
1,200 \\
\end{tabular} & \begin{tabular}{|l|} 
N.G. \\
\end{tabular} & N.G. & & $\mathrm{Ok}$ & & N.G.G. & \\
\hline 20 & 25 & 20 & 0.423 & 0.465 & \begin{tabular}{|l|l|}
0.481 \\
\end{tabular} & 0.574 & 0.151 & 1.036 & 1.133 & \begin{tabular}{|l|l|l|}
1,166 \\
\end{tabular} & 1.363 & $\begin{array}{c}0.613 \\
\end{array}$ & 0.668 & 0.684 & 0.788 & 0.710 & 0.743 & \begin{tabular}{|l|}
1.200 \\
\end{tabular} & ok & OK & 57 & $\mathrm{Ok}$ & \begin{tabular}{|l|}
0.600 \\
0.0
\end{tabular} & \begin{tabular}{|l|} 
N.G. \\
\end{tabular} & \\
\hline$-\frac{20}{20}-$ & -30 & $-\frac{20}{50}-$ & 0,297 & $-0,326$ & 0,037 & 0.399. & 0,102 & 0,758 & 0.830 & $-0,853$ & 1,018 & $0,46^{2}$ & {$[0.503$} & $-0,517$ & -0.619 . & $-0.533-$ & -0.556 & $-\frac{1,200}{1}, 200$ & $-\frac{\mathrm{O}}{\mathrm{NG}}-$ & $-\frac{\mathrm{O}}{\mathrm{N}} \frac{\mathrm{k}}{\mathrm{G}}$. & $\left.\div \frac{0.857}{0.857}\right\rceil$ & $-\frac{O \mathrm{k}}{\mathrm{N}}$ & $-0,6000$ & $-\frac{O k}{N G}$ & $\frac{O \mathrm{k}}{\mathrm{N}} \frac{\mathrm{G}}{\mathrm{G}}$ \\
\hline$-\frac{20}{20}-$ & 25 & $=\frac{50}{-50}$ & 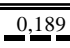 & 0.207. & -0.214. & $\overline{0.253}$ & 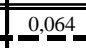 & -0.421 & $\begin{array}{l}0.459 \\
.049\end{array}$ & -0.472 & 0.0 .552 & 0.232 & 0.252 & -0.258 & 0.0 .300$. & $.0,271$ & -0.283. & 1.200 & $=\frac{O k}{2}$ & $-\frac{0 k}{0.03}$. & $\begin{array}{l}0.8577 \\
\frac{0.857}{10}\end{array}$ & $-0 \mathrm{k}$ & $-0.600=$ & $10 \mathrm{OK}$ & $0 \mathrm{Ok}$ \\
\hline$=2$ & & -70 & 0 & 0 & 0.204 & 0.242 & $\overline{0.062}$ & 0.0 .395 & 0.432 & 0,444 & $0.0,520$ & $\overline{0.215}$ & 0.234 & \begin{tabular}{|c|}
0.240 \\
\end{tabular} & 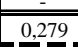 & 0.252 & 0.264 & 1,200 & L & - Ok & 0,8 & OK & - 0,600 & L & L_ok \\
\hline & & $\frac{100}{100}$ & & & --1 & 4 & & & & & & & & & & & & 1,200 & & $\overline{\mathrm{N}} \cdot \overline{\mathrm{G}} \mathbf{.}$ & & $5 \overline{6}=$ & $0, \overline{60}-8$ & 5 & \\
\hline 20 & 25 & 100 & 0,177 & & & & 0,061 & 0,386 & 0,422 & 0,434 & 0.509 & 0,210 & 0,228 & 0,234 &, 272 & 0,245 & 0,257 & & & & & & & Dk & \\
\hline
\end{tabular}




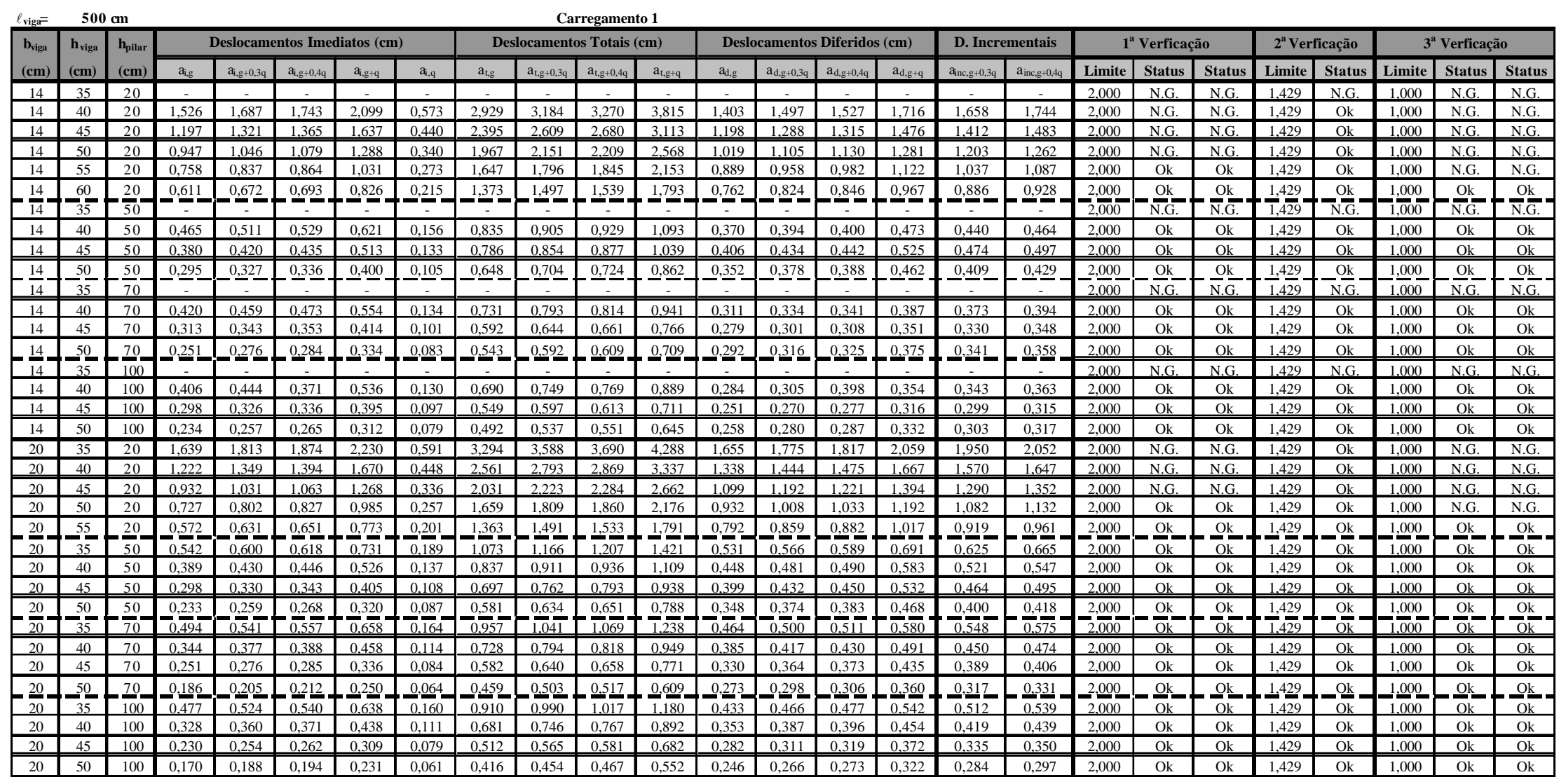


$f_{\text {ck }}(\mathrm{MPa})=35$

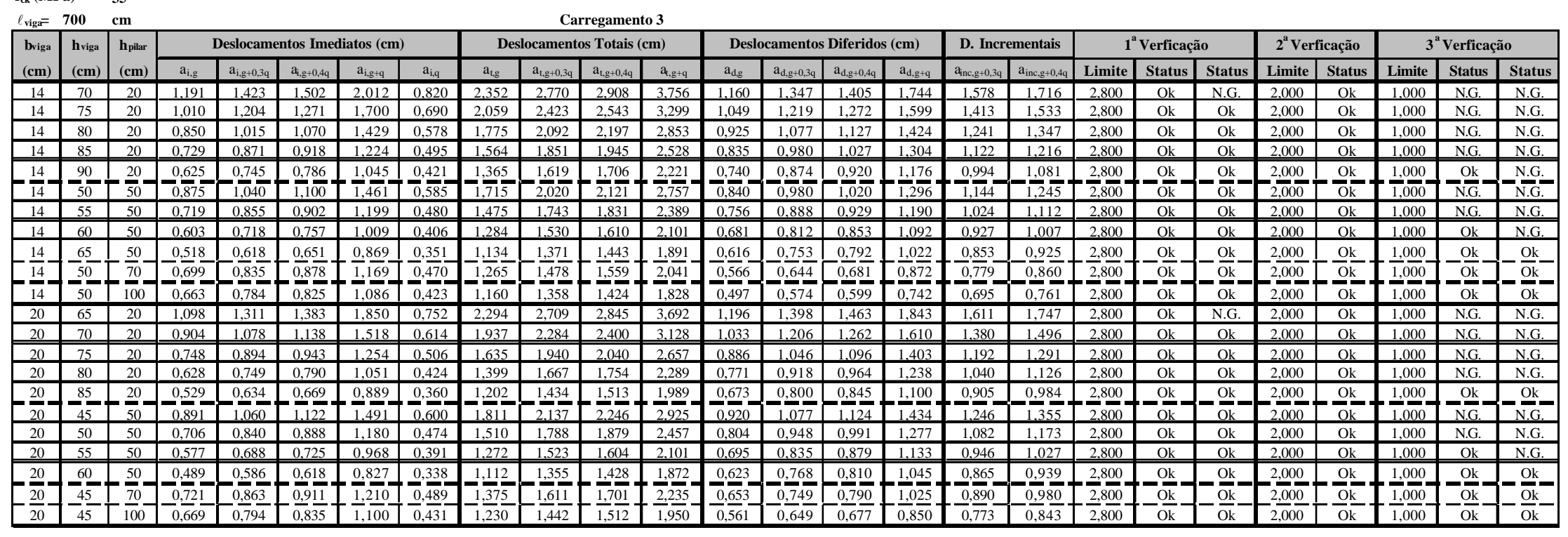




\section{REFERÊNCIAS BIBLIOGRÁFICAS}

AGHAYERE, A. O.; MACGREGOR, J.G. (1990). Test on reinforced concrete plates under combined in-plane and transverse loads. ACI Structural Journal. v.87, n.6, p.615-622, Nov-Dec.

AL-ZAID, R.Z.; AL-SHAIKH, A.H; ABU-HUSSEIN, M.M. (1991). Effect of loading type on the effective moment of inertia of reinforced concrete beams. ACI Structural Journal, v.88, n.2, p.184-190, Mar-Apr.

AL-SHAIKH, A.H.; AL-ZAID, R.Z. (1993). Effect of reinforcement ratio on the effective moment of inertia of reinforced concrete beams. ACI Structural Journal, v.90, n.2, p.144149, Mar-Apr.

AMERICAN CONCRETE INSTITUTE (1992). ACI 209R - Prediction of creep, shrinkage, and temperature effects in concrete structures. In: (1994). ACI manual of concrete practice. Detroit, ACI. part 3.

AMERICAN CONCRETE INSTITUTE (2002). ACI 318/02 - Building code requirements for reinforced concrete. Farmington Hills, ACI.

AMERICAN CONCRETE INSTITUTE (1995). ACI 435R-95 - Control of deflections in concrete structures. Detroit, ACI.

AMERICAN CONCRETE INSTITUTE (1966). ACI 435.2R - Deflections of reinforced concrete flexural members (reapproved 1989). In: (1994). ACI manual of concrete practice. Detroit, ACI. part 4. 
AMERICAN CONCRETE INSTITUTE (1973). ACI 435.5R - Deflections of continuous concrete beams (reapproved 1989). In: (1994). ACI manual of concrete practice. Detroit, ACI. part 4.

AMERICAN CONCRETE INSTITUTE (1974). ACI 435.6R - Deflection of two-way reinforced concrete floor systems: state-of-the-art report (reapproved 1989). In: (1994). ACI manual of concrete practice. Detroit, ACI. part 3.

AMERICAN CONCRETE INSTITUTE (1985). ACI 435.9R - State-of-the-art report on control of two-way slab deflections (reapproved 1991). In: (1994). ACI manual of concrete practice. Detroit, ACI. part 4.

ASSOCIAÇÃO BRASILEIRA DE NORMAS TÉCNICAS (2003). NBR 6118 - Projeto de estruturas de concreto.

BAKOSS, S.L.; GILBERT, R.I.; FAULKES, K.A.; PULMANO, V.A. (1982). Long-term deflections of reinforced-concrete beams. Magazine of Concrete Research. v.34, n.121, p.203-212.

BAZANT, Z.P. (2001). Prediction of creep and shrinkage: past, present and future. Nuclear Engineering and Design. v.203, n.1, p.27-38.

BEEBY, A.W. (1999). Deformation. FIB Bulletin, v.2, p.103-139, Apr.

BRANSON, D.E. (1977). Deformation of concrete structures. New York. McGraw Hill.

BRANSON, D.E. (1971). Compression steel effect on long-time deflections. Journal of the American Concrete Institute, v.68, n.8, p.555-559, Aug.

BRANSON, D. E. (1965). Instantaneous and time-dependent deflections of simple and continuous reinforced concrete beams. HPR Publication n.7, Part1. Alabama Highway Department, U.S. Bureau of Publis Roads. Aug. p.1-78

CLARKE, G.; SCHOLZ, H.; ALEXANDER, M. (1988). New method to predict the creep deflection on cracked reinforced concrete flexural members. ACI Materials Journal. v.85, n.12, p.95-101. March-April.

COMITÉ EURO-INTERNACIONAL DU BÉTON (1985). Design manual on cracking and deformation. CEB Bulletin dÍnformation, n.158-E.

COMITÉ EURO-INTERNACIONAL DU BÉTON (1991). CEB-FIP Model Code: Final Draft. CEB Bulletin d'Infomation, n.203/204. 
CUNHA, C. H. M.; FRANÇA, R. L. S. (2000). Deformabilidade das estruturas de concreto: Impacto das novas tipologias estruturais e das modificações dos materiais, cimentos, agregados e aditivos. In: IV SIMPÓSIO EPUSP SOBRE ESTRUTURAS DE CONCRETO. São Paulo, Anais, 2000, São Paulo.

DOTREPPE, J.C.; SCHNOBRICH, W.C.; PECKNOLD, D.A. (1973). Layered finite element procedure for inelastic analysis of reinforced concrete slabs. IABSE Publications, 33-11, p.53-68.

ELSTNER, R.C.; HOGNESTAD, E. (1956). Shearing strength of reinforced concrete slabs. Journal of The American Concrete Institute, v.28, n.1, p.29-58. July.

EUROCODE 2 (1992). Design of concrete structures. Part 1: general rules and rules for buildings. Brussel, CEN.

EUROCODE 2 (2001). Design of concrete structures. Part 1: general rules and rules for buildings. (Only for consult). Brussel, CEN.

FANELLA, D.A.; MUNSHI, J.A.; RABBAT, B.G., eds. (1999). Notes on ACI 318-99 Building code requirements for structural concrete - with design applications. 7.ed. Skokie, Portland Cement Association.

FÉDÉRATION INTERNATIONALE DU BETON - FIB (1999). Structural Concrete: Textbook on behavior, design and performance. v.1 e 2, Lausanne.

GHALI, A. (1993). Deflection of reinforced concrete members: a critical review. ACI Structural Journal, v.90, n.4, p.364-373, July-Aug.

GHALI, A.; FAVRE, R. (1986). Concrete structures: stresses and deformations. London, Chapman and Hall.

GILBERT, R.I. (2001). Shrinkage, cracking and deflection - The serviceability of concrete structures. Electronic Journal of Structural Engineering (www.civag.unimelb.edu.au/ajse). v.1, n.1, p.15-37. December.

GILBERT, R.I. (1999). Deflection calculation for reinforced concrete structures - Why we sometimes get it wrong. ACI Structural Journal, v.96, n.6, p.1027-1032, Nov-Dec.

GILBERT, R.I. (1985). Deflection control of slabs using allowable span to depth ratios. Journal of the American Concrete Institute, v.82, n.1, p.67-72, July-Aug.

GRAHAM, C.J.; SCANLON, A. (1986). Long time multipliers for estimating two-way slab deflections. Journal of the American Concrete Institute, v.83, n.6, p.899-908, Nov-Dec. 
GRAHAM, C.J.; SCANLON, A. (1985). Deflections of concrete slabs under construction loading. In: SABNIS, G., ed. Deflections of Concrete Structures. Detroit, American Concrete Institute. p.167-184. (ACI-SP 86).

GROSSMAN, J. (1981). Simplified computations of effective moment of inertia Ie and minimum thickness to avoid deflection computations. The Journal of the American Concrete Institute. v.78, n.6. p.423-439. Nov-Dec.

GRUNDY, P.; KABAILA, A. (1963). Construction loads on slabs with shored formwork in multistory buildings. Journal of the American Concrete Institute, v.60, n.12, p.17291738, Dec.

HWANG, S.J.; CHANG, K.Y. (1996). Deflection control of two-way reinforced concrete slabs. Journal of Structural Engineering - ASCE. v.122, n.2. p.160-168, February.

HILSDORF, H.K.; MULLER, H.S. (1999). Concrete. FIB Bulletin, v.1, p.21-83, Apr.

JOFRIET, J.C.; MCNEICE, G.M. (1971). Finite element analysis of reinforced concrete slabs. Journal of the Structural Division, ASCE. v.97, n.3, p.785-806, March.

LEONHARDT, F.; MÖNNIG, E. (1977). Construções de concreto - Princípios básicos do dimensionamento de estruturas de concreto armado. v.1. Rio de Janeiro. Editora Interciência LTDA.

MACGREGOR, J.G. (1992). Reinforced concrete: mechanics and design. 2.ed. Prentice Hall, New Jersey.

MEHTA, P.K.; MONTEIRO, P.J.M. (1994). Concreto, estrutura, propriedades e materiais. 1.ed. São Paulo, Editora Pini Ltda.

NAWY, E.G. (1996). Reinforced concrete: a fundamental approach. 3.ed. New Jersey, Prentice-Hall.

OLIVEIRA, R.S. (2001). Análise de pavimentos de edifícios de concreto armado com a consideração da não-linearidade física - modelagem e metodologia de aplicação a projetos. São Carlos. Tese (Doutorado) - Escola de Engenharia de São Carlos, Universidade de São Paulo.

PARK, R.; GAMBLE, W.L. (2000). Reinforced concrete slabs. 2.ed. New York, John Wiley $\&$ Sons.

PAULSON, K.A.; NILSON, A.H.; HOVER, K.C. (1991). Long-term deflection of high strength concrete beams. ACI Materials Journal, v.88, n.2, p.197-206, Mar-Apr. 
PINHEIRO, L.M. (1993). Concreto armado: tabelas e ábacos. Escola de Engenharia de São Carlos, Universidade de São Paulo. São Carlos.

PINHEIRO, L.M.; GIONGO, J.S. (1999). Concreto armado: Propriedades dos materiais. Escola de Engenharia de São Carlos, Universidade de São Paulo. São Carlos.

PRÁTICA RECOMENDADA IBRACON (2003). Prática recomendada IBRACON Comentários técnicos da NB-1

RAMALHO, M.A. (1990). Sistema para análise de estruturas considerando interação com meio elástico. São Carlos. Tese (Doutorado) - Escola de Engenharia de São Carlos, Universidade de São Paulo.

RANGAN, B.V. (1982). Control of beam deflections by allowable span to depth ratios. Journal of the American Concrete Institute, v.79, n.5, p.372-377, Sept-Oct.

RANGAN, B.V. (1976). Prediction of long-term deflections of flat plates and slabs. The Journal of the American Concrete Institute. v.73, n.4. p.223-226. April.

SBAROUNIS, J.A. (1984). Multistory flat plate buildings: effect of construction loads on long-term deflections. Concrete International, v.6, n.2, p.70-77, Feb.

SCANLON, A.; MURRAY, D.W. (1982). Practical calculation of two-way slab deflections. Concrete International, v.4, n.11, p.43-50, Nov.

SHERIF, A.G.; DILGER, W.H. (1998). Critical review of the CSA A23.3-94 deflection prediction for normal and high strength concrete beams. Canadian Journal of Civil Engineering, v.25, n.3, p.474-489, Jun.

SILVA, I.S. (1995). Concreto de alta resistência: composição, propriedades e dimensionamento. São Carlos. Dissertação (Mestrado) - Escola de Engenharia de São Carlos, Universidade de São Paulo.

SILVANY, T.T. (1996). Deslocamentos transversais em lajes cogumelo. São Carlos. Dissertação (Mestrado) - Escola de Engenharia de São Carlos, Universidade de São Paulo.

TAM, K.S.S.; SCANLON, A. (1986). Deflection of two-way slabs subjected to restrained volume change and transverse loads. The Journal of the American Concrete Institute. v.83, n.5. p.737-744. Sep-Oct.

WANG, C.K.; SALMON, C.G. (1985). Reinforced concrete design. 4.ed. New York. Harper $\&$ Row, Publishers. 
YU, B.V.; WINTER, G. (1960). Instantaneous and long-time deflections of reinforced concrete beams under working loads. Journal of the American Concrete Institute, v.57, n.1, p.29-50, July.

ZIENKIEWICZ, O.C. (1977). The finite element method. 3ed. Maidenhead, McGraw-Hill. 


\section{BIBLIOGRAFIA COMPLEMENTAR}

ACKER, P., ULM, F.J. (2001). Creep and shrinkage of concrete: physical origins and practical measurements. Nuclear Engineering and Design v.203, n.2-3, p.143-158, January.

AMERICAN CONCRETE INSTITUTE (1968). ACI 435.3R - Allowable deflections (reapproved 1989). In: (1994). ACI manual of concrete practice. Detroit, ACI. part 3.

ANG, A.H-S.; TANG, W.H. (1984). Probability concepts in engineering planning and design. New York, John Wiley \& Sons. v.1: basic principles.

BEEBY, A.W. (2001). Serviceability provisions in the new eurocode for the design of concrete structures. In: NAWY, E.G.; SCANLON, A., eds. Code Provisions for Deflection Control in Concrete Structures. Farmington Hills, American Concrete Institute. p.15-31. (ACI SP-203).

BEEBY, A.W.; NARAYANAN, R.S. (1995). Chapter 8 - Serviceability limit states. IN: Designers' Handbook to Eurocode 2 - Part 1.1: Design of Concrete Structures. Thomas Telford, London. p.132-183.

BRANSON, D.E. (1985). Deflections. IN: Handbook of Concrete Engineering. FINTEL, M., ed. New York, Van Nostrand Reinhold Co. p.53-80.

BRANSON, D.E.; TROST, H. (1982). Unified procedures for predicting the deflection and centroidal axis location of partially cracked nonprestressed and prestressed concrete members. ACI Journal Proceedings. v.79, n.2, p.119-130, March-April. 
BRANSON, D.E. (1970). Discussion of: Proposed revision of ACI 318-63: building code requirements for reinforced concrete, ACI Committee 318. Journal of the American Concrete Institute, v.67, n.9, p.692-695, Sept.

CARVAlHO, R.C.; FIGUEIREDO FILHO, J.R. (2001). Cálculo e detalhamento de estruturas usuais de concreto armado. São Carlos. Editora da Universidade Federal de São Carlos.

CARVALHO, R.C.; FIGUEIREDO FILHO, J.R.; FURLAN JUNIOR, S.; MOLINA JUNIOR, V.E. (2000). Verificação automática do estado limite de deformação excessiva de pavimentos de concreto armado considerando a fissuração e a fluência do concreto. In: XXIX JORNADAS SUDAMERICANAS DE INGENIERIA ESTRUCTURAL. Punta Del Este, UR, 2000, Anais, Punta Del Este.

CARVALHO, R.C. (1994). Análise não-linear de pavimentos de edifícios de concreto armado através da analogia de grelhas. São Carlos. Tese (Doutorado) - Escola de Engenharia de São Carlos, Universidade de São Paulo.

CHANG, K.Y.; HWANG, S.J. (1996). Practical estimation of two-way slab deflections. Journal of Structural Engineering - ASCE. v.122, n.2. p.150-159, Feb.

CHOI, B.S; OH, B.H.; SCANLON, A. (2002). Probabilistic assessment of ACI 318 minimum thickness requirements for one-way members. ACI Structural Journal. v.99, n.3. p.344-351. May-June.

CORLEY, W.G.; SOZEN, M.A. (1966). Time-dependent deflections of reinforced concrete beams. The Journal of the American Concrete Institute. v.63, n.3. p.373-386. March.

CORREAA, M.R.S. (1991). Aperfeiçoamento de modelos usualmente empregados no projeto de sistemas estruturais de edifícios. São Carlos. Tese (Doutorado) - Escola de Engenharia de São Carlos, Universidade de São Paulo.

ESPION, B.; HALLEUX, P. (1990). Long-term deflections of reinforced concrete beams: Reconsideration of their variability. ACI Structural Journal. v.87, n.2. p.232-236. MarchApril.

FLING, R.S. (1992). Practical considerations in computing deflection of reinforced concrete. In: NAWY, E.G.; SCANLON, A., ed. Designing concrete structures for serviceability and safety. Detroit, American Concrete Institute. p.69-91 (ACI SP-133). 
GARDNER, N. J. (2001). Span/thickness limitations for deflection control. In: NAWY, E.G.; SCANLON, A., eds. Code Provisions for Deflection Control in Concrete Structures. Farmington Hills, American Concrete Institute. p.95-114. (ACI SP-203).

GARDNER, N.J.; ZHAO, J.W. (1993). Creep and shrinkage revisited. ACI Materials Journal. v.90, n.3. p.236-246. May-June.

GHALI, A. (1989). Prediction of deflections of two-way floor systems. ACI Structural Journal. v.86, n.5. p.551-562.Sep-Oct.

GHALI, A.; AZARNEJAD, A. (1999). Deflection prediction of members of any concrete strength. ACI Structural Journal. v.96, n.5. p.807-816, Sep-Oct.

GILBERT, R.I.; RANGAN, V.B. (1985). Deflection control and code provisions. In: SABNIS, G., ed. Deflections of Concrete Structures. Detroit, American Concrete Institute. p.121-136. (ACI-SP 86).

HEIMAN, J.L. (1974). A comparison of measured and calculated deflections of flexural members in four reinforced concrete buildings. In: Deflections of Concrete Structures. Detroit, American Concrete Institute. p.515-545. (ACI-SP 43).

IGARASHI, S.; BENTUR, A.; KOVLER, K. (2000). Autogenous shrinkage and induced restraining stresses in high-strength concretes. Cement and Concrete Research. v.30, n.11, p.1701-1707, November.

LI, J.Y.; YAO, Y. (2001). A study on creep and drying shrinkage of high performance concrete. Cement and Concrete Research. v.31, n.8, p.1203-1206, August.

KHOR, E.H.; ROSOWSKY, D.V.; STEWART, M.G. (2001). Probabilistic analysis of timedependent deflections of RC flexural members. Computers \& Structures. v.79, n.16, p.1461-1472, June.

KRIPANARAYANAN, K.M.; BRANSON, D. (1976). Short-time deflections of flat plates, flat slabs, and two-way slabs. The Journal of the American Concrete Institute. v.73, n.12. p.686-690. Dec.

NIE, J.; CAI, C.S. (2000). Deflection of cracked RC beams under sustained loading. Journal of Structural Engineering - ASCE. v.126, n.6. p.708-716. June.

PERSSON, B. (2001). Correlating laboratory and field tests of creep in high-performance concrete. Cement and Concrete Research. v.31, n.3, p.389-395, March. 
POLAK, M.A.; SCANLON, A.; PHILLIPS, D.V. (1996). Deflection analysis of reinforced concrete members using finite element method. In: NAWY, E. G., ed. Recent developments in deflection evaluation of concrete. Farmington Hills, American Concrete Institute. p.75-96 (ACI SP-161).

PRETORIOUS, P.C. (1985). Deflections of reinforced concrete members: A simple approach. The Journal of the American Concrete Institute. v.82, n.6. p.805-812. NovDec.

RANGAN, B.V. (1992). Serviceability design in current Australian code. In: NAWY, E.G.; SCANLON, A., ed. Designing concrete structures for serviceability and safety. Detroit, American Concrete Institute. p.93-109 (ACI SP-133).

RESHEIDAT, M.R. (1985). Deflection of reinforced concrete slabs. In: SABNIS, G., ed. Deflections of Concrete Structures. Detroit, American Concrete Institute. p.407-419. (ACI-SP 86)

ROSOWSKY, D.V.; STEWART, M.G.; KHOR, E.H. (2000). Early-age loading and longterm deflections of reinforced concrete beams. ACI Structural Journal. v.97, n.3, p.517524, May-June.

SAMRA, R.M. (1997). Renewed assessment of creep and shrinkage effects in reinforced concrete beams. ACI Structural Journal. v.94, n.6. p.745-751, Nov-Dec.

SANCHES JR.,F. (1998). Cálculo de esforços e deslocamentos em pavimentos de edifícios considerando-se modelos próprios para o concreto armado. São Carlos. Dissertação (Mestrado) - Escola de Engenharia de São Carlos, Universidade de São Paulo.

SCANLON, A.; ORSAK, D.R.C.; BUETTNER, D.R. (2001). ACI code requirements for deflection control: a critical review. In: NAWY, E.G.; SCANLON, A., ed. Code Provisions for Deflection Control in Concrete Structures. Farmington Hills, American Concrete Institute. p.1-14.

(ACI SP-203).

SCANLON, A.; CHOI, B.S. (1999). Evaluation of ACI 318 minimum thickness requirements for one-way slabs. ACI Structural Journal. v.96, n.4. p.616-621, Jul-Aug.

SCANLON, A.; THOMPSON, D.P. (1990). Evaluation of ACI 318 Requirements for control of two-way slab deflections. ACI Structural Journal. v.87, n.6. p.657-661, Nov-Dec.

SCANLON, A.; MURRAY, D.W. (1974). Time-dependent reinforced concrete slab deflections. Journal of the Structural Division - ASCE. v.100, n.ST9. p.1911-1924, Sep. 
SOPKO, S.J. (1992). Design and serviceability of reinforced concrete floor systems. In: NAWY, E.G.; SCANLON, A., ed. Designing concrete structures for serviceability and safety. Detroit, American Concrete Institute. p.121-132 (ACI SP-133).

THOMPSON, D.P.; SCANLON, A. (1988). Minimum thickness requirements for control of two-way slab deflections. ACI Structural Journal. v.85, n.1. p.12-22, Jan-Feb.

VANDEWALLE, L. (2000). Concrete creep and shrinkage at cyclic ambient conditions. Cement \& Concrete Composites. v..22, n.3, p.201-208, June.

WALRAVEN, J.C. (1999). Tension stiffening. FIB Bulletin, v.1, p.189-196, Apr.

WALRAVEN, J.C. (1999). Moment-curvature. FIB Bulletin, v.1, p.197-205, Apr. 